\title{
O MODELO QRSP PARA A QUANTIFICAÇÃO DO RISCO NA SAÍDA DE VEÍCULOS DA PISTA EM RODOVIAS
}

Tese apresentada à Escola de Engenharia de São Carlos, da Universidade de São Paulo, como partes dos requisitos para a obtenção do título de Doutor em Ciências, Programa de Pós-graduação em Engenharia de Transportes.

Área de concentração: Planejamento e Operação de Sistema de Transporte.

Orientador: Prof. Dr.

Antonio Clóvis Pinto Ferraz 


\section{AUTORIZO A REPRODUÇÃO E DIVULGAÇÃO TOTAL OU PARCIAL DESTE TRABALHO, POR QUALQUER MEIO CONVENCIONAL OU ELETRONICO, PARA FINS DE ESTUDO E PESQUISA, DESDE QUE CITADA A FONTE.}

Ficha catalográfica preparada pela Seção de Tratamento da Informação do Serviço de Biblioteca - EESC/USP

A553m Andrade, Candido Moreira
O modelo QRSP para a quantificação do risco na saída
de veículos da pista em rodovias / Cândido Moreira
Andrade ; orientador Antonio Clovis Pinto Ferraz. -- São
Carlos, 2011.
Tese (Doutorado-Programa de Pós-Graduação em
Engenharia de Transportes e Área de Concentraçăo em
Planejamento e Operação de Sistema de Transporte) --
Escola de Engenharia de São Carlos da Universidade de São
Paulo, 2011.
1. Segurança rodoviária. 2. Rodovia que perdoa.
3. Saída de pista. 4. Modelo QRSP. 5. Pista dupla.
Lateral da via. I. Título.




\section{FOLHA DE JULGAMENTO}

Candidato: Engenheiro CÂNDIDO MOREIRA ANDRADE

Título da tese: 0 modelo QRSP para a quantificação do risco na saída de veículos da pista em rodovias.

Data da defesa: 19/09/2011:

\section{Comissão Julgadora:}

Prof. Titular Antonio Clóvis Pinto Ferraz (Orientador) (Escola de Engenharia de São Carlos/EESC)

Prof. Associado Antônio Nélson Rodrigues da Silva (Escola de Engenharia de São Carlos/EESC)

Prof. Dr. Carlos Alberto Bandeira Guimarães

(Universidade Estadual de Campinas/UNICAMP)

Prof. Dr. David Duarte Lima

(Universidade de Brasília/UNB)

Prof . Associada Fernanda Antonio Simões (Universidade Estadual de Maringá/UEM)
Resultado:

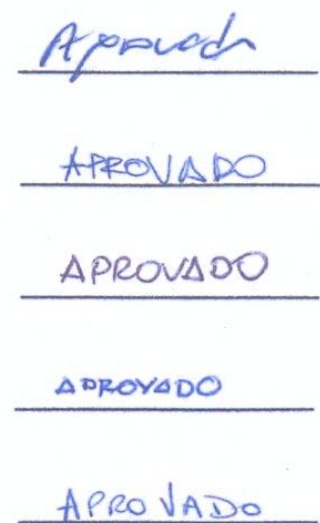

Coordenador do Programa de Pós-Graduação em Engenharia de Transportes e Presidente da Comissão de Pós-Graduação:

Prof. Associado Paulo Cesar Lima Segantine 
Ao Kallen Bernardo, pelo amor, pelo futuro 

À nação brasileira, pela oportunidade para a minha superação profissional, cultural e espiritual.

Ao Programa de Pós-Graduação em Engenharia de Transportes do Departamento de Transportes da Escola de Engenharia de São Carlos, Universidade de São Paulo, pelas condições materiais e humanas oferecidas para a realização deste trabalho.

Ao Conselho Nacional de Desenvolvimento Científico e Tecnológico - CNPq -, pelo suporte financeiro.

Ao Prof. Dr. Antonio Clóvis Pinto Ferraz (Coca), pela orientação e apoio em meu desenvolvimento acadêmico e pessoal.

À Prof ${ }^{\mathrm{a}}$ Dr $^{\mathrm{a}}$ Bárbara Stolte Bezerra e aos colegas Eng ${ }^{\mathrm{o}}$ Jorge Tiago Bastos, Eng $^{\mathrm{a}} \mathrm{Karla}$ Cristina Rodrigues Silva e Célio Fortes Gomes, estudante de medicina na UFSCar, pelo apoio, confiança, experiência transmitida e oportunidade de trabalho compartilhado.

A todos os colegas do Departamento de Transporte da USP - São Carlos, pelo companheirismo. Em particular, David Grubba, Cassiano Isler, Francisco Arcelino Lima, José Elievam, André Cunha, Sérgio Soncim, Walter Sidrónio Júnior, Isabela Fornaciari, Luciana Spigolon, André Anitelli e Fernando Hideki Hirose.

À minha mulher, Carla Bernardo, com admiração e gratidão pela sua compreensão, presença e incansável apoio, pelo amor companheiro e sorriso imprescindível.

Enfim, a todos os que contribuíram, de uma forma ou de outra, para que o meu doutorado e este trabalho tenham sido possíveis. 

ANDRADE, C. M. O modelo QRSP para a quantificação do risco na saída de veículos da pista em rodovias. São Carlos, 2011. Tese (Doutorado) - Escola de Engenharia de São Carlos, Universidade de São Paulo.

Uma parcela significativa dos acidentes de trânsito nas rodovias ocorre devido à saída de veículos da pista, o que pode resultar em choques com obstáculos fixos, quedas em espaços vazios, tombamento, capotagem, etc. Esse tipo de acidente é, em geral, grave, em razão das altas velocidades desenvolvidas nas rodovias. Cerca de 1/3 dos acidentes rodoviários com vítimas fatais nos Estados Unidos resultam de saída de pista. No Brasil, estima-se que 30\% dos acidentes rodoviários estão relacionados com saída da pista, sendo esse valor da ordem de $25 \%$ nos casos dos acidentes com vítimas fatais. Neste trabalho é apresentado o Modelo QRSP (formado pelas letras iniciais das palavras: Quantificação - Risco - Saída - Pista) em rodovias. O modelo permite quantificar o nível de proteção existente em cada segmento particular da rodovia (análise microscópica) e, a partir dessa informação, quantificar o nível de proteção considerando trechos longos (análise macroscópica). No modelo desenvolvido, a avaliação é feita considerando separadamente os dois lados da pista (direito e esquerdo), podendo os resultados serem compostos no caso da quantificação de trechos longos. $\mathrm{O}$ modelo foi desenvolvido para o caso de rodovias de múltiplas faixas por sentido (denominadas comumente de pista dupla), podendo, no entanto, também ser empregado no caso das rodovias de duas faixas e duplo sentido (rodovias de pista simples). O modelo QRSP permite determinar parâmetros não fornecidos pelos métodos ABNT (2007) - norma brasileira - e AASHTO (2002) - norma americana, proporcionando, dessa forma, uma melhor quantificação do risco na saída de veículos da pista. A análise dos resultados fornecidos pelo modelo QRSP mostra que o mesmo representa a realidade de maneira satisfatória. As informações quantitativas fornecidas pelo modelo são de grande utilidade na elaboração de projetos de melhoria das características das laterais de rodovias existentes, bem como na preparação de projetos de novas rodovias.

Palavras-chave: Segurança Viária. Rodovia que perdoa. Saída de pista. Modelo QRSP. Pista dupla. Lateral da via. 

ANDRADE, C. M. The QRSP model to quantify the risk in the runway exit of vehicles on highways. São Carlos, 2011. Thesis (Ph.D.) - Escola de Engenharia de São Carlos, Universidade de São Paulo.

A significant portion of road traffic accidents on highways occurs because of the exit of vehicles from the runway, which may result in collisions with fixed obstacles, falls in empty spaces, overturning, roll over, etc. This kind of accident is in general quite severe, due to the high speeds on highways. Approximately one third of road accidents with fatalities in the United States result from the runway exit. In Brazil, it is estimated that $30 \%$ of road accidents are also related to the runway exit, bringing this value at $25 \%$ in the cases of accidents with fatal victims. The QRRE that stands for Quantification the Risk in the Runway Exit of vehicles on highways is presented in this research. The model allows to quantify the level of protection in each particular segment of the highway (microscopic analysis) and from this information, it permits to quantify the level of protection considering long segments (macroscopic analysis). In the developed model, the assessment is done considering separately the left and right sides of the runway, and the results can be compounded in the case of long segments quantification. The model was developed for the case of multilanes highways in each direction, however, this model can also be used in the case of two lanes highways with two-ways direction. The QRRE model allows to determine parameters that are not provided by the methods ABNT (2007) -Brazilian standard, - and AASHTO (2002) - American standard, which provides a better measurement of risk in the exit of vehicles from the runway. The results obtained by QRRE model show that it clearly represents the reality. The quantitative information provided by the model are useful for the development of projects in order to improve the characteristics of the roadside highways available, and the development of projects for new highways.

Keywords: Traffic Safety. Forgiving Roadside. Runway Exit. QRRE Model. Multilanes Highway. Roadside. 



\section{LISTA DE FIGURAS}

Figura 1.1 - Evolução de mortes, frota e população no período 2000-2008, (BASTOS, 2010).

Figura 1.2 - Mortes por bilhão de quilômetros (BASTOS, 2010) .......................................... 22

Figura 2.1 - Sonorizadores ao lado da pista no acostamento. (IPR, 2010). .......................... 28

Figura 2.2 - Largura da zona livre $\left(\mathrm{L}_{\mathrm{C}}\right)$ em função do VDM, do tipo de talude e da velocidade

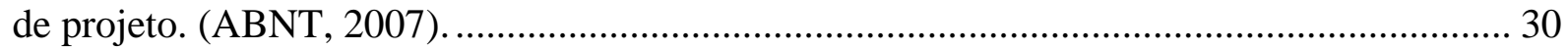

Figura 2.3 - Classificação de taludes de aterro. (AASHTO, 2002, adaptada)......................... 33

Figura 2.4 - Veículo batendo em um tronco de árvore. (IPR, 2010) ....................................... 35

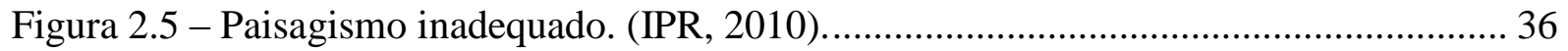

Figura 3.1 - Necessidade de proteções laterais em função de talude. (ABNT, 2007)............. 39

Figura 3.2 - Comprimento de barreira em tráfego unidirecional. (ABNT, 2007)................... 51

Figura 3.3 - Comprimento de barreira em tráfego bidirecional. (ABNT, 2007).................... 51

Figura 3.4 - Esboço (Layout) das variáveis da barreira de aproximação. (AASHTO, 2002). 52

Figura 3.5- Esboço (Layout) para a barreira de aproximação para o tráfego.

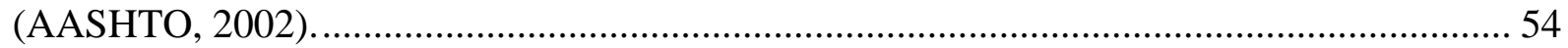

Figura 3.6 - Classificação de terminal de abertura de defensas. (AASHTO, 2002). .............. 56

Figura 3.7- Classificação do terminal de não-abertura de guardrail (AASHTO, 2002)......... 56

Figura 3.8 - Acidente grave de moto com o piloto e o acompanhante.................................. 57

Figura 3.9 - Foto distante do amortecedor de impacto implantado no km 112,5 da Rodovia SP-332.

Figura 3.10 - Foto próxima do amortecedor de impacto implantado no km 112,5 da Rodovia SP-332

Figura 3.11 - Produção do equipamento amortecedor de impacto no parque fabril do grupo LINDSAY.

Figura 3.12 - Instalação de amortecedor de impacto na rodovia SP - 340 em Mogi-Guaçu. . 61

Figura 4.1 - Foto do local onde os testes de campo foram realizados. (GOOGLE, 2011)...... 65

Figura 4.2 - Foto do terreno onde foram realizados os testes de campo. Fonte: foto feita pelo

autor.

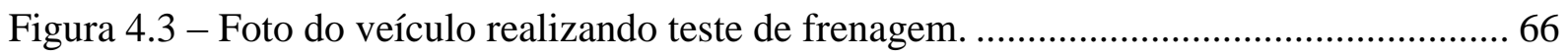

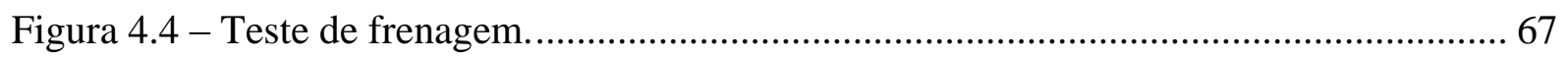

Figura 4.5 - Distância percorrida durante a frenagem versus velocidade inicial. .................. 69

Figura 4.6 - Foto mostrando o local preparado para a realização do teste. ............................. 71

Figura 4.7 - Foto mostrando detalhe do local preparado para a realização do teste. .............. 71

Figura 4.8 - Foto mostrando as marcas do pneu em um dos testes. ..................................... 72 
Figura 4.9 - Representação esquemática do teste de desvio associado com frenagem.

Figura 4.10 - Representação gráfica dos valores obtidos nos testes...................................... 78

Figura 4.11 - Representação gráfica dos valores obtidos. .................................................... 79

Figura 4.12 - Curvas da distância longitudinal versus velocidade inicial para os diversos valores da distância transversal.

Figura 4.13 - Curvas da distância longitudinal versus distância transversal para as diversas velocidades

Figura 5.1 - Trajetórias seguidas pelos veículos nas saídas de pista.

Figura 5.2 - Trajetórias seguidas pelos veículos nas saídas de pista quando atingem valeta de drenagem

Figura 5.3 - Curva da probabilidade acumulada de a saída da pista ocorrer em diferentes ângulos nos trechos em tangente.

Figura 5.4 - Trajetória do veículo com desvio à esquerda para velocidade de saída da pista igual a $110 \mathrm{~km} / \mathrm{h}$

Figura 5.5 - Trajetória do veículo com desvio à direita para velocidade de saída da pista igual a $110 \mathrm{~km} / \mathrm{h}$. .97

Figura 5.6 - Situação correspondente à saída da pista em curva. 98

Figura 5.7 - Trajetória do veículo com desvio à esquerda para velocidade de saída da pista igual a $110 \mathrm{~km} / \mathrm{h}$ em curva de raio $500 \mathrm{~m}$.

Figura 5.8 - Trajetória do veículo com desvio à direita para velocidade de saída da pista igual a $110 \mathrm{~km} / \mathrm{h}$ em curva de raio $500 \mathrm{~m}$.

Figura 5.9 - Esquema de localização do trecho crítico. 105

Figura 5.10 - Esquema da localização dos segmentos com distintos níveis de risco. 106

Figura 5.11 - Esquema de localização do trecho em valeta de drenagem 113

Figura 5.12 - Curvas para rodovias de "pista dupla". 120

Figura 5.13 - Curvas para rodovias de "pista simples". 


\section{LISTA DE TABELAS}

Tabela 2.1 - Largura da zona livre em metros a partir da borda da pista de rolamento.

(AASHTO, 2002). 31

Tabela 2.2 - Fatores de ajuste $\left(\mathrm{K}_{\mathrm{C}}\right)$ para curvas horizontais. (ABNT, 2007). 32

Tabela 3.1 - Necessidade ou não de barreiras na faixa lateral das rodovias (AASHTO, 2002) $)^{1,2}$.

Tabela 3.2 - Barreiras de proteção na faixa lateral de vias e níveis de testes de aprovação (AASHTO, 2002).

Tabela 3.3 - Níveis de testes de contenção (ABNT, 2007)

Tabela 3.4 - Critérios de seleção para barreiras de proteção na faixa lateral de rodovias (AASHTO, 2002).

Tabela 3.5 - Valores sugeridos para o efeito do atrito lateral (AASHTO, 2002)

Tabela 3.6 - Sugestão de deflexão lateral em função da velocidade de projeto. (ABNT, 2007).

Tabela 3.7 - Comprimento de área de escape proposto para projeto de barreira. (AASHTO, 2002).

Tabela 4.1 - Valores da distância percorrida durante a frenagem, obtidos nos testes de campo.

Tabela 4.2 - Valores da distância percorrida durante a frenagem para diferentes velocidades iniciais.

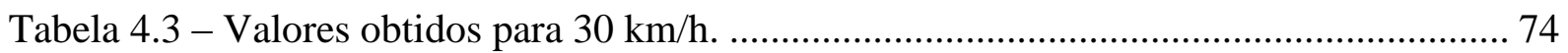

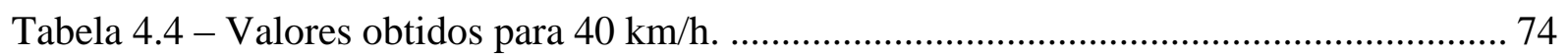

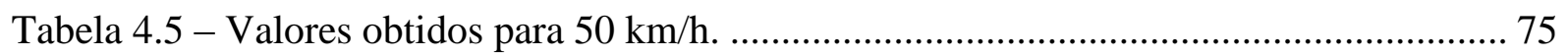

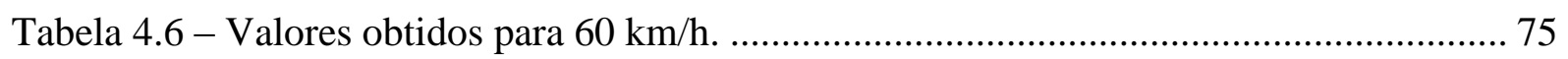

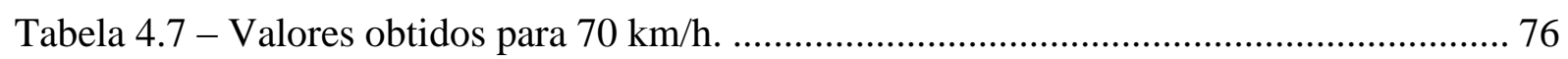

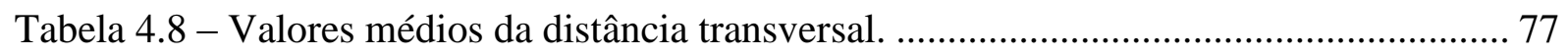

Tabela 4.9 - Valores da distância longitudinal obtidos na Figura 4.10 ................................. 79

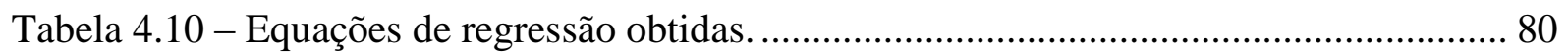

Tabela 4.11 - Valores da distância longitudinal em metros obtidos com as equações de regressão.

Tabela 5.1 - Valores da distância percorrida no caso de frenagem pura (F) e no caso de frenagem mais desvio $(\mathrm{F}+\mathrm{D})$.

Tabela 5.2 - Distâncias percorridas do ponto de saída da pista até atingir as velocidades indicadas em uma possível colisão.

Tabela 5.3 - Distâncias percorridas, em metros, para a velocidade atingir os valores indicados.

Tabela 5.4 - Tipos de situações associadas à saída de veículos da pista. 
Tabela 5.5 - Níveis de risco associados à saída imprevista de veículos da pista.....................92

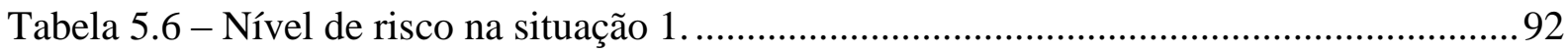

Tabela 5.7 - Nível de risco nas situações 2 e 3 ..................................................................... 93

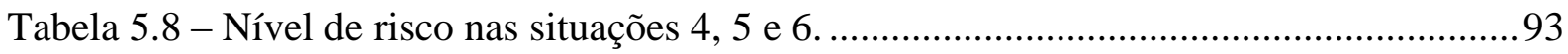

Tabela 5.9 - Nível de risco nas situações $7,8,9,10,11$ e 12 ..............................................93

Tabela 5.10 - Nível de risco nas situações 13, 14, 15 e 16................................................ 93

Tabela 5.11 - Nível de risco na situação 17 ..........................................................................93

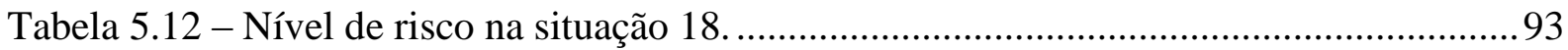

Tabela 5.13 - Valores da probabilidade acumulada de a saída da pista ocorrer em diferentes

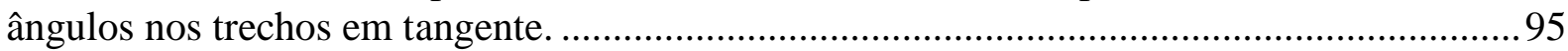

Tabela 5.14 - Situação com e sem a presença de barreiras relativa ao exemplo 10 ..............111

Tabela 5.15 - Situação com e sem a presença de barreiras relativa ao exemplo 11 ..............112

Tabela 5.16 - Situação com e sem a presença de barreiras relativa ao exemplo 12 ..............112

Tabela 5.17- Situação com e sem a presença de barreiras relativa ao exemplo 13 ...............114

Tabela 5.18 - Valores da largura da faixa lateral livre para trecho em tangente ................... 122

Tabela 5.19 - Fatores de ajuste para curvas horizontais ${ }^{\text {a,b,c. }}$.............................................. 123

Tabela 5.20 - Distância em metros da extremidade mais afastada da barreira e a face mais próxima do obstáculo. 


\section{LISTA DE SIGLAS}

AASHTO - American Association of State Highway and Transportation Officials

ABNT - Associação Brasileira de Normas Técnicas

ADM - Apenas Danos Materiais

AOV - Alta Ocupação Veicular

ASV - Auditoria de Segurança Viária

AUSTROADS - Association of Australian and New Zealand Road Transport and Traffic Authorities

CNHPR - National Cooperative Highway Research Program

DAER - Departamento Autônomo de Estradas e Rodagem

DER - Departamento de Estradas e Rodagem

DNIT - Departamento Nacional de Infraestrutura de Transportes

FHWA - Federal Highway Administration

GSA - Guia Sonora de Acostamento (Shoulder rumble strips)

GSE - Guia Sonora de Eixo (Centerline rumble strips)

GS - Guia Sonora de Pista (Roadway rumble strips)

HCM - Highway Capacity Manual

HOV - High Occupancy Vehicle

HSM - Highway Safety Manual

IPEA - Instituto de Pesquisas Econômicas Aplicadas

IPR - Instituto de Pesquisa Rodoviárias

MT - Ministério dos Transportes

NBR - Norma Brasileira

NEST-USP - Núcleo de Estudos de Segurança no Trânsito da Universidade de São Paulo

NT - Nível de Teste (Test Level)

ONU - Organização das Nações Unidas

PRA - Programa de Redução de Acidentes da Autovias

QRSP - (Quantificação - Risco - Saída - Pista) em rodovias

RDG - Roadside Design Guide

SHA - State Highway Administration

SP - Saída de Pista

SP - São Paulo

SC.USP - Departamento de Transportes, São Carlos, Universidade de São Paulo

VDM - Volume Diário Médio (Veículo Diário Médio) 



\section{SUMÁRIO}

1 INTRODUÇÃO.....................................................................................................20

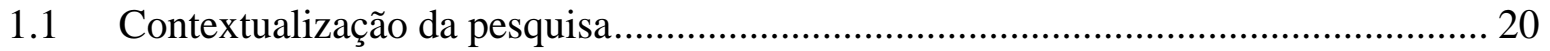

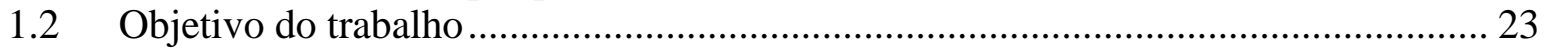

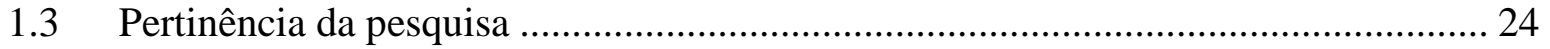

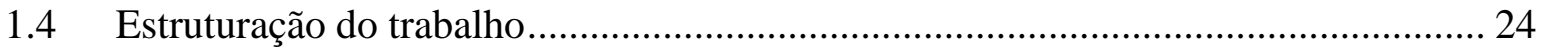

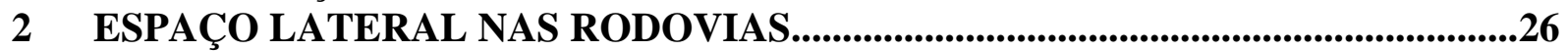

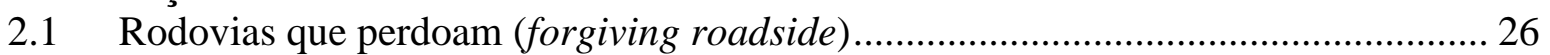

2.2 Zona livre de obstáculos na lateral das rodovias .................................................... 28

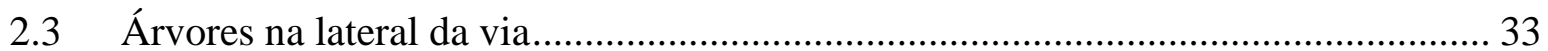

3 BARREIRAS DE CONTENÇÃ̂.............................................................................38

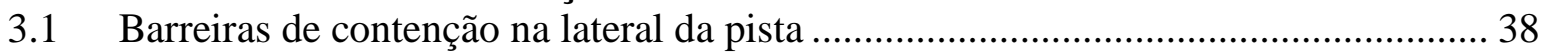

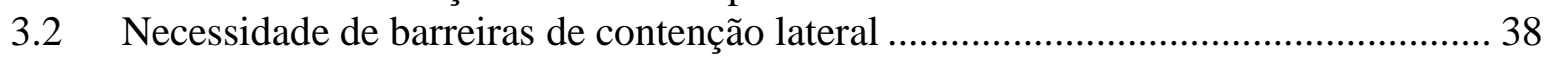

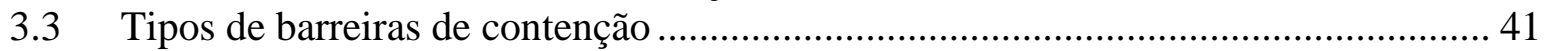

3.4 Testes de resistência das barreiras de contenção ........................................................ 44

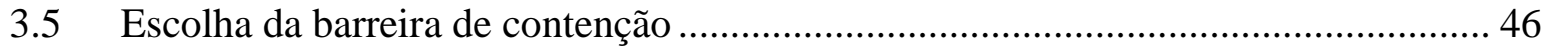

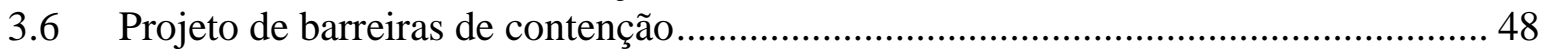

3.7 Melhoria de sistema de barreiras de contenção existentes ......................................... 54

3.8 Terminais de barreiras de contenção e amortecedores de impactos ........................... 55

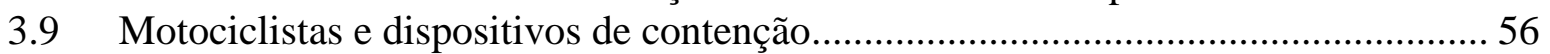

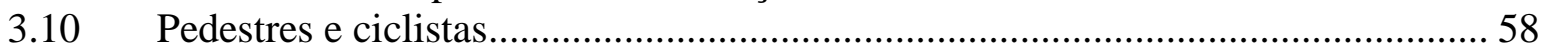

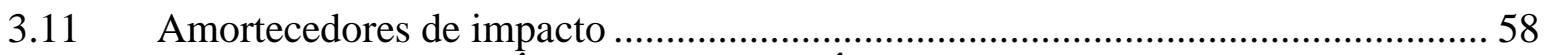

4 DESEMPENHO DOS VEÍCULOS NAS SAÍDAS IMPREVISTAS DA PISTA ......64

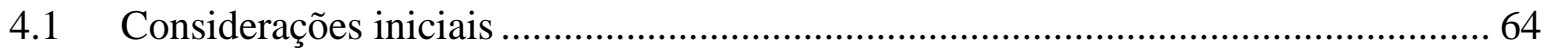

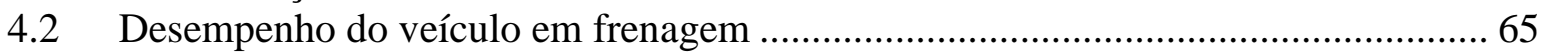

4.3 Desempenho do veículo em desvio com frenagem ................................................ 70

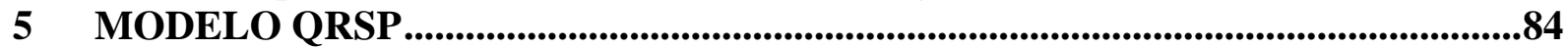

5.1 Comportamento dos condutores e desempenho dos veículos nas saídas imprevistas

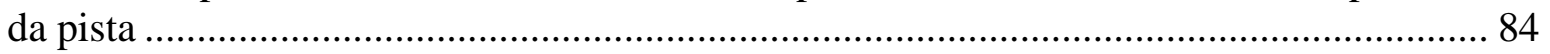

5.2 Situações possíveis de ocorrer nas saídas da pista e nível de risco associado .......... 91

5.3 Superfície do terreno na lateral da rodovia ............................................................ 94

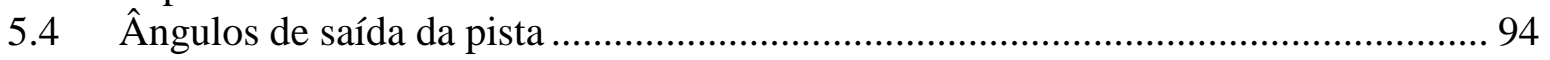

5.5 Probabilidade da saída em diferentes ângulos...................................................... 94

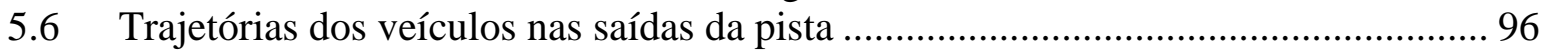

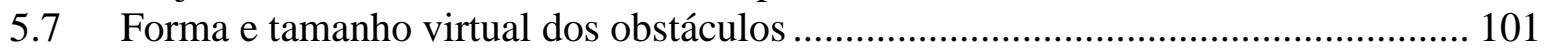

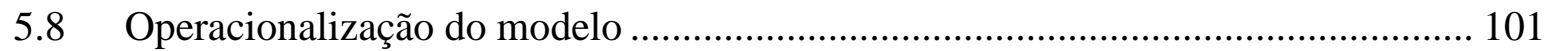

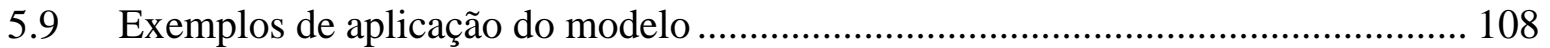

5.10 Análise macroscópica do desempenho de segmentos longos ............................. 117

5.11 Análise dos resultados fornecidos pelo modelo QRSP ....................................... 120

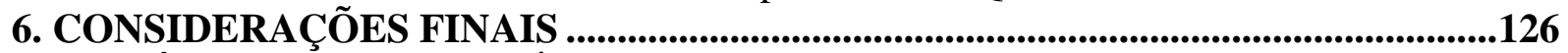

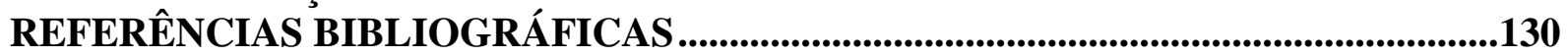

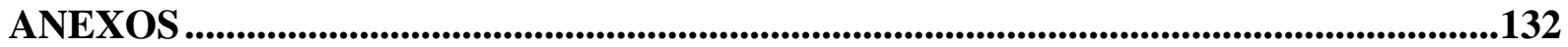





\section{INTRODUÇÃO}

\subsection{CONTEXTUALIZAÇÃO DA PESQUISA}

O acidente de trânsito é atualmente uma das principais causas de mortes violentas e de pessoas que ficam com seqüelas graves definitivas, seja de ordem física, mental e/ou psicológica. Isso causa grandes prejuízos econômicos e sociais para a sociedade, o sofrimento de milhares de pessoas e a desestruturação de uma quantidade imensa de famílias. O problema é agravado a cada ano pelo crescimento do número de acidentes e vítimas em razão do aumento da frota de veículos em circulação - em particular de motocicletas, que apresentam maior risco de acidentalidade e letalidade.

Hoje, os acidentes de trânsito provocam, no mundo, cerca de 1,3 milhão de mortes e perto de 50 milhões por ano de feridos, com um custo para a sociedade de mais de US\$ 600 bilhões. Aproximadamente $80 \%$ dos óbitos ocorrem nos países não desenvolvidos. A previsão do número de mortes atingirá a cifra de 2 milhões, no ano 2020, caso políticas adequadas não sejam colocadas em prática.- fazendo com que os acidentes envolvendo veículos de transporte terrestre ocupem a $6^{a}$ posição em causa de mortes, com 3,4\% do total. (NEST - USP - Núcleo de Estudos de Segurança no Trânsito da Escola de Engenharia de São Carlos da Universidade de São Paulo, 2011).

Desde o advento do automóvel, no final do século XIX, até o ano de 2011, cerca de 40 milhões de pessoas morreram em razão de acidentes de trânsito. (NEST - USP, 2011).

No Brasil, na atualidade são os seguintes os valores anuais, relativos aos acidentes de trânsito: cerca de 40 mil mortes e 500 mil feridos (milhares ficando com seqüelas graves definitivas), mais de 1 milhão de acidentes e um custo para o país de mais de 30 bilhões de reais (NEST - USP, 2011).

O número de mortes no trânsito vem crescendo anualmente (NEST - USP (2011): entre 2000 e 2008 cresceu 3,55\% ao ano - tendência que aponta para um maior agravamento da situação no futuro.

A Figura 1.1 (NEST - USP, 2011) mostra o crescimento do número de mortes, da frota de veículos e da população no período 2000-2008 Bastos 2010. As taxas anuais de crescimento são as seguintes: número de mortes $=3,55 \%$, onde População $=1,39 \%$, Frota $=$ $7,87 \%$. 
$\multimap-$ Mil mortes $\quad \multimap-$ Milhões de habitantes $\quad \multimap-$ Milhões de veículos

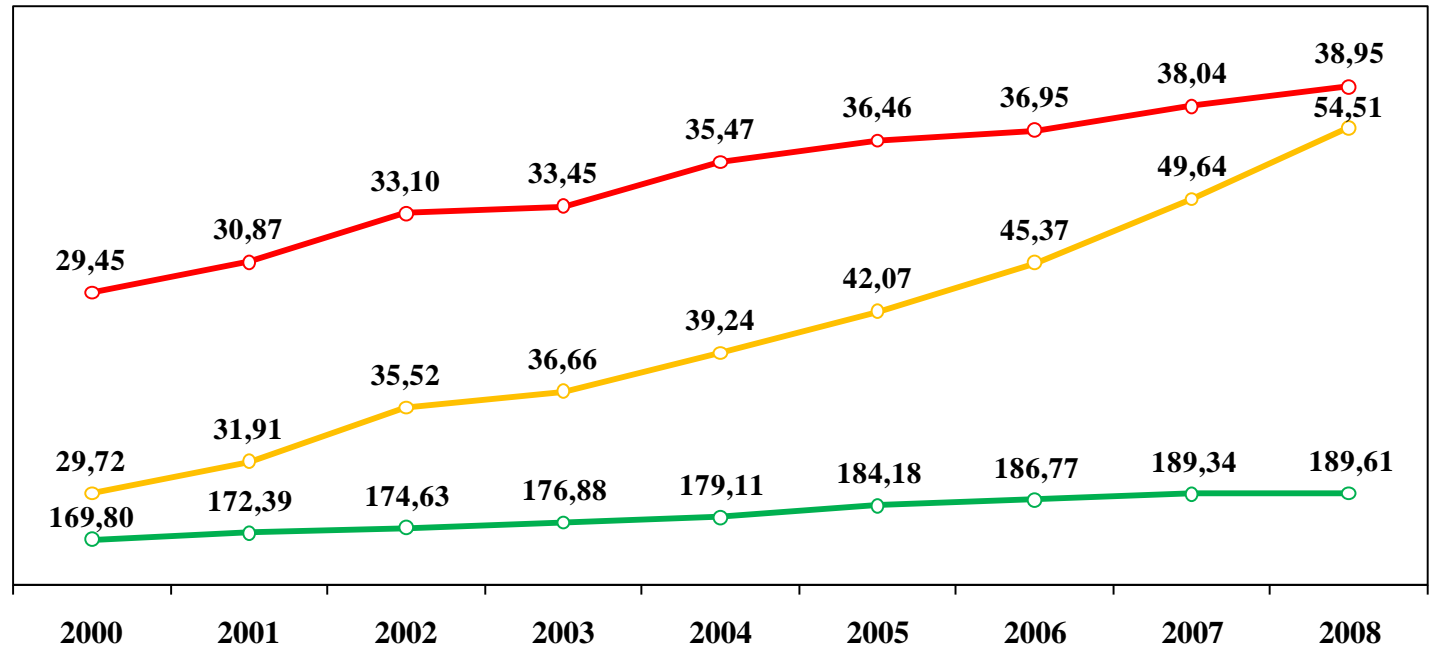

Figura 1.1 - Evolução de mortes, frota e população no período 2000-2008, (BASTOS, 2010).

No Brasil, os acidentes de trânsito têm assumido números elevados, registrando uma grande quantidade de feridos e danos materiais, como demonstram os dados de 2005, em que ocorreram 36 mil mortes e 515 mil feridos. Os acidentes com vítimas foram 385 mil, sendo $82 \%$ nas cidades e $18 \%$ nas rodovias. Isso ocorre, dentre outros motivos, devido ao aumento progressivo da ocupação das vias urbanas, resultante do aumento do número de viagens realizadas por carros e motocicletas (SIMÕES, 2001).

Segundo Mantovani (2004), na década de 1990, o Brasil participava com aproximadamente $3,3 \%$ do número de veículos da frota mundial, mas era o responsável por 5,5\% do total de acidentes fatais em todo o mundo. Segundo a Organização das Nações Unidas - ONU, o índice de 3 mortos por 10 mil veículo/ano é tido como aceitável. Entretanto, no ano de 2000, no Brasil, houve aproximadamente 6,8 mortos por 10 mil veículos/ano, enquanto na maioria dos países desenvolvidos esse número não ultrapassou 1 morte por 10 mil veículos.

De acordo com Bastos (2010), em 2008, o Brasil apresentou um índice de 57,7 mortes por bilhão de quilômetros rodado pela frota de veículos rodoviários, o que reflete uma situação extremamente grave considerando ser esse valor entre sete e treze vezes maior do que nos países desenvolvidos.

Na Figura 1.2 estão indicados os índices de alguns países desenvolvidos, relativos ao ano de 2009, e o índice obtido para o Brasil, relativo ao ano de 2008. 


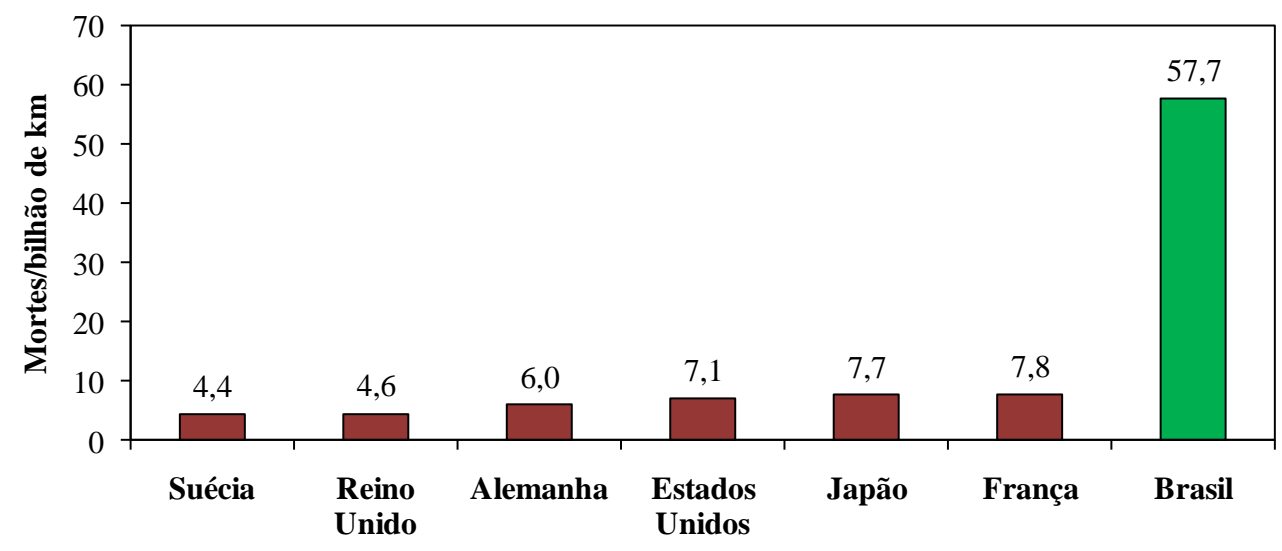

Figura 1.2 - Mortes por bilhão de quilômetros (BASTOS, 2010).

Isso mostra que o combate à acidentalidade - sobretudo à mortalidade - no trânsito deve ser colocado como uma das prioridades do país. É preciso investir em educação, fiscalização e punição dos infratores, em melhoria da segurança das rodovias e vias urbanas e em aperfeiçoamento dos serviços médicos de urgência (NEST - USP, 2011). No entanto, a ação mais importante é conscientizar a sociedade acerca da gravidade do problema e da necessidade de todos (população, políticos, autoridades, técnicos, empresas etc.) se engajarem no propósito de criar uma cultura de segurança no trânsito do país, visando à redução de acidentes, de mortos e feridos. Para isso, é preciso fazer campanhas eficazes utilizando todas as formas de mídia e colocar em prática processos eficientes de educação para o trânsito, no âmbito escolar, nas empresas, nas organizações sociais etc. (NEST - USP, 2011).

A violência no trânsito é um problema complexo que exige um tratamento multidisciplinar que englobe todas as esferas do governo (municipal, estadual e federal), através de programas integrados, com objetivos bem definidos e resultados focalizados em tais objetivos.

Nos países em desenvolvimento, incluindo o Brasil, as condições políticas e sociais contribuem muito para a acidentalidade viária. Nesses países, a falta de planejamento adequado e de investimentos necessários para a manutenção das redes viárias levou a uma rápida e crescente deterioração física dessas redes, tornando-as inseguras para o trânsito.

O problema, aliás, não se restringe aos países emergentes, mas também aos países desenvolvidos, nos quais, embora haja um maior desejo político da população com relação ao conceito de segurança, os fundos para recuperação das rodovias também são escassos, como mostra AASHTO - American Association of State Highway and Transportation Officials (2002), em relação aos Estados Unidos. 
Os programas que tratam da segurança viária nos Estados Unidos e na União Européia, diferentemente do que se passa no Brasil são coordenados no sentido de haver a coleta e a criação de bancos de dados de acidentes, por meio das quais são extraídas todas as informações relativas à segurança no trânsito. No Brasil, a criação desses bancos de dados se mostra necessária para o auxílio na tomada de decisões acerca da segurança no trânsito.

A questão das concessionárias ilustra uma das diferenças mais expressivas entre as cidades e/ou estados brasileiros no que se refere às rodovias, como, por exemplo, no estado de São Paulo, onde há maior número de rodovias privatizadas e em que as estradas apresentam melhores condições de tráfego no que se refere à segurança e ao conforto dos usuários. Nesses casos, a população também tem maior poder de reivindicação, uma vez que paga pedágios, e os governantes têm um maior desejo político, visto que são cobrados pelos usuários dessas rodovias. Diferentemente do que ocorre, em geral, nas rodovias sob responsabilidade dos governos, que se encontram, na maioria das vezes, em estado precário, oferecendo, assim, risco de vida aos usuários.

Uma parcela significativa dos acidentes de trânsito ocorre devido à saída dos veículos da pista em rodovias que resulta em choques com obstáculos fixos, quedas em espaços vazios, tombamento, capotagem etc. Em geral, esse tipo de acidente é grave em razão das altas velocidades desenvolvidas nas rodovias.

De acordo com AASHTO (2002), cerca de 30\% dos acidentes rodoviários com vítimas fatais nos Estados Unidos resultam de saída de pista. No Brasil, com base nos números citados por Ferraz et. al. (2008), estima-se que 30\% dos acidentes rodoviários estão relacionados com saída da pista, sendo esse valor da ordem de $25 \%$ nos casos dos acidentes com vítimas fatais.

\subsection{OBJETIVO DO TRABALHO}

O objetivo desta pesquisa foi desenvolver um modelo QRSP (formado pelas letras iniciais das palavras: (Quantificação - Risco - Saída - Pista) em rodovias, que pudesse fornecer novos parâmetros para uma quantificação mais adequada do risco na saída de veículos da pista em comparação com os métodos convencionais.

O modelo permite quantificar o nível de proteção existente em cada segmento particular da rodovia (análise microscópica) e, a partir dessa informação quantificar o nível de proteção considerando trechos longos (análise macroscópica). 
No modelo desenvolvido, a avaliação é feita considerando separadamente os dois lados da pista (direito e esquerdo), podendo os resultados ser compostos no caso da quantificação de trechos longos.

O modelo foi desenvolvido para o caso de rodovias de múltiplas faixas por sentido (denominadas comumente de pista dupla), podendo, no entanto, também ser empregado no caso das rodovias de duas faixas e duplo sentido (rodovias de pista simples).

\subsection{PERTINÊNCIA DA PESQUISA}

Existem poucos estudos sobre o impacto das características do espaço lateral das rodovias na acidentalidade e na severidade dos acidentes. Desse modo, a pesquisa é bastante pertinente, uma vez que permite proceder à análise quantitativa em nível microscópico (localizado), bem como à análise quantitativa de segmentos longos, permitindo, assim, a comparação do nível de proteção existente em distintos trechos de rodovias.

Essas informações quantitativas são de grande utilidade na elaboração de projetos de melhoria das características das laterais de rodovias existentes, bem como na preparação de projetos de novas rodovias.

\subsection{ESTRUTURAÇÃO DO TRABALHO}

O trabalho está estruturado da forma descrita a seguir.

Capítulo 1 reúne os tópicos: contextualização da pesquisa, objetivo do trabalho, pertinência da pesquisa e estruturação do trabalho.

No Capítulo 2, discute-se a maneira como atualmente é tratada a questão do espaço lateral das rodovias, havendo a apresentação dos principais conceitos e aspectos relacionados com o tema.

No Capítulo 3, é realizada uma ampla discussão sobre o emprego de barreiras de contenção lateral e amortecedores de choque: tipos, necessidade, projeto, etc.

No Capítulo 4, são apresentadas as características do desempenho dos veículos (variação da velocidade e trajetória seguida) quando sai da pista, bem como é descrita a metodologia utilizada para a obtenção dessas características (testes de campo e extrapolações matemáticas).

No Capítulo 5, é apresentado o Modelo QRSP: premissas, operacionalização, análise dos resultados fornecidos e exemplos de aplicação. 
No Capítulo 6 são feitas, à guisa de conclusão, algumas observações relevantes sobre o trabalho. 


\section{ESPAÇO LATERAL NAS RODOVIAS}

Neste capítulo será tratado o conceito fundamental na segurança viária que é o de rodovia que perdoa (forgiving roadside) com o objetivo de minimizar a severidade dos acidentes. A zona livre de obstáculos, a classificação dos taludes e as árvores na lateral das rodovias.

\subsection{RODOVIAS QUE PERDOAM (FORGIVING ROADSIDE)}

Um conceito fundamental na segurança viária é o de rodovias que perdoam (forgiving roadside), que corresponde à concepção do espaço lateral da via que tolera erros dos condutores que saem da pista (AASHTO, 2002).

A intenção emanada do conceito de forgiving roadside é ter uma rodovia segura e benevolente, oferecendo aos motoristas, diante de uma potencial falha na direção (causada por fatores humanos, mecânicos ou do meio ambiente), a possibilidade de controlar o veículo em um nível de desaceleração suportável pelo organismo humano e retornar à pista com danos mínimos (idealmente sem danos). Ainda que o conceito de dano se refira essencialmente aos seres humanos (condutor e passageiros), ele também contempla os veículos e os elementos da rodovia, tais como barreiras de contenção, sinalização etc.

Segundo AASHTO (2002), são muitas as razões pelas quais um veículo pode deixar a faixa de rolamento e invadir a lateral da via, entre as quais podem ser citadas:

- Fadiga ou desatenção do condutor;

- Excesso de velocidade;

- Condução sob a influência de drogas ou álcool;

- Tentativa de evitar uma colisão com outros veículos;

- Condições climáticas adversas;

- Falha nos componentes do veículo;

- Baixa visibilidade;

- Desvio de obstáculo (buraco, animal etc). na pista; 
De acordo com AASHTO (2002), independentemente do motivo que faça um veículo sair da pista, a faixa lateral da via livre de objetos fixos rígidos e com taludes planos aumenta a chance da não ocorrência de acidentes, sobretudo de acidentes graves.

Pesquisas recentes têm levado ao aperfeiçoamento do conceito de forgiving roadside, de tal modo que o projeto de lateral da rodovia passou a integrar o próprio projeto da rodovia. Segundo AASHTO (2002), entre as medidas mais importantes para a redução dos choques com obstáculos fixos rígidos na lateral da via, podem ser citadas:

- Remover o obstáculo fixo rígido (árvore de grande porte, poste de iluminação etc.);

- Projetar o obstáculo para que possa ser traspassado com segurança (exemplo: reduzir a altura de caixa de coleta de água pluvial);

- Realocar o obstáculo para um lugar onde tenha menor probabilidade de ser atingido;

- Substituir o obstáculo rígido por um dispositivo colapsível para reduzir a gravidade do impacto;

- "Proteger" o obstáculo com dispositivo de contenção projetado para redirecionar os veículos, ou utilizar um amortecedor de impacto;

- Delinear (sinalizar) o obstáculo, se as alternativas anteriores não forem apropriadas.

Uma medida de relativamente baixo custo para reduzir os acidentes associados à saída de veículos da pista é o emprego de guias sonoras laterais (faixas protuberantes transversais de baixa altura espaçadas sobre as linhas de demarcação laterais ou ao lado das mesmas, e que são denominadas na língua inglesa de shoulder rumble strips). As guias sonoras alertam aos motoristas, por meio de ruídos e vibrações de que os seus veículos atravessaram a borda da faixa, aumentando a probabilidade de permanecerem na pista ou regressarem à mesma rapidamente e sem danos ou com danos mínimos.

O emprego de sonorizadores é particularmente eficiente em trechos longos e monótonos de rodovias, nos quais os motoristas ficam mais sonolentos. Diversos estudos mostram que o uso de guias sonoras laterais reduz significativamente a quantidade de acidentes causados por veículos saindo da rodovia.

Várias formas de sonorizadores podem ser empregadas, sendo uma delas mostrada na foto da Figura 2.1, neste caso, tem também a função de evitar que os condutores usem o acostamento como faixa de tráfego. 


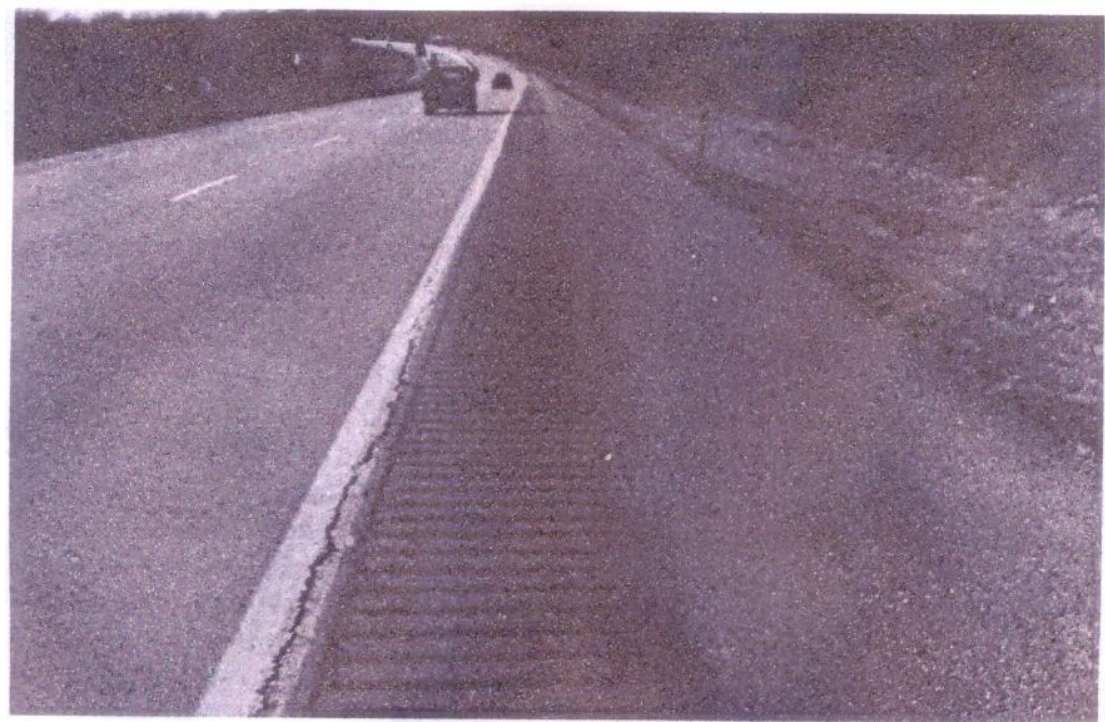

Figura 2.1 - Sonorizadores ao lado da pista no acostamento. (IPR, 2010).

\subsection{ZONA LIVRE DE OBSTÁCULOS NA LATERAL DAS RODOVIAS}

Segundo State Highway Administration (SHA, 2006), a zona livre na lateral das rodovias é conceituada como:

"[...] a área da borda da lateral da via, começando na borda da pista de rolamento, disponível para uso seguro pelos veículos desgovernados. Esta área pode consistir de um acostamento, um talude recuperável e/ou um talude traspassável, mas não recuperável e uma área de escape. Um talude de aterro "recuperável" é definido como não mais íngreme do que $4 \mathrm{H}: 1 \mathrm{~V}$, um talude "traspassável mas nãorecuperável" é mais íngreme do que $4 \mathrm{H}: 1 \mathrm{~V}$ mas não do que $3 \mathrm{H}: 1 \mathrm{~V}$ (um talude "crítico" é mais íngreme do que 3H:1V e considerado um obstáculo); taludes de corte tão íngremes quanto 3H:1V são considerados recuperáveis. A largura desejável da zona livre, do ponto de vista da segurança da lateral da via, é tão ampla quanto possível no que se refere ao custo-eficácia. Entretanto, algum valor prático necessita ser estabelecido para os objetivos do projeto. Os valores do projeto da zona livre têm sido determinados e dependem das velocidades do tráfego e da geometria da lateral da via."

Em AASHTO (1974), é colocado que, para haver uma segurança adequada deve ser mantido um espaço de recuperação da lateral da via livre de, no mínimo, $9 \mathrm{~m}$ de largura, principalmente em rodovias de alta velocidade, permitindo, dessa forma, a recuperação do controle dos veículos que saem da pista sem que ocorra o acidente em cerca de $80 \%$ dos casos.

Após a publicação de AASHTO (1974), a maioria dos obstáculos dentro da zona livre, nos Estados Unidos, foi removida, realocada ou escudada com barreira, em especial em pistas com grande volume de tráfego e alta velocidade. 
Em AASHTO (1977), foi modificado o conceito de zona livre com largura fixa de 9 m, passando a largura da zona livre a ser calculada em função da velocidade, da declividade lateral e do VDM (Volume Diário Médio).

Na Figura 2.2 é apresentada a versão do gráfico que permite determinar a largura livre lateral em função da velocidade, do VDM e da declividade lateral do terreno em segmentos em tangente (retos), apresentado em AASHTO (2002) e adotado pela ABNT (2007). Os valores também podem ser obtidos na Tabela 2.1.

Nos trechos em curva, esses valores devem ser corrigidos com a aplicação dos fatores de correção indicados na Tabela 2.2, mediante a expressão:

$$
\mathrm{Lc}=\mathrm{Lt} . \mathrm{Kc}
$$

Em que: Lc: largura da zona livre para trecho em curva, Lt: largura da zona livre calculada para trecho em tangente, Kc: fator de correção para trechos em curva dado na Tabela 2.2. 


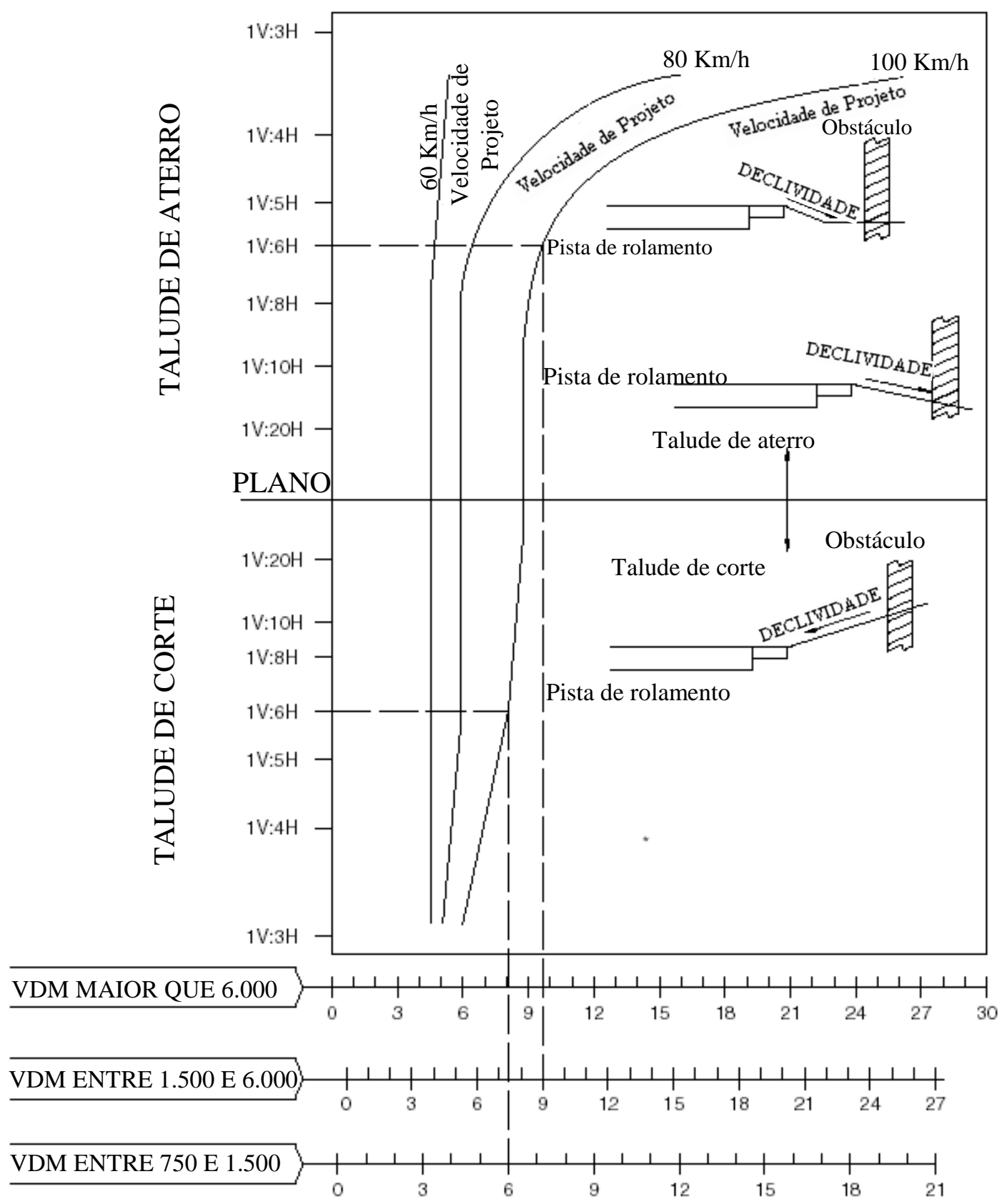

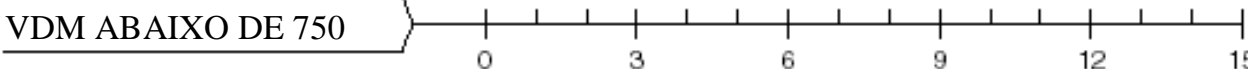

LARGURA DA ZONA LIVRE (m)

Figura 2.2 - Largura da zona livre $\left(L_{C}\right)$ em função do VDM, do tipo de talude e da velocidade de projeto. (ABNT, 2007). 
Tabela 2.1 - Largura da zona livre em metros a partir da borda da pista de rolamento. (AASHTO, 2002).

\begin{tabular}{|c|c|c|c|c|c|c|c|}
\hline \multirow[b]{2}{*}{$\begin{array}{l}\text { Velocidade } \\
\text { de Projeto }\end{array}$} & \multirow[b]{2}{*}{ Projeto VDM } & \multicolumn{3}{|c|}{ Talude Frontal } & \multicolumn{3}{|c|}{ Talude Posterior } \\
\hline & & $\begin{array}{c}\text { 6H:1V } \\
\text { ou mais }\end{array}$ & $\begin{array}{c}5 H: 1 \mathrm{~V} \\
\text { para } \\
\mathbf{4 H}: 1 \mathrm{~V}\end{array}$ & 3H:1V & 3H:1V & $\begin{array}{c}5 H: 1 \mathrm{~V} \\
\text { para } \\
\text { 4H:1V }\end{array}$ & $\begin{array}{c}6 \mathrm{H}: 1 \mathrm{~V} \\
\text { ou mais }\end{array}$ \\
\hline \multirow{6}{*}{$\begin{array}{l}60 \mathrm{~km} / \mathrm{h} \text { ou } \\
\text { menos }\end{array}$} & & & & $* *$ & $2,0-3,0$ & $2,0-3,0$ & $2,0-3,0$ \\
\hline & Abaixo de 750 & $2,0-3,0$ & $2,0-3,0$ & & & & \\
\hline & $750-1500$ & $3,0-3,5$ & $3,5-4,5$ & $* *$ & $3,0-3,5$ & $3,0-3,5$ & $3,0-3,5$ \\
\hline & $1500-6000$ & $3,5-4,5$ & $4,5-5,0$ & $* *$ & $3,5-4,5$ & $3,5-4,5$ & $3,5-4,5$ \\
\hline & Acima de 6000 & $4,5-5,0$ & $5,0-5,5$ & & & & \\
\hline & & & & $* *$ & $4,5-5,0$ & $4,5-5,0$ & $4,5-5,0$ \\
\hline \multirow{6}{*}{$70-80 \mathrm{~km} / \mathrm{h}$} & & $3,0-3,5$ & $3,5-4,5$ & & $2,5-3,0$ & $2,5-3,0$ & $3,0-3,5$ \\
\hline & Abaixo de 750 & & & $* *$ & & & \\
\hline & $750-1500$ & $4,5-5,0$ & $5,0-6,0$ & $* *$ & $3,0-3,5$ & $3,5-4,5$ & $4,5-5,0$ \\
\hline & $1500-6000$ & $5,0-5,5$ & $6,0-8,0$ & $* *$ & $3,5-4,5$ & $4,5-5,0$ & $5,0-5,5$ \\
\hline & Acima de 6000 & & & & & & \\
\hline & & $6,0-6,5$ & $7,5-8,5$ & $* *$ & $4,5-5,0$ & $5,5-6,0$ & $6,0-6,5$ \\
\hline \multirow{6}{*}{$90 \mathrm{~km} / \mathrm{h}$} & & $3,5-4,5$ & $4,5-5,5$ & & $2,5-3,0$ & $3,0-3,5$ & $3,0-3,5$ \\
\hline & Abaixo de 750 & & & $* *$ & & & \\
\hline & $750-1500$ & $5,0-5,5$ & $6,0-7,5$ & $* *$ & $3,0-3,5$ & $4,5-5,0$ & $5,0-5,5$ \\
\hline & $1500-6000$ & $6,0-6,5$ & $7,5-9,0$ & $* *$ & $4,5-5,0$ & $5,0-5,5$ & $6,0-6,5$ \\
\hline & Acima de 6000 & & & & & & \\
\hline & & $6,5-7,5$ & $8,0-10,0^{*}$ & $* *$ & $5,0-5,5$ & $6,0-6,5$ & $6,5-7,5$ \\
\hline \multirow{6}{*}{$100 \mathrm{~km} / \mathrm{h}$} & & & $6,0-7,5$ & & & & \\
\hline & & $5,0-5,5$ & $8.0-10.0 *$ & & $3,0-3,5$ & $3,5-4,5$ & $4,5-5,0$ \\
\hline & $750-1500$ & & $\begin{array}{c}0,0-10,0 \\
10,0\end{array}$ & $* *$ & $35-45$ & 5055 & $60-65$ \\
\hline & $1500-6000$ & $8,0-9,0$ & $12,0 *$ & $* *$ & $\begin{array}{l}5,5-4,5 \\
4,5-5,5\end{array}$ & $\begin{array}{l}5,0-5,5 \\
5,5-6,5\end{array}$ & $\begin{array}{l}0,0-0,5 \\
7,5-8,0\end{array}$ \\
\hline & Acima de 6000 & & & & & & \\
\hline & & $9,0-10,0$ & $\begin{array}{l}11,0- \\
13,5^{*}\end{array}$ & $* *$ & $6,0-6,5$ & $7,5-8,0$ & $8,0-8,5$ \\
\hline \multirow{7}{*}{$110 \mathrm{~km} / \mathrm{h}$} & & & $6,0-8,0$ & & & & \\
\hline & & $5,5-6,0$ & & & $3,0-3,5$ & $4,5-5,0$ & $4,5-5,0$ \\
\hline & Abaixo de 750 & & $8,5-11,0^{*}$ & $* *$ & & & \\
\hline & $750-1500$ & $7,5-8,0$ & $10,5-$ & $* *$ & $3,5-5,0$ & $5,5-6,0$ & $6,0-6,5$ \\
\hline & 1500-6000 & $8,5-10,0^{*}$ & $13,0^{*}$ & $* *$ & $5,0-6,0$ & $6,5-7,5$ & $8,0-8,5$ \\
\hline & Acima de 6000 & & & & & & \\
\hline & & $9,0-10,5^{*}$ & $\begin{array}{l}11,5- \\
14,0^{*}\end{array}$ & $* *$ & $6,5-7,5$ & $8,0-9,0$ & $8,5-9,0$ \\
\hline
\end{tabular}

* Em um local específico onde a pesquisa indica uma alta probabilidade de acidentes contínuos, ou em que tais ocorrências são indicadas pelo histórico de acidente, podem-se fornecer as distâncias da zona livre maiores do que a zona livre apresentada na Tabela 2.1. As zonas livres podem ser reduzidas a $9 \mathrm{~m}$ para a prática e para proporcionar uma rodovia modelo consistente se houver experiências anteriores com projetos semelhantes ou desenhos que indiquem desempenho satisfatório.

** Desde que os taludes recuperáveis sejam menos prováveis sobre declividades traspassáveis não escudadas de $3 \mathrm{H}: 1 \mathrm{~V}$, os obstáculos fixos não devem estar próximos do pé desses taludes. A recuperação de veículo e a alta velocidade que os faz invadirem além da borda do acostamento podem ocorrer além do pé do talude. A determinação da largura da área de recuperação no pé do talude deverá levar em consideração a disponibilidade da preferência, as preocupações ambientais, os fatores econômicos, as necessidades de segurança e o histórico de colisões. Além disso, a distância entre a borda da pista de rolamento e o início do talude de 3H:1V deve influenciar a área de recuperação desde o pé do talude. Embora a aplicação possa ser limitada por vários fatores, os parâmetros do talude frontal que podem entrar na determinação da área de recuperação máxima desejável são ilustrados na Figura 2.2. 
Tabela 2.2 - Fatores de ajuste $\left(K_{C}\right)$ para curvas horizontais. (ABNT, 2007).

\begin{tabular}{ccccccc}
\hline \multirow{2}{*}{ Raio $(\mathrm{m})$} & 60 & 70 & 80 & 90 & 100 & 110 \\
\hline 900 & 1,1 & 1,1 & 1,1 & 1,2 & 1,2 & 1,2 \\
700 & 1,1 & 1,1 & 1,2 & 1,2 & 1,2 & 1,4 \\
600 & 1,1 & 1,2 & 1,2 & 1,2 & 1,3 & 1,4 \\
500 & 1,1 & 1,2 & 1,2 & 1,3 & 1,3 & 1,5 \\
450 & 1,2 & 1,2 & 1,3 & 1,3 & 1,4 & - \\
400 & 1,2 & 1,2 & 1,3 & 1,3 & 1,4 & - \\
350 & 1,2 & 1,2 & 1,3 & 1,4 & 1,5 & - \\
300 & 1,2 & 1,3 & 1,4 & 1,5 & 1,5 & - \\
250 & 1,3 & 1,3 & 1,4 & 1,5 & - & - \\
200 & 1,3 & 1,4 & 1,5 & - & - & - \\
150 & 1,4 & 1,5 & - & - & - & - \\
100 & 1,5 & - & - & - & - & - \\
\hline
\end{tabular}

* Os fatores de correção devem ser aplicados somente para a área externa das curvas com raio maior que $900 \mathrm{~m}$.

De acordo com AASHTO (2002), os taludes de aterro paralelos ao fluxo de tráfego (laterais à via) podem ser classificados como recuperáveis, não recuperáveis e críticos, como mostrado na Figura 2.3.

Taludes recuperáveis - são os que apresentam declividade de 4H:1V (desejável de $6 \mathrm{H}: 1 \mathrm{~V}$, ou menor), sendo traspassáveis e livres de obstáculos fixos, permitindo ao motorista conduzir o veículo a uma parada segura ou reduzir a velocidade para retornar à pista com segurança. Do ponto de vista da segurança, o ideal são superfícies suaves, sem descontinuidades significativas e sem objetos fixos protuberantes, não havendo, nesse caso, necessidade de dispositivos de contenção viária na lateral da via.

Taludes não recuperáveis - conforme a área hachurada da Figura 2.3, a declividade encontra-se entre 3H:1V e 4H:1V, sendo traspassáveis, suaves e livres de obstáculos fixos. Neste caso, a maioria dos veículos não consegue parar ou retornar à pista com facilidade. Os veículos normalmente atingem o fundo do talude onde deve haver uma área de escape e, caso essa zona livre não exista, deve ser colocado um dispositivo de contenção próximo à via.

Taludes críticos - com declividade maior do que $3 \mathrm{H}: 1 \mathrm{~V}$, a maioria dos veículos tende a capotar. Os taludes que estão dentro da zona livre devem ser protegidos com dispositivos de contenção.

Se uma rodovia estiver localizada em uma seção de corte, pode ser traspassável dependendo da sua suavidade e da ausência de obstáculos fixos. Por outro lado, os cortes em rocha são perigosos se a superfície formada puder provocar enganchamento dos veículos em vez de permitir um redirecionamento suave. Em compensação, se o talude entre o corte e a 
pista for traspassável (mais plano que 3H:1V) e o corte for livre de obstáculos fixos, o talude pode não ser considerado um obstáculo, independente da sua distância da pista.

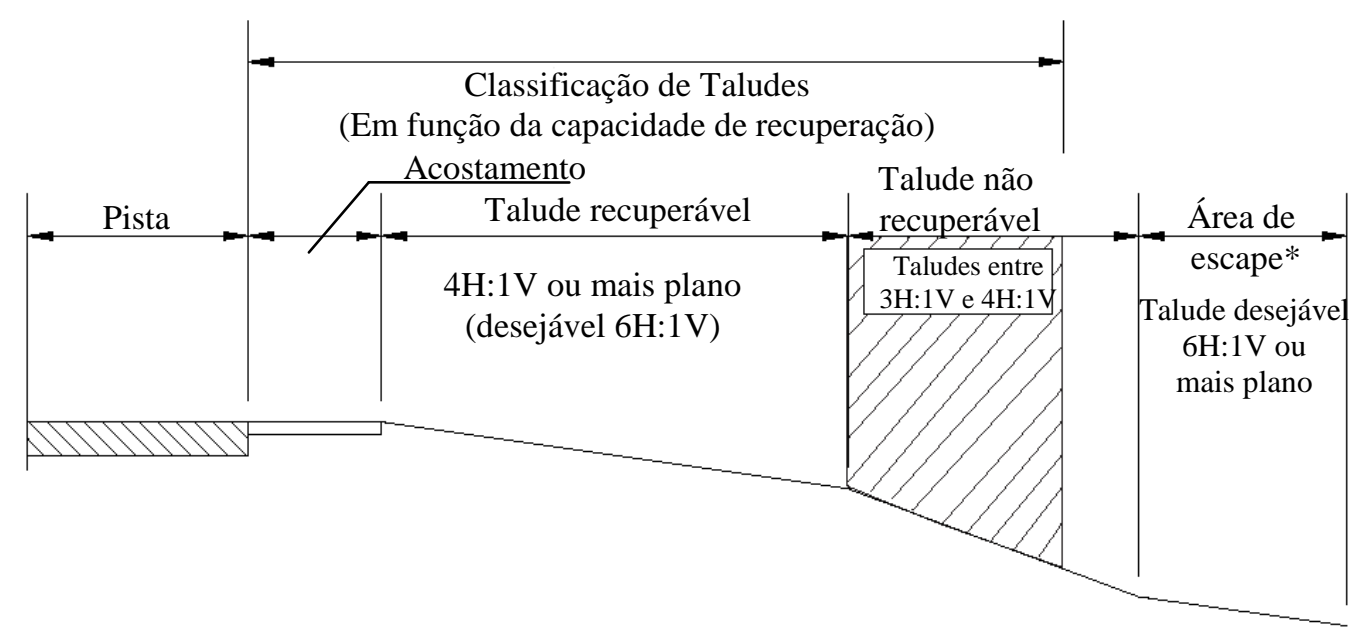

*A Área de Escape é adicional ao espaço da zona livre, necessária, pois a parcela da Zona Livre Requerida (área sombreada) cai sobre o talude não-recuperável. A largura da Área de Escape é igual à parcela da Distância da Zona Livre que é localizada sobre o talude não-recuperável.

Figura 2.3 - Classificação de taludes de aterro. (AASHTO, 2002, adaptada)

\section{3 ÁRVORES NA LATERAL DA VIA}

Para se avaliar o perigo relacionado à lateral da via, devem-se conhecer a contagem de tráfego diário; a probabilidade da ocorrência de um acidente, levando em conta os limites de velocidade; o projeto geométrico do trecho existente da pista da rodovia; a localização de obstáculos fixos; a localização e a densidade de árvores ou de outro tipo de vegetação, uma vez que as árvores e os arbustos de grande altura constituem um problema de segurança para os motoristas.

Sendo assim sendo, as árvores são potenciais obstruções em virtude do seu tamanho e de sua localização em relação ao tráfego. Para isso existem duas opções de tratamento que consiste na remoção ou na proteção das árvores.

A remoção de árvores individuais deve ser considerada quando essas árvores são definidas tanto como obstruções quanto por estarem em um local onde são suscetíveis de serem atingidas. Essas árvores podem ser identificadas pelos históricos de acidentes passados em locais semelhantes, por marcas indicando acidentes anteriores ou por pesquisas de campo.

A remoção de árvores individuais não reduzirá a probabilidade de que um veículo deixe a pista naquele ponto, mas diminuirá a gravidade do acidente resultante. Como a 
remoção da árvore pode ser cara e ter impactos ambientais adversos, é importante que isso seja feito apenas quando se mostrar eficaz. Por exemplo, taludes com inclinação $3 \mathrm{H}: 1 \mathrm{~V}$ e mais planos podem ser traspassáveis, mas um veículo em um talude de $3 \mathrm{H}: 1 \mathrm{~V}$ normalmente irá atingir o fundo. Assim, se houver várias árvores no pé do talude, a remoção de árvores isoladas sobre o talude não irá reduzir significativamente o risco de um acidente. Do mesmo modo, se a zona livre lateral estabelecida para uma determinada rodovia é de $7 \mathrm{~m}$ (incluindo o acostamento), a remoção de árvores a partir desse ponto não vai alterar muito o risco de acidentes.

Se uma árvore (ou grupo de árvores) está em um local vulnerável e é de difícil remoção, um dispositivo de contenção lateral deve ser utilizado para evitar o choque dos veículos com as árvores. No entanto, a barreira lateral somente deve ser utilizada se a gravidade de atingir a árvore é maior do que a de atingir a barreira.

De acordo com AASHTO (2002), nos Estados Unidos, as colisões de veículos simples com árvores representam quase $25 \%$ das colisões fatais com obstáculos fixos, resultando na morte de aproximadamente 3.000 pessoas por ano.

O problema é mais grave no caso de grupos de árvores ou no caso do não alinhamento das árvores. O agrupamento de árvores e sua localização são fatores mais preocupantes do que a altura das mesmas, principalmente dentro da zona livre de construções de novas rodovias e de reconstruções, onde, em geral, as árvores de grande porte precisam ser retiradas.

Um dos métodos eficientes e de baixo custo adotados quando existem árvores na lateral da via é o emprego de sinalização lateral de alto impacto, como os sonorizadores, os delineadores verticais ("sargentos") e outros sinais. Melhorias como reconstrução de curvas ou a ampliação do acostamento são mais onerosas.

Nos Estados Unidos, segundo AASHTO (2002), as árvores devem ser removidas quando localizadas:

- Dentro dos limites de 2,44 m da seção da pista de vias principais.

- Dentro dos limites de 2,44 $\mathrm{m}$ da pista de vias locais com um volume de tráfego de 500 veículos ou mais por dia.

- Dentro dos limites de 1,8 m de pistas locais com uma contagem de tráfego menor do que 500 veículos por dia. 
Outros fatos podem justificar a remoção de árvores, propiciando uma lateral da via que perdoa, como no caso de uma fila de árvores, uma vez que oferecem ao condutor uma dificuldade de reação ainda maior.

Por outro lado, há casos que justificam a manutenção das árvores de acordo com AASHTO (2002), entre os quais:

- Por questões paisagísticas;

- Se forem raras ou se estiverem em extinção;

- Se estiverem em áreas em que a remoção afete negativamente a qualidade da água ou das zonas úmidas ou resulte em erosão ou em efeitos de sedimentação.

No Brasil, IPR - Instituto de Pesquisas Rodoviárias (2010), indica que árvores ou arbustos de grande altura constituem um problema de segurança para os motoristas. Por esta razão, deve ser adotado o procedimento de remover todas as árvores e arbustos com mais de $10 \mathrm{~cm}$ de diâmetro situados na área de recuperação lateral de todas as rodovias com tráfego de alta velocidade. Além disso, não deve ser permitido o plantio de árvores pequenas ou arbustos que possam crescer e atingir certas condições consideradas inseguras. IPR (2010), também estabelece que as árvores de pequeno diâmetro devem ser cortadas no máximo a uma altura de $10 \mathrm{~cm}$ do solo e as de grande diâmetro no nível do solo.

Árvores de quaisquer dimensões em um talude devem ser cortadas ao nível do solo do talude para evitar o problema de provocarem o descontrole e mesmo o tombamento ou rolamento de um veículo, como mostrado na Figura 2.4.
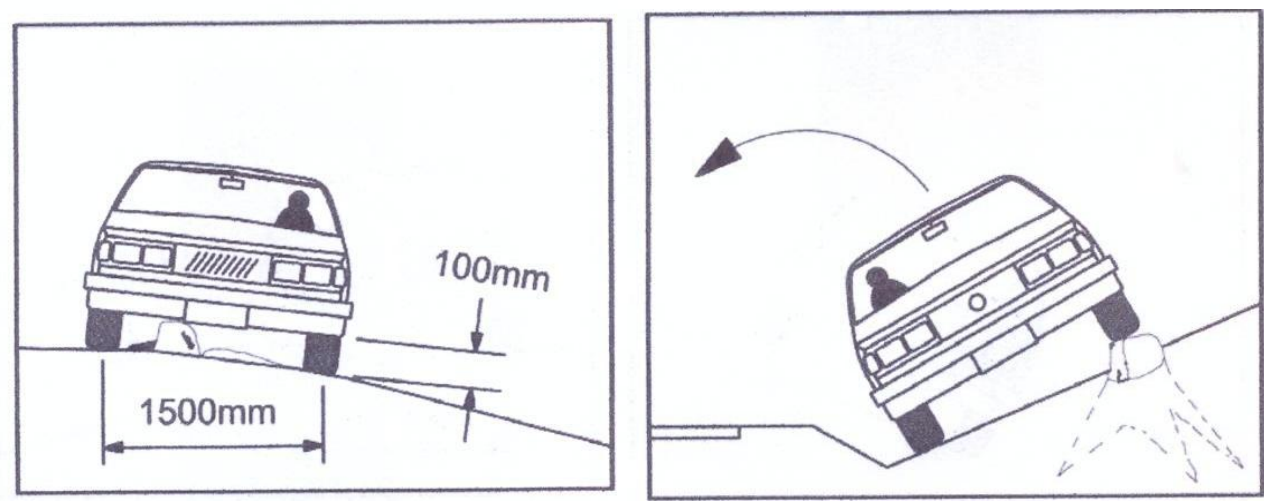

Figura 2.4 - Veículo batendo em um tronco de árvore. (IPR, 2010)

Como orientação, as árvores não devem ser plantadas dentro das áreas de recuperação laterais, mesmo as de pequeno porte, em virtude de poderem ser atingidas por veículos desgovernados. Árvores plantadas em frente a barreiras de contenção, quando adquirem certo 
porte podem-se inclinar após o choque, levando o veículo a ultrapassar ou subir na barreira, aumentando, assim, a severidade do acidente.

Árvores de grande porte, no lado interno de uma curva, ao atingirem maior porte, podem reduzir de forma considerável a distância de visibilidade, como mostra a Figura 2.5.

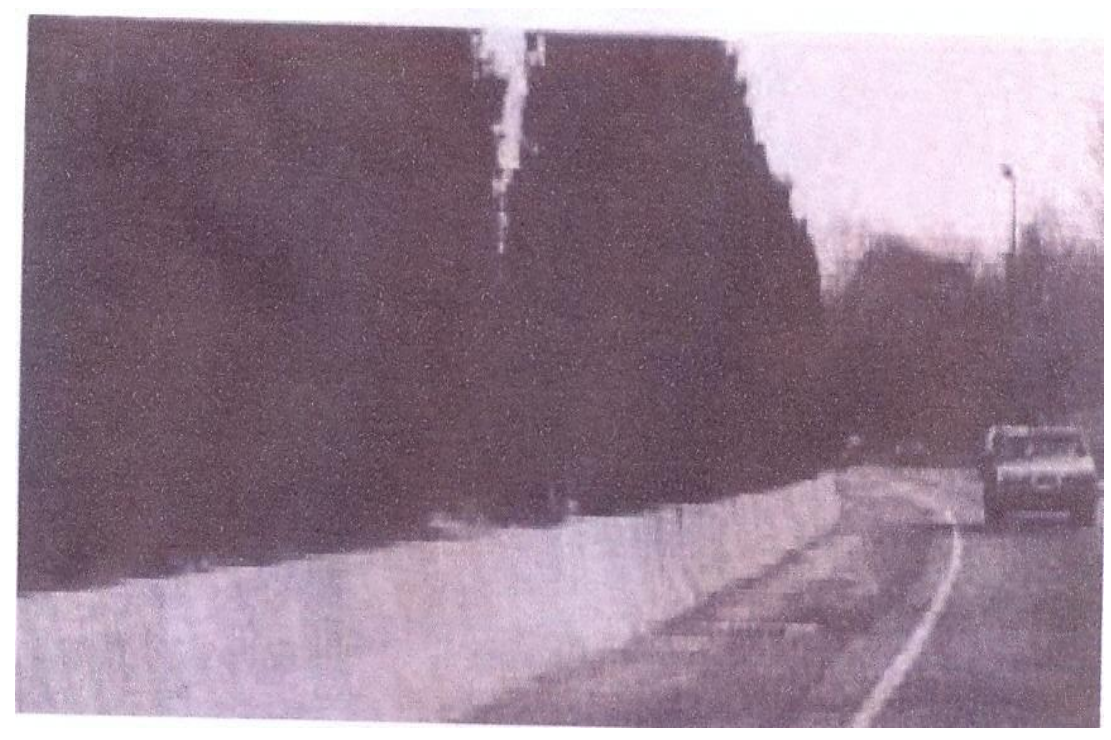

Figura 2.5 - Paisagismo inadequado. (IPR, 2010).

Portanto, a vegetação ao longo de uma rodovia pode limitar a visão que os motoristas têm dos pedestres, animais, sinais e semáforos, da estrada à sua frente e de outros veículos. Interseções sem controle em local plano às vezes, têm sua visibilidade prejudicada pelo capim alto; assim como lavouras muito próximas da rodovia, também podem prejudicar a visibilidade de um veículo que se aproxima da interseção.

Como as árvores causam mais acidentes fatais que quaisquer outros objetos fixos, a sua remoção na lateral de rodovias com tráfego de alta velocidade é indispensável para a segurança. 


\section{BARREIRAS DE CONTENÇÃO}

No capítulo 3 é descrito a necessidade de colocação, os tipos, os testes de resistência, a escolha e o projeto de barreiras de contenção na lateral das rodovias. É descrito também os dispositivos de contenção para motocicletas, as necessidades de pedestres e ciclistas nas rodovias que não tem controle pleno de acesso. Também é tratado o uso de amortecedores de impacto, barreiras de contenção frontal e o seu uso e a sua construção no Brasil segundo a norma ANBT (2007).

\subsection{BARREIRAS DE CONTENÇÃO NA LATERAL DA PISTA}

Barreiras de contenção são dispositivos instalados longitudinalmente na faixa lateral da via com a finalidade de proteger os veículos de choques com objetos fixos rígidos (naturais ou artificiais), queda em barrancos e outros espaços vazios, entrada em locais perigosos (lagos, pântanos etc.) situados próximos da pista. As barreiras de contenção também são conhecidas como defensas ou guardrails.

\subsection{NECESSIDADE DE BARREIRAS DE CONTENÇÃO LATERAL}

O emprego de barreiras de contenção visa somente reduzir a gravidade dos acidentes no local em que são implantadas, e não reduzir o número de acidentes, que, em geral, tende a aumentar em razão da presença da barreira.

A decisão da instalação de barreiras de contenção pode depender de alguma medida da análise subjetiva do projetista acerca dos elementos e condições da faixa lateral da via. Se as consequências da saída da pista forem consideradas mais graves do que o choque com uma barreira de contenção, esta será, considerada necessária. No entanto, existem casos em que, não se pode precisar o que oferece maior risco - se a barreira de contenção ou a sua ausência.

A eficiência da implantação de uma barreira de proteção também pode ser justificada por meio da análise custo-benefício, levando em conta elementos como velocidade, volume de tráfego, custos de instalação, manutenção e acidente. O custo-benefício desses elementos é comparado tanto no caso da presença quanto no caso da ausência da barreira de tráfego. Em geral, são três as opções existentes:

- remover ou reduzir a área de preocupação de forma que esta não mais necessite da barreira, 
- instalar uma barreira de tráfego apropriada,

- deixar a área de preocupação desprotegida.

Dois fatores básicos a serem considerados na determinação da necessidade de barreiras de proteção de tráfego são a altura dos taludes e a sua declividade lateral, conforme mostrado na Figura 3.1, extraída da ABNT (2007). Taludes com combinações de altura e declividade situados abaixo da curva não necessitam de proteção, a não ser que tenham obstáculos dentro da zona livre.

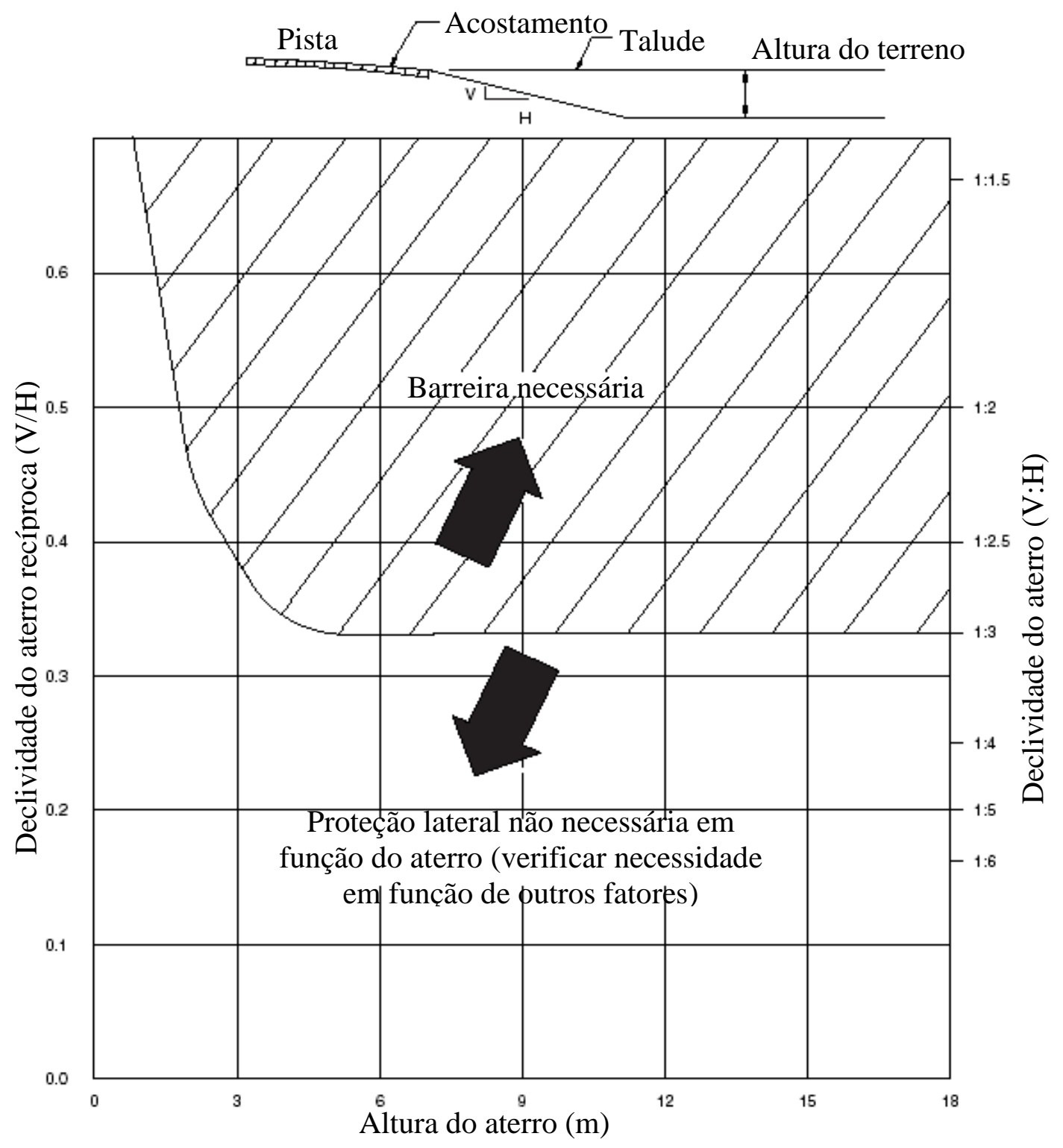

Figura 3.1 - Necessidade de proteções laterais em função de talude. (ABNT, 2007)

Os obstáculos na faixa lateral de rodovias incluem os terrenos não traspassáveis e os objetos fixos naturais (árvores, p. ex.) ou construídos artificialmente (como galerias de 
escoamento ou bueiros). A necessidade da barreira de tráfego para os obstáculos depende do seu tipo e da probabilidade de serem atingidos. Uma barreira de tráfego só deve ser instalada quando for evidente que o resultado da colisão de um veículo com a barreira é menos severo do que uma colisão com um objeto sem proteção.

Na Tabela 3.1 são descritas características do espaço lateral da pista que exigem ou não a colocação de barreira de contenção lateral.

Tabela 3.1 - Necessidade ou não de barreiras na faixa lateral das rodovias (AASHTO, 2002) $)^{1,2}$.

\begin{tabular}{|c|c|}
\hline Obstáculo & Necessidade. \\
\hline Colunas, pilar e parapeitos de pontes & Geralmente é solicitada proteção. \\
\hline Grandes rochas arredondadas & $\begin{array}{l}\text { Decisão baseada na natureza da superfície } \\
\text { das rochas e na probabilidade de impacto. }\end{array}$ \\
\hline $\begin{array}{l}\text { Galerias de escoamento ou bueiros, dutos, } \\
\text { e paredões. }\end{array}$ & $\begin{array}{l}\text { Decisão baseada no tamanho, forma e } \\
\text { localização desses elementos. }\end{array}$ \\
\hline Cortes e aterros de taludes (suaves) & Geralmente não é solicitada proteção. \\
\hline Cortes e aterros de taludes (íngremes) & $\begin{array}{l}\text { Decisão baseada na probabilidade de } \\
\text { impacto. }\end{array}$ \\
\hline Valas (paralelas) & $\begin{array}{l}\text { Preferidas para seções transversais com } \\
\text { taludes de corte e aterro com mudanças } \\
\text { graduais e abruptas. }\end{array}$ \\
\hline Valas (transversais) & $\begin{array}{l}\text { Geralmente é solicitada proteção se a } \\
\text { probabilidade de impacto frontal for alta. } \\
\text { (Head-on impact). }\end{array}$ \\
\hline Diques & $\begin{array}{l}\text { Decisão baseada em aterros de taludes (ver } \\
\text { Figura 3.1). }\end{array}$ \\
\hline Muros de contenção & $\begin{array}{l}\text { Decisão baseada na angulação suave } \\
\text { relativa da parede e ângulo máximo de } \\
\text { impacto antecipado. }\end{array}$ \\
\hline $\begin{array}{lrlll}\text { Suportes } & \text { e postes } & \text { de } & \text { sinalização } & \text { e } \\
\text { iluminação } & & & & \\
\end{array}$ & $\begin{array}{l}\text { Geralmente é requerida proteção para os } \\
\text { suportes e postes não separáveis. }\end{array}$ \\
\hline Suportes de sinais de trânsito ${ }^{4}$ & $\begin{array}{l}\text { Suportes de sinais de trânsito isolados em } \\
\text { uma zona livre em vias rurais de alta } \\
\text { velocidade podem requerer proteção. }\end{array}$ \\
\hline Árvores & $\begin{array}{l}\text { Decisão baseada em situações específicas } \\
\text { do local. }\end{array}$ \\
\hline $\begin{array}{l}\text { Postes de utilidade pública (telefone, } \\
\text { energia elétrica etc.) }\end{array}$ & $\begin{array}{l}\text { Pode ser requerida proteção para cada } \\
\text { caso. }\end{array}$ \\
\hline Corpos/poças de água permanente & $\begin{array}{l}\text { Decisão baseada na localização e } \\
\text { profundidade da água e probabilidade de } \\
\text { transbordamentos. }\end{array}$ \\
\hline
\end{tabular}

1. A proteção para terrenos não traspassáveis ou obstáculos na faixa lateral da via normalmente só é necessária quando estiverem dentro da zona livre e não puderem ser removidos, deslocados ou separados de forma prática e econômica, estabelecendo-se que a barreira de proteção de tráfego fornece maior segurança do que sua ausência.

2. Situações especiais quanto à colocação ou não de barreiras de proteção são geralmente decididas a partir da análise de acidentes tanto no local como em um local semelhante. 
3. Quando possível, os suportes e postes de sinalização e iluminação que correm o risco de serem atingidos por motoristas devem ser isolados, independente de sua distância na faixa lateral da rodovia. A colocação e a localização de suportes e postes separáveis também devem levar em conta a segurança dos pedestres (para não serem atingidos por fragmentos resultantes de impactos).

4. Na prática, poucos suportes de sinalização de trânsito são protegidos (como luzes que piscam, p. ex.). Se a proteção é considerada necessária, são utilizados amortecedores de impacto em vez de barreiras de proteção de tráfego longitudinais.

$\mathrm{Na}$ maior parte dos objetos artificiais de uma rodovia, quando estes são projetados para reduzirem os riscos aos motoristas, a proteção por meio de barreiras se mostra desnecessária. Este é o caso dos elementos de drenagem, como bueiros e valas.

\subsection{TIPOS DE BARREIRAS DE CONTENÇÃO}

De acordo com a NBR 15486 da Associação Brasileira de Normas Técnicas (ABNT, 2007), dependendo da deflexão característica do sistema sob impacto, os sistemas de contenção lateral são em geral classificados como flexíveis, semi-rígidos ou rígidos, como conceituado a seguir:

Sistemas flexíveis - Exemplos: barreiras de cabo de aço, defensas metálicas de dupla onda (com poste fraco) e barreira de madeira reforçada com aço. Quanto mais flexível o sistema, mais energia de impacto é dissipada pela deflexão da barreira, e as forças de impacto impostas aos veículos são menores.

Sistemas semi-rígidos - Exemplos: viga-caixote (com poste fraco), defensa metálica de dupla onda, defensa metálica de tripla onda, defensa metálica de tripla onda modificada e barreiras de madeira reforçadas com aço.

Sistemas rígidos - Exemplos: barreira de concreto tipo New Jersey, barreira de concreto tipo-F, muro liso vertical e muro com revestimento em pedra.

A seguir são comentados os principais tipos de barreiras.

Defensas Metálicas ou Guardrails - De acordo com o DER-SP (2006), defensa metálica é:

“[...] o dispositivo ou sistema de proteção contínua, constituído por perfis metálicos implantados ao longo das vias com circulação de veículos projetados na sua forma, resistência e dimensões, para absorver a energia cinética, através da deformação do dispositivo, de veículos desgovernados [...]."

Pereira (2008), conceitua as defensas metálicas como lâminas de aço galvanizado a fogo por imersão total, que possuem alta tecnologia e uma elevada resistência na qual o material amortece o veículo em caso de colisão, ao contrário do que ocorre com as barreiras de concreto. De acordo com pesquisa realizada pelo Departamento de Estradas e Rodagem do 
Estado de São Paulo (DER-SP, 2006), locais que utilizam essas proteções obtiveram um decréscimo em média de $90 \%$ no registro de acidentes fatais.

O DER - SP (2006) indica quatro tipos de defensas:

Defensa simples - é o tipo de defensa metálica formada por apenas uma linha de lâminas e suportada por uma única linha de postes;

Defensa dupla - é o tipo de defensa metálica formada por duas linhas de lâminas paralelas e suportada por uma única linha de postes;

Defensa maleável - é o tipo de defensa metálica, simples ou dupla, composto por lâminas, postes maleáveis, espaçadores maleáveis, garras de fixação, plaquetas, cintas (somente no caso de defensas simples), parafusos, porcas e arruelas. Este dispositivo tende a se deformar com o impacto de veículos. Neste dispositivo, o espaçamento entre postes é de 4 m no modelo duplo e de 2 m no modelo simples;

Defensa semi-maleável - é o modelo de defensa metálica, simples ou dupla, composto por lâminas, postes semi-maleáveis, espaçadores simples, calços, plaquetas, parafusos, porcas e arruelas. Este modelo tem o poste mais rígido do que o da defensa maleável, conferindo-lhe maior tendência de deformação nas lâminas e nos espaçadores simples. Neste dispositivo o espaçamento entre postes é de $4 \mathrm{~m}$.

A NBR 6971 (ABNT, 1999), considera ainda dois outros tipos de defensas:

Defensas semi-rígidas - são obtidas a partir da defensa semi-maleável através da eliminação dos espaçadores simples;

Defensas rígidas - também são obtidas a partir da defensa semi-maleável pela diminuição do espaçamento entre os postes.

Os tipos de barreiras mais utilizados estão relacionados na Tabela 3.2. 
Tabela 3.2 - Barreiras de proteção na faixa lateral de vias e níveis de testes de aprovação (AASHTO, 2002)

Sistema de barreira de proteção

a) SISTEMAS FLEXÍVEIS

- Barreiras de Cabo de Aço Triplo (Poste Leve) (SGR01 a e b)

- Viga-W (Poste Leve) (SGR02)

- Viga-W (Poste Leve) (SGR02) modificado

- Barreira de Proteção de Madeira Dura Estética

b) SISTEMAS SEMI-RÍGIDOS

- Viga Caixote (Poste fraco) (SGR03)

- Defensa Metálica Dupla Viga-W (Poste Pesado)

- Poste de Aço ou Madeira com Bloco de Madeira ou Plástico (SGR04a e b)

- Poste de Aço com Bloco de Aço (SGR04a)

- Defensa Metálica de Tripla Onda (Poste Pesado)

- Poste de Aço ou Madeira com Bloco de Madeira ou Plástico (SGR09a e c)

- Viga Tripla Modificada (Poste Pesado) (SGR09b)

- Guardrail Estético Merritt Parkway

- Guardrail de Toras de Madeira Reforçadas com Aço

c) SISTEMAS RÍGIDOS (CONCRETO E ALVENARIA):

- Barreira de Formato (tipo) Seguro New Jersey

- 810 mm de altura (SGM 11a)

- 1070 mm de altura (SGM 11b)

- Barreira de Formato F

- 810 mm (SGM 10a)

-1070 mm (GM10b)

- Barreira de Concreto

- Muro liso vertical

$-810 \mathrm{~mm}$

$-1070 \mathrm{~mm}$

- Barreira de Talude Único

$-810 \mathrm{~mm}$

$-1070 \mathrm{~mm}$
NT-3

NT-3

Nível do teste

NT-3

NT-2

NT-3

NT-3

NT-2

NT-3

NT-4

NT-3

NT-3

NT-4

NT-5

NT-4

NT-5

NT-4

NT-5

NT-4

NT-5 
- Barreira Ontário Muro Alto do Canteiro Central (SGM12)

NT-5

-Barreiras de Paredes de Alvenaria de Pedra/Parede de Alvenaria

NT-3 Pré-Moldada

As seções de transição são necessárias para a continuidade da proteção lateral quando duas barreiras de proteção diferentes são unidas. A seção de transição deve aumentar gradualmente a rigidez entre o sistema de menor rigidez para o de maior rigidez, de modo a fornecer uma transição segura.

Todo sistema de contenção deve ser introduzido e finalizado com segurança. Desse modo, todo terminal de barreira que tenha a possibilidade de ser impactado deve ter características que reduzam os efeitos do impacto.

\subsection{TESTES DE RESISTÊNCIA DAS BARREIRAS DE CONTENÇÃO}

As barreiras de proteção de tráfego na faixa lateral da via têm como função principal impedir que um veículo saia do acostamento e colida com um objeto fixo ou com uma irregularidade do terreno (o que seria mais perigoso do que uma colisão com a própria barreira), também possibilitando o redirecionamento do veículo.

Os dispositivos de contenção em geral são projetados para veículos leves, não apresentando pois, o mesmo desempenho para veículos pesados. Apesar disso, alguns dispositivos têm sido desenvolvidos para conter e redirecionar veículos pesados com o porte de caminhões articulados.

Dessa forma, fatores devem ser considerados na escolha do tipo de contenção a ser utilizado em um trecho de rodovia:

- Velocidade dos veículos;

- Porcentagem de veículos pesados na composição do tráfego;

- Características geométricas adversas (como curvas e rampas acentuadas, geralmente combinadas com distâncias de visibilidade baixa);

- Consequências dos acidentes (p. ex., caso um veículo pesado penetre ou atravesse o dispositivo de contenção).

Nos Estados Unidos, as condições de teste e os critérios de avaliação para cada tipo de dispositivo de contenção na lateral da via, em especial as defensas metálicas são especificadas conforme TRB - Transportation Research Board (1993). No Brasil são seguidas as mesmas especificações (Tabela 3.3), conforme preconizado na NBR 15486 (ABNT, 2007). 
Tabela 3.3 - Níveis de testes de contenção (ABNT, 2007)

\begin{tabular}{|c|c|c|c|}
\hline Níveis de Testes & $\begin{array}{c}\text { Tipos e Características } \\
\text { do Veículo }\end{array}$ & $\begin{array}{l}\text { Velocidade de impacto } \\
\mathrm{km} / \mathrm{h}\end{array}$ & $\begin{array}{c}\text { Ângulo de impacto } \\
\text { Graus }\end{array}$ \\
\hline \multirow{3}{*}{1} & $820 \mathrm{C}$ & 50 & 20 \\
\hline & $700 \mathrm{C}$ & 50 & 20 \\
\hline & $2000 \mathrm{P}$ & 50 & 25 \\
\hline \multirow{3}{*}{2} & $820 \mathrm{C}$ & 70 & 20 \\
\hline & $700 \mathrm{C}$ & 70 & 20 \\
\hline & $2000 \mathrm{P}$ & 70 & 25 \\
\hline \multirow{3}{*}{3} & $820 \mathrm{C}$ & 100 & 20 \\
\hline & $700 \mathrm{C}$ & 100 & 20 \\
\hline & $2000 \mathrm{P}$ & 100 & 25 \\
\hline \multirow{4}{*}{4} & $820 \mathrm{C}$ & 100 & 20 \\
\hline & $700 \mathrm{C}$ & 100 & 20 \\
\hline & $2000 \mathrm{P}$ & 100 & 25 \\
\hline & $8000 \mathrm{~S}$ & 80 & 15 \\
\hline \multirow{4}{*}{5} & $820 \mathrm{C}$ & 100 & 20 \\
\hline & $700 \mathrm{C}$ & 100 & 20 \\
\hline & $2000 \mathrm{P}$ & 100 & 25 \\
\hline & $36000 \mathrm{~V}$ & 80 & 15 \\
\hline \multirow{4}{*}{6} & $820 \mathrm{C}$ & 100 & 20 \\
\hline & $700 \mathrm{C}$ & 100 & 20 \\
\hline & $2000 \mathrm{P}$ & 100 & 25 \\
\hline & $36000 \mathrm{~T}$ & 80 & 15 \\
\hline
\end{tabular}

C - Small Car (Automóvel); P - Pickup Truck (Caminhonete); S - Single-Unit Van Truck (Caminhão Utilitário); $\mathrm{V}$ - Tractor/Van Trailer (Caminhão trator + Semi-reboque baú); $\mathrm{T}$ - Tractor/tank trailer (Caminhão articulado).

São estabelecidos seis níveis de testes de colisão que variam de acordo com a velocidade de impacto, de 35 a $100 \mathrm{~km} / \mathrm{h}$, e com ângulos de colisão entre $0^{\circ}$ a $25^{\circ}$. No estabelecimento dos critérios atuais levam-se em conta as barreiras de tráfego, as avaliações de risco dos ocupantes, a adequação estrutural e o comportamento dos veículos após a colisão, sendo ainda considerados diferentes pesos de veículos, velocidades e ângulos de impacto.

Os níveis de teste NT-1, NT-2, e NT-3 obtiveram êxito com um veículo de $820 \mathrm{~kg}$ (automóveis) colidindo com uma barreira de proteção de tráfego em um ângulo de $20^{\circ}$ e uma caminhonete de $2.000 \mathrm{~kg}$ colidindo com uma barreira em um ângulo de $25^{\circ}$ com velocidades 
de $50 \mathrm{~km} / \mathrm{h}, 70 \mathrm{~km} / \mathrm{h}$ e $100 \mathrm{~km} / \mathrm{h}$, respectivamente. O teste NT-4, acrescentou um caminhão unitário de $8.000 \mathrm{~kg}$, com um ângulo de impacto de $15^{\circ}$, a $80 \mathrm{~km} / \mathrm{h}$, com a matriz do teste NT3. O teste NT-5, substituiu um caminhão trator + semi-reboque (baú) de $36.000 \mathrm{~kg}$ por um caminhão unitário, e o teste NT-6, substituiu um caminhão trator + semi-reboque (tanque) de $36.000 \mathrm{~kg}$ (AASHTO, 2002).

São as agências permissionárias que definem os níveis de teste de acordo com as características de segurança das rodovias, levando em conta fatores como condições do local, condições e volume do tráfego, e ainda a relação custo-eficácia desses fatores de segurança por elas selecionados.

Pressupõe-se que as características habilitadas para o NT-1 são aceitáveis para rodovias e vias urbanas locais de volume muito baixo e de baixa velocidade. Pressupõe-se que as características habilitadas para o NT-2 são apropriadas para a maioria das vias urbanas locais e rodovias urbanas coletoras. A maioria das características dos testes de colisão em uso nas rodovias nos EUA tem obtido êxito nos testes de nível 3. As características de segurança habilitadas para o NT-3 são aceitáveis para uma série ampla de velocidades altas em rodovias arteriais. Já os NT4 a 6 são provavelmente determinados pelo volume de veículos pesados na corrente de tráfego e são aplicáveis apenas para barreiras longitudinais. (TRB, 1993, tradução do autor).

\subsection{ESCOLHA DA BARREIRA DE CONTENÇÃO}

O melhor sistema de contenção é, em geral, o que oferece a maior proteção ou relação custo-benefício para um caso específico. Na Tabela 3.4 são relacionados os fatores a serem considerados para a adequada escolha desse tipo de dispositivo. 
Tabela 3.4 - Critérios de seleção para barreiras de proteção na faixa lateral de rodovias (AASHTO, 2002).

\section{Capacidade de Desempenho}

A barreira deve ser estruturalmente capaz de conter e redirecionar um veículo.

\section{Deflexão}

A deflexão esperada da barreira não deve exceder a distância disponível para a deflexão.

\section{Condições do Local}

Talude nas proximidades da barreira e a distância da pista de rolagem podem impedir o uso de certas barreiras.

\section{Compatibilidade}

A barreira deve ser compatível com o apoio final e ser capaz de fazer transição com outras barreiras (tais como parapeito de pontes).

\section{Custo}

Sistemas de barreira padrão são relativamente consistentes com relação ao custo, mas barreiras de alto desempenho podem ter um custo bem mais alto.

\section{Manutenção}
A. Rotina
Poucos sistemas requerem uma grande quantidade de manutenção de rotina.
B. Colisão
Em geral, sistemas flexíveis ou semi-rígidos requerem muito
C. Material mais manutenção após uma colisão do que sistemas rígidos ou de alto desempenho.
Quanto menos sistemas diferentes forem utilizados, menos itens em
D. Simplicidade estoque e menor espaço de armazenagem são requeridos.
Designs simples, além de terem menor custo, requerem pessoas menos experientes para sua reconstrução.

\section{Estética}

Ocasionalmente, a estética de uma barreira é um fator importante para sua seleção.

\section{Experiência de campo}

Os requerimentos de desempenho e manutenção de sistemas disponíveis deveriam ser monitorados para identificar problemas que poderiam ser minimizados ou eliminados pelo uso de um tipo diferente de barreira.

As características para a seleção do tipo de dispositivo de contenção indicadas na Tabela 3.4 são detalhadas a seguir.

Desempenho - A primeira decisão a ser tomada na seleção de uma barreira de tráfego apropriada é sobre o nível de desempenho requerido para conter e redirecionar o veículo conforme o projeto, de modo seguro.

Características de Deflexão - Quando o nível de desempenho ou a capacidade da barreira de proteção for determinado, a distância disponível para a deflexão pode ser o fator determinante na seleção do tipo de barreira a ser instalado.

Condições do Local - A escolha do tipo de barreira é influenciada pelas condições locais. Se a barreira for colocada em um talude mais íngreme do que $10 \mathrm{H}: 1 \mathrm{~V}$, aproximadamente, uma barreira flexível ou semi-rígida deve ser utilizada. A declividade do 
terreno de aproximação e a distância da pista podem excluir o uso de algum tipo de dispositivo de contenção.

Compatibilidade - Em geral, as agências rodoviárias usam poucos tipos de sistemas de barreiras de proteção de tráfego nas laterais de rodovias em construções novas (porque as novas construções já incluem a lateral da via nos projetos geométricos) ou em reformas (para a redução do custo-benefício). Por outro lado, o dispositivo de contenção deve ser compatível com o terminal de ancoragem planejado e ser capaz de fazer transição com outros sistemas adjacentes.

Manutenção - Agrupa-se em três categorias: manutenção de rotina, manutenção imediata após o impacto e estoque de determinados materiais ou sua fácil obtenção para a manutenção de rotina após colisão. Note-se que após uma colisão, os sistemas flexíveis e semi-rígidos requerem uma manutenção maior do que os sistemas rígidos.

Custos - Os custos de manutenção de rotina não variam muito para os diferentes tipos de sistemas de barreira de proteção. Por outro lado, uma vez que a maioria dos custos de manutenção se deve ao reparo após acidente, os custos de reparação têm um papel importante na seleção da barreira. Em áreas onde o volume de tráfego é alto e os acidentes com barreiras são freqüentes, a utilização de barreiras de tráfego rígidas (como as de concreto) é a melhor escolha.

\subsection{PROJETO DE BARREIRAS DE CONTENÇÃO}

Após decidir sobre a necessidade da instalação de uma barreira de proteção em um local e ter selecionado o tipo de barreira, é preciso definir o projeto da barreira. Os principais fatores considerados são comentados a seguir.

\section{Afastamento lateral em relação à pista de rolamento}

A barreira deve ser implantada o mais longe possível da pista de rolamento, a fim de que o motorista tenha maior oportunidade de recuperar o controle do veículo sem se chocar contra a barreira. Também deve haver um alinhamento uniforme dos objetos laterais o que aumenta a segurança da rodovia reduzindo a preocupação e a reação dos motoristas (semelhantemente ao que se dá com os conjuntos de árvores já vistos).

Chama-se linha de afastamento à distância da borda da pista de rolamento, além da qual um objeto na lateral da via não será percebido como um obstáculo e onde haverá uma 
redução de velocidade pelo motorista ou uma mudança de posição do veículo na rodovia. Essa distância varia de acordo com a velocidade, conforme indicado na Tabela 3.5.

Tabela 3.5 - Valores sugeridos para o efeito do atrito lateral (AASHTO, 2002).

\begin{tabular}{cc}
\hline Velocidade de projeto $(\mathrm{km} / \mathrm{h})$ & Faixa do atrito lateral $(\mathrm{m})$ \\
\hline 130 & 3,7 \\
120 & 3,2 \\
110 & 2,8 \\
100 & 2,4 \\
90 & 2,2 \\
80 & 2,0 \\
70 & 1,7 \\
60 & 1,4 \\
50 & 1,1 \\
\hline
\end{tabular}

A distância entre a barreira e o objeto fixo rígido deve considerar a deflexão da barreira após sofrer um impacto, de modo a evitar o enganchamento do veículo no objeto fixo.

\section{Efeitos do terreno}

As condições do terreno entre a barreira e a pista de rolamento podem ter um efeito importante no desempenho da barreira. Independentemente do tipo de barreira a ser utilizado na faixa lateral de rodovias, do seu tamanho e do tipo do veículo que colide com ela, as colisões menos severas ocorrem, desde que, todas as rodas do veículo estejam no chão no momento de impacto e seu sistema de suspensão não seja comprimido nem distendido.

Assim, é preciso ter cuidado com guias e taludes na lateral da via, bem como com o sistema de drenagem (que deve ser colocado atrás do dispositivo de contenção ou enterrado). Do mesmo modo, deve-se evitar a combinação entre defensa metálica/meio-fio em trechos com alta velocidade e ângulos de impacto elevados. Não havendo alternativa, deve-se enrijecer a defensa metálica para evitar deflexão; no caso do meio-fio, este deve ter uma altura de, no máximo, dez centímetros. Cada caso deve ser analisado levando em conta a velocidade e as consequiências do choque do veículo.

\section{Deflexão lateral}

AASHTO (2002), considera que uma barreira na lateral da via deve ser sinalizada quando não estiver paralela à borda da pista de rolamento. A deflexão é normalmente usada para:

- Localizar o terminal da barreira mais distante da rodovia;

- Minimizar a reação do motorista diante de um obstáculo perto da estrada por meio da introdução gradual de uma instalação de barreira paralela; 
- Fazer transição de uma barreira na lateral da via para um obstáculo mais próximo da rodovia, tal como os parapeitos de proteção de uma ponte;

- Reduzir o comprimento total das lâminas necessárias.

A existência de deflexão lateral apresenta algumas desvantagens, sendo a primeira quanto maior a taxa de deflexão, maior o ângulo com o qual a barreira é atingida. Conseqüentemente, como o ângulo de impacto aumenta a gravidade do acidente também aumenta, principalmente no caso de barreiras rígidas e semi-rígidas. A segunda há um aumento da probabilidade de um veículo ser direcionado de volta ou para o meio da pista de rolamento após um impacto, o que é especialmente perigoso em rodovias de pista simples, pois o veículo pode ser redirecionado para o tráfego de passagem na direção oposta.

A taxa máxima de deflexão recomendada depende da velocidade do projeto da rodovia e do tipo de barreira, conforme indicado na Tabela 3.6.

Tabela 3.6 - Sugestão de deflexão lateral em função da velocidade de projeto.

(ABNT, 2007).

\begin{tabular}{cccc}
\hline & & \multicolumn{2}{c}{$\begin{array}{c}\text { Deflexão lateral atrás da linha de } \\
\text { preocupação }\end{array}$} \\
\cline { 3 - 4 } Projeto $(\mathrm{km} / \mathrm{h})$ & $\begin{array}{c}\text { Deflexão lateral dentro da } \\
\text { linha de preocupação }\end{array}$ & $\begin{array}{c}\text { Barreira } \\
\text { rígida }\end{array}$ & $\begin{array}{c}\text { Barreira semi- } \\
\text { rígida }\end{array}$ \\
\hline 110 & $30: 1$ & $20: 1$ & $15: 1$ \\
100 & $26: 1$ & $18: 1$ & $14: 1$ \\
90 & $24: 1$ & $16: 1$ & $12: 1$ \\
80 & $21: 1$ & $14: 1$ & $11: 1$ \\
70 & $18: 1$ & $12: 1$ & $10: 1$ \\
60 & $16: 1$ & $10: 1$ & $8: 1$ \\
50 & $13: 1$ & $8: 1$ & $7: 1$ \\
\hline
\end{tabular}

\section{Comprimento necessário}

Para determinar o comprimento necessário de um sistema de contenção lateral, o método mais simples é determinar graficamente o comprimento de barreira que intercepte a trajetória do veículo, tendo estabelecido um ângulo de impacto de no máximo $15^{\circ}$, e de modo que o veículo não atinja o obstáculo, conforme Figura 3.2 (tráfego unidirecional), Figura 3.3 (tráfego bidirecional) (ABNT, 2007). 


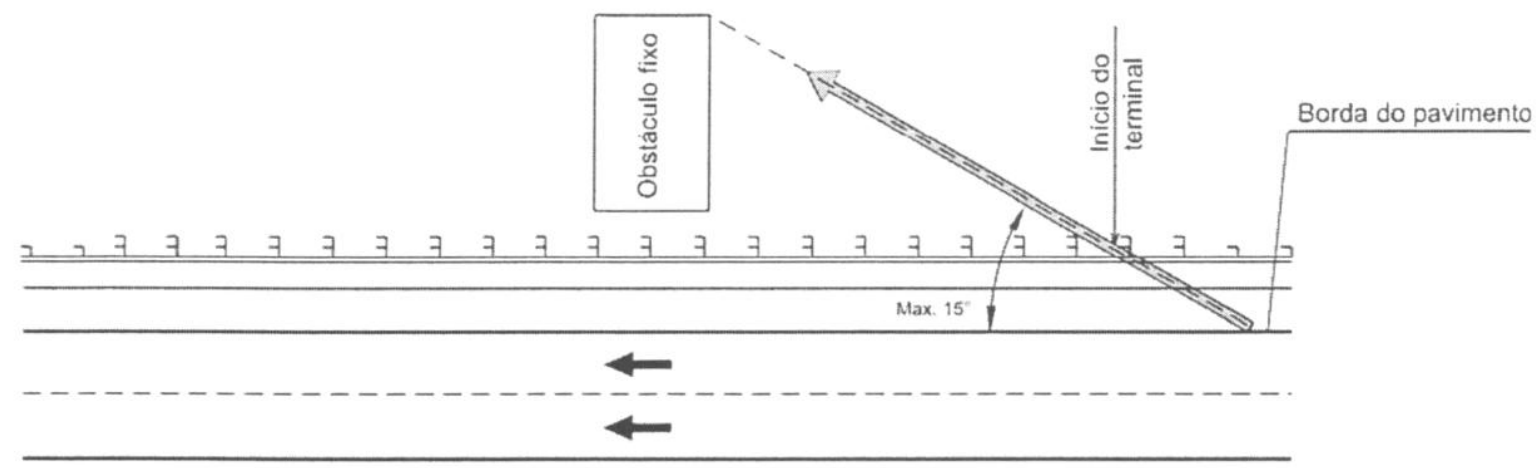

Figura 3.2 - Comprimento de barreira em tráfego unidirecional. (ABNT, 2007).

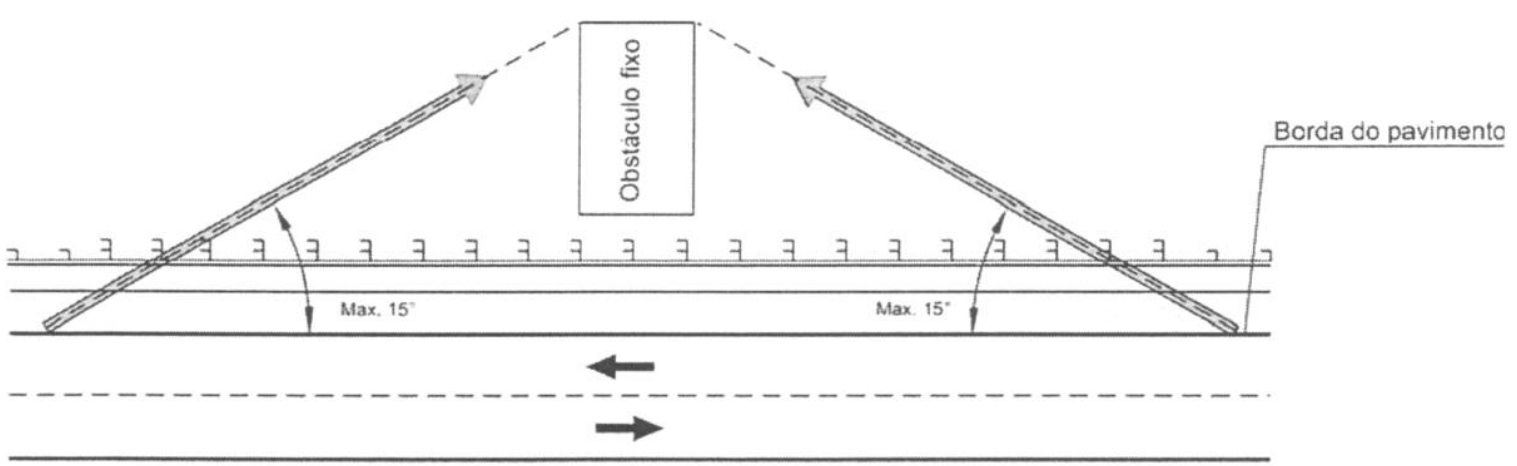

Figura 3.3 - Comprimento de barreira em tráfego bidirecional. (ABNT, 2007).

AASHTO (2002) preconiza o procedimento descrito a seguir para a determinação do comprimento de barreiras de contenção lateral (ver Figura 3.4).

Distância lateral da área de preocupação $\left(\mathbf{L}_{\mathbf{A}}\right)$ - É a distância da borda da pista de rolamento até a borda oposta em relação à rodovia do obstáculo a ser protegido. A seleção da distância $\mathrm{L}_{\mathrm{A}}$ apropriada é a parte mais crítica no processo de concepção.

Largura da zona livre $\left(\mathbf{L}_{\mathbf{C}}\right)$ - É a distância da borda da pista até um aterro ou um objeto fixo que se estende além da zona livre.

Comprimento da área de escape/saída $\left(\mathbf{L}_{\mathbf{R}}\right)$ - É a distância teórica necessária para um veículo que saiu da pista de rolamento voltar a parar. É medida a partir do ponto da obstrução ao longo da lateral da via até o ponto em que o veículo deixa a pista de rolamento.

Estas distâncias são variáveis baseadas nas velocidades de operação e na fricção disponível entre os pneus do veículo e o chão. Os números da Tabela 3.7 são baseados nos resultados dos ajustes encontrados por Hutchinson e Kennedy (1966), no estudo de enganchamentos de veículos no canteiro central em vias expressas e nas reações dos motoristas e nas características de parada de veículos com baixa velocidade. 
Quando as distâncias $\mathrm{L}_{\mathrm{A}}$ e $\mathrm{L}_{\mathrm{R}}$ forem estabelecidas, o comprimento da barreira necessário para um determinado local dependerá do comprimento tangente da barreira a montante da Área de interesse $\left(\mathrm{L}_{1}\right)$, de sua distância lateral da borda da pista de rolamento $\left(\mathrm{L}_{2}\right)$ e da taxa de deflexão lateral (a:b) especificada para a instalação.

Alguns fatores a serem considerados na seleção destas variáveis para o projeto de barreiras de proteção se ligam à necessidade de instalar a barreira de tráfego o mais longe possível da pista de rolamento para:

- diminuir a probabilidade de ser atingida, fornecendo ao motorista uma área suficiente traspassável e desobstruída,

- evitar que a barreira faça o motorista desacelerar, mudar de pista ou alterar sua posição dentro da pista em que se encontra.

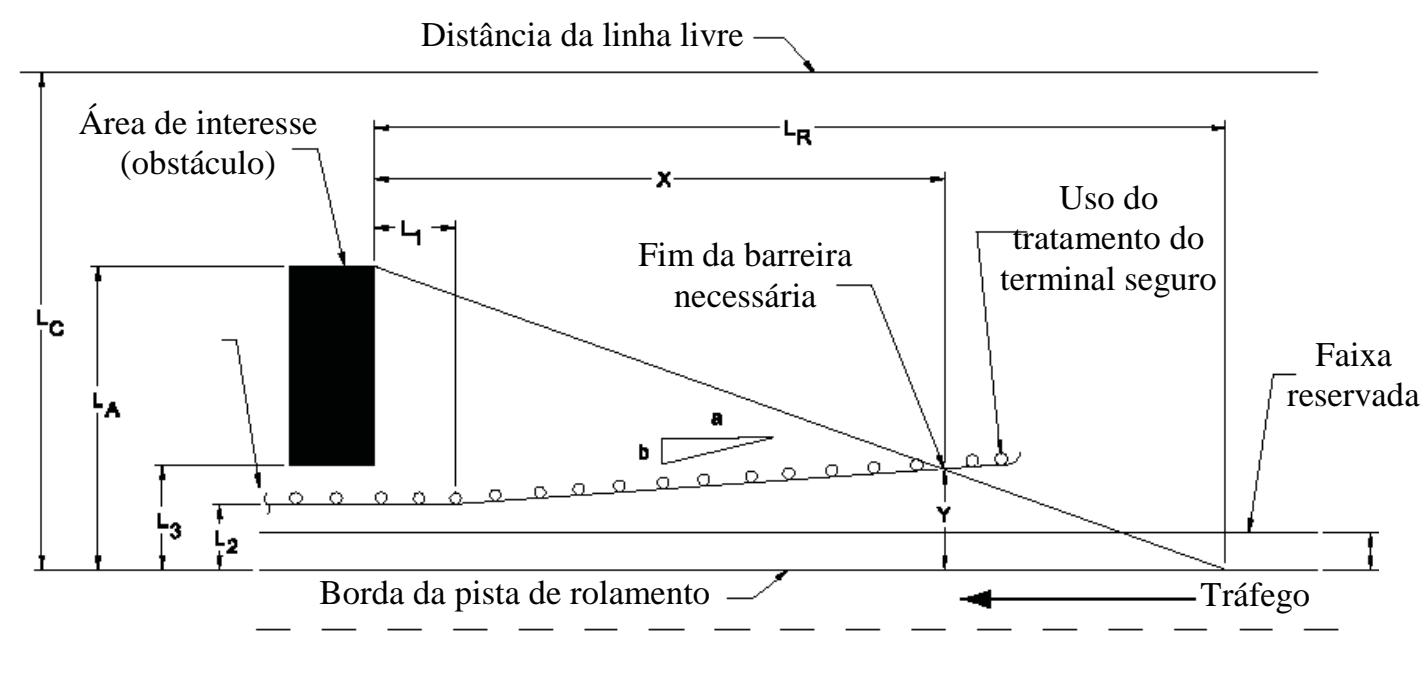

Figura 3.4 - Esboço (Layout) das variáveis da barreira de aproximação. (AASHTO, 2002).

Tabela 3.7 - Comprimento de área de escape proposto para projeto de barreira. (AASHTO, 2002).

\begin{tabular}{|c|c|c|c|c|}
\hline \multirow{4}{*}{$\begin{array}{l}\text { Velocidade do } \\
\text { Projeto }(\mathrm{km} / \mathrm{h})\end{array}$} & \multicolumn{4}{|c|}{ Comprimento da Área de Escape (Saída $\mathrm{L}_{\mathrm{R}}, \mathrm{m}$ ) } \\
\hline & VDM acima de & VDM entre & VDM entre & VDM abaixo \\
\hline & 6.000 & $2.000-6.000$ & $800-2.000$ & de 800 \\
\hline & veículos/dia & veículos/dia & veículos/dia & veículos/dia \\
\hline 110 & 145 & 135 & 120 & 110 \\
\hline 100 & 130 & 120 & 105 & 100 \\
\hline 90 & 110 & 105 & 95 & 85 \\
\hline 80 & 100 & 90 & 80 & 75 \\
\hline 70 & 80 & 75 & 65 & 60 \\
\hline 60 & 70 & 60 & 55 & 50 \\
\hline 50 & 50 & 50 & 45 & 40 \\
\hline
\end{tabular}


A variável final a ser estabelecida para calcular o comprimento necessário de defensas metálicas de um local específico é a Taxa de Deflexão Lateral. Quanto mais íngreme for esta taxa de deflexão, mais distante da rodovia começa a barreira e menor será seu comprimento necessário. No entanto, uma deflexão lateral relativamente alta resulta em um aumento do ângulo de impacto e na necessidade de achatamento (estreitamento) para o talude na área entre a barreira e a rodovia.

A taxa de deflexão lateral máxima recomendada para barreiras semi-rígidas e rígidas é mostrada na Tabela 3.6. Note-se que a taxa de deflexão lateral para barreiras dentro da linha de preocupação (faixa de atrito lateral) é aproximadamente duas vezes maior do que para barreiras localizadas fora desta área.

Quando as variáveis apropriadas da Tabela 3.6, forem selecionadas, a distância necessária requerida (X - Comprimento Necessário), antecedente à área de interesse para seções da rodovia retas ou quase retas, pode ser calculada através da Equação 2.1:

$$
X=\frac{L_{A}+(b / a) \cdot\left(L_{1}\right)-L_{2}}{(b / a)+\left(L_{A} / L_{R}\right)}
$$

Para uma instalação paralela (sem taxa de deflexão lateral), a Equação 2.1 se reduz à Equação 2.2:

$$
X=\frac{L_{A}-L_{2}}{L_{A} / L_{R}}
$$

O Afastamento Lateral (Y), desde a borda da pista de rolamento até o início do comprimento necessário, pode ser calculado pela Equação 2.3:

$$
Y=\frac{L_{A}}{L_{R}}(X)
$$

A Figura 3.5 ilustra o esboço (layout) das variáveis de uma barreira de aproximação para o tráfego no sentido oposto. O Comprimento Necessário (X) é determinado como descrito na Equação 2.1, com as dimensões laterais medidas a partir da margem esquerda da pista de rolamento. 


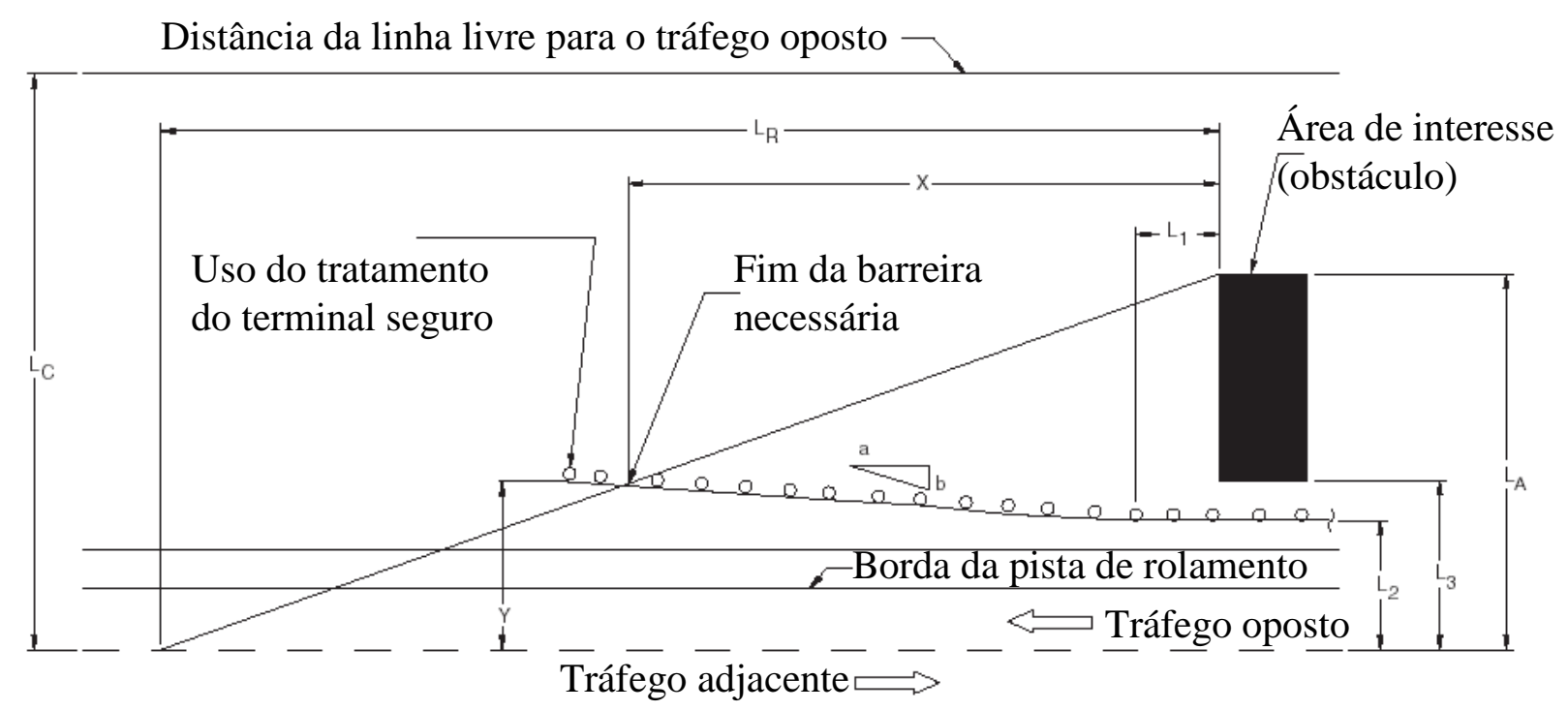

Figura 3.5- Esboço (Layout) para a barreira de aproximação para o tráfego. (AASHTO, 2002).

Existem três intervalos da largura da zona livre $\left(\mathrm{L}_{\mathrm{C}}\right)$ que merecem atenção especial:

a) Se a barreira estiver além da zona livre apropriada, não há necessidade de uma barreira adicional nem de tratamento especial contra colisões (acidentes);

b) Se a barreira estiver dentro da zona livre apropriada, mas a área de preocupação estiver além dela, não há necessidade de outra barreira adicional, mas um tratamento especial (seguro) do final do terminal contra acidentes deve ser utilizado.

c) Se a área de interesse estender-se bem além da zona livre (um rio, por exemplo), devese escolher apenas escudar a porção do trecho dentro da zona livre, igualando os valores de $\mathrm{L}_{\mathrm{A}}$ e $\mathrm{L}_{\mathrm{C}},\left(\mathrm{L}_{\mathrm{A}}=\mathrm{L}_{\mathrm{C}}\right)$.

\subsection{MELHORIA DE SISTEMA DE BARREIRAS DE CONTENÇÃO EXISTENTES}

É grande o índice de acidentes fatais com objetos fixos envolvendo barreiras de tráfego, sendo este índice menor somente para aqueles acidentes que envolvem postes e árvores. (AASHTO, 2002) Isso possivelmente ocorre devido ao fato de que as rodovias antigas muitas vezes não alcançam os níveis de desempenho atualmente recomendados por falta de estrutura ou inadequação estrutural. Percebe-se, desse modo, que não só novos projetos ligados às barreiras de contenção devem ser empreendidos, mas que as rodovias antigas também devem ser adequadas aos padrões atuais através de melhorias ou de projetos de reabilitação e restauração. Nota-se igualmente a importância do tratamento de sistemas de 
contenção na lateral da via para projetos que visem ao estudo da redução da severidade dos acidentes em rodovias de múltiplas faixas.

\subsection{TERMINAIS DE BARREIRAS DE CONTENÇÃO E AMORTECEDORES DE IMPACTOS}

Segundo a NBR 15486 (ABNT, 2007), a colisão de um veículo com terminais de barreira sem tratamento seguro ou com um objeto fixo pode ter graves conseqüências pela parada brusca do veículo, como por exemplo, possíveis capotamentos provocados pela penetração de elementos da barreira no veículo impactante.

Os terminais de barreiras e os amortecedores de impacto devem atender aos requisitos do Relatório 350 da NCHRP (TRB, 1993), que exigem a parada gradual do veículo impactante ou seu redirecionamento pelos amortecedores de impacto e terminais de barreiras em impactos frontais ou ainda o redirecionamento seguro dos veículos que impactam a lateral dos dispositivos.

Os terminais podem ser classificados como de abertura ou não abertura, dependendo de seu comportamento quando impactados sobre a superfície perto do início. Um terminal de abertura permite que um veículo impactando em ângulo o nariz ou a lateral da unidade atravesse a unidade (dispositivo). O terminal de não abertura é capaz de redirecionar um veículo impactando em ângulo o nariz ou a lateral da unidade em toda a sua extensão, como no caso de trechos de rodovias em corte ou de trechos de transição de corte para aterro. Esse sistema oferece proteção total, eliminando os possíveis impactos frontais com o terminal e minimizando a possibilidade de um veículo passar por trás do sistema de proteção (AASHTO, 2002).

Quase todos os terminais de barreira são considerados de abertura. Como o veículo atravessa o dispositivo, neste caso, a área em torno dos terminais deve ser traspassável e livre de obstáculos fixos. A área em frente ao terminal e entre a pista e o terminal deve ser plana (com declividade máxima de 10 H:1V).

As Figuras 3.6 e 3.7 indicam a classificação mais comum de traçados para terminais de abertura e de não abertura de defensas (guardrails) e para o final do terminal, respectivamente. 


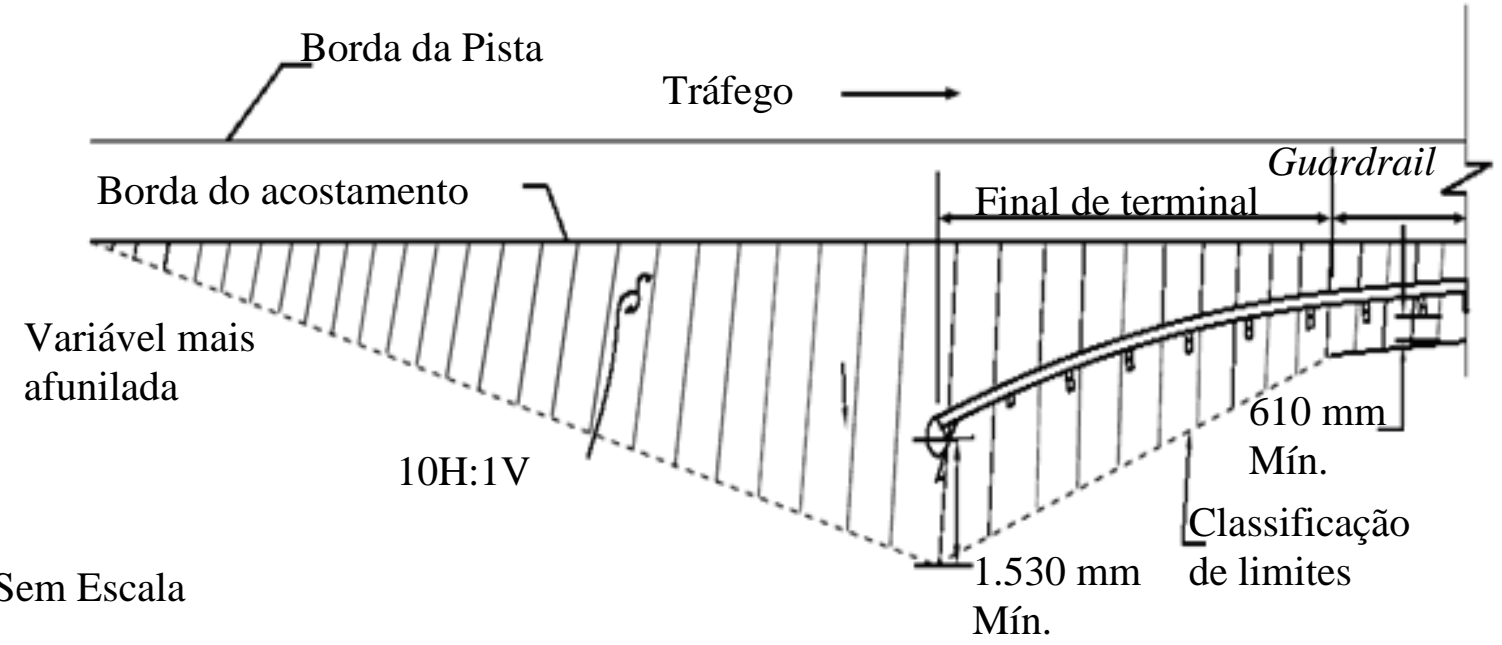

Figura 3.6 - Classificação de terminal de abertura de defensas. (AASHTO, 2002).
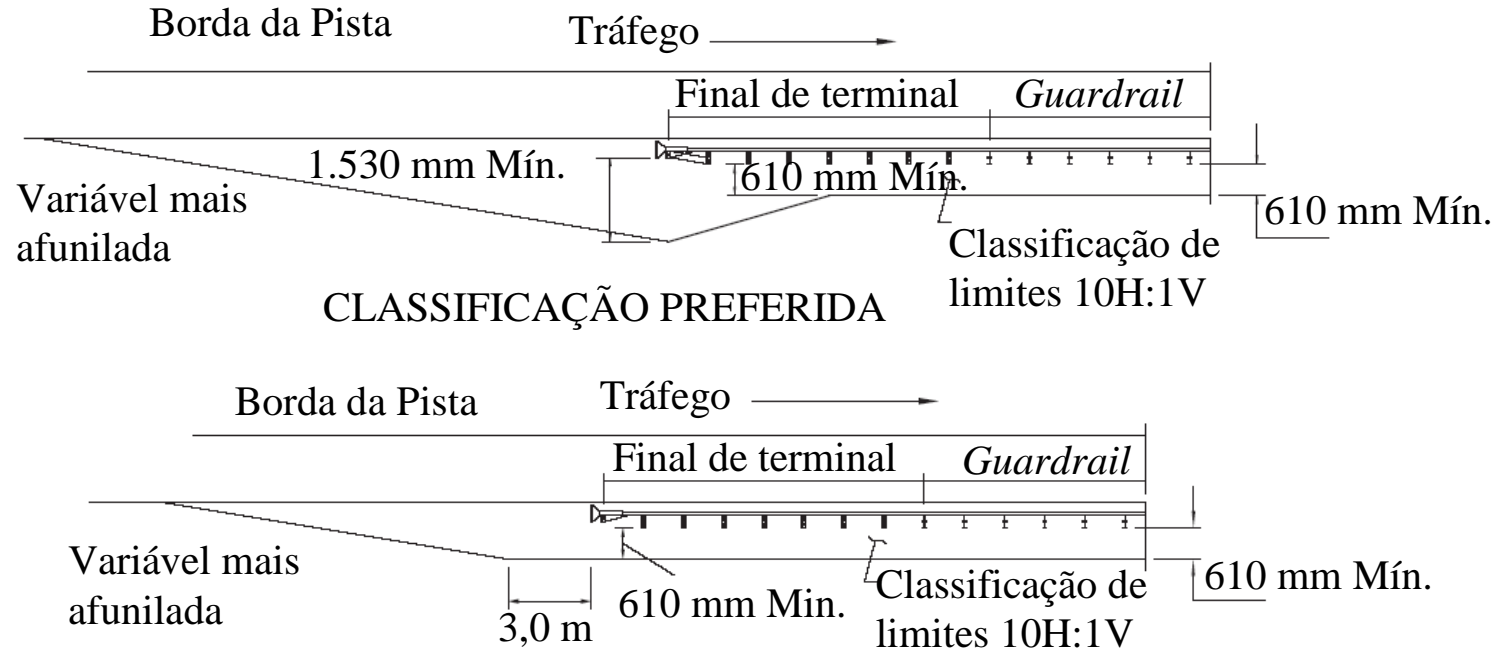

Sem Escala

CLASSIFICAÇÃO ALTERNATIVA

Figura 3.7- Classificação do terminal de não-abertura de guardrail (AASHTO, 2002).

\subsection{MOTOCICLISTAS E DISPOSITIVOS DE CONTENÇÃO}

As barreiras, de um modo geral, oferecem pouca ou nenhuma proteção no caso das motocicletas.

Rocha (s.d), aponta a partir do título de seu artigo Guardrails, segurança para carros, morte para motociclistas, que as defensas metálicas em muitos casos, além de não protegerem os motociclistas, podem agravar a severidade dos acidentes em que estes se envolvam, levando-os à morte, assim como seus acompanhantes. Isso porque, em uma queda de moto, o corpo do motociclista (e/ou do acompanhante) é lançado para fora do veículo pela inércia. Se o acidentado estiver bem equipado e seu corpo deslizar pelo asfalto, o atrito o fará parar sem 
consequiências fatais. A proteção, portanto, é mínima (a indumentária especial) e de menor efeito no caso de o acidentado se chocar contra uma barreira de contenção, como as defensas metálicas, que fazem "com que o seu perfil em $H$ atue como se fosse uma guilhotina ou ceifadeira contra seu corpo", sobretudo as extremidades (pés, mãos, etc.), além de provocarem traumatismos.

A Figura 3.8 denota a necessidade de se tomarem medidas que protejam adequadamente os motociclistas.
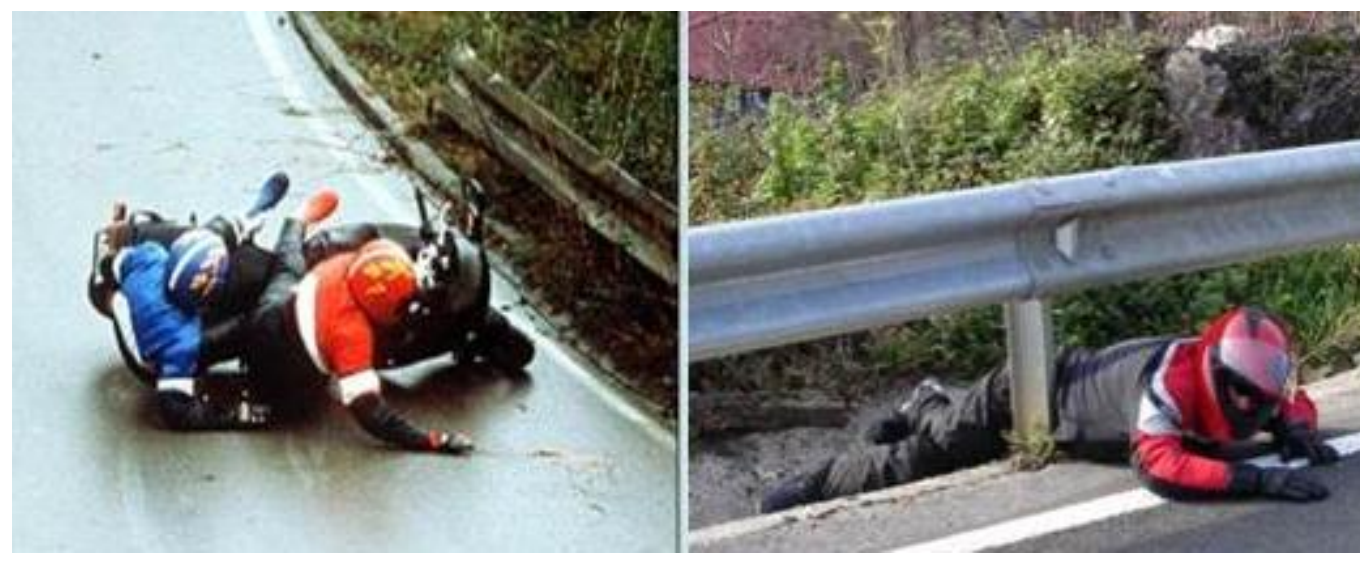

Figura 3.8 - Acidente grave de moto com o piloto e o acompanhante

Os países da União Européia (como a Espanha e a França) têm tomado algumas medidas no sentido de oferecerem maior segurança aos motociclistas, como a adoção de barriletes de Poliespan, de protetores para defensas metálicas e a proteção total da parte inferior da defensa (Doble bionda) com poliuretano, madeira, plástico e outros materiais. Esta última, para Rocha (s.d.), é o mais efetiva de todas, uma vez que o corpo do acidentado não se lança abaixo do guardrail, evitando-se que seja cortado. Desse modo, uma das sugestões é o uso de uma barreira de proteção lisa e não vazada semelhante a uma barreira de concreto que possa reduzir a probabilidade de ferimentos traumáticos nos motociclistas que sofrem colisão. (AASHTO, 2002)

Embora alguns países europeus estejam tentando solucionar o perigo das barreiras metálicas para os motociclistas nos locais com alto índice de colisões, ainda não há uma abordagem sistemática desenvolvida para a questão devido ao caráter aleatório dos acidentes com motocicletas e à eficiência questionável das modificações feitas nas barreiras de proteção de tráfego. Além disso, existem poucos estudos sobre o custo-eficácia de tais barreiras, faltando, pois, base para projetos mais metódicos de desenvolvimento de barreiras de proteção de motociclistas (AASHTO, 2002) 
Assim, avanços têm sido alcançados na pesquisa de defensas metálicas no que tange aos motociclistas, mas ainda há muito a ser feito para minorar a severidade de acidentes nesses casos.

\subsection{PEDESTRES E CICLISTAS}

Todas as rodovias que não têm controle pleno de acesso devem ser planejadas, construídas, operadas e conservadas, levando em conta o uso e as necessidades de pedestres e ciclistas, sobretudo quando a quantidade destes tipos de usuários é grande.

Pedestres e ciclistas incluem pessoas de todas as idades e habilidades. Suas ações são menos previsíveis do que as dos motoristas. No Brasil, como em todos os países, não há cursos especiais ou licenças para andar ou dirigir uma bicicleta e a fiscalização para obrigar a obedecer às leis de tráfego é sempre muito frouxa. Sendo assim, pedestres e ciclistas devem ser levados em conta no que se refere à instalação de barreiras de proteção. O ideal é separálos do tráfego de veículos, o que na realidade quase nunca é feito.

Não há critérios objetivos para a necessidade de separar pedestres e ciclistas dos veículos. Geralmente, em vias com baixa velocidade, basta um meio-fio para separar os pedestres e ciclistas do tráfego. Contudo, quando as velocidades são maiores, recomenda-se o emprego de barreiras de proteção (AASHTO, 2002). Também deve haver preocupação quanto à instalação de barreiras de proteção perto de imóveis situados em locais onde já houve casos de acidentes de saída da pista, como por exemplo, próximos a escolas.

\subsection{AMORTECEDORES DE IMPACTO}

Os amortecedores de impacto (barreiras de contenção frontal) são dispositivos de proteção que impedem os veículos desgovernados de colidir frontalmente com objetos fixos.

Quando um veículo colide com um obstáculo fixo rígido (como um poste, por exemplo), o impacto ou os fragmentos desse obstáculo podem provocar uma parada muito brusca, desgovernar o veículo ou mesmo perfurá-lo. Assim, os dispositivos amortecedores de impacto têm a função de desacelerar gradualmente os veículos até a parada, de modo a evitar o choque brusco, ou redirecionar os veículos, afastando-os do obstáculo. Portanto, os dispositivos amortecedores de impacto têm a função de diminuir a gravidade dos acidentes, não impedindo, contudo, que eles ocorram.

Os objetos fixos que geralmente exigem proteção, quando localizados dentro da zona livre de uma rodovia específica, estão listados na Tabela 3.1. 
Os amortecedores de impacto podem ser classificados como redirecionáveis e não redirecionáveis. Os dispositivos redirecionáveis controlam impactos frontais e laterais, enquanto os dispositivos não redirecionáveis controlam impactos frontais, mas possuem capacidade limitada de controlar impactos laterais. Desta forma, deve-se tomar cuidado ao dispor os amortecedores não redirecionáveis, de modo que não se deixem desprotegidos os objetos a serem escudados.

Segundo a NBR 15486 (ABNT, 2007), os amortecedores de impacto são projetados para veículos de $800 \mathrm{~kg}$ a $2.000 \mathrm{~kg}$ e para velocidade de impacto variando de $50 \mathrm{~km} / \mathrm{h}$ a $110 \mathrm{~km} / \mathrm{h}$, considerando diferentes ângulos de impacto. Embora não sejam projetados para caminhões e veículos de transporte coletivo, têm um efeito positivo também nesses casos.

Os amortecedores de impacto são ideais para uso em locais onde os objetos fixos não podem ser removidos, realocados, tornar-se colapsíveis ou ser adequadamente escudados por uma barreira longitudinal. Eles são utilizados para a escudagem de certos obstáculos da lateral da via que não possam receber outro tipo de dispositivo de proteção. Dentre os fatores de sua indicação, pode-se citar a proteção de equipes que trabalhem em manutenção na rodovia, sendo, então, mais utilizados os amortecedores de impacto portáteis.

O Relatório 350 da NCHRP (TRB, 1993), estabelece três níveis de testes $\left(\mathrm{NT}_{\mathrm{S}}\right)$ para os terminais de barreira e amortecedores de impacto. Todos os níveis exigem impactos em locais especificados e ângulos, tanto com um carro de $820 \mathrm{~kg}$ quanto com uma caminhonete de $2.000 \mathrm{~kg}$ a velocidades de impacto de 50, 70, e $100 \mathrm{~km} / \mathrm{h}$ para NT-1, 2 e 3, respectivamente.

No Brasil, tais dispositivos foram implantados em 2008, no km 112,5 da Rodovia SP332, em Campinas, de forma experimental, com o intuito de fabricar tais amortecedores no país de acordo com a NBR 15486, aprovada em junho de 2007, que regulamenta os equipamentos de proteção rodoviária no Brasil.

Segundo a empresa Barrier Systems Inc. (FERRAZ, RAIA JR e BEZERRA, 2008), “é provável que mesmo num choque a $100 \mathrm{~km} / \mathrm{h}$, o mesmo não resulte em acidente fatal, o que certamente aconteceria se a colisão fosse com um pilar de concreto”.

A principal vantagem de um amortecedor de impacto é a sua capacidade de absorver a energia, parando um veículo impactante em uma distância relativamente curta, de modo a reduzir a possibilidade de ferimento grave dos ocupantes (AASHTO, 2002). Nas Figuras 3.9 a 3.12 são mostradas fotos de amortecedores utilizados no Brasil. 


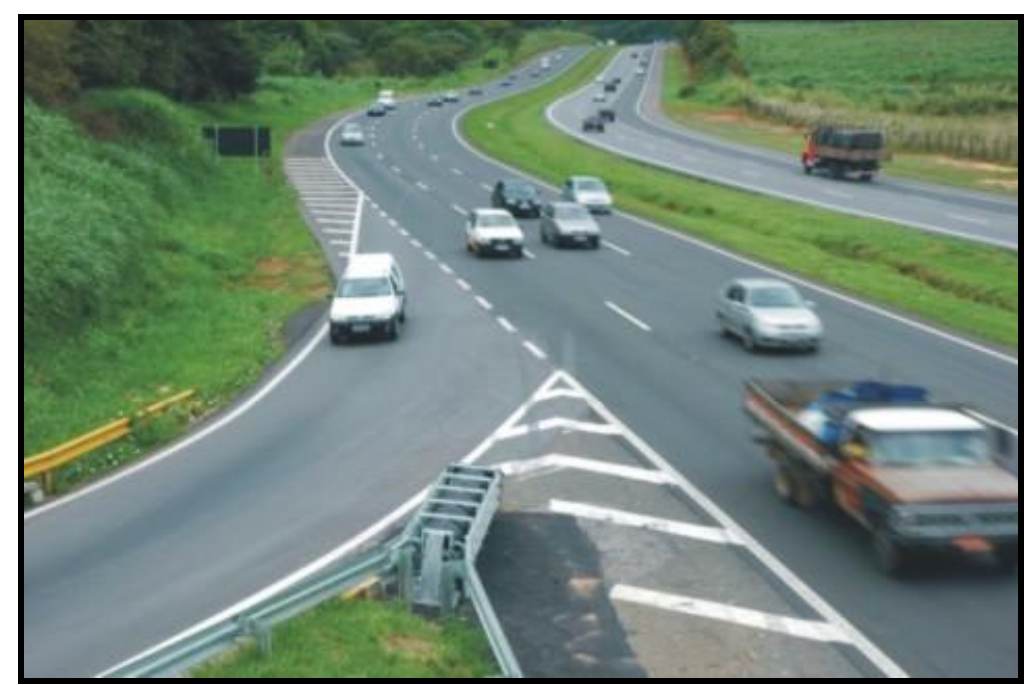

Figura 3.9 - Foto distante do amortecedor de impacto implantado no km 112,5 da Rodovia SP-332.

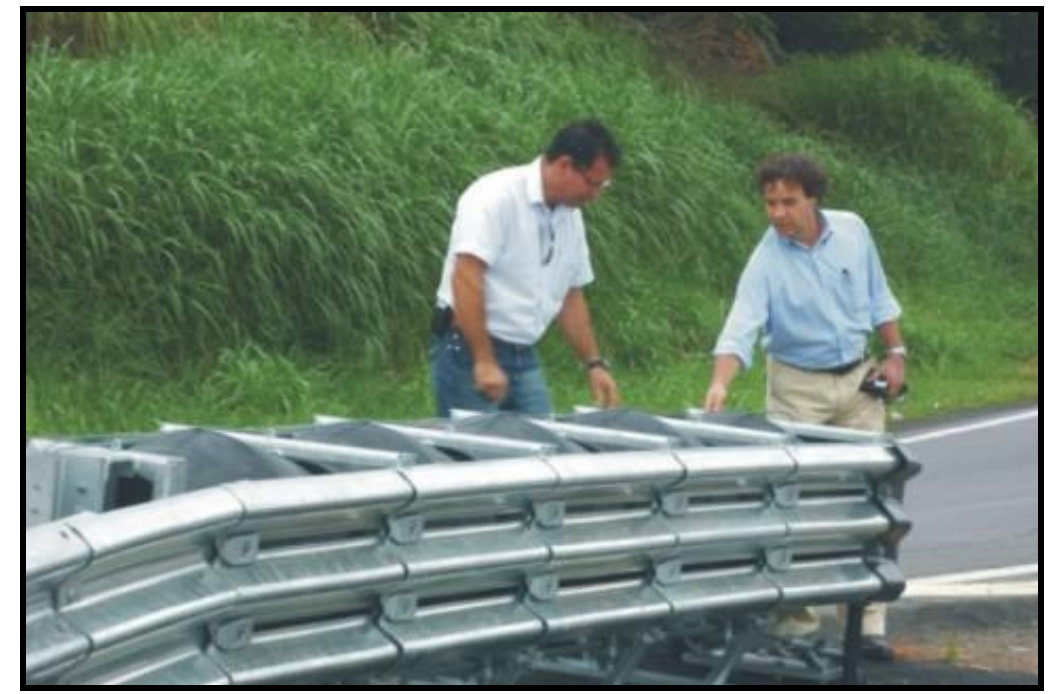

Figura 3.10 - Foto próxima do amortecedor de impacto implantado no km 112,5 da Rodovia SP-332 


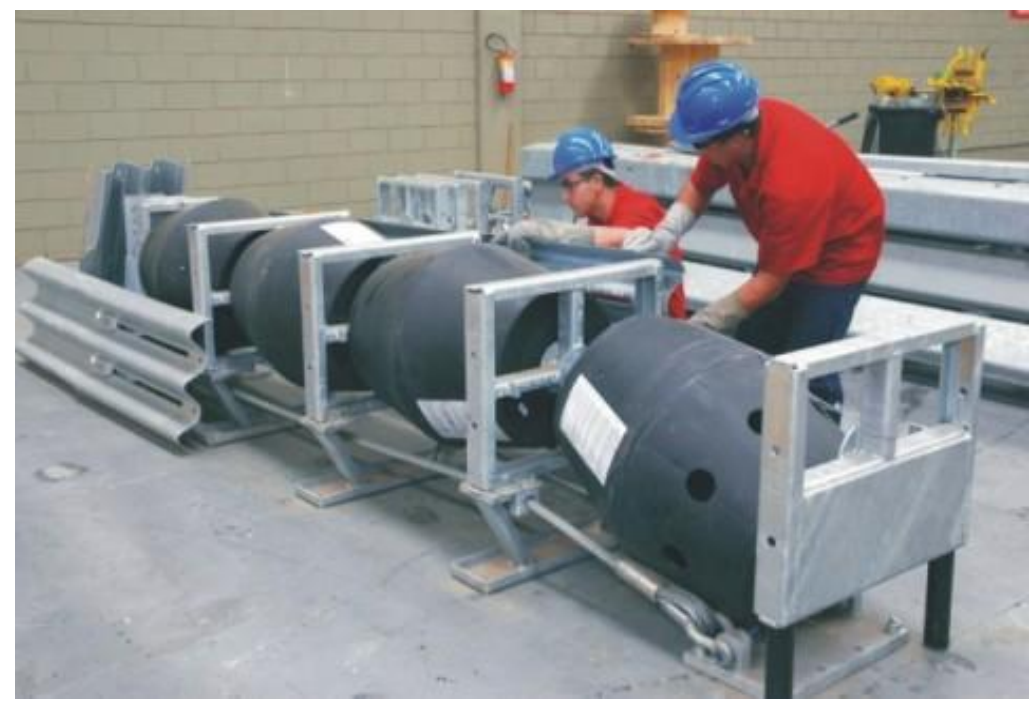

Figura 3.11 - Produção do equipamento amortecedor de impacto no parque fabril do grupo LINDSAY.

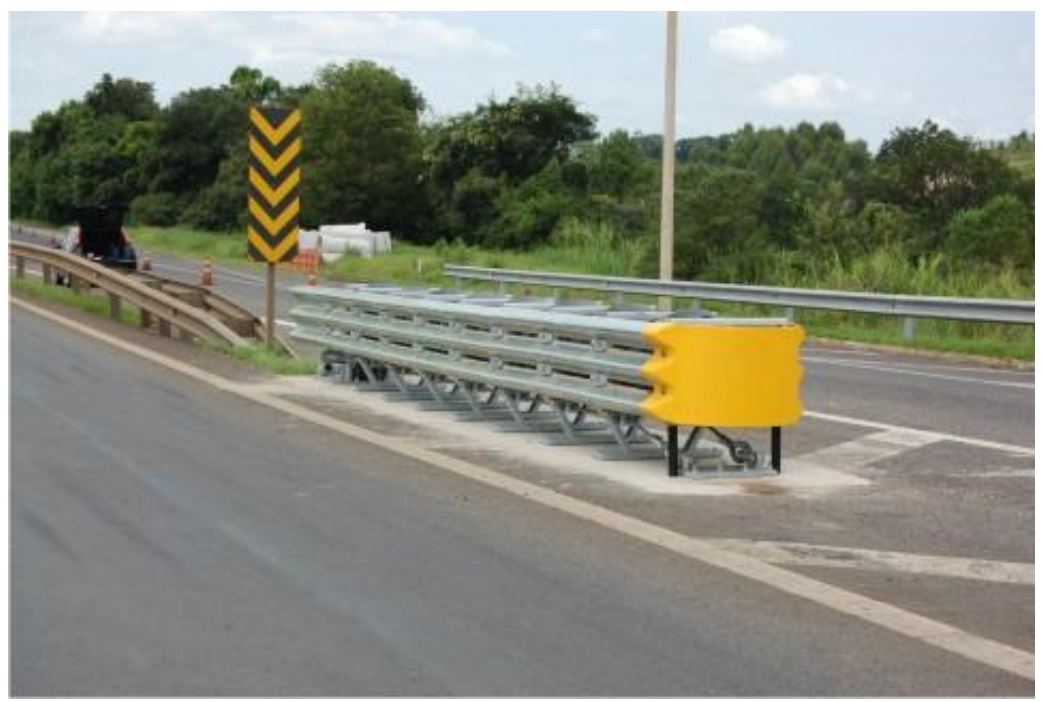

Figura 3.12 - Instalação de amortecedor de impacto na rodovia SP - 340 em MogiGuaçu.

Quando é possível estabelecer que o uso do amortecedor de impacto é a melhor forma de proteger a rodovia, devem-se levar em conta variados fatores antes da seleção final do tipo de amortecedor a ser empregado, dentre os quais:

a) as características do local;

b) a estrutura e as características de segurança dos sistemas escolhidos;

c) o custo;

d) as características de manutenção.

Os amortecedores de impacto são projetados e testados em terreno nivelado. Desse modo, um sistema implantado em terreno não nivelado pode apresentar desempenho 
62

imprevisível ou ineficaz (AASHTO, 2002) O terreno entre a pista de rolamento e o dispositivo deve possuir uma declividade igual ou inferior a $10 \mathrm{H}: 1 \mathrm{~V}$, não devendo apresentar obstruções e irregularidades. Outro fator importante é que não se deve instalar guias nos locais de instalação de amortecedores de impacto, pois elas podem fazer o veículo saltar e atingir o sistema em uma posição que comprometa o desempenho do dispositivo de segurança.

A análise do custo de instalação dos amortecedores de impacto deve incluir fatores como os gastos com o material, a preparação do local, as despesas de instalação, os gastos com a manutenção, com o conserto ou com a substituição de materiais.

Em locais com altos índices de acidentes, recomenda-se a escolha de amortecedores de impacto que possam ser reutilizados. 


\section{DESEMPENHO DOS VEÍCULOS NAS SAÍDAS IMPREVISTAS DA PISTA}

\subsection{CONSIDERAÇÕES INICIAIS}

$\mathrm{Na}$ avaliação do risco da ocorrência de acidentes graves no caso das saídas imprevistas de veículos da pista é necessário conhecer o desempenho do veículo (trajetória percorrida e variação da velocidade). Ao sair da pista de maneira imprevista, em razão de distração, cochilo, desvio de objeto na pista etc., os condutores realizam, em geral, um dos seguintes procedimentos:

- Acionam totalmente o pedal do freio para tentar diminuir a velocidade e parar o veículo o mais rápido possível. Neste caso, o veículo segue uma trajetória praticamente reta e ocorre o travamento das rodas se o veículo não for equipado com sistema de freios ABS (Anti-Lock Braking System).

- Viram o volante para mudar a trajetória do veículo, tentando voltar à pista ou desviar de obstáculos (objetos, buracos, espaços vazios, barrancos etc.) e, ao mesmo tempo, acionam o pedal do freio, mas não a ponto de travar as rodas, pois, nesse caso, o veículo não mudaria a sua trajetória.

Para obter o desempenho dos veículos o mais próximo possível do que ocorre nas situações reais de saída imprevista da pista, foram realizados testes de campo para simular o caso das duas situações mencionadas, sendo os resultados obtidos extrapolados de forma adequada.

Esses testes foram realizados em área localizada no município de Araraquara, às margens da Rodovia António Machado Santana (SP-255). Na Figura 4.1, é mostrada foto aérea dessa área e, na Figura 4.2, foto da superfície do terreno.

No local dos testes, o terreno é regular, gramado (situação típica encontrada na área lateral das rodovias) e praticamente plano. 


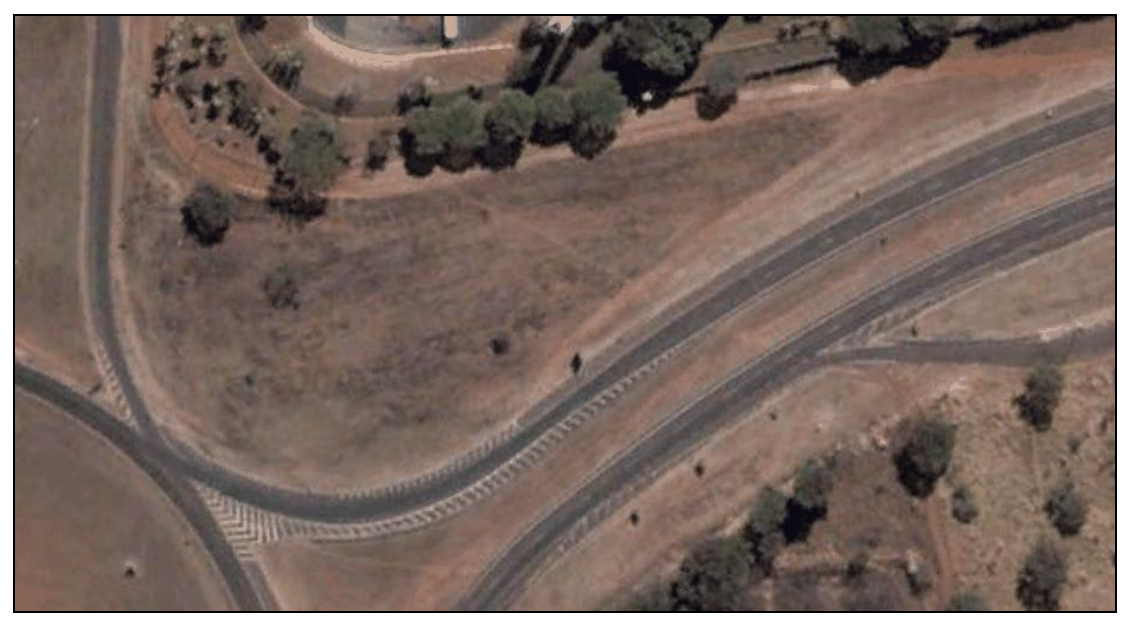

Figura 4.1 - Foto do local onde os testes de campo foram realizados. (GOOGLE, 2011)

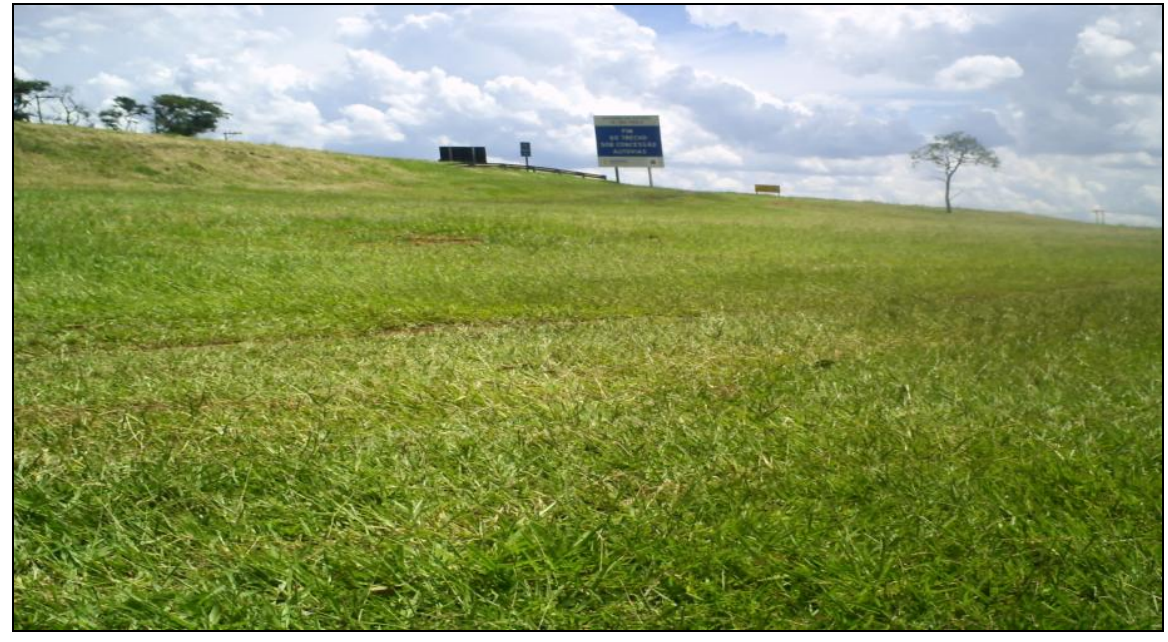

Figura 4.2 - Foto do terreno onde foram realizados os testes de campo. Fonte: foto feita pelo autor.

Os testes foram realizados com um veículo de marca Fox da Volkswagen, dotado de sistema de freio comum (sem ABS), cujas dimensões aproximadas são: $3,70 \mathrm{~m}$ de comprimento e 1,60 m de largura, em condições de tempo bom e com grama seca.

\subsection{DESEMPENHO DO VEÍCULO EM FRENAGEM}

Os testes para simular o processo de frenagem foram realizados no dia 02 de fevereiro de 2011. Tais testes consistiram em medir a distância percorrida durante a frenagem do veículo com o acionamento total do pedal do freio e conseqüente travamento das rodas, uma vez que o veículo não tem freios $\mathrm{ABS}$.

A trajetória do veículo era mantida em linha reta, ou seja, sem desvio da sua trajetória. O teste foi realizado para velocidades iniciais de 30, 40, 50, 60 e $70 \mathrm{~km} / \mathrm{h}$. Não foram 
realizados testes com velocidades maiores por razões de segurança, uma vez que a partir de $70 \mathrm{~km} / \mathrm{h}$, foi constatado que o veículo já apresentava instabilidade.

Na Figura 4.3 é mostrada foto do veículo realizando um dos testes de frenagem.

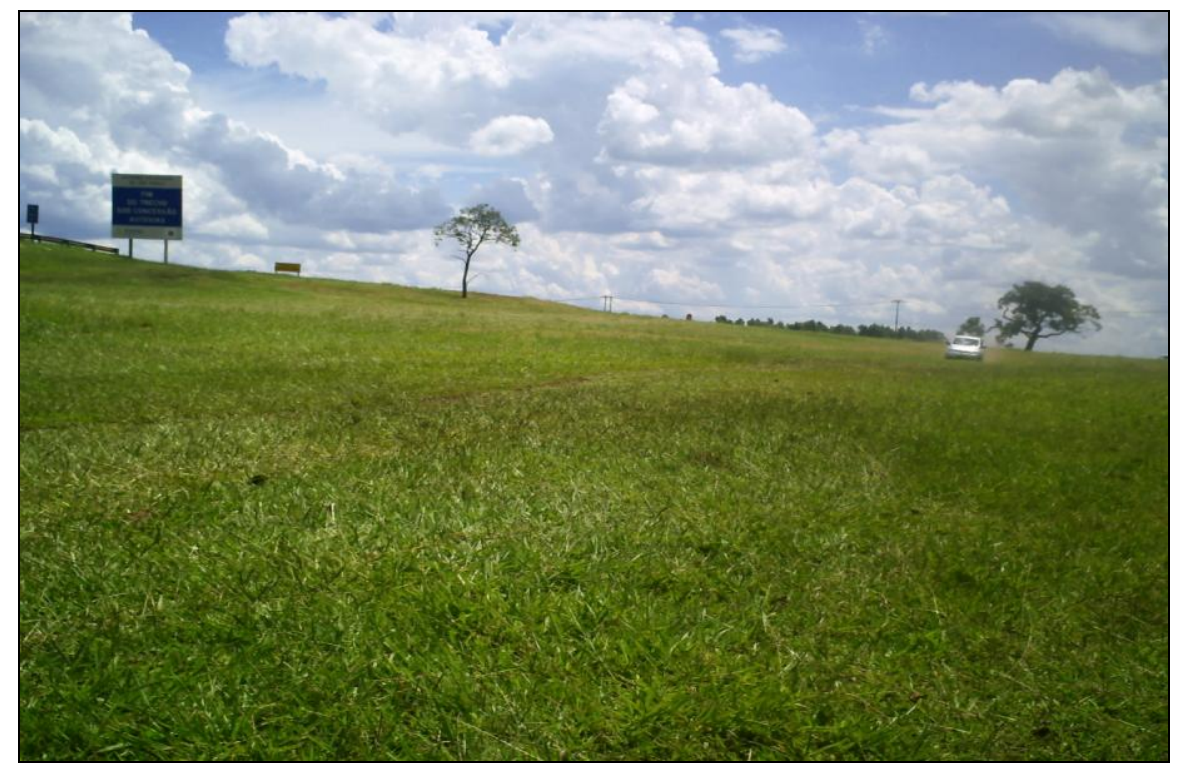

Figura 4.3 - Foto do veículo realizando teste de frenagem.

Uma representação esquemática do teste realizado é mostrada na Figura 4.4. 


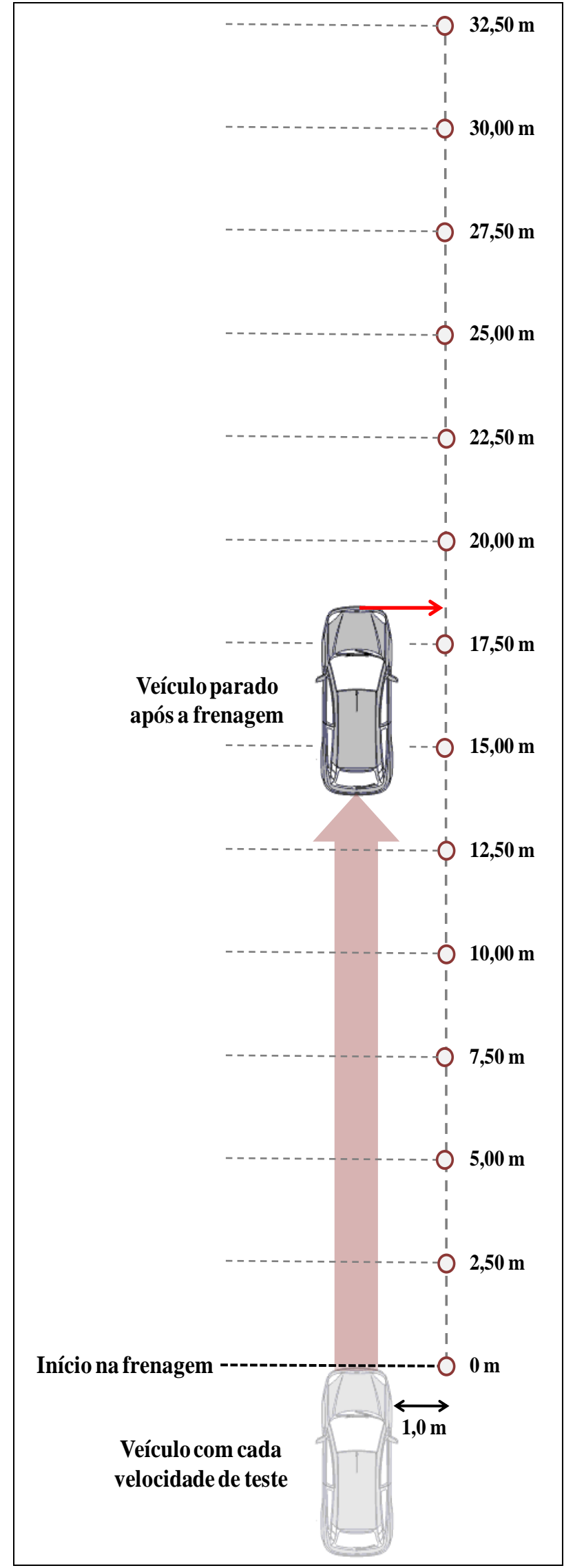

Figura 4.4 - Teste de frenagem. 
Na Tabela 4.1 estão indicados todos os valores da distância percorrida durante a frenagem para diferentes velocidades iniciais.

Tabela 4.1 - Valores da distância percorrida durante a frenagem, obtidos nos testes de campo.

\begin{tabular}{|c|c|c|c|c|c|c|}
\hline Velocidade inicial $(\mathrm{km} / \mathrm{h})$ & 20 & 30 & 40 & 50 & 60 & 70 \\
\hline \multirow{9}{*}{$\begin{array}{l}\text { Distâncias percorridas } \\
\text { durante a frenagem (m) }\end{array}$} & 2,00 & 4,00 & 7,30 & 12,00 & 18,80 & 25,00 \\
\hline & 2,00 & 4,95 & 8,00 & 12,70 & 20,80 & 28,70 \\
\hline & 2,10 & 5,00 & 8,75 & 13,60 & 24,80 & 30,55 \\
\hline & 2,15 & 5,20 & 8,80 & 15,70 & 24,80 & 31,20 \\
\hline & 2,30 & 5,30 & 9,00 & 17,40 & 27,30 & 31,95 \\
\hline & 2,50 & 5,80 & 9,10 & 17,50 & 27,45 & 33,30 \\
\hline & 2,50 & 5,85 & 9,20 & 17,70 & - & - \\
\hline & 2,65 & 6,40 & 10,05 & - & - & - \\
\hline & 3,70 & - & - & - & - & - \\
\hline $\begin{array}{c}\text { Valor médio das distâncias } \\
\text { de frenagem (m) }\end{array}$ & 2,28 & 5,50 & 8,97 & 15,77 & 22,30 & 31,14 \\
\hline $\begin{array}{l}\text { Valores do coeficiente de } \\
\text { atrito }(\mu), \text { obtidos com a }\end{array}$ & 0,68 & 0,63 & 0,69 & 0,61 & 0,62 & 0,61 \\
\hline expressão 4.1 (Página 68) & & & & & & \\
\hline $\begin{array}{c}\text { Valores da distância de } \\
\text { frenagem, obtidos com a } \\
\text { expressão } 4.1 \text { para } \mu=0,61\end{array}$ & 2,53 & 5,69 & 10,12 & 15,81 & 22,77 & 30,99 \\
\hline
\end{tabular}

Os valores da Tabela 4.1, assinalados com sombra, foram excluídos da amostra e, portanto, não foram considerados nas análises, por se mostrarem discrepantes em relação aos demais.

$\mathrm{Na}$ Figura 4.5, é mostrado gráfico dos pontos correspondentes aos valores obtidos nos testes, tendo a linha de tendência sido obtida por meio de regressão, considerando como equação um polinômio do segundo grau (parábola) passando pela origem. $\mathrm{O}$ valor de $\mathrm{R}^{2}=$ 0,9812 para o coeficiente de determinação indica uma ótima aderência dos valores empíricos aos valores teóricos fornecidos pela equação de regressão. 


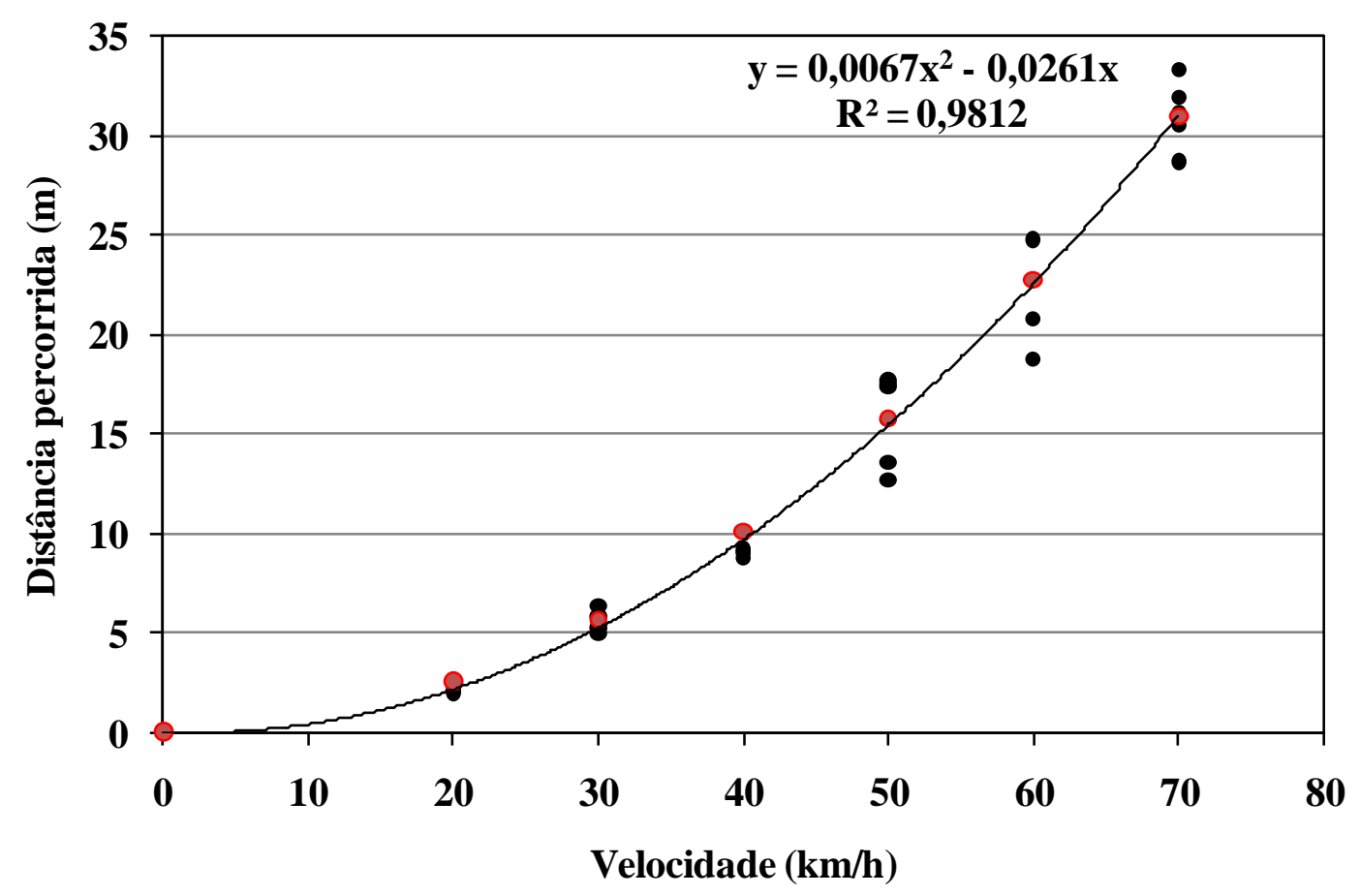

- Nuvem de pontos

- $\boldsymbol{\mu}=\mathbf{0 , 6 1}$

— Linha de tendência da nuvem de pontos

Figura 4.5 - Distância percorrida durante a frenagem versus velocidade inicial.

Considerando ser o terreno praticamente plano, a força de frenagem que atua no veículo é a força de atrito, resultando, portanto, em uma desaceleração $a=\mu . g$, em que $\mu$ é o coeficiente de atrito dinâmico pneu-grama e g a aceleração da gravidade.

A equação racional de Torricelli da Física clássica relaciona a distância percorrida durante a frenagem (D) com a velocidade inicial (V), o coeficiente de atrito ( $\mu$ ) e aceleração da gravidade $(\mathrm{g})$, por intermédio da equação:

$$
\mathrm{D}=\mathrm{V}^{2} / 2 \cdot \mathrm{a}=\mathrm{V}^{2} / 2 \cdot \mu \cdot \mathrm{g}
$$

Para D em $\mathrm{m}, \mathrm{V}$ em $\mathrm{km} / \mathrm{h}$ e admitindo $\mathrm{g}=10 \mathrm{~m} / \mathrm{s}^{2}$, resulta:

$$
\mathrm{D}=\mathrm{V}^{2} / 259,20 \cdot \mu
$$

$\mathrm{Na}$ Tabela 4.1, estão indicados os valores do coeficiente de atrito $(\mu)$ obtidos a partir dos valores médios da distância percorrida durante a frenagem (D).

Também na Tabela 4.1, estão relacionadas as distâncias percorridas durante a frenagem, obtidas utilizando-se a equação 4.1 e um coeficiente de atrito $\mu=0,61$ (que corresponde ao menor valor encontrado considerando todas as velocidades testadas). Os pontos correspondentes a esses valores são mostrados na Figura 4.5. 
A análise dos valores da Tabela 4.1 e da Figura 4.5 mostra ser aceitável considerar para cálculo da distância percorrida durante a frenagem em terreno plano e grama seca o fator de atrito $\mu=0,61$ - como visto, corresponde ao menor valor observado (o que significa proceder a favor da segurança).

Com base na equação 4.1 e considerando $\mu=0,61$, foram obtidos os valores da distância percorrida durante a frenagem para valores da velocidade de 80, 90, 100, 110 e 120 $\mathrm{km} / \mathrm{h}$, os quais estão indicados na Tabela 4.2 juntamente com os valores correspondentes às velocidades de $30,40,50,60$ e $70 \mathrm{~km} / \mathrm{h}$.

Tabela 4.2 - Valores da distância percorrida durante a frenagem para diferentes velocidades iniciais.

\begin{tabular}{cc}
\hline $\mathbf{V}(\mathbf{k m} / \mathbf{h})$ & $\mathbf{D}(\mathbf{m})$ \\
\hline 30 & 5,69 \\
40 & 10,12 \\
50 & 15,81 \\
60 & 22,77 \\
70 & 30,99 \\
80 & 40,48 \\
90 & 51,23 \\
100 & 63,25 \\
110 & 76,53 \\
120 & 91,07
\end{tabular}

No caso de veículos dotados de freios ABS, não ocorre o travamento das rodas e a força de atrito é estática. Como o coeficiente de atrito estático é maior que o dinâmico, a distância percorrida durante a frenagem resultaria menor.

\subsection{DESEMPENHO DO VEÍCULO EM DESVIO COM FRENAGEM}

Os testes para simular o processo de desvio com frenagem simultânea foram realizados no dia 09 de fevereiro de 2011.

O teste de virar o volante e frear ao mesmo tempo consistiu em caracterizar a trajetória do veículo, desde o ponto em que se iniciava a virada do volante e o acionamento do pedal do freio, até a parada completa. Isso foi feito mediante a realização de medidas das distâncias longitudinais e transversais ao longo da trajetória da roda dianteira direita do veículo. 
Para a realização do teste, foram demarcadas no solo linhas perpendiculares com cal (para se identificar as marcas do pneu dianteiro direito passando sobre a linha) situadas longitudinalmente a cada 2,5m, conforme mostrado nas fotos das Figuras 4.6, 4.7 e 4.8.

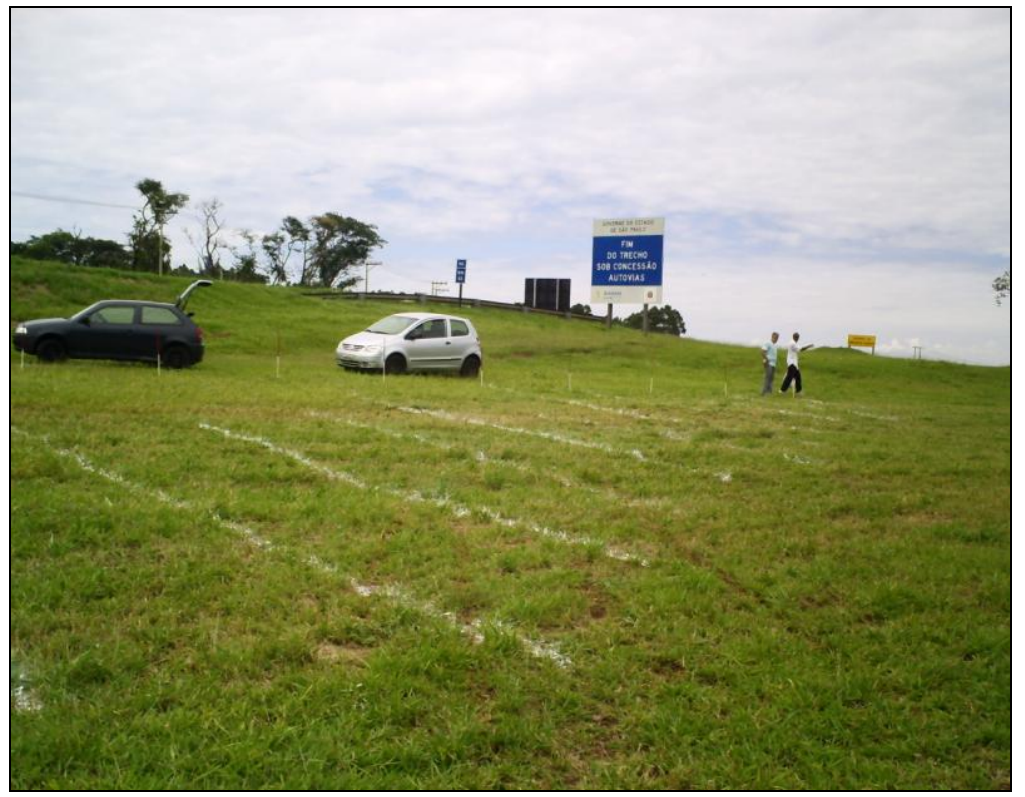

Figura 4.6 - Foto mostrando o local preparado para a realização do teste.

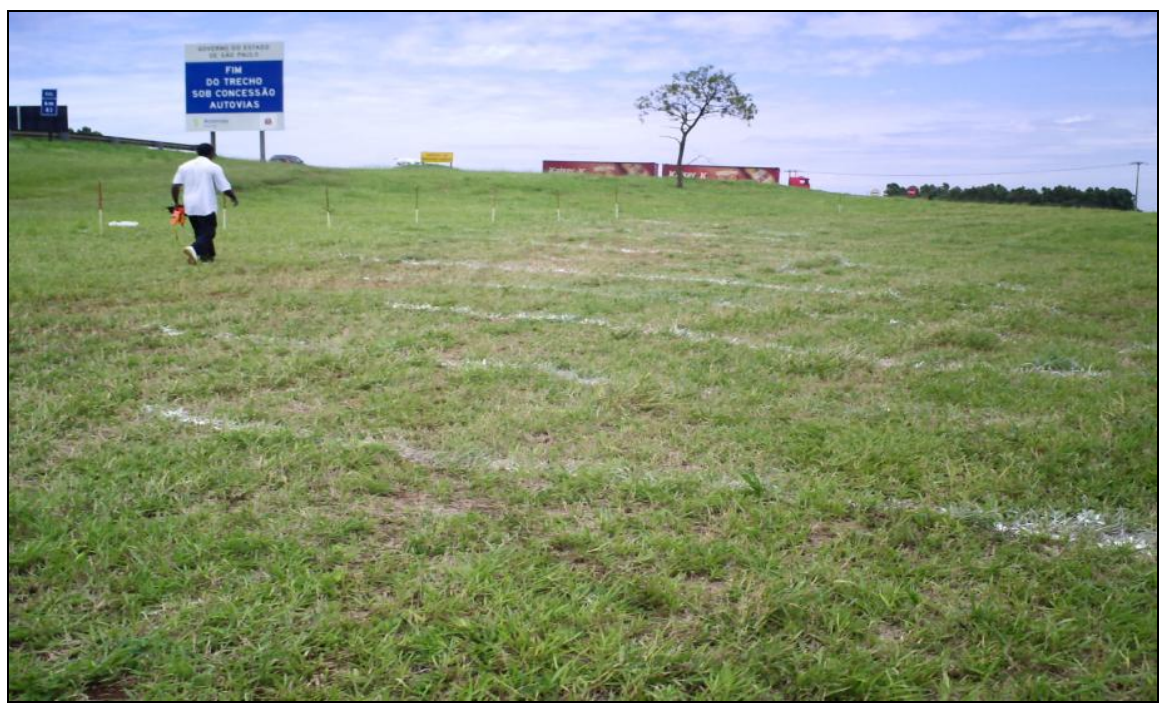

Figura 4.7 - Foto mostrando detalhe do local preparado para a realização do teste. 


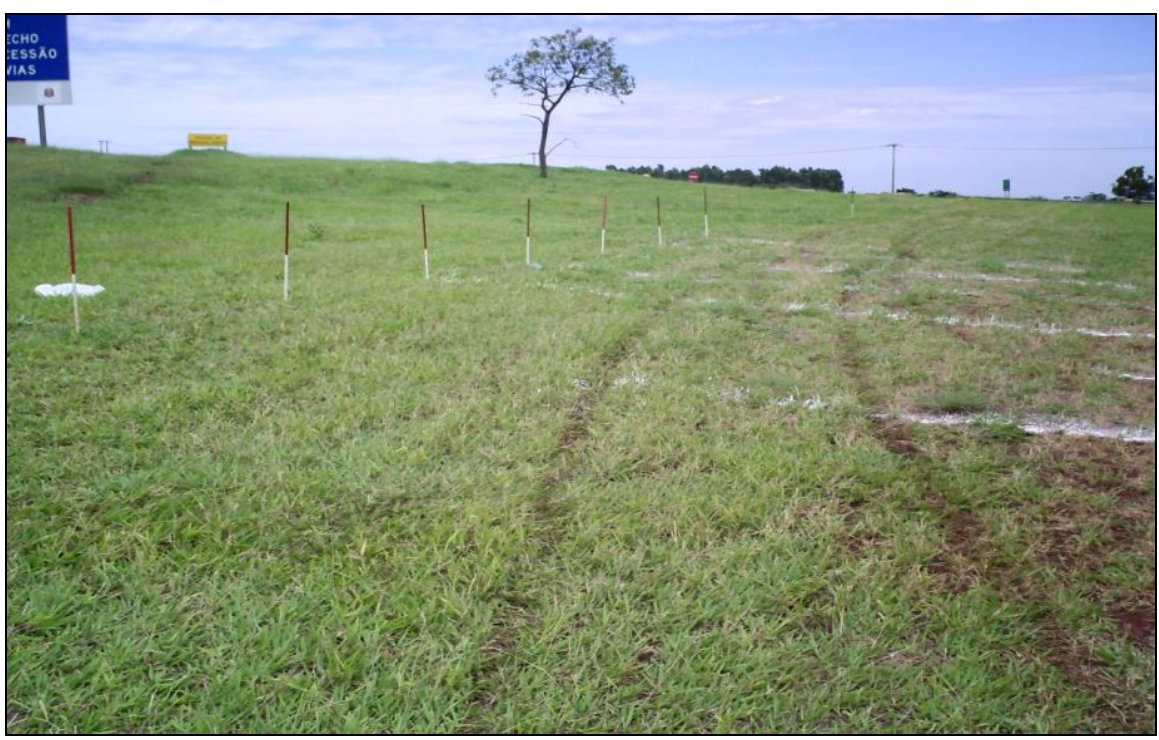

Figura 4.8 - Foto mostrando as marcas do pneu em um dos testes.

Uma representação esquemática do teste realizado é apresentada na Figura 4.9. 
Veículo parado após a

frenagem em curva
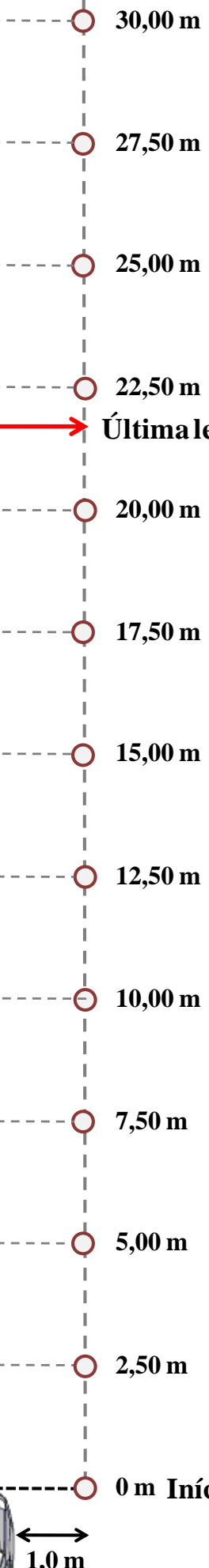

Veículo com cada velocidade de teste

Figura 4.9 - Representação esquemática do teste de desvio associado com frenagem. 
Este teste também foi realizado para velocidades iniciais de $30,40,50,60$ e $70 \mathrm{~km} / \mathrm{h}$. Por razões de segurança, foi decidido não efetuar o teste com velocidades de $80 \mathrm{~km} / \mathrm{h}$ e superiores em razão de o veículo já apresentar certa instabilidade.

Foram realizados seis testes para cada velocidade, estando os valores obtidos relacionados nas Tabelas 4.3, 4.4, 4.5, 4.6 e 4.7. Também nessas tabelas são mostrados os valores médios das distâncias transversais correspondentes. Os valores assinalados com sombra, que correspondem aos extremos (inferior e superior) do conjunto de dados, foram excluídos da amostra, não sendo, portanto, considerados nas análises.

Tabela 4.3 - Valores obtidos para $30 \mathrm{~km} / \mathrm{h}$.

\begin{tabular}{cccccccc}
\hline $\begin{array}{c}\text { Distância } \\
\text { longitudinal }\end{array}$ & \multicolumn{7}{c}{ Distâncias transversais (m) } \\
\cline { 2 - 8 }$(\mathbf{m})$ & 1 & 2 & 3 & 4 & 5 & 6 & Média \\
\hline 2,50 & 0,50 & 0,60 & 0,65 & 0,45 & 0,40 & 0,65 & 0,55 \\
5,00 & 2,95 & 3,75 & 3,40 & 3,25 & 3,50 & 3,35 & 3,38 \\
$6,45^{*}$ & - & - & - & - & - & - & $6,00^{*}$ \\
\hline
\end{tabular}

* Coordenadas médias do ponto de parada.

Tabela 4.4 - Valores obtidos para 40 km/h.

\begin{tabular}{cccccccc}
\hline $\begin{array}{c}\text { Distância } \\
\text { longitudinal } \\
(\mathbf{m})\end{array}$ & \multicolumn{7}{c}{ Distâncias transversais (m) } \\
\cline { 2 - 8 } & 1 & 2 & 3 & 4 & 5 & 6 & Média \\
\hline 2,50 & 0,55 & 0,60 & 0,35 & 0,55 & 0,50 & 0,40 & 0,50 \\
5,00 & 1,15 & 1,50 & 1,00 & 1,75 & 1,10 & 0,95 & 1,19 \\
7,50 & 2,95 & 4,50 & 3,75 & 3,40 & 4,00 & 3,10 & 3,56 \\
10,00 & 7,05 & 8,10 & 7,70 & 7,00 & 6,70 & 6,75 & 7,13 \\
12,50 & 13,20 & 10,95 & 11,80 & 11,95 & 12,80 & 9,90 & 11,88 \\
$13,25^{*}$ & - & - & - & - & - & - & $12,00^{*}$ \\
\hline
\end{tabular}

*Coordenadas médias do ponto de parada. 
Tabela 4.5 - Valores obtidos para $50 \mathrm{~km} / \mathrm{h}$.

\begin{tabular}{cccccccc}
\hline $\begin{array}{c}\text { Distância } \\
\text { longitudinal } \\
(\mathbf{m})\end{array}$ & 1 & 2 & 3 & 4 & 5 & 6 & Média \\
\cline { 2 - 8 } & 0,45 & 0,55 & 0,35 & 0,35 & 0,45 & 0,35 & 0,40 \\
2,50 & 0,90 & 0,80 & 0,70 & 0,80 & 0,65 & 0,70 & 0,75 \\
5,00 & 1,55 & 1,90 & 1,70 & 1,70 & 1,60 & 1,60 & 1,65 \\
7,50 & 2,40 & 2,80 & 2,25 & 2,85 & 2,60 & 2,75 & 2,64 \\
10,00 & 4,00 & 4,65 & 4,90 & 5,15 & 4,70 & 3,80 & 4,56 \\
12,50 & 6,30 & 9,00 & 6,55 & 6,50 & 8,00 & 7,00 & 7,01 \\
15,00 & 9,05 & 12,20 & 9,50 & 11,90 & 8,80 & 9,40 & 9,96 \\
17,50 & - & - & - & - & - & - & $14,00 *$ \\
$20,00 *$ & - & & & & &
\end{tabular}

*Coordenadas médias do ponto de parada.

Tabela 4.6 - Valores obtidos para $60 \mathrm{~km} / \mathrm{h}$.

\begin{tabular}{cccccccc}
\hline $\begin{array}{c}\text { Distância } \\
\text { longitudinal } \\
(\mathbf{m})\end{array}$ & \multicolumn{7}{c}{ Distâncias transversais (m) } \\
\cline { 2 - 8 } 2,50 & 1 & 2 & 3 & 4 & 5 & 6 & Média \\
\cline { 2 - 8 } 5,00 & 0,15 & 0,30 & 0,20 & 0,20 & 0,25 & 0,15 & 0,20 \\
7,50 & 0,45 & 0,30 & 0,30 & 0,45 & 0,40 & 0,50 & 0,40 \\
10,00 & 1,25 & 1,45 & 1,55 & 1,35 & 1,30 & 1,45 & 1,40 \\
12,50 & 2,00 & 2,65 & 1,90 & 1,90 & 2,20 & 2,00 & 2,03 \\
15,00 & 3,70 & 3,00 & 3,05 & 3,15 & 3,50 & 3,30 & 3,25 \\
17,50 & 5,00 & 4,70 & 5,05 & 4,20 & 4,50 & 4,80 & 4,75 \\
20,00 & 6,70 & 6,00 & 7,00 & 5,95 & 7,30 & 6,35 & 6,51 \\
22,50 & 9,25 & 8,50 & 7,55 & 9,10 & 8,80 & 7,80 & 8,55 \\
25,00 & 12,05 & 9,60 & 10,80 & 11,00 & 12,60 & 9,45 & 10,86 \\
27,50 & 13,20 & 15,10 & 12,00 & 14,00 & 13,70 & 12,95 & 13,46 \\
$28,30 *$ & - & - & - & - & - & - & $14,10 *$ \\
\hline
\end{tabular}

*Coordenadas médias do ponto de parada. 
Tabela 4.7 - Valores obtidos para $70 \mathrm{~km} / \mathrm{h}$.

\begin{tabular}{cccccccc}
\hline $\begin{array}{c}\text { Distância } \\
\text { longitudinal } \\
(\mathbf{m})\end{array}$ & \multicolumn{7}{c}{ Distâncias transversais (m) } \\
\cline { 2 - 8 } 2,50 & 1 & 2 & 3 & 4 & 5 & 6 & Média \\
\cline { 2 - 8 } 5,00 & 0,05 & 0,15 & 0,05 & 0,20 & 0,10 & 0,10 & 0,10 \\
7,50 & 0,15 & 0,30 & 0,15 & 0,35 & 0,40 & 0,20 & 0,25 \\
10,00 & 0,35 & 0,65 & 0,35 & 0,55 & 0,50 & 0,60 & 0,50 \\
12,50 & 1,05 & 0,85 & 1,10 & 0,75 & 0,95 & 0,70 & 0,90 \\
15,00 & 1,00 & 1,50 & 1,60 & 1,65 & 1,10 & 1,00 & 1,30 \\
17,50 & 1,95 & 2,45 & 2,20 & 1,60 & 1,55 & 1,85 & 1,90 \\
20,00 & 3,00 & 2,05 & 2,20 & 2,30 & 1,90 & 1,90 & 2,11 \\
22,50 & 3,60 & 2,50 & 3,90 & 2,90 & 2,50 & 3,20 & 3,05 \\
25,00 & 5,05 & 4,05 & 4,50 & 4,00 & 3,90 & 3,25 & 4,11 \\
27,50 & 6,40 & 4,55 & 5,50 & 5,15 & 4,60 & 6,20 & 5,36 \\
30,00 & 6,30 & 8,25 & 7,25 & 5,80 & 6,45 & 7,00 & 6,75 \\
32,50 & 9,80 & 7,85 & 6,90 & 9,00 & 8,00 & 8,50 & 8,29 \\
35,00 & 11,50 & 14,30 & 12,75 & 11,60 & 11,50 & 10,00 & 11,84 \\
$36,00 *$ & - & - & - & - & - & - & $13,95 *$ \\
\hline
\end{tabular}

*Coordenadas médias do ponto de parada.

$\mathrm{Na}$ Tabela 4.8, estão expostos os valores médios da distância transversal para os diferentes valores da distância longitudinal em função da velocidade. 
Tabela 4.8 - Valores médios da distância transversal.

\begin{tabular}{|c|c|c|c|c|c|}
\hline \multirow{2}{*}{$\begin{array}{c}\text { Distância } \\
\text { longitudinal } \\
\text { (m) }\end{array}$} & \multicolumn{5}{|c|}{ Velocidade $(\mathbf{k m} / \mathbf{h})$} \\
\hline & 30 & 40 & 50 & 60 & 70 \\
\hline 2,50 & 0,55 & 0,50 & 0,40 & 0,20 & 0,10 \\
\hline 5,00 & 3,38 & 1,19 & 0,75 & 0,40 & 0,25 \\
\hline 7,50 & & 3,56 & 1,65 & 0,80 & 0,50 \\
\hline 10,00 & & 7,13 & 2,64 & 1,40 & 0,90 \\
\hline 12,50 & & 11,88 & 4,56 & 2,03 & 1,30 \\
\hline 15,00 & & & 7,01 & 3,25 & 1,90 \\
\hline 17,50 & & & 9,96 & 4,75 & 2,11 \\
\hline 20,00 & & & & 6,51 & 3,05 \\
\hline 22,50 & & & & 8,55 & 4,11 \\
\hline 25,00 & & & & 10,86 & 5,36 \\
\hline 27,50 & & & & 13,46 & 6,75 \\
\hline 30,00 & & & & & 8,29 \\
\hline 32,50 & & & & & 9,99 \\
\hline 35,00 & & & & & 11,84 \\
\hline $\begin{array}{l}\text { Coordenadas } \\
\text { do ponto de } \\
\text { parada }\end{array}$ & $\begin{array}{c}6,45 \\
x \\
6,00\end{array}$ & $\begin{array}{c}13,25 \\
x \\
12,00\end{array}$ & $\begin{array}{c}20,00 \\
\quad x \\
14,00\end{array}$ & $\begin{array}{c}28,30 \\
\quad x \\
14,10\end{array}$ & $\begin{array}{c}36,00 \\
x \\
13,95\end{array}$ \\
\hline
\end{tabular}

$\mathrm{Na}$ Figura 4.10, são mostrados os pontos correspondentes aos pares de distância x distância longitudinal obtidos para as diversas velocidades, bem como os segmentos de reta unindo os valores médios. 


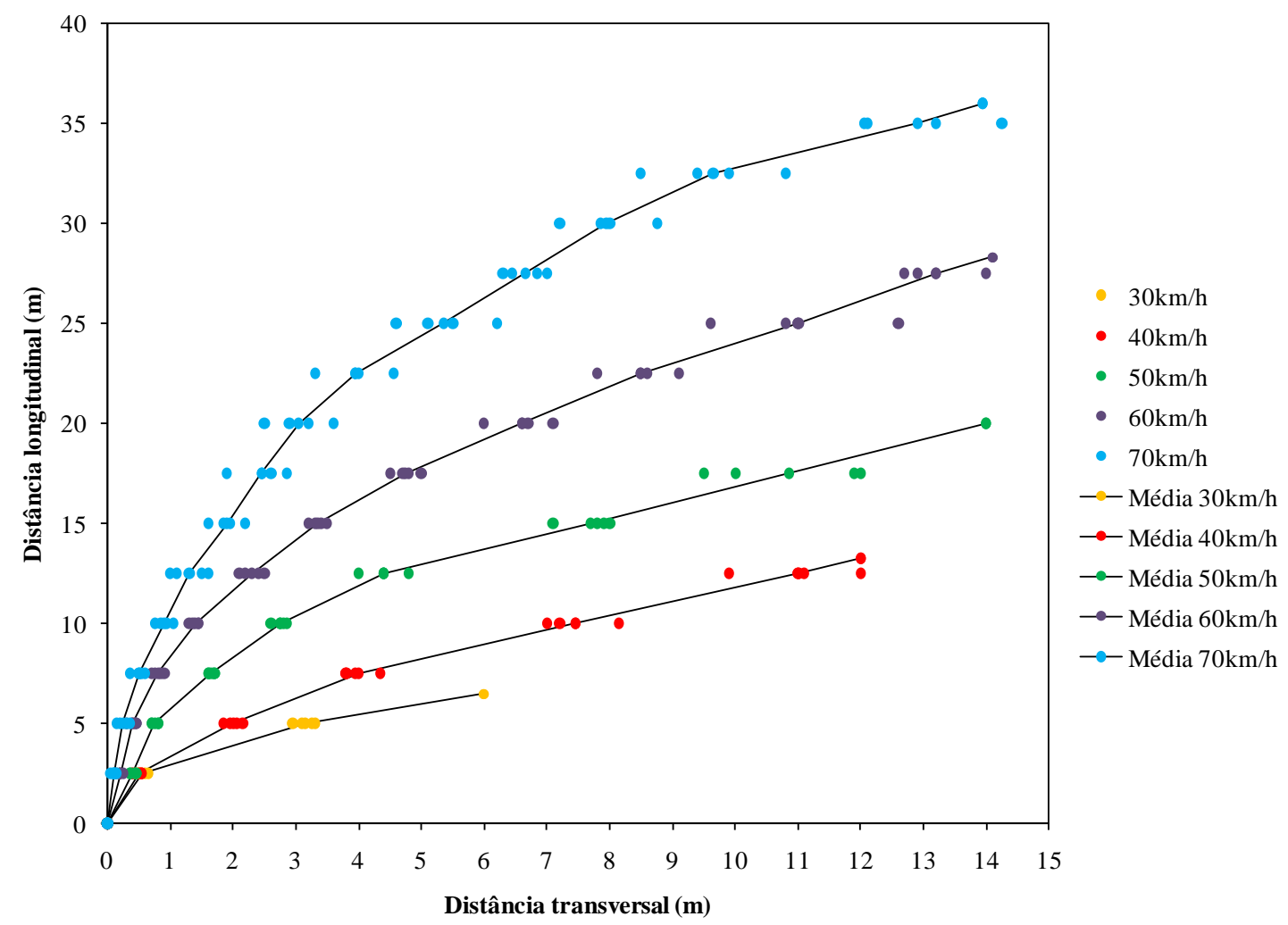

Figura 4.10 - Representação gráfica dos valores obtidos nos testes.

A partir das curvas apresentadas da Figura 4.10, foram obtidos os valores da distância longitudinal em função de valores da distância transversal, de metro em metro, para todas as velocidades. Os valores obtidos estão indicados na Tabela 4.9, e representados graficamente na Figura 4.11. 
Tabela 4.9 - Valores da distância longitudinal obtidos na Figura 4.10.

\begin{tabular}{cccccc}
\hline Distância & \multicolumn{5}{c}{ Velocidade (km/h) } \\
\cline { 2 - 6 } transversal (m) & $\mathbf{3 0}$ & $\mathbf{4 0}$ & $\mathbf{5 0}$ & $\mathbf{6 0}$ & $\mathbf{7 0}$ \\
\hline 1,0 & 3,0 & 4,0 & 6,0 & 8,5 & 11,0 \\
2,0 & 4,0 & 5,5 & 8,5 & 12,0 & 15,5 \\
3,0 & 5,0 & 7,0 & 10,5 & 14,5 & 19,5 \\
4,0 & 5,5 & 8,0 & 12,0 & 16,5 & 22,5 \\
5,0 & 6,0 & 9,0 & 13,0 & 18,0 & 24,5 \\
6,0 & 6,5 & 9,5 & 14,0 & 19,5 & 26,5 \\
7,0 & - & 10,00 & 15,0 & 21,0 & 28,5 \\
8,0 & - & 10,5 & 16,0 & 22,0 & 30,5 \\
9,0 & - & 11,0 & 17,0 & 23,0 & 32,0 \\
10,0 & - & 11,5 & 18,0 & 24,0 & 33,0 \\
11,0 & - & 12,0 & 18,5 & 25,0 & 34,0 \\
12,0 & - & 12,5 & 19,0 & 26,0 & 35,0 \\
13,0 & - & - & 19,5 & 27,0 & 36,0 \\
14,0 & - & - & 20,0 & 28,0 & 37,0 \\
\hline & & & & &
\end{tabular}

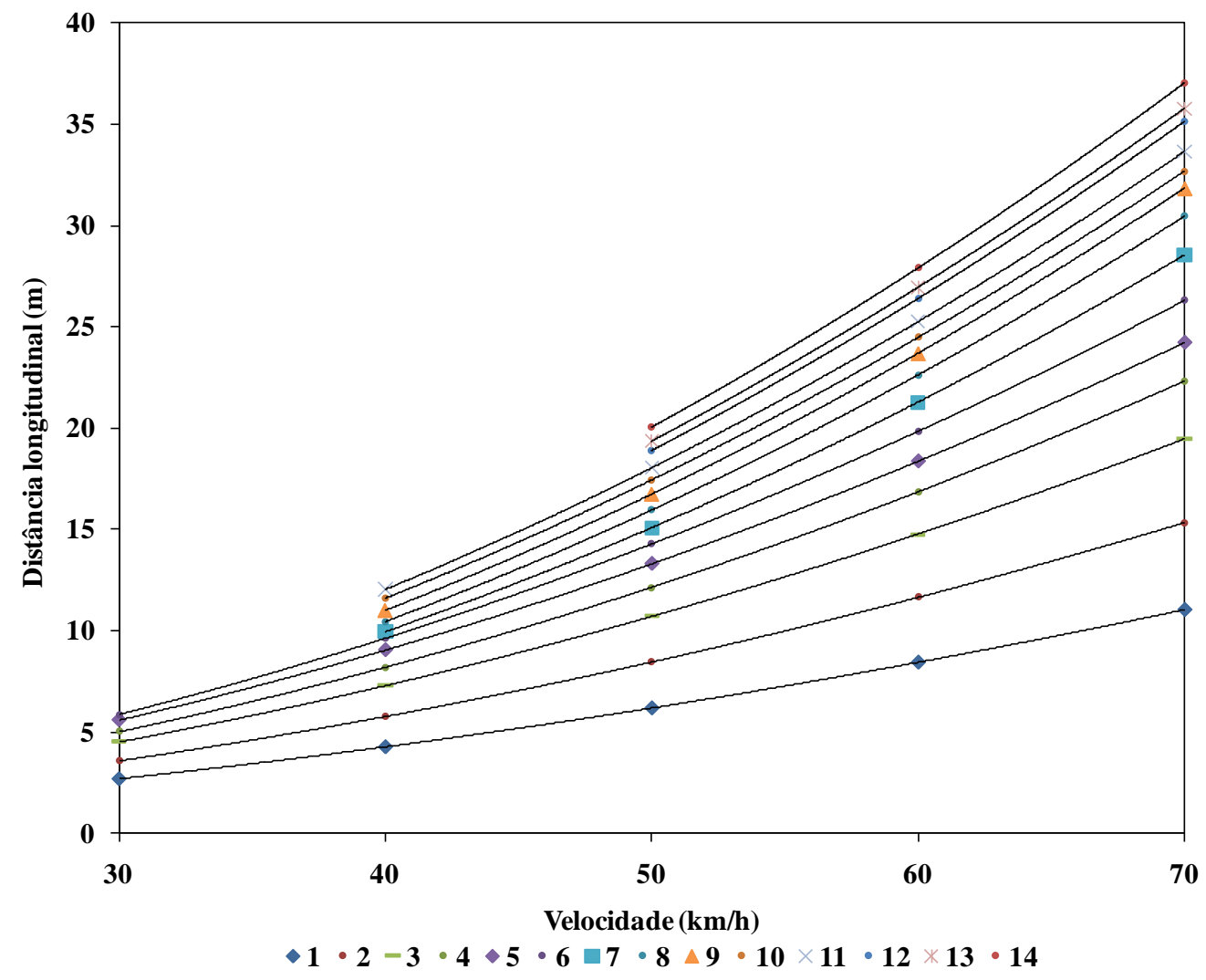

Figura 4.11 - Representação gráfica dos valores obtidos. 
Com base nos valores da Tabela 4.9 foram obtidas equações relacionando, para cada valor da distância transversal (T), os valores da distância longitudinal (L) com a velocidade (V), por meio de regressão, considerando como equação uma parábola do segundo grau passando pela origem. As equações obtidas e os respectivos coeficientes de determinação encontram-se na Tabela 4.10.

Os altos valores dos coeficientes de determinação $\mathrm{R}^{2}$ (todos acima de 0,995 ) indicam excelente aderência dos valores empíricos aos valores teóricos fornecidos pelas equações de regressão.

Tabela 4.10 - Equações de regressão obtidas.

\begin{tabular}{ccc}
\hline $\begin{array}{c}\text { Distância lateral } \\
(\mathbf{m})\end{array}$ & Equações & $\mathbf{R}^{\mathbf{2}}$ \\
\hline 1 & $\mathrm{~L}=0,0017 \mathrm{~V}^{2}+0,0386 \mathrm{~V}$ & 0,995 \\
2 & $\mathrm{~L}=0,0025 \mathrm{~V}^{2}+0,0440 \mathrm{~V}$ & 0,997 \\
3 & $\mathrm{~L}=0,0032 \mathrm{~V}^{2}+0,0541 \mathrm{~V}$ & 0,998 \\
4 & $\mathrm{~L}=0,0038 \mathrm{~V}^{2}+0,0529 \mathrm{~V}$ & 0,998 \\
5 & $\mathrm{~L}=0,0040 \mathrm{~V}^{2}+0,0660 \mathrm{~V}$ & 0,998 \\
6 & $\mathrm{~L}=0,0045 \mathrm{~V}^{2}+0,0607 \mathrm{~V}$ & 0,998 \\
7 & $\mathrm{~L}=0,0053 \mathrm{~V}^{2}+0,0367 \mathrm{~V}$ & 1,000 \\
8 & $\mathrm{~L}=0,0058 \mathrm{~V}^{2}+0,0291 \mathrm{~V}$ & 0,999 \\
9 & $\mathrm{~L}=0,0060 \mathrm{~V}^{2}+0,0349 \mathrm{~V}$ & 0,998 \\
10 & $\mathrm{~L}=0,0059 \mathrm{~V}^{2}+0,0539 \mathrm{~V}$ & 0,998 \\
11 & $\mathrm{~L}=0,0060 \mathrm{~V}^{2}+0,0608 \mathrm{~V}$ & 0,999 \\
12 & $\mathrm{~L}=0,0062 \mathrm{~V}^{2}+0,0678 \mathrm{~V}$ & 1,000 \\
13 & $\mathrm{~L}=0,0062 \mathrm{~V}^{2}+0,0771 \mathrm{~V}$ & 1,000 \\
14 & $\mathrm{~L}=0,0064 \mathrm{~V}^{2}+0,0810 \mathrm{~V}$ & 1,000 \\
\hline
\end{tabular}

Na Figura 4.11, também são mostradas as curvas correspondentes às equações de regressão geradas. A observação dessa figura confirma a excelente aderência entre os valores reais e os fornecidos pelas equações de regressão.

Utilizando as equações de regressão, foram gerados os valores da distância longitudinal em função da distância transversal, para velocidades variando de 30 a $120 \mathrm{~km} / \mathrm{h}$. Esses valores encontram-se na Tabela 4.11. 
Tabela 4.11 - Valores da distância longitudinal em metros obtidos com as equações de regressão.

\begin{tabular}{|c|c|c|c|c|c|c|c|c|c|c|}
\hline \multirow{2}{*}{$\begin{array}{c}\text { Distância } \\
\text { transversal } \\
(\mathbf{m})\end{array}$} & \multicolumn{10}{|c|}{ Velocidades $(\mathrm{km} / \mathrm{h})$} \\
\hline & 30 & 40 & 50 & 60 & 70 & 80 & 90 & 100 & 110 & 120 \\
\hline 1 & 2,69 & 4,26 & 6,18 & 8,44 & 11,03 & 13,97 & 17,24 & 20,86 & 24,82 & 29,11 \\
\hline 2 & 3,57 & 5,76 & 8,45 & 11,64 & 15,33 & 19,52 & 24,21 & 29,40 & 35,09 & 41,28 \\
\hline 3 & 4,50 & 7,28 & 10,71 & 14,77 & 19,47 & 24,81 & 30,79 & 37,41 & 44,67 & 52,57 \\
\hline 4 & 5,01 & 8,20 & 12,15 & 16,85 & 22,32 & 28,55 & 35,54 & 43,29 & 51,80 & 61,07 \\
\hline 5 & 5,58 & 9,04 & 13,30 & 18,36 & 24,22 & 30,88 & 38,34 & 46,60 & 55,66 & 65,52 \\
\hline 6 & 5,87 & 9,63 & 14,29 & 19,84 & 26,30 & 33,66 & 41,91 & 51,07 & 61,13 & 72,08 \\
\hline 7 & 5,87 & 9,95 & 15,09 & 21,28 & 28,54 & 36,86 & 46,23 & 56,67 & 68,17 & 80,72 \\
\hline 8 & 6,09 & 10,44 & 15,96 & 22,63 & 30,46 & 39,45 & 49,60 & 60,91 & 73,38 & 87,01 \\
\hline 9 & 6,45 & 11,00 & 16,75 & 23,69 & 31,84 & 41,19 & 51,74 & 63,49 & 76,44 & 90,59 \\
\hline 10 & 6,93 & 11,60 & 17,45 & 24,47 & 32,68 & 42,07 & 52,64 & 64,39 & 77,32 & 91,43 \\
\hline 11 & 7,22 & 12,03 & 18,04 & 25,25 & 33,66 & 43,26 & 54,07 & 66,08 & 79,29 & 93,70 \\
\hline 12 & 7,61 & 12,63 & 18,89 & 26,39 & 35,13 & 45,10 & 56,32 & 68,78 & 82,48 & 97,42 \\
\hline 13 & 7,89 & 13,00 & 19,36 & 26,95 & 35,78 & 45,85 & 57,16 & 69,71 & 83,50 & 98,53 \\
\hline 14 & 8,19 & 13,48 & 20,05 & 27,90 & 37,01 & 47,44 & 59,13 & 72,10 & 86,35 & 101,88 \\
\hline
\end{tabular}

A partir dos valores da Tabela 4.11, foram construídas as curvas apresentadas nas Figuras 4.12 e 4.13.

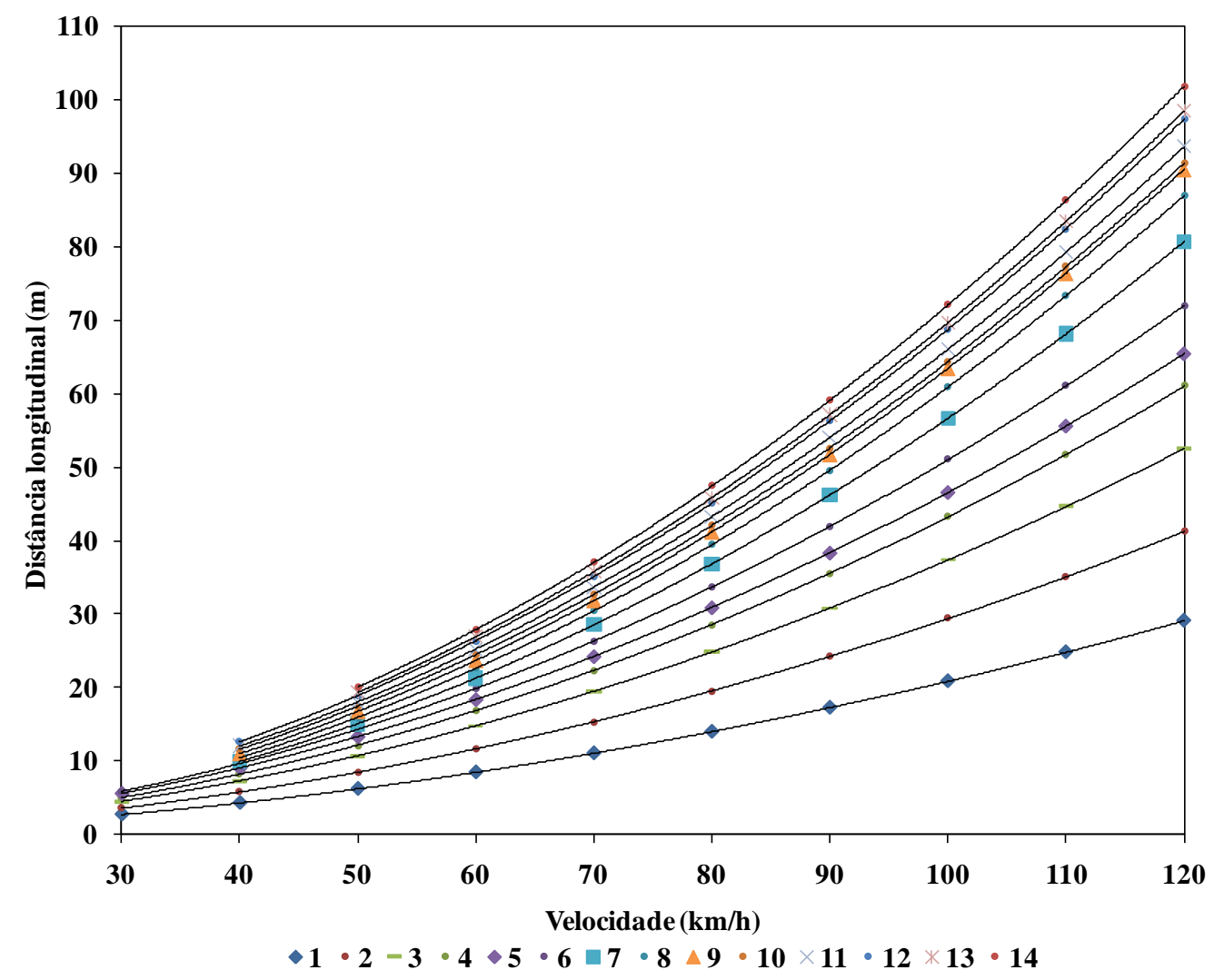

Figura 4.12 - Curvas da distância longitudinal versus velocidade inicial para os diversos valores da distância transversal. 


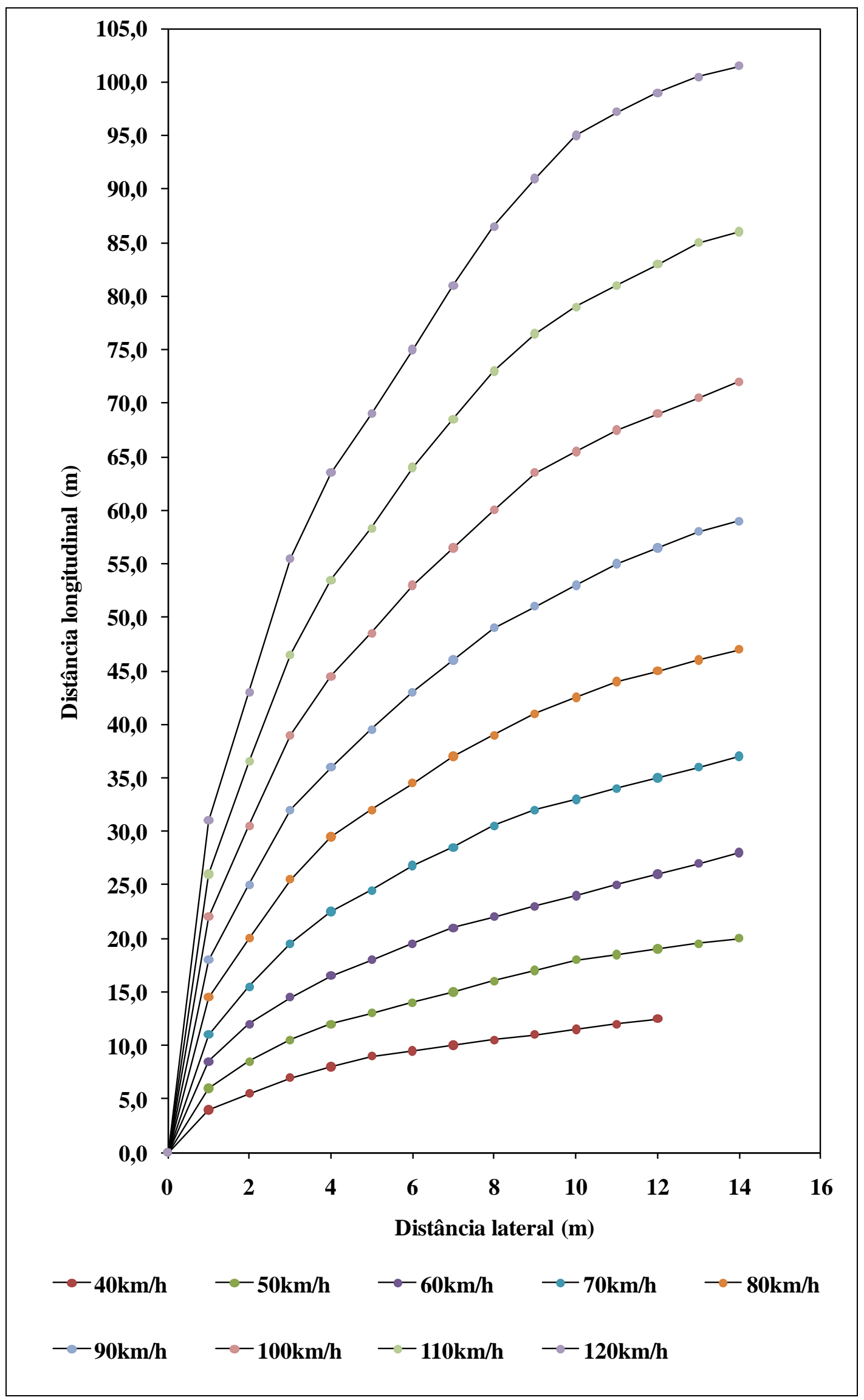

Figura 4.13 - Curvas da distância longitudinal versus distância transversal para as diversas velocidades. 
As curvas apresentadas na Figura 4.13, representam as trajetórias dos veículos para as diferentes velocidades, desde que seja utilizada a mesma escala gráfica nos dois eixos (horizontal e vertical). 


\section{MODELO QRSP}

\subsection{COMPORTAMENTO DOS CONDUTORES E DESEMPENHO DOS VEÍCULOS NAS SAÍDAS IMPREVISTAS DA PISTA}

\section{Trajetória seguida}

Ao sair da pista de maneira imprevista, o mais provável é que o balanço do veículo no momento em que a roda dianteira situada ao lado da saída que deixa a pista e toca o acostamento seja o estímulo que leva o condutor a perceber o fato e a reagir, realizando as ações para evitar o choque com obstáculos situados ao lado da rodovia, ou para retornar à pista.

O intervalo de tempo decorrido entre o estímulo e o início das ações é denominado tempo de percepção e reação. Nesse intervalo, o veículo segue, em geral, uma trajetória próxima a uma linha reta com praticamente a mesma velocidade com que saiu da pista. $\mathrm{O}$ tempo de percepção e reação varia normalmente entre 1 e 2 segundos, dependendo da idade e do estado físico e mental do condutor. Admitindo que somente condutores experientes e em boa condição física utilizem o limite legal de velocidade da rodovia, é razoável adotar para esse tempo o valor de 1,2 segundo. Supõe-se que os condutores que não se enquadram nessa situação utilizem velocidades menores, com o maior tempo de percepção e reação, sendo, em grande medida, compensados pela menor velocidade.

Decorrido o tempo de percepção e reação, o condutor adota um dos seguintes procedimentos:

1. Pisa no pedal de freio e vira o volante, visando mudar a direção do veículo para voltar à pista e/ou desviar do obstáculo (caso 1d da Figura 5.1); em alguns casos, o volante é virado no sentido contrário, afastando o veículo da pista para desviar do obstáculo (caso 1e da Figura 5.1). Isso para o caso de saída do lado do acostamento (direito); no caso de saída do lado do canteiro (esquerdo), a situação é inversa. O acionamento do freio tem o propósito de auxiliar a desviar do obstáculo, permitindo fazer curvas de menor raio à medida que a velocidade diminui e também para reduzir a velocidade do choque - se possível parar o veículo antes de colidir com o obstáculo. As trajetórias das curvas para a esquerda ou para a direita da linha de saída são aquelas mostradas na Figura 5.1.

2. Pisa no pedal de freio, mas não vira a direção (seguindo, portanto, uma trajetória próxima de uma reta, como indicado no caso 2 da Figura 5.1), com o propósito de 
reduzir a velocidade do veículo para atenuar o efeito do choque ou evitá-lo com a parada do veículo.

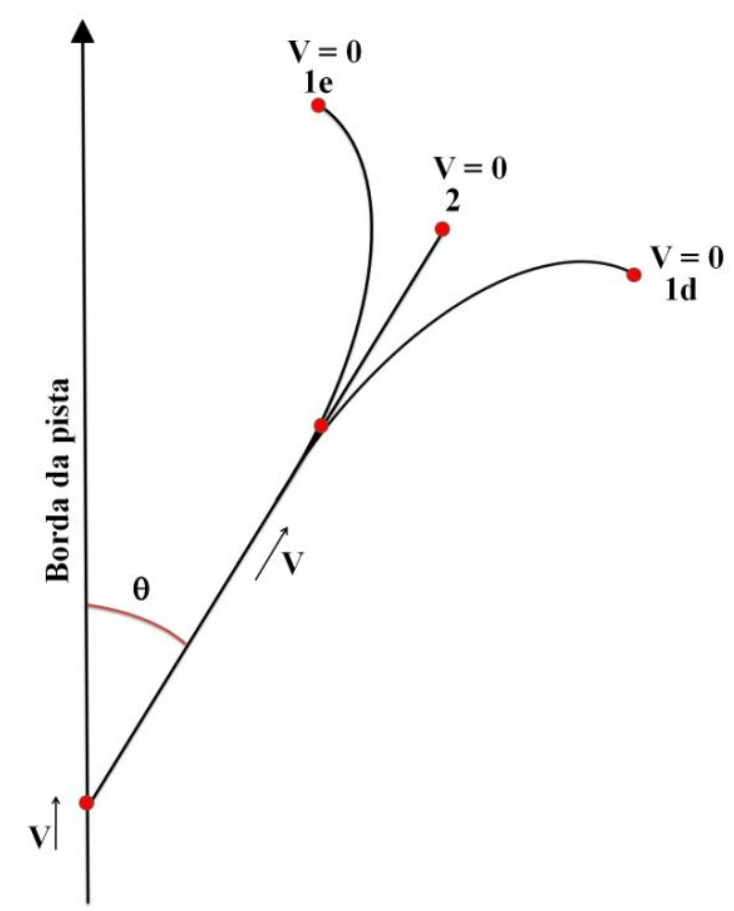

Figura 5.1 - Trajetórias seguidas pelos veículos nas saídas de pista.

A caracterização da trajetória real, como se pode observar na Figura 5.1, depende do ângulo de saída da pista $(\theta)$.

O primeiro procedimento é na maioria das vezes, o utilizado pelos condutores, o segundo empregado quando não há possibilidade de desviar do obstáculo, seja porque ele está muito próximo seja porque há restrições para fazer o desvio (presença de outro obstáculo, invasão da pista contrária etc.).

Quando a superfície do terreno não for regular, as irregularidades podem modificar a trajetória dos veículos. No caso da entrada em valeta de drenagem disposta longitudinalmente, o veículo fica, em geral, confinado à valeta e movendo-se dentro da mesma, como mostrado na Figura 5.2. 


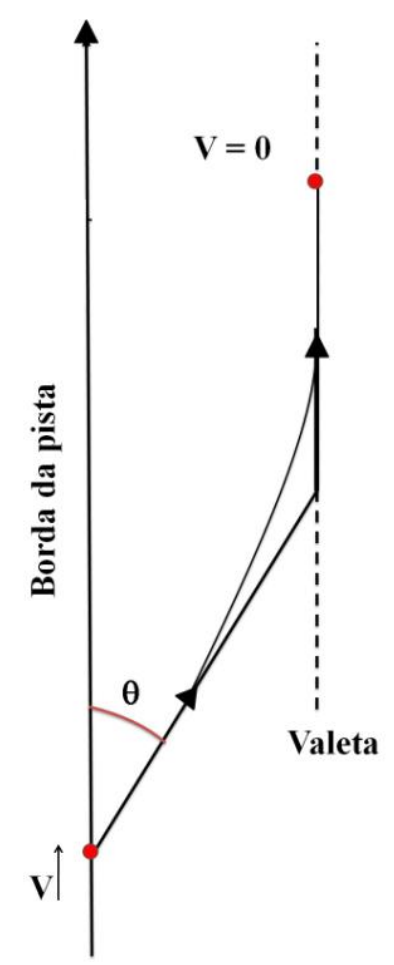

Figura 5.2 - Trajetórias seguidas pelos veículos nas saídas de pista quando atingem valeta de drenagem.

\section{Distância de parada e forma de variação da velocidade}

\section{Caso em que ocorre apenas o acionamento do freio}

A distância percorrida pelo veículo desde que sai da pista até que ocorra a parada deve ser determinada por intermédio da seguinte equação clássica da Física:

$$
\mathrm{D}=\mathrm{D}_{1}+\mathrm{D}_{2} \text {, sendo } \mathrm{D}_{1}=\mathrm{V} \times \mathrm{T}_{\mathrm{pr}}, \mathrm{D}_{2}=\mathrm{V}^{2} / 2 \times \mathrm{A}
$$

em que, D: distância de frenagem (m); $\mathrm{D}_{1}$ : distância percorrida antes do acionamento do freio (m); $\mathrm{D}_{2}$ : distância percorrida após o acionamento do freio $(\mathrm{m}) ; \mathrm{V}$ : velocidade inicial $(\mathrm{m} / \mathrm{s})$; $\mathrm{T}_{\mathrm{pr}}$ : tempo de percepção e reação $(\mathrm{s})$ e A: desaceleração média $\left(\mathrm{m} / \mathrm{s}^{2}\right)$.

O valor da desaceleração depende da força empregada no acionamento do pedal do freio, do tipo de freio (se comum ou ABS), do tipo e estado da superfície de rolamento e dos pneus do veículo (o que influi no valor do coeficiente de atrito). No caso de frenagem radical, com o acionamento total do pedal de freio, o valor máximo da desaceleração depende apenas do coeficiente de atrito entre os pneus e a superfície de rolamento e da inclinação do terreno, sendo dada pela equação:

$$
A=g(\mu+i)
$$

em que, A: desaceleração de frenagem; $\mu$ : coeficiente de atrito; g: aceleração da gravidade e i: inclinação da via [ (positivo (+) se em aclive e (-) se em declive) ].

Considerando as unidades de medida usuais na prática e o valor de A da equação anterior, resulta: 


$$
\mathrm{D}=\mathrm{D}_{1}+\mathrm{D}_{2} \text {, sendo } \mathrm{D}_{1}=\mathrm{V} \cdot \mathrm{T}_{\mathrm{pr}} / 3,6 \text { e } \mathrm{D}_{2}=\mathrm{V}^{2} / 25,92 . \mathrm{g}(\mu+\mathrm{i})
$$

em que, D: distância de frenagem $(\mathrm{m}) ; \mathrm{D}_{1}$ : distância percorrida antes do acionamento do freio (m); $\mathrm{D}_{2}$ : distância percorrida após o acionamento do freio $(\mathrm{m}) ; \mathrm{V}$ : velocidade inicial $(\mathrm{km} / \mathrm{h})$; $\mathrm{T}_{\mathrm{pr}}$ : tempo de percepção e reação (s); g: aceleração da gravidade $\left(\mathrm{m} / \mathrm{s}^{2}\right) ; \mu$ : coeficiente de atrito (adimensional) e i: inclinação da via (adimensional).

Desconsiderando o valor de i, por ser, em geral, significativamente menor que o valor de $\mu$, e adotando $\mathrm{T}_{\mathrm{pr}}=1,2 \mathrm{~s}, \mathrm{~g}=10 \mathrm{~m} / \mathrm{s}^{2}$ e $\mu=0,61$ (valor obtido nos testes de campo com tempo seco e superfície gramada para frenagem em linha reta), resultam:

$$
\mathrm{D}=\mathrm{D}_{1}+\mathrm{D}_{2} \text {, sendo } \mathrm{D}_{1}=\mathrm{V} / 3 \text { e } \mathrm{D}_{2}=\mathrm{V}^{2} / 158,11
$$

em que, D: distância de frenagem $(\mathrm{m}) ; \mathrm{D}_{1}$ : distância percorrida antes do acionamento do freio (m); $\mathrm{D}_{2}$ : distância percorrida após o acionamento do freio $(\mathrm{m})$ e $\mathrm{V}$ : velocidade inicial $(\mathrm{km} / \mathrm{h})$.

Muitas vezes, não há distância suficiente para o veículo parar antes de atingir o obstáculo, sendo necessário determinar a velocidade no momento do choque. Para isso, devem ser empregadas as seguintes expressões:

$$
\mathrm{V}_{\mathrm{c}}=\mathrm{V} \text {, se } \mathrm{D}_{\mathrm{o}} \leq \mathrm{D}_{1}
$$

(neste caso, não há tempo/distância suficiente para acionar o freio)

$$
V_{c}^{2}=V^{2}-158,11\left(D_{0}-D_{1}\right) \text { para } D_{0}>D_{1}
$$

(neste caso, há tempo/distância suficiente para acionar o freio)

em que, $V_{c}$ : velocidade no choque $(\mathrm{km} / \mathrm{h}) ; \mathrm{V}$ : velocidade inicial $(\mathrm{km} / \mathrm{h}) ; \mathrm{D}_{\mathrm{o}}$ : distância do ponto de saída da pista até o obstáculo $(\mathrm{m})$ e $\mathrm{D}_{1}$ : distância percorrida antes do acionamento do freio $(\mathrm{m})$.

\section{Caso em que ocorre o acionamento do freio e o desvio da trajetória}

No caso da trajetória em curva decorrente do acionamento do freio e virada da direção, a questão é mais complexa. No entanto, nas aplicações práticas, podem ser utilizadas as mesmas expressões deduzidas para o caso da trajetória em linha reta com acionamento apenas do freio, pois a diferença é pequena. Para mostrar que a diferença de valores é realmente reduzida, na Tabela 5.1, são comparadas as distâncias percorridas até a parada do veículo na frenagem pura e na frenagem mais desvio à esquerda e à direita - neste caso, com a distância medida ao longo do eixo longitudinal e considerando a saída com ângulo de $1^{\circ}$ (situação em que a diferença é a maior). 
Tabela 5.1 - Valores da distância percorrida no caso de frenagem pura (F) e no caso de frenagem mais desvio $(\mathrm{F}+\mathrm{D})$.

\begin{tabular}{cccccccc}
\hline & & \multicolumn{3}{c}{ À esquerda } & \multicolumn{3}{c}{ A direita } \\
\cline { 3 - 7 } $\mathbf{V}$ & $\mathbf{F}(\mathbf{m})$ & $\mathbf{F}+\mathbf{D}$ & $\begin{array}{c}\text { Diferença } \\
\mathbf{a b s o l u t a} \\
(\mathbf{m})\end{array}$ & $\begin{array}{c}\text { Diferença } \\
\text { relativa } \\
(\mathbf{\%})\end{array}$ & $\begin{array}{c}\mathbf{F}+\mathbf{D} \\
(\mathbf{m})\end{array}$ & $\begin{array}{c}\text { Diferença } \\
\text { absoluta } \\
(\mathbf{m})\end{array}$ & $\begin{array}{c}\text { Diferença } \\
\text { relativa } \\
(\mathbf{\%})\end{array}$ \\
\hline 120 & 131,07 & 141,72 & 10,65 & $7,51 \%$ & 141,23 & 10,16 & $7,19 \%$ \\
110 & 113,19 & 122,88 & 9,69 & $7,89 \%$ & 122,41 & 9,22 & $7,53 \%$ \\
100 & 96,58 & 105,5 & 8,92 & $8,45 \%$ & 104,58 & 8 & $7,65 \%$ \\
90 & 81,23 & 89,22 & 7,99 & $8,96 \%$ & 88,75 & 7,52 & $8,47 \%$ \\
80 & 67,14 & 73,89 & 6,75 & $9,14 \%$ & 73,42 & 6,28 & $8,55 \%$ \\
70 & 54,32 & 60,56 & 6,24 & $10,30 \%$ & 60,09 & 5,77 & $9,60 \%$ \\
60 & 42,77 & 48,23 & 5,46 & $11,32 \%$ & 47,76 & 4,99 & $10,45 \%$ \\
\hline
\end{tabular}

$\mathrm{Na}$ Tabela 5.2, são mostradas as distâncias percorridas pelos veículos até atingir alguns valores de velocidade pré-estabelecidos, para diferentes valores da velocidade inicial, calculadas com base nas equações 5.5 ou 5.6. 
Tabela 5.2 - Distâncias percorridas do ponto de saída da pista até atingir as velocidades indicadas em uma possível colisão.

\begin{tabular}{|c|c|c|c|c|}
\hline \multicolumn{5}{|c|}{ Velocidade na saída da pista: $V s=120 \mathrm{~km} / \mathrm{h}$} \\
\hline $\mathbf{V}_{\mathrm{c}}(\mathbf{k m} / \mathbf{h})$ & $\mathbf{D}_{1}(\mathbf{m})$ & $\mathbf{D}_{2}(\mathbf{m})$ & $\mathbf{D}(\mathbf{m})$ & D prático (m) \\
\hline 90 & 40,00 & 39,85 & 79,85 & 80 \\
\hline 70 & 40,00 & 60,08 & 100,08 & 100 \\
\hline 50 & 40,00 & 75,26 & 115,26 & 115 \\
\hline 0 & 40,00 & 91,07 & 131,07 & 130 \\
\hline \multicolumn{5}{|c|}{ Velocidade na saída da pista: $V s=110 \mathrm{~km} / \mathrm{h}$} \\
\hline $\mathbf{V}_{\mathbf{c}}(\mathbf{k m} / \mathbf{h})$ & $\mathbf{D}_{1}(\mathbf{m})$ & $\mathbf{D}_{2}(\mathbf{m})$ & $\mathbf{D}(\mathbf{m})$ & D prático $(\mathbf{m})$ \\
\hline 90 & 36,67 & 25,30 & 61,97 & 60 \\
\hline 70 & 36,67 & 45,54 & 82,20 & 80 \\
\hline 50 & 36,67 & 60,72 & 97,38 & 95 \\
\hline 0 & 36,67 & 76,52 & 113,19 & 115 \\
\hline \multicolumn{5}{|c|}{ Velocidade na saída da pista: Vs $=100 \mathrm{~km} / \mathrm{h}$} \\
\hline $\mathbf{V}_{\mathbf{c}}(\mathbf{k m} / \mathbf{h})$ & $\mathbf{D}_{1}(\mathbf{m})$ & $\mathbf{D}_{2}(\mathbf{m})$ & $\mathbf{D}(\mathbf{m})$ & D prático $(\mathbf{m})$ \\
\hline 90 & 33,33 & 12,02 & 45,35 & 45 \\
\hline 70 & 33 & 32,26 & & 65 \\
\hline 50 & & & & 80 \\
\hline 0 & 33,33 & 63,24 & 96,58 & 95 \\
\hline \multicolumn{5}{|c|}{ Velocidade na saída da pista: $\mathrm{Vs}=90 \mathrm{~km} / \mathrm{h}$} \\
\hline $\mathbf{V}_{\mathbf{c}}(\mathbf{k m} / \mathbf{h})$ & $D_{1}(\mathrm{~m})$ & $\mathrm{D}_{2}(\mathrm{~m})$ & $\mathbf{D}(\mathbf{m})$ & prático (m) \\
\hline 70 & & & 50 & 50 \\
\hline 50 & & & & 65 \\
\hline 0 & 30,00 & 51,23 & 81,23 & 80 \\
\hline \multicolumn{5}{|c|}{ Velocidade na saída da pista: $\mathrm{Vs}=80 \mathrm{~km} / \mathrm{h}$} \\
\hline$(\mathrm{km} / \mathrm{h})$ & $\mathbf{D}_{1}(\mathbf{m})$ & $\mathbf{D}_{2}(\mathbf{m})$ & $\mathbf{D}(\mathbf{m})$ & prático $(\mathbf{m})$ \\
\hline 70 & & & & 35 \\
\hline 50 & 57 & 24,67 & 51 & 50 \\
\hline 0 & 26,67 & 40,48 & 67,14 & 65 \\
\hline \multicolumn{5}{|c|}{ Velocidade na saída da pista: $\mathrm{Vs}=70 \mathrm{~km} / \mathrm{h}$} \\
\hline$(\mathbf{k m} / \mathbf{h})$ & $\mathbf{D}_{1}(\mathrm{~m})$ & $\mathbf{D}_{2}(\mathbf{m})$ & $\mathbf{D}(\mathbf{m})$ & D prático $(\mathbf{m})$ \\
\hline 50 & 23,33 & 15,18 & 38,51 & 40 \\
\hline 0 & 23,33 & 30,99 & 54,32 & 55 \\
\hline \multicolumn{5}{|c|}{ Velocidade na saída da pista: $V s=60 \mathrm{~km} / \mathrm{h}$} \\
\hline$(\mathbf{k m} / \mathbf{h})$ & $\mathbf{D}_{1}(\mathrm{~m})$ & $\mathbf{D}_{2}(\mathbf{m})$ & $\mathbf{D}(\mathbf{m})$ & D prático (m) \\
\hline 50 & 20,00 & 6,96 & 26,96 & 25 \\
\hline 0 & 20,00 & 22,77 & 42,77 & 45 \\
\hline
\end{tabular}

Os valores apresentados na Tabela 5.2 correspondem ao caso de frenagem contando apenas com o atrito das rodas com a superfície gramada do terreno que se supõe estar seca, ou seja, para $\mu=0,61$. 
A Tabela 5.3 contém uma síntese dos resultados da Tabela 5.2.

Tabela 5.3 - Distâncias percorridas, em metros, para a velocidade atingir os valores indicados.

\begin{tabular}{ccccc}
\hline $\begin{array}{c}\text { Velocidade na } \\
\text { saída da pista }\end{array}$ & \multicolumn{4}{c}{ Velocidade no momento do choque - Vc $(\mathbf{k m} / \mathbf{h})$} \\
\cline { 2 - 5 } Vs $(\mathbf{k m} / \mathbf{h})$ & $\mathbf{9 0}$ & $\mathbf{7 0}$ & $\mathbf{5 0}$ & $\mathbf{0}$ \\
120 & 80 & 100 & 115 & 130 \\
110 & 60 & 80 & 95 & 115 \\
100 & 45 & 65 & 80 & 95 \\
90 & 0 & 50 & 65 & 80 \\
80 & - & 35 & 50 & 65 \\
70 & - & 0 & 40 & 55 \\
60 & - & - & 25 & 45 \\
\hline
\end{tabular}

Caso em que o veículo se move confinado dentro de valeta de drenagem

No caso da entrada em valeta de drenagem que mantém o veículo confinado movendose dentro da mesma, duas situações podem ocorrer.

Primeira - a desaceleração do veículo é devida apenas ao acionamento do sistema de freio, o que acontece quando a valeta tem a forma aberta de $\boldsymbol{U}$ ou $\boldsymbol{V}$. Nesta situação, no caso de superfície gramada seca, são válidas as equações 5.5 e 5.6.

Segunda - o veículo fica enganchado na valeta, o que acontece quando a valeta tem a forma fechada de $\boldsymbol{U}$ ou $\boldsymbol{V}$, sendo, neste caso, a desaceleração maior e originada, principalmente, pela resistência do terreno ao ser rompido e arrastado pelas partes do veículo que se encontram enganchadas. Nesta situação, o valor da desaceleração varia muito dependendo das condições do enganche. Como valor tentativo, a favor da segurança, pode-se considerar uma desaceleração duas vezes maior do que a conseguida apenas com o acionamento do freio, o que resultaria na validade das seguintes equações:

$$
\begin{aligned}
\mathrm{D}_{\mathrm{v}} & =\mathrm{V}_{\mathrm{ev}}{ }^{2} / 316,22 \\
\mathrm{~V}_{\mathrm{o}}{ }^{2} & =\mathrm{Vev}^{2}-316,22 \mathrm{D}_{\mathrm{o}}
\end{aligned}
$$

em que, $D_{\mathrm{v}}$ : distância percorrida dentro da valeta $(\mathrm{m})$ e $\mathrm{V}_{\mathrm{e}}$ : velocidade ao entrar na valeta $(\mathrm{km} / \mathrm{h}) ; \mathrm{V}_{\mathrm{o}}$ : velocidade ao chegar ao obstáculo $(\mathrm{km} / \mathrm{h}) ; \mathrm{D}_{\mathrm{o}}$ : distância do ponto de entrada na valeta até o obstáculo (m). 


\subsection{SITUAÇÕES POSSÍVEIS DE OCORRER NAS SAÍDAS DA PISTA E NÍVEL DE RISCO ASSOCIADO}

\section{Situações possíveis de ocorrer}

Para a definição das 18 situações distintas possíveis de ocorrer nas saídas imprevistas de veículos da pista, fez-se reunião em escritório com um painel de especialistas e discussão e visita no campo conforme descrição na Tabela 5.4.

Tabela 5.4 - Tipos de situações associadas à saída de veículos da pista.

\begin{tabular}{|c|c|}
\hline Situações & Descrição \\
\hline 1 & $\begin{array}{l}\text { Percurso em terreno com superfície sem irregularidades, } \\
\text { inclinação lateral nula ou pequena (menor que } 6 \mathrm{H}: 1 \mathrm{~V} \text { ) e } \\
\text { revestimento com grama. }\end{array}$ \\
\hline 2 & $\begin{array}{l}\text { Entrada em terreno com superfície sem irregularidades, } \\
\text { inclinação lateral nula ou pequena (menor que } 6 \mathrm{H}: 1 \mathrm{~V} \text { ), com } \\
\text { vegetação de baixa resistência ao choque (cana-de-açúcar, } \\
\text { capim, etc.) e/ou com objetos colapsíveis. Não ocorre choque. }\end{array}$ \\
\hline 3 & $\begin{array}{l}\text { Percurso em terreno com superfície sem irregularidades, } \\
\text { inclinação lateral média (entre } 6 \mathrm{H}: 1 \mathrm{~V} \text { e } 4 \mathrm{H}: 1 \mathrm{~V} \text { ) e } \\
\text { revestimento com grama. }\end{array}$ \\
\hline 4 & $\begin{array}{l}\text { Percurso em terreno com irregularidades, mas que não } \\
\text { provocam enganche, tombamento ou capotagem, com } \\
\text { inclinação lateral menor que } 4 \mathrm{H}: 1 \mathrm{~V} \text {, revestimento com grama } \\
\text { ou com vegetação de baixa resistência ao choque (cana-de- } \\
\text { açúcar, capim, etc.), podendo haver objetos colapsíveis. }\end{array}$ \\
\hline 5 & $\begin{array}{l}\text { Choque lateral com barreira de contenção (defensa metálica, } \\
\text { muro de concreto tipo New Jersey ou similar etc.). }\end{array}$ \\
\hline 6 & $\begin{array}{l}\text { Choque lateral com talude de corte bastante inclinado (se } \\
\text { assemelhando a uma parede vertical) com superfície regular } \\
\text { de terra. }\end{array}$ \\
\hline 7 & $\begin{array}{l}\text { Choque frontal com obstáculo fixo flexível: árvores de } \\
\text { pequeno porte, monte de terra, barreira de contenção metálica } \\
\text { etc. }\end{array}$ \\
\hline 8 & $\begin{array}{l}\text { Choque lateral com elemento rígido de baixa altura (guia, } \\
\text { caixa de captação de água, base de concreto, mureta etc.). }\end{array}$ \\
\hline 9 & $\begin{array}{l}\text { Choque frontal com elemento rígido de baixa altura (guia, } \\
\text { caixa de captação de água, base de concreto, mureta etc.). }\end{array}$ \\
\hline 10 & $\begin{array}{l}\text { Entrada em valeta onde o veículo se move confinado, sem se } \\
\text { enganchar no terreno. }\end{array}$ \\
\hline 11 & $\begin{array}{l}\text { Entrada em valeta onde o veículo se move confinado e } \\
\text { enganchado no terreno. }\end{array}$ \\
\hline 12 & $\begin{array}{l}\text { Entrada em talude de corte ou aterro com inclinação lateral } \\
\text { média (entre } 4 \mathrm{H}: 1 \mathrm{~V} \text { e } 3 \mathrm{H}: 1 \mathrm{~V}) \text {. }\end{array}$ \\
\hline
\end{tabular}


13

Choque lateral com talude de corte bastante inclinado (assemelhando-se a uma parede vertical) com superfície irregular com reentrâncias e protuberâncias.

14

Entrada em talude de corte com grande inclinação lateral (maior que $3 \mathrm{H}: 1 \mathrm{~V}$ ).

15 Choque com veículo estacionado ao lado da rodovia.

16 Choque frontal com obstáculo fixo rígido: pilares de viadutos, postes, árvores de grande porte etc.

17 Choque frontal com veículo se deslocando em sentido contrário.

18 Queda em espaço vazio de grande altura: passagem inferior em desnível, rios, lagos, barrancos altos (taludes de aterro com inclinação maior 3H:1V) etc.

\section{Níveis de risco da saída imprevista da pista que pode resultar em acidente grave}

São considerados cinco níveis de risco associados à saída imprevista de veículos da pista, definidas em reunião feita em escritório com painel de especialistas de forma a estabelecer consenso sobre a probabilidade de serem graves os acidentes associados às 18 situações da Tabela 5.4 e as notas a serem atribuídas ao nível de risco da ocorrência de acidente grave conforme descrito na Tabela 5.5.

Tabela 5.5 - Níveis de risco associados à saída imprevista de veículos da pista.

\begin{tabular}{cc}
\hline Risco da ocorrência de acidente grave & Nota associada \\
\hline Inexistente & 0 \\
Insignificante & 1 \\
Pequeno & 2 \\
Médio & 3 \\
Grande & 4 \\
\hline
\end{tabular}

Os dois parâmetros levados em conta na definição do nível de risco foram o tipo de situação encontrada fora da pista e a velocidade ao chegar ao obstáculo (quando for o caso). Nas Tabelas 5.6 a 5.12, estão indicadas as condições associadas aos diferentes níveis de risco considerados.

Tabela 5.6 - Nível de risco na situação 1.

\begin{tabular}{cl}
\hline Velocidade do percurso na colisão $\mathbf{V}_{\mathbf{c}}(\mathbf{k m} / \mathbf{h})$ & Nível de risco \\
\hline $0-120$ & 0 (Inexistente) \\
\hline
\end{tabular}


Tabela 5.7 - Nível de risco nas situações 2 e 3.

\begin{tabular}{cc}
\hline Velocidade na colisão $\mathbf{V}_{\mathbf{c}}(\mathbf{k m} / \mathbf{h})$ & Nível de risco \\
\hline $0-120$ & 1 (Insignificante) \\
\hline Tabela $\mathbf{5 . 8}-$ Nível de risco nas situações $\mathbf{4 , 5} \mathbf{5} \mathbf{6 .}$ \\
\hline Velocidade na colisão $\mathbf{V}_{\mathbf{c}}(\mathbf{k m} / \mathbf{h})$ & Nível de risco \\
$0-90$ & 1 (Insignificante) \\
& 2 (Pequeno) \\
\hline
\end{tabular}

Tabela 5.9 - Nível de risco nas situações 7, 8, 9, 10, 11 e 12.

\begin{tabular}{cc}
\hline Velocidade na colisão $\mathbf{V}_{\mathbf{c}}(\mathbf{k m} / \mathbf{h})$ & Nível de risco \\
\hline $0-70$ & 1 (Insignificante) \\
$70-90$ & 2 (Pequeno) \\
$90-120$ & 3 (Médio) \\
\hline
\end{tabular}

Tabela 5.10 - Nível de risco nas situações 13, 14, 15 e 16.

\begin{tabular}{cc}
\hline Velocidade na colisão $\mathbf{V}_{\mathbf{c}}(\mathbf{k m} / \mathbf{h})$ & Nível de risco \\
\hline $0-50$ & 1 (Insignificante) \\
$50-70$ & 2 (Pequeno) \\
$70-90$ & 3 (Médio) \\
$90-120$ & 4 (Grande) \\
\hline
\end{tabular}

Tabela 5.11 - Nível de risco na situação 17.

\begin{tabular}{cc}
\hline Velocidade na colisão $\mathbf{V}_{\mathbf{c}}(\mathbf{k m} / \mathbf{h})$ & Nível de risco \\
\hline $0-70$ & 3 (Médio) \\
$70-120$ & 4 (Grande)
\end{tabular}

Tabela 5.12 - Nível de risco na situação 18.

\begin{tabular}{cc}
\hline Velocidade na colisão $\mathbf{V}_{\mathbf{c}}(\mathbf{k m} / \mathbf{h})$ & Nível de risco \\
\hline $0-120$ & 4 (Grande) \\
\hline
\end{tabular}




\subsection{SUPERFÍCIE DO TERRENO NA LATERAL DA RODOVIA}

O modelo pressupõe que a superfície do terreno na lateral da rodovia seja gramado e esteja seco, com coeficiente de aderência pneu-grama igual aos obtidos nos ensaios/testes de campo realizados, ou seja, $\mu=0,61$.

$\mathrm{Na}$ análise da frenagem com acionamento apenas do sistema de freios, seria simples simular o fenômeno para outros valores do fator de aderência. No entanto, no caso de acionamento do freio e giro da direção para mudança da trajetória, seria bastante complexo simular o fenômeno para outros valores do fator de aderência.

O ideal seria realizar os testes em outros locais (tipos de gramado) e em condições de grama molhada para verificar o efeito disso no desempenho dos veículos nas saídas imprevistas da pista. Somente à luz dessas informações seria possível concluir sobre qual situação deveria ser considerada como padrão de referência nas análises, levando em conta, inclusive a questão econômica (relação custo-benefício).

\section{4 ÂNGULOS DE SAÍdA DA PISTA}

De acordo com informações contidas em Hutchinson \& Kennedy (1966), em trabalho sobre saída de veículos da pista em duas rodovias americanas, 80\% das saídas de pista ocorrem com ângulos menores que $15^{\circ}$.

As saídas com ângulos maiores que $15^{\circ}$ ocorrem, quase sempre, quando o condutor sai deliberadamente da pista para desviar de um obstáculo que se encontra na mesma (objeto de grande porte, veículo, animal, pessoa etc.), sendo as condições de saída diferentes do caso das saídas imprevistas, que, na sua maioria, acontecem com ângulos menores que $15^{\circ}$.

Nas saídas imprevistas, o percurso do tempo de percepção e reação é feito fora da pista, diferentemente da saída deliberada, em que o condutor sai da pista com o volante já virado e o freio já acionado. Assim, do ponto de vista da segurança, são muito mais críticas as saídas imprevistas em relação às saídas deliberadas.

À luz do exposto, foi admitido, nos trechos em tangente, apenas saídas da pista imprevistas em ângulos de valor inteiro entre $1^{\circ}$ e $15^{\circ}$.

\subsection{PROBABILIDADE DA SAÍDA EM DIFERENTES ÂNGULOS}

Os valores da probabilidade acumulada de a saída da pista ocorrer em diferentes ângulos foram definidos com base em informações contidas em Hutchinson \& Kennedy 
(1966), devidamente adaptadas. Na Tabela 5.13, estão indicados os valores adotados e, na Figura 5.3, a curva correspondente.

Tabela 5.13 - Valores da probabilidade acumulada de a saída da pista ocorrer em diferentes ângulos nos trechos em tangente.

\begin{tabular}{ccccccccc}
\hline$\theta\left({ }^{\circ}\right)$ & 0 & 1 & 2 & 3 & 4 & 5 & 6 & 7 \\
$\mathrm{P} \leq \theta$ & 100 & 82,5 & 67,9 & 55,9 & 46 & 38 & 31 & 26 \\
$\theta\left({ }^{\circ}\right)$ & 8 & 9 & 10 & 11 & 12 & 13 & 14 & 15 \\
$\mathrm{P} \leq \theta$ & 21,5 & 17,9 & 14,5 & 11 & 8 & 5 & 2,3 & 0 \\
\hline
\end{tabular}

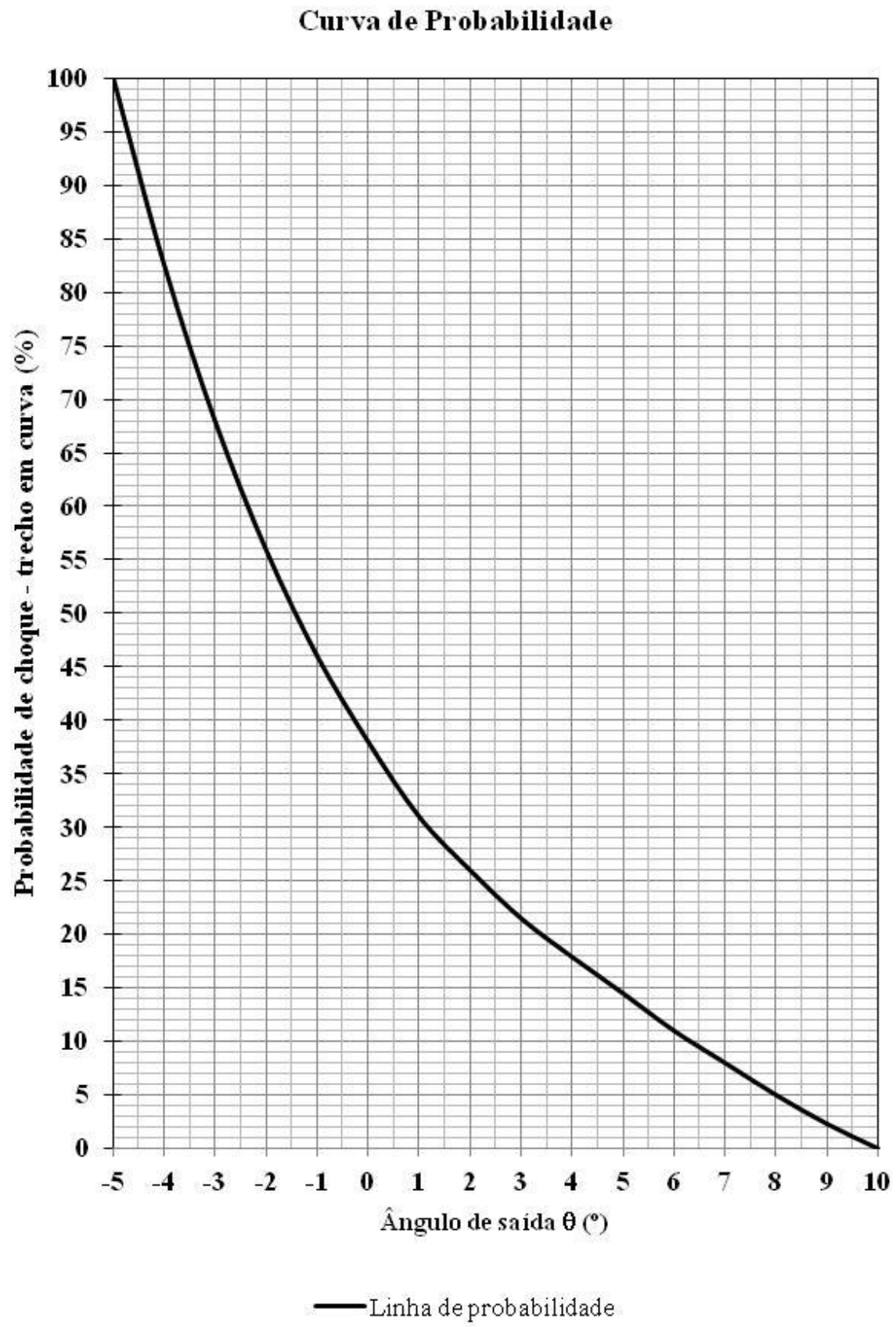

Figura 5.3 - Curva da probabilidade acumulada de a saída da pista ocorrer em diferentes ângulos nos trechos em tangente. 


\subsection{TRAJETÓRIAS DOS VEÍCULOS NAS SAÍDAS DA PISTA}

\section{Trecho em tangente (reto)}

Na Figura 5.4 (desvio à esquerda) e na Figura 5.5 (desvio à direita), são mostradas as linhas correspondentes às trajetórias seguidas para os diferentes ângulos de saída da pista, no caso de velocidade igual a $110 \mathrm{~km} / \mathrm{h}$. As linhas associadas às outras velocidades comumente adotadas nas rodovias brasileiras $(60 \mathrm{~km} / \mathrm{h}, 70 \mathrm{~km} / \mathrm{h}, 80 \mathrm{~km} / \mathrm{h}, 90 \mathrm{~km} / \mathrm{h}, 100 \mathrm{~km} / \mathrm{h}$ e $120 \mathrm{~km} / \mathrm{h}$ ) encontram-se em anexo. Nessas figuras, também estão indicados os pontos de parada dos veículos que saem da pista e apenas acionam o sistema de freio, ou seja, não viram a direção para mudar a trajetória.

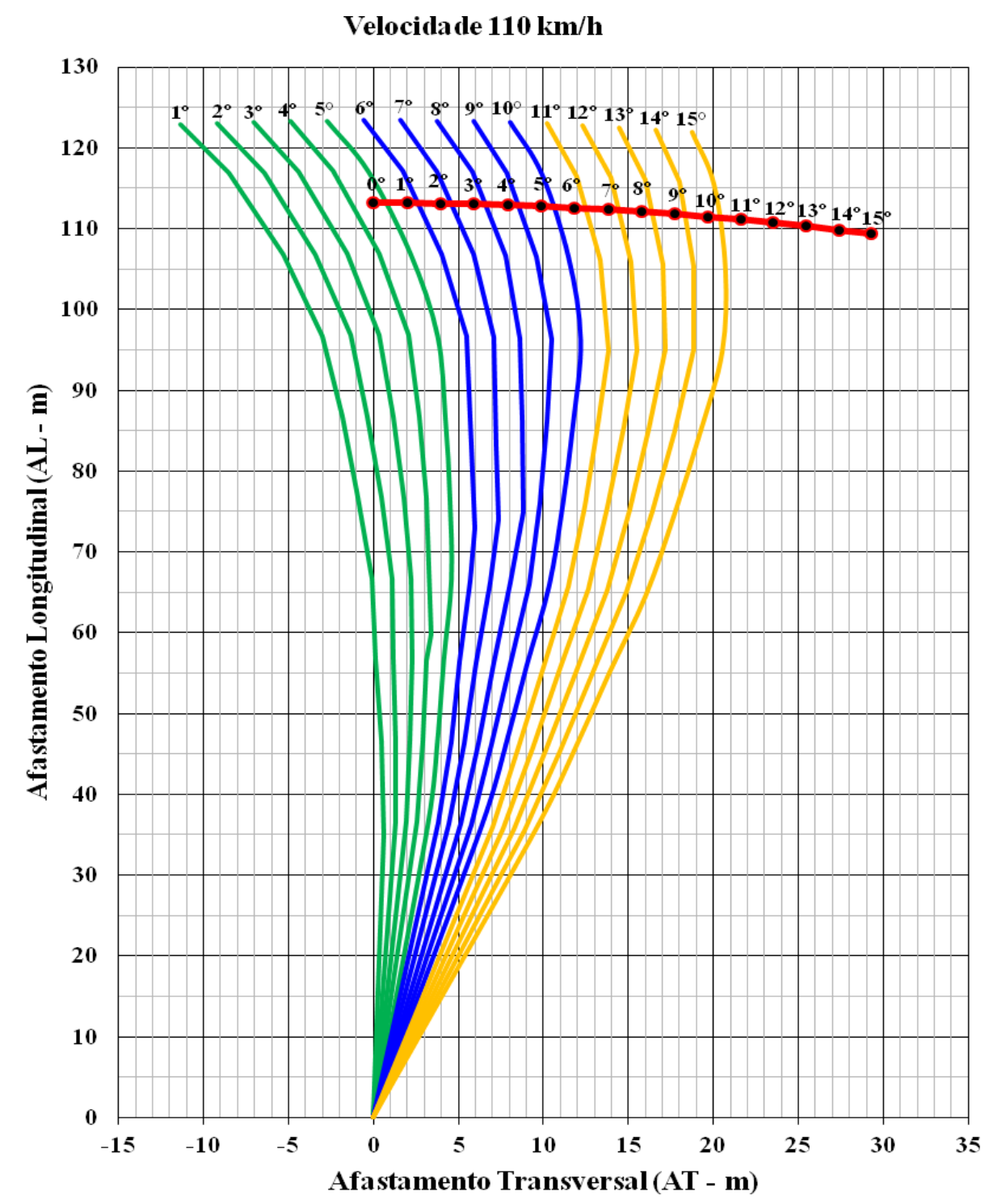

Figura 5.4 - Trajetória do veículo com desvio à esquerda para velocidade de saída da pista igual a $110 \mathrm{~km} / \mathrm{h}$. 


\section{Velocidade $110 \mathrm{~km} / \mathrm{h}$}

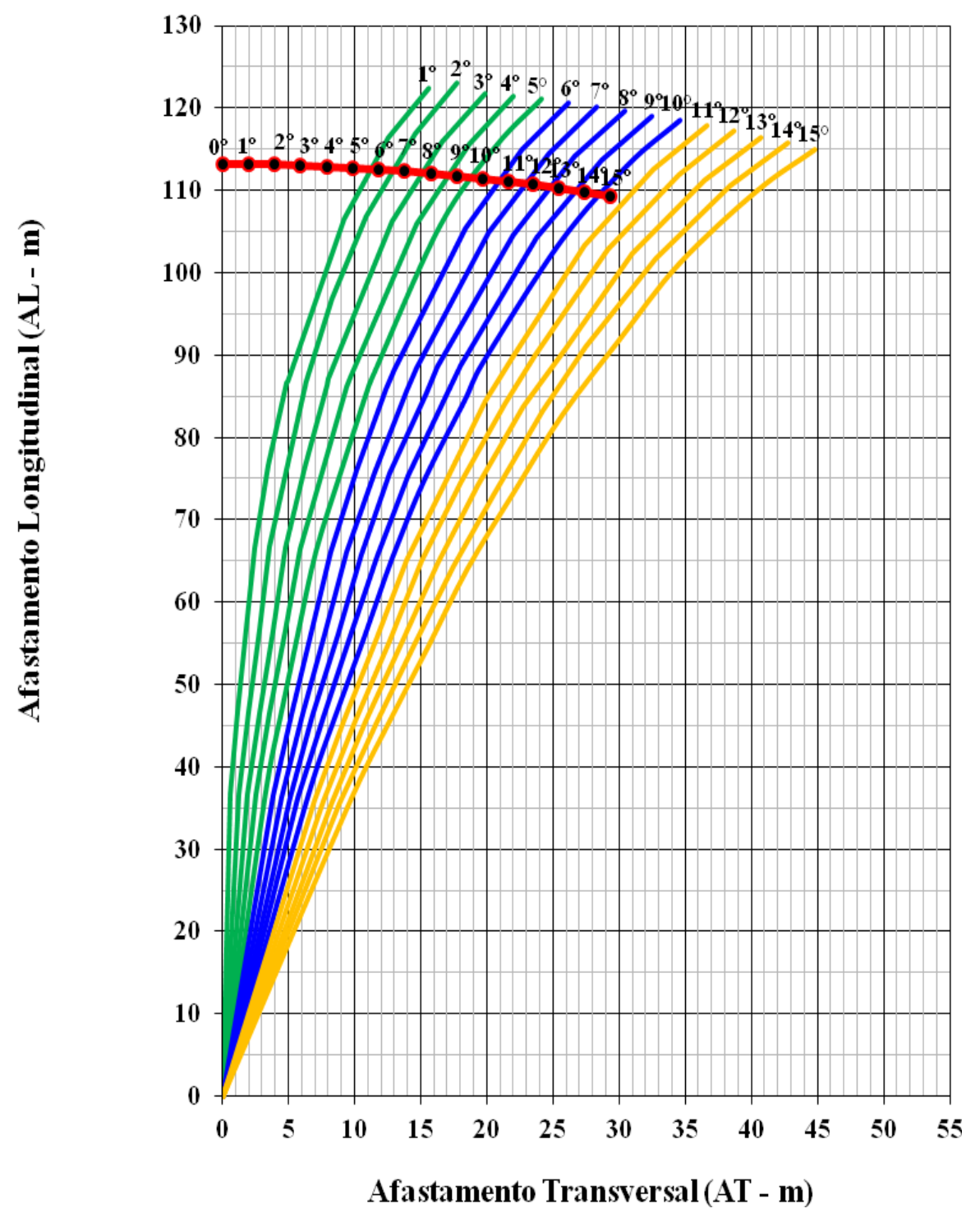

Figura 5.5 - Trajetória do veículo com desvio à direita para velocidade de saída da pista igual a $110 \mathrm{~km} / \mathrm{h}$.

Admite-se que a variação da velocidade ao longo do eixo vertical (longitudinal) siga o padrão apresentado na Tabela 5.3.

\section{Trechos em curva}

A situação correspondente à saída da pista em curva é ilustrada na Figura 5.6. 


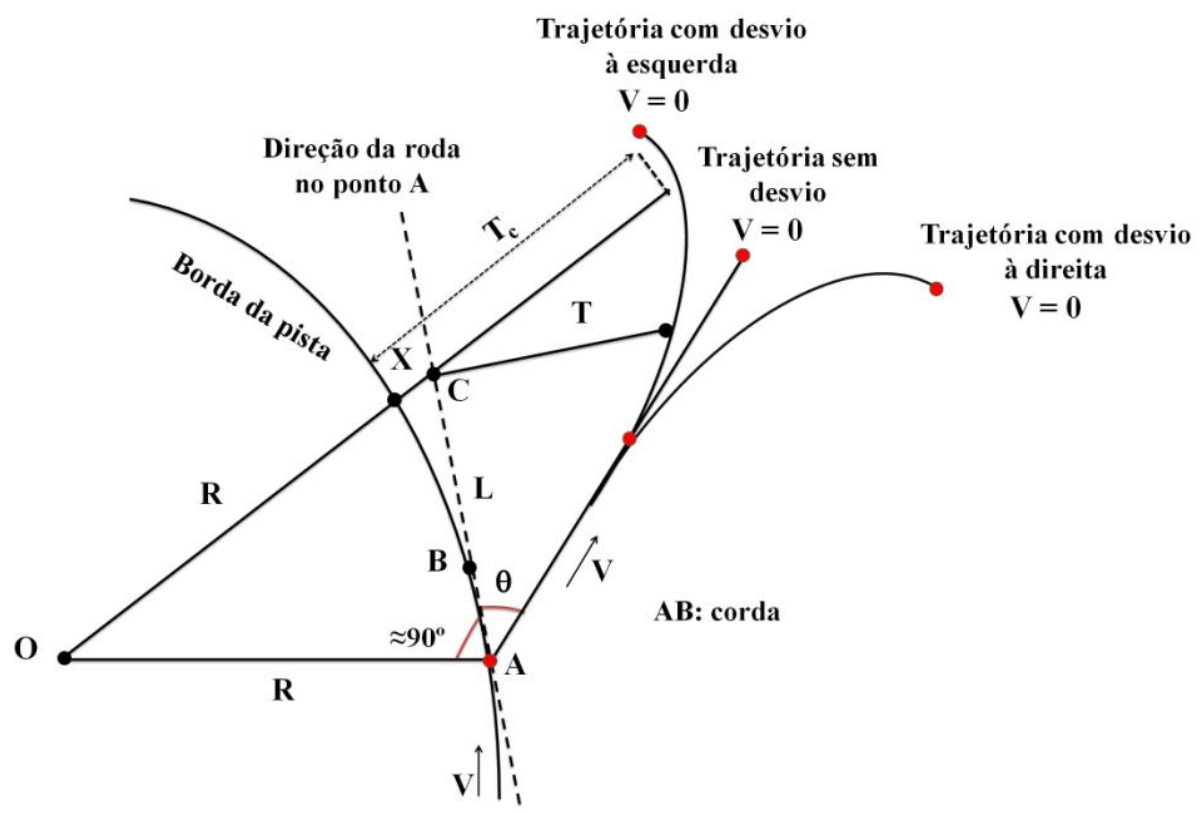

Figura 5.6 - Situação correspondente à saída da pista em curva.

A roda dianteira mais próxima do bordo da pista tem a direção reta definida pela corda A-B e o ângulo de saída $(\theta)$ é medido a partir dessa corda. A trajetória do veículo em relação à direção da corda A-B é a mesma da saída da pista num trecho reto. Para determinar as coordenadas da trajetória em relação à curva, pode-se considerar a distância longitudinal (L) medida sobre a curva como praticamente igual à distância medida sobre a reta $\mathrm{AB}$ e a distância transversal (Tc) correspondente determinada, de maneira aproximada, mediante a seguinte equação:

$$
\mathrm{Tc}=\mathrm{T}+\mathrm{X}
$$

em que, Tc: distância entre a trajetória do veículo e curva medida ao longo do raio; T: distância entre a trajetória e a pista suposta em tangente ao longo da reta $\mathrm{AB}$ e X: distância entre a reta $\mathrm{AB}$ e a curva cujo valor aproximado é deduzido a seguir.

$\mathrm{O}$ ângulo $\mathrm{A}$ do triângulo $\triangle \mathrm{OAC}$ pode ser considerado como aproximadamente reto $\left(90^{\circ}\right)$, valendo, assim, a relação de Pitágoras:

$$
(\mathrm{R}+\mathrm{X})^{2}=\mathrm{R}^{2}+\mathrm{L}^{2}, \mathrm{R}^{2}+\mathrm{X}^{2}+2 \cdot \mathrm{R} \cdot \mathrm{X}=\mathrm{R}^{2}+\mathrm{L}^{2}, \mathrm{X}^{2}+2 \cdot \mathrm{R} \cdot \mathrm{X}=\mathrm{L}^{2}
$$

Como $X \ll<R$, pode-se admitir: $X^{2}+2 \cdot R \cdot X=2 . R \cdot X$

$$
\begin{aligned}
& \text { Assim, 2.R.X }=\mathrm{L}^{2} \quad \mathrm{e} \\
& \mathrm{X}=\mathrm{L}^{2} / 2 . \mathrm{R}
\end{aligned}
$$

Na Figura 5.7 (desvio à esquerda) e na Figura 5.8 (desvio à direita), são mostradas as linhas correspondentes às trajetórias seguidas para diferentes ângulos de saída da pista em uma curva de raio 500 metros, no caso de velocidade igual a $110 \mathrm{~km} / \mathrm{h}$. As linhas associadas às demais velocidades usuais nas rodovias brasileiras $(60 \mathrm{~km} / \mathrm{h}, 70 \mathrm{~km} / \mathrm{h}, 80 \mathrm{~km} / \mathrm{h}, 90 \mathrm{~km} / \mathrm{h}$, 
$100 \mathrm{~km} / \mathrm{h}$ e $120 \mathrm{~km} / \mathrm{h}$ ) para os valores comumente empregados dos raios de curva encontramse em anexo.

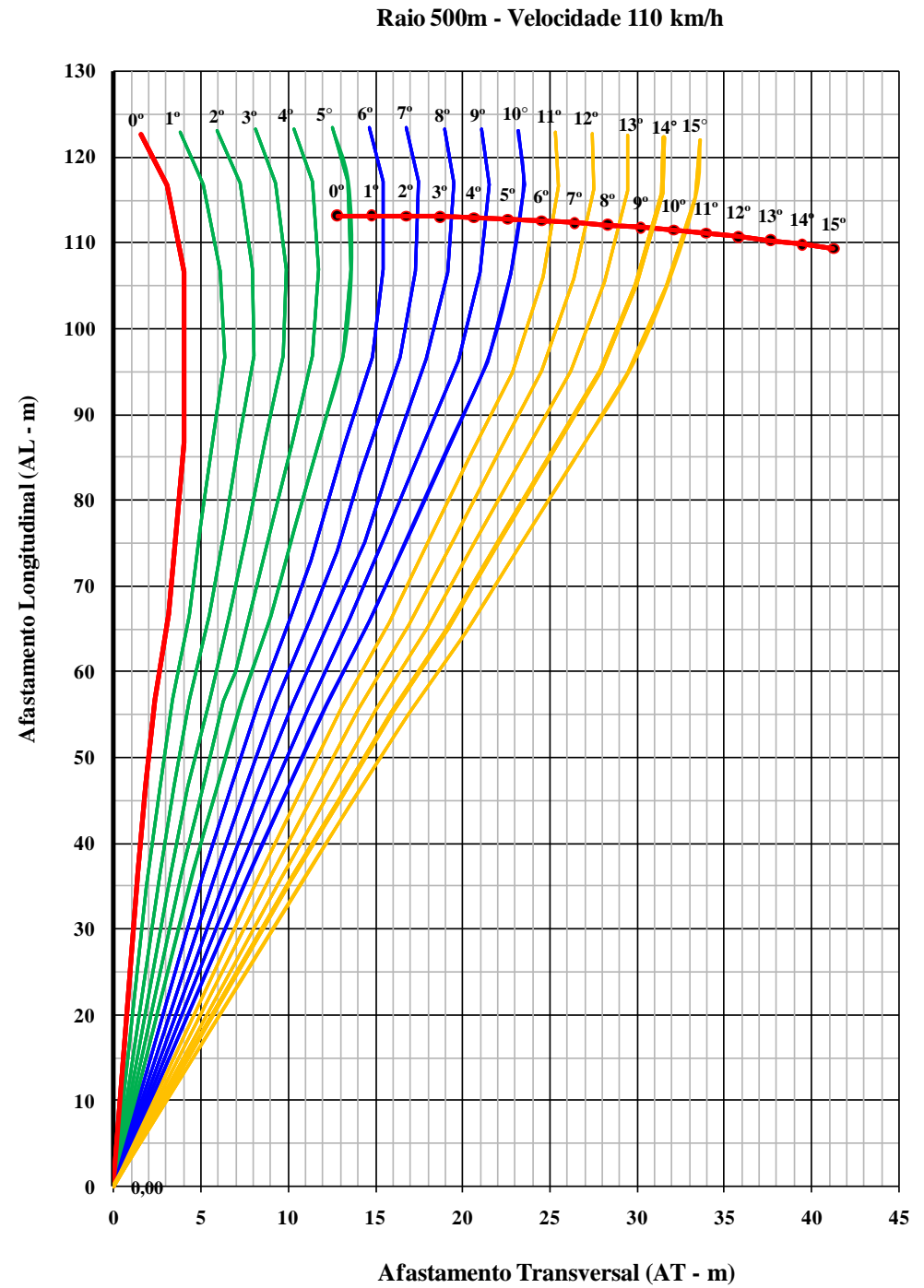

Figura 5.7 - Trajetória do veículo com desvio à esquerda para velocidade de saída da pista igual a $110 \mathrm{~km} / \mathrm{h}$ em curva de raio $500 \mathrm{~m}$. 


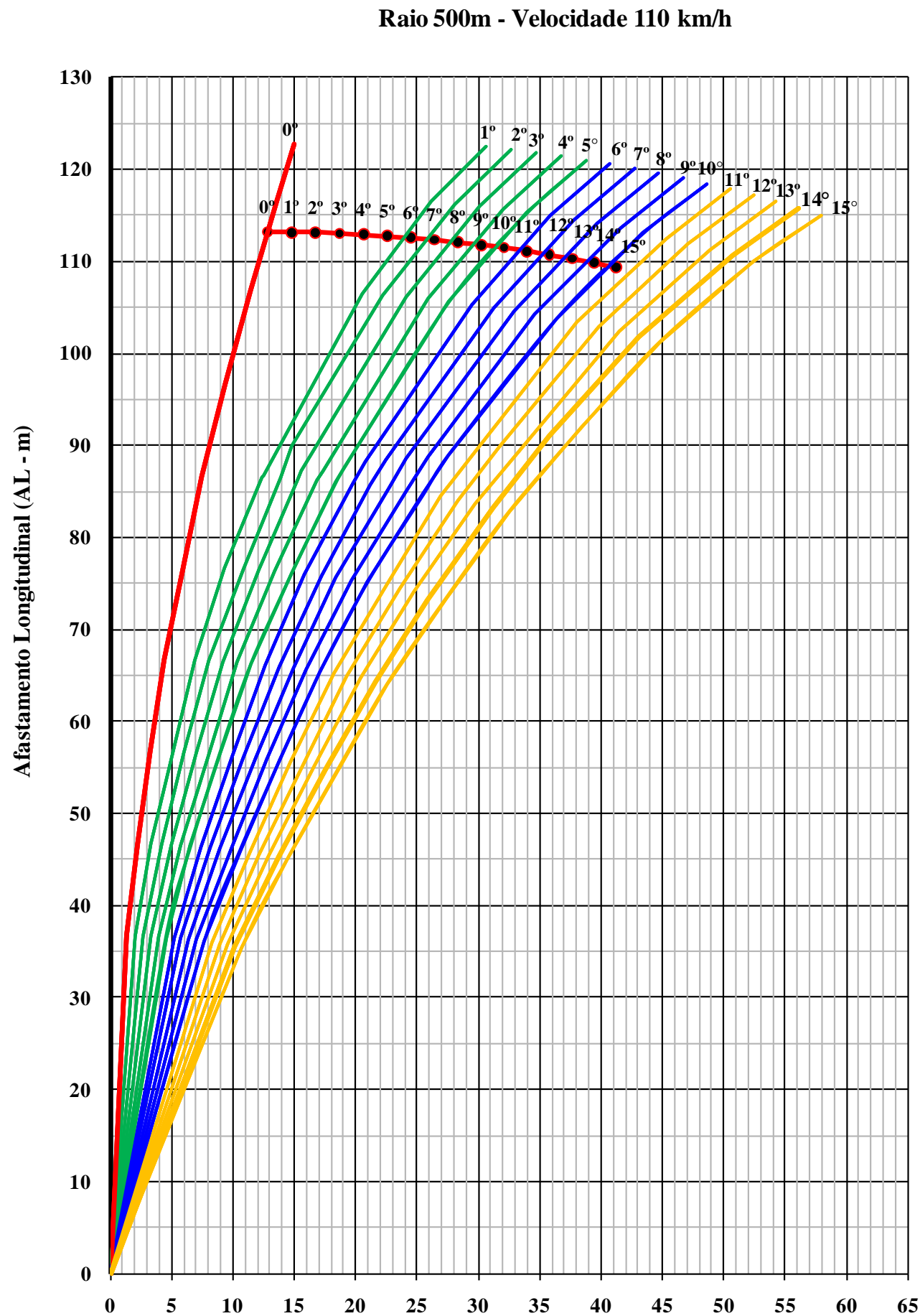

Afastamento Transversal (AT - m)

Figura 5.8 - Trajetória do veículo com desvio à direita para velocidade de saída da pista igual a $110 \mathrm{~km} / \mathrm{h}$ em curva de raio $500 \mathrm{~m}$.

\section{Entrada em valeta de drenagem}

No caso de saída da pista e entrada em valeta de drenagem, deve ser analisado o choque com a valeta e, também, verificada a possibilidade da ocorrência de um segundo choque com outro tipo de obstáculo, uma vez que o veículo se move dentro da valeta. 
Conforme colocado no item 5.1, podem ocorrer as seguintes situações quando o veículo se move confinado dentro da valeta:

- O veículo não fica enganchado no terreno e a desaceleração, após o tempo de percepção e reação contado a partir do momento da saída da pista, é dada apenas pelo sistema de freio. Neste caso, valem as equações 5.5 e 5.6 .

- O veículo fica enganchado no terreno e a desaceleração é maior e originada, principalmente, pela resistência do terreno ao ser rompido e arrastado pelas partes do veículo que se encontram enganchadas. Neste caso, valem as equações 5.7 e 5.8.

\subsection{FORMA E TAMANHO VIRTUAL DOS OBSTÁCULOS}

O modelo QRSP foi desenvolvido considerando os obstáculos com forma retangular, com um dos lados paralelo à pista e o outro perpendicular. Assim, os obstáculos existentes devem ser contornados com linhas tangentes de forma a resultarem em retângulos na posição descrita.

Outro aspecto a ser considerado diz respeito ao fato de o modelo considerar os veículos como pontos materiais, isto é, sem dimensões. Considerando ser a largura dos veículos da ordem de 2 metros, um desempenho mais real do modelo é obtido acrescentando 1 metro a mais em cada extremidade dos lados do retângulo que contorna o obstáculo com linhas tangentes.

\subsection{OPERACIONALIZAÇÃO DO MODELO}

A seguir, estão relacionadas as principais informações que podem ser fornecidas pelo Modelo QRSP e os procedimentos para obtê-las. Para facilitar o entendimento, são citadas na descrição dos procedimentos as figuras associadas a trecho em tangente e velocidade de saída da pista igual a $110 \mathrm{~km} / \mathrm{h}$ : Figura 5.4 para trajetórias com desvio à esquerda e Figura 5.5 para trajetórias com desvio à direita, considerando como referência saída da pista à direita (do lado do acostamento).

\section{Largura ideal da faixa lateral livre}

A largura ideal da faixa lateral livre de obstáculos Lid, corresponde à largura em que a probabilidade da ocorrência de acidente no choque com obstáculo Pc é igual a zero (Pc = $0 \%)$.

O valor da largura ideal, assim como das outras larguras definidas na seqüência, depende da velocidade de saída da pista Vs (velocidade de projeto da rodovia) e das 
características do traçado em planta da rodovia (em tangente ou em curva com determinado raio); valendo tanto para saída à direita (do lado do acostamento) como para saída à esquerda (do lado do canteiro central).

O valor de Lid é obtido na figura com as trajetórias de desvio à esquerda (Figura 5.4), e corresponde ao afastamento transversal $(\mathrm{T})$ do ponto mais afastado do eixo longitudinal da curva associada ao ângulo de $15^{\circ}$.

\section{Largura da faixa lateral livre para uma determinada probabilidade de choque}

A largura da faixa lateral livre associada a uma determinada probabilidade da ocorrência de acidente no choque com obstáculo Lp é determinada a partir do valor da probabilidade do choque Pc, determinado com base na Figura 5.3, o valor do ângulo abaixo do qual o choque não vai ocorrer $\theta \mathrm{c}$; o valor da largura Lp corresponde ao valor do afastamento transversal do ponto mais afastado do eixo longitudinal da curva para o ângulo $\theta \mathrm{c}$, na Figura 5.4, com as trajetórias de desvio à esquerda.

\section{Probabilidade de choque para uma determinada largura da faixa lateral livre}

Neste caso, o procedimento é o seguinte: o ângulo máximo em que não ocorre o choque $\theta \mathrm{c}$ está associado à curva na figura com as trajetórias de desvio à esquerda (Figura 5.4) que mais se aproxima da linha vertical correspondente a um afastamento lateral igual à largura dada Ld; o valor da probabilidade de choque Pc é determinado, com base na Figura 5.3, em função do ângulo $\theta$ c.

\section{Largura da faixa lateral livre para uma determinada probabilidade de choque e um determinado risco de o acidente resultar grave}

Este valor é determinado, como segue:

- Identificação do tipo de obstáculo após a faixa livre (Tabela 5.4).

- Definição do nível de risco de o acidente resultar grave (Tabela 5.5).

- Determinação da velocidade máxima de choque Vc (Tabelas 5.6 a 5.12 em função do nível de risco de o acidente resultar grave).

- Determinação do valor da distância longitudinal (L) percorrida desde a saída da pista até atingir a velocidade de choque (Tabela 5.3 em função da velocidade de saída da pista Vs e da velocidade de choque $\mathrm{Vc}$ ). 
- Fixação da probabilidade de choque Pc.

- Determinação do ângulo máximo em que o choque não ocorre $\theta c$ (Figura 5.3 em função de Pc).

- Determinação do valor do afastamento lateral $\mathrm{T}=\mathrm{Lpr}$ a partir do valor de $\mathrm{L}$ e de $\theta \mathrm{c}$, mediante a figura com as trajetórias de desvio à esquerda (Figura 5.4).

\section{Localização do trecho de rodovia onde existe risco da ocorrência de acidente próximo a um obstáculo situado dentro da faixa livre lateral (trecho crítico)}

Para a identificação do trecho crítico supondo saída à direita (Figura 5.9), devem ser realizados os seguintes passos:

- Com base na figura, com as trajetórias de desvio à esquerda (Figura 5.4), é determinada a distância longitudinal Li entre o ponto de saída da pista e o ponto em que a curva à esquerda, associada ao ângulo de $15^{\circ}$, toca a extremidade esquerda da face de trás do obstáculo, estando a face esquerda do obstáculo a uma distância $\mathrm{X}$ da borda da pista. A distância Li determina o ponto inicial do trecho crítico I, admitindo a origem do eixo longitudinal na face de trás do obstáculo.

- Com base na figura com as trajetórias de desvio à esquerda (Figura 5.4), é identificada a curva à esquerda que mais se aproxima da linha vertical correspondente a um afastamento lateral igual distância do obstáculo à borda da pista $X$ - a qual está associada ao máximo valor do ângulo de saída da pista em que não ocorre o choque $\theta \mathrm{c}$.

- Com base na figura com as trajetórias de desvio à direita (Figura 5.5), é determinada a distância longitudinal Lf' entre o ponto de saída da pista e o ponto em que a curva à direita associada ao ângulo de saída $\theta$ c toca a extremidade direita da face da frente do obstáculo; estando a face direita do obstáculo a uma distância $\mathrm{X}+\mathrm{Y}$ da borda da pista. $\mathrm{O}$ ponto final do trecho crítico F está localizado a uma distância Lf da origem, dada por: Lf $=\mathrm{Lf}^{\prime}+\mathrm{Z}$, onde Z é o comprimento do obstáculo no sentido longitudinal.

- Com base na Figura 5.3, é determinada a probabilidade de choque com o obstáculo Pc em função do ângulo $\theta c$. 


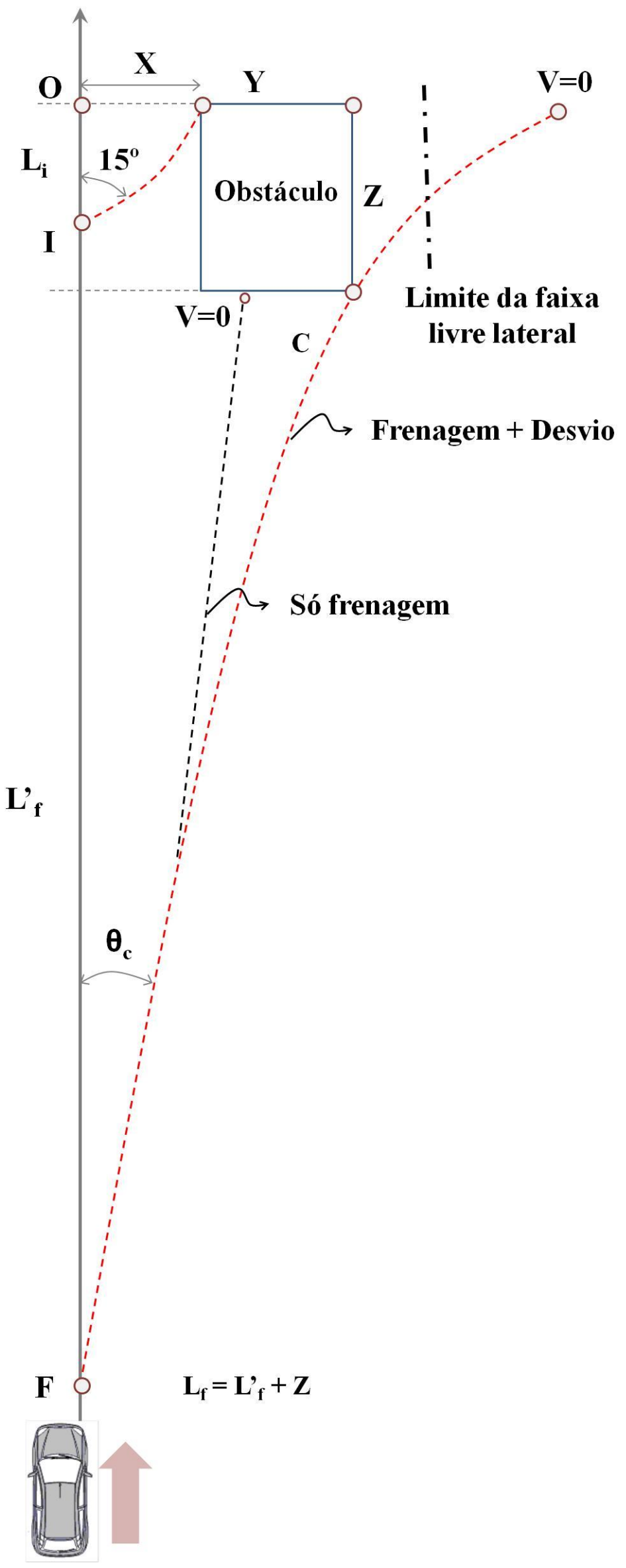




\section{Figura 5.9 - Esquema de localização do trecho crítico.}

Como se pode observar na Figura 5.9, o desvio à direita do obstáculo considerado na análise supõe que os veículos possam avançar além da faixa livre, eventualmente transpondo objetos de baixa resistência ao choque (vegetação, arbustos, cercados etc.) que estejam à frente. Se houver restrições severas ao avanço, além da faixa livre, em razão da presença de obstáculo rígido, espaço vazio de grande altura etc., o mais provável é que o condutor atue no sentido de não sair da faixa livre freando o veículo para reduzir a velocidade de choque com o obstáculo, ou a parada antes do choque; e, se necessário para evitar o avanço além do espaço lateral livre, virando a direção e desviando o veículo para a esquerda em direção à pista. Neste caso, o ponto final do trecho crítico $\mathrm{F}$ deve ser determinado considerando Lf' como sendo a distância de frenagem fornecida na Tabela 5.3, em função da velocidade de saída da pista (Vs).

\section{Localização dos segmentos associados aos distintos níveis de risco de acidente grave dentro do trecho crítico}

Uma vez definido o trecho crítico, é necessário determinar a posição e extensão dos segmentos associados aos distintos níveis de risco (grande, médio, pequeno e insignificante) de o acidente resultar grave nas proximidades de um obstáculo situado na faixa lateral livre.

Para isso, é necessário, inicialmente, identificar o tipo de obstáculo na Tabela 5.4 e as velocidades de choque $\mathrm{Vc}$ associadas aos diversos níveis de risco em uma das Tabelas de 5.6 a 5.12. Em seguida, devem ser determinadas as distâncias Dc associadas às diversas velocidades de choque Vc em função da velocidade de saída da pista Vs, utilizando a Tabela 5.3 .

Admitindo que o choque ocorra com a face da frente do obstáculo, às distâncias calculadas, devem ser somadas ao valor do comprimento do obstáculo $\mathrm{Z}$ para obter as distâncias em relação à origem (suposta estar na parte de trás do obstáculo) de cada segmento associado a um dado nível de risco.

Na Figura 5.10 estão indicados os segmentos associados aos diferentes níveis de risco correspondentes aos diversos tipos de obstáculos apresentados na Tabela 5.4. 


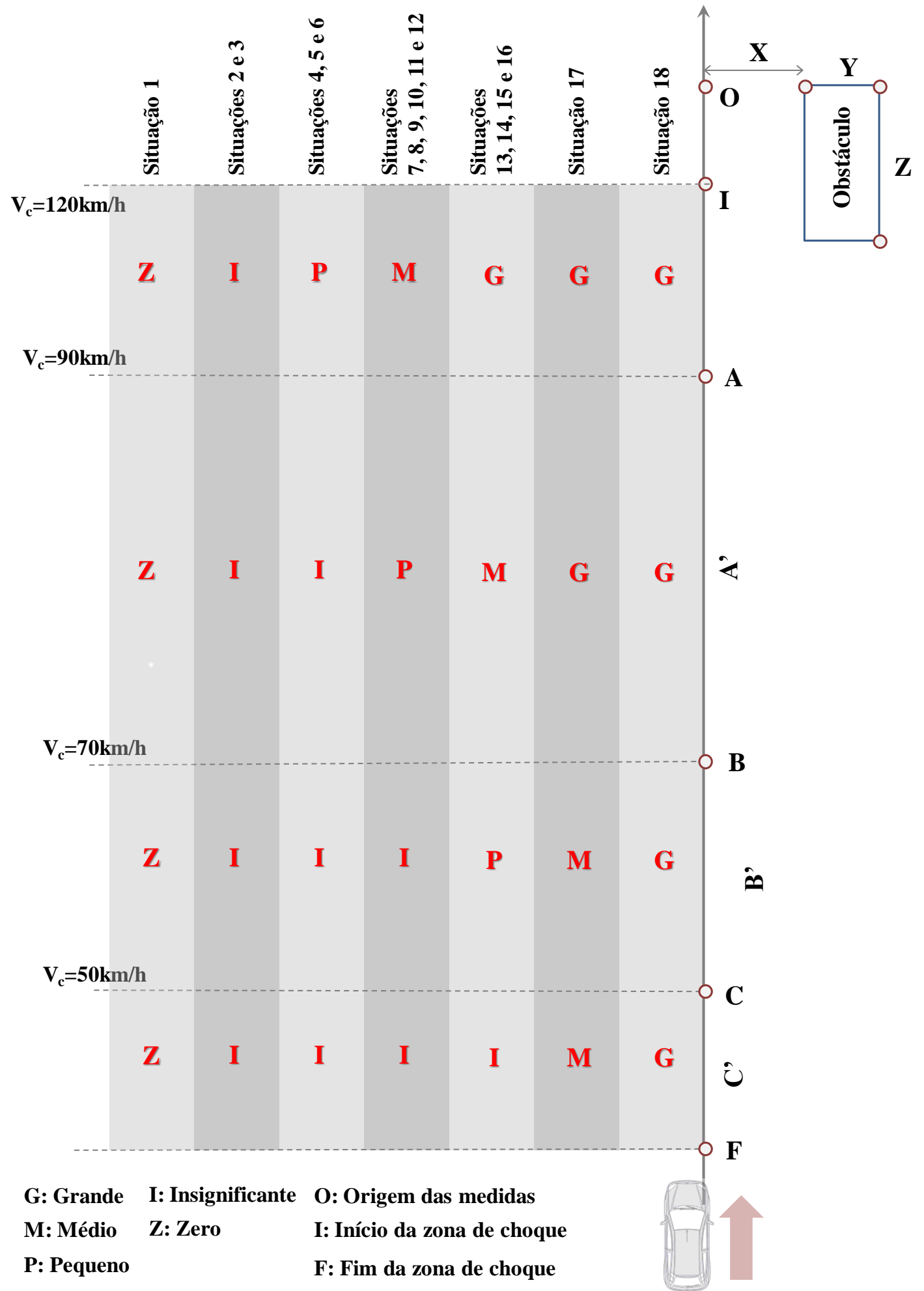

Figura 5.10 - Esquema da localização dos segmentos com distintos níveis de risco.

\section{Localização de barreira de contenção}

A posição e a extensão da barreira de contenção dependem do objetivo: impedir o choque com o obstáculo (muitas vezes para evitar danos ao mesmo); impedir o choque com o obstáculo associado a risco grande de acidente grave; impedir o choque com o obstáculo 
associado a risco grande e médio de acidente grave; impedir o choque com o obstáculo associado a risco grande, médio e pequeno de acidente grave e impedir o choque com o obstáculo associado a risco grande, médio, pequeno e insignificante de acidente grave (que significa o mesmo que impedir o choque com o obstáculo).

Como o próprio choque com a barreira de contenção lateral envolve algum risco de acidente grave (conforme Tabela 5.8: insignificante para $\mathrm{Vc}=0-90 \mathrm{~km} / \mathrm{h}$ e pequeno para $\mathrm{Vc}=$ 90-120 km/h), o usual é colocar a barreira apenas para evitar acidentes associados com nível de risco grande e médio.

Outro aspecto que reforça a tese de colocar barreira apenas nos segmentos associados a nível grande e médio de acidente grave é o fato de a presença da barreira sempre mais próxima da borda da pista, do que o obstáculo aumentar a probabilidade de ocorrência de acidente.

Qualquer que seja a decisão, se a barreira for colocada na borda da pista, a sua localização coincide com os segmentos associados com risco grande, médio, pequeno e insignificante de o acidente resultar grave. Cabe observar que, neste caso, a probabilidade de ocorrência de acidente decorrente de saída da pista é de 100\%, pois a barreira está localizada junto à borda.

Quando a barreira se localiza afastada da borda, como é mais comum, a sua localização deve ser definida com base nas curvas da figura de trajetórias de desvio à esquerda (Figura 5.4) ou à direita (Figura 5.5), dependendo do caso, como exemplificado no próximo item. Neste caso, também deve ser determinada a probabilidade de choque com a barreira e comparada com a probabilidade do choque com o obstáculo que vai "proteger".

\section{O caso especial do segundo choque no caso de entrada em valeta de drenagem}

No caso da entrada do veículo em valeta de drenagem, deve ser investigada a possibilidade da ocorrência de um segundo choque com obstáculo situado na extremidade da valeta, ou nas proximidades, uma vez que o veículo se move confinado dentro da mesma.

Neste caso, a localização do trecho crítico dos segmentos associados a distintos níveis de risco de acidente grave e da barreira de contenção deve ser analisada detalhadamente, utilizando os procedimentos anteriormente descritos e as equações 5.4 a 5.8. 


\subsection{EXEMPLOS DE APLICAÇÃO DO MODELO}

Para exemplificar a aplicação do Modelo QRSP, a seguir são determinados os parâmetros referidos no item anterior para uma rodovia de pista dupla com canteiro central e velocidade de projeto igual a $110 \mathrm{~km} / \mathrm{h}$, no caso de trecho em tangente e em curva de raio de 500 metros.

\section{Largura ideal da faixa lateral livre}

- Trecho em tangente: $\theta \mathrm{c}=15^{\circ}$ (Figura 5.3, para $\mathrm{Pc}=0 \%$ ), Lid $=\mathrm{T}=21 \mathrm{~m}$ (Figura 5.4, ponto mais distante do eixo vertical da curva para $\theta \mathrm{c}=15^{\circ}$ ).

- Trecho em curva de raio 500m: $\theta \mathrm{c}=15^{\circ}$ (Figura 5.3, para Pc $=0 \%$ ), Lid $=\mathrm{T}=34 \mathrm{~m}$ (Figura 5.7, ponto mais distante do eixo vertical da curva para $\theta \mathrm{c}=15^{\circ}$ ).

\section{Largura da faixa lateral livre para probabilidade de choque igual a $10 \%$}

- Trecho em tangente: $\theta \mathrm{c}=11^{\circ}$ (Figura 5.3, para Pc $\left.=10 \%\right), \mathrm{Lp}=\mathrm{T}=14 \mathrm{~m}$ (Figura 5.4, ponto mais distante do eixo vertical da curva para $\left.\theta \mathrm{c}=11^{\circ}\right)$.

- Trecho em curva: $\theta \mathrm{c}=11^{\circ}$ (Figura 5.3, para $\mathrm{Pc}=10 \%$ ), $\mathrm{Lp}=\mathrm{T}=26 \mathrm{~m}$ (Figura 5.7, ponto mais distante do eixo vertical da curva para $\theta \mathrm{c}=11^{\circ}$ ).

\section{Largura da faixa lateral livre para probabilidade de choque igual a $20 \%$}

- Trecho em tangente: $\theta \mathrm{c}=8^{\circ}$ (Figura 5.3, para $\mathrm{Pc}=20 \%$ ), $\mathrm{Lp}=\mathrm{T}=9 \mathrm{~m}$ (Figura 5.4, ponto mais distante do eixo vertical da curva para $\theta \mathrm{c}=8^{\circ}$ ).

- Trecho em curva: $\theta \mathrm{c}=8^{\circ}$ (Figura 5.6, para $\mathrm{Pc}=10 \%$ ), $\mathrm{T}=20 \mathrm{~m}$ (Figura 5.7, ponto mais distante do eixo vertical da curva para $\theta \mathrm{c}=8^{\circ}$ ).

\section{Probabilidade de choque para largura da faixa lateral livre igual a $8 \mathrm{~m}$}

- Trecho em tangente: $\theta \mathrm{c}=7^{\circ}$ (Figura 5.4, curva situada à esquerda que mais se aproxima da linha vertical correspondente a $\mathrm{T}=\mathrm{Ld}=8 \mathrm{~m}), \mathrm{Pc}=26 \%\left(\right.$ Figura 5.3, para $\theta \mathrm{c}=7^{\circ}$ ).

- Trecho em curva: $\theta \mathrm{c}=2^{\circ}$ (Figura 5.7, curva situada à esquerda que mais se aproxima da linha vertical correspondente a $\mathrm{T}=\mathrm{Ld}=8 \mathrm{~m}), \mathrm{Pc}=67 \%\left(\right.$ Figura 5.3, para $\theta \mathrm{c}=2^{\circ}$ ).

\section{Largura da faixa lateral livre para probabilidade de choque igual a $10 \%$ e risco de} acidente grave pequeno no choque com obstáculo rígido

- Situação 16 (Tabela 5.4, obstáculo rígido). $\mathrm{Vc}=70 \mathrm{~km} / \mathrm{h}$ (Tabela 5.10, risco pequeno), L $=80 \mathrm{~m}($ Tabela 5.3, para Vs $=110 \mathrm{~km} / \mathrm{h}$ e $=70 \mathrm{~km} / \mathrm{h}), \theta \mathrm{c}=11^{\circ}($ Figura 5.3, para Pc $=$ $10 \%)$.

- Trecho em tangente: $\mathrm{Lpr}=\mathrm{T}=13 \mathrm{~m}$ (Figura 5.4, para $\mathrm{L}=80 \mathrm{~m}$ e $\theta \mathrm{c}=11^{\circ}$ ).

- Trecho em curva: $\mathrm{Lpr}=19 \mathrm{~m}$ (Figura 5.7, para $\mathrm{L}=80 \mathrm{~m}$ e $\theta \mathrm{c}=11^{\circ}$ ). 
6. Localização do trecho crítico no caso de obstáculo em trecho reto com as seguintes características $X=8 \mathrm{~m}, Y=7 \mathrm{~m}, Z=30 \mathrm{~m}, X+Y=15 \mathrm{~m}$ (Figura 5.9)

- $\mathrm{Li}=29 \mathrm{~m}$ (Figura 5.4, para $\left.\theta \mathrm{c}=15^{\circ} \mathrm{e} \mathrm{T}=\mathrm{X}=8 \mathrm{~m}\right), \theta \mathrm{c}=7^{\circ}$ (Figura 5.4, para $\mathrm{T}=\mathrm{X}=8 \mathrm{~m}$ ), $\mathrm{Lf}^{\prime}=90 \mathrm{~m}$ (Figura 5.5, para $\theta \mathrm{c}=7^{\circ}$ e $\left.\mathrm{T}=\mathrm{X}+\mathrm{Y}=15 \mathrm{~m}\right), \mathrm{Lf}=\mathrm{Lf}^{\prime}+\mathrm{Z}=90+30=120 \mathrm{~m}$, logo: $\mathrm{I}=29$ e $\mathrm{F}=120 \mathrm{~m}, \mathrm{Pc}=26 \%\left(\right.$ Figura 5.3 , para $\left.\theta \mathrm{c}=7^{\circ}\right)$.

- Neste caso, a distância do avanço lateral desde a borda da pista livre até a parada do veículo pode chegar até $45 \mathrm{~m}$, o que acontece no caso da saída em ângulo de $15^{\circ}$ e não realização de manobra de desvio após passar pelo obstáculo (Figura 5.5). No caso da impossibilidade do avanço, o valor de Lf' seria de $115 \mathrm{~m}$ (distância para parar dada na Tabela 5.3), Lf $=$ Lf $^{\prime}+\mathrm{Z}=115+30=145 \mathrm{~m}$, logo: $\mathrm{I}=29$ e $\mathrm{F}=145 \mathrm{~m}$.

7. Localização dos segmentos associados aos distintos níveis de risco para o caso do exemplo 6, supondo ser o obstáculo rígido

- Tabela 5.10 (obstáculo rígido): risco insignificante: $\mathrm{Vc}=0-50 \mathrm{~km} / \mathrm{h}$, risco pequeno: $\mathrm{Vc}$ $=50-70 \mathrm{~km} / \mathrm{h}$, risco médio: $\mathrm{Vc}=70-90 \mathrm{~km} / \mathrm{h}$, risco grande: $\mathrm{Vc}=90-110 \mathrm{~km} / \mathrm{h}$.

- Tabela $5.3(\mathrm{Vs}=110 \mathrm{~km} / \mathrm{h}):$ Dc $(\mathrm{Vc}=90 \mathrm{~km} / \mathrm{h})=60 \mathrm{~m}, \quad$ Dc $(\mathrm{Vc}=70 \mathrm{~km} / \mathrm{h})=80 \mathrm{~m}, \mathrm{Dc}$ $(\mathrm{Vc}=50 \mathrm{~km} / \mathrm{h})=95 \mathrm{~m}$.

- Figura 5.10 (obstáculo rígido): $\mathrm{A}=\mathrm{Dc}(\mathrm{Vc}=90 \mathrm{~km} / \mathrm{h})+\mathrm{Z}=60+30=90 \mathrm{~m}, \mathrm{~B}=\mathrm{Dc}$ $(\mathrm{Vc}=70 \mathrm{~km} / \mathrm{h})+\mathrm{Z}=80+30=110 \mathrm{~m}, \mathrm{C}=\mathrm{Dc}(\mathrm{Vc}=50 \mathrm{~km} / \mathrm{h})+\mathrm{Z}=95+30=125 \mathrm{~m}>\mathrm{F}=$ 120m, logo: $\mathrm{C}=120 \mathrm{~m}$.

- Portanto: segmento associado ao risco de ocorrência de acidente (choque com o obstáculo): 29m-120m (extensão = 91m); segmentos associados aos diferentes níveis de risco de acidente grave: grande: $29 \mathrm{~m}$ - 90m (extensão $=61 \mathrm{~m}$ ), médio: 90m-110m (extensão $=20 \mathrm{~m})$, pequeno: $110 \mathrm{~m}-120 \mathrm{~m}($ extensão $=10 \mathrm{~m})$.

8. Localização dos segmentos associados aos distintos níveis de risco para o caso do exemplo 6, supondo ser o obstáculo flexível

- Tabela 5.9 (obstáculo flexível): risco insignificante: $\mathrm{Vc}=0-70 \mathrm{~km} / \mathrm{h}$, risco pequeno: $\mathrm{Vc}$ $=70-90 \mathrm{~km} / \mathrm{h}$, risco médio: $\mathrm{Vc}=90-120 \mathrm{~km} / \mathrm{h}$.

- Tabela $5.3(\mathrm{Vs}=110 \mathrm{~km} / \mathrm{h})$ : Dc $(\mathrm{Vc}=90 \mathrm{~km} / \mathrm{h})=60 \mathrm{~m}, \mathrm{Dc}(\mathrm{Vc}=70 \mathrm{~km} / \mathrm{h})=80 \mathrm{~m}$.

- Figura 5.10 (obstáculo flexível): $A=\mathrm{Dc}(\mathrm{Vc}=90 \mathrm{~km} / \mathrm{h})+\mathrm{Z}=60+30=90 \mathrm{~m}, \mathrm{~B}=\mathrm{Dc}$ $(\mathrm{Vc}=70 \mathrm{~km} / \mathrm{h})+\mathrm{Z}=80+30=110 \mathrm{~m}, \mathrm{C}=\mathrm{Dc}(\mathrm{Vc}=50 \mathrm{~km} / \mathrm{h})+\mathrm{Z}=95+30=125 \mathrm{~m}>\mathrm{F}=$ 120m, logo: $\mathrm{C}=120 \mathrm{~m}$. 
- Portanto: segmento associado ao risco de ocorrência de acidente (choque com o obstáculo): 29m-120m (extensão = 91m); segmentos associados aos diferentes níveis de risco de acidente grave: médio: $29 \mathrm{~m}-90 \mathrm{~m}$ (extensão $=61 \mathrm{~m}$ ), pequeno: $90 \mathrm{~m}-110 \mathrm{~m}$ (extensão $=20 \mathrm{~m})$, insignificante: $110 \mathrm{~m}-120 \mathrm{~m}($ extensão $=10 \mathrm{~m})$.

9. Localização dos segmentos associados aos distintos níveis de risco para o caso do exemplo 6, supondo ser o obstáculo um espaço vazio de grande altura

- Tabela 5.12 (espaço vazio de grande altura): risco grande: $\mathrm{Vc}=0-120 \mathrm{~km} / \mathrm{h}$.

- Tabela $5.3(\mathrm{Vs}=110 \mathrm{~km} / \mathrm{h}):$ Dc $(\mathrm{Vc}=0 \mathrm{~km} / \mathrm{h})=115 \mathrm{~m}$.

- Figura 5.10 (obstáculo rígido): $\mathrm{A}=\mathrm{Dc}(\mathrm{Vc}=0 \mathrm{~km} / \mathrm{h})+\mathrm{Z}=115+30=145>\mathrm{F}=120 \mathrm{~m}$, logo: $A=120 \mathrm{~m}$.

- Portanto: segmento associado ao risco de ocorrência de acidente (choque com o obstáculo): 29m-120m (extensão = 91m); segmentos associados aos diferentes níveis de risco de acidente grave: grande: $29 \mathrm{~m}-120 \mathrm{~m}$ (extensão $=91 \mathrm{~m})$.

10. Localização de barreira de contenção suposta na borda da pista para o caso do exemplo 6 (obstáculo rígido)

- Para impedir o choque com o obstáculo: $\mathrm{I}=29 \mathrm{~m}$ (não é alterado), F deve ser alterado, pois o veículo que sai da pista não tem mais espaço lateral para desviar do obstáculo, $\mathrm{D}_{\mathrm{f}}=$ $115 \mathrm{~m}($ Tabela 5.3, para Vs $=110 \mathrm{~km} / \mathrm{h}), \mathrm{F}=\mathrm{Dp}+\mathrm{Z}=115+30=145 \mathrm{~m}$, barreira no segmento $29 \mathrm{~m}-145 \mathrm{~m}$ (extensão $=116 \mathrm{~m})$.

- Para impedir o choque com o obstáculo associado a risco grande de o acidente resultar grave: $29 \mathrm{~m}-90 \mathrm{~m}$ (extensão $=61 \mathrm{~m})$.

- Para impedir o choque com o obstáculo associado a risco grande e médio de o acidente resultar grave: $29 \mathrm{~m}-110 \mathrm{~m}$ (extensão $=81 \mathrm{~m})$.

- Para impedir o choque com o obstáculo associado a risco grande, médio e pequeno de o acidente resultar grave: $29 \mathrm{~m}-120 \mathrm{~m}$ (extensão $=91 \mathrm{~m})$.

- Para impedir o choque com o obstáculo associado a risco grande, médio, pequeno e insignificante de o acidente resultar grave: $29 \mathrm{~m}-145 \mathrm{~m}($ extensão $=116 \mathrm{~m})$.

- Efeito da presença da barreira: $\mathrm{Pc}=100 \%$, risco pequeno de acidente grave (Tabela 5.4, para $\mathrm{Vc}=\mathrm{Vs}=110 \mathrm{~km} / \mathrm{h}$ ).

- Situação nos diversos segmentos com e sem a presença de barreira. (Ver Tabela 5.14). 
Tabela 5.14 - Situação com e sem a presença de barreiras relativa ao exemplo 10

\begin{tabular}{ccc}
\hline Segmento & Sem barreira & Com barreira \\
\hline 29m-90m & Risco grande, Probabilidade de & Risco pequeno, probabilidade de \\
acidente $=26 \%$ & acidente $=100 \%$ \\
90m-110m & Risco médio, probabilidade de & Risco pequeno, probabilidade de \\
& acidente $=26 \%$ & acidente $=100 \%$ \\
110m-120m & Risco pequeno, probabilidade de & Risco pequeno, probabilidade de \\
& acidente $=26 \%$ & acidente $=100 \%$ \\
120m-145m & Risco inexistente, probabilidade de & Risco pequeno, probabilidade de \\
& acidente $=0 \%$ & acidente $=100 \%$ \\
\hline
\end{tabular}

- Conclusão: a barreira de contenção deve ser colocada no trecho de $29 \mathrm{~m}-110 \mathrm{~m}$, a menos que se queira proteger o obstáculo do choque, quando, então, ela deve ser colocada no trecho de $29-145 \mathrm{~m}$.

\section{Localização de barreira de contenção suposta na borda da pista para o caso do exemplo 7 (obstáculo flexível)}

- Para impedir o choque com o obstáculo: 29m-145m (extensão = 116m).

- Para impedir o choque com o obstáculo associado a risco médio de o acidente resultar grave: $29 \mathrm{~m}-90 \mathrm{~m}$ (extensão $=61 \mathrm{~m})$.

- Para impedir o choque com o obstáculo associado a risco médio e pequeno de o acidente resultar grave: $29 \mathrm{~m}-110 \mathrm{~m}$ (extensão $=81 \mathrm{~m})$.

- Para impedir o choque com o obstáculo associado a risco médio, pequeno e insignificante de o acidente resultar grave: $29 \mathrm{~m}-120 \mathrm{~m}($ extensão $=91 \mathrm{~m})$.

- Efeito da presença da barreira: $\mathrm{Pc}=100 \%$, Risco pequeno de acidente grave (Tabela 5.4, para $\mathrm{Vc}=\mathrm{Vs}=110 \mathrm{~km} / \mathrm{h})$.

- Situação nos diversos segmentos com e sem a presença de barreira. (Ver Tabela 5.15). 
Tabela 5.15 - Situação com e sem a presença de barreiras relativa ao exemplo 11

\begin{tabular}{ccc}
\hline Segmento & Sem barreira & Com barreira \\
\hline $29 \mathrm{~m}-90 \mathrm{~m}$ & Risco médio, Probabilidade de & Risco pequeno, probabilidade de \\
acidente $=26 \%$ & acidente $=100 \%$ \\
90m-110m & Risco pequeno, probabilidade de & Risco pequeno, probabilidade de \\
& acidente $=26 \%$ & acidente $=100 \%$ \\
$110 \mathrm{~m}-120 \mathrm{~m}$ & Risco insignificante, probabilidade & Risco pequeno, probabilidade de \\
& de acidente $=26 \%$ & acidente $=100 \%$ \\
$120 \mathrm{~m}-145 \mathrm{~m}$ & Risco inexistente, probabilidade de & Risco pequeno, probabilidade de \\
& acidente $=0 \%$ & acidente $=100 \%$ \\
\hline
\end{tabular}

- Conclusão: a barreira de contenção deve ser colocada no trecho de 29m-90m, a menos que se queira proteger o obstáculo do choque, quando, então, ela deve ser colocada no trecho de 29-145m.

12. Localização de barreira de contenção suposta na borda da pista para o caso do exemplo 8 (espaço vazio de grande altura)

- Para impedir o choque com o obstáculo: 29m-145m (extensão = 116m).

- Para impedir o choque com o obstáculo associado a risco grande de o acidente resultar grave: $29 \mathrm{~m}-120 \mathrm{~m}$ (extensão $=91 \mathrm{~m})$.

- Efeito da presença da barreira: $\mathrm{Pc}=100 \%$, Risco pequeno de acidente grave (Tabela 5.4, para $\mathrm{Vc}=\mathrm{Vs}=110 \mathrm{~km} / \mathrm{h})$.

- Situação nos diversos segmentos com e sem a presença de barreira. (Ver Tabela 5.16).

Tabela 5.16 - Situação com e sem a presença de barreiras relativa ao exemplo 12

\begin{tabular}{ccc}
\hline Segmento & Sem barreira & Com barreira \\
\hline $29 \mathrm{~m}-120 \mathrm{~m}$ & Risco grande, Probabilidade de & Risco pequeno, probabilidade de \\
& acidente $=26 \%$ & acidente $=100 \%$ \\
\multirow{2}{*}{$120 \mathrm{~m}-145 \mathrm{~m}$} & Risco inexistente, probabilidade de & Risco pequeno, probabilidade de \\
& acidente $=0 \%$ & acidente $=100 \%$ \\
\hline
\end{tabular}

- Conclusão: a barreira de contenção deve ser colocada no trecho de $29 \mathrm{~m}-120 \mathrm{~m}$.

13. Localização de barreira de contenção suposta a $6 \mathrm{~m}$ da borda da pista para o caso do exemplo 6 (obstáculo rígido) - Figura 5.11 


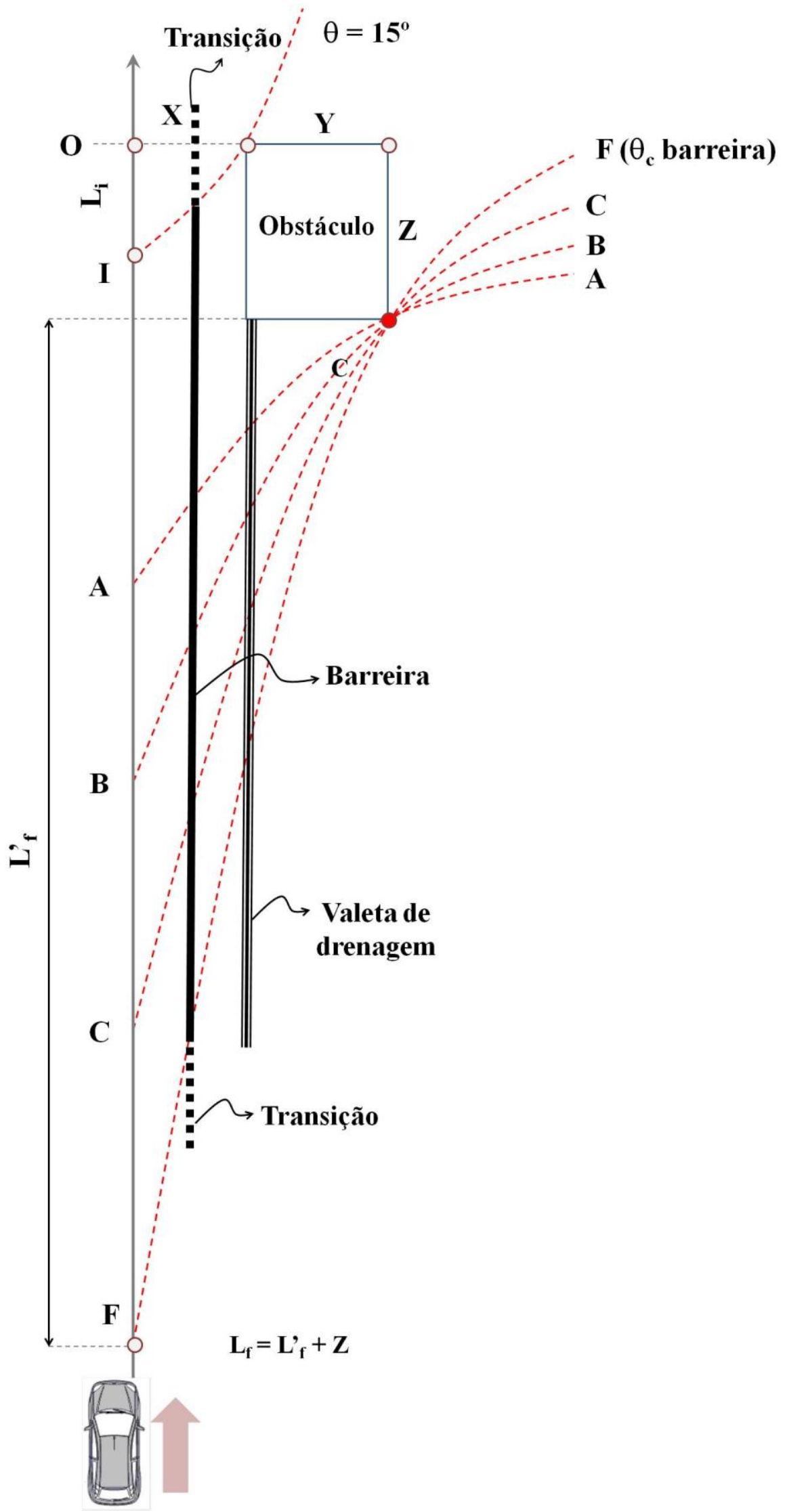

Figura 5.11 - Esquema de localização do trecho em valeta de drenagem 
- Para impedir o choque com o obstáculo: $\mathrm{i}=22 \mathrm{~m}$ (Figura 5.4, para $\theta=15^{\circ}$ e $\left.\mathrm{T}=6 \mathrm{~m}\right), \mathrm{Ib}=$ $\mathrm{I}-\mathrm{i}=29-22=7 \mathrm{~m}, \theta \mathrm{c}=5^{\circ}($ Figura 5.4, para $\mathrm{T}=6 \mathrm{~m}), \mathrm{L}=102 \mathrm{~m}$ (Figura 5.5, para $\theta \mathrm{c}=$ $5^{\circ}$ e $\mathrm{T}=\mathrm{X}+\mathrm{Y}=15 \mathrm{~m}$ ), $\mathrm{L}=58 \mathrm{~m}$ (Figura 5.5, para $\theta \mathrm{c}=5^{\circ}$ e $\mathrm{T}=6 \mathrm{~m}$ ), Lf' $=102-58=$ $44 \mathrm{~m}, \mathrm{~L}_{\mathrm{f}}=\mathrm{Lf}^{\prime}+\mathrm{Z}=44+30=74 \mathrm{~m}, \log \mathrm{o}: \mathrm{I}=29$ e F $=74 \mathrm{~m}$, choque com a barreira: $\mathrm{Pc}=$ $38 \%$ (Figura 5.3, para $\theta \mathrm{c}=5^{\circ}$ ).

- Para impedir o choque com o obstáculo associado a risco grande de o acidente resultar grave: $A=90 \mathrm{~m}, \theta \mathrm{c}=13^{\circ}$ (Figura 5.5, para $\mathrm{L}=\mathrm{A}-\mathrm{Z}=90-30=60 \mathrm{~m}$ e $\mathrm{T}=15 \mathrm{~m}$ ), $\mathrm{L}=$ $26 \mathrm{~m}$ (Figura 5.5, para $\theta \mathrm{c}=13^{\circ}$ e $\mathrm{T}=6 \mathrm{~m}$ ), $\mathrm{Fb}=90-26=64 \mathrm{~m}$, ou seja, no intervalo de $7 \mathrm{~m}-64 \mathrm{~m}$ (extensão $=57 \mathrm{~m})$.

- Para impedir o choque com o obstáculo associado a risco grande e médio de o acidente resultar grave: $\mathrm{B}=110 \mathrm{~m}, \theta \mathrm{c}=8^{\circ}$ (Figura 5.5, para $\mathrm{L}=\mathrm{B}-\mathrm{Z}=80 \mathrm{~m}$ e $\mathrm{T}=15 \mathrm{~m}$ ), $\mathrm{L}=42 \mathrm{~m}$ (Figura 5.5, para $\theta \mathrm{c}=8^{\circ}$ e $\mathrm{T}=6 \mathrm{~m}$ ), $\mathrm{Fb}=110-42=68 \mathrm{~m}$, ou seja, no intervalo de $7 \mathrm{~m}$ $68 \mathrm{~m}($ extensão $=61 \mathrm{~m})$.

- Para impedir o choque com o obstáculo associado a risco grande, médio e pequeno de o acidente resultar grave: $\mathrm{C}=120 \mathrm{~m}, \theta \mathrm{c}=7^{\circ}$ (Figura 5.5, para $\mathrm{L}=\mathrm{C}-\mathrm{Z}=120-30=90 \mathrm{~m} \mathrm{e}$ $\mathrm{T}=15 \mathrm{~m}$ ), $\mathrm{L}=45 \mathrm{~m}$ (Figura 5.5, para $\theta \mathrm{c}=7^{\circ} \mathrm{e} \mathrm{T}=6 \mathrm{~m}$ ), $\mathrm{F}_{\mathrm{b}}=120-45=75 \mathrm{~m}$, ou seja, no intervalo de $7 \mathrm{~m}-75 \mathrm{~m}$ (extensão $=68 \mathrm{~m})$.

- Efeito da presença da barreira: $\theta \mathrm{c}=5^{\circ}$ (Figura 5.4, para $\mathrm{T}=6 \mathrm{~m}$ ): $\mathrm{Pc}=38 \%$ (Figura 5.3, para $\theta \mathrm{c}=5^{\circ}$ ), Risco pequeno de acidente grave (Tabela 5.4, para $\mathrm{Vc}=\mathrm{Vs}=110 \mathrm{~km} / \mathrm{h}$ ).

- Situação nos diversos segmentos com e sem a presença de barreira. (Ver Tabela 5.17).

Tabela 5.17- Situação com e sem a presença de barreiras relativa ao exemplo 13

\begin{tabular}{ccc}
\hline Segmento & Sem barreira & $\begin{array}{c}\text { Com barreira a 6m } \\
\text { da borda da pista }\end{array}$ \\
\hline $29 \mathrm{~m}-90 \mathrm{~m}$ & Risco grande, Probabilidade de & Risco pequeno, probabilidade de \\
& acidente $=26 \%$ & acidente $=38 \%$ \\
90m-110m & Risco médio, probabilidade de & Risco pequeno, probabilidade de \\
& acidente $=26 \%$ & acidente $=38 \%$ \\
$110 \mathrm{~m}-120 \mathrm{~m}$ & Risco pequeno, probabilidade de & Risco pequeno, probabilidade de \\
& acidente $=26 \%$ & acidente $=38 \%$
\end{tabular}

- Conclusão: a barreira de contenção, colocada a $6 \mathrm{~m}$ da borda da pista, deve ser colocada no trecho de 29m-110m, a menos que se queira proteger o obstáculo do choque. 


\section{Localização de barreira de contenção no caso da entrada em valeta de drenagem com obstáculo do tipo espaço vazio em uma das extremidades}

No caso do exemplo 13, a barreira de contenção, suposta situada a $6 \mathrm{~m}$ da borda da pista, deve estar localizada no trecho de 7m-75m para evitar o choque com o obstáculo.

Admitindo que o obstáculo seja um espaço vazio de grande altura e que exista uma valeta de drenagem na posição indicada na Figura 5.11, a questão que se coloca é qual a nova posição da barreira de contenção para evitar a queda no espaço vazio (que está associada a risco grande de o acidente resultar grave). Segue a análise da situação para os dois casos seguintes: sem e com enganche do veículo na valeta.

\section{Sem enganche do veículo na valeta}

- Distância da extremidade da barreira até o ponto mais distante de saída da pista em que o veículo entra na valeta (Dbd): ângulo abaixo do qual não ocorre o choque com a barreira $\theta c=5^{\circ}$ (Figura 5.4, para $\mathrm{T}=6 \mathrm{~m}$ ), $\mathrm{Dbd}=58 \mathrm{~m}$ (Figura 5.5, para $\theta \mathrm{c}=5^{\circ}$ e $\mathrm{T}=6 \mathrm{~m}$ ); distância do ponto mais distante de saída da pista em que o veículo entra na valeta até o ponto de entrada na valeta: (Dvd): Dvd=72m (Figura 5.5, para $\theta \mathrm{c}=5^{\circ}$ e $\mathrm{T}=8 \mathrm{~m}$ ).

- Distância da extremidade da barreira até o ponto mais próximo de saída da pista em que o veículo entra na valeta (Dbp): $\mathrm{Dbp}=22 \mathrm{~m}$ (Figura 5.5, para $\theta=15^{\circ}$ e $\mathrm{T}=6 \mathrm{~m}$ ); distância do ponto mais próximo de saída da pista em que o veículo entra na valeta até o ponto de entrada na valeta: (Dvp): $\mathrm{Dvp}=30 \mathrm{~m}$ (Figura 5.5, para $\theta=15^{\circ}$ e $\mathrm{T}=8 \mathrm{~m}$ ).

- Distância crítica da extremidade da barreira até o ponto de saída da pista em que o veículo entra na valeta: menor entre $(\mathrm{Dbd}, \mathrm{Dbp})=\mathrm{Dbp}=22 \mathrm{~m}$.

- Distância percorrida desde o ponto de saída da pista até o veículo parar: distância percorrida com $\quad \mathrm{Vs}=110 \mathrm{~km} / \mathrm{h} \quad$ (equação 5.1 ): $\quad \mathrm{D}_{1}=\mathrm{V} / 3=110 / 3=36,67 \mathrm{~m}$, $\mathrm{Dp}=\mathrm{D}_{1}+\mathrm{Vs}^{2} / 158,11=36,67+110^{2} / 158,11=113,20 \mathrm{~m}$.

- Distância da borda do espaço vazio até a extremidade da barreira para que o veículo não caia: $\quad$ Deb=Dp-Dbp=113,20-22=91,2m (91m), posição da barreira: $\quad \mathrm{Ib}=7 \mathrm{~m}$, $\mathrm{Fb}=91+30=121 \mathrm{~m}$, portanto: barreira no trecho de $7 \mathrm{~m}-121 \mathrm{~m})$, extensão total $=114 \mathrm{~m}$. 
- Situação se a barreira fosse mantida apenas no trecho de $7 \mathrm{~m}-75 \mathrm{~m}$ com extensão de $68 \mathrm{~m}$ (que foi definido sem que houvesse a valeta de drenagem): pode ocorrer queda no espaço vazio sendo definida a não existência de barreira no trecho de $75 \mathrm{~m}-121 \mathrm{~m}$.

\section{Com enganche do veículo na valeta}

- Distância da extremidade da barreira até o ponto mais distante de saída da pista em que o veículo entra na valeta (Dbd): ângulo acima do qual não ocorre o choque com a barreira $\theta \mathrm{c}=5^{\circ}$ (Figura 5.4, para $\mathrm{T}=6 \mathrm{~m}$ ), Dbd=58m (Figura 5.5, para $\theta \mathrm{c}=5^{\circ}$ e $\mathrm{T}=6 \mathrm{~m}$ ); distância do ponto mais distante de saída da pista em que o veículo entra na valeta até o ponto de entrada na valeta: (Dvd): Dvd=72m (Figura 5.5, para $\theta \mathrm{c}=5^{\circ}$ e $\left.\mathrm{T}=8 \mathrm{~m}\right)$.

- Distância crítica da extremidade da barreira até o ponto de saída da pista em que o veículo entra na valeta: menor entre $(\mathrm{Dbd}, \mathrm{Dbp})=\mathrm{Dbp}=22 \mathrm{~m}$.

- Distância da extremidade da barreira até o ponto mais próximo de saída da pista em que o veículo entra na valeta (Dbp): $\mathrm{Dbp}=22 \mathrm{~m}$ (Figura 5.5, para $\theta=15^{\circ}$ e $\mathrm{T}=6 \mathrm{~m}$ ); distância do ponto mais próximo de saída da pista em que o veículo entra na valeta até o ponto de entrada na valeta: (Dvp): Dvp=30m (Figura 5.5, para $\theta=15^{\circ}$ e $\mathrm{T}=8 \mathrm{~m}$ ).

- Distância crítica da extremidade da valeta até o ponto de saída da pista em que o veículo entra na valeta: menor entre $($ Dvd, Dvp $)=\operatorname{Dvp}=30 \mathrm{~m}$.

- Velocidade de entrada na valeta no caso da saída do ponto mais próximo da valeta (Vev): $\mathrm{Dvp}=30 \mathrm{~m}<\mathrm{D}_{1}=36,67 \mathrm{~m}, \mathrm{Vev}=110 \mathrm{~km} / \mathrm{h}$.

- Distância percorrida dentro da valeta: $\mathrm{Dv}=\mathrm{Vev}^{2} / 316,22=110^{2} / 316,22=38,27 \mathrm{~m}$.

- Distância da borda do espaço vazio até a extremidade da barreira para que o veículo não caia: $\quad \operatorname{Deb}=\mathrm{D}_{\mathrm{v}}+\mathrm{Dvp}=38,27+30=68,27 \mathrm{~m} \quad(68 \mathrm{~m})$, posição da barreira: $\mathrm{Ib}=7 \mathrm{~m}$, $\mathrm{Fb}=68+30=98 \mathrm{~m}$, portanto: barreira no trecho de $7 \mathrm{~m}-98 \mathrm{~m}$, extensão total $=91 \mathrm{~m}$.

- Situação se a barreira fosse mantida apenas no trecho de $7 \mathrm{~m}-75 \mathrm{~m}$ com extensão de $68 \mathrm{~m}$ (que foi definido sem que houvesse a valeta de drenagem): pode ocorrer queda no espaço vazio sendo definida a não existência de barreira no trecho de $75 \mathrm{~m}-98 \mathrm{~m}$. 
$\underline{\text { Observações quanto à colocação de barreira de contenção }}$

Os resultados dos exemplos apresentados confirmam alguns aspectos de grande relevância no tocante ao emprego de barreiras de contenção. A seguir são relacionados esses aspectos e citados valores obtidos nos exemplos.

1. A probabilidade de choque com a barreira é menor quanto mais afastada ela estiver da borda da pista. No caso do exemplo 10, quando ela está situada na borda da pista, é de 100\%, enquanto, no caso do exemplo 13, quando está situada a $6 \mathrm{~m}$ da pista, é de $38 \%$.

2. A extensão da barreira de contenção resulta menor quanto mais afastada ela fica da borda da pista. No caso do exemplo 10, quando ela está situada na borda da pista, é de $91 \mathrm{~m}$ para evitar o choque com obstáculo e $61 \mathrm{~m}$ para evitar choque com grande risco de acidente grave, enquanto, no caso do exemplo 13, quando está situada a $6 \mathrm{~m}$ da pista, esses valores são, respectivamente, $68 \mathrm{~m}$ e $57 \mathrm{~m}$.

3. As observações 1 e 2 indicam que a barreira deve ser colocada o mais longe possível da borda da pista.

4. A probabilidade de choque com a barreira é sempre maior do que com o obstáculo que "protege", pois ela sempre vai estar mais próxima da borda da pista. No caso do exemplo 10, a probabilidade de choque com o obstáculo é de $26 \%$, enquanto, com a barreira, é de $100 \%$ quando ela está na borda da pista, e de $38 \%$ quando ela está afastada de $6 \mathrm{~m}$.

5. Se o choque com o obstáculo mostra ser de risco grave e médio de o acidente resultar grave, a colocação da barreira transforma o risco em pequeno (quando o choque ocorre com velocidade acima de $90 \mathrm{~km} / \mathrm{h}$ ) e insignificante, (quando abaixo de $90 \mathrm{~km} / \mathrm{h}$ ). No caso do exemplo 13, no trecho de 29m-90m, sem a barreira, o risco é grande e, com a barreira, pequeno; no trecho de 90m-110m, sem a barreira, o risco é médio e, com a barreira, pequeno.

6. As observações 4 e 5 indicam que a colocação de barreira de contenção aumenta a probabilidade de acidente, mas reduz o risco associado ao acidente.

\subsection{ANÁLISE MACROSCÓPICA DO DESEMPENHO DE SEGMENTOS LONGOS}

Uma vez identificados os diversos segmentos particulares de um trecho de rodovia associados a diferentes níveis de risco de a saída da pista resultar em acidente grave, é possível quantificar o desempenho dos segmentos longos no que tange à proteção proporcionada aos veículos nas saídas de pista. 
Essa quantificação é feita mediante o cálculo da média ponderada das notas atribuídas a cada segmento particular, seguindo o estabelecido na Tabela 5.5, ou seja:

- Risco grande: nota $=4$.

- Risco médio: nota $=3$.

- Risco pequeno: nota $=2$.

- Risco insignificante: nota $=1$

- Risco inexistente: nota $=0$.

O cálculo da média é realizado utilizando a equação:

$$
N=\frac{\sum_{i=1}^{n}\left(N_{i} \times L_{i}\right)}{L}
$$

em que, $\mathrm{N}_{\mathrm{i}}$ : nota atribuída aos segmentos conforme o nível de risco de acidente grave, $\mathrm{L}_{\mathrm{i}}$ : soma da extensão dos segmentos com nota $\mathrm{N}_{\mathrm{i}}$ e L: extensão do trecho de rodovia analisado, ou seja: $\mathrm{L}=\sum L_{i}$.

O cálculo da nota que caracteriza o desempenho do trecho de rodovia quanto ao nível de segurança proporcionada aos veículos nas saídas de pista deve ser desagregado, por sentido e por lado, para permitir a classificação de cada lado, em cada sentido, e a identificação do sentido/lado crítico.

Exemplo de aplicação: trecho de rodovia com 10km, com as seguintes características:

- Lado direito no sentido norte-sul: risco grande (nota 4$)=2,0 \mathrm{~km}$, risco médio (nota 3 ) = $2,0 \mathrm{~km}$, risco pequeno $($ nota 2$)=2,0 \mathrm{~km}$, risco insignificante $($ nota 1$)=2,0 \mathrm{~km}$, risco inexistente $($ nota 0$)=2,0 \mathrm{~km}$.

- Lado esquerdo no sentido norte-sul: risco grande (nota 4$)=0,0 \mathrm{~km}$, risco médio (nota 3 ) $=0,0 \mathrm{~km}$, risco pequeno $($ nota 2$)=1,0 \mathrm{~km}$, risco insignificante $($ nota 1$)=1 \mathrm{~km}$, risco inexistente $($ nota 0$)=8 \mathrm{~km}$.

- Lado direito no sentido sul-norte: risco grande (nota 4$)=3,5 \mathrm{~km}$, risco médio (nota 3$)=$ $1,0 \mathrm{~km}$, risco pequeno $($ nota 2$)=2,5 \mathrm{~km}$, risco insignificante $($ nota 1$)=2,0 \mathrm{~km}$, risco inexistente $($ nota 0$)=1,0 \mathrm{~km}$. 
- Lado esquerdo no sentido sul-norte: risco grande (nota 4$)=1,0 \mathrm{~km}$, risco médio (nota 3) $=2,0 \mathrm{~km}$, risco pequeno $($ nota 2$)=2,0 \mathrm{~km}$, risco insignificante $($ nota 1$)=3,0 \mathrm{~km}$, risco inexistente $($ nota 0$)=2,0 \mathrm{~km}$.

As notas obtidas mediante a equação 5.10 são as seguintes:

- Lado direito no sentido norte-sul: $\mathrm{N}=2,0\left(\mathrm{~N}_{\mathrm{n}}=5,0\right)$.

- Lado esquerdo no sentido norte-sul: $\mathrm{N}=0,3\left(\mathrm{~N}_{\mathrm{n}}=9,25\right)$.

- Lado direito no sentido sul-norte: $\mathrm{N}=2,4\left(\mathrm{~N}_{\mathrm{n}}=4,0\right)$.

- Lado esquerdo no sentido sul-norte: $\mathrm{N}=1,7\left(\mathrm{~N}_{\mathrm{n}}=5,75\right)$.

A obtenção das notas globais por sentido e para o trecho de rodovia englobando os dois sentidos é realizada mediante média aritmética simples. Assim, os valores correspondentes a cada caso são os seguintes:

- Sentido norte-sul: $\mathrm{N}=1,15\left(\mathrm{~N}_{\mathrm{n}}=7,13\right)$.

- Sentido sul-norte: $\mathrm{N}=2,05\left(\mathrm{~N}_{\mathrm{n}}=4,88\right)$.

- Trecho de rodovia (nos dois sentidos): $\mathrm{N}=1,6\left(\mathrm{~N}_{\mathrm{n}}=6,0\right)$.

Se as notas forem normalizadas no intervalo $0-10,0$; sendo a nota normalizada 10,0 (dez) associada à nota original 0,0 (risco inexistente) e a nota normalizada 0,0 (zero) associada à nota original 4,0 (risco grande), a nota normalizada é determinada pela equação:

$$
N_{n}=2,5 \times \mathbb{4}-N^{-}
$$

Onde, $\mathrm{N}_{\mathrm{n}}$ : nota normalizada e $\mathrm{N}$ : nota original.

As notas normalizadas $(\mathrm{Nn})$ foram calculadas após a nota original nos casos anteriormente citados.

Conclusões:

- A situação do lado esquerdo no sentido norte-sul pode ser considerada muito boa; do lado direito no sentido sul-norte, ruim. Nos outros dois casos, a situação pode ser considerada regular.

- A situação do trecho de rodovia no sentido norte-sul pode ser considerada boa e no sentido sul-norte de regular para ruim. 
- A situação do trecho de rodovia considerando os dois sentidos pode ser considerada como regular.

- As ações corretivas deveriam começar pelo lado direito no sentido sul-norte, que constitui a pior situação.

Na comparação do desempenho dos segmentos rodoviários longos também pode ser levado em conta o volume diário médio anual de tráfego (VDM), fator diretamente associado ao número total de acidentes.

\subsection{ANÁLISE DOS RESULTADOS FORNECIDOS PELO MODELO QRSP}

Probabilidades associadas ao afastamento lateral nas saídas de pista em trechos retos

Nas Figura 5.12 e Figura 5.13 são mostradas as curvas da distribuição da probabilidade associadas a diferentes valores da distância lateral percorrida, fornecidas pelo Modelo QRSP e apresentadas em TRB (2003). Os valores de TRB (2003) da Figura 5.12 referem-se a rodovias de múltiplas faixas (rodovias de "pista dupla") e os da Figura 5.13, a rodovias de duas faixas e dois sentidos (rodovias de "pista simples"). No tocante ao Modelo QRSP, os valores correspondem às velocidades de $110 \mathrm{~km} / \mathrm{h}$, no caso da Figura 5.12 , e 90 km/h, no caso da Figura 5.13. Essas velocidades são as velocidades de projeto comumente utilizadas nas rodovias de "pista dupla" e "pista simples", respectivamente.

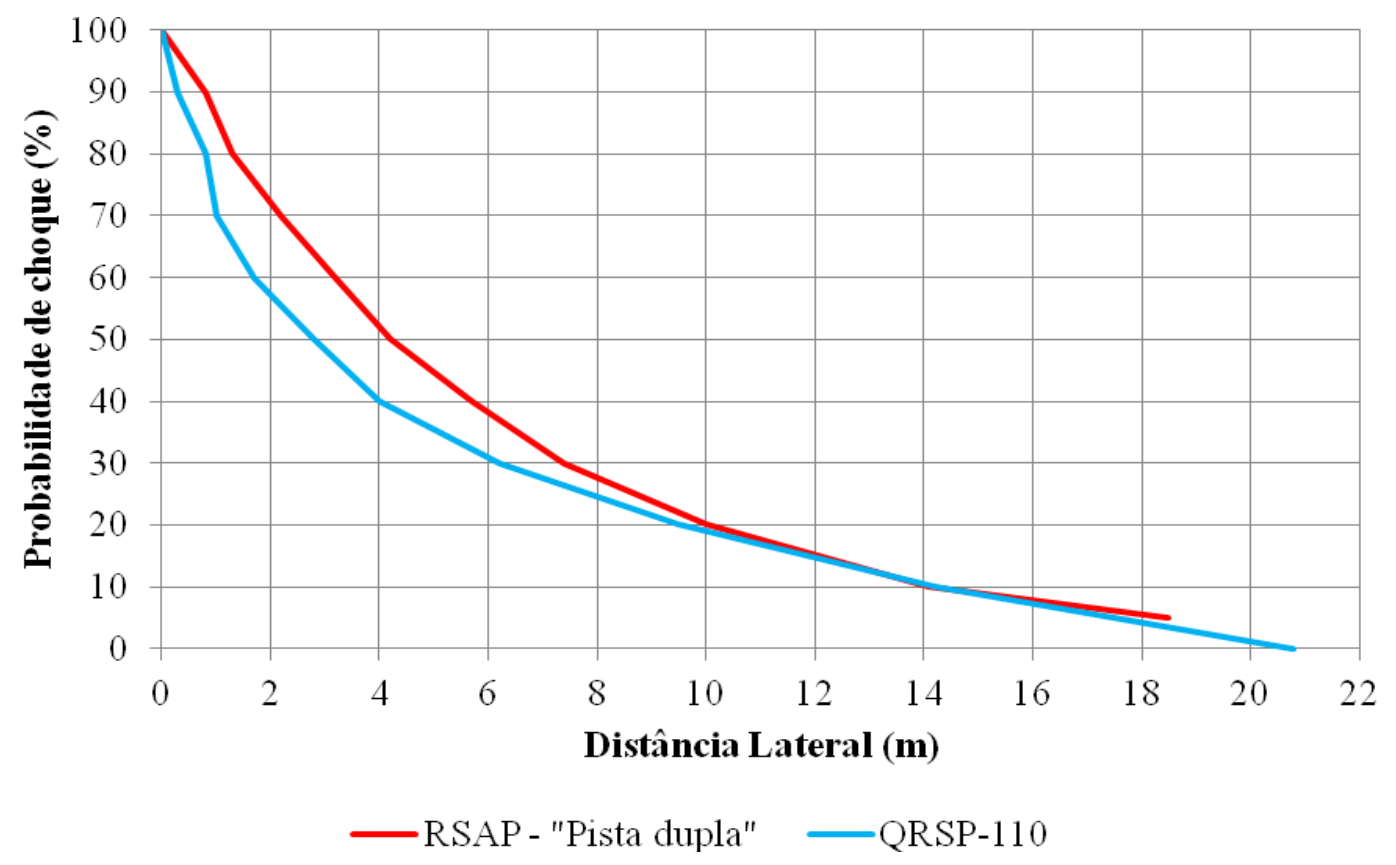

Figura 5.12 - Curvas para rodovias de "pista dupla". 


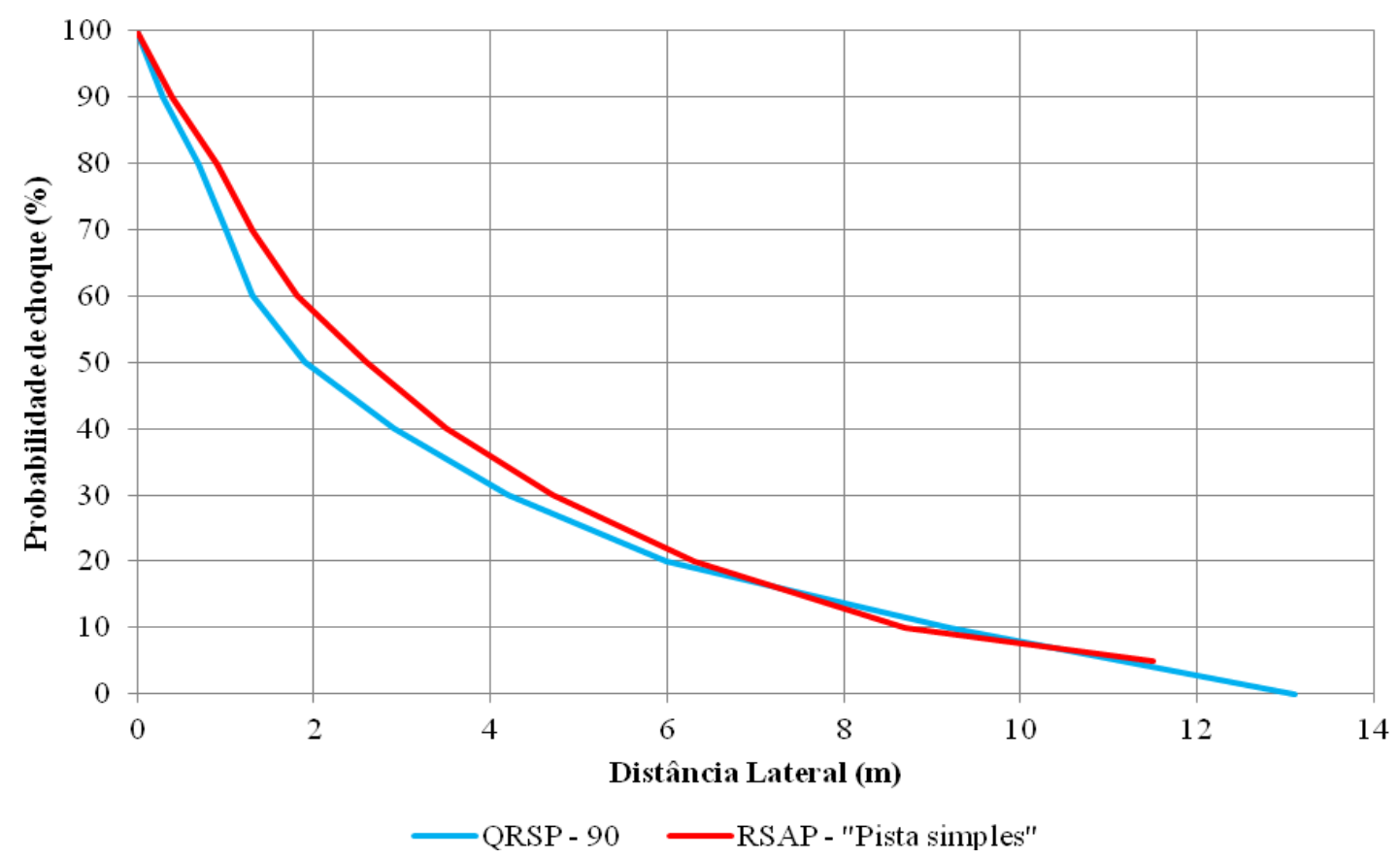

Figura 5.13 - Curvas para rodovias de "pista simples".

Como se pode observar, os valores da probabilidade apresentados por TRB (2003) são pouco superiores para distâncias menores (até cerca de 8m, no caso da Figura 5.12, e 6m, no caso da Figura 5.13). Para distâncias maiores os valores praticamente coincidem. Segue explicação para tal fato.

O modelo QRSP utiliza como referência as curvas apresentadas por Hutchinson \& Kennedy (1966), devidamente adaptadas, para gerar os valores da probabilidade versus distância. A adaptação foi feita para levar em conta as saídas em que o afastamento lateral era menor que 1 metro, pois isso não foi considerado como saída de pista no trabalho Hutchinson \& Kennedy (1966) em razão da saída se limitar à área do acostamento pavimentado tornando praticamente impossível detectar marcas dos pneus .

Por outro lado, o método do TRB (2003) utiliza como referência as curvas apresentadas por Cooper, que adaptou as curvas apresentadas por Hutchinson \& Kennedy (1966), mas não leva em conta as saídas de pista em que o afastamento lateral é menor que 4 metros.

Considerando, no entanto, que a saída de pista constitui um fenômeno complexo impossível de ser reproduzido em experimentos controlados e que parâmetros importantes, como, por exemplo, o fator de aderência pneus-superfície do espaço lateral, podem variar significativamente de um local para outro, pode-se considerar que os valores fornecidos pelo Modelo QRSP são plenamente satisfatórios. 


\section{Largura livre para trecho de rodovia em tangente}

$\mathrm{Na}$ Tabela 5.18 estão indicados os valores da largura da faixa lateral livre de obstáculos, para um trecho em tangente de uma rodovia, fornecidos pelo método da Norma NBR 15486 da ABNT (2007), conforme a Figura 2.2, para o caso de terreno com inclinação lateral 1V:6H e volume médio diário acima de 6.000 veículos por dia, e pelo Modelo QRSP, para o caso de terreno com inclinação lateral menor que $1 \mathrm{~V}: 6 \mathrm{H}$ e valores da probabilidade de choque com obstáculo situado na borda da faixa lateral livre igual a $0 \%$ e $10 \%$.

Tabela 5.18 - Valores da largura da faixa lateral livre para trecho em tangente

\begin{tabular}{cccc}
\hline Referência & \multicolumn{3}{c}{ Velocidade $(\mathbf{k m} / \mathbf{h})$} \\
Método ABNT (2007) & $\mathbf{6 0}$ & $\mathbf{8 0}$ & $\mathbf{1 0 0}$ \\
\hline $\begin{array}{c}\text { Modelo QRSP para que a probabilidade de choque com obstáculo } \\
\text { situado na borda da faixa livre seja igual a 0\% }\end{array}$ & $6 \mathrm{~m}$ & $7 \mathrm{~m}$ & $10 \mathrm{~m}$ \\
$\begin{array}{c}\text { Modelo QRSP para que a probabilidade de choque com obstáculo } \\
\text { situado na borda da faixa livre seja menor que 10\% }\end{array}$ & $11 \mathrm{~m}$ & $16 \mathrm{~m}$ \\
$\begin{array}{c}\text { Modelo QRSP para que a probabilidade de choque com obstáculo } \\
\text { rígido situado na borda da faixa livre seja igual a 10\% e que o risco } \\
\text { de acidente grave seja pequeno }\end{array}$ & $7 \mathrm{~m}$ & $11 \mathrm{~m}$ \\
\hline & $0 \mathrm{~m}$ & $6 \mathrm{~m}$ & $10 \mathrm{~m}$ \\
\hline
\end{tabular}

A análise dos valores da Tabela 5.18 indica que os valores da largura da faixa livre lateral fornecidos pelo método ABNT (2007) praticamente coincidem com os fornecidos pelo Modelo QRSP para o caso da probabilidade de choque com obstáculo situado na borda da faixa livre ser igual a $10 \%$.

Cabe destacar que, no desenvolvimento do método ABNT (2007), certamente esteve presente a questão econômica, pois a utilização de faixas com largura lateral livre para evitar todos os acidentes implica em custos de implantação de rodovias bem mais elevados, em decorrência da maior faixa de desapropriação. Dessa forma, a relação custo-benefício acaba por levar à fixação de valores menores para a largura da faixa. A prática rodoviária tem mostrado que, com as larguras determinadas com base no método ABNT (2007), entre 80\% e 90\% dos casos de saída de veículos da pista não resultam em acidentes, permitindo que os veículos voltem à pista sem ou com pequenos danos.

Em vista do exposto, pode-se dizer que o Modelo QRSP representa, de maneira adequada, o fenômeno de saída de pista em trechos de rodovia em tangente no que diz respeito aos valores da largura da faixa lateral livre de obstáculos.

\section{Largura livre para trecho de rodovia em curva}


$\mathrm{Na}$ Tabela 5.19, estão indicados os valores da relação entre a largura livre em curvas e em tangente para diferentes velocidades e valores do raio preconizados pelo método ABNT (2007) e fornecidos pelo Modelo QRSP.

Tabela 5.19 - Fatores de ajuste para curvas horizontais ${ }^{\text {a,b,c. }}$

\begin{tabular}{cccccccc}
\hline \multirow{2}{*}{$\mathbf{R}(\mathbf{m})$} & $\mathbf{6 0}$ & $\mathbf{7 0}$ & $\mathbf{8 0}$ & $\mathbf{9 0}$ & $\mathbf{1 0 0}$ & $\mathbf{1 1 0}$ & $\mathbf{1 2 0}$ \\
\hline $\mathbf{9 0 0}$ & $1,1 / 1,09$ & $1,1 / 1,13$ & $1,1 / 1,17$ & $1,2 / 1,21$ & $1,2 / 1,29$ & $1,2 / 1,32$ & $---1,35$ \\
$\mathbf{8 0 0}$ & $---/ 1,09$ & $---/ 1,14$ & $---/ 1,19$ & $---/ 1,23$ & $---/ 1,32$ & $---/ 1,37$ & $---/ 1,41$ \\
$\mathbf{7 0 0}$ & $1,1 / 1,10$ & $1,1 / 1,17$ & $1,2 / 1,22$ & $1,2 / 1,28$ & $1,2 / 1,37$ & $1,3 / 1,43$ & $---/ 1,48$ \\
$\mathbf{6 0 0}$ & $1,1 / 1,12$ & $1,2 / 1,25$ & $1,2 / 1,25$ & $1,2 / 1,34$ & $1,3 / 1,44$ & $1,4 / 1,50$ & $---/ 1,57$ \\
$\mathbf{5 0 0}$ & $1,1 / 1,14$ & $1,2 / 1,23$ & $1,2 / 1,30$ & $1,3 / 1,42$ & $1,3 / 1,55$ & $1,4 / 1,62$ & $---/ 1,71$ \\
$\mathbf{4 0 0}$ & $1,2 / 1,19$ & $1,2 / 1,28$ & $1,3 / 1,39$ & $1,3 / 1,54$ & $1,4 / 1,71$ & & \\
$\mathbf{3 0 0}$ & $1,2 / 1,24$ & $1,3 / 1,38$ & $1,4 / 1,56$ & $1,5 / 1,80$ & & & \\
$\mathbf{2 0 0}$ & $1,3 / 1,36$ & $1,4 / 1,65$ & $1,5 / 1,94$ & & & & \\
$\mathbf{1 0 0}$ & $1,5 / 2,05$ & & & & & & \\
\hline
\end{tabular}

${ }^{a}$ Os valores à esquerda são os preconizados pelo método ABNT (2007) e os à direita são os fornecidos pelo modelo QRSP.

${ }^{\mathbf{b}}$ Os espaços assinalados com --- correspondem a valores não fornecidos pelo método ABNT (2007) e AASHTO (2002)

${ }^{\mathbf{c}}$ Os valores sombreados representam os casos em que a diferença dos valores é maior que $20 \%$.

A análise dos valores da Tabela 5.19 mostra que o modelo QRSP é mais conservador, pois os valores fornecidos por esse modelo são ligeiramente maiores que os preconizados pelo método ABNT (2007) (exceto nos três casos extremos de curva com pequeno raio assinalados com sombra, onde a diferença supera $20 \%$ ).

Também neste caso, certamente a questão econômica contou para a fixação de valores pouco menores em relação ao ideal no método ABNT (2007). Isso fica evidenciado quando este método especifica, para uma mesma velocidade de projeto, valores iguais para curvas com raios distintos, como é, por exemplo, o caso das curvas de raio de $600 \mathrm{~m}, 700 \mathrm{~m}, 800 \mathrm{~m}$ e $900 \mathrm{~m}$ para velocidade de $90 \mathrm{~km} / \mathrm{h}$ (em todos eles, o fator é 1,2).

Cabe observar que os valores dos fatores de correção fornecidos pelo Modelo QRSP são mais consistentes, uma vez que são diferentes para raios de curva distintos - como deve ser do ponto de vista lógico.

Em vista do exposto, pode-se dizer que o Modelo QRSP representa, de maneira adequada, o fenômeno de saída de pista, em trechos de rodovia em curva, no tocante aos valores da largura da faixa lateral livre de obstáculos.

\section{Comprimento da barreira de contenção}

Outro aspecto relevante no que tange à saída de veículos da pista é o comprimento da barreira de contenção, onde necessária. Dessa forma, é importante verificar a compatibilidade 
e a consistência dos valores fornecidos pelo Modelo QRSP com os obtidos nos métodos ABNT (2007) e AASHTO (2002). Para isso, foi considerado o caso comum de um obstáculo localizado dentro da faixa lateral, que deveria ser livre (com a face mais próxima da borda da pista a $3 \mathrm{~m}$ da mesma e a mais distante a $7 \mathrm{~m}$ ), e de barreira de contenção situada a $1 \mathrm{~m}$ da borda. A análise foi realizada para dois valores típicos de velocidade de projeto: $110 \mathrm{~km} / \mathrm{h}$ e $80 \mathrm{~km} / \mathrm{h}$. Os resultados obtidos, que se referem à distância da extremidade mais afastada da barreira e a face mais próxima do obstáculo, são mostrados na Tabela 5.20. Os valores referentes ao modelo QRSP foram determinados de acordo com o método descrito neste trabalho, e os valores dos métodos ABNT (2007) e AASHTO (2002), como descritos no item 3.6.

Tabela 5.20 - Distância em metros da extremidade mais afastada da barreira e a face mais próxima do obstáculo.

\begin{tabular}{|c|c|c|c|c|}
\hline \multirow{2}{*}{$\begin{array}{l}\text { Tipo de obstáculo } \\
\text { Velocidade }(\mathbf{k m} / \mathrm{h})\end{array}$} & \multicolumn{2}{|c|}{ Espaço vazio } & \multicolumn{2}{|c|}{ Rígido } \\
\hline & 80 & 110 & 80 & 110 \\
\hline $\begin{array}{l}\text { Modelo QRSP para impedir o } \\
\text { choque com o obstáculo }\end{array}$ & 31 & 57 & 31 & 57 \\
\hline $\begin{array}{l}\text { Modelo QRSP para impedir choque } \\
\text { com risco grande de acidente grave }\end{array}$ & 31 & 57 & - & 50 \\
\hline $\begin{array}{c}\text { AASHTO (2002) (não especificado } \\
\text { o tipo de choque nem o tipo de } \\
\text { obstáculo) }\end{array}$ & $64^{\mathrm{a}}-86^{\mathrm{b}}$ & $94^{\mathrm{a}}-124^{\mathrm{b}}$ & $64^{a}-86^{b}$ & $94^{a}-124^{b}$ \\
\hline $\begin{array}{l}\text { Norma ABNT (2007) (não } \\
\text { especificado o tipo de choque, nem o } \\
\text { tipo de obstáculo e a velocidade) }\end{array}$ & & & & \\
\hline
\end{tabular}

A análise dos valores da Tabela 5.20 permite inferir as conclusões que seguem.

O valor fornecido pelo método ABNT (2007) é muito menor que os valores fornecidos pelo método AASHTO (2002) (grosso modo, 3 a 6 vezes menor).

Os valores fornecidos pelo Modelo QRSP situam-se em patamares intermediários entre os valores dos métodos ABNT (2007) e AASHTO (2002) (grosso modo, 1,5 a 2,5 vezes maiores que os de ABNT (2007) e 2 vezes menor que os de AASHTO (2002).

Tudo leva a crer que o método ABNT (2007) foi desenvolvido, por razões econômicas, com o objetivo de impedir apenas um percentual dos acidentes graves no choque com o obstáculo.

O fato de o método ABNT (2007) não considerar em conta a velocidade leva a valores inconsistentes do comprimento da barreira. No caso analisado, por exemplo, o comprimento de $22 \mathrm{~m}$ é insuficiente para impedir o choque com risco de acidente grave para $\mathrm{V}=110 \mathrm{~km} / \mathrm{h}$ (que, de acordo com modelo QRSP, deveria ser de 50m no caso de obstáculo rígido) e 
exagerado para $\mathrm{V}=80 \mathrm{~km} / \mathrm{h}$ (que, de acordo com modelo QRSP, não precisaria ser colocado no caso de objeto rígido).

Por outro lado, os valores fornecidos por AASHTO (2002), indicam que o método tem por premissa impedir o choque com obstáculos e não leva em conta a possibilidade de execução de manobras de desvio da trajetória como previsto no modelo QRSP. Ainda mais, AAHSTO (2002) considera que as distâncias para parada são superiores às adotadas no modelo QRSP: $115 \mathrm{~m}$ para $\mathrm{V}=110 \mathrm{~km} / \mathrm{h}$ e $65 \mathrm{~m}$ para $\mathrm{V}=80 \mathrm{~km} / \mathrm{h}$, no modelo QRSP, e, conforme indicado no item 3.6, $110 \mathrm{~m}$ a $145 \mathrm{~m}$ para $\mathrm{V}=110 \mathrm{~km} / \mathrm{h}$ e $75 \mathrm{~m}$ a $100 \mathrm{~m}$ para $\mathrm{V}=80 \mathrm{~km} / \mathrm{h}$, no caso AASHTO (2002). Isso significa que o valor do coeficiente de atrito considerado em AASHTO (2002), é menor do que em QRSP e o tempo de percepção e reação é maior.

Em vista disso, se não for considerada a possibilidade do desvio da trajetória, os valores fornecidos pelo modelo QRSP seriam pouco menores que os fornecidos por AASHTO (2002). 


\section{CONSIDERAÇÕES FINAIS}

O objetivo deste trabalho de pesquisa foi desenvolver um modelo que representasse melhor o fenômeno real da saída imprevista de veículos da pista em rodovias (para isso foram realizados diversos ensaios/testes em campo) e, ao mesmo tempo, fornecer parâmetros para uma quantificação mais adequada do risco associado à saída da pista.

O modelo desenvolvido, denominado QRSP (formado pelas letras iniciais das palavras: Quantificação - Risco - Saída - Pista) fornece valores de diversos parâmetros de grande relevância na quantificação do risco associado à saída de veículos da pista em rodovias, que constituem informações valiosas para o projeto da faixa lateral das rodovias e de barreiras de contenção (lateral e frontal).

A análise dos valores fornecidos pelo modelo QRSP mostram que o mesmo representa, de maneira adequada, o fenômeno de saída imprevista da pista em rodovias. Os valores da largura da faixa lateral livre de obstáculos nos trechos de rodovia em tangente são consistentes com os valores obtidos no método ABNT (2007) e AASHTO (2002). O mesmo se pode dizer dos fatores de ajuste para a largura da faixa livre lateral nos trechos em curva.

Um atributo relevante do modelo é levar em conta o fato de o condutor virar a direção do veículo, mudando a trajetória simultaneamente com o acionamento do sistema de freio - o que, em geral, ocorre na realidade, tanto que, quando há espaço lateral suficiente com superfície regular, o condutor retorna com o veículo à pista sem que o incidente seja caracterizado como um acidente. O desvio de trajetória não é levado em conta no método AASHTO (2002), que considera que o condutor aciona apenas o sistema de freio.

Essas distintas premissas influem bastante na quantificação do risco associado à saída imprevista da pista, em particular no comprimento necessário das barreiras de contenção lateral. No modelo QRSP, os valores resultam, grosso modo, duas vezes menores em relação aos fornecidos pelo método AASHTO (2002), em razão da possibilidade de desvio da trajetória.

Os valores fornecidos pelo método ABNT (2007) são muito menores que os valores fornecidos pelo método AASHTO (2002) (grosso modo, 3 a 6 vezes menores). Tudo leva a crer que o método ABNT (2007) foi desenvolvido para impedir apenas uma porcentagem dos 
acidentes graves no choque com obstáculos. É surpreendente, no entanto, que os valores necessários para o comprimento das barreiras de contenção nesse método resultem tão baixos - com conseqüente prejuízo para a segurança.

Outro problema do método ABNT (2007), e que leva a resultados inconsistentes, é o fato de não considerar a velocidade de projeto da rodovia.

O modelo QRSP permite quantificar o nível de proteção existente em cada segmento próximo de obstáculos situados na lateral da rodovia (análise microscópica) e, a partir dessas informações, quantificar o nível de proteção, considerando trechos longos (análise macroscópica). Neste último caso, o estudo é desagregado por sentido e lado da rodovia.

O modelo QRSP foi desenvolvido para o caso de rodovias de múltiplas faixas por sentido (denominadas comumente de pista dupla), podendo, no entanto, também ser empregado no caso das rodovias de duas faixas e duplo sentido (rodovias de pista simples).

As informações quantitativas fornecidas pelo modelo são de grande utilidade na elaboração de projetos de melhoria das características das laterais de rodovias existentes, bem como na preparação de projetos de novas rodovias.

Um ponto crítico do modelo QRSP é a utilização de dados obtidos em condições de grama seca e em apenas um local. Mais: por razões de segurança, os resultados dos ensaios/testes de campo foram obtidos para velocidades de até $70 \mathrm{~km} / \mathrm{h}$; os valores para velocidades maiores tiveram que ser extrapolados.

O valor de 0,61 para o fator de aderência roda-grama, obtido nos ensaios/testes de campo utilizado no modelo, pode não ser verificado em outros locais, mesmo com a grama estando seca. Nesse sentido, outra questão a ser colocada é o fato de que, em uma parte considerável do tempo, a grama pode estar molhada ou úmida, havendo, neste caso, redução significativa do fator de aderência. Como levar isso em conta é algo que necessita ser minuciosamente estudado.

Outro ponto discutível é a adoção de um tempo de percepção e reação igual a 1,2 segundos no modelo; valor que pode ser considerado baixo para muitos dos usuários.

Em vista do exposto, é relevante deixar registradas as seguintes recomendações no sentido de aperfeiçoamento do modelo QRSP:

- Realização de ensaios/testes de campo em diversos locais e condições da superfície gramada, sobretudo seca e molhada, inclusive para velocidades maiores que $70 \mathrm{~km} / \mathrm{h}$ (o 
ideal seria realizar testes para velocidades até $120 \mathrm{~km} / \mathrm{h}$ - limite superior da velocidade de projeto em rodovias no país).

- Estudo e ensaio/testes de campo visando à possível modificação no valor do tempo de percepção e reação adotado.

- Estudo de acidentes reais visando ao aprimoramento dos parâmetros constantes da Tabela 5.3 e das Tabelas 5.6 a 5.12 .

- Estudo dos acidentes envolvendo saída imprevista da pista, visando, possivelmente, estabelecer relações mais reais entre o valor do ângulo de saída da pista e a probabilidade associada de ocorrência do acidente.

- Definição, à luz da questão econômica e das condições climáticas de cada região, sobre qual situação considerar como padrão de referência na determinação da largura da faixa lateral livre, do comprimento das barreiras de contenção e de outros parâmetros, tendo em conta o fato de a superfície gramada na lateral da rodovia permanecer seca, em parte do tempo, e molhada no restante. 


\section{REFERÊNCIAS BIBLIOGRÁFICAS}

AASHTO. Guide for Selecting, Locating, and Designing Traffic Barriers. Washington, D. C.: American Association of State Highway and Transportation Officials, 1977.

-. Highway Design and Operational Practices Related to Highway Safety. Washington, D. C.: American Association of State Highway and Transportation Officials, 1974.

-. Roadside Design Guide. Washington, D. C.: American Association of State Highway and Transportation Officials, 2002.

-. Roadside Design Guide. Washington, D. C.: American Association of State Highway and Transportation Officials. atualização, 2006.

ABNT. “Associação Brasileira de Normas Técnicas.” NBR 15.486- Norma Brasileira.

Segurança no Tráfego - Dispositivo de Contenção Viária - Diretrizes. 2007.

Disponível em: <http://www.abnt.org.br> (acesso em Julho de 2009).

—. “Associação Brasileira de Normas Técnicas.” NBR 6971 - Defensas Metálicas - Projeto e Implantação. 1999. Disponível em: <http://www.abnt.org.br>.

BASTOS, J. T. Geografia da mortalidade no trânsito no Brasil. Dissertação de Mestrado, São Carlos: Escola de Engenharia de São Carlos, Universidade de São Paulo, 2010, 146 p.

DER-SP. "Departamento de Estradas de Rodagem do Estado de São Paulo, Secretaria dos Transportes, Diretoria de Engenharia." Defensas Metálicas. Março de 2006.

Disponível em: http//www.der.sp.gov/documentos/normas/mas_ET_sinalização.aspx (acesso em 13 de Outubro de 2009).

FERRAZ, A. C., A. A RAIA JR, e B. S BEZERRA. Segurança no trânsito. São Carlos: Grupo Gráfico São Francisco, 2008.

GOOGLE. Google maps. 2011. http://maps.google.com.br/maps (acesso em Junho de 2011).

HUTCHINSON, W. J., e W. T. KENNEDY. Medians of Divided Highways-Frequency and Nature of Vehicle Encroachments. University of Illinois at Urbana Champaign Library Large-scale Digitization Project, 1966.

IPR. Instituto de pesquisas rodoviárias. 2010. Disponível em: <http://ipr.dnit.gov.br/> (acesso em Novembro de 2010).

MONTAVANI, V. R. Proposta de um sistema integrado de gestão em segurança de tráfego SIG SET. Dissertação de Mestrado, São Carlos: Programa de Pós-Graduação em Engenharia Urbana do Centro de Ciências Exatas e de Tecnologia do Departamento de Engenharia Civil da Universidade de São Carlos (UFSCar), 2004, 175 p.

NEST-USP. Núcleo de Estudos de Segurança no Trânsito da Universidade de São Paulo. 2011. http://www.stt.eesc.usp.br/nest/ (acesso em Junho de 2011). 
ONU. Organização das Nações Unidas. 2011. Disponível em <http://www.onubrasil.org.br/>.

PEREIRA, J. P. Análise dos Dispositivos de segurança para acidentes com saída de pista: um enfoque para barreiras de tráfego. Trabalho de Conclusão de Curso de Graduação em Engenharia Civil, Santa Maria. Rio Grande do Sul: Universidade Federal de Santa Maria, 2008.

ROCHA, A. A. "Segurança para Carros, Morte para Motociclistas.” Projeto Inicial: Colaboradores do Falcononline. s.d. Disponível em: http://www.motosegurança.com/br/downloads/Guard_rails.pdf (acesso em 2 de Abril de 2009).

SHA. "State Highway Administration." Guidelines for Traffic Barrier Placement and End Treatment Design. 2006. Disponível em: http://www.marylandroads.com/businessWithSHA/bizStdsSpecs/desManualStDpub/p ublicationonline/ohd/bookstd/index.asp (acesso em Março de 2006).

SIMÕES, F. A. SEGTRANS - Sistema de Segurança no Trânsito Urbano. Tese de Doutorado, Escola de Engenharia de São Carlos, São Carlos: Universidade de São Paulo, 2001, 220p.

TRB. NCHRP Report 350 - Recommended Procedures for the Safety Performance Evaluation of Highway Features. National Cooperative Highway Research Program, Transportation Research Board National Research Council, National Academy Press, 1993.

TRB. NCHRP Report 492 - Roadside Safety Analisis Program (RSAP) -Engineer's Manual. National Cooperative Highway Research Program, Transportation Research Board National Research Council, National Academy Press, 2003. 


\section{SITUAÇÃO TANGENTE - DESVIO ESQUERDA}

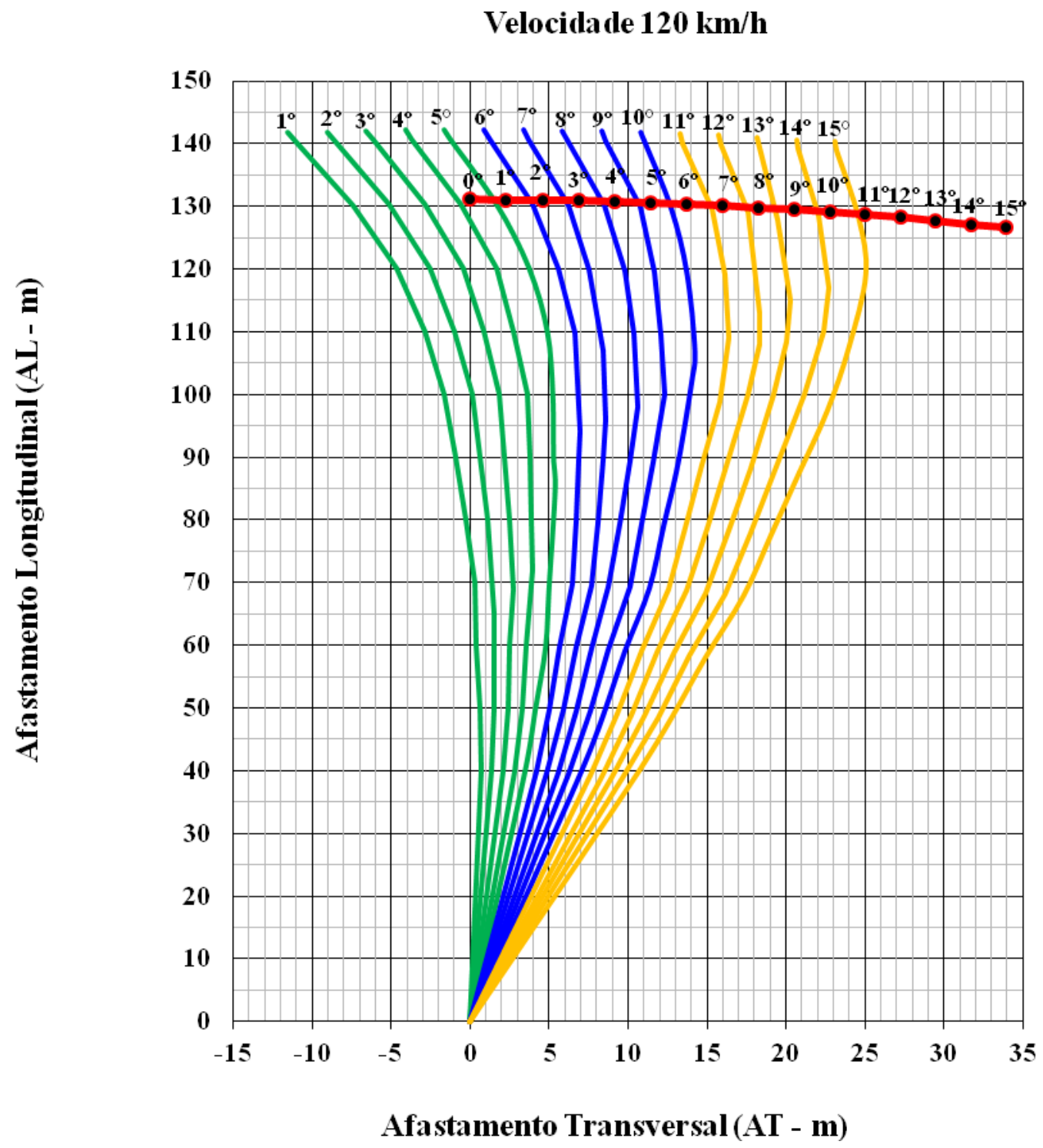




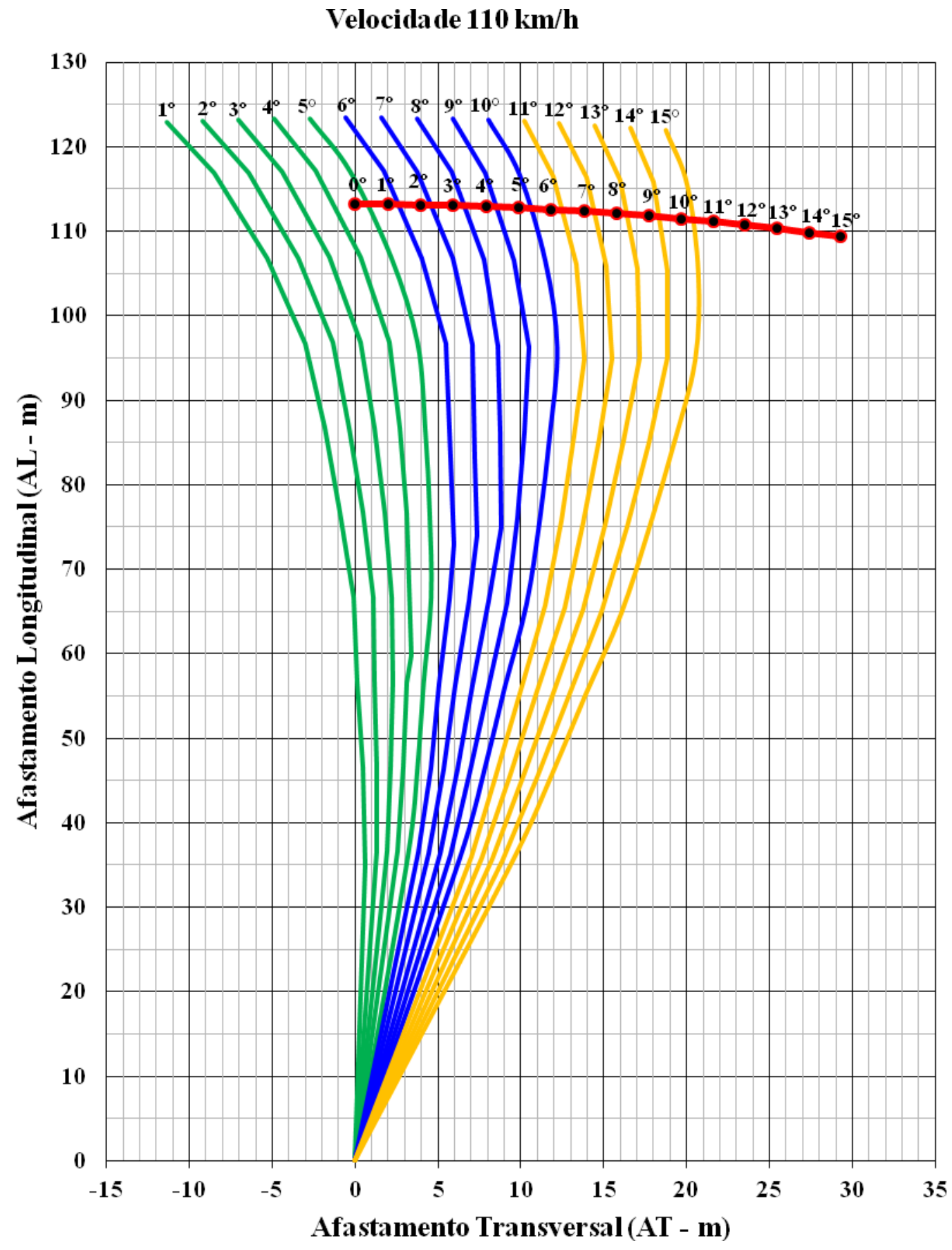




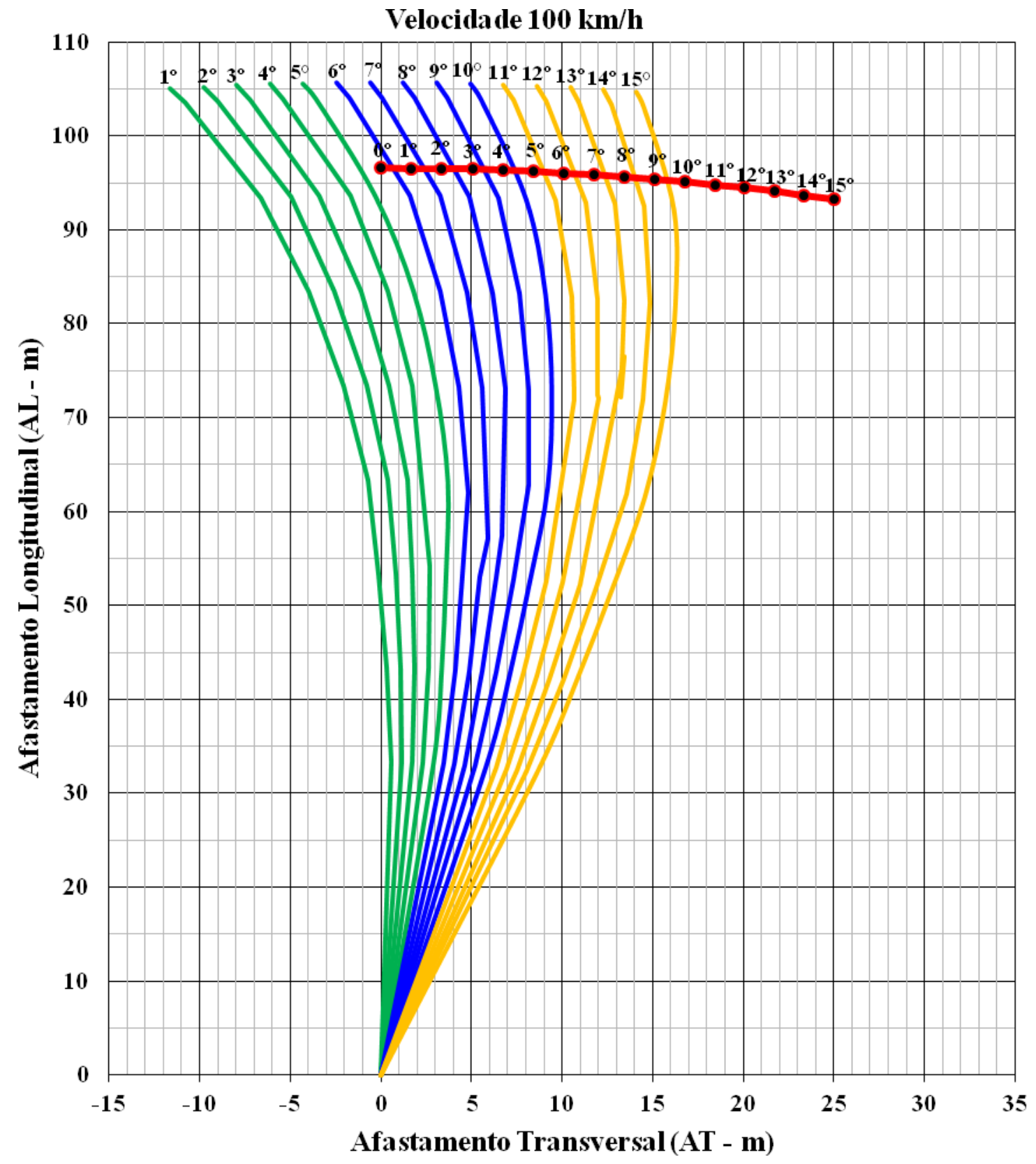




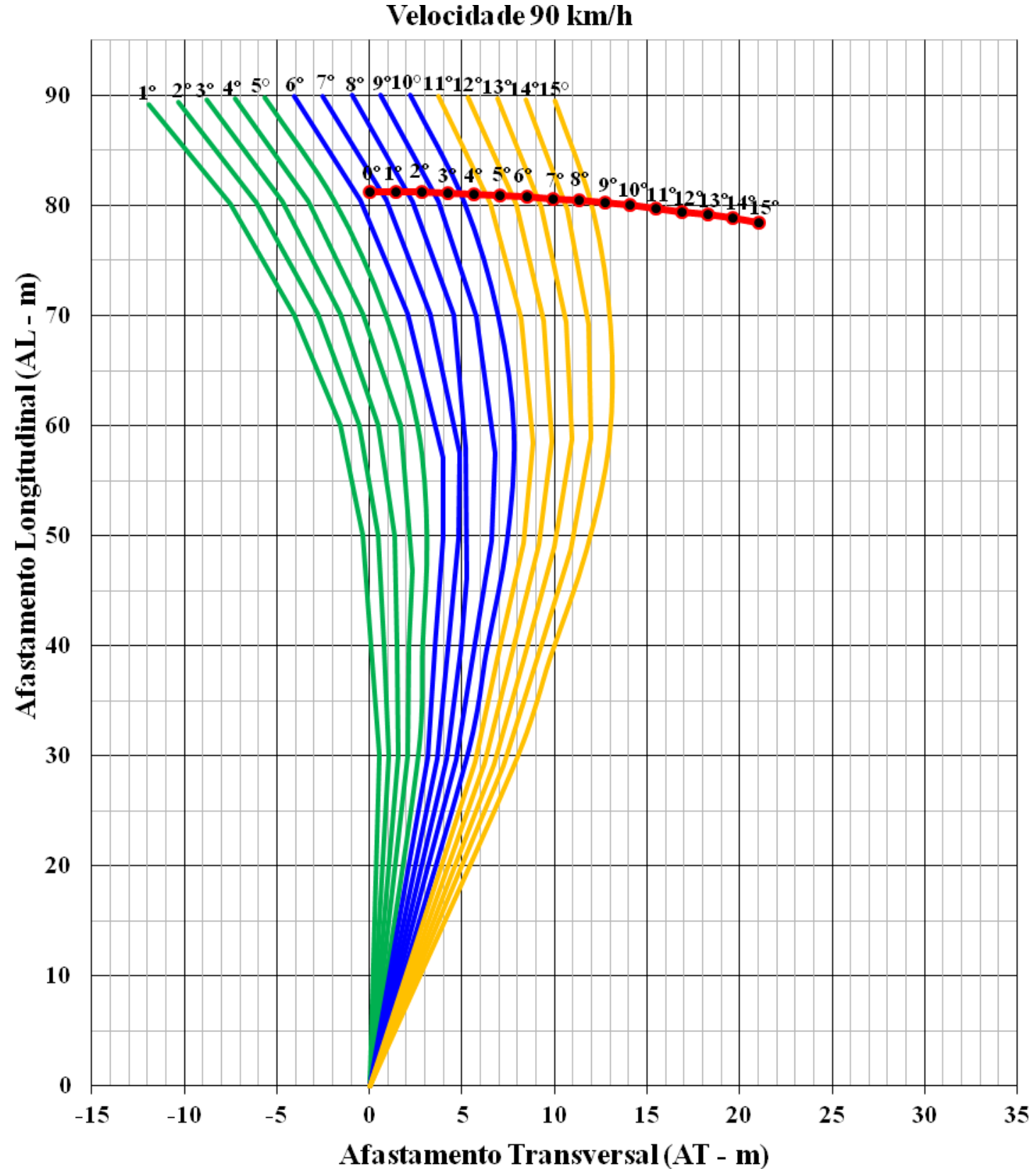


Velocidade $80 \mathrm{~km} / \mathrm{h}$

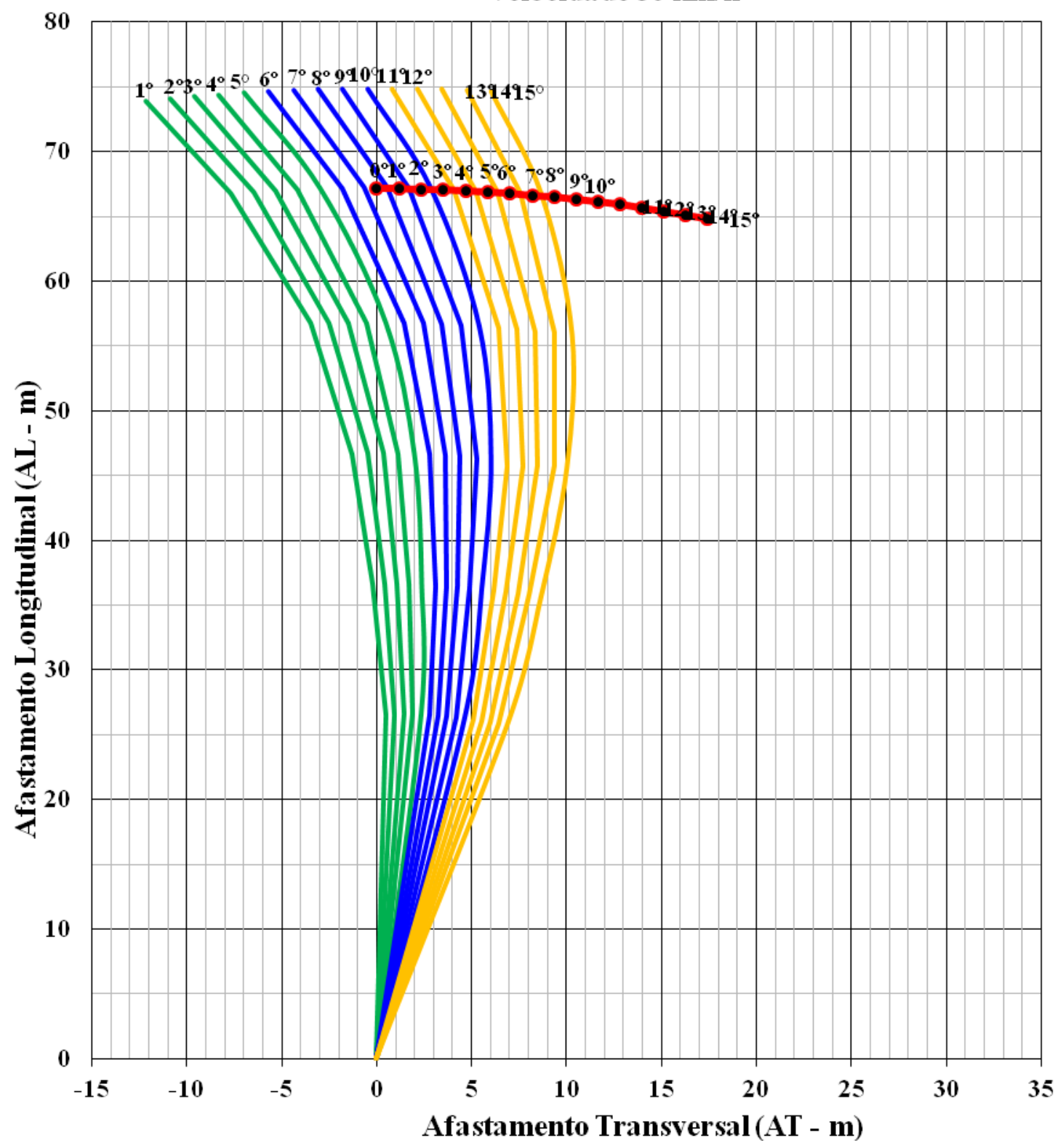




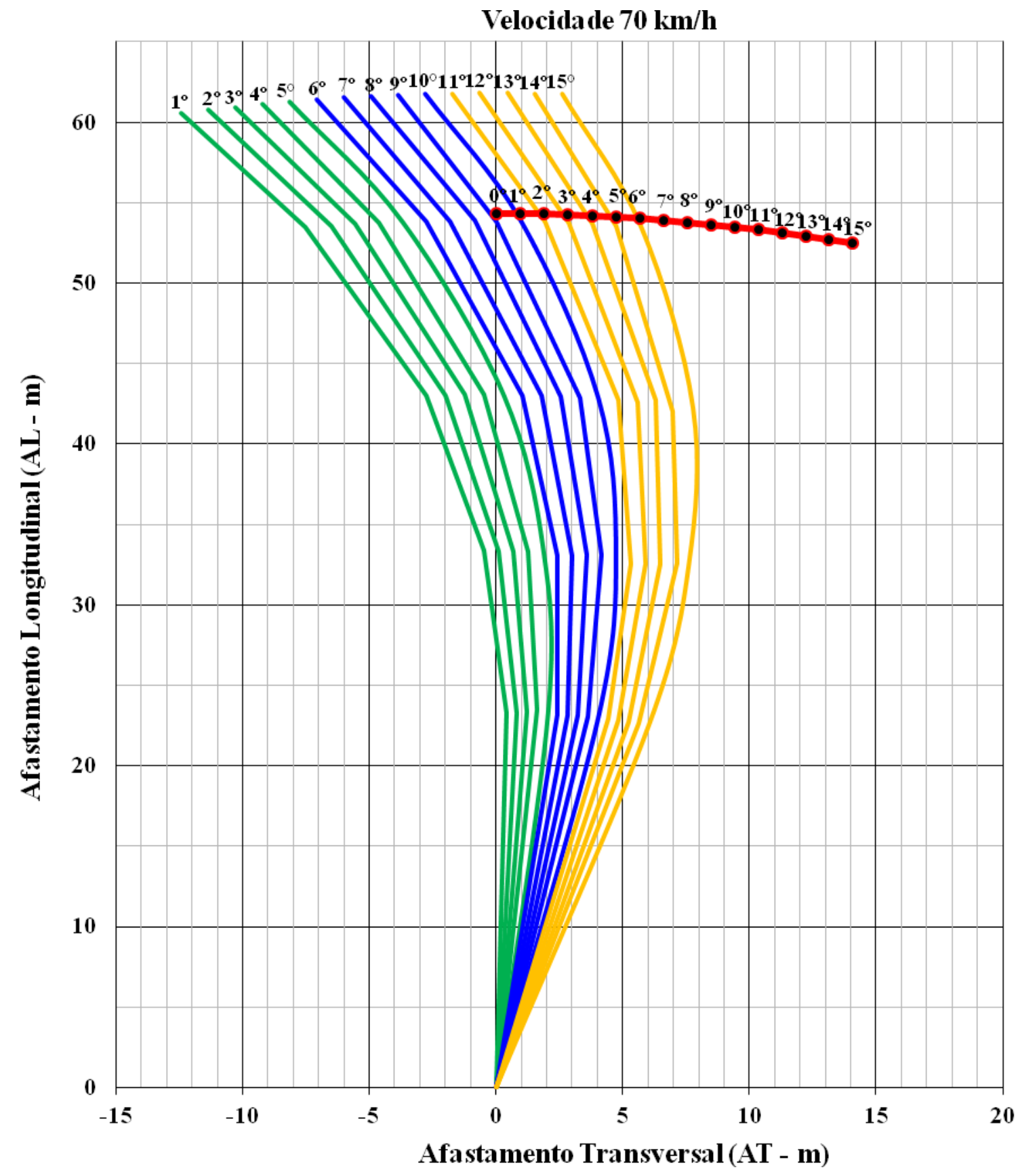


Velocidade $60 \mathrm{~km} / \mathrm{h}$

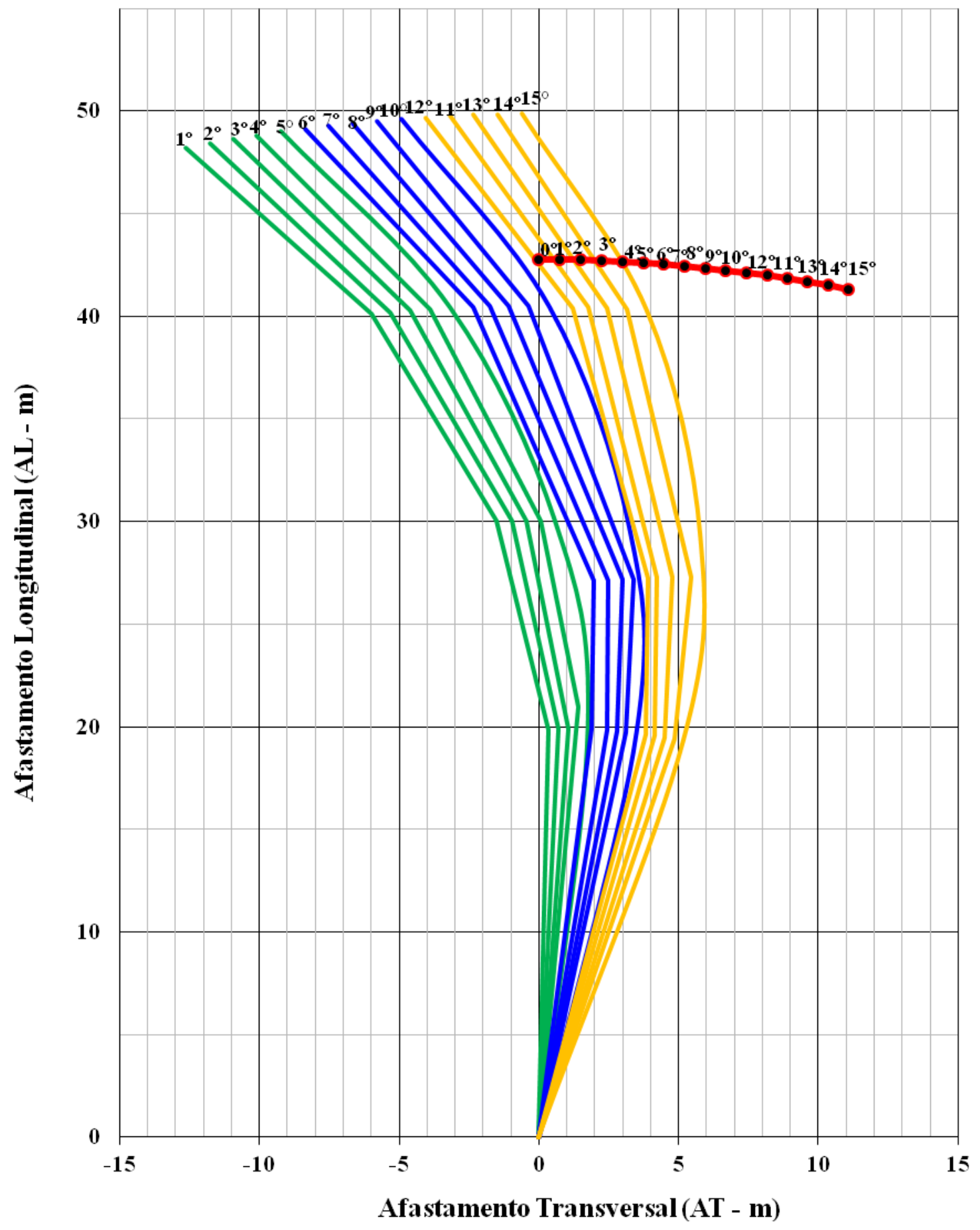




\section{SITUAÇÃO TANGENTE - DESVIO DIREITA}

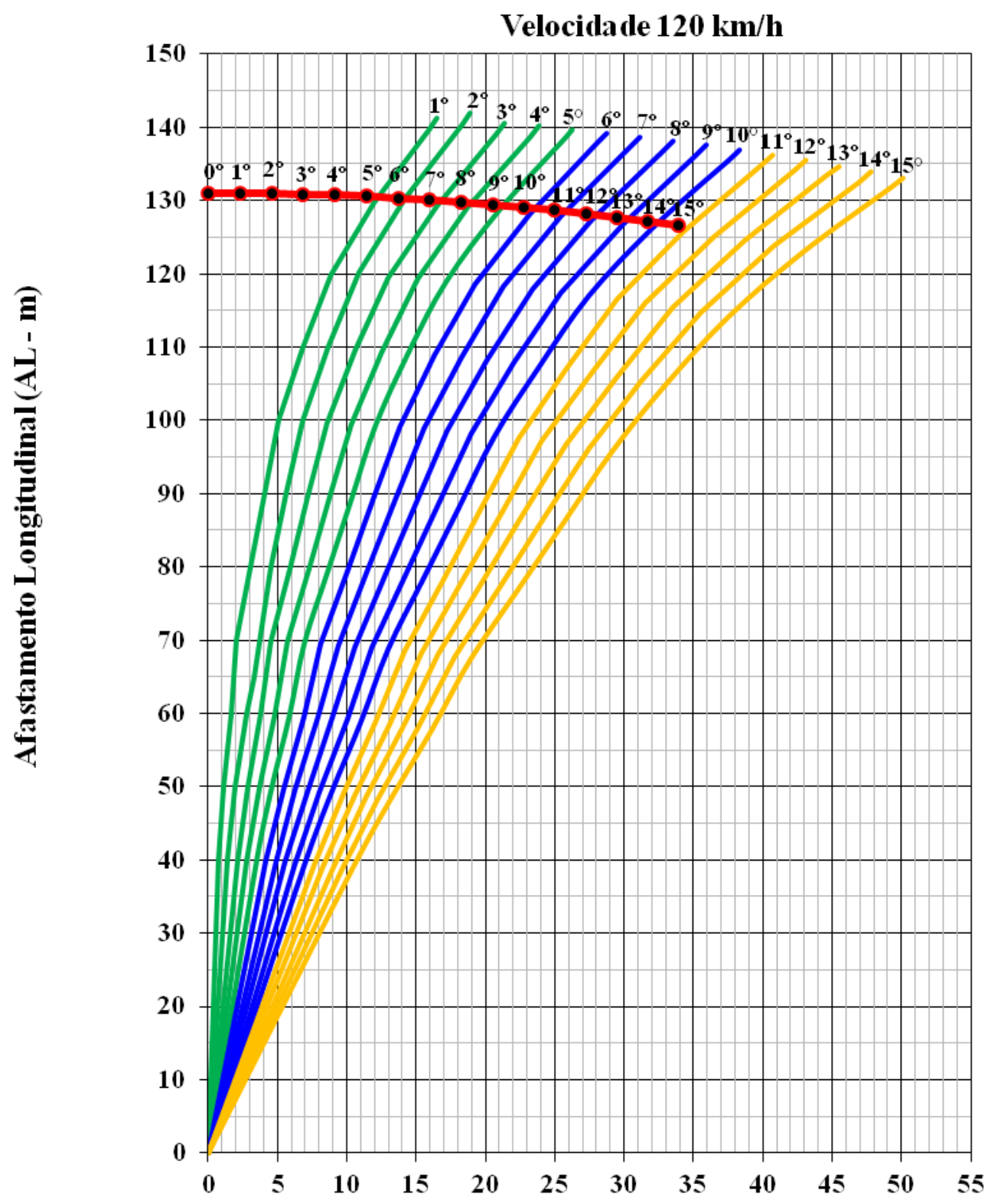

Afastamento Transversal (AT - m) 
Velocidade $110 \mathrm{~km} / \mathrm{h}$

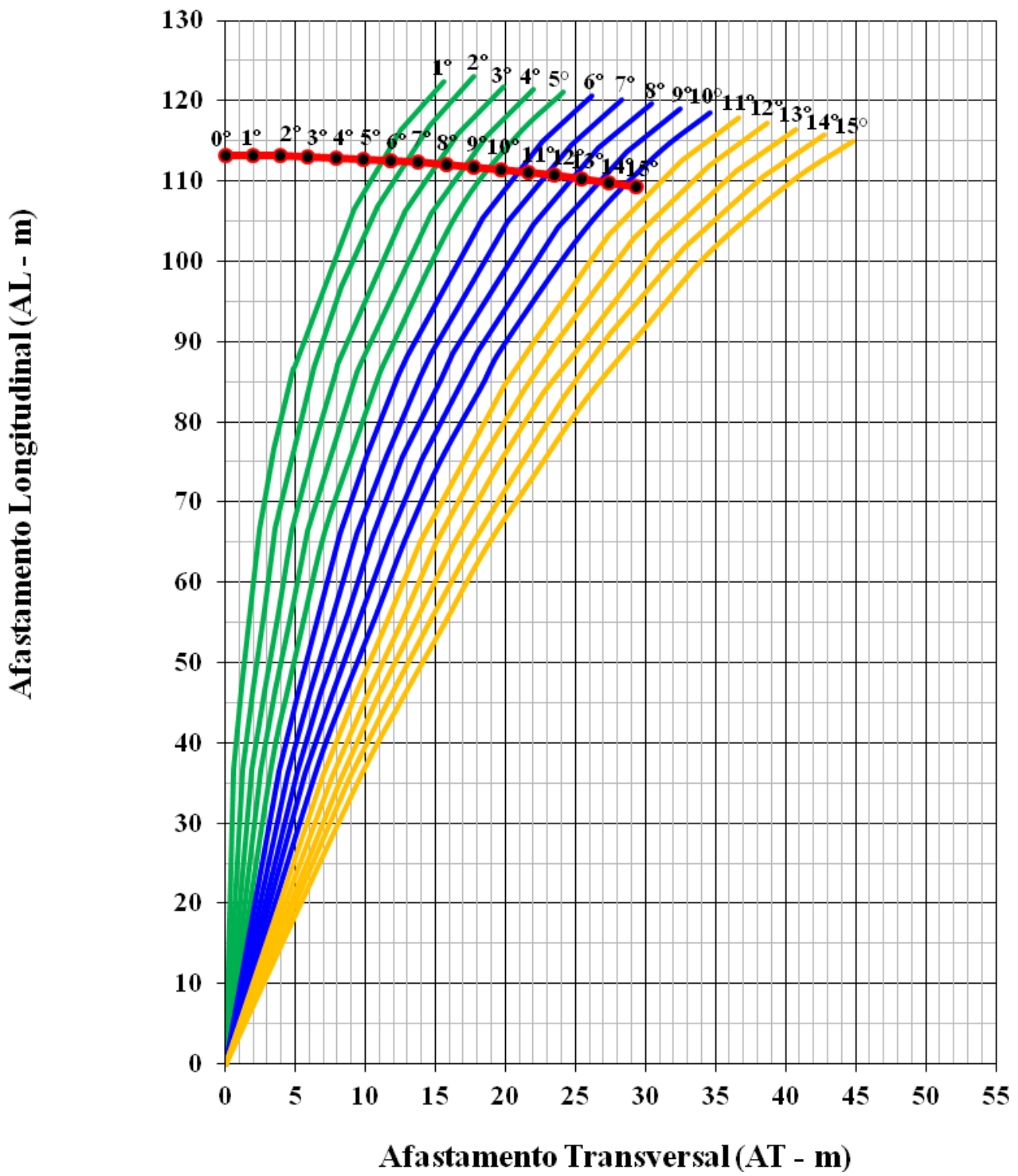




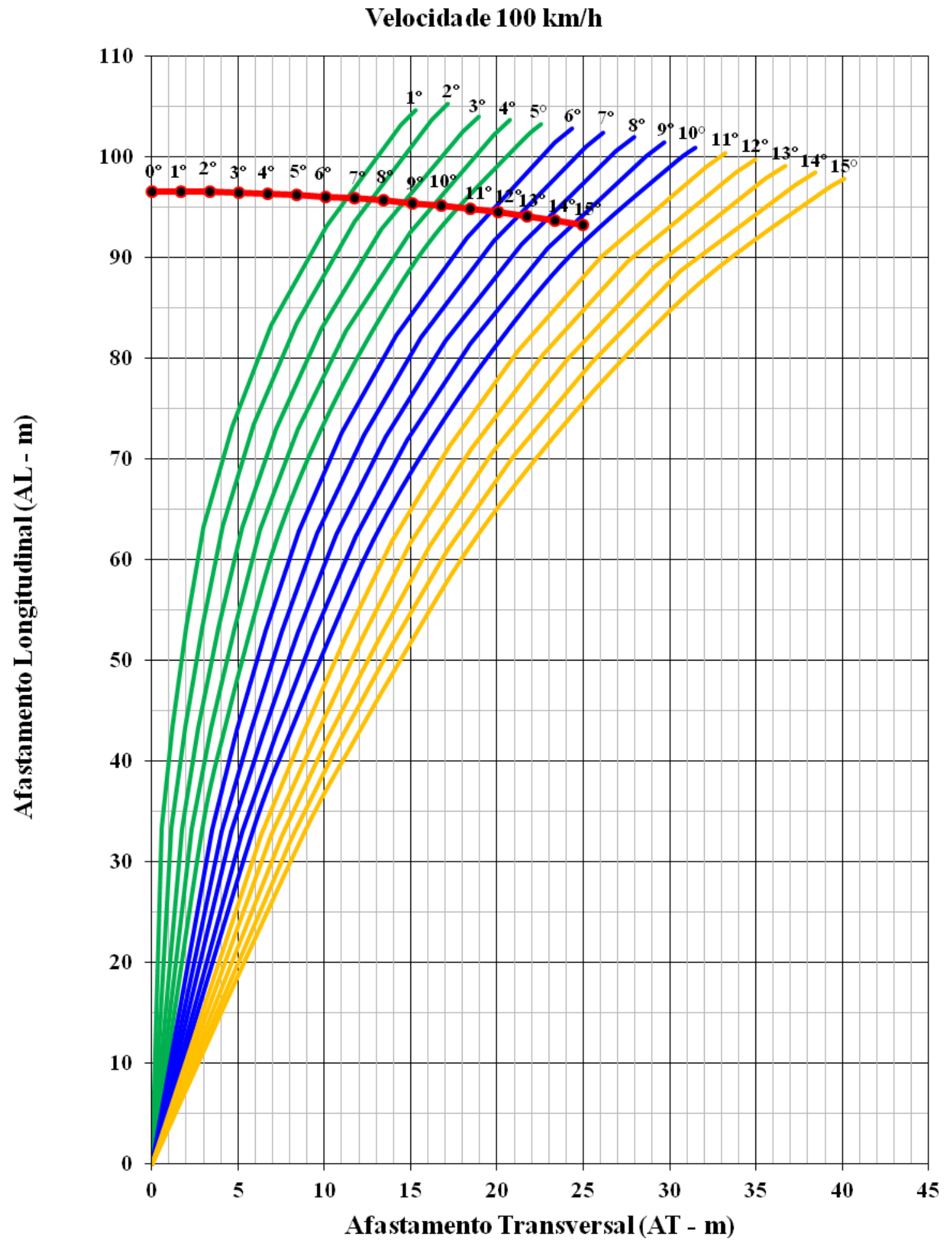


Velocidade $90 \mathrm{~km} / \mathrm{h}$

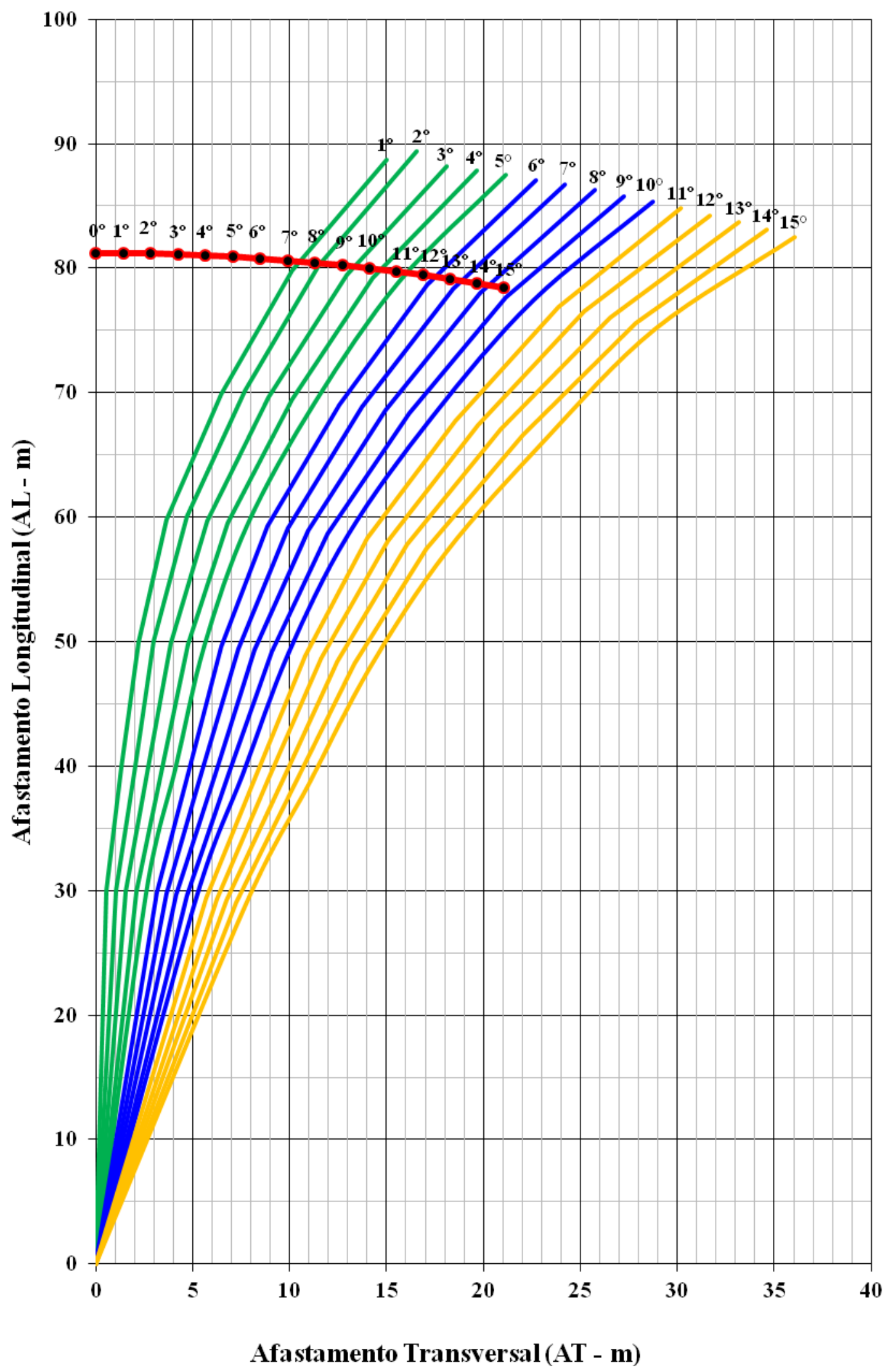




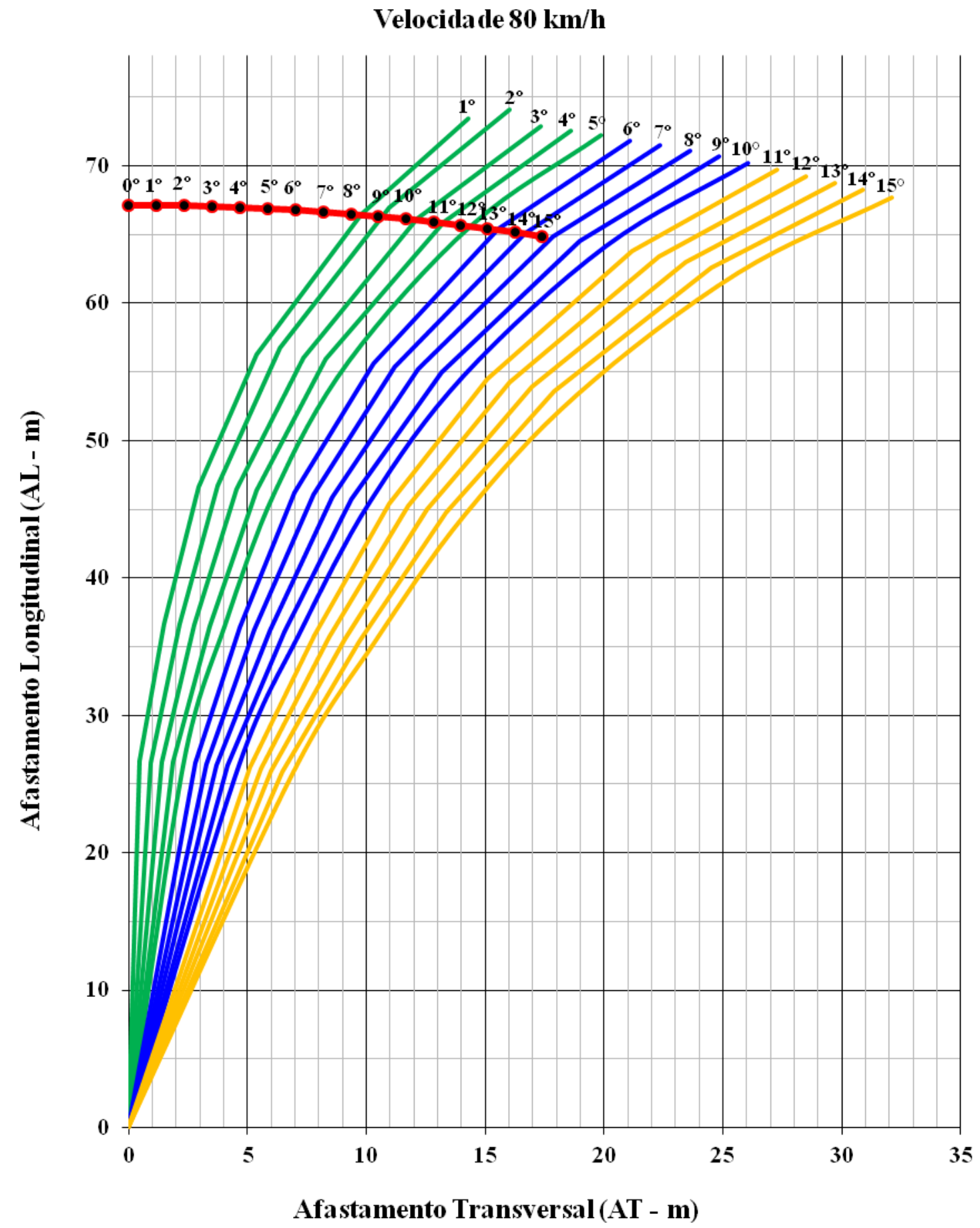




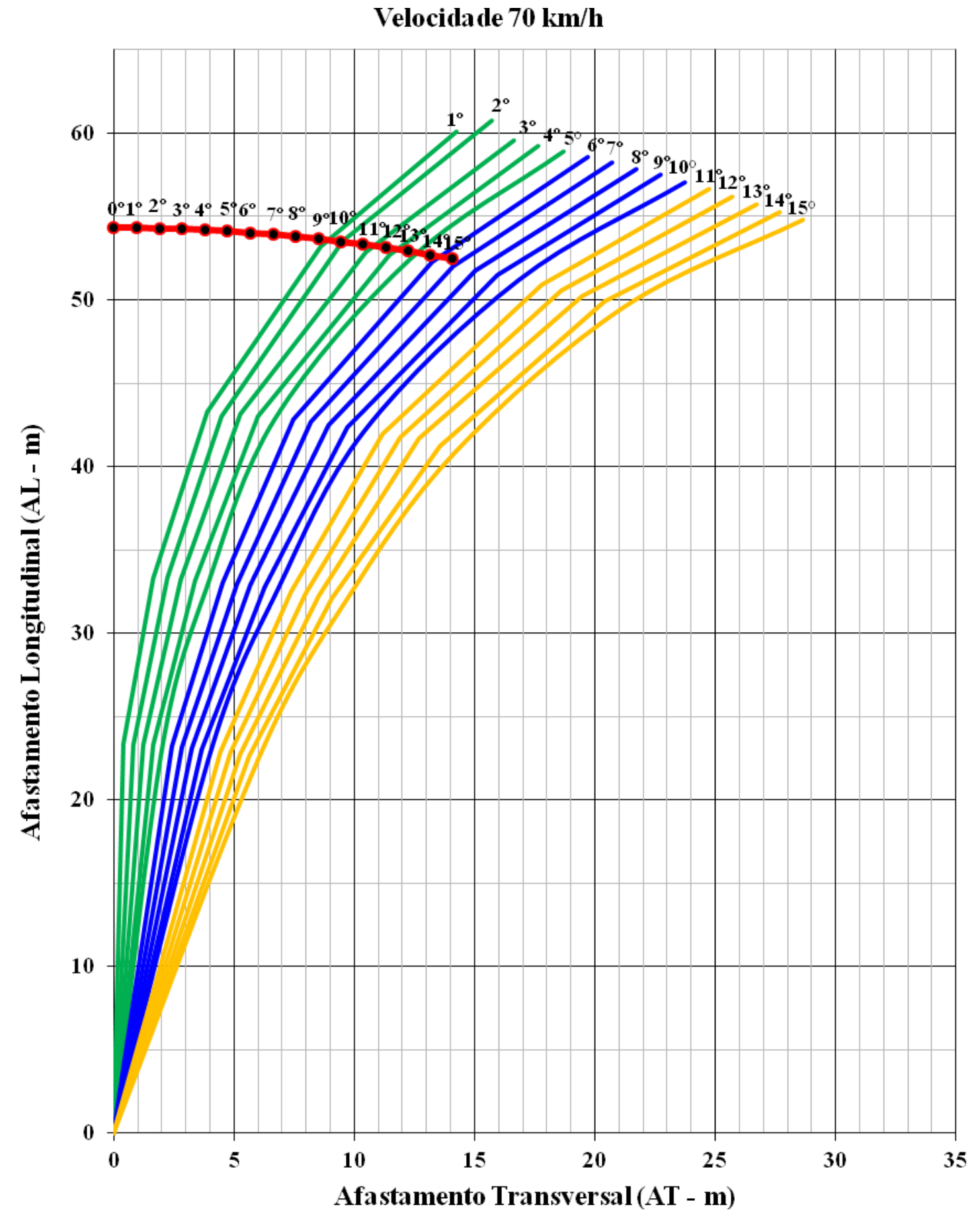


Velocidade $60 \mathrm{~km} / \mathrm{h}$

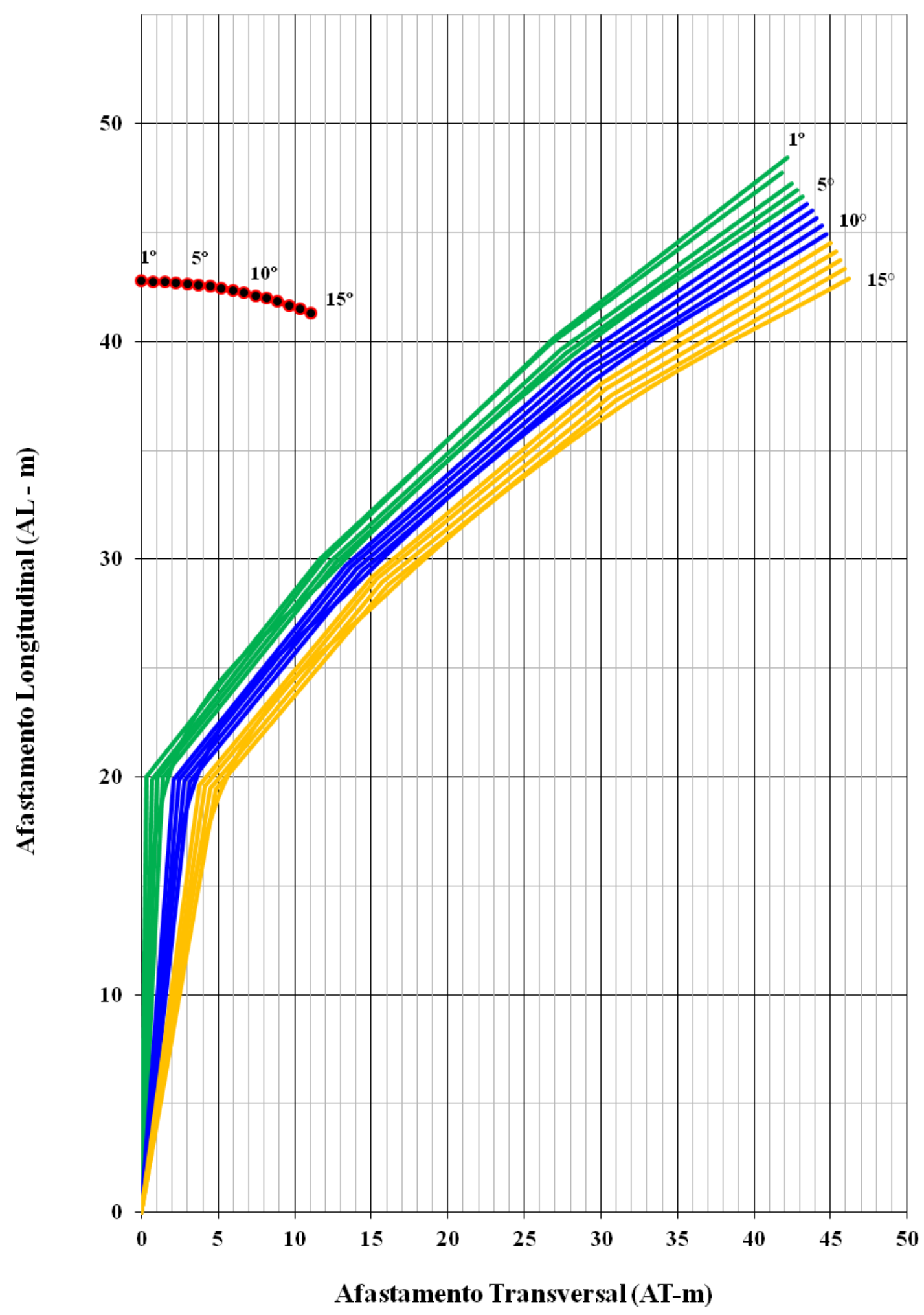


SITUAÇÃO EM CURVA - DESVIO ESQUERDA

Raio 1000m - Velocidade $120 \mathrm{~km} / \mathrm{h}$

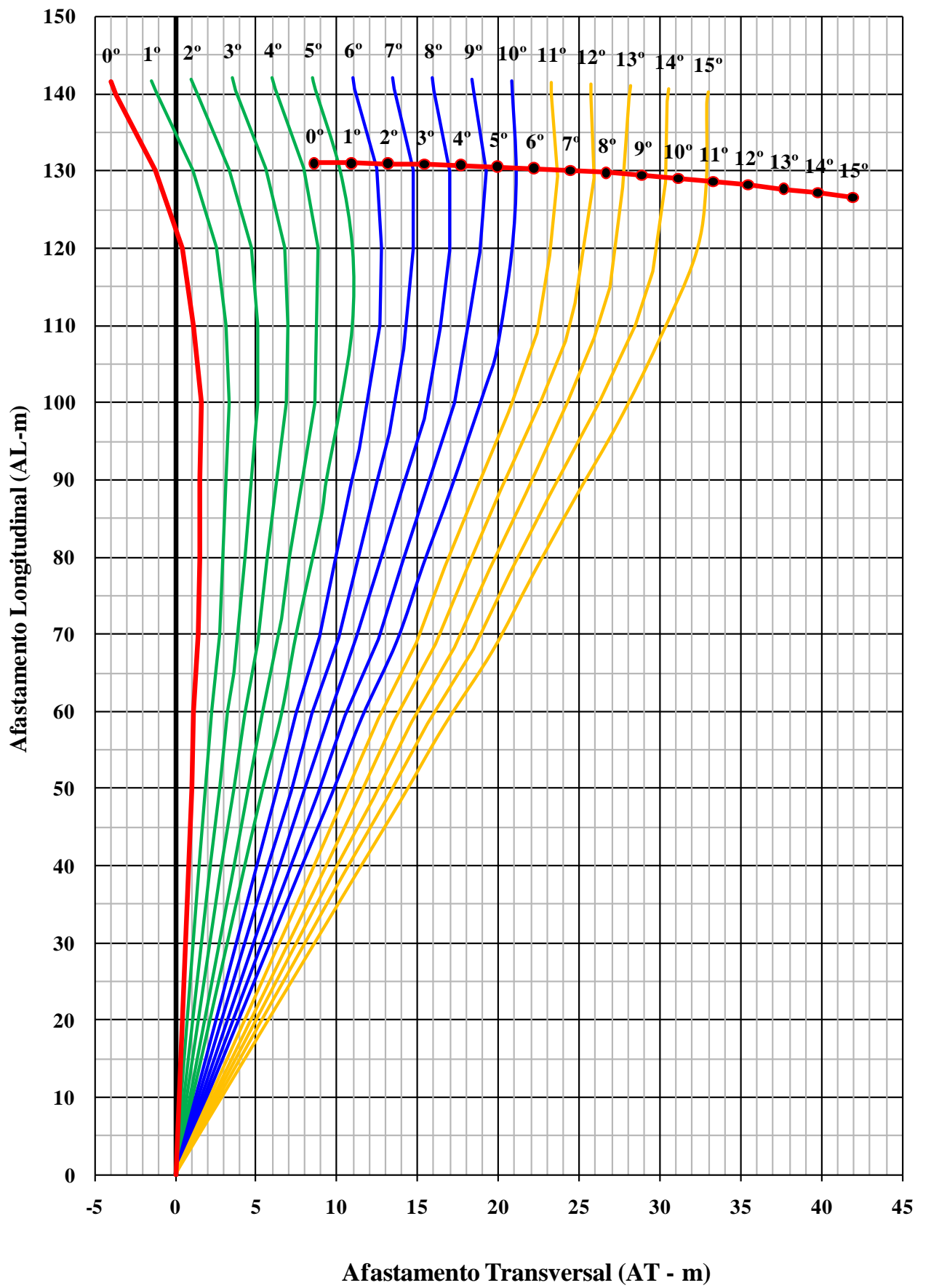


Raio 1000m - Velocidade 110 km/h

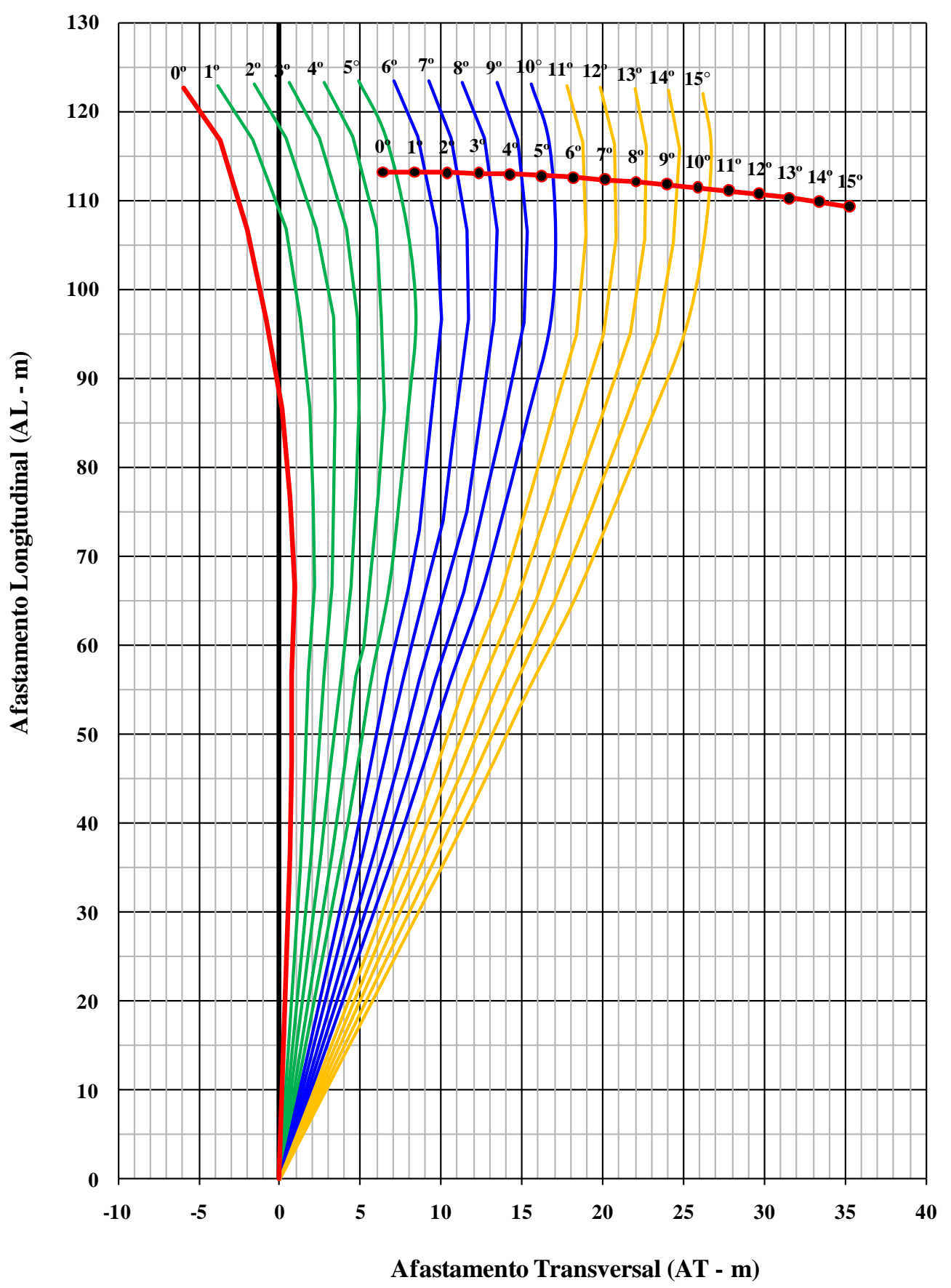


Raio 1000m - Velocidade 100 km/h

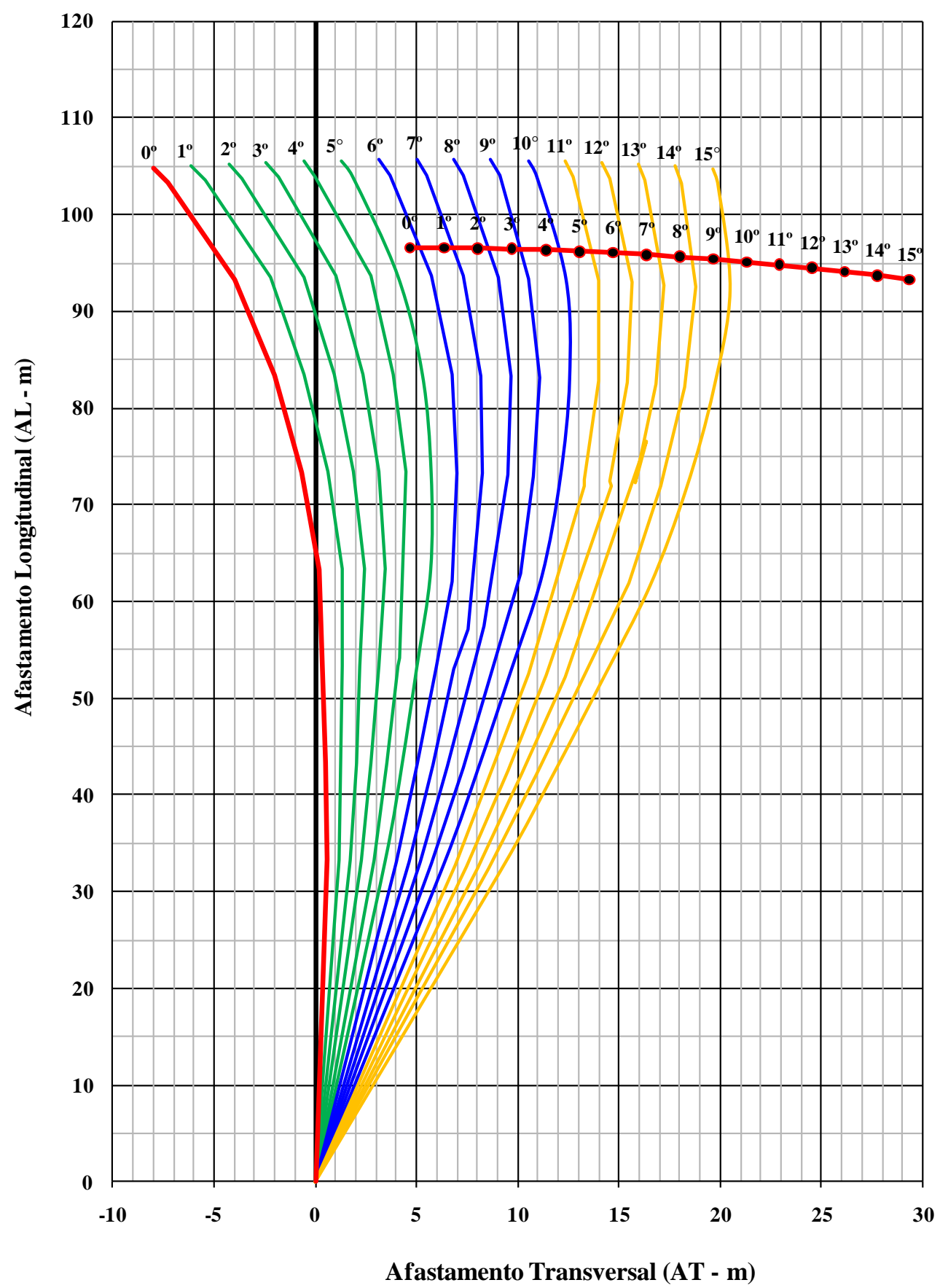


Raio 1000m - Velocidade 90 km/h

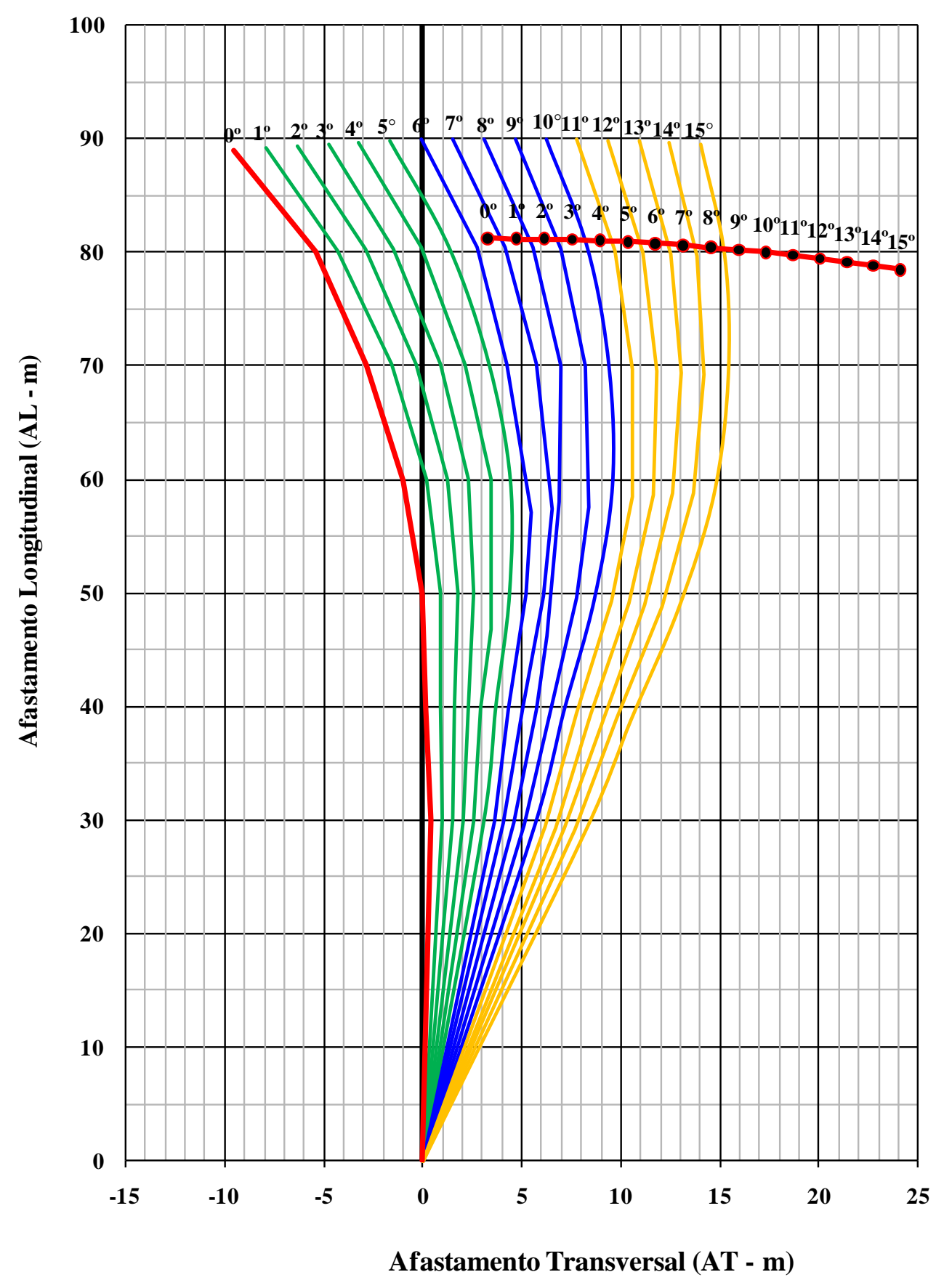




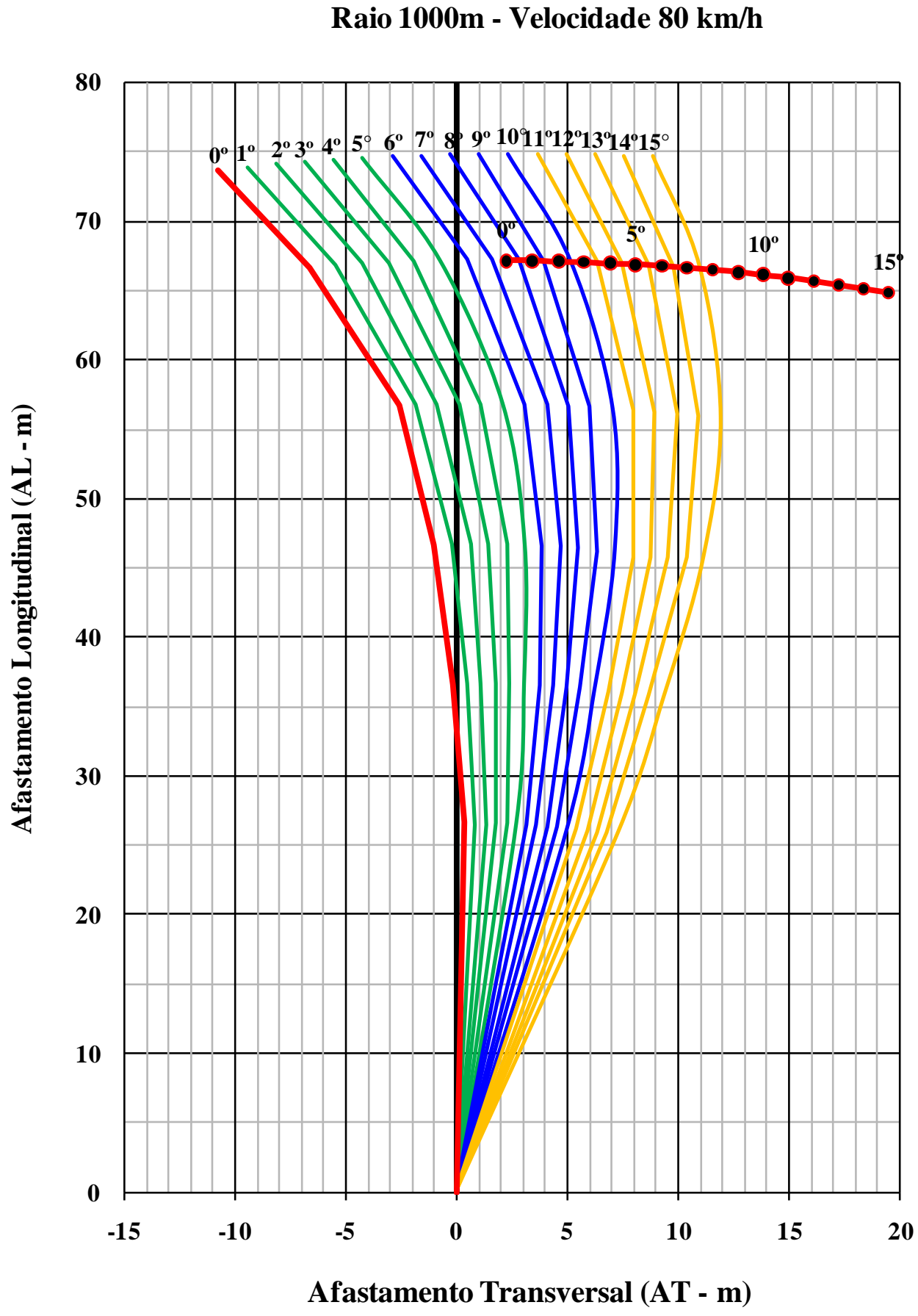




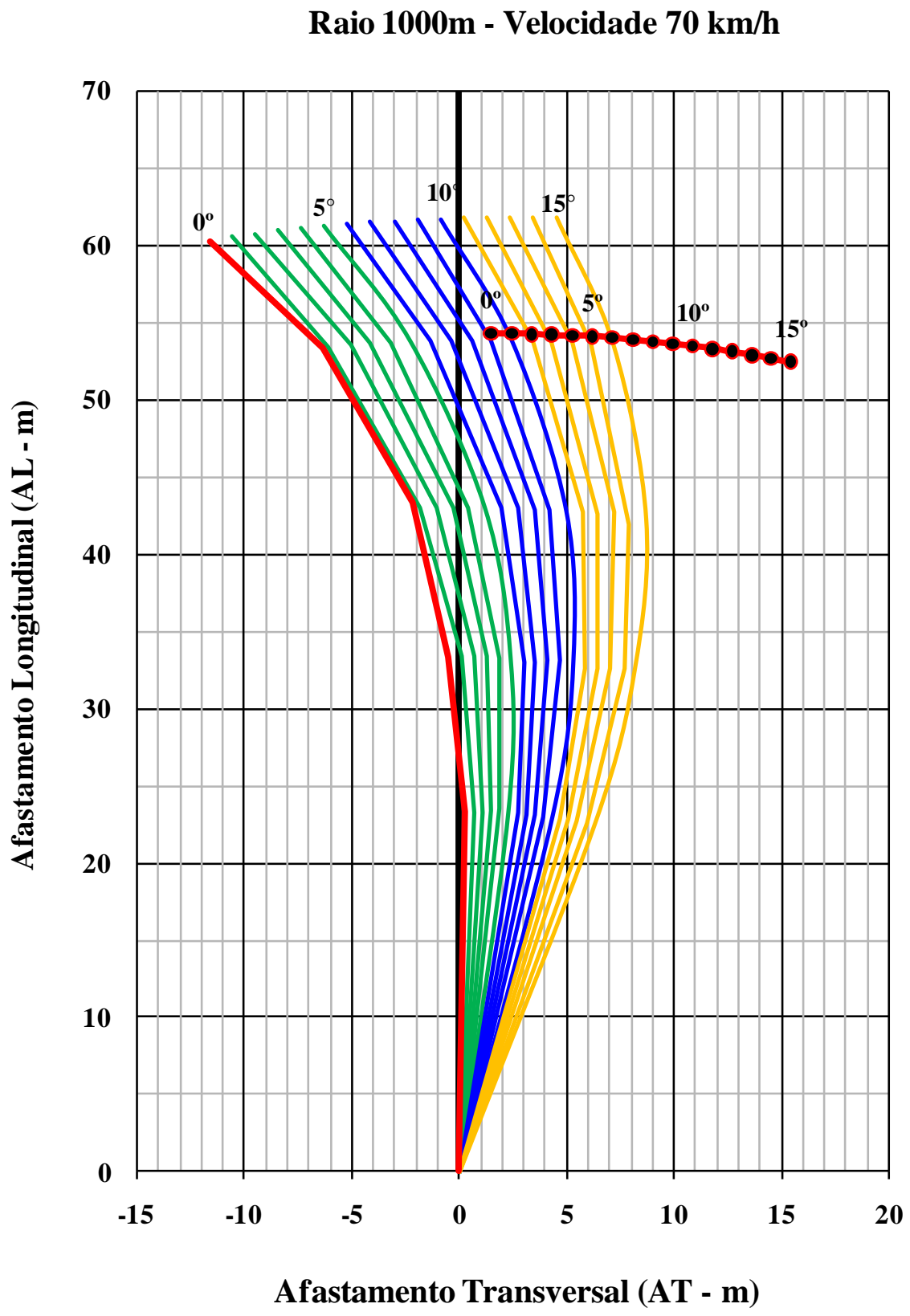




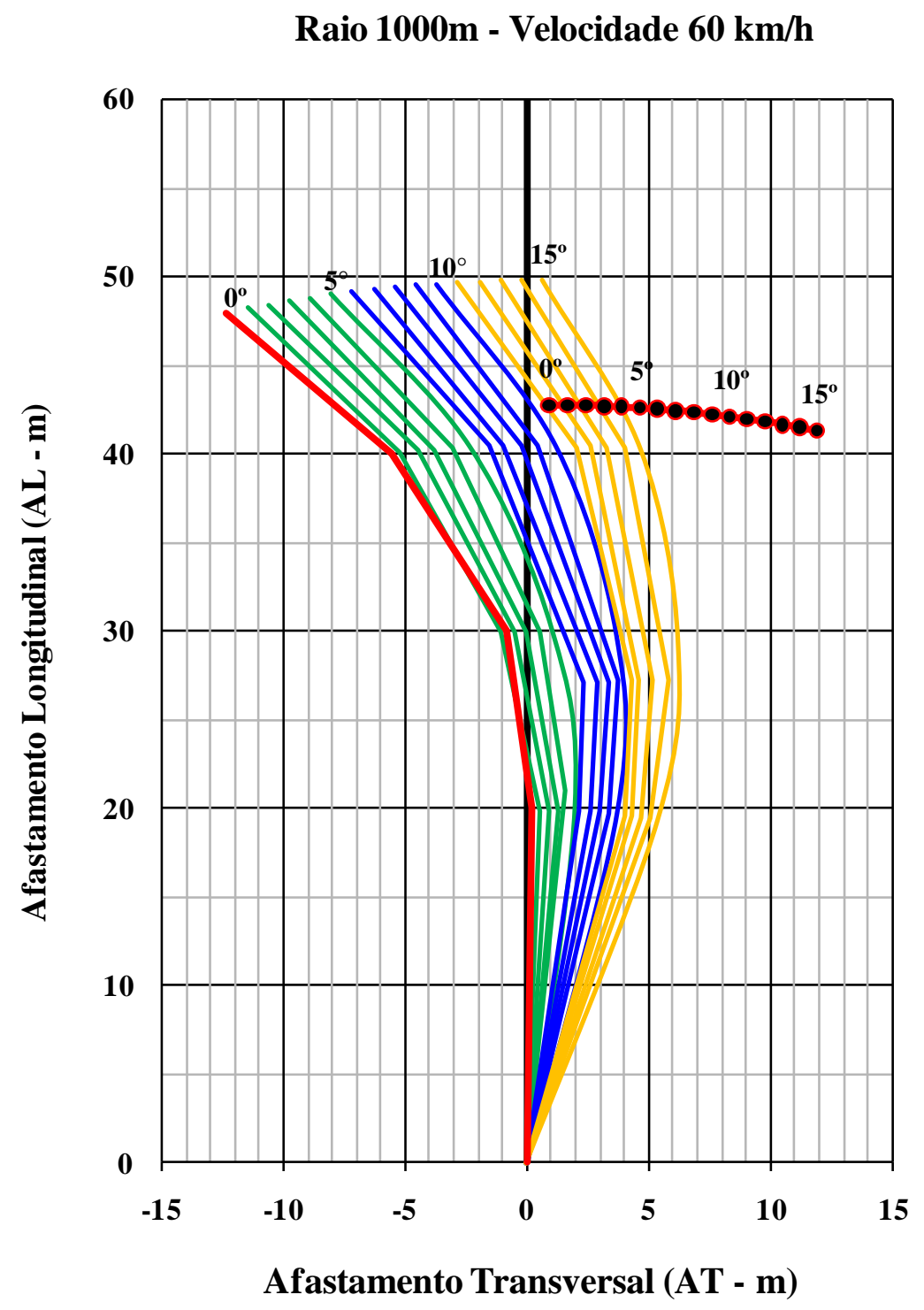


Raio 900m - Velocidade $120 \mathrm{~km} / \mathrm{h}$

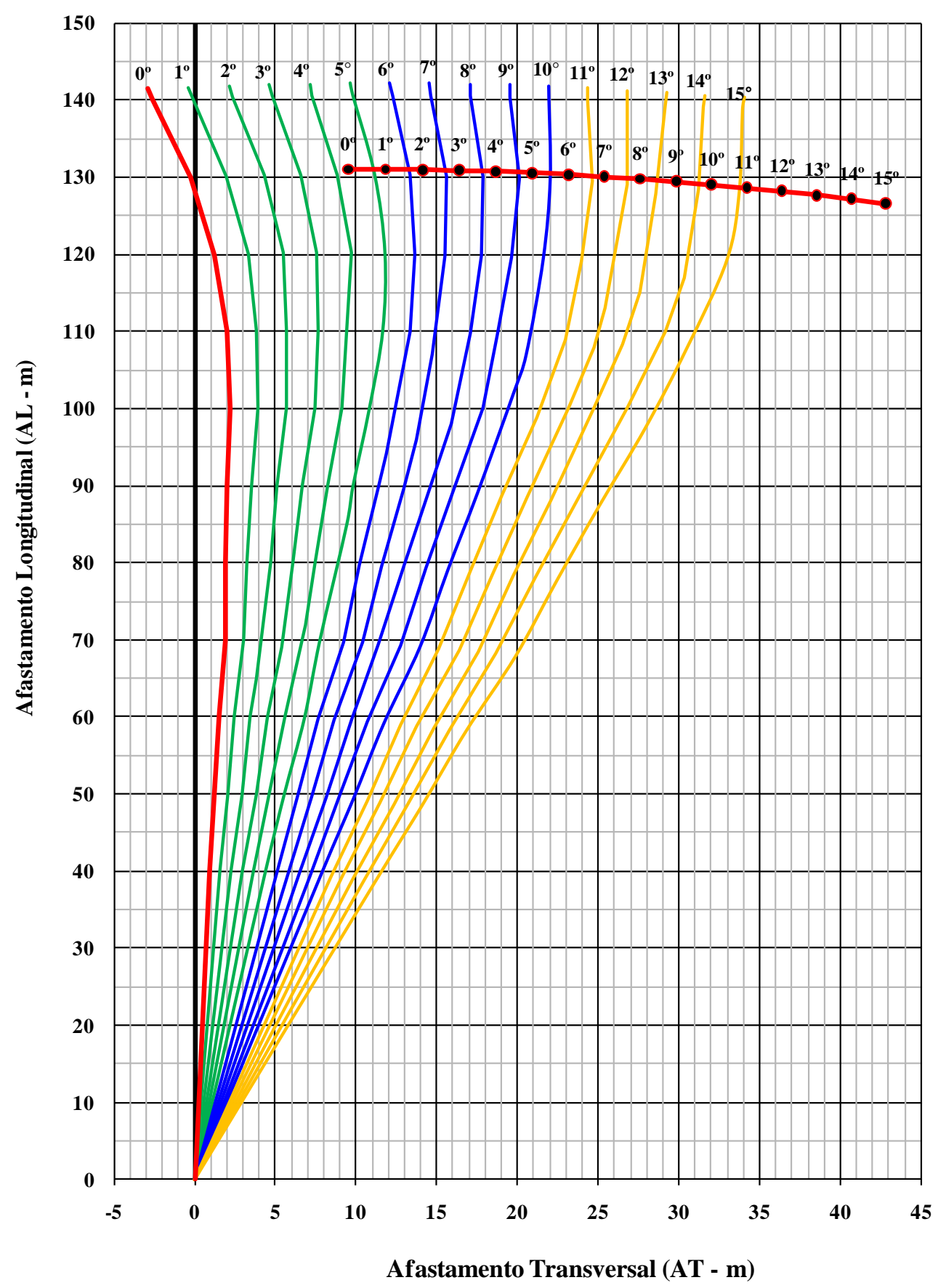


Raio 900m - Velocidade $110 \mathrm{~km} / \mathrm{h}$

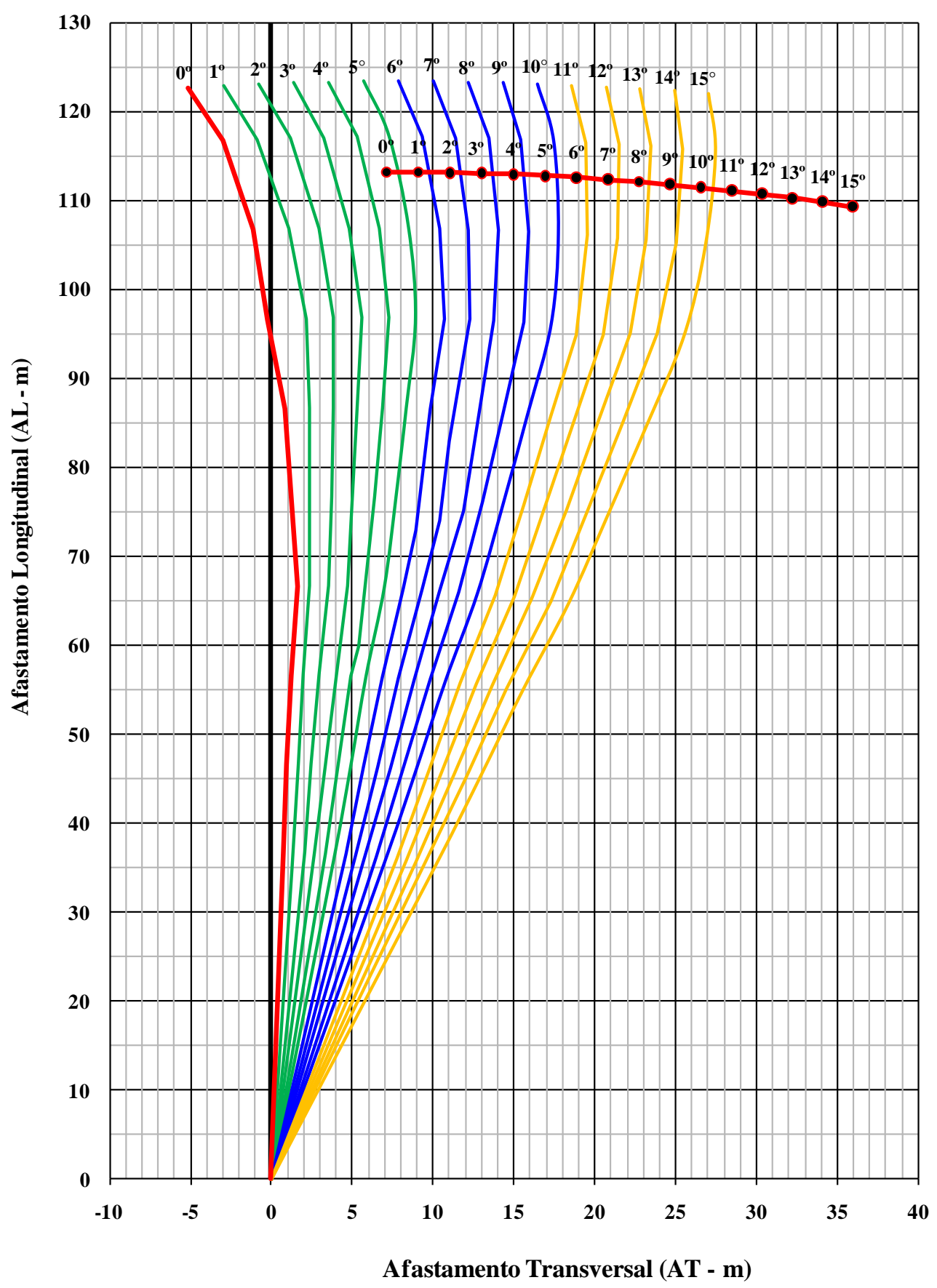


Raio 900m - Velocidade 100 km/h

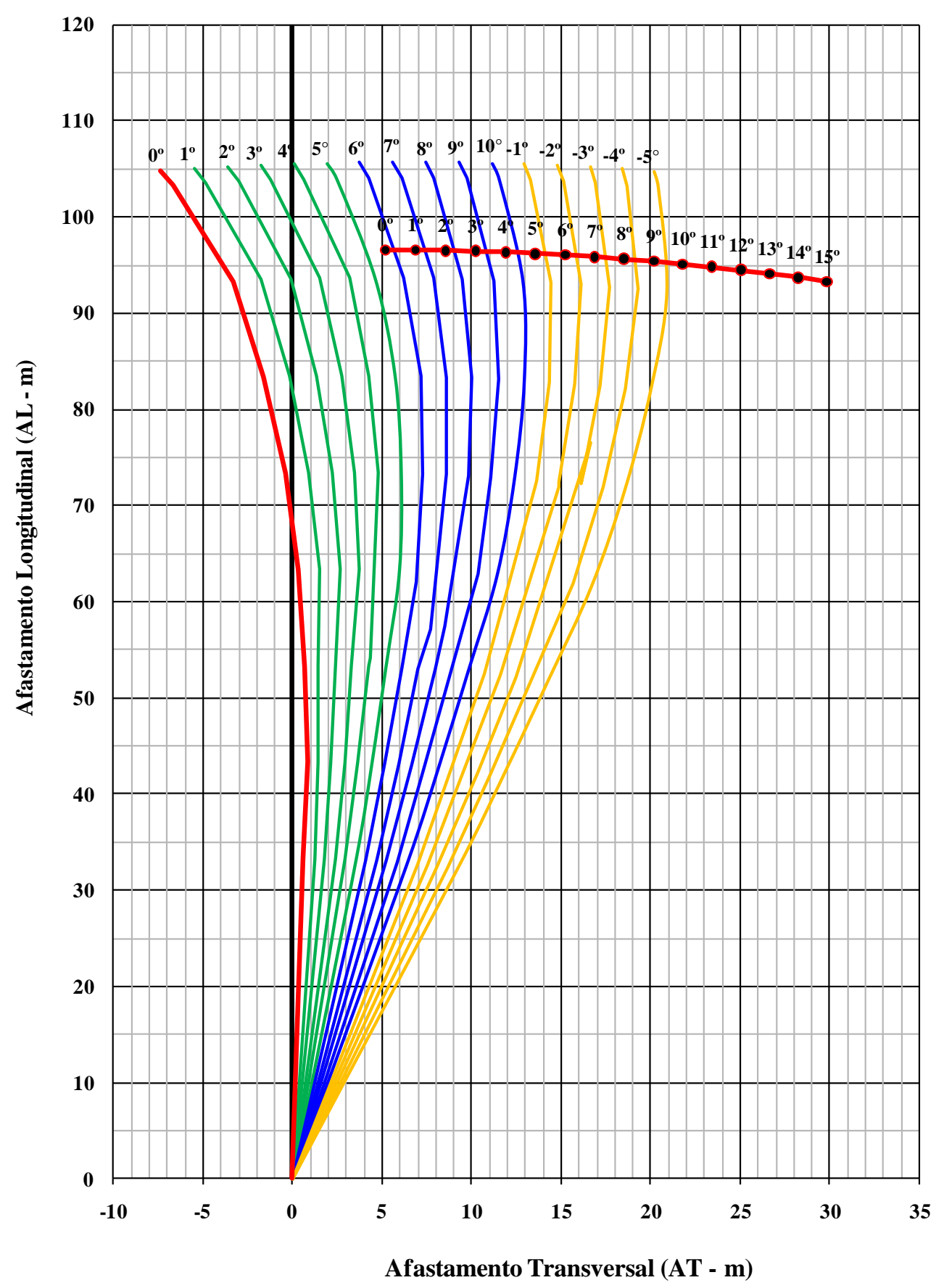


Raio 900m - Velocidade 90 km/h

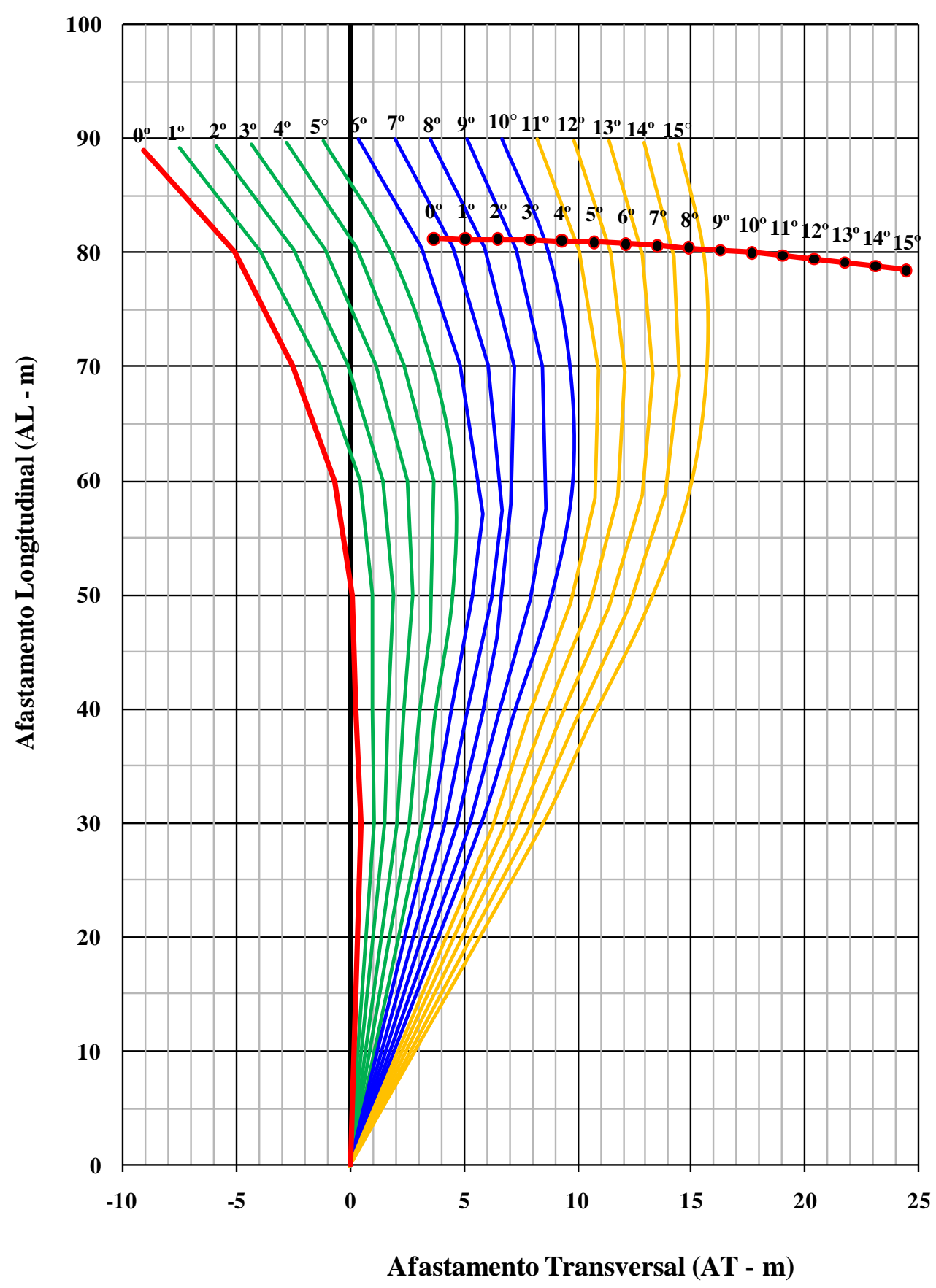


Raio 900m - Velocidade $80 \mathrm{~km} / \mathrm{h}$

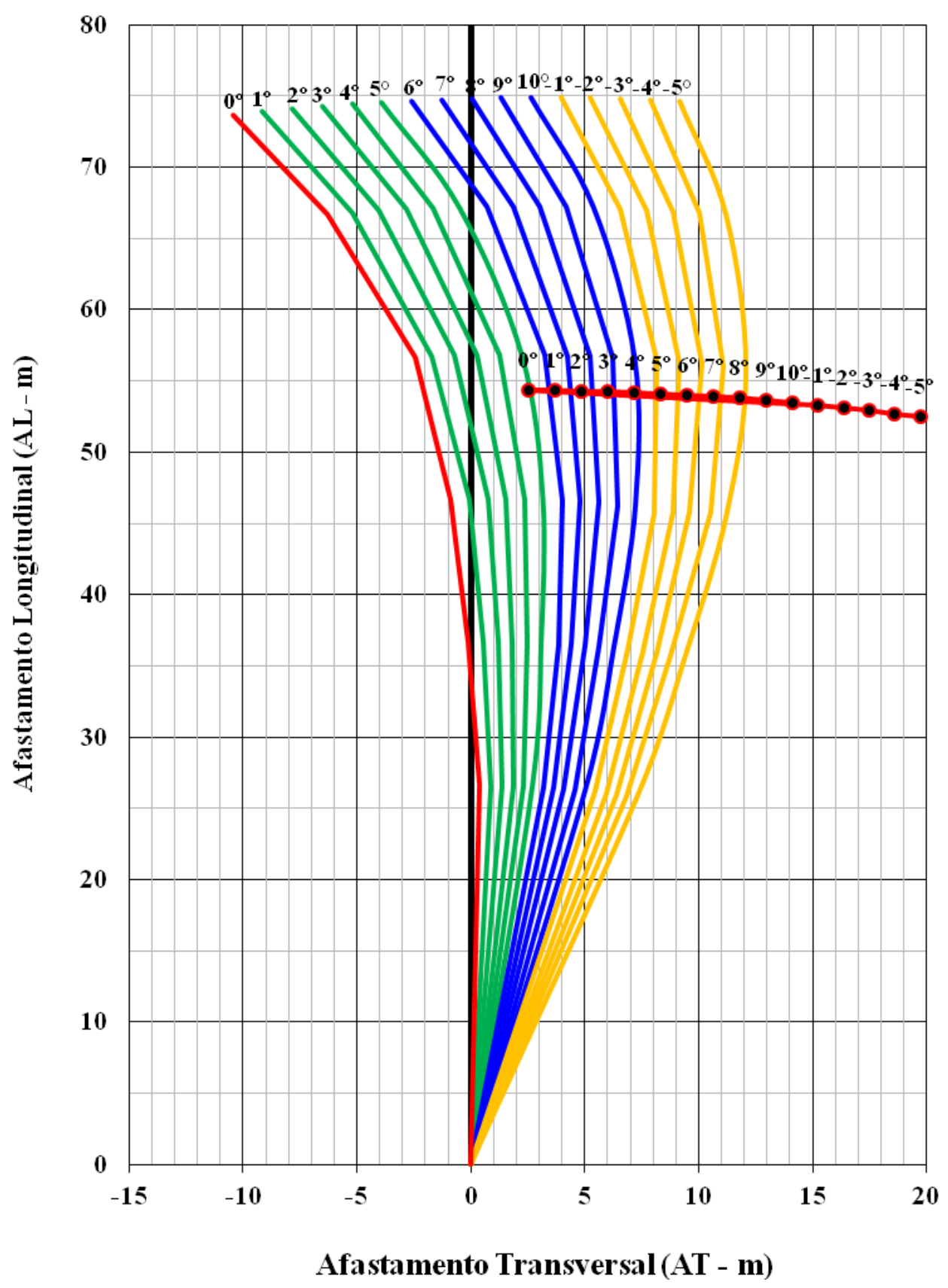




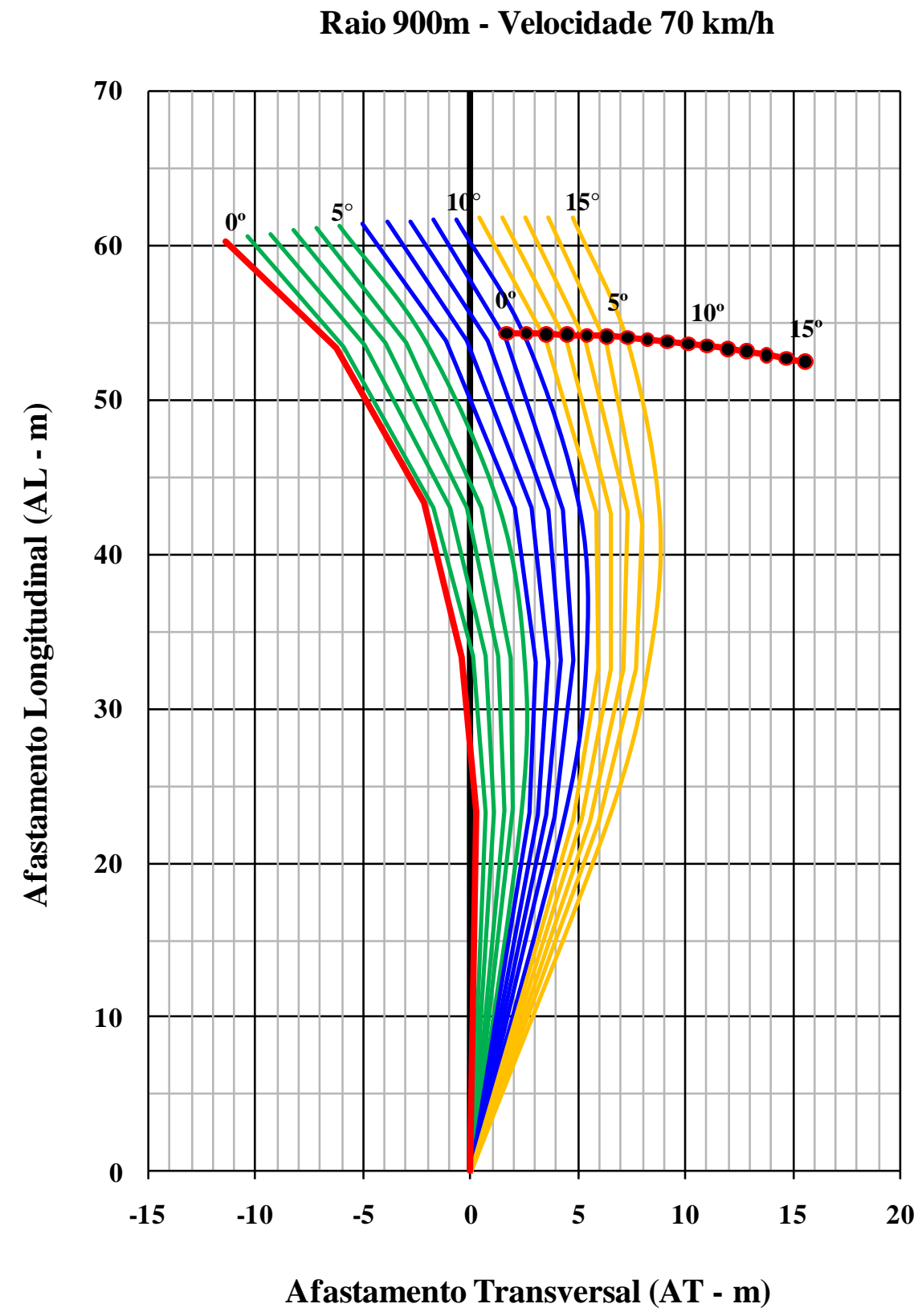




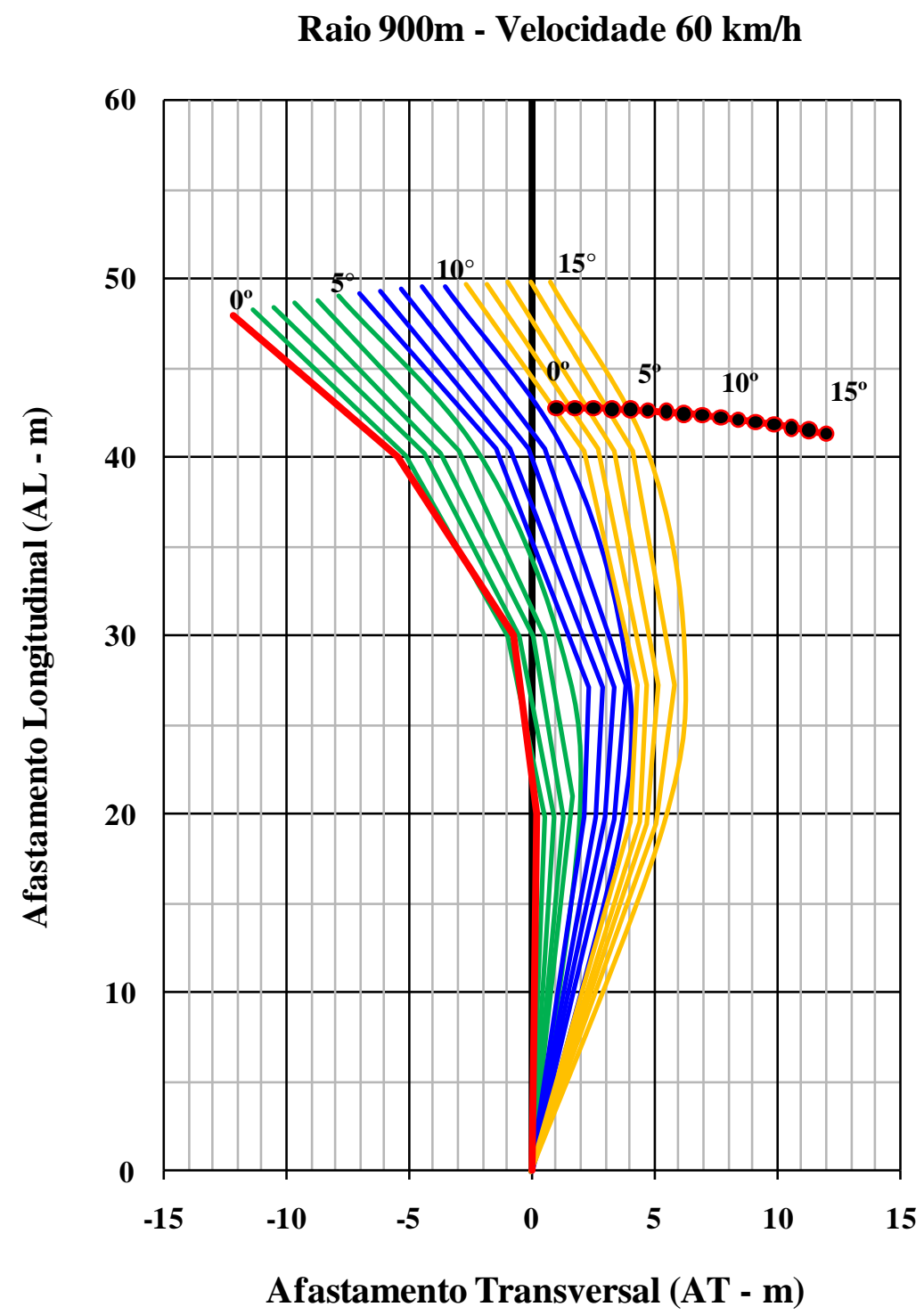


Raio 800m - Velocidade $120 \mathrm{~km} / \mathrm{h}$

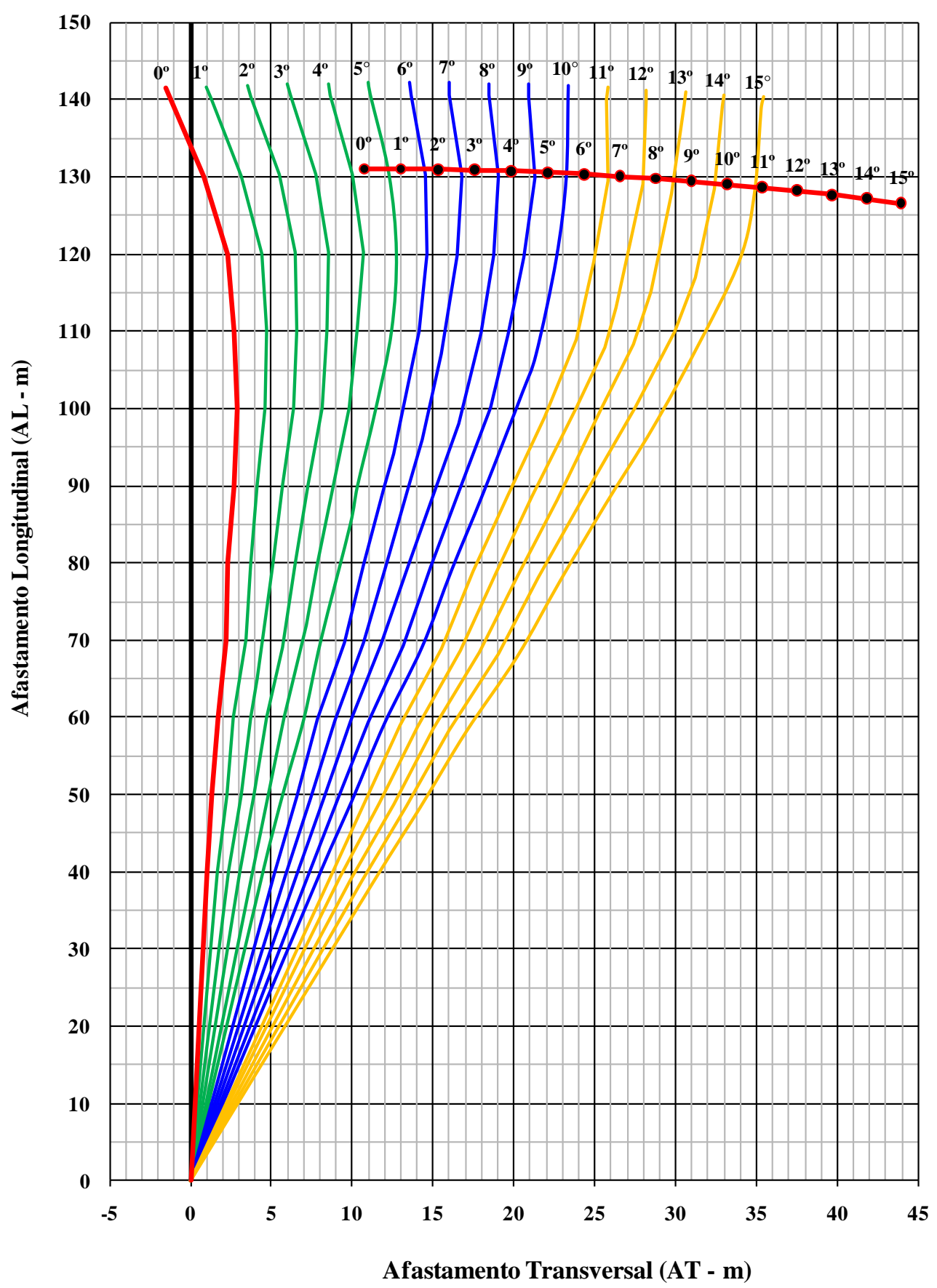


Raio 800m - Velocidade 110 km/h

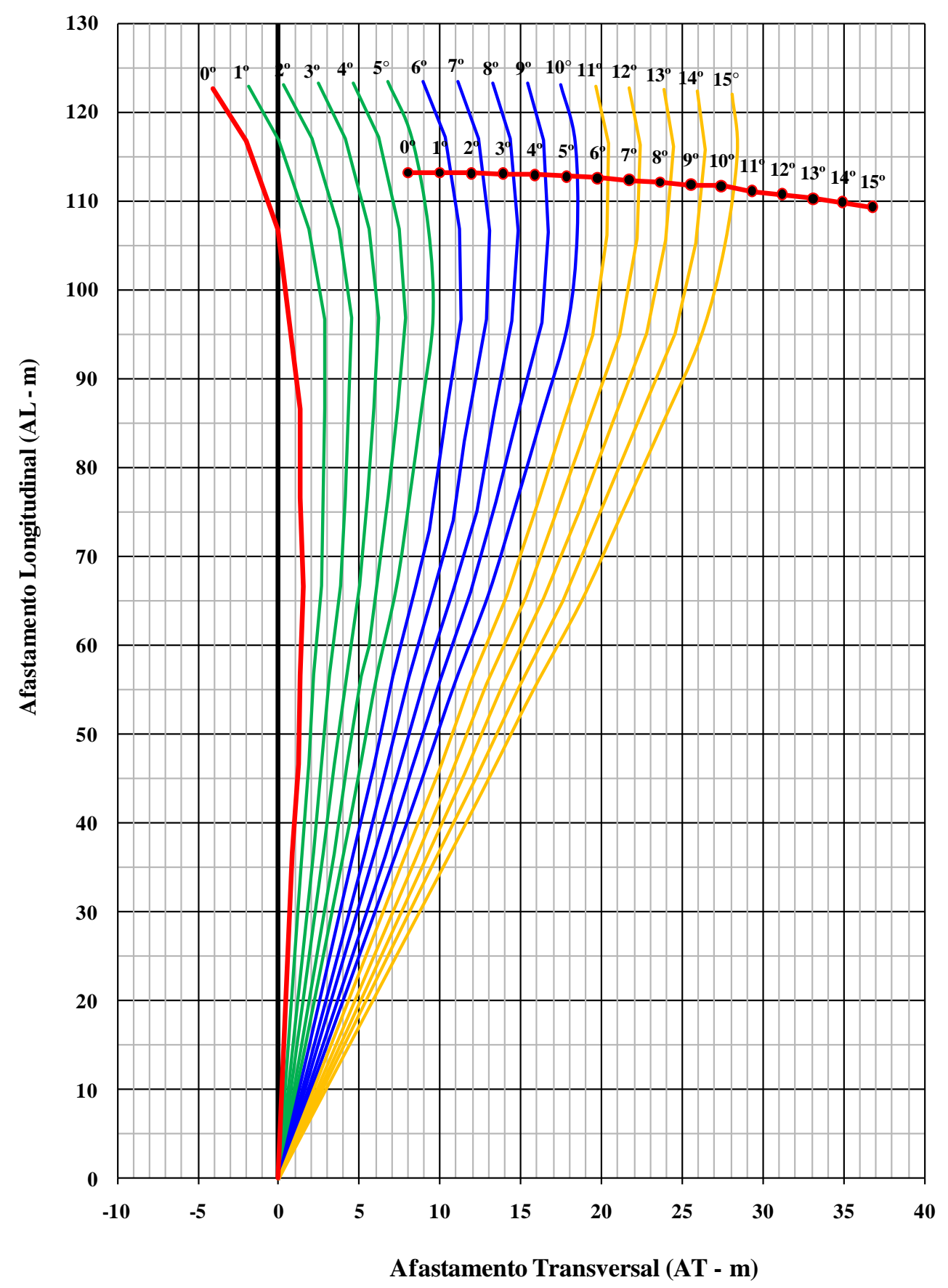


Raio 800m - Velocidade 100 km/h

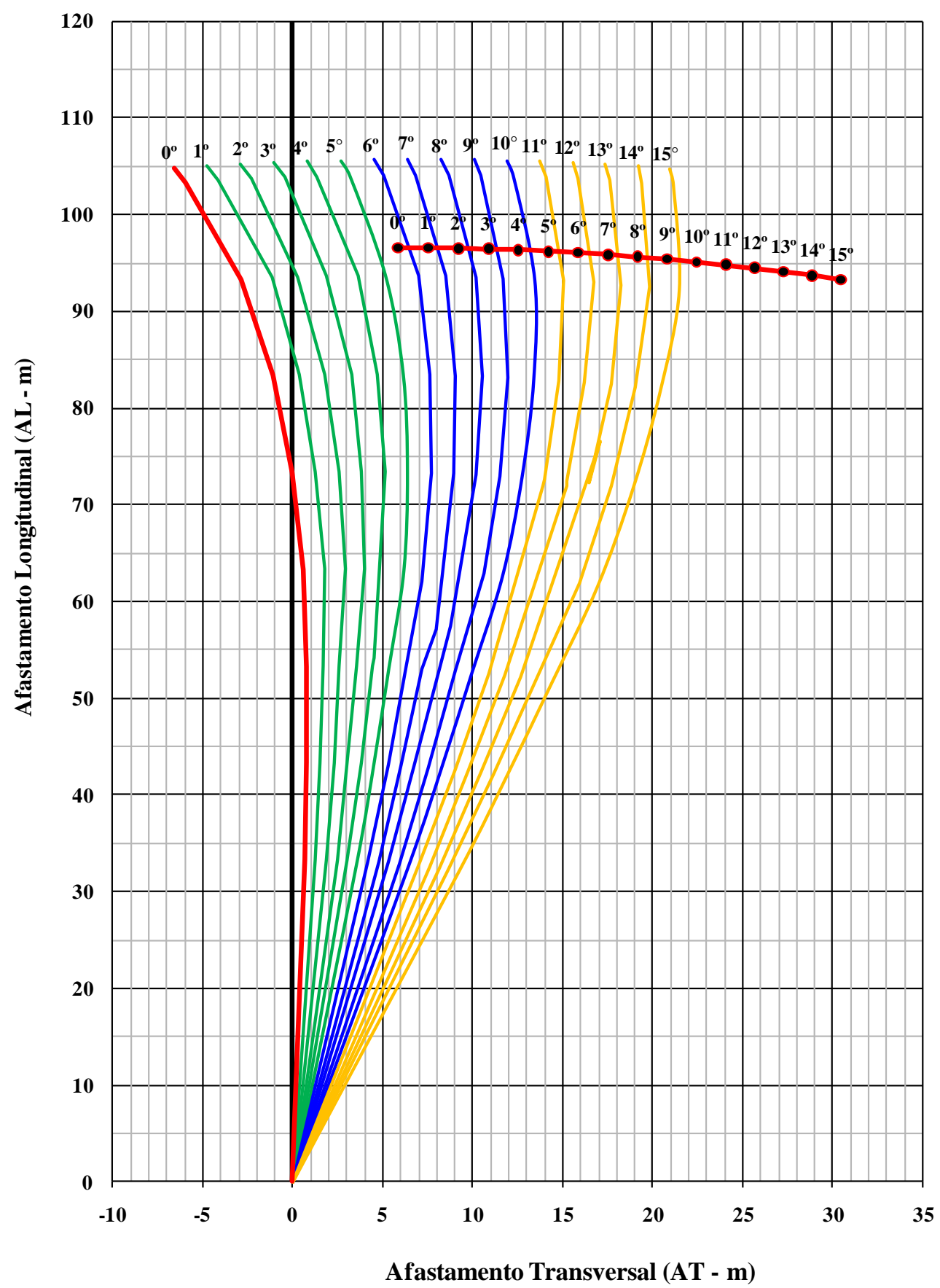




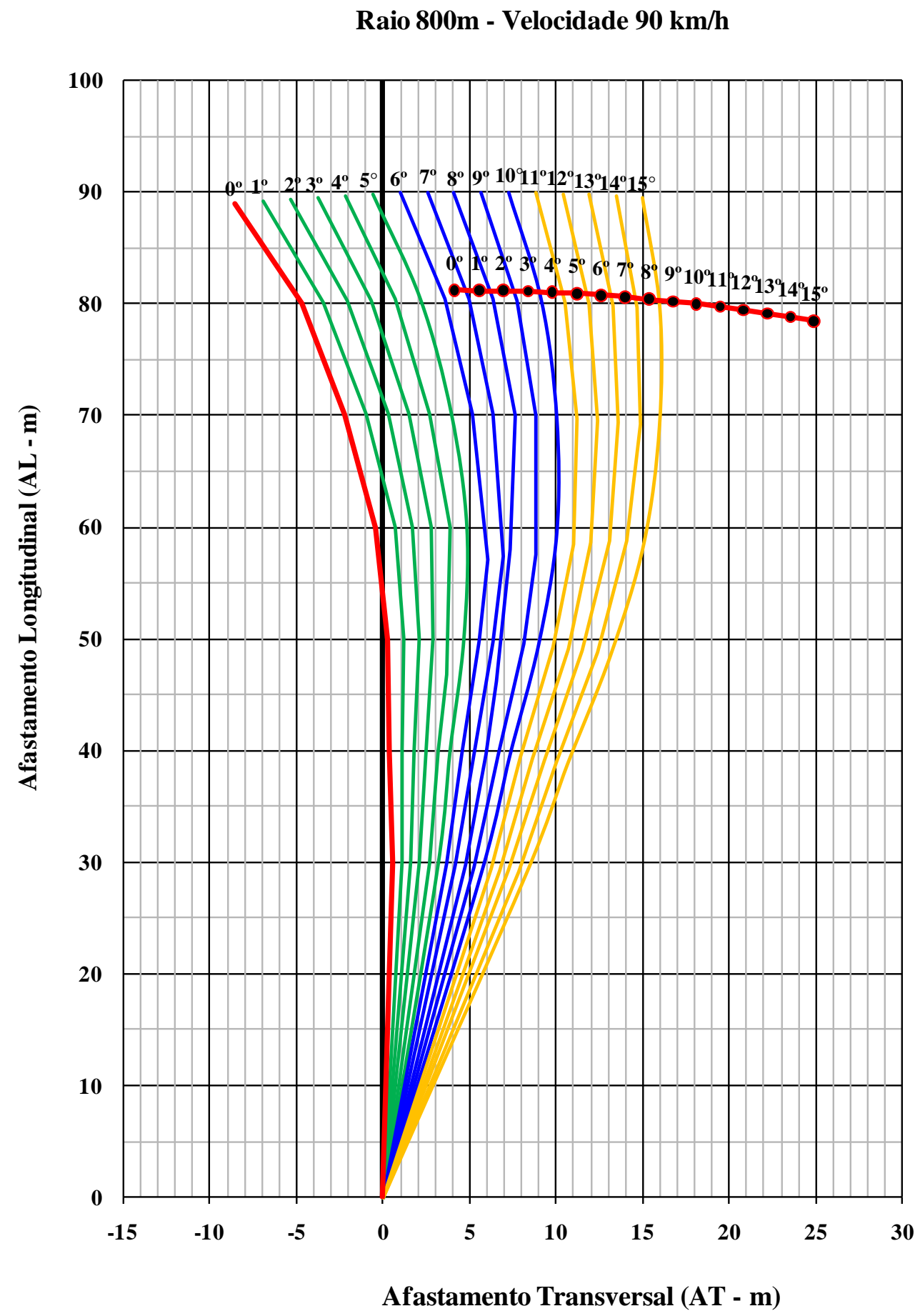




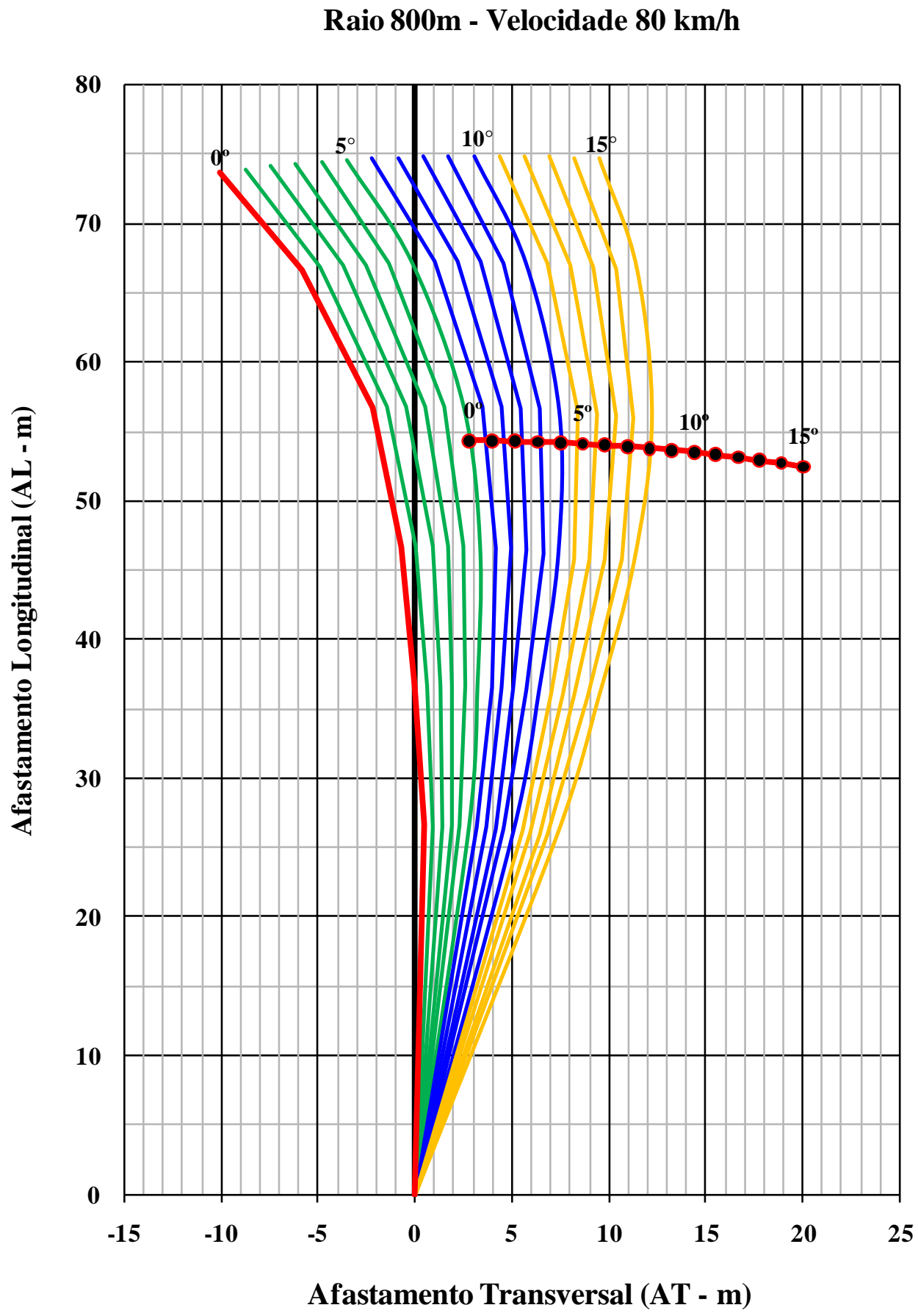




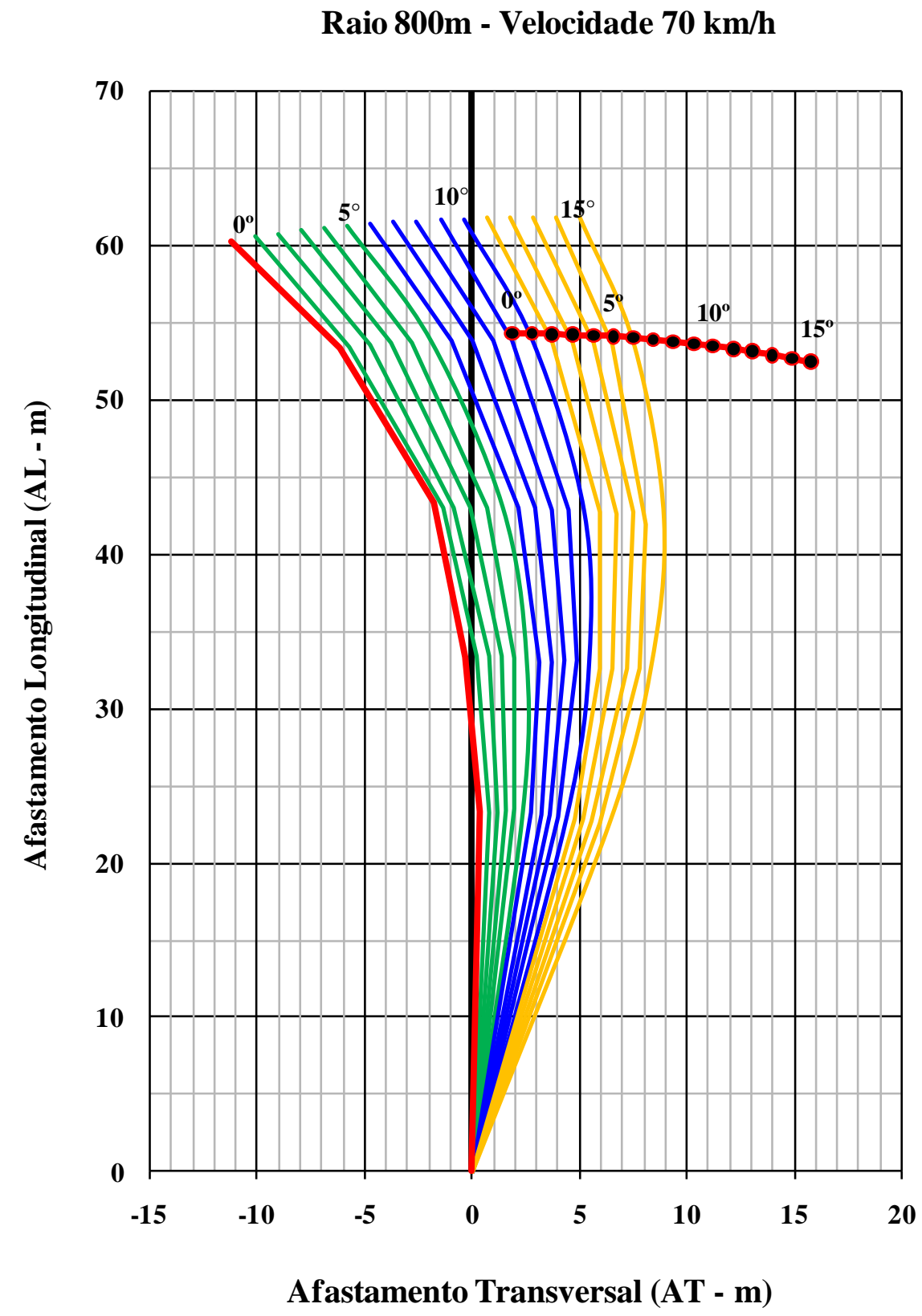




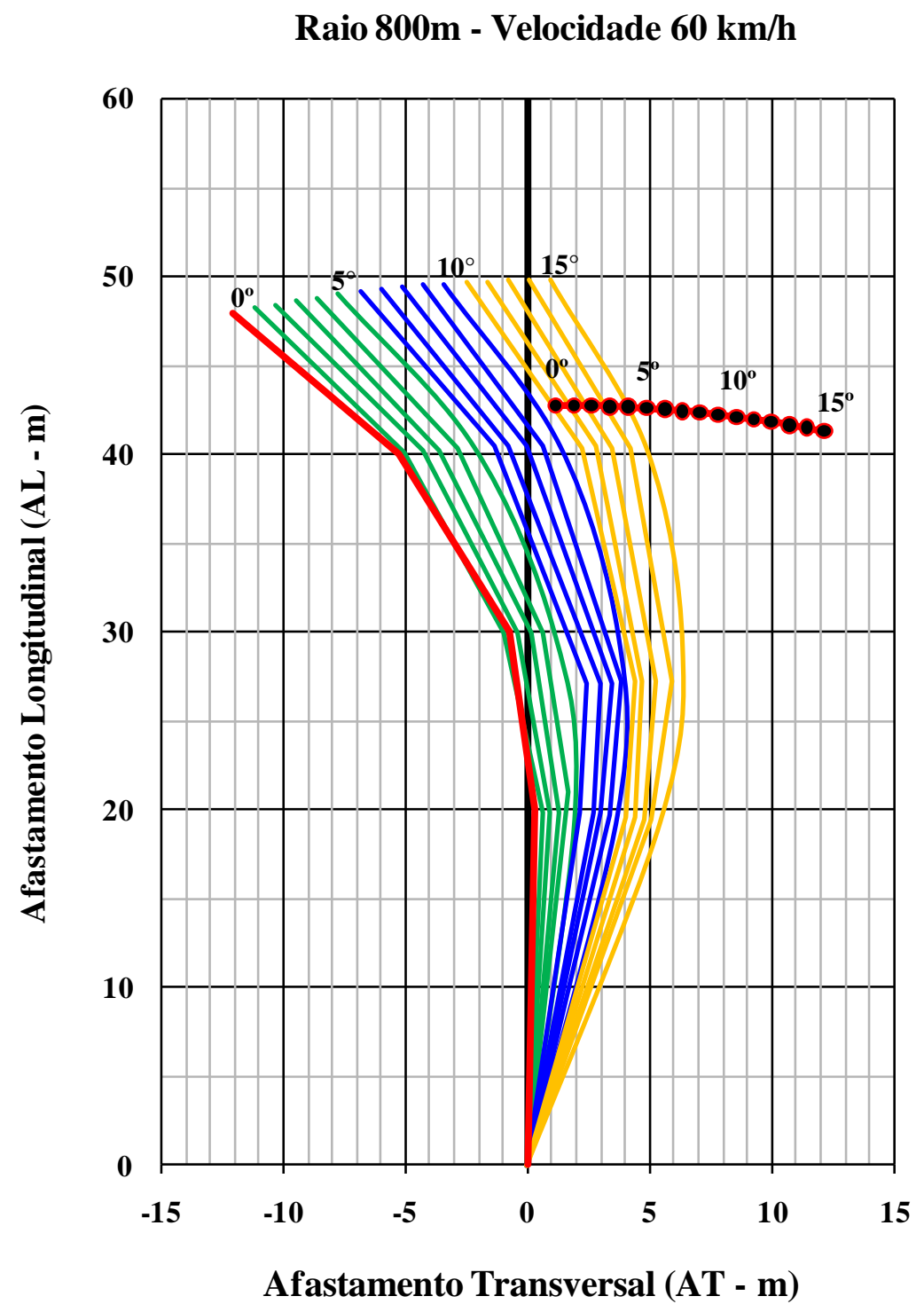


Raio 700m - Velocidade $120 \mathrm{~km} / \mathrm{h}$

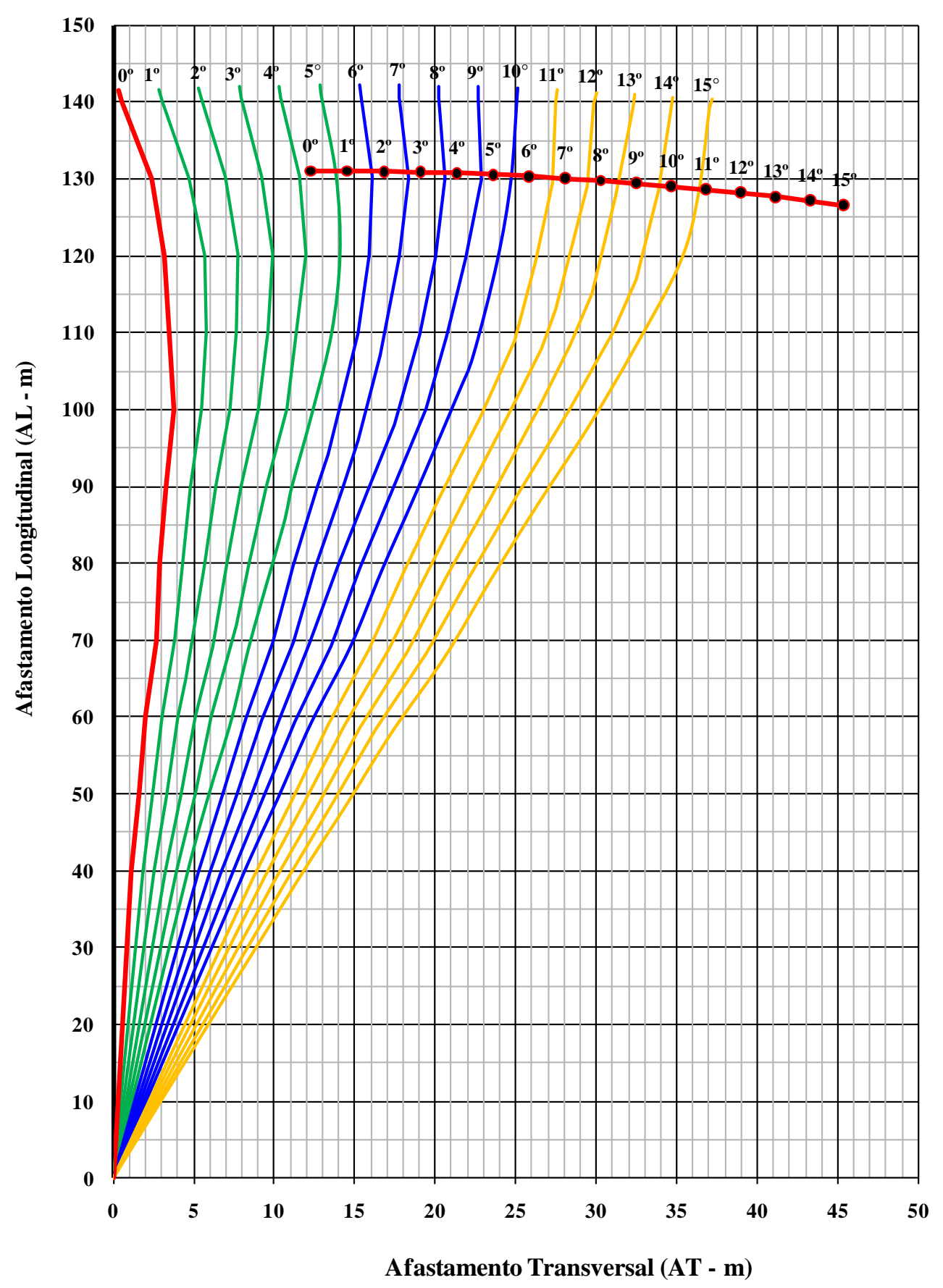




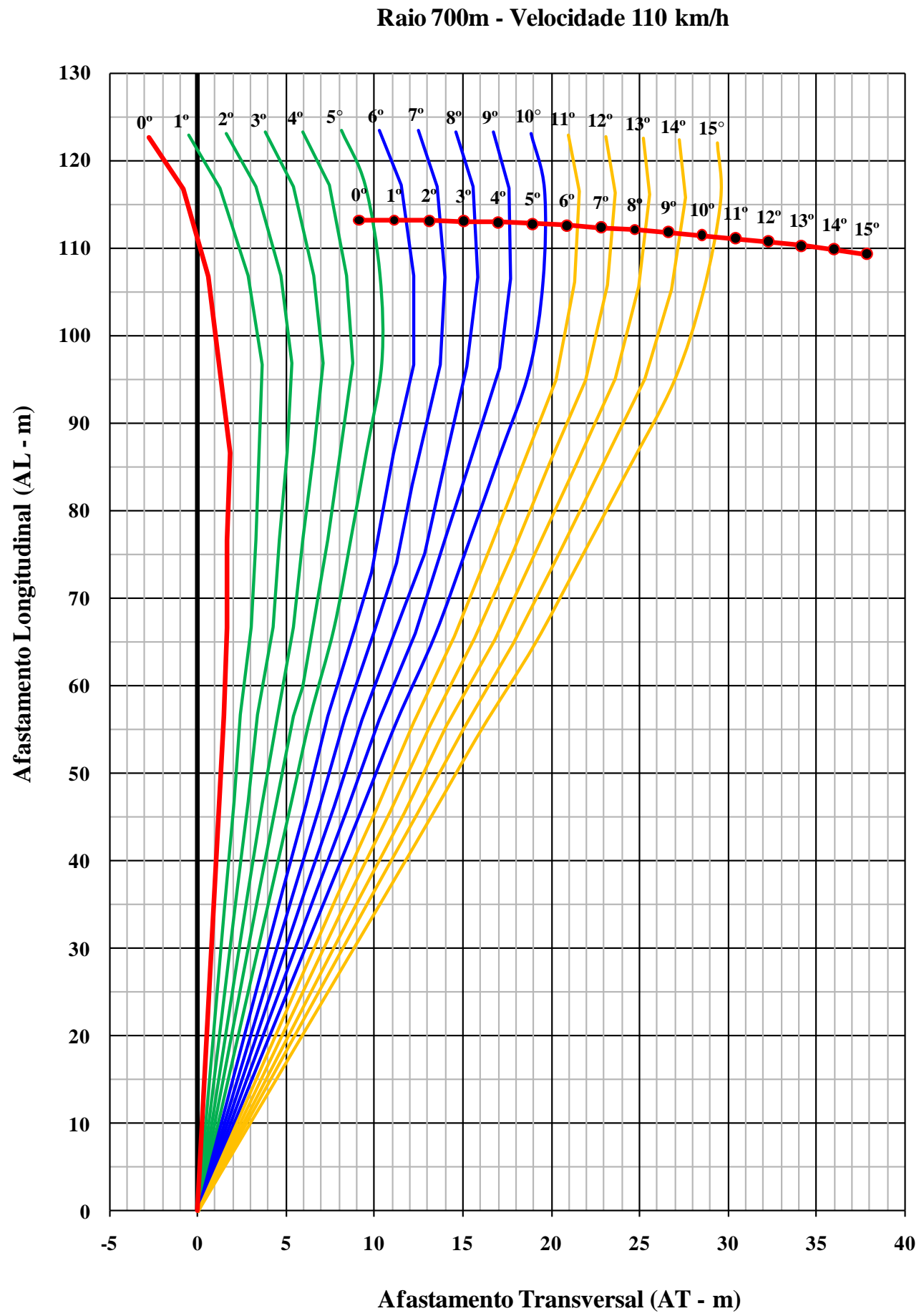


Raio 700m - Velocidade 100 km/h

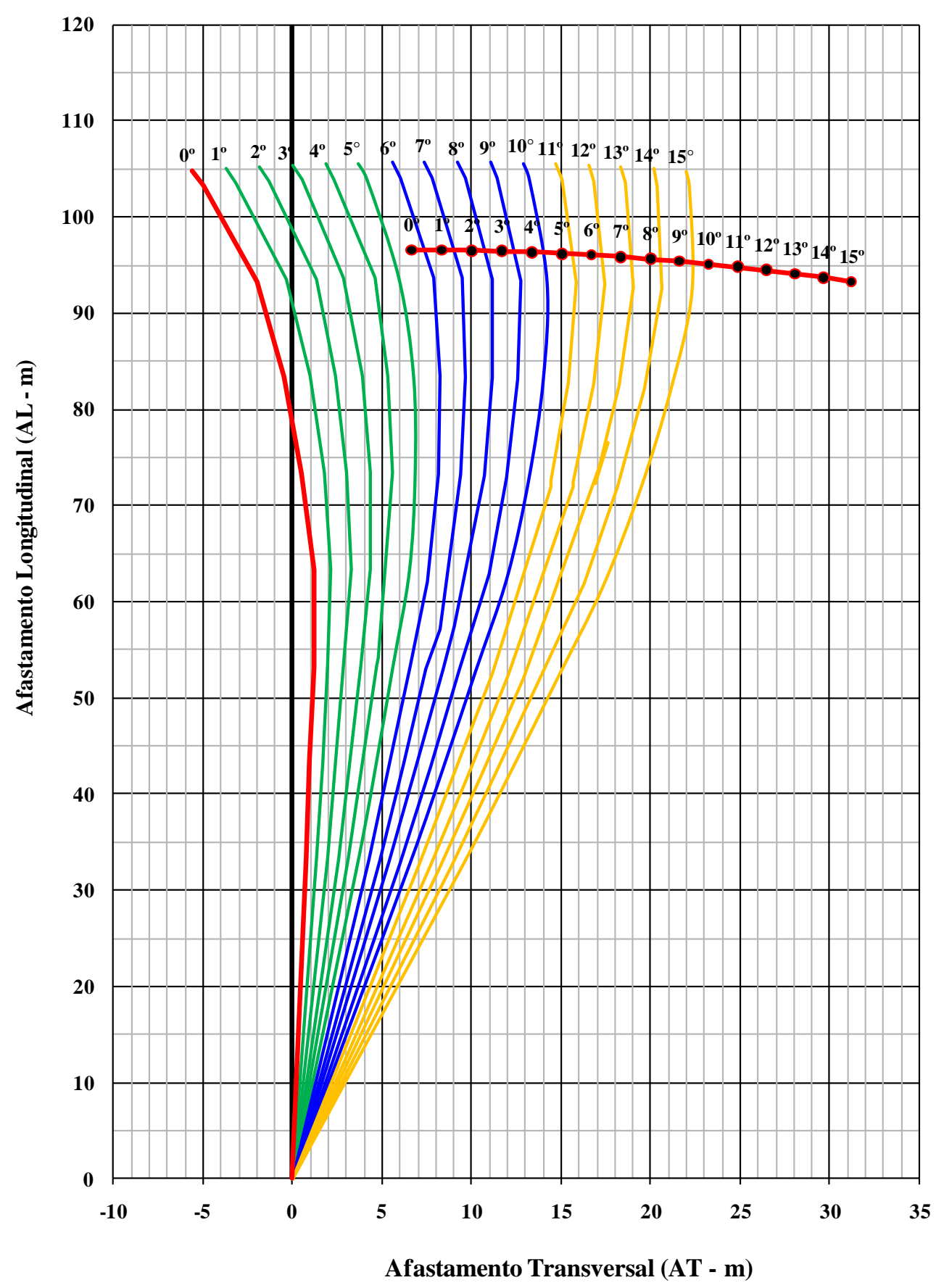


Raio 700m - Velocidade 90 km/h

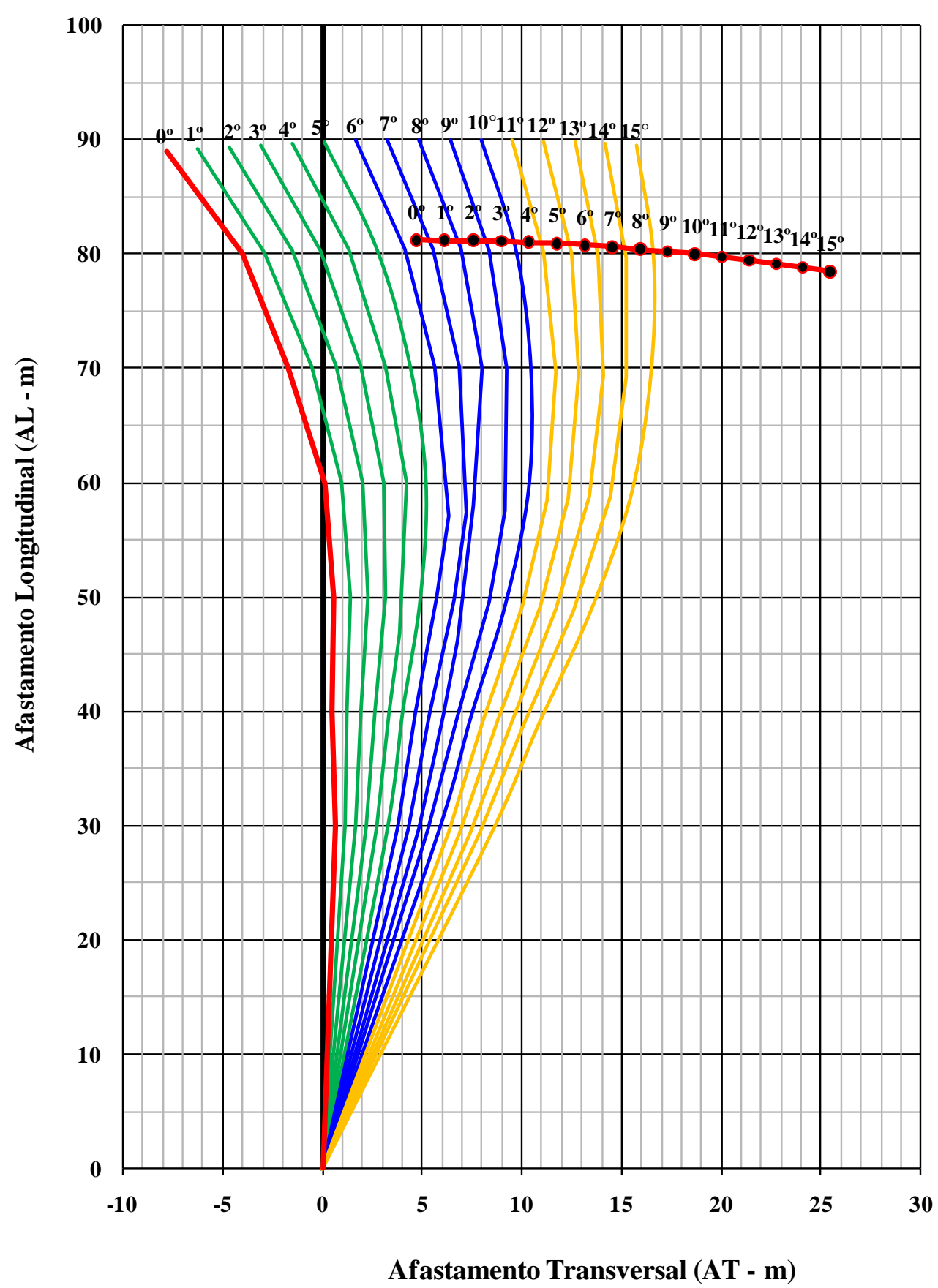




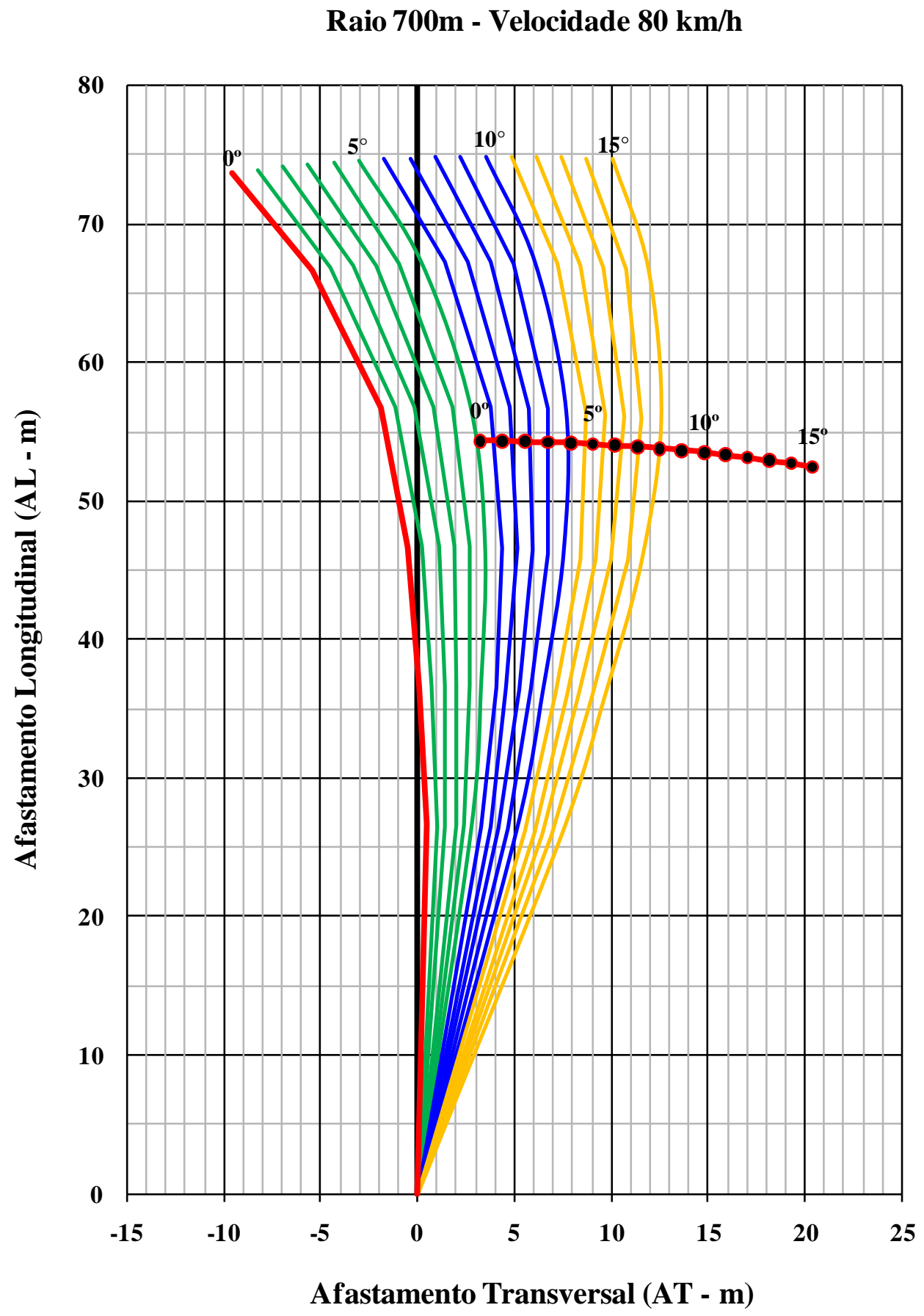




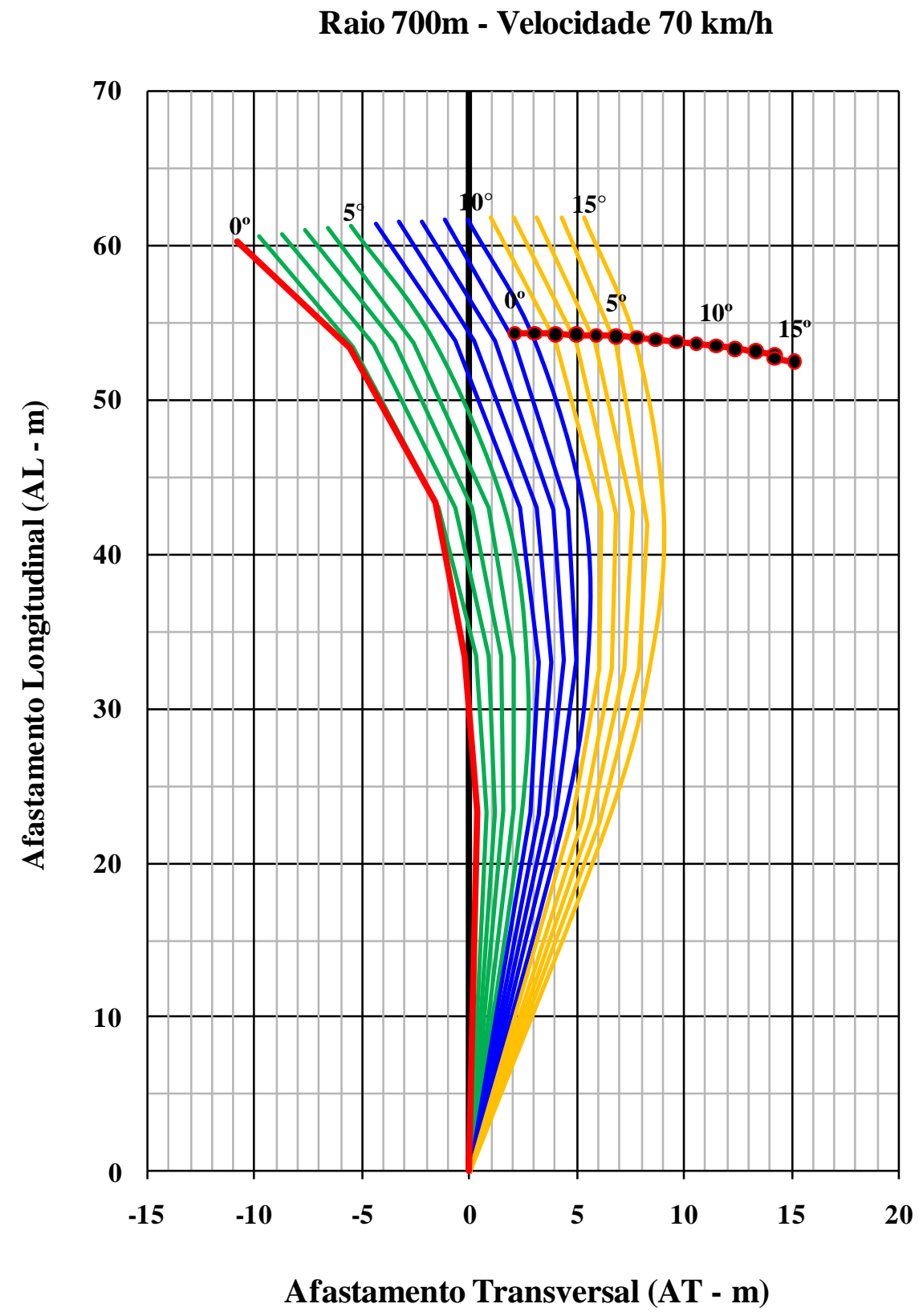




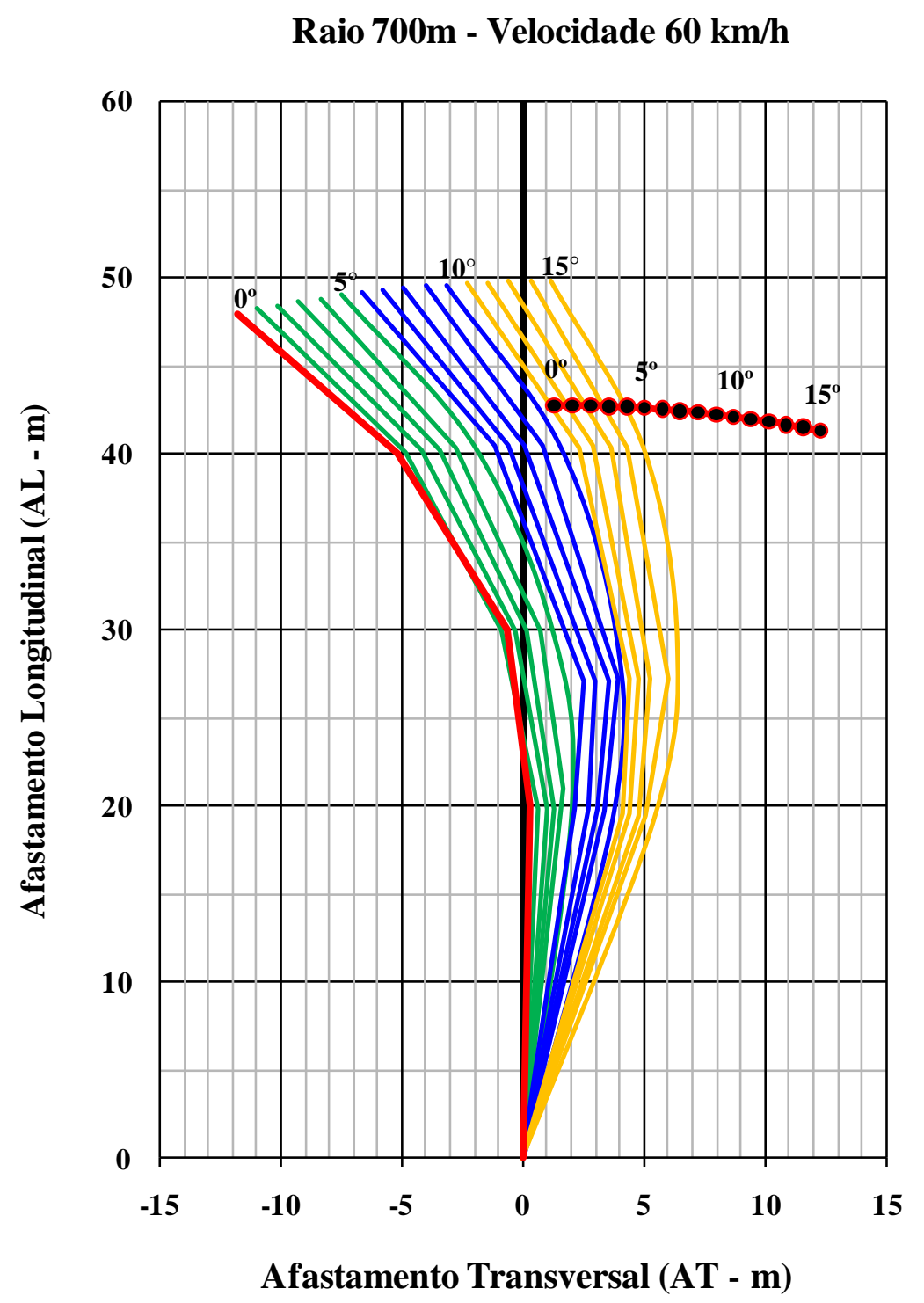


Raio 600m - Velocidade $120 \mathrm{~km} / \mathrm{h}$

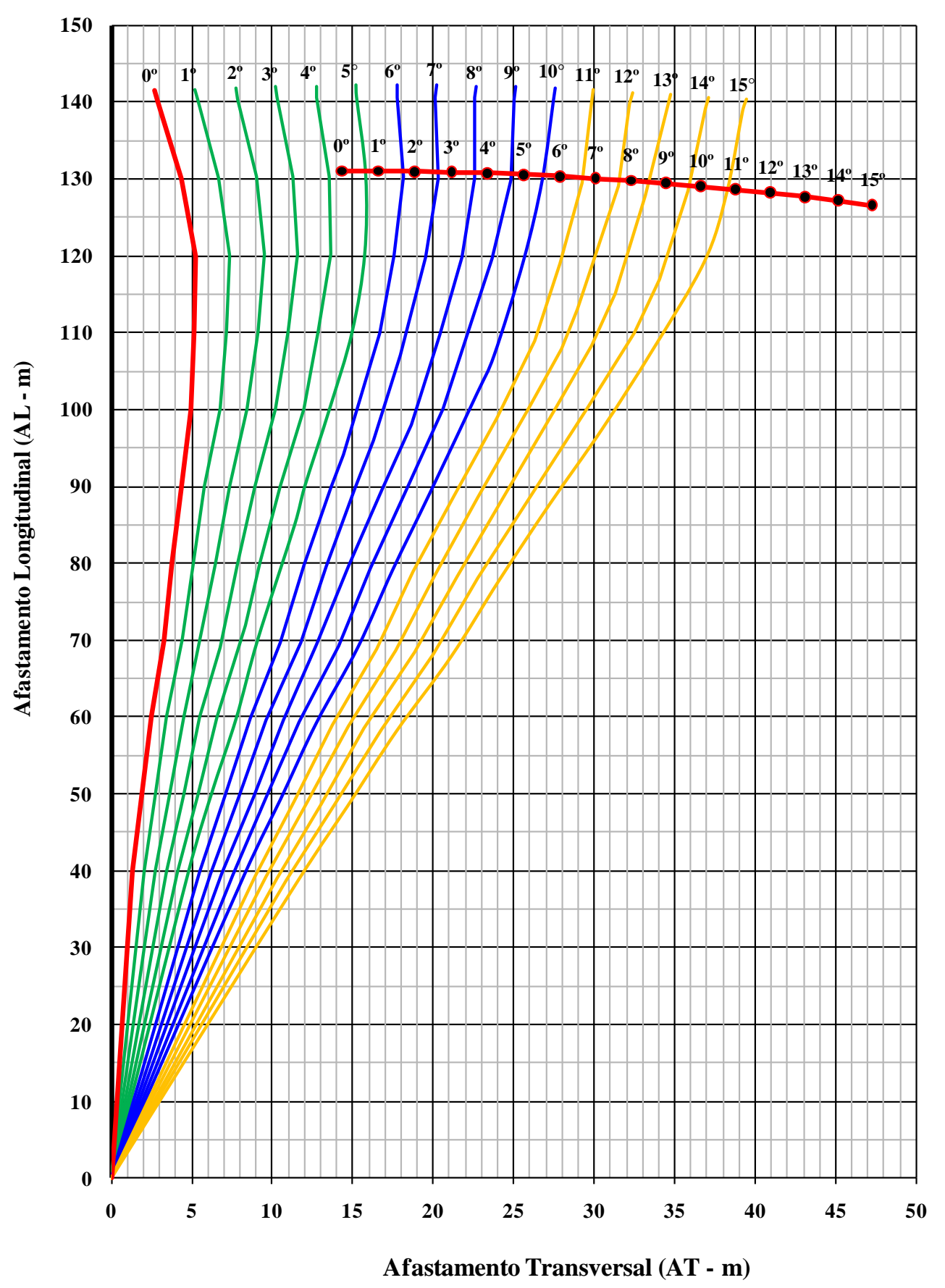


Raio 600m - Velocidade 110 km/h

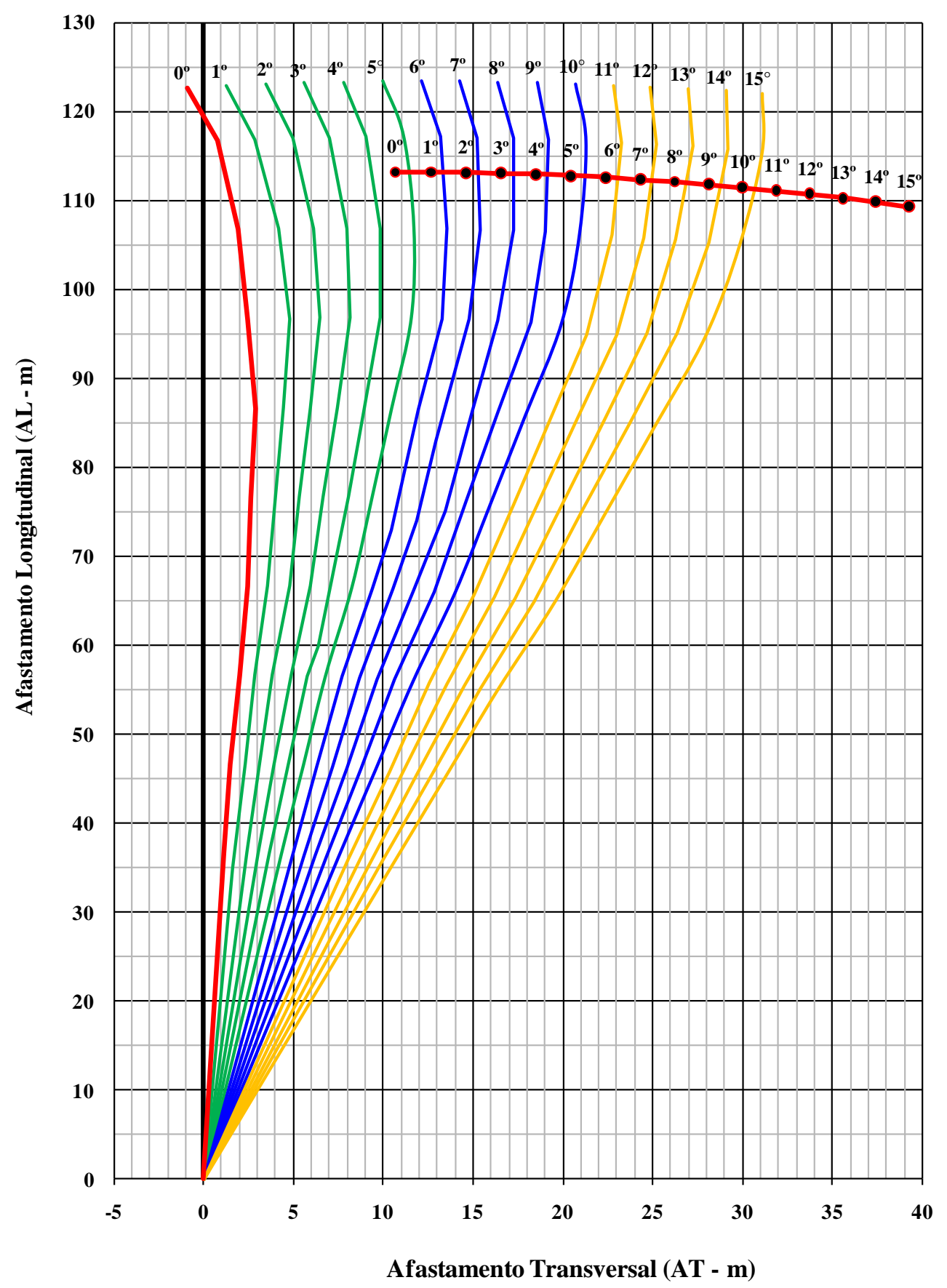


Raio 600m - Velocidade 100 km/h

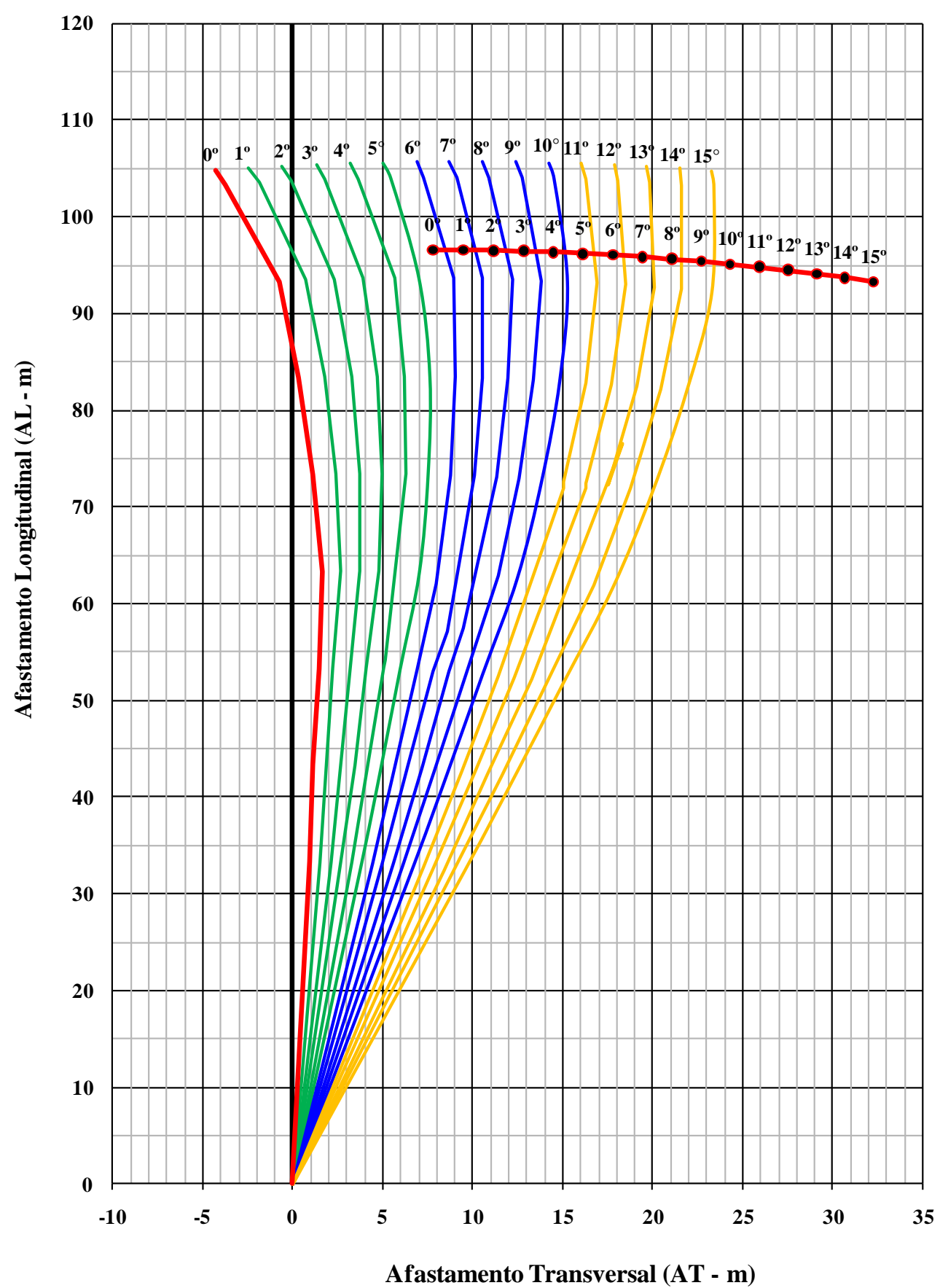




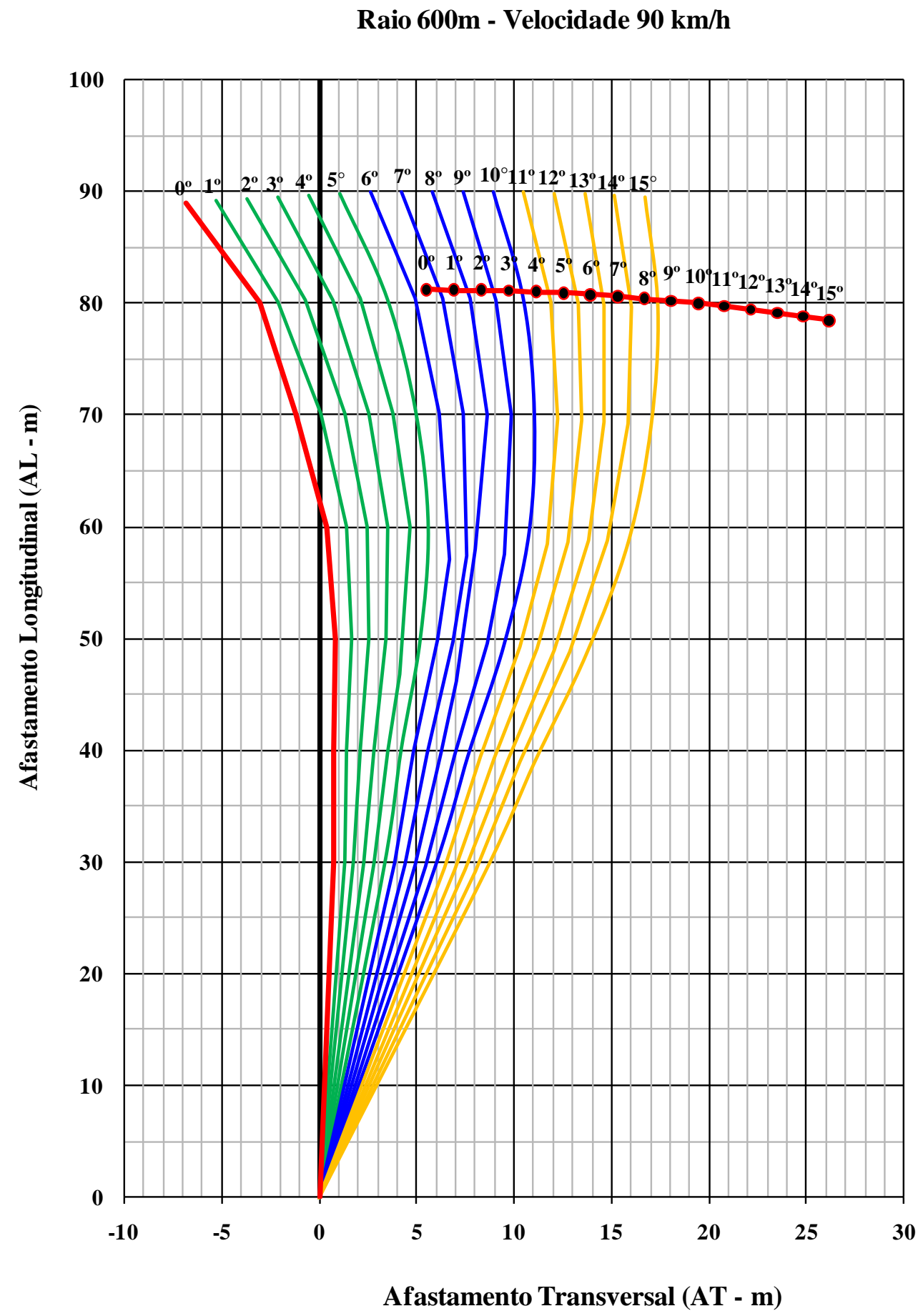


Raio 600m - Velocidade $80 \mathrm{~km} / \mathrm{h}$

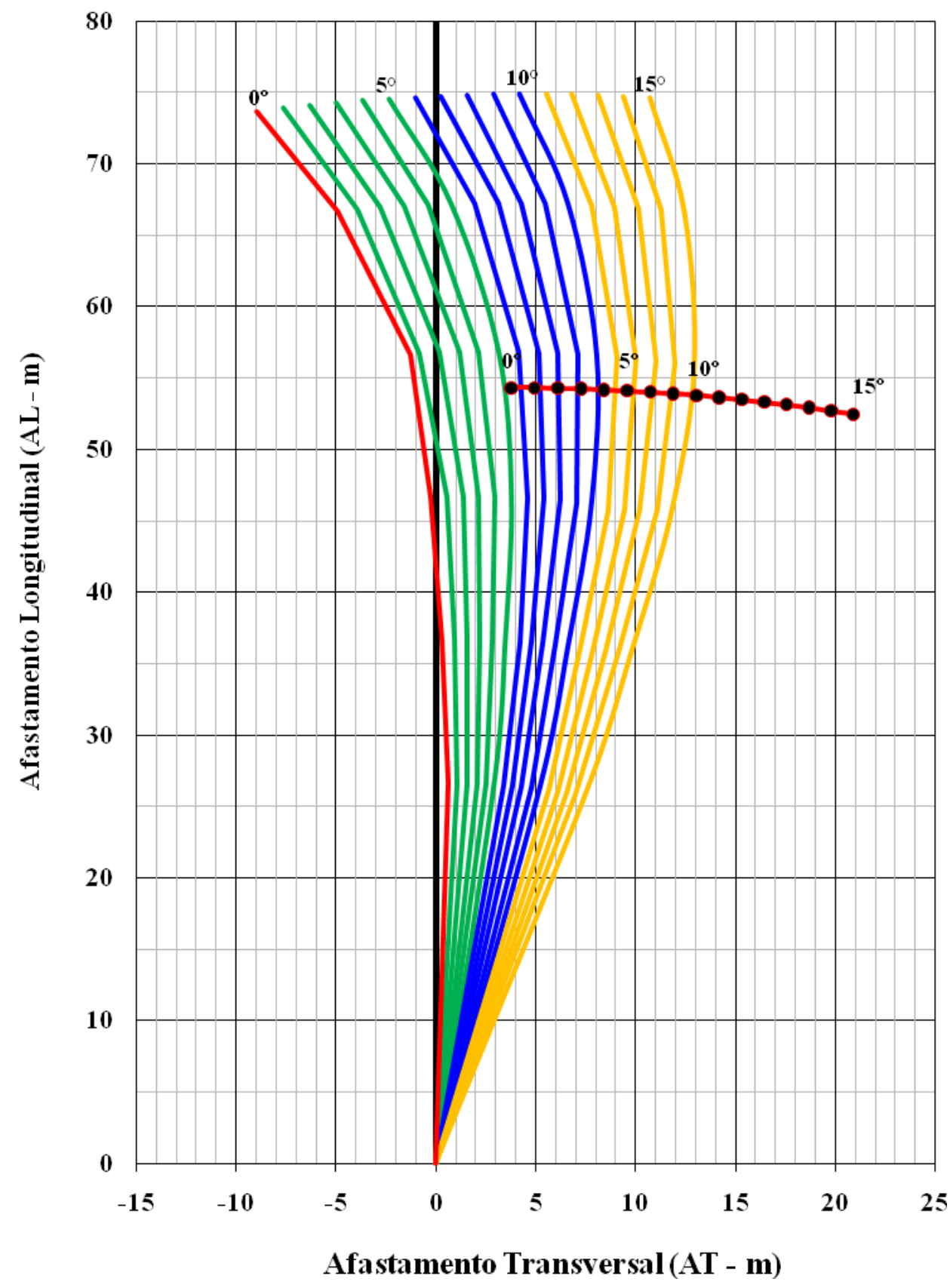




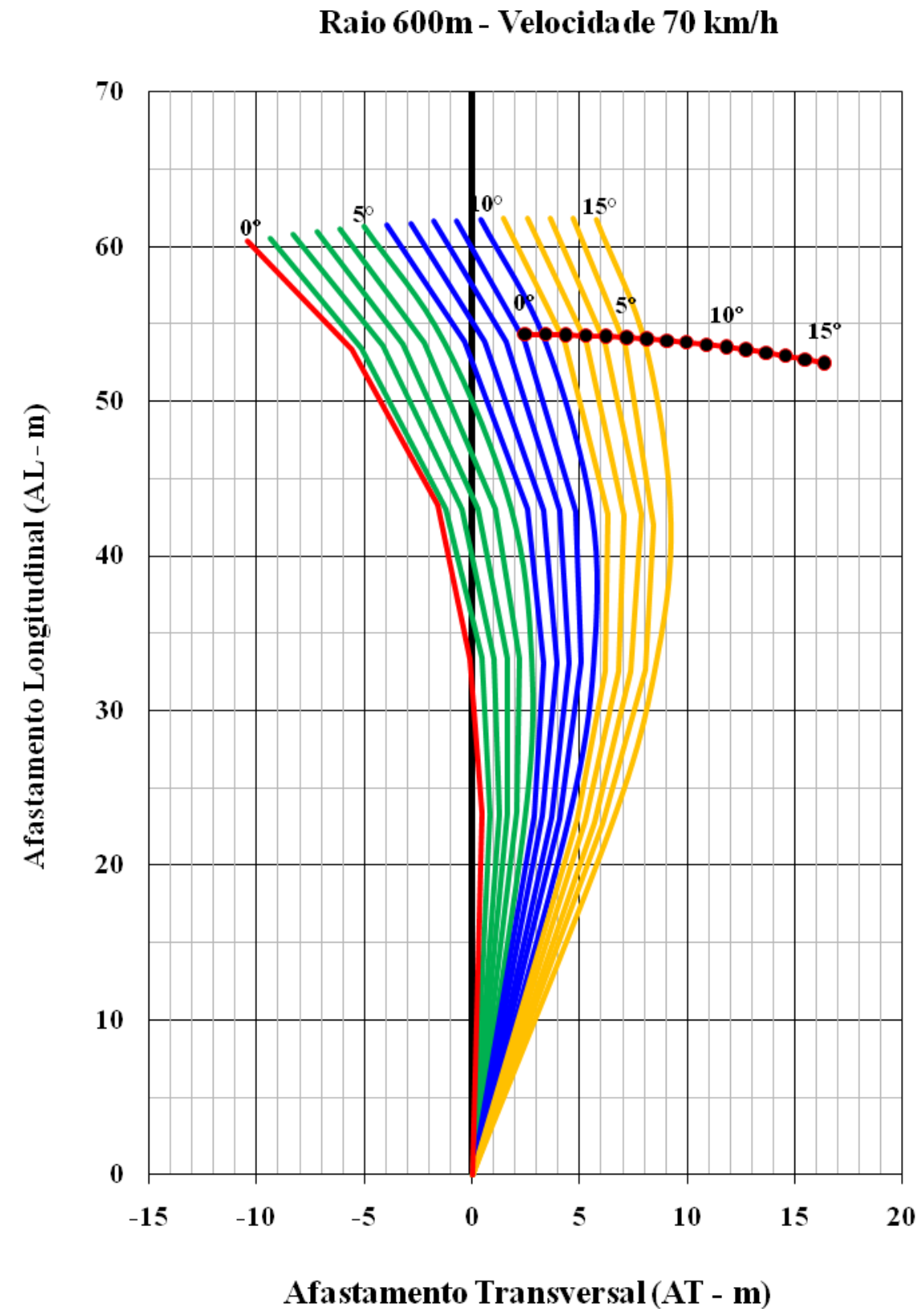




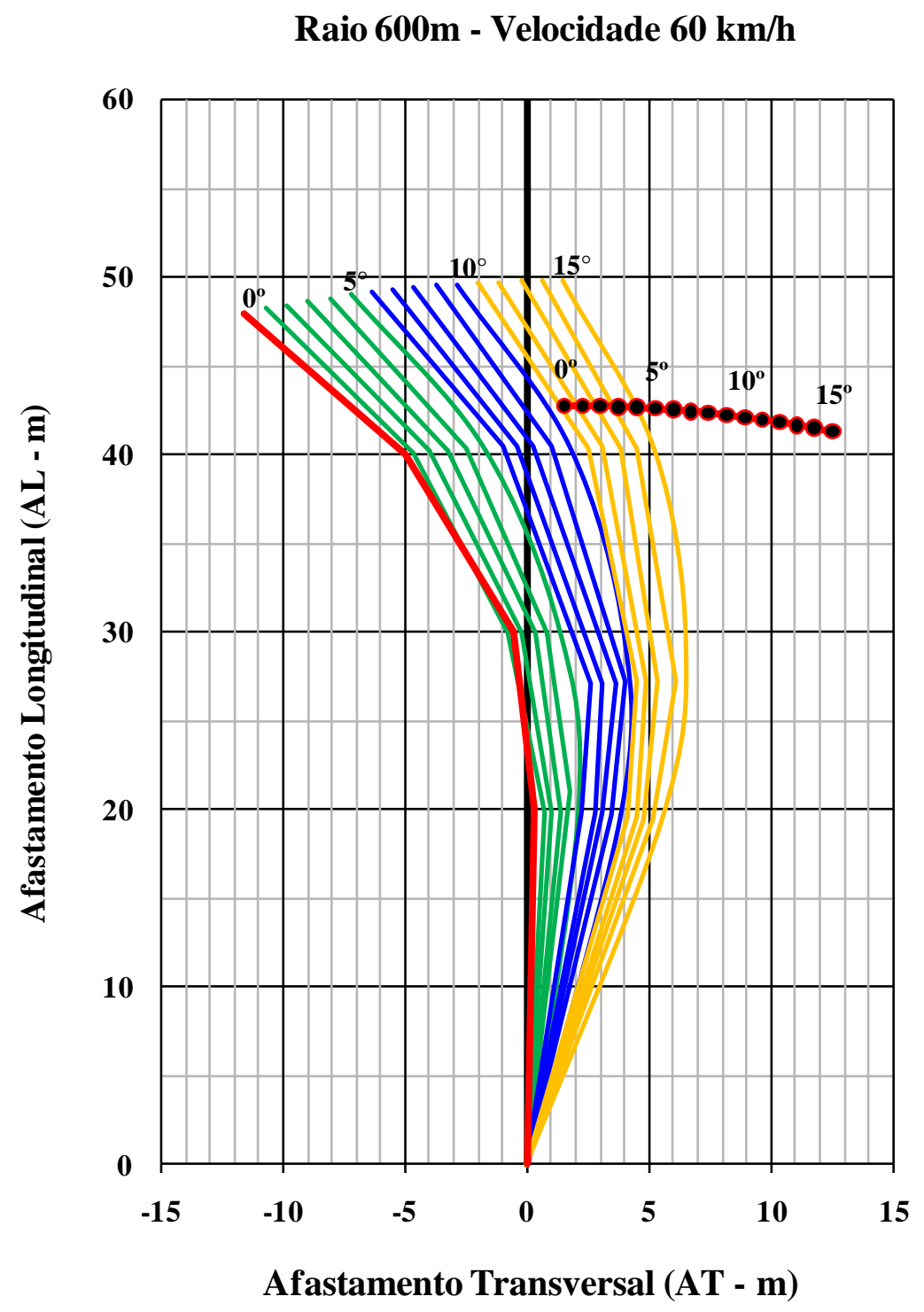


Raio 500m - Velocidade $120 \mathrm{~km} / \mathrm{h}$

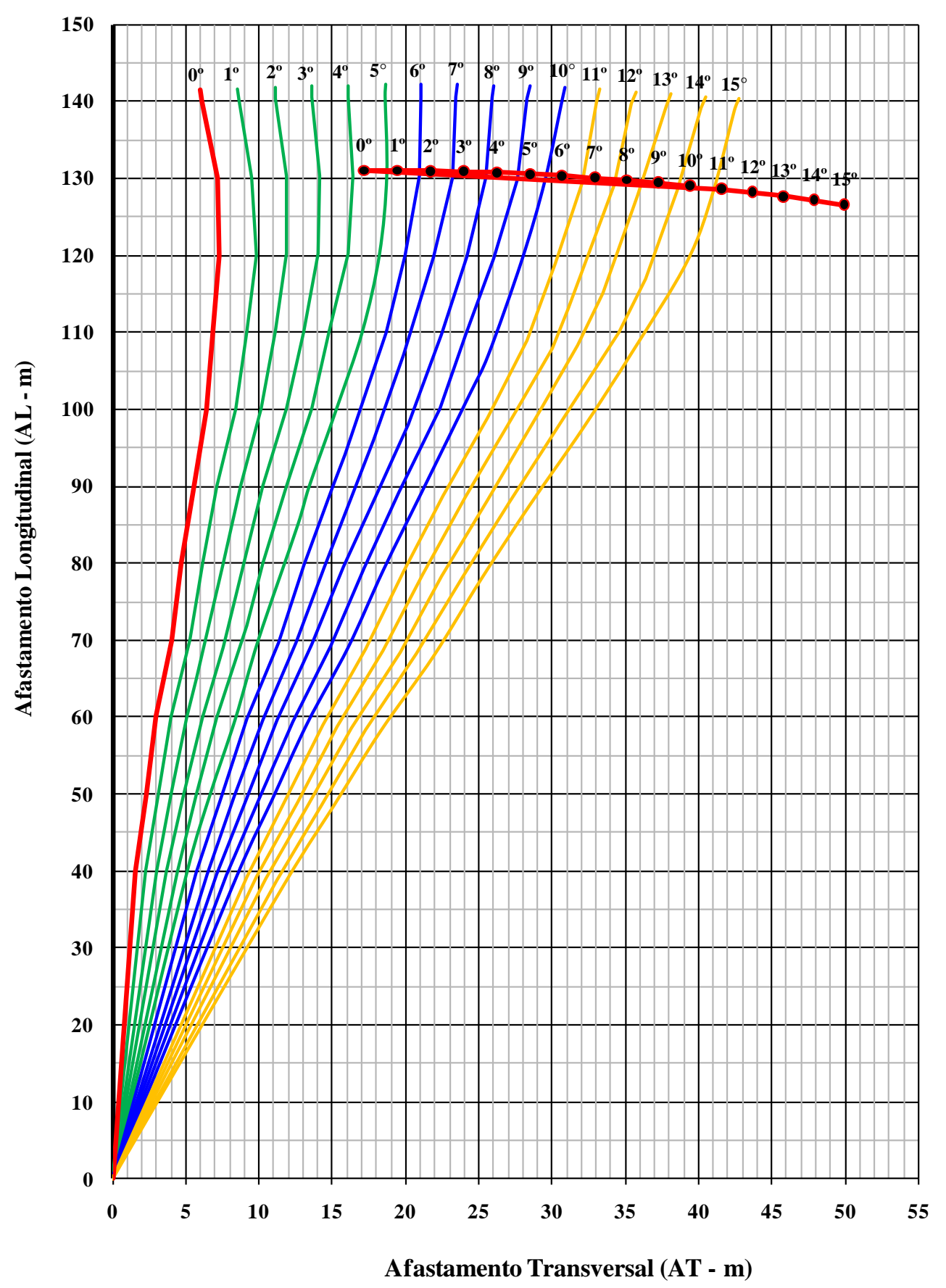




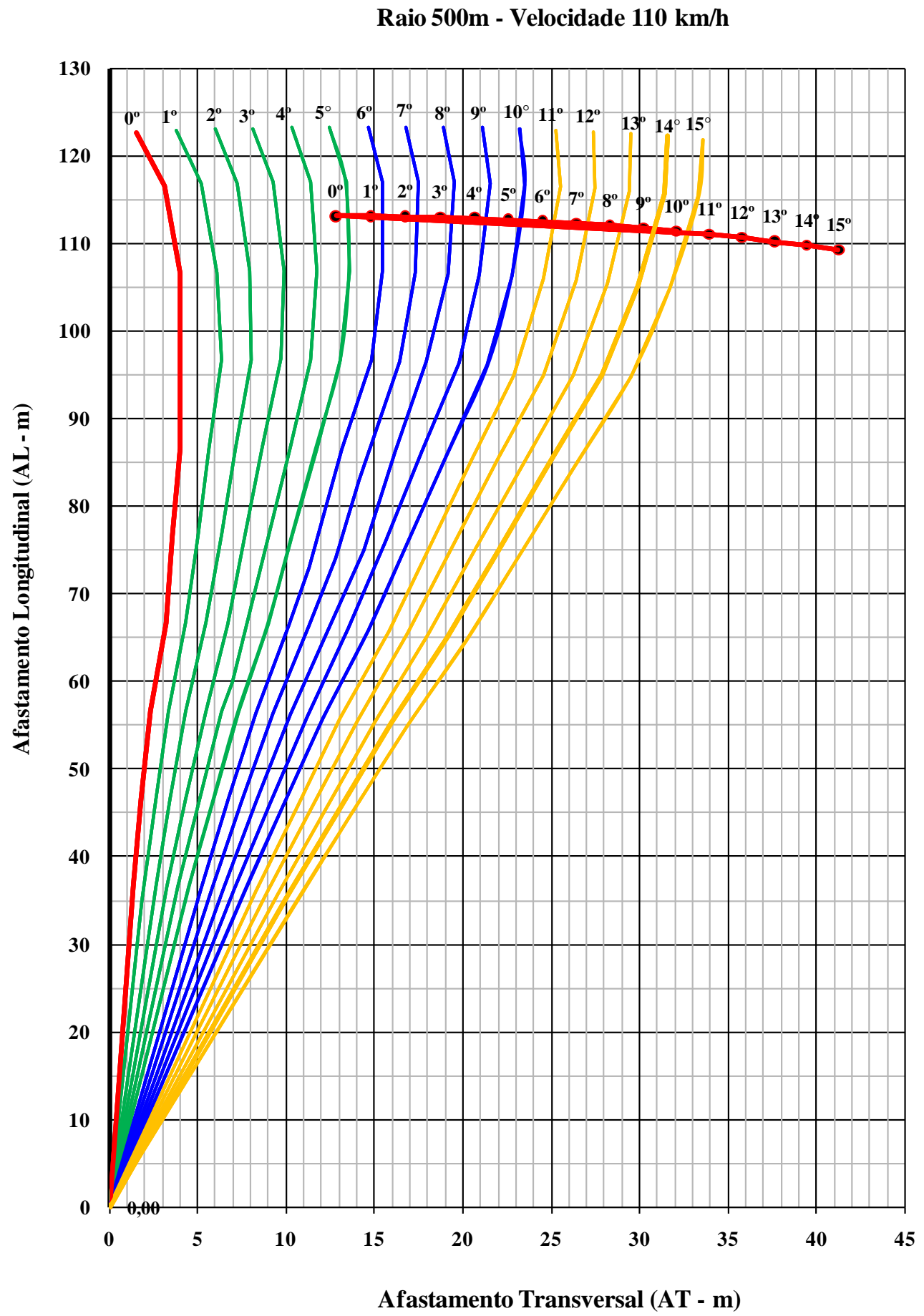


Raio 500m - Velocidade 100 km/h

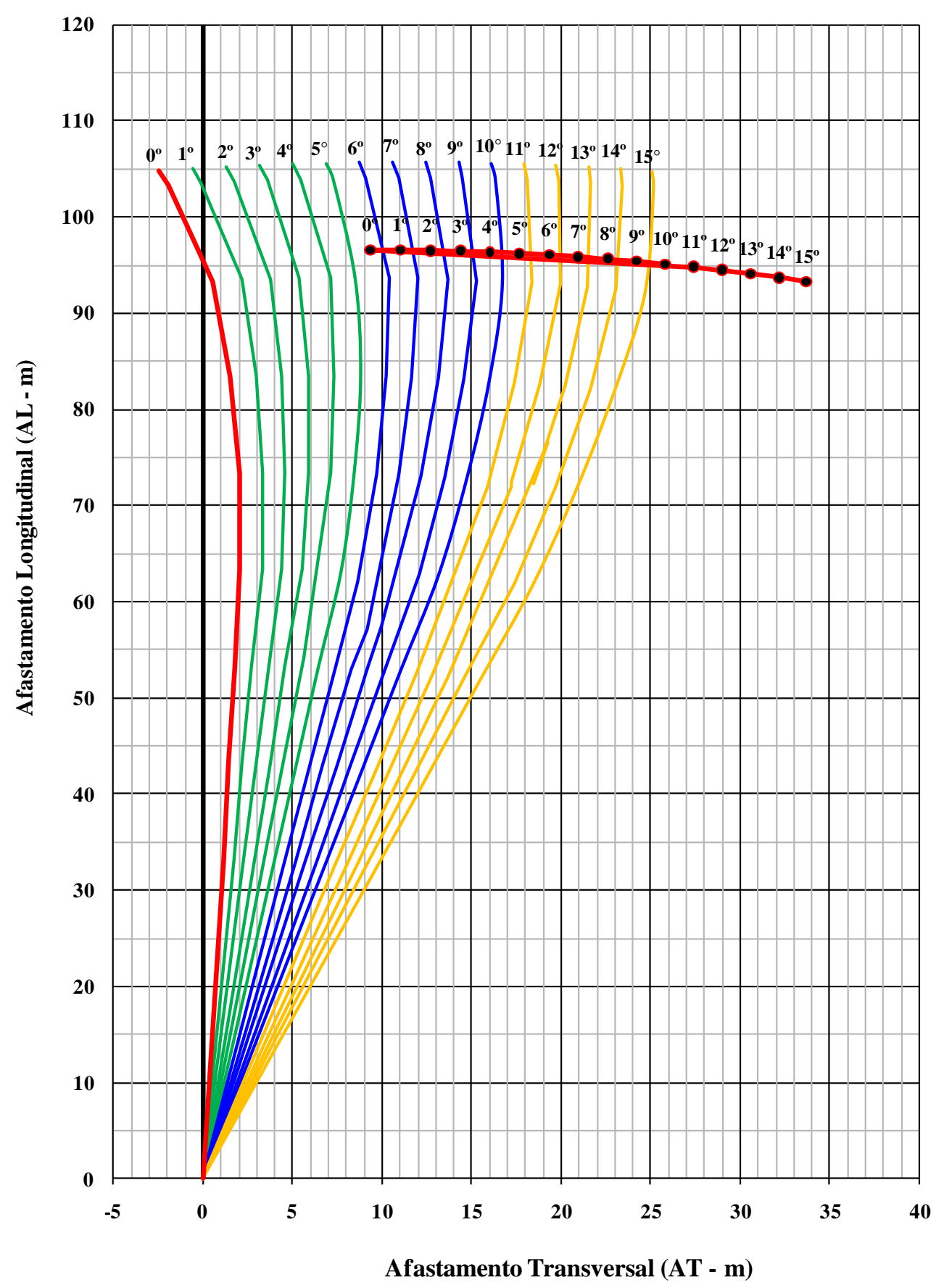


Raio 500m - Velocidade 90 km/h

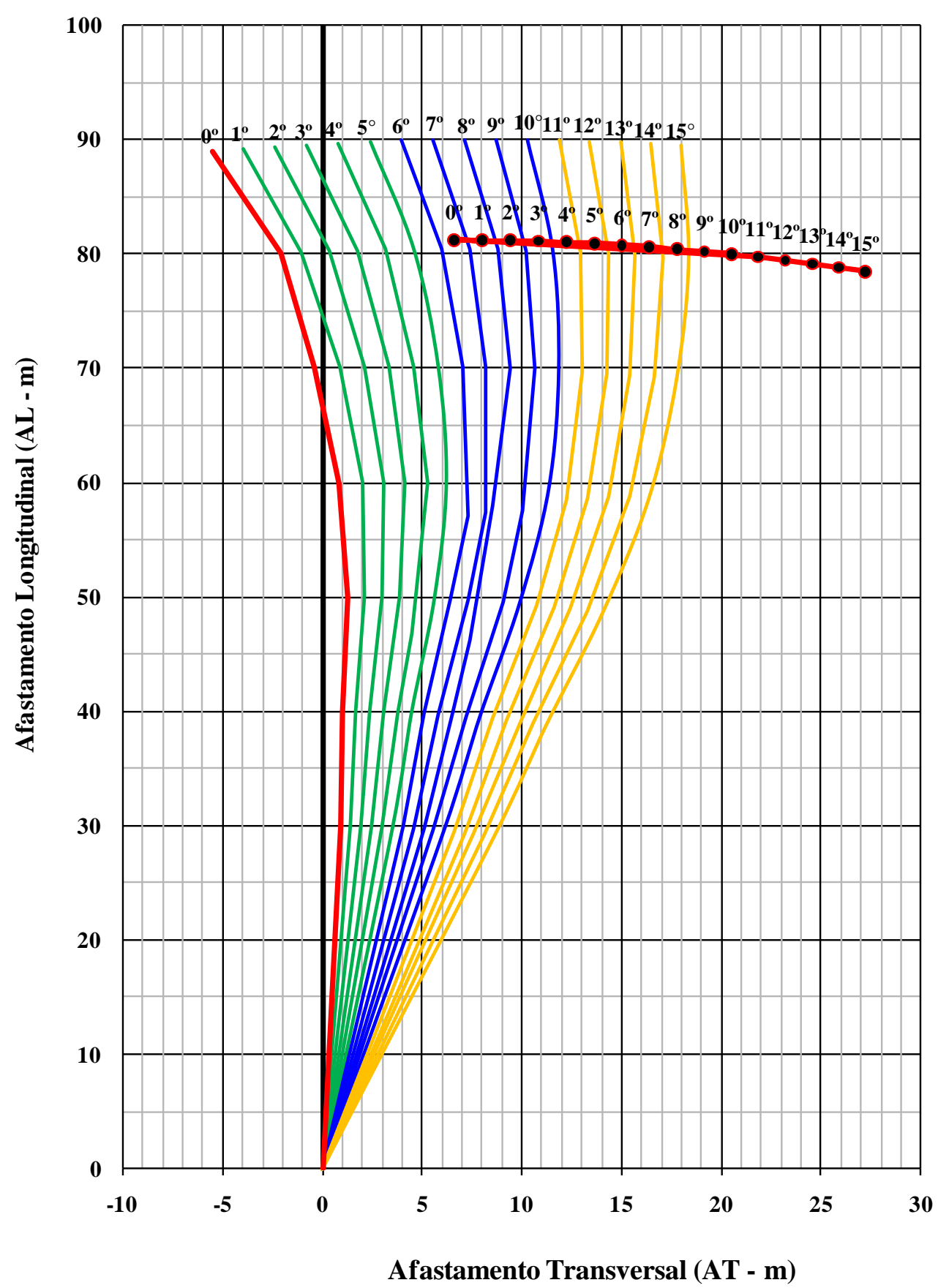




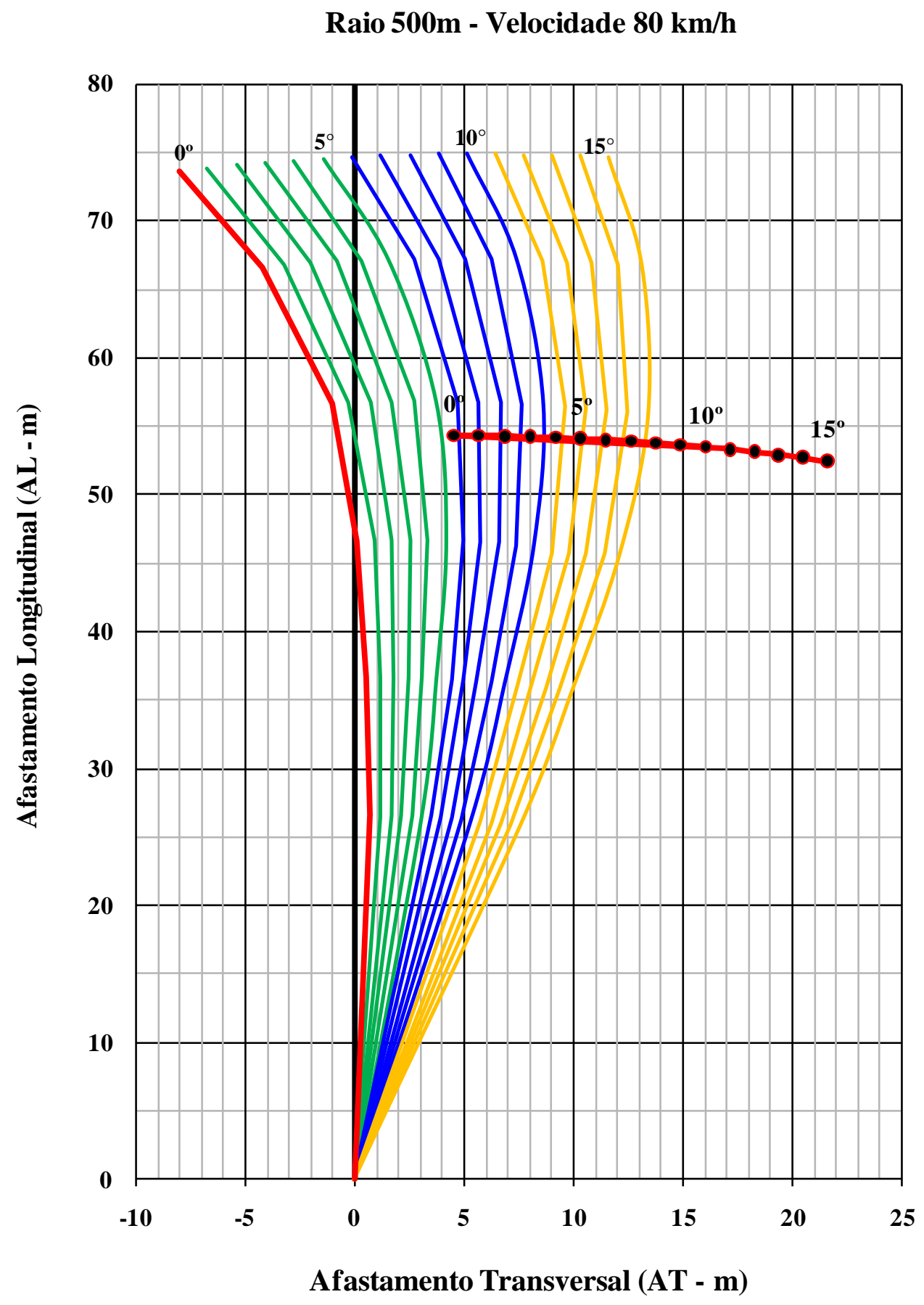




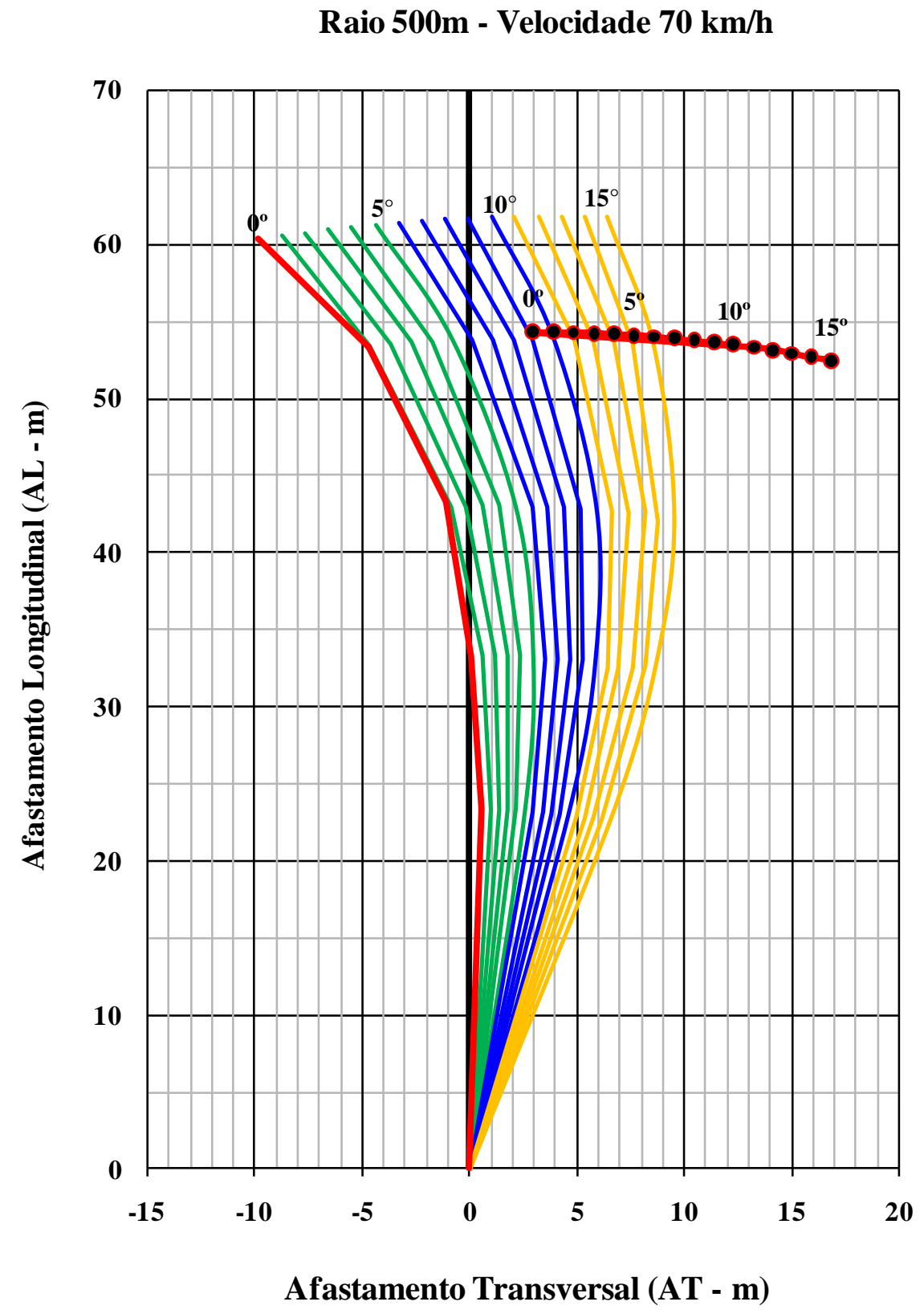




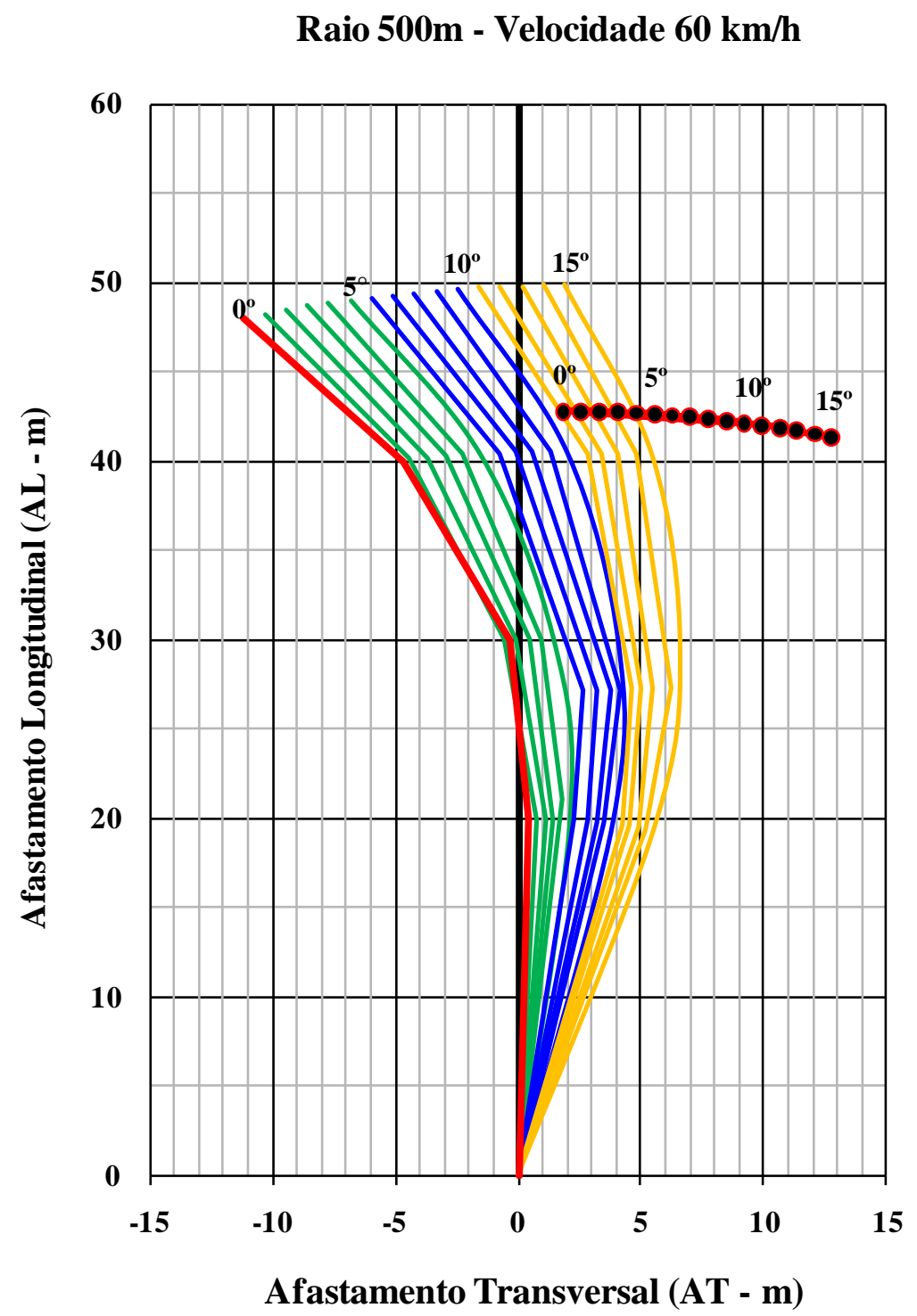


Raio 400m - Velocidade $110 \mathrm{~km} / \mathrm{h}$

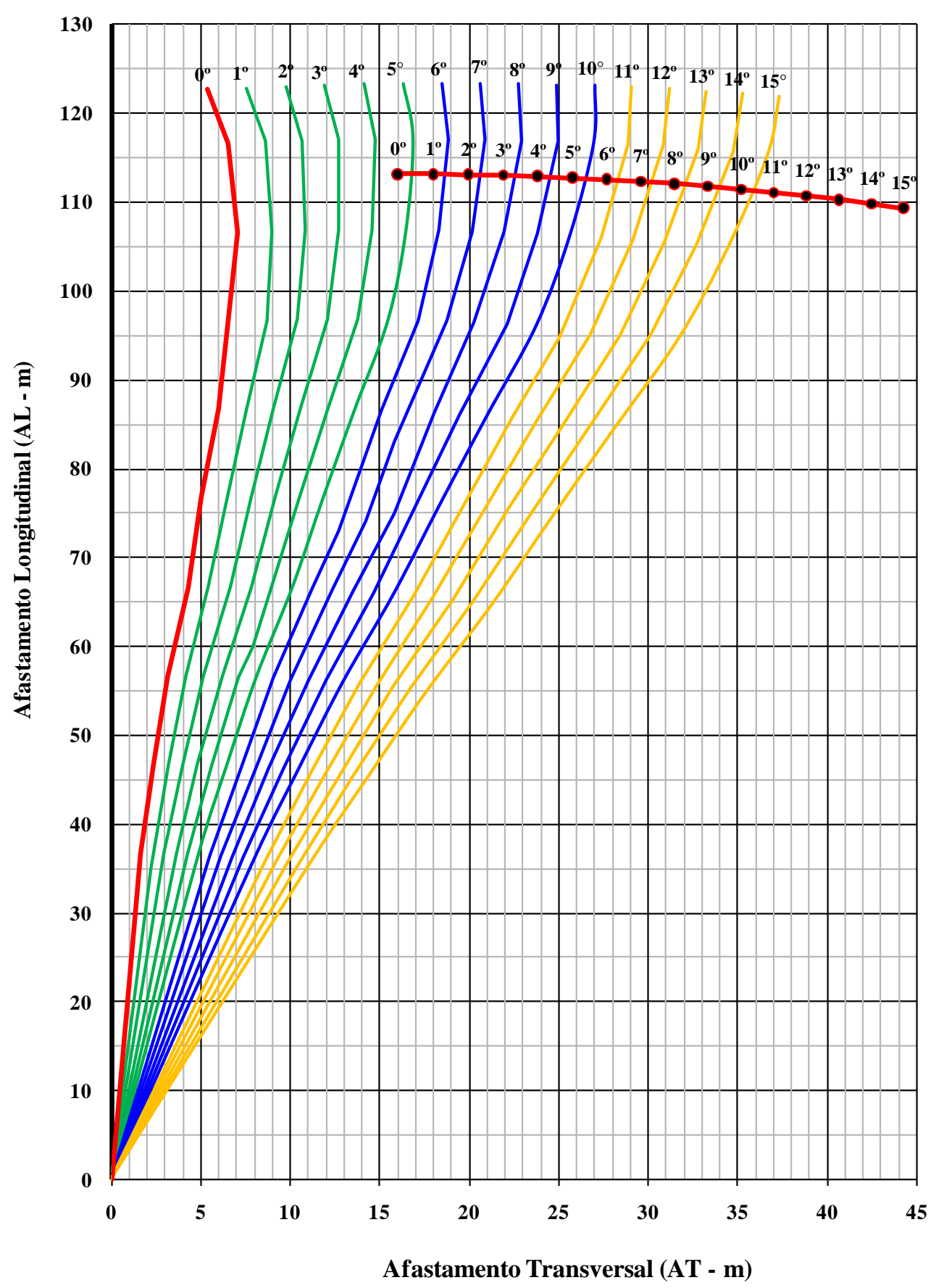


Raio 400m - Velocidade 100 km/h

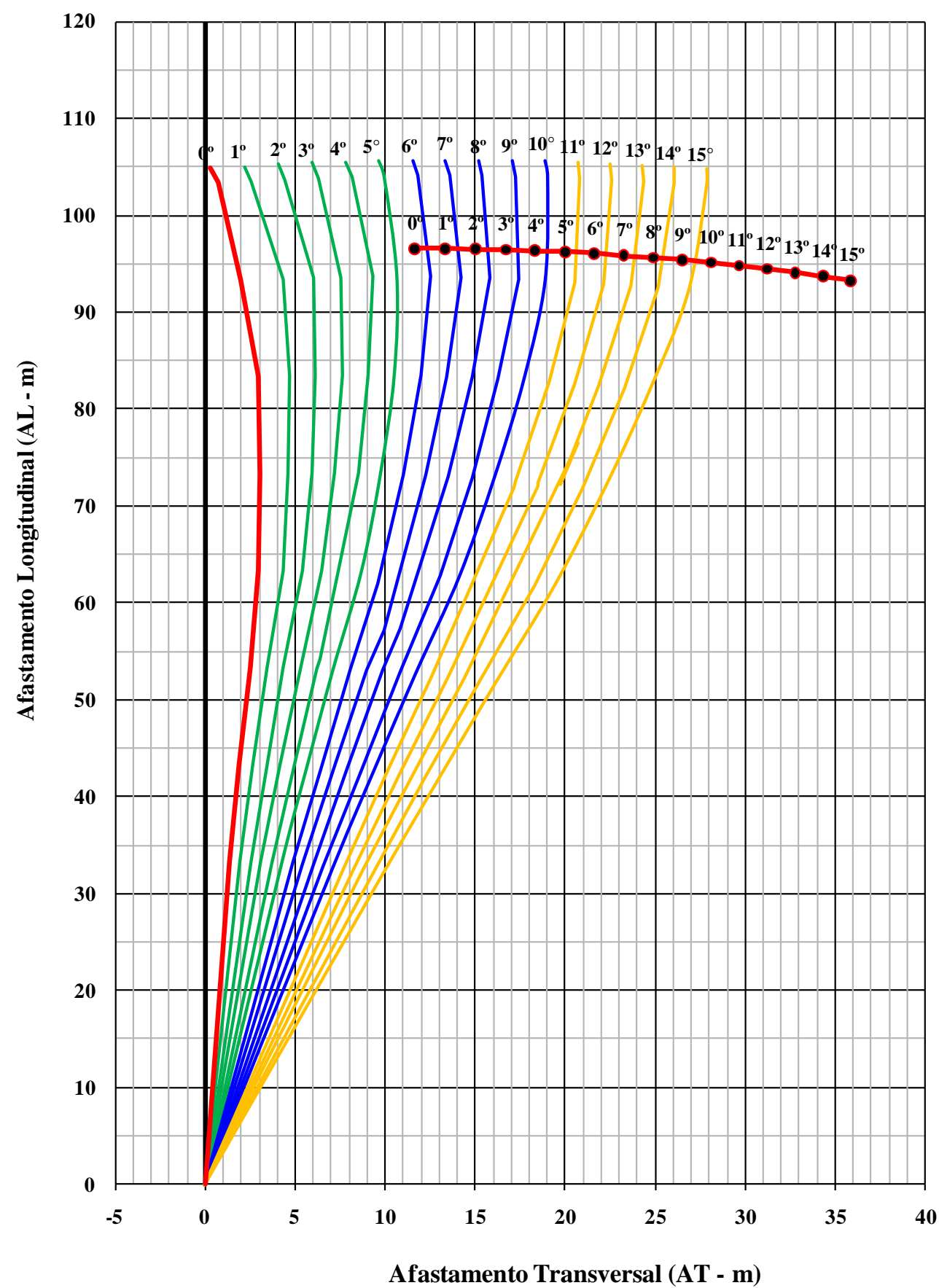




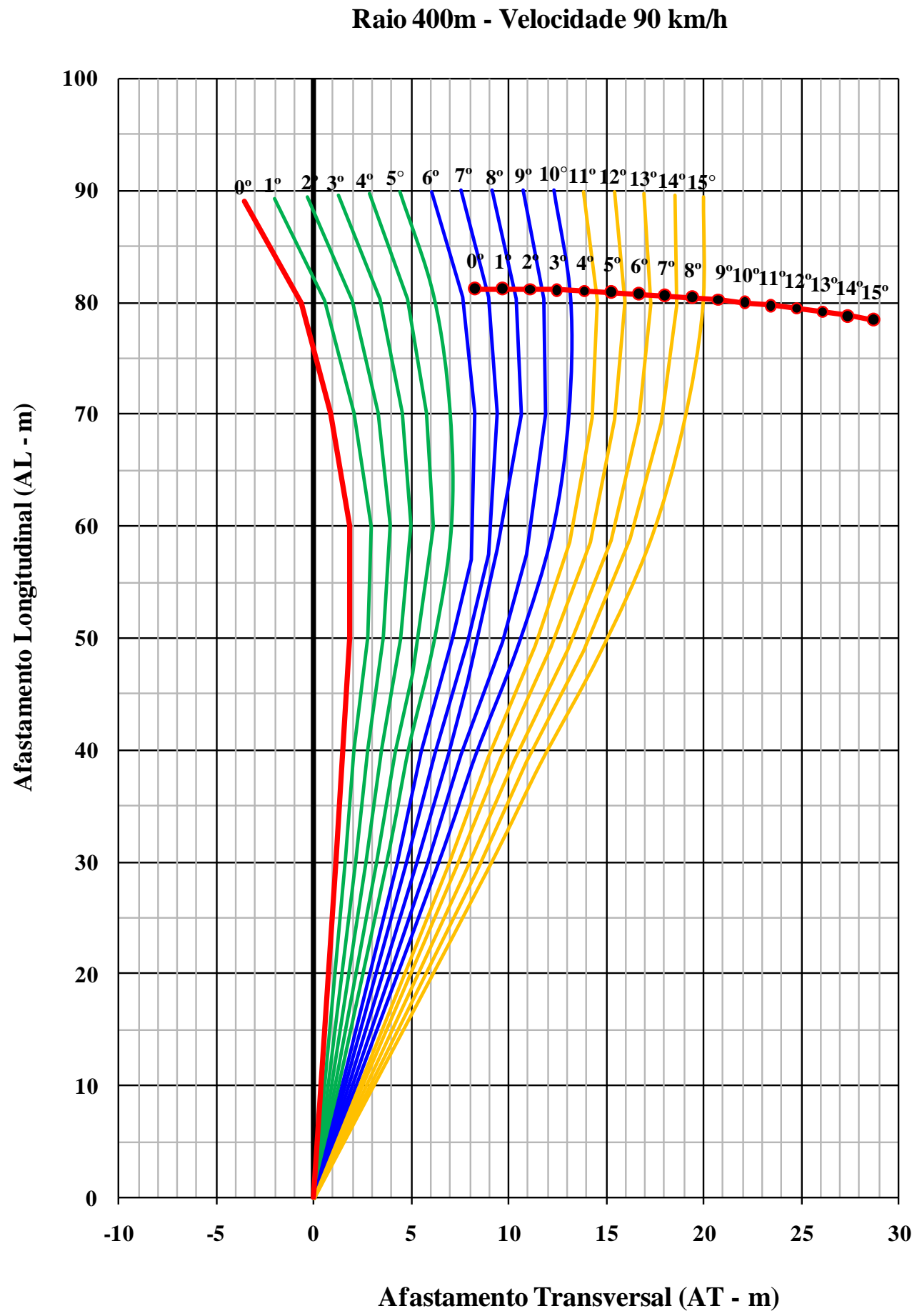




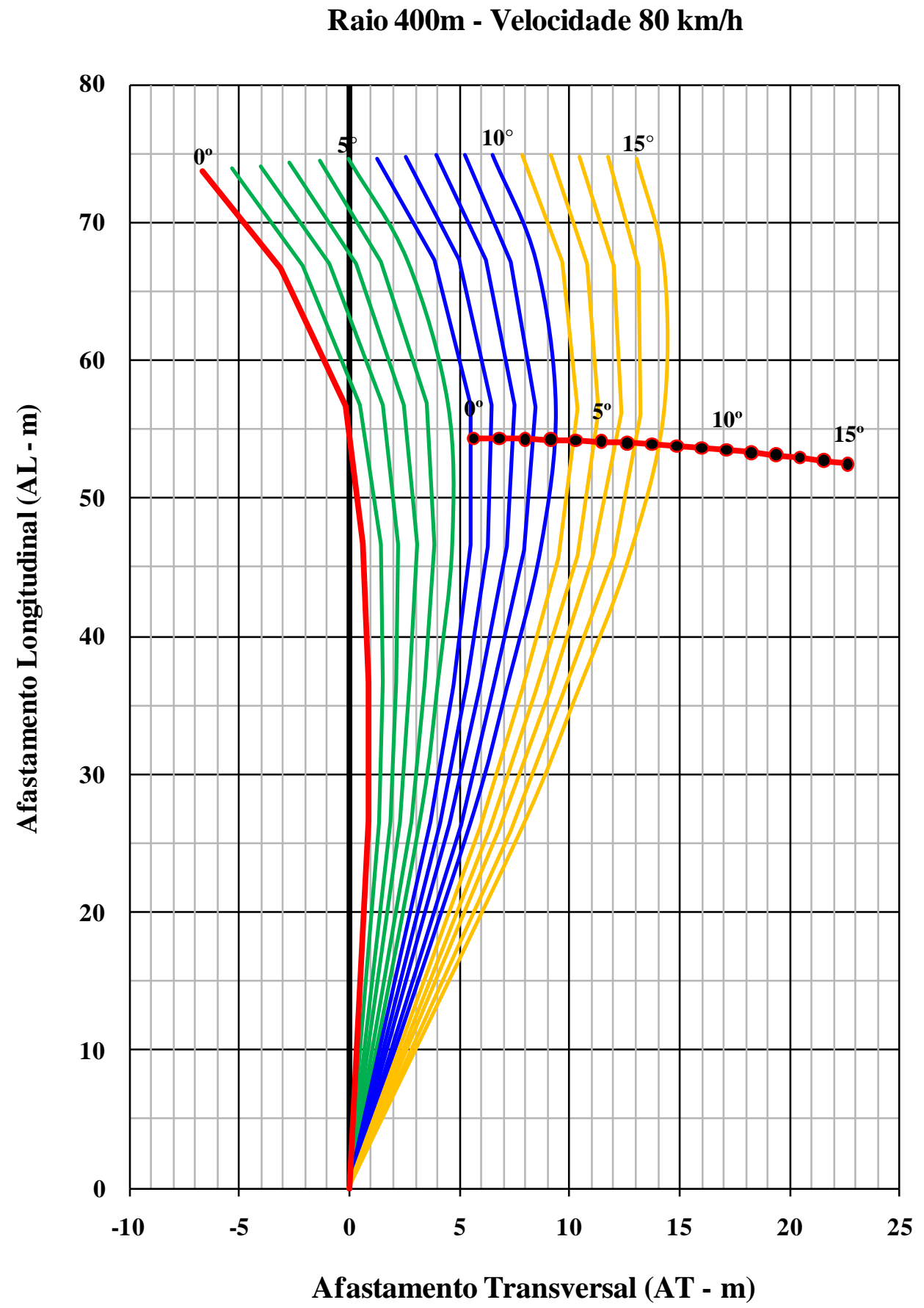




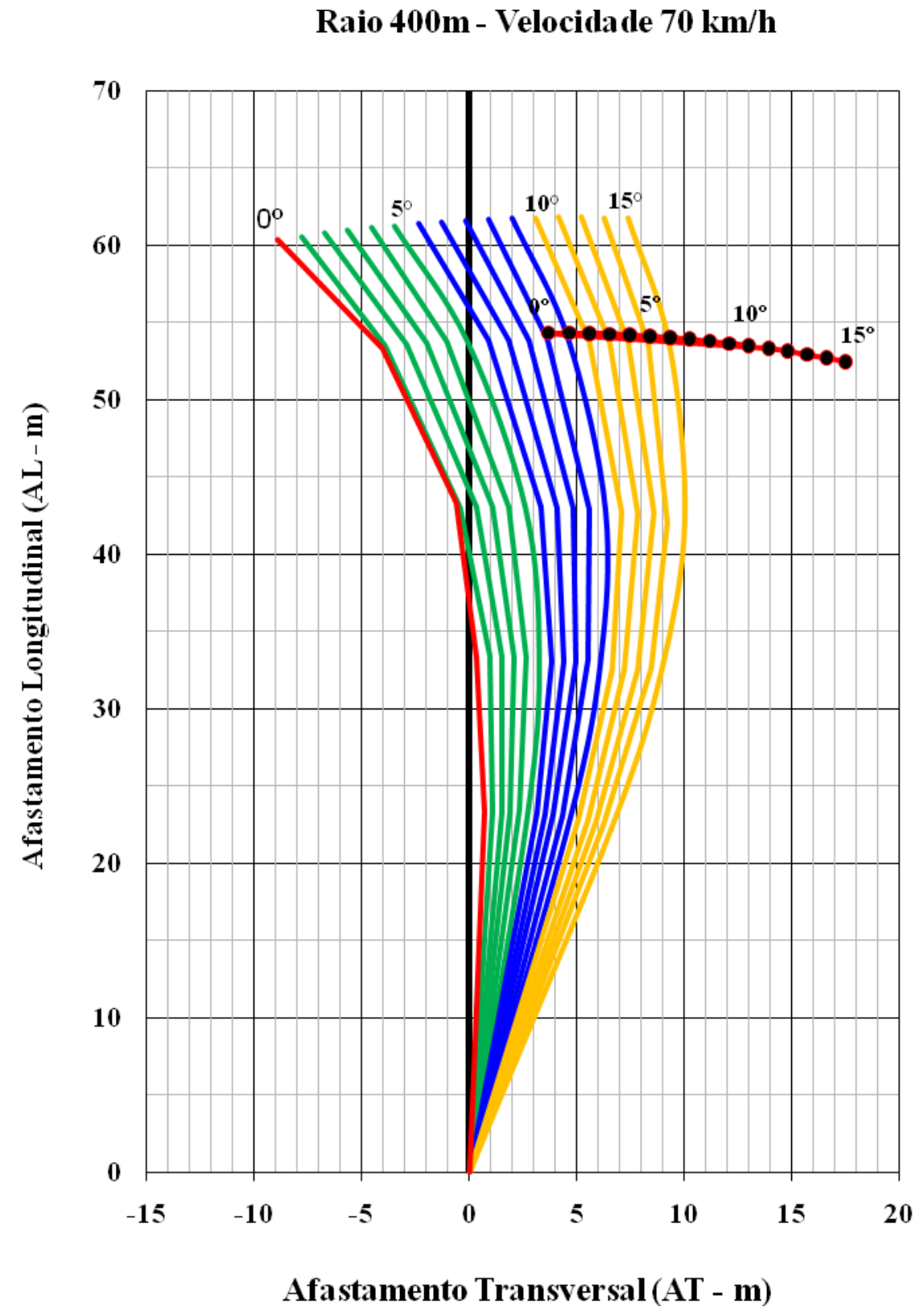




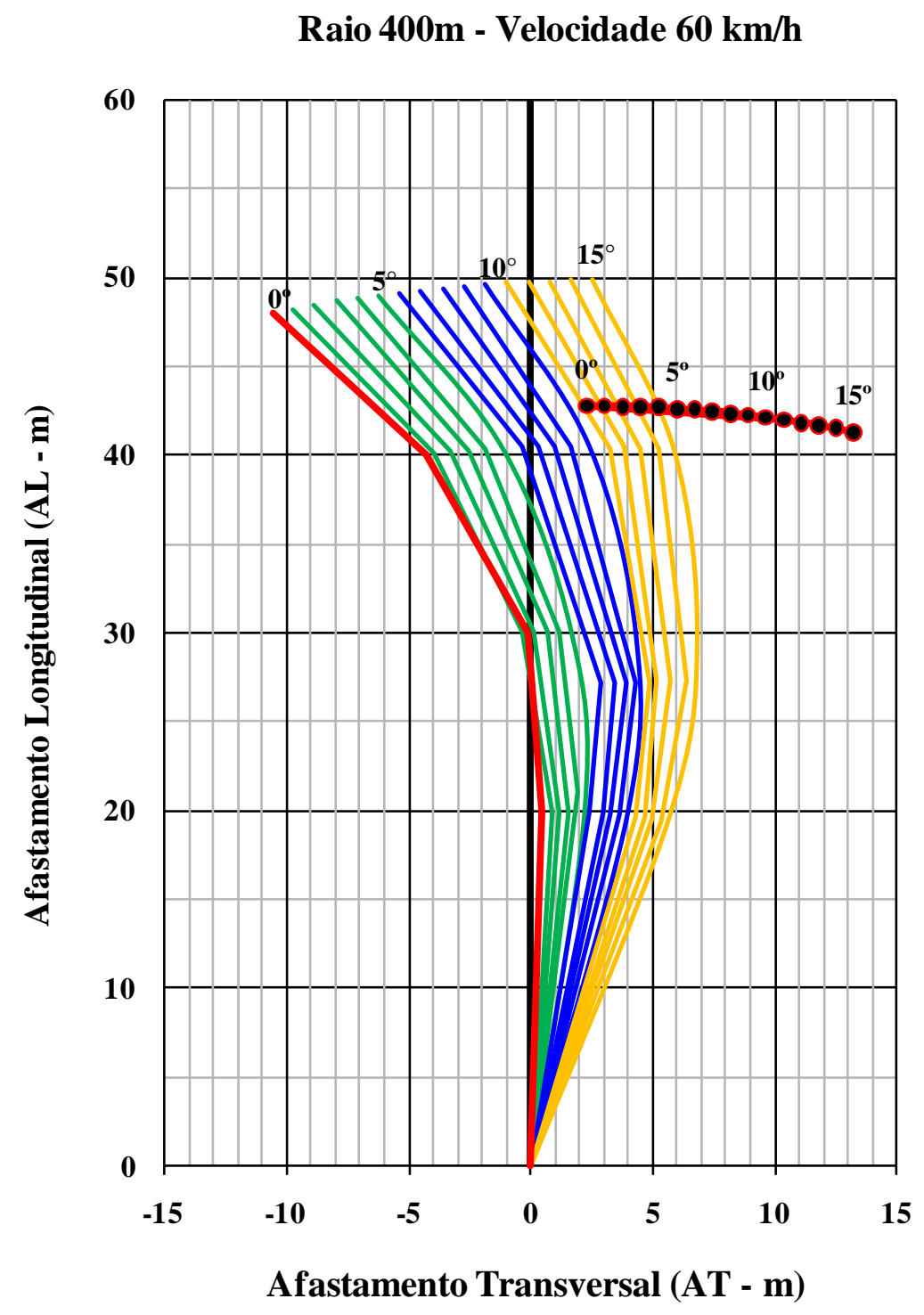


Raio 300m - Velocidade $100 \mathrm{~km} / \mathrm{h}$

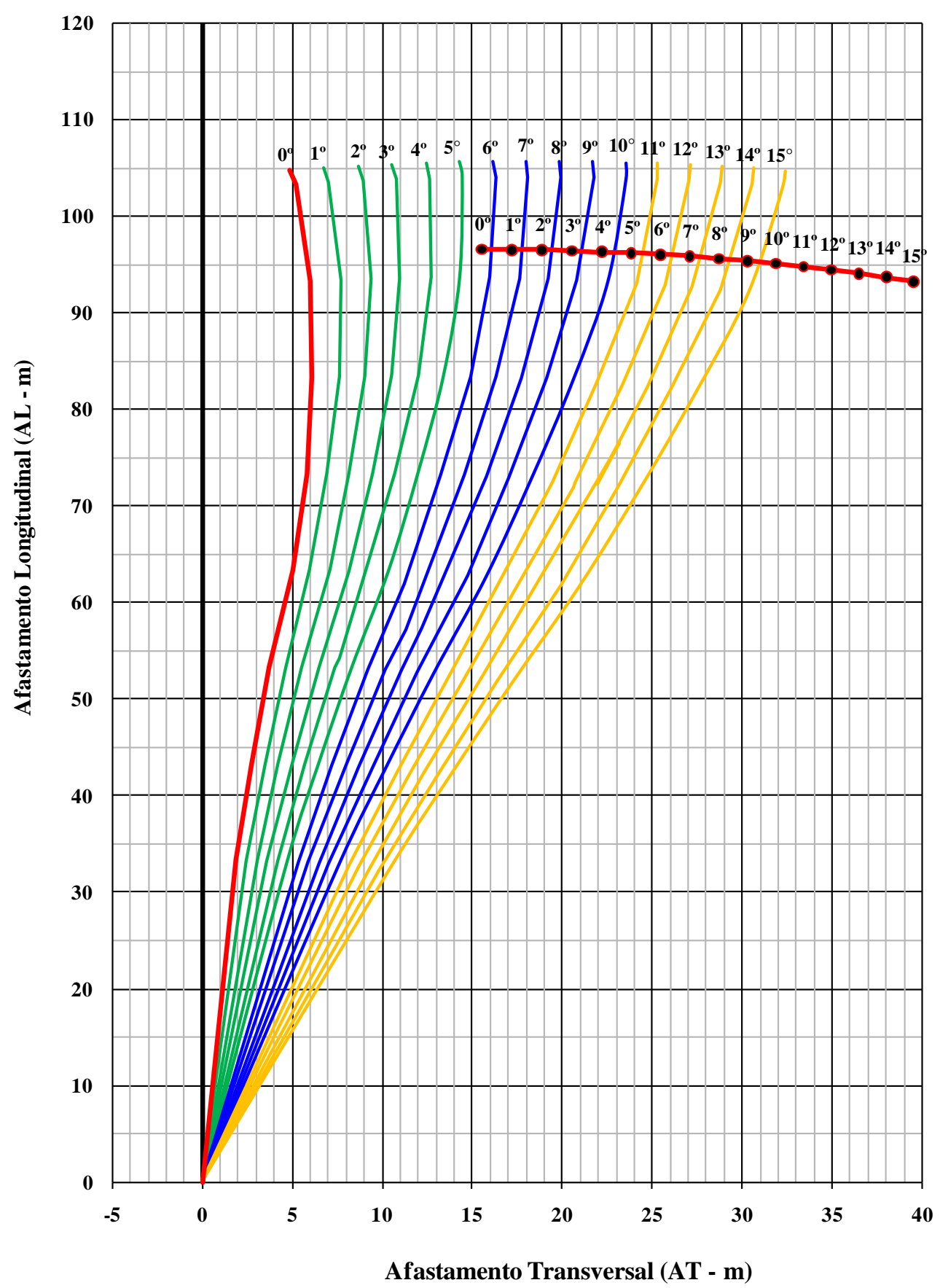


Raio 300m - Velocidade $90 \mathrm{~km} / \mathrm{h}$

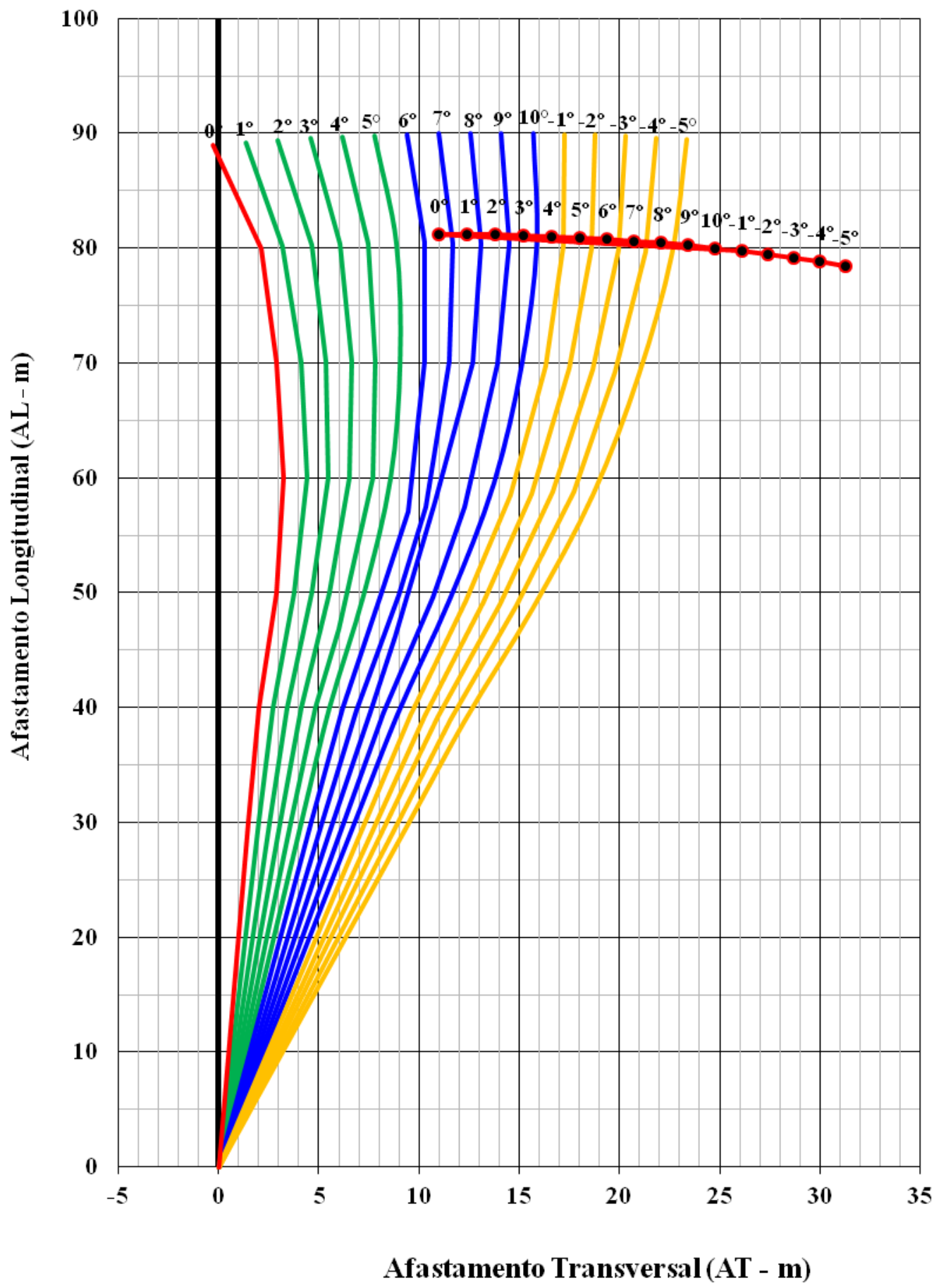


Raio 300m - Velocidade $80 \mathrm{~km} / \mathrm{h}$

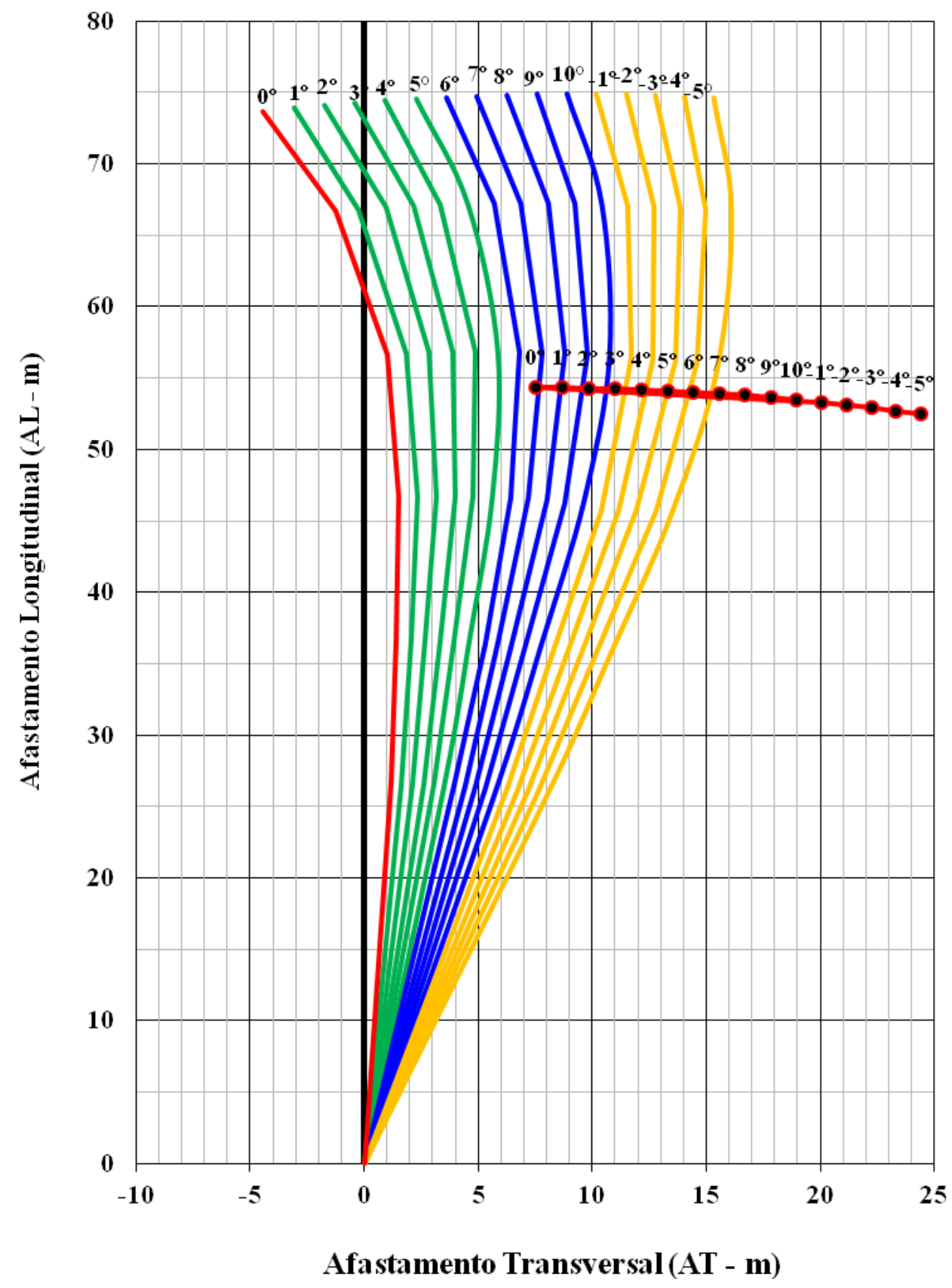


Raio 300m - Velocidade 70 km/h

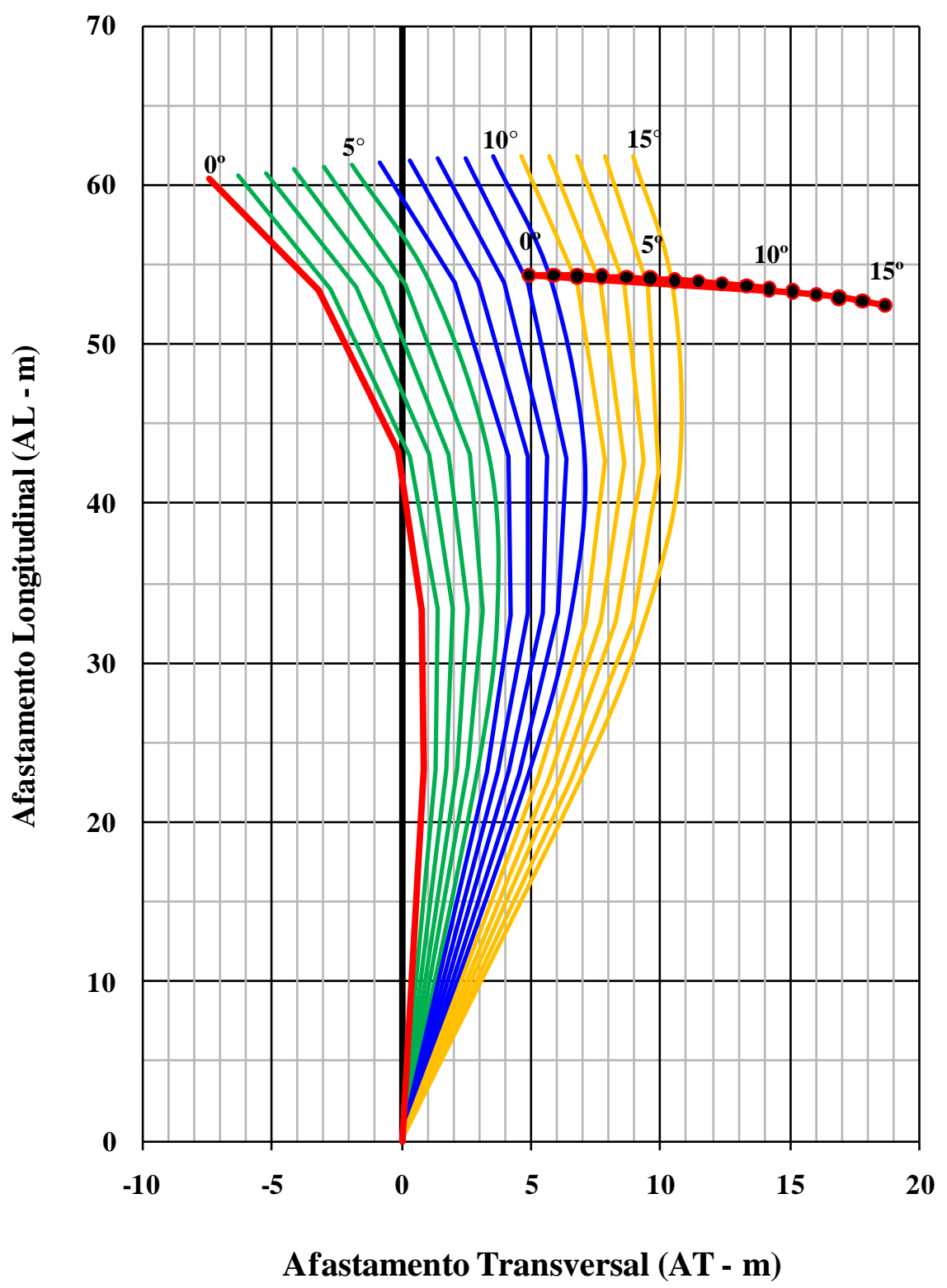




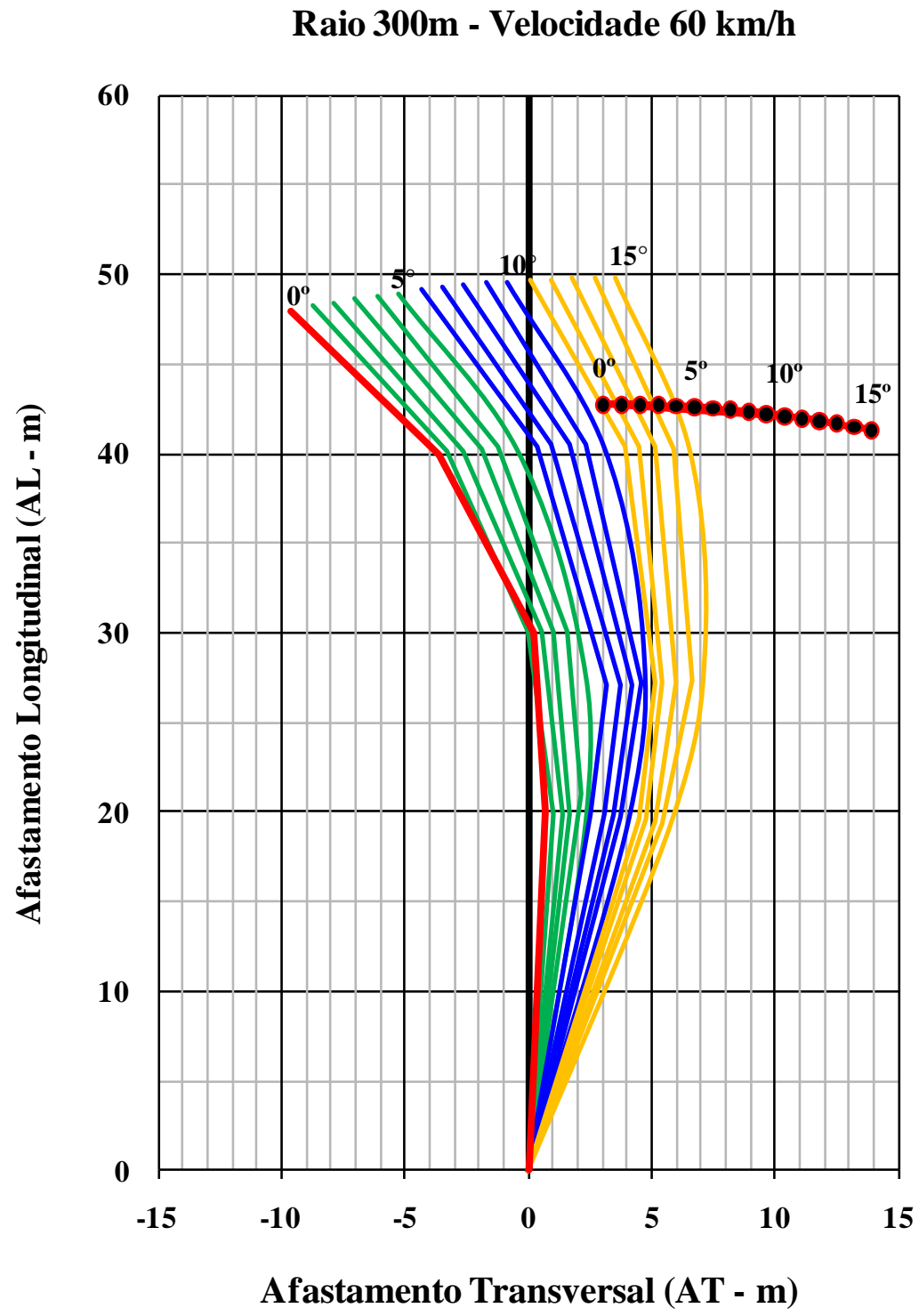


Raio 200m - Velocidade 90 km/h

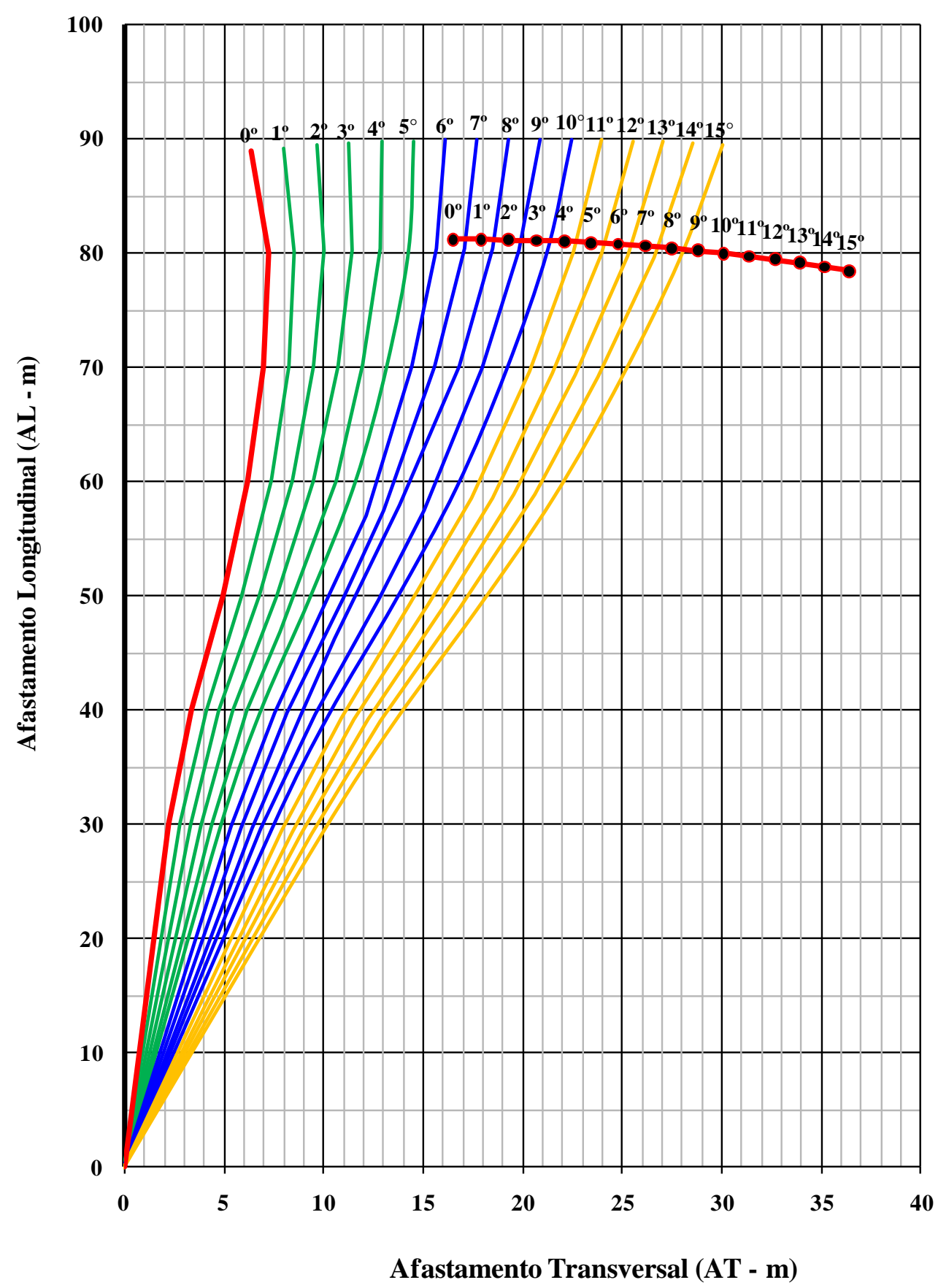


Raio 200m - Velocidade 80 km/h

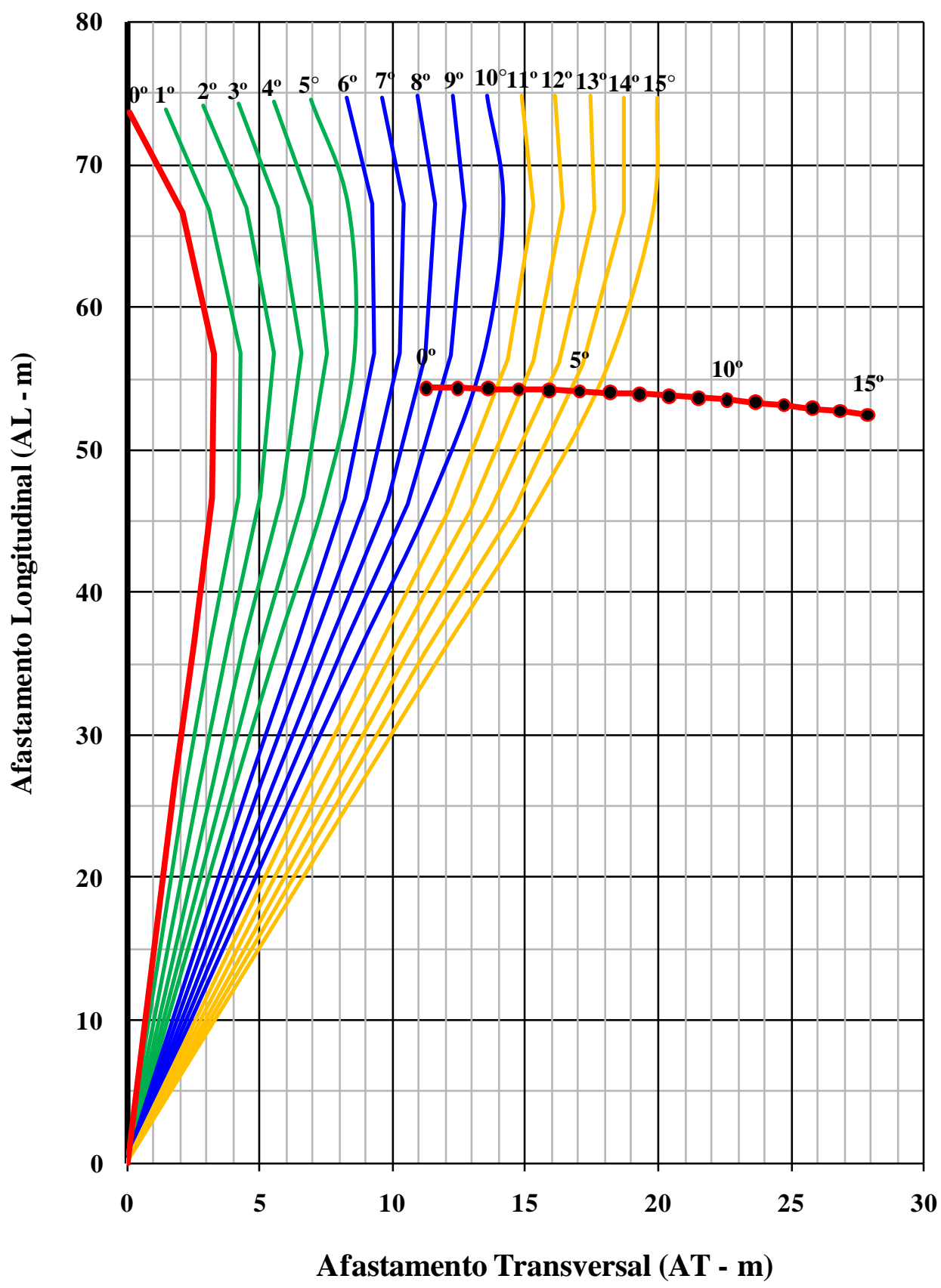


Raio 200m - Velocidade 70 km/h

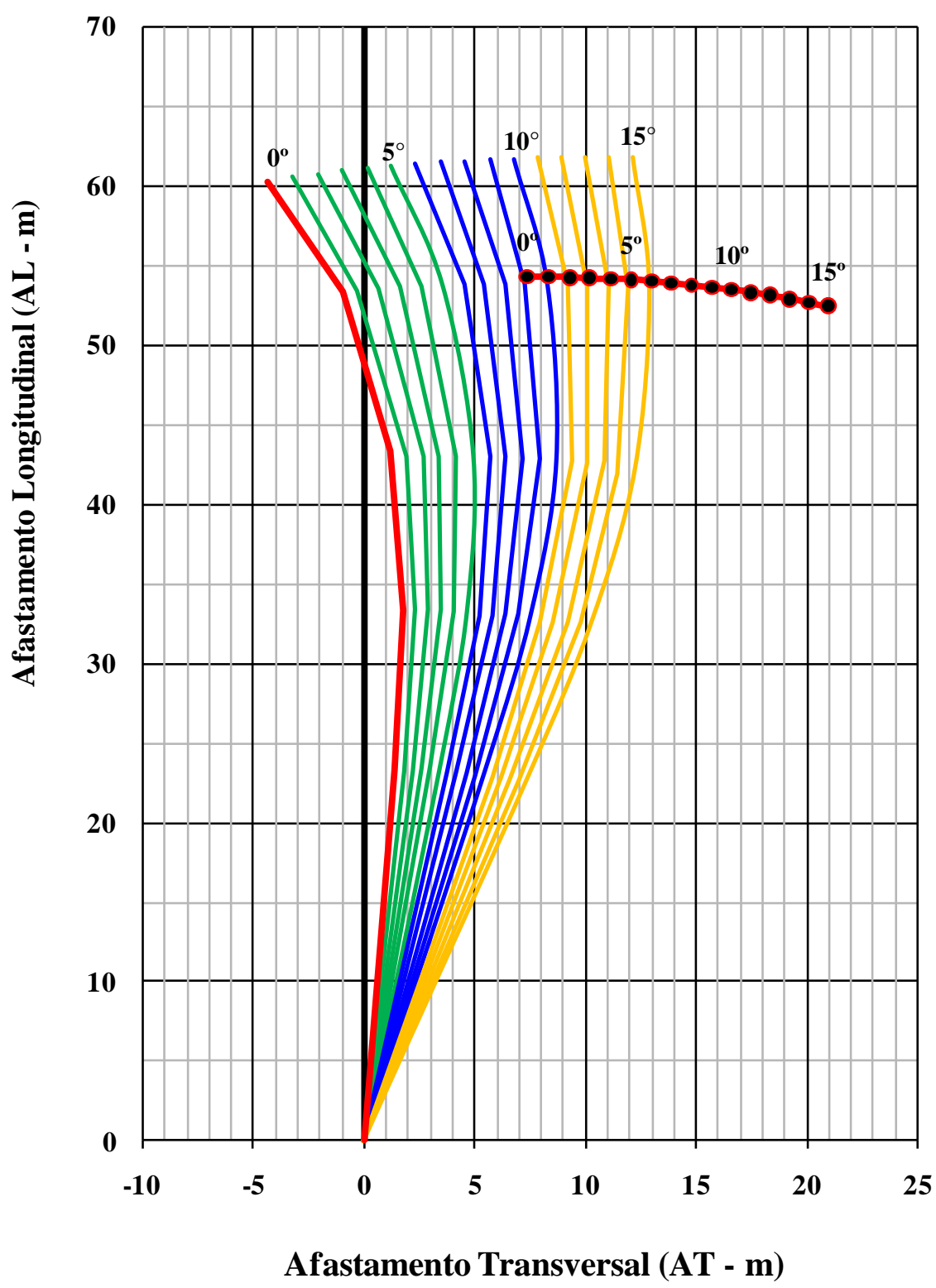




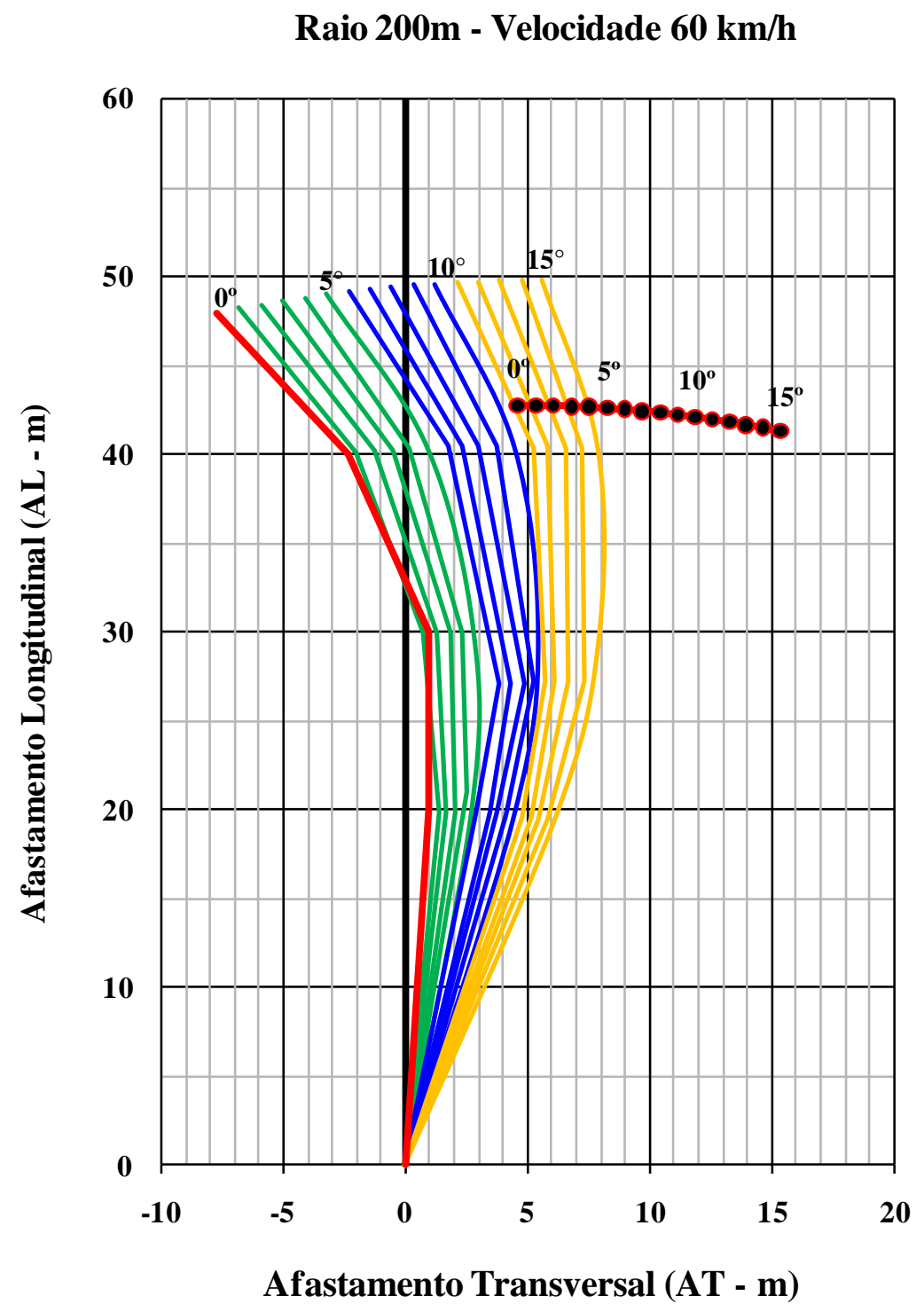


Raio 100m - Velocidade 70 km/h

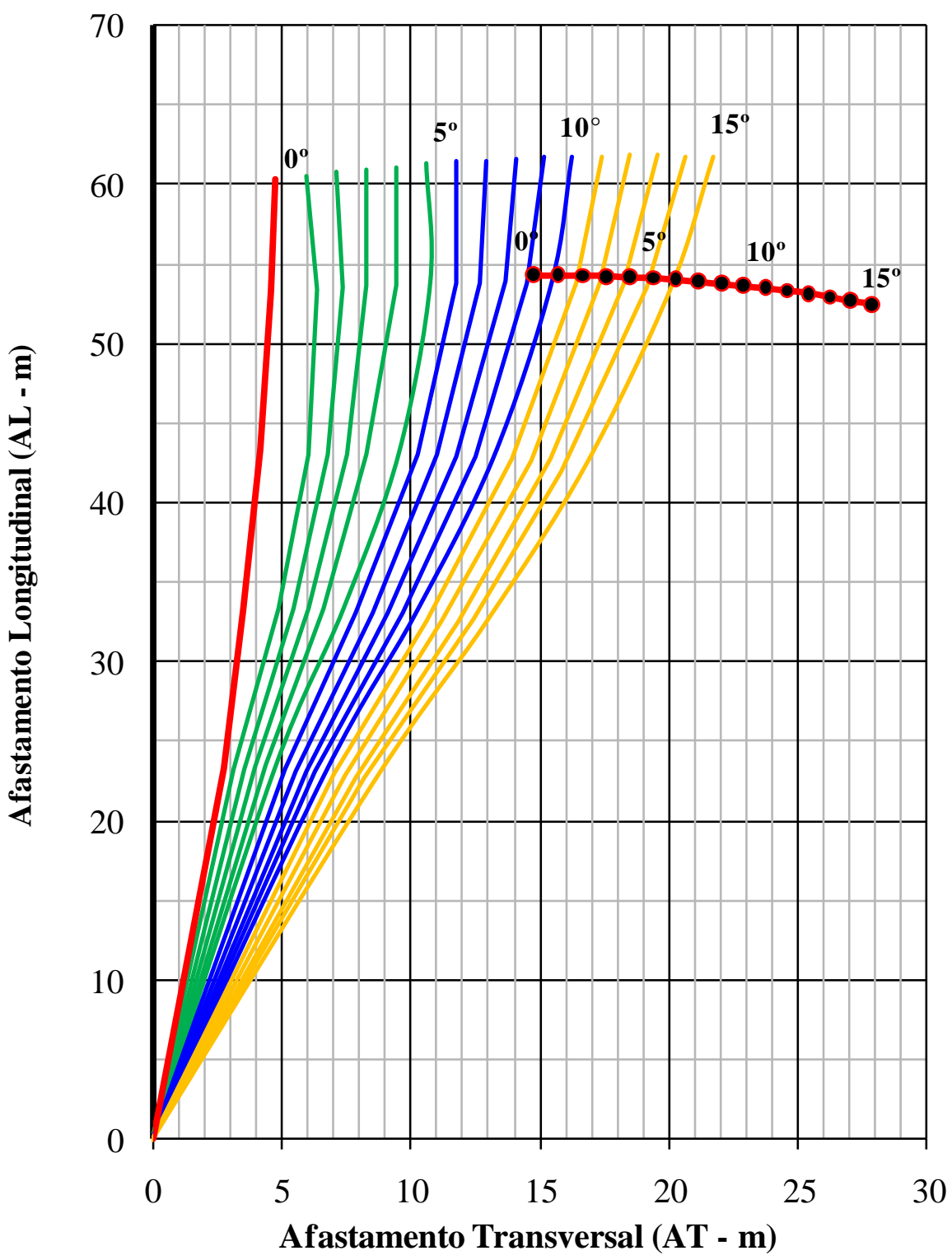




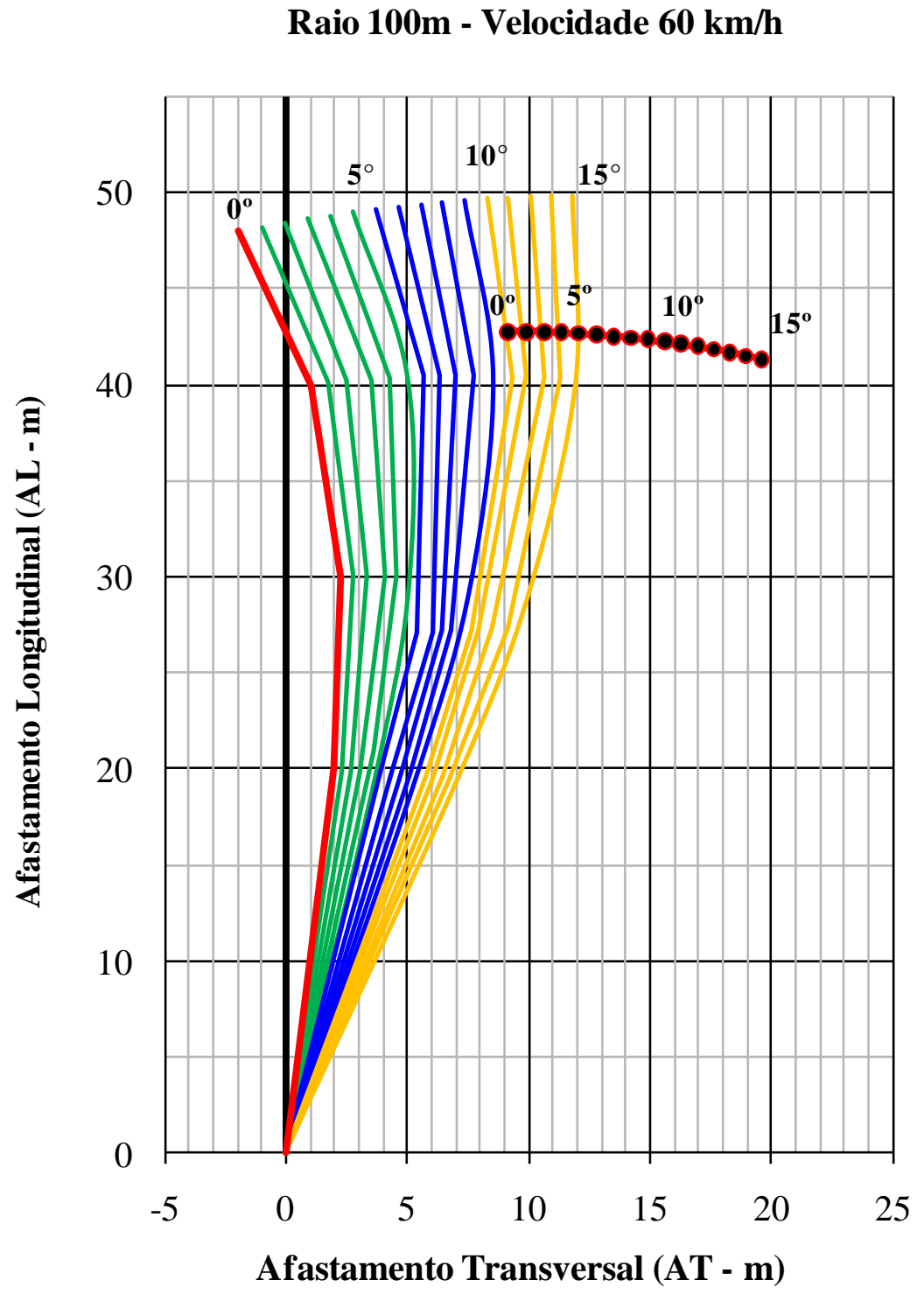




\section{SITUAÇÃO EM CURVA - DESVIO DIREITA}

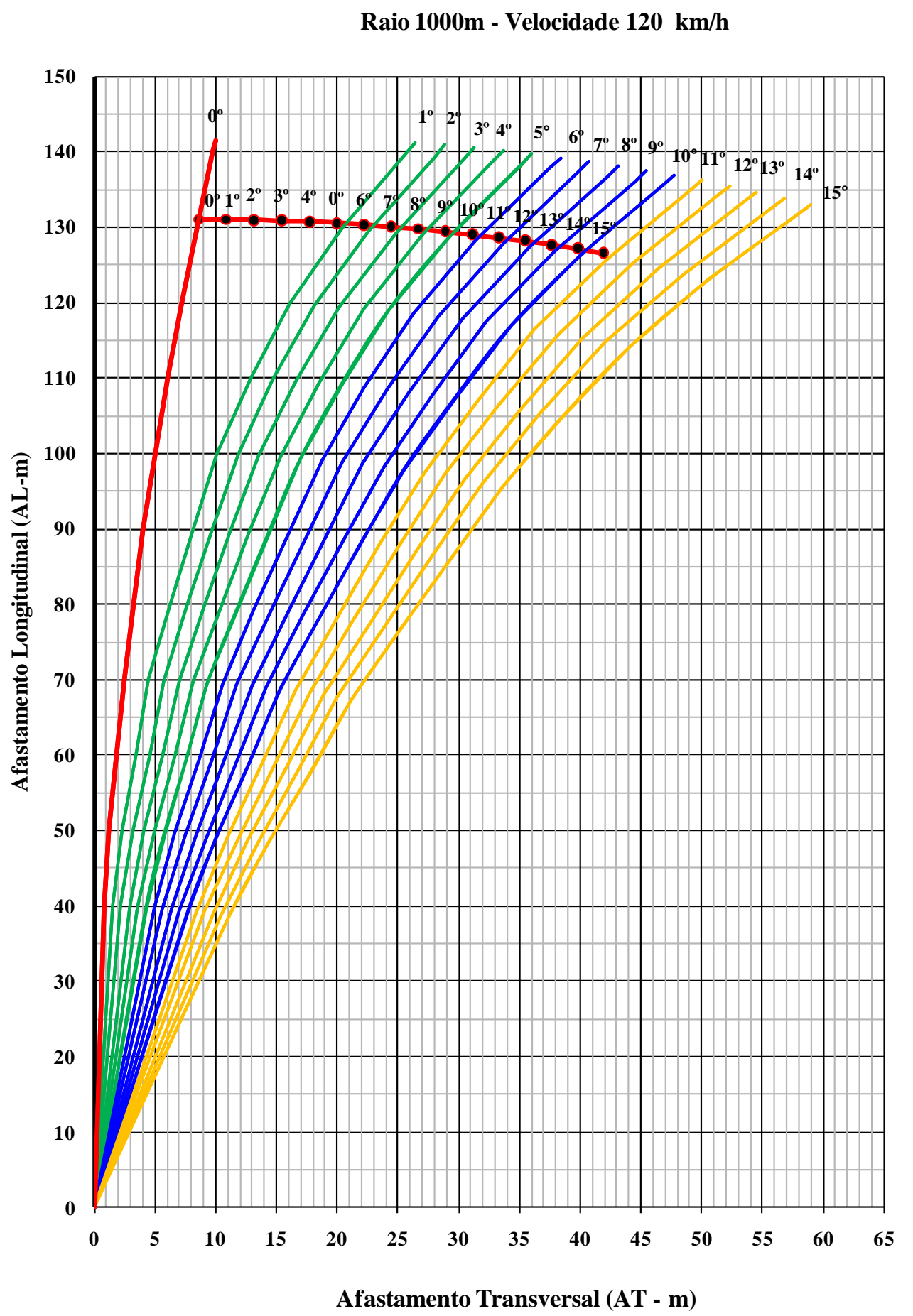


Raio 1000m - Velocidade $110 \mathrm{~km} / \mathrm{h}$

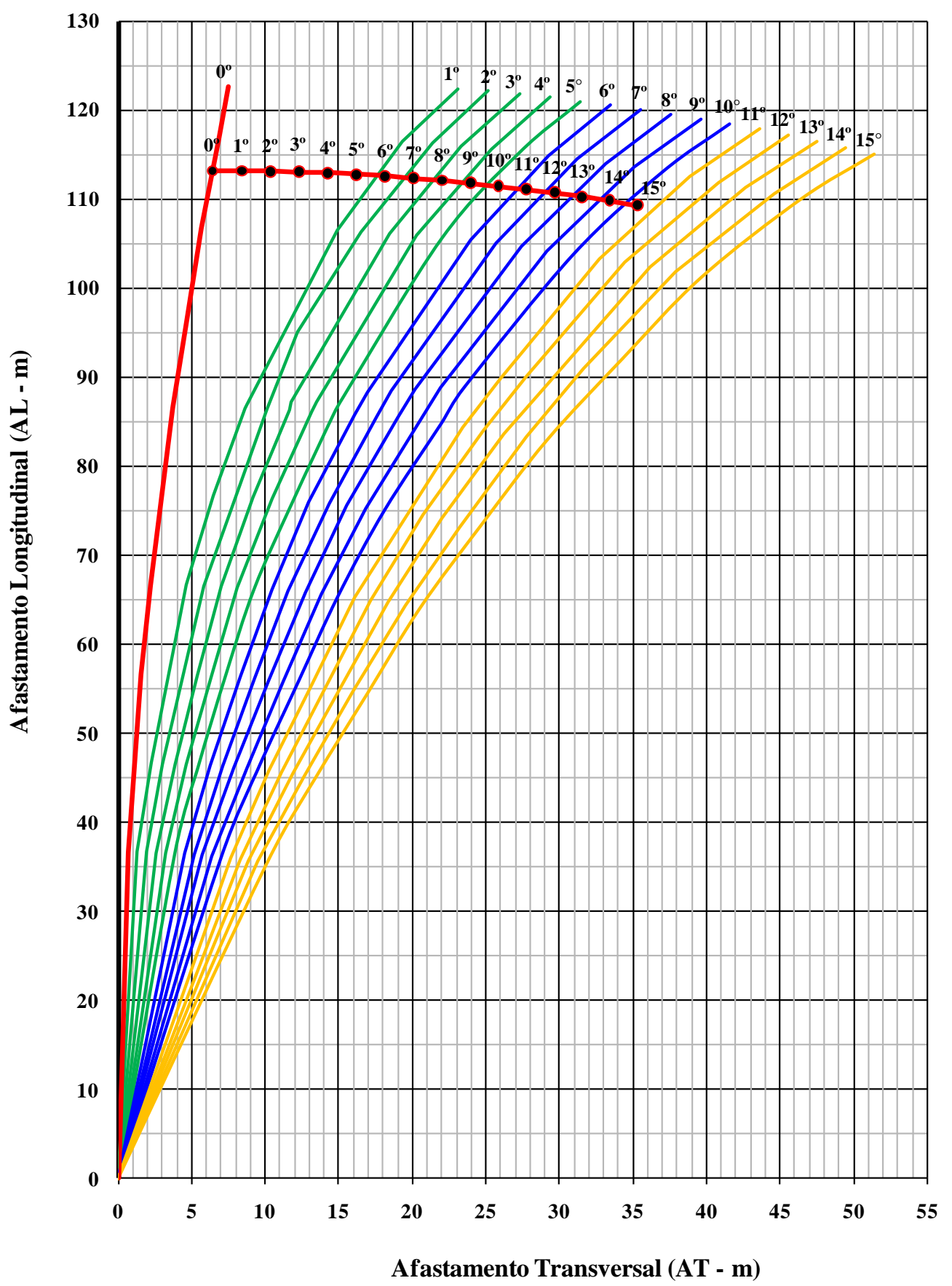


Raio 1000m - Velocidade 100 km/h

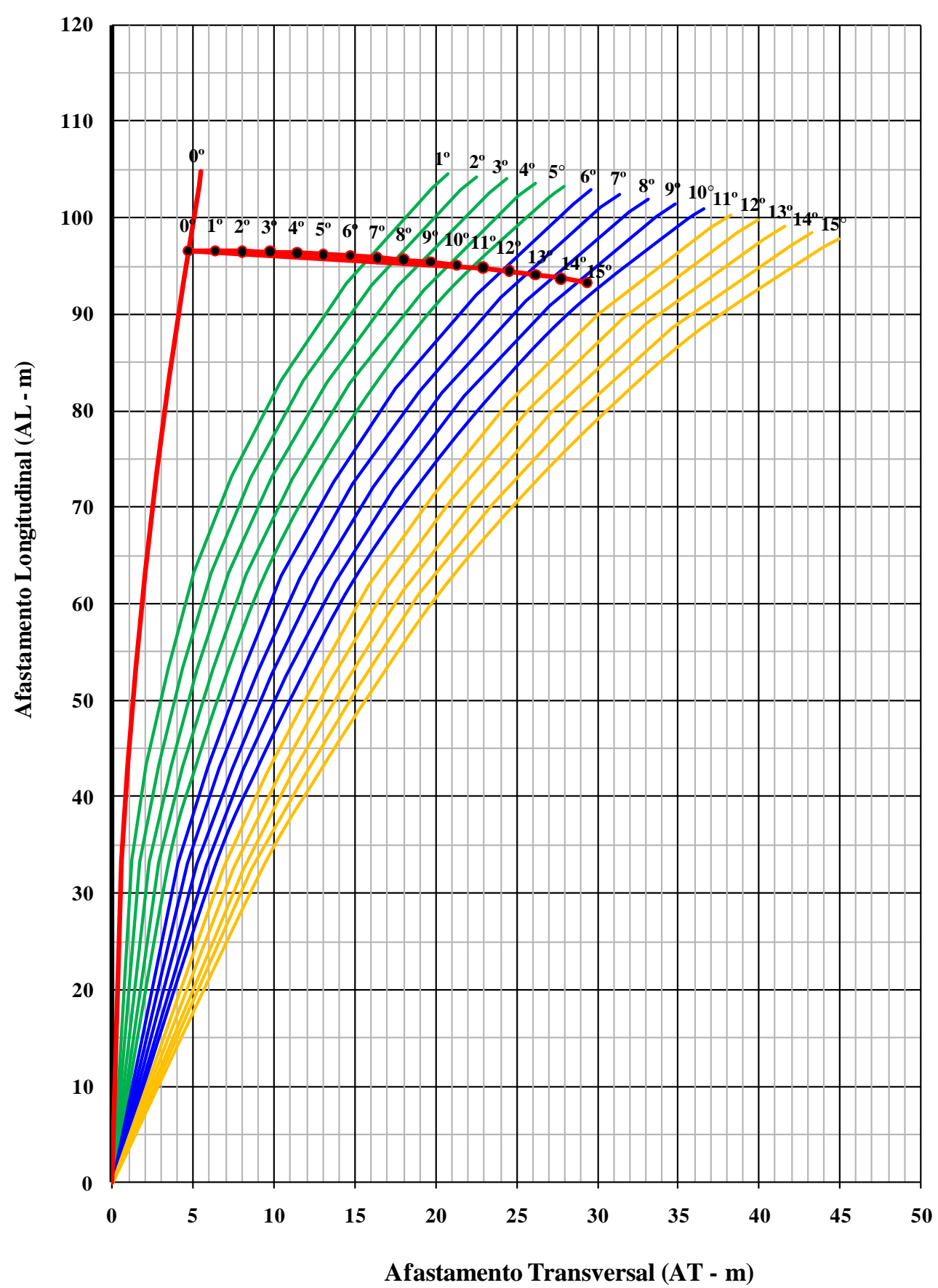


Raio 1000m - Velocidade 90 km/h

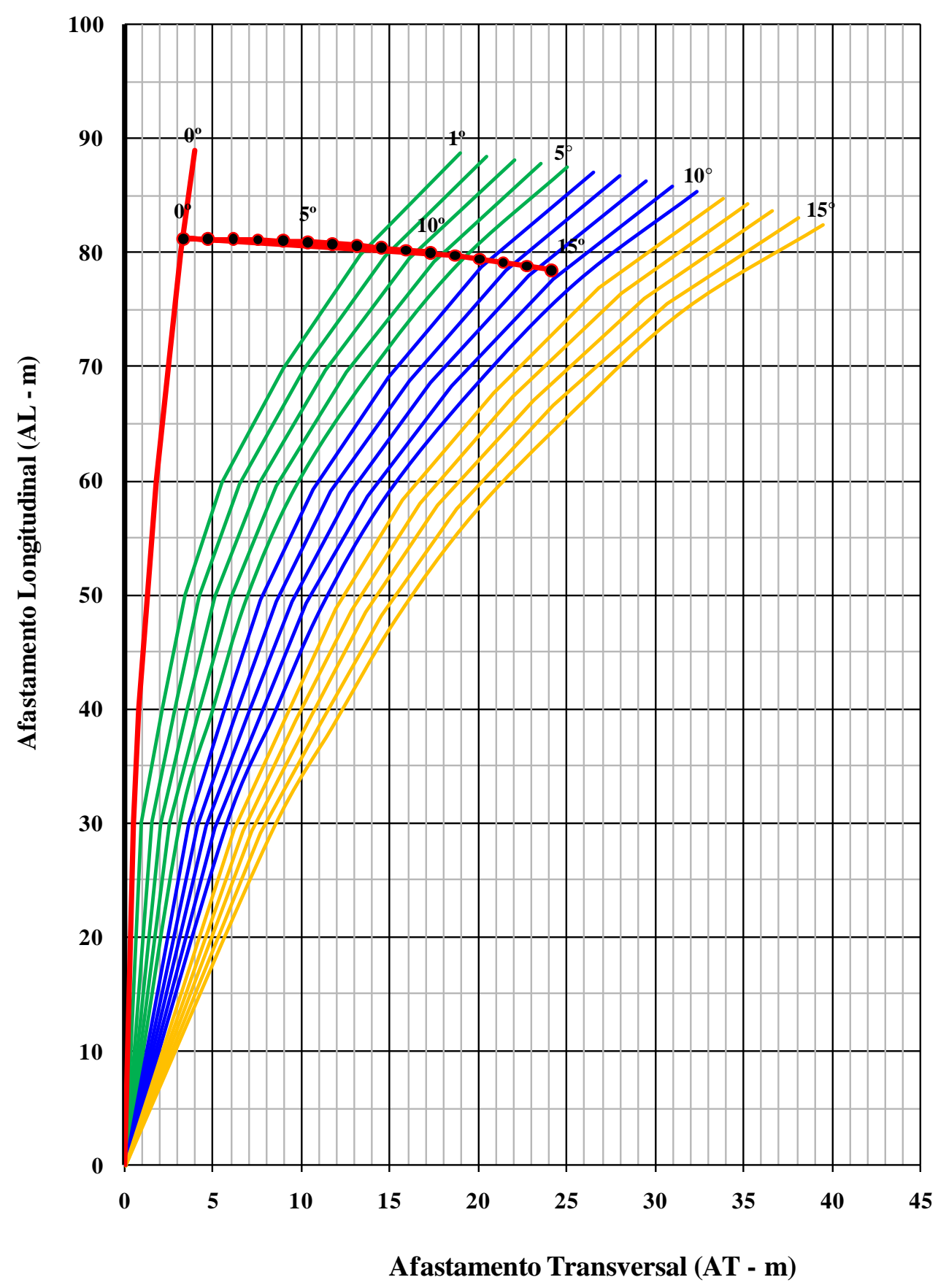




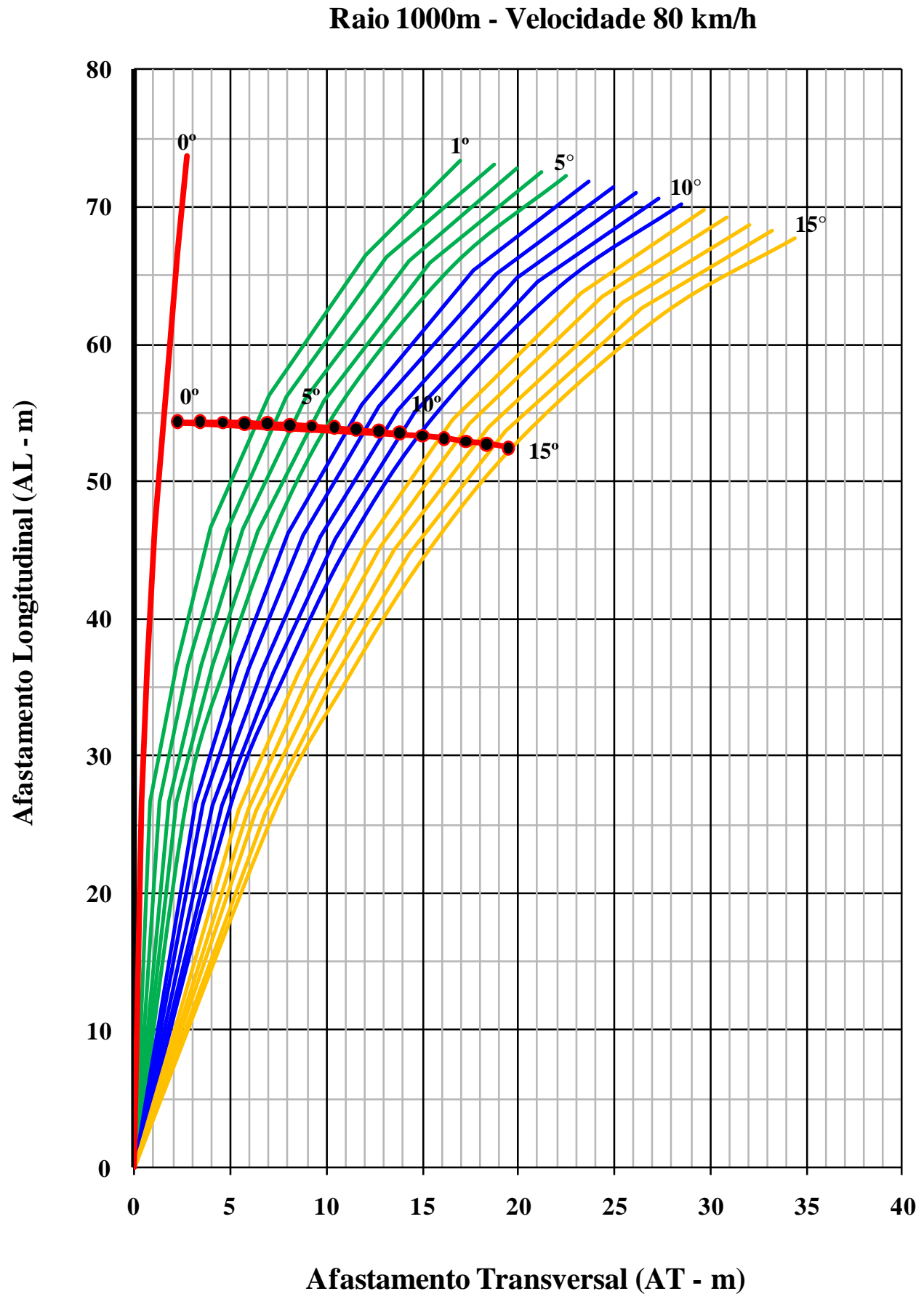


Raio 1000m - Velocidade 70 km/h

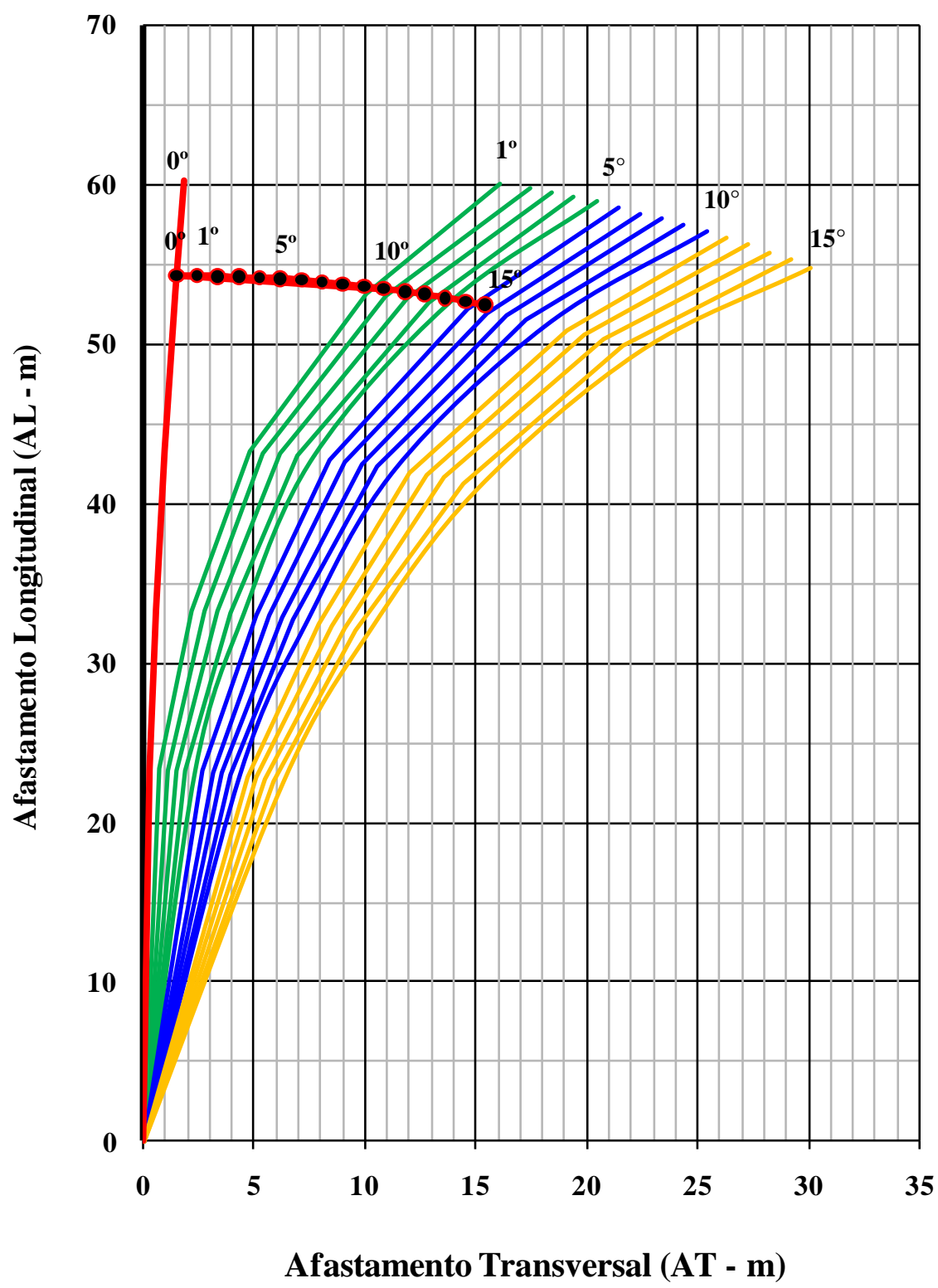




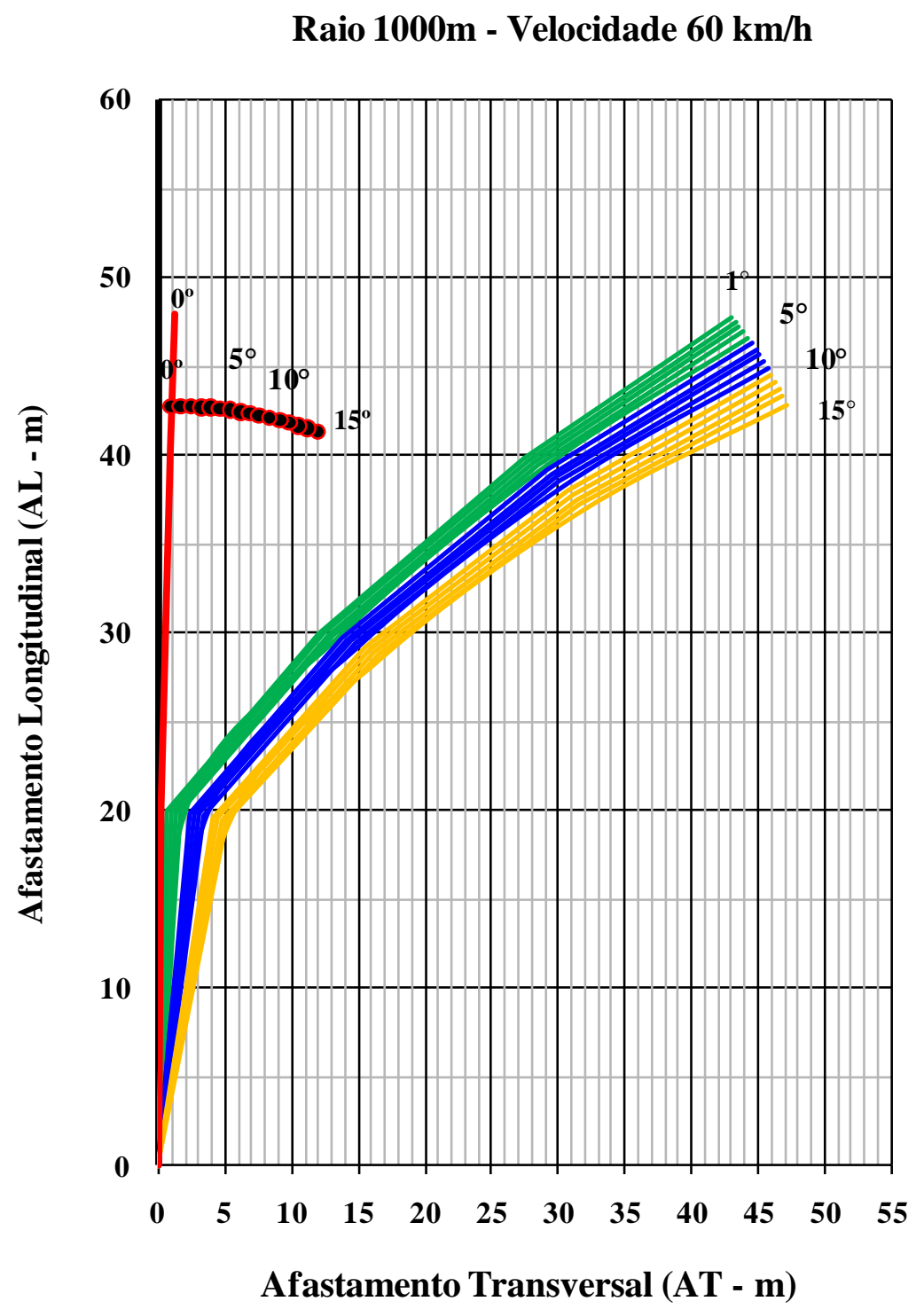


Raio 900m - Velocidade $120 \mathrm{~km} / \mathrm{h}$

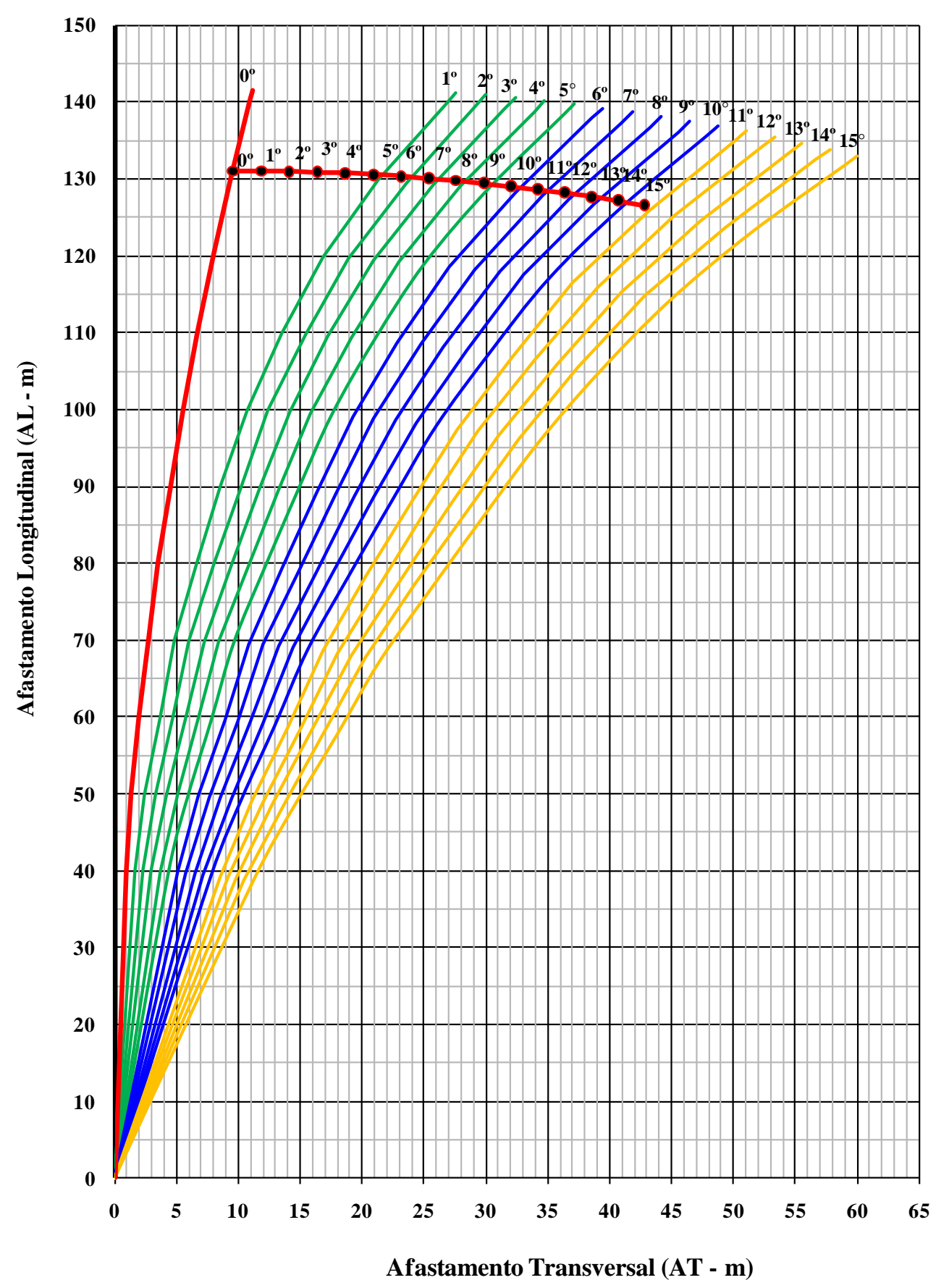


Raio 900m - Velocidade $110 \mathrm{~km} / \mathrm{h}$

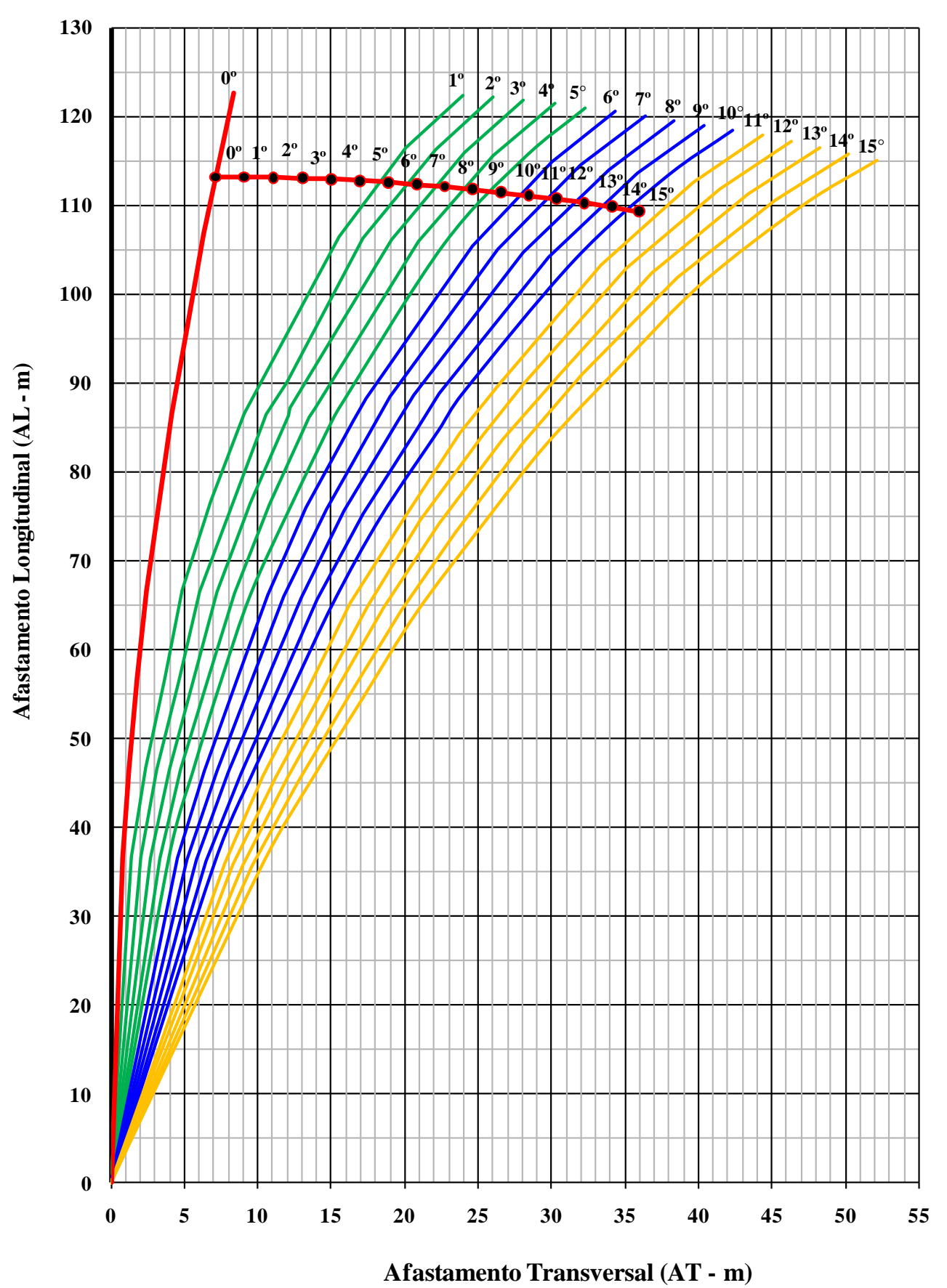


Raio 900m - Velocidade $100 \mathrm{~km} / \mathrm{h}$

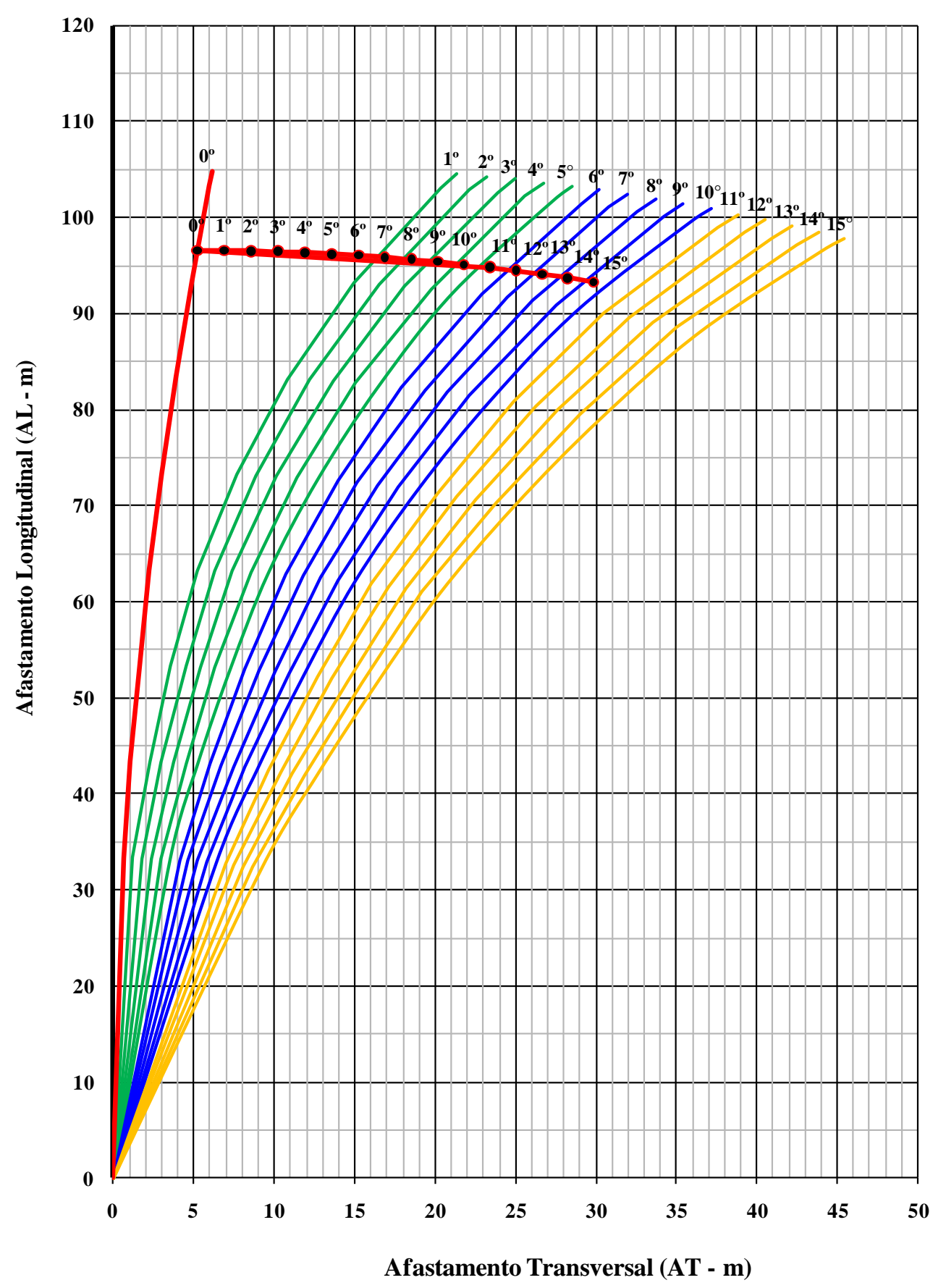


Raio 900m - Velocidade 90 km/h

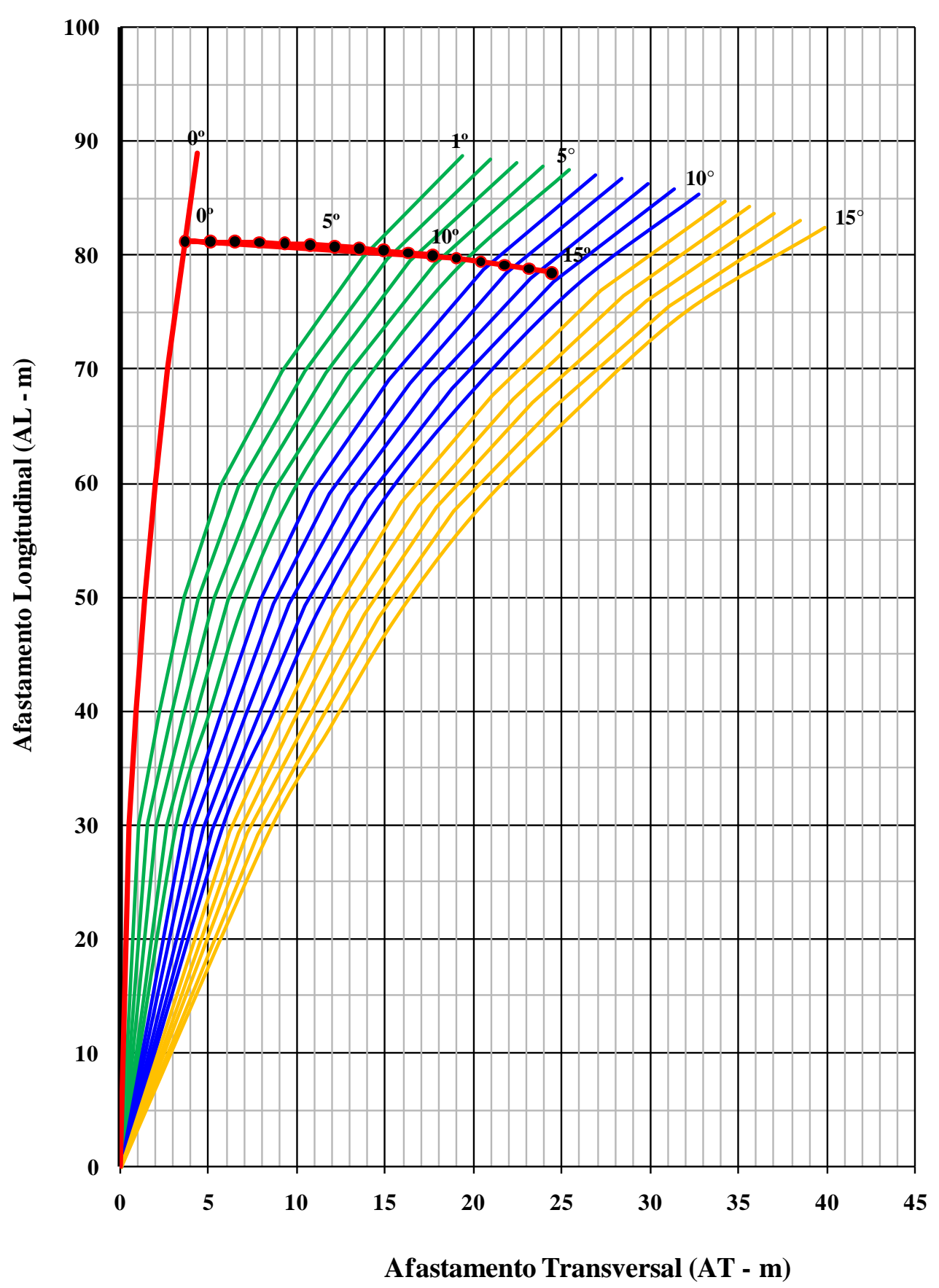


Raio 900m - Velocidade $80 \mathrm{~km} / \mathrm{h}$

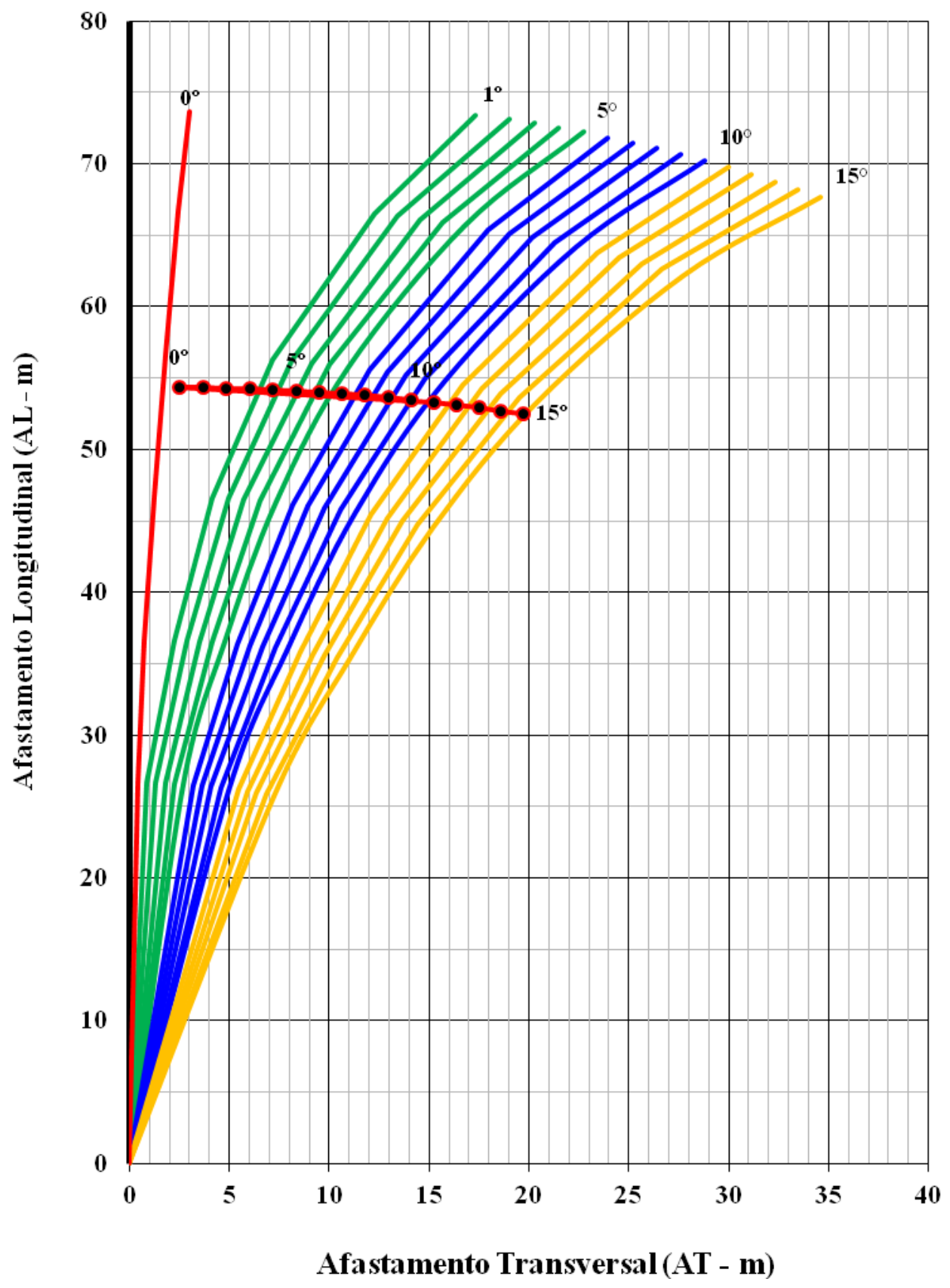




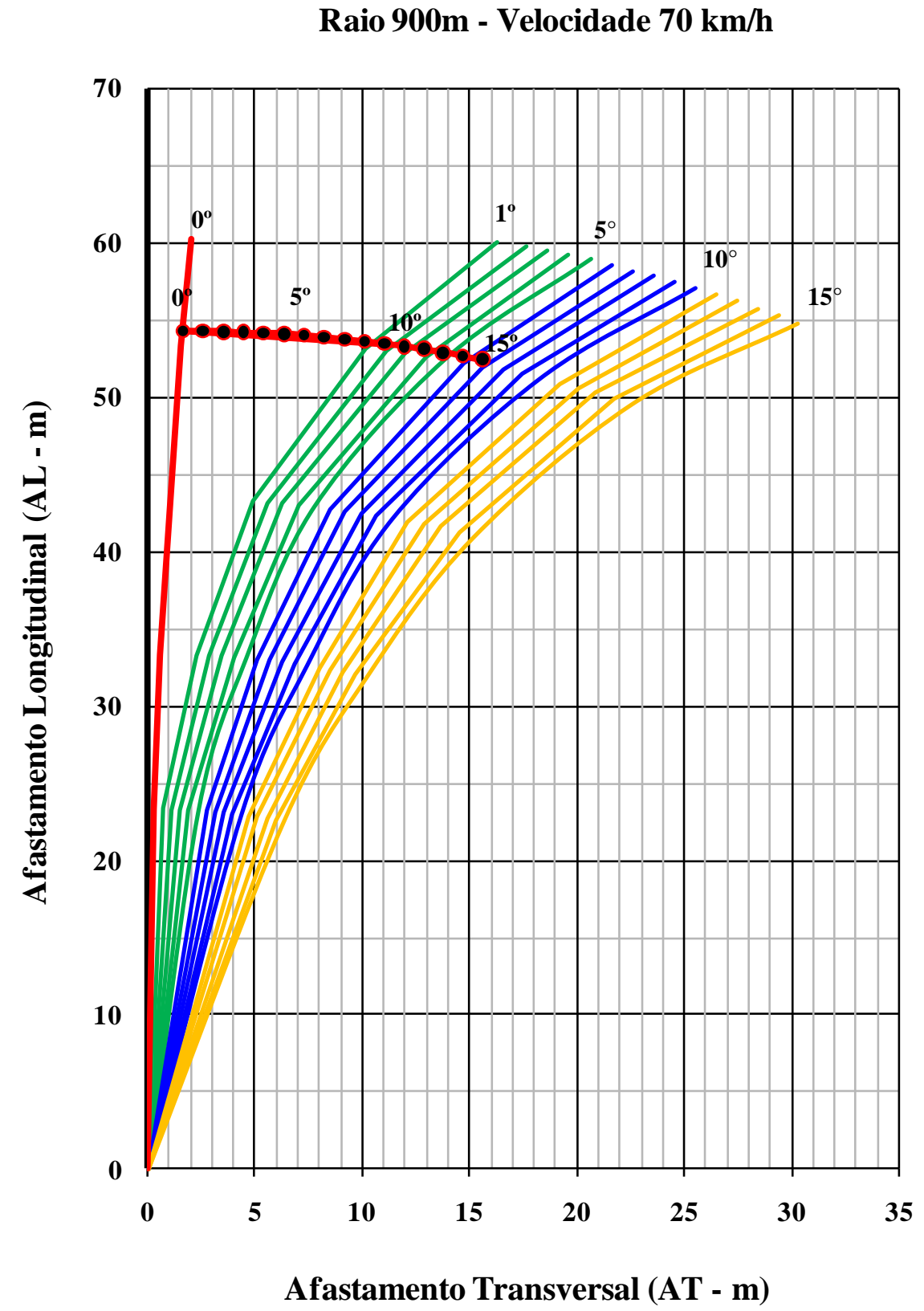




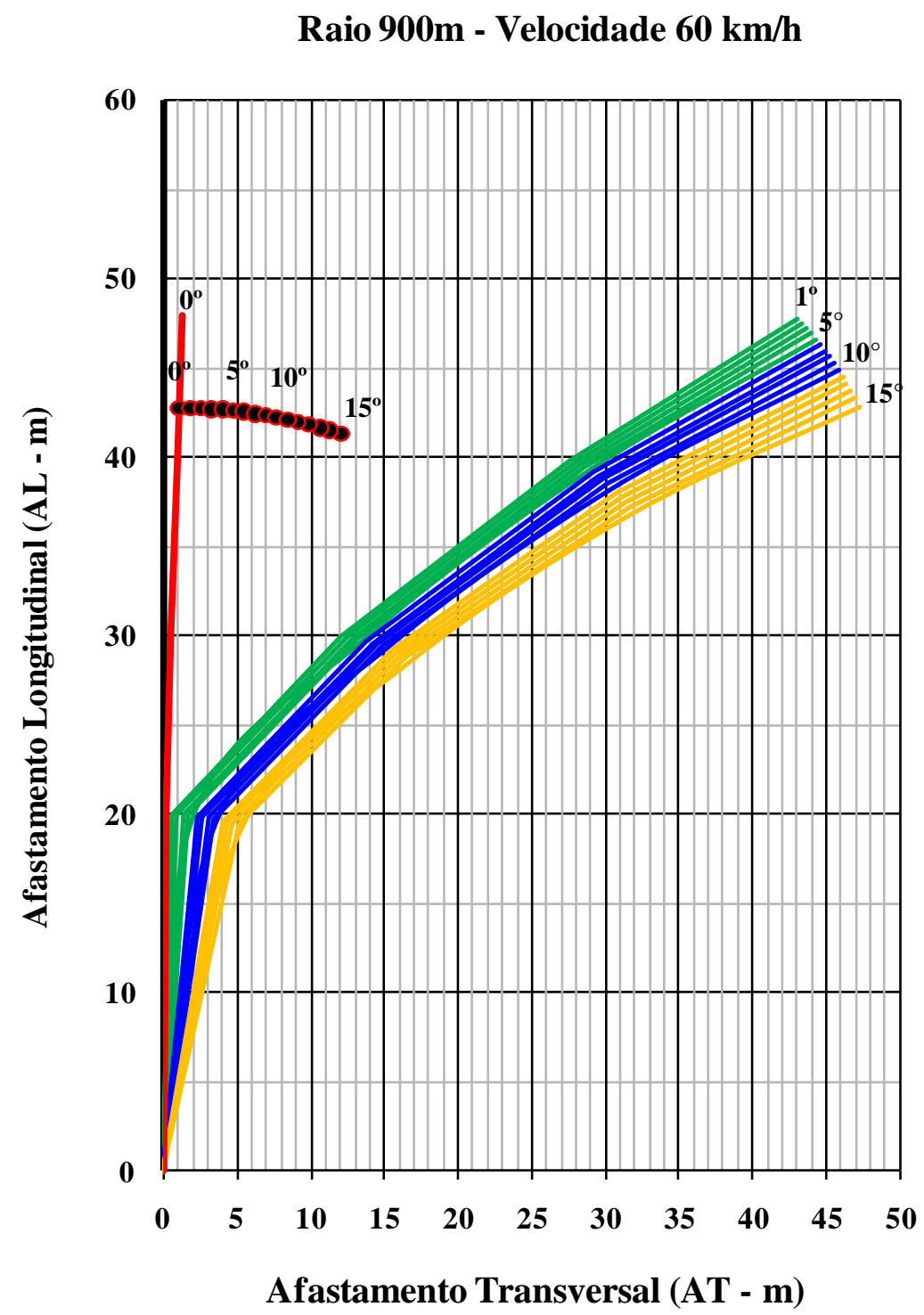


Raio 800m - Velocidade $120 \mathrm{~km} / \mathrm{h}$

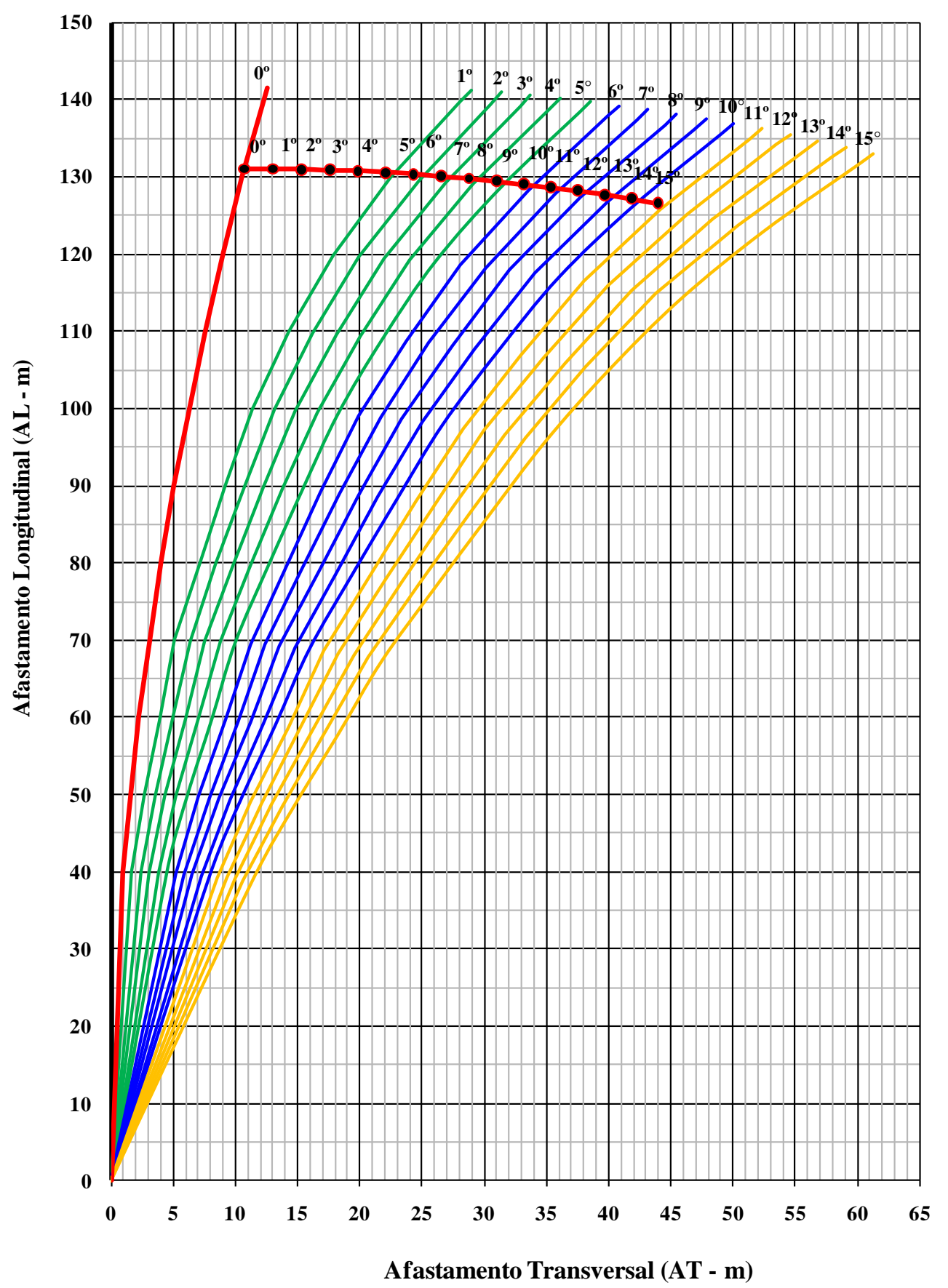


Raio 800m - Velocidade 110 km/h

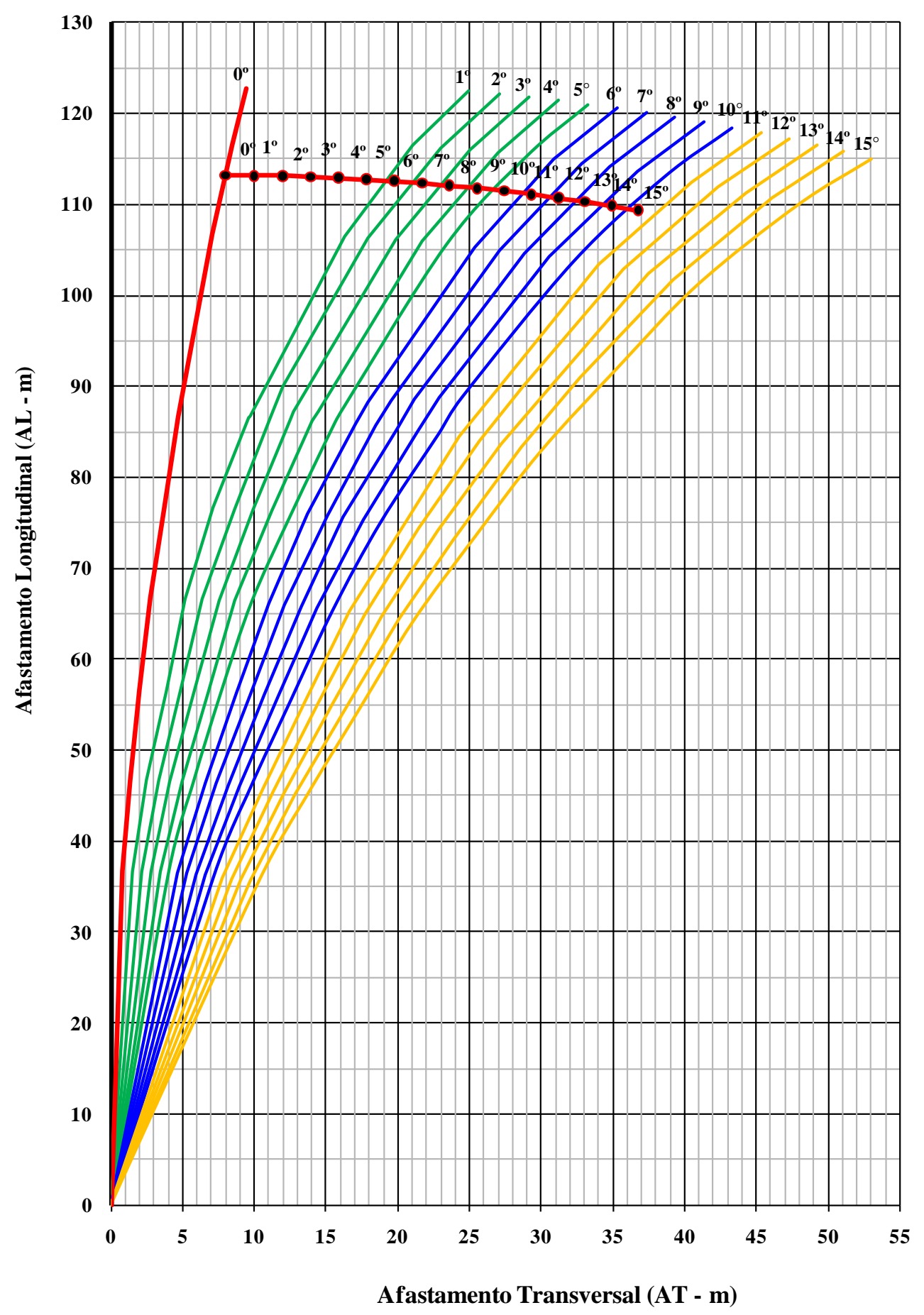


Raio 800m - Velocidade $100 \mathrm{~km} / \mathrm{h}$

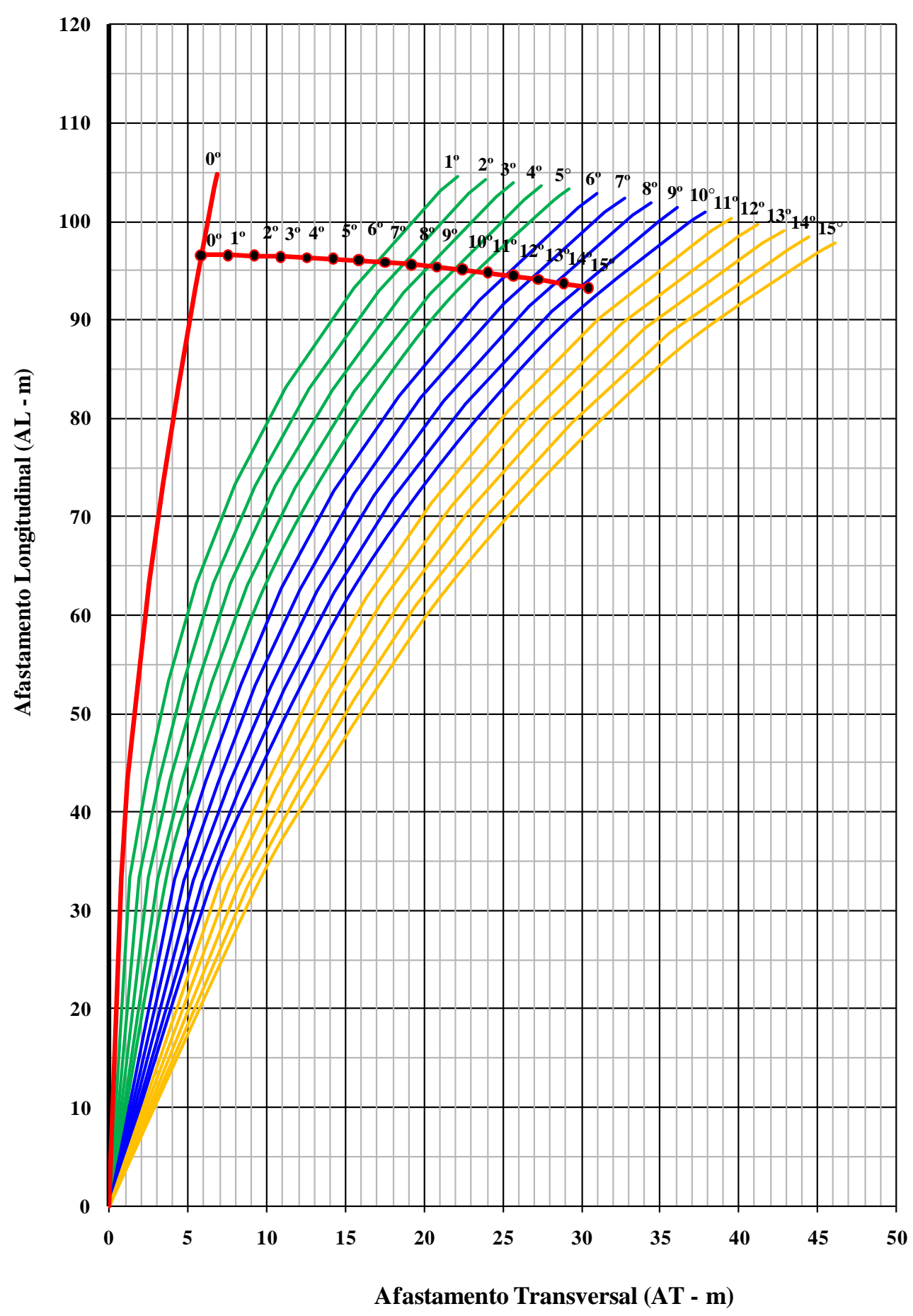


Raio 800m - Velocidade 90 km/h

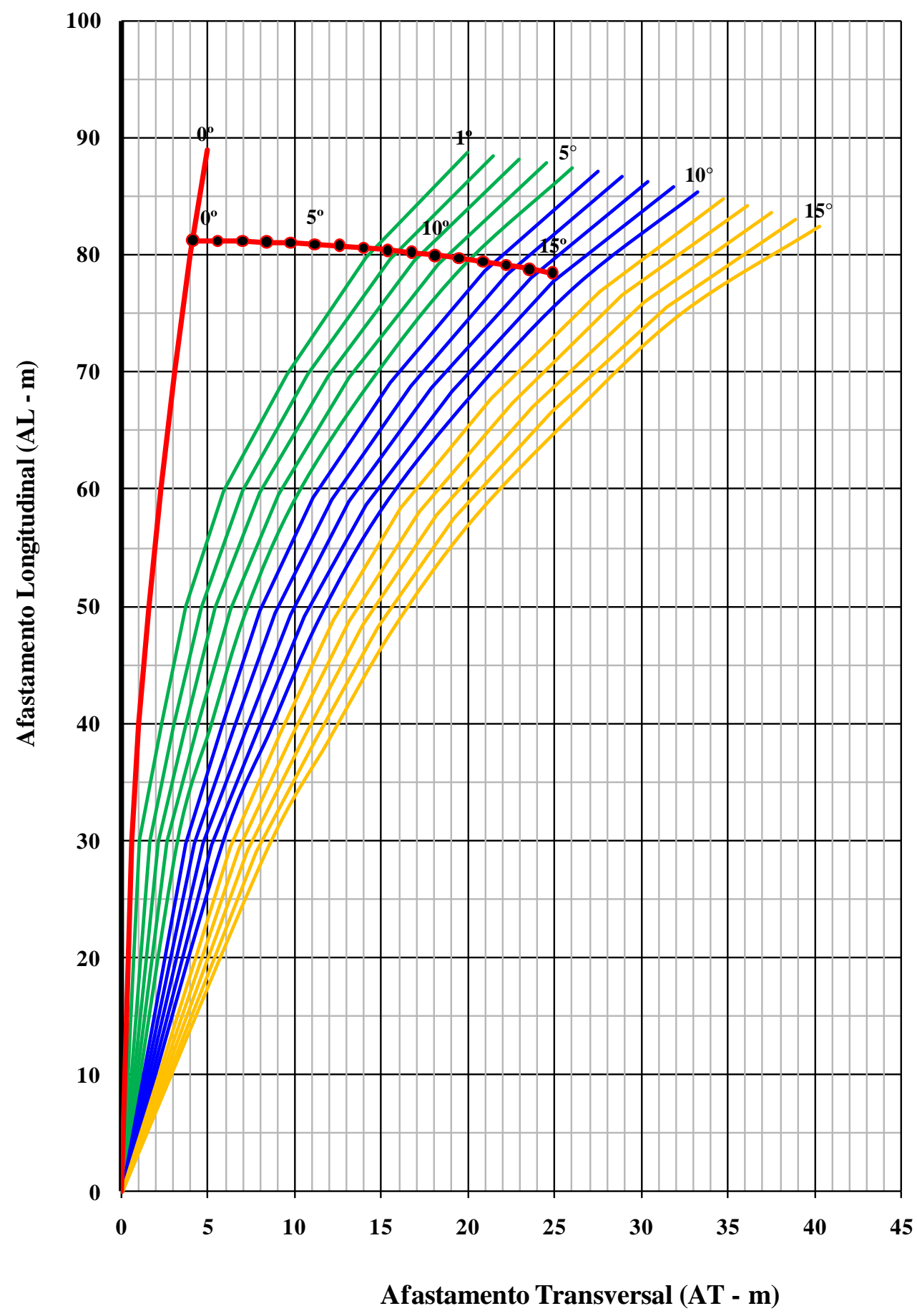




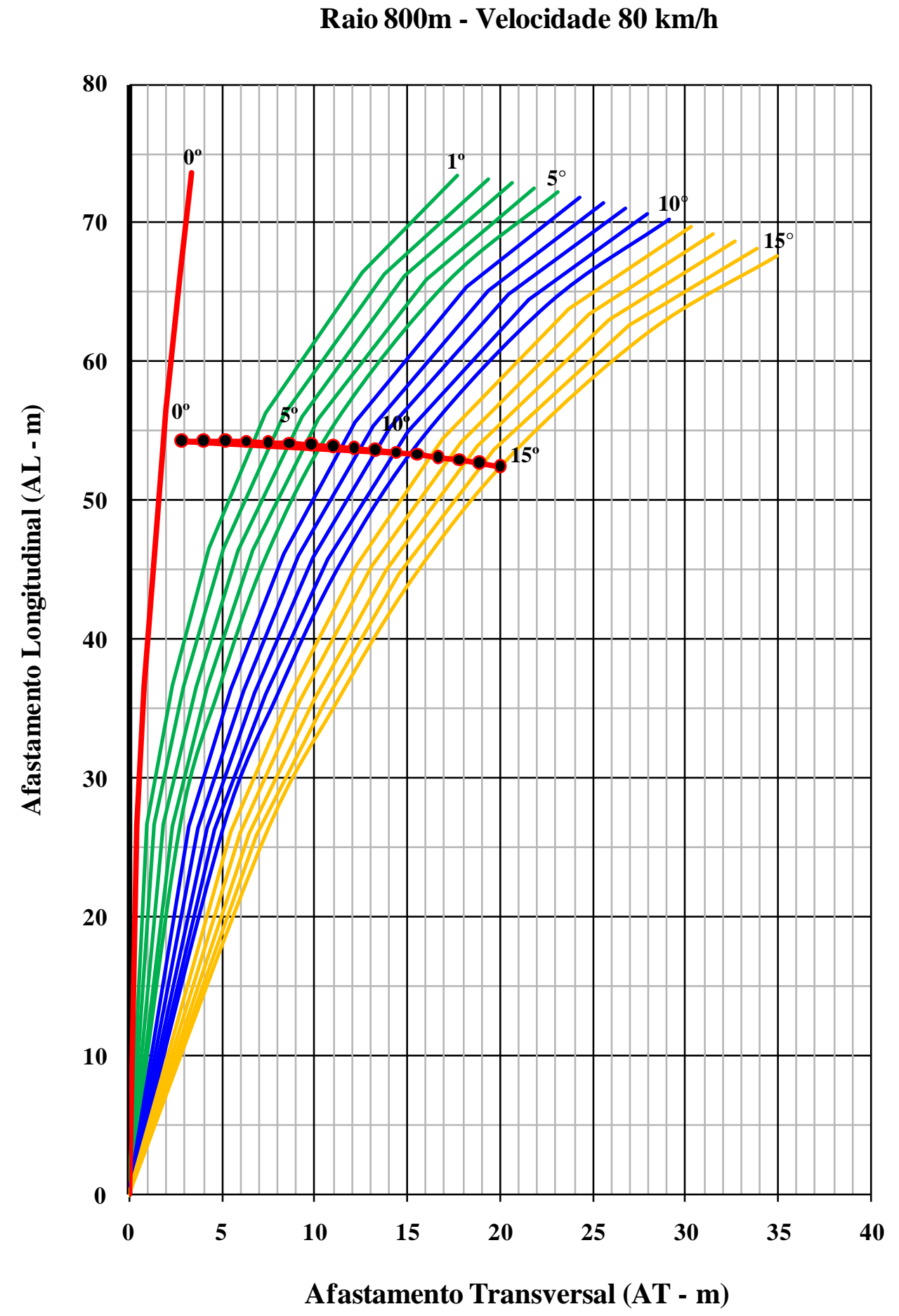


Raio 800m - Velocidade 70 km/h

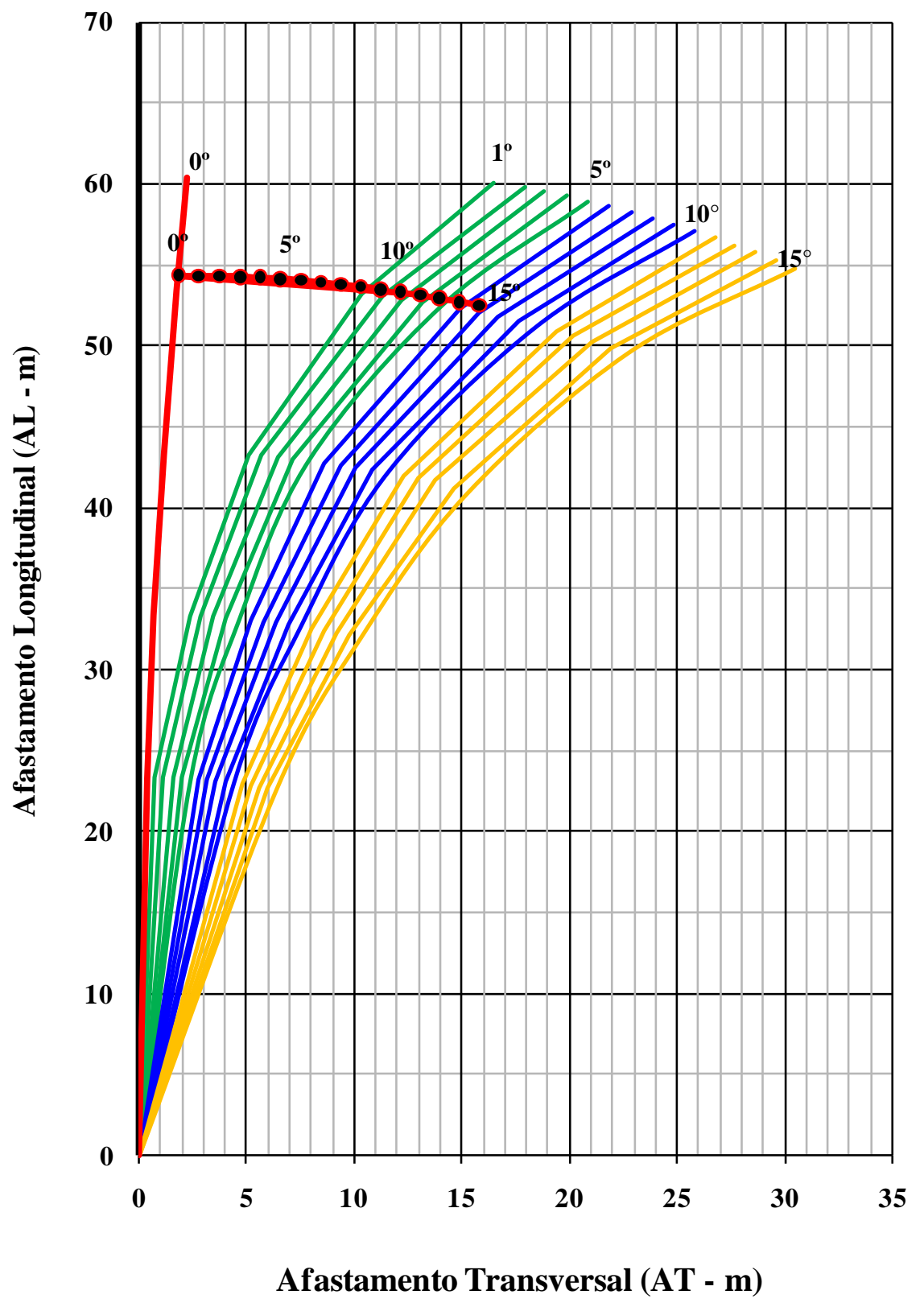




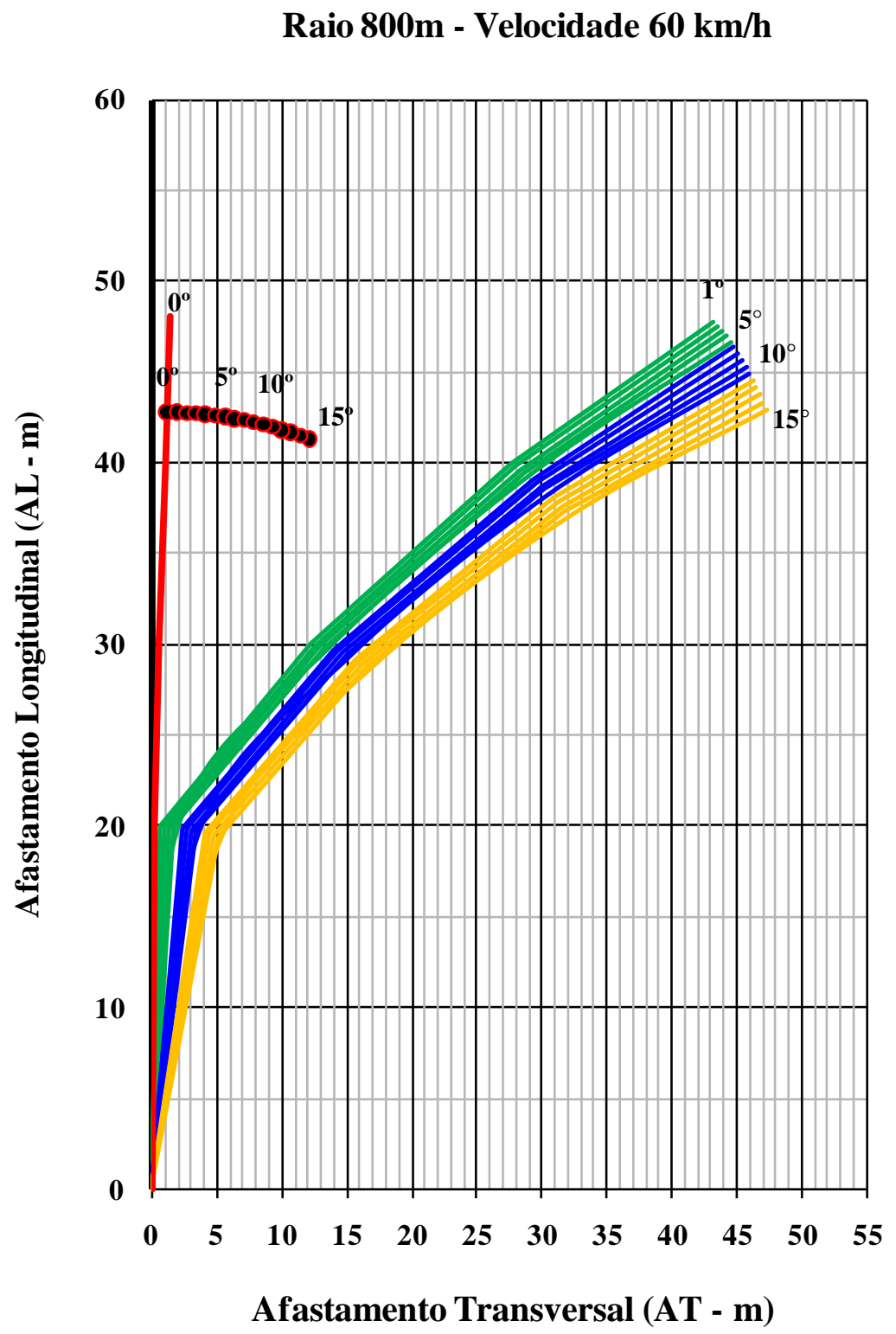


Raio 700m - Velocidade $120 \mathrm{~km} / \mathrm{h}$

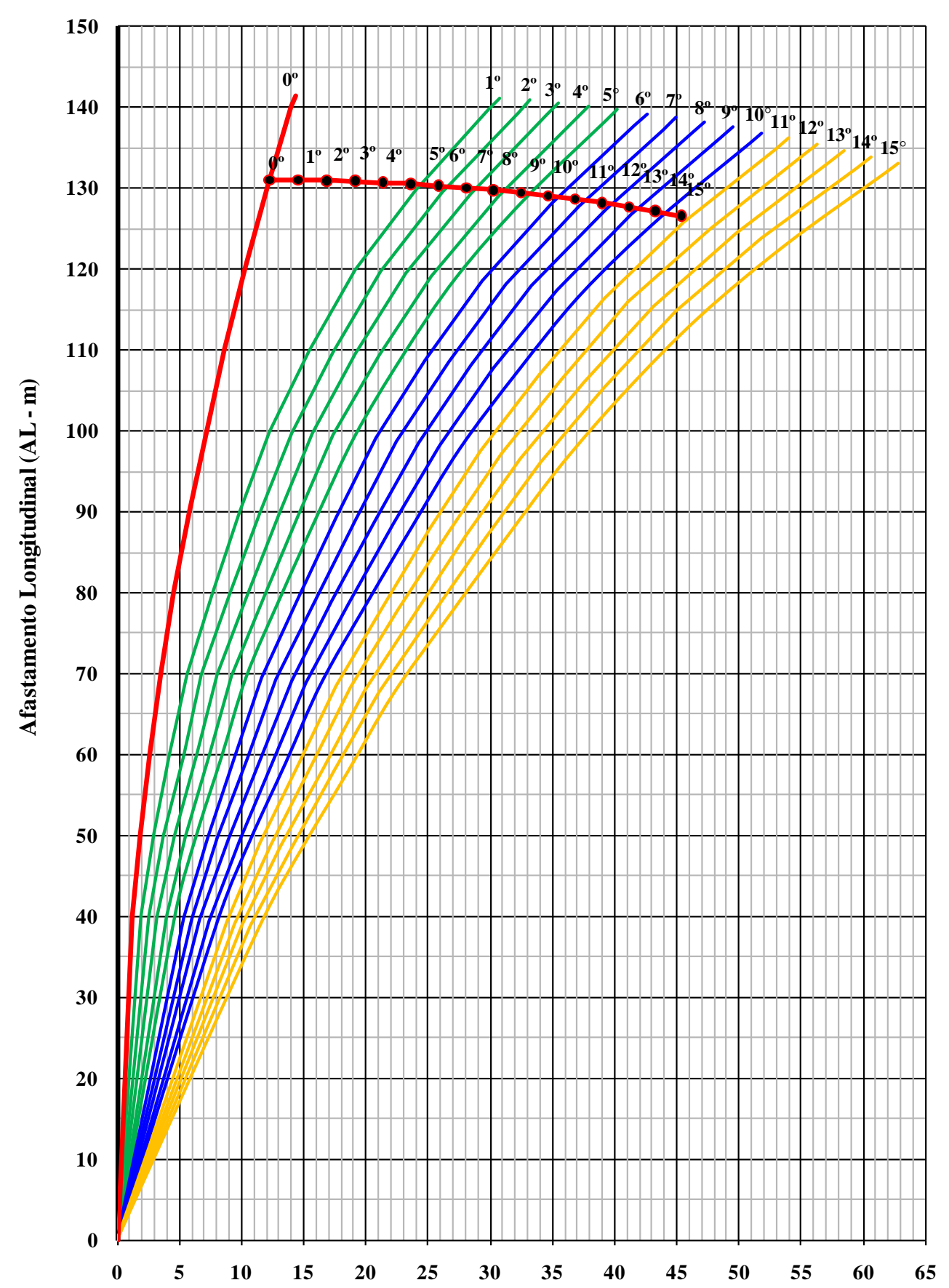

Afastamento Transversal (AT - m) 
Raio 700m - Velocidade 110 km/h

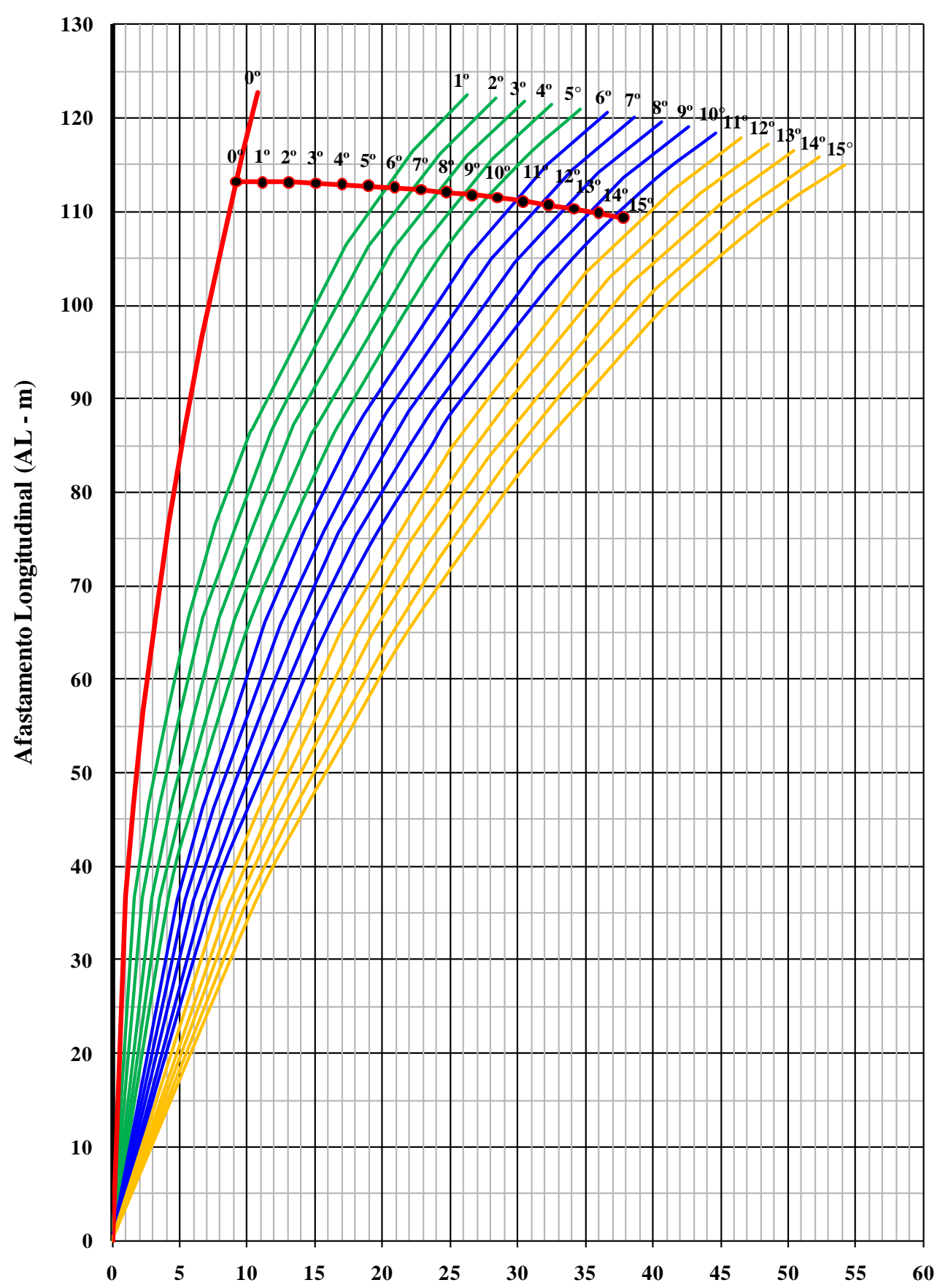

Afastamento Transversal (AT - m) 
Raio 700m - Velocidade 100 km/h

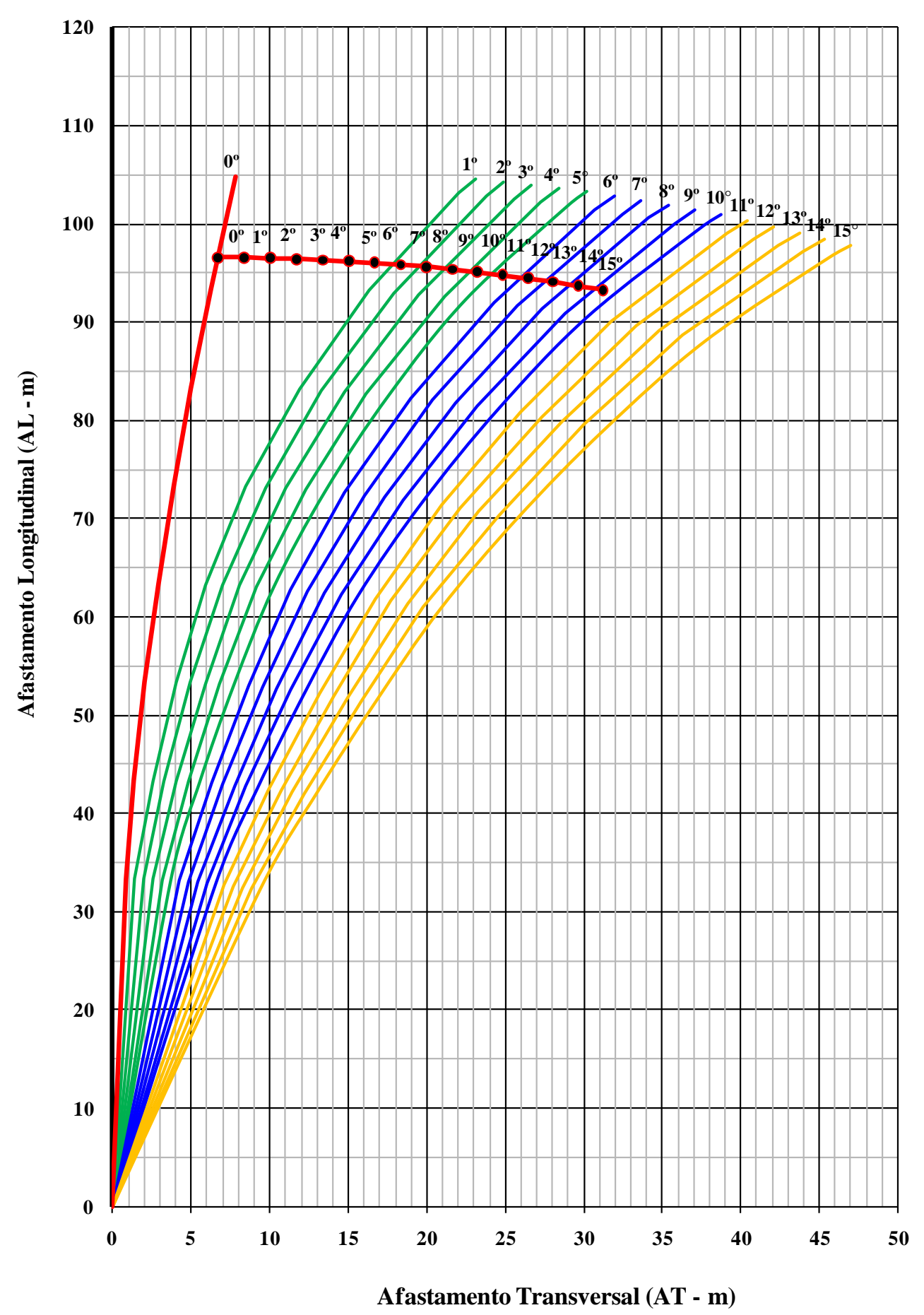


Raio 700m - Velocidade 90 km/h

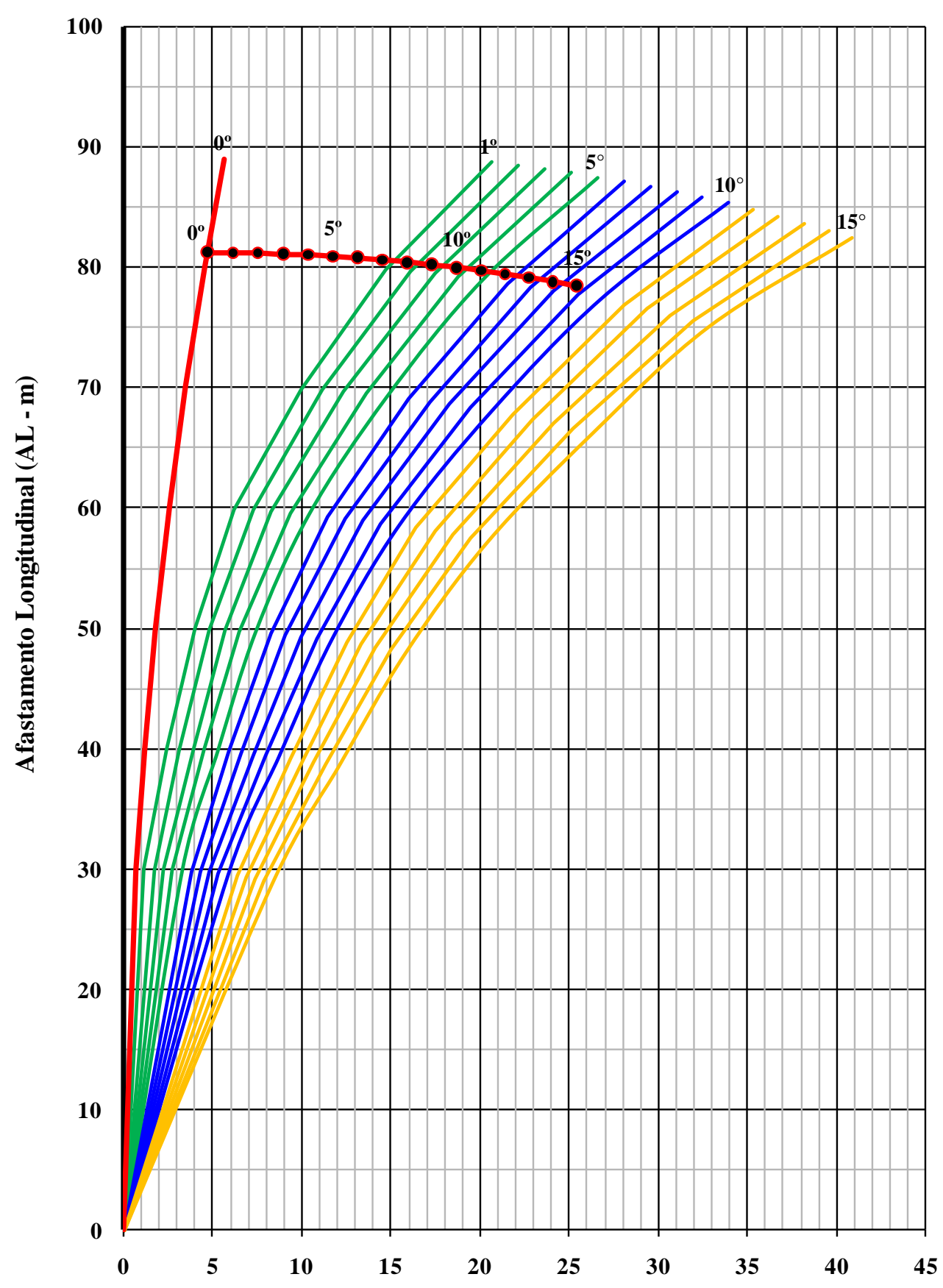

Afastamento Transversal (AT - m) 
Raio 700m - Velocidade 80 km/h

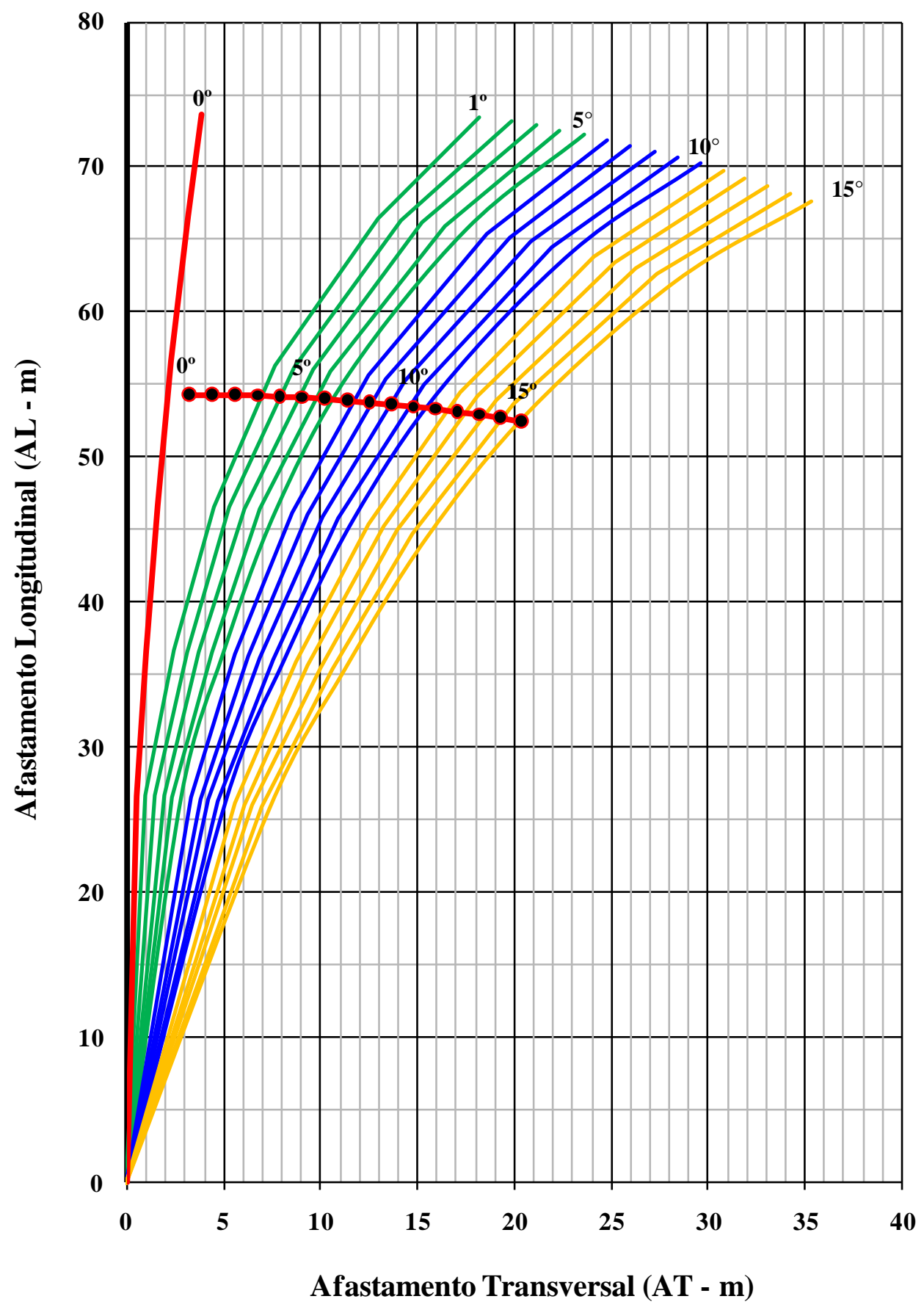


Raio 700m - Velocidade 70 km/h

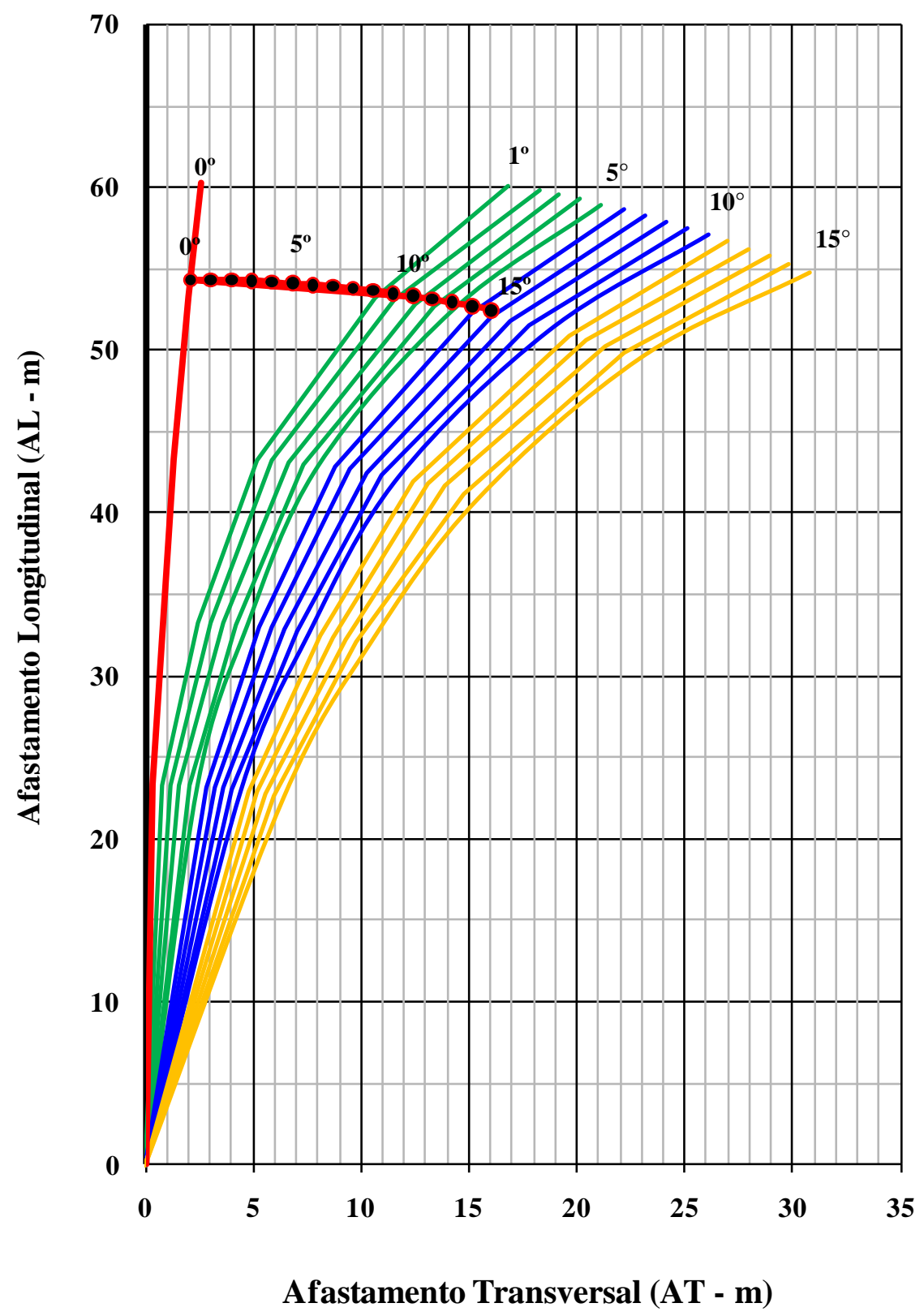




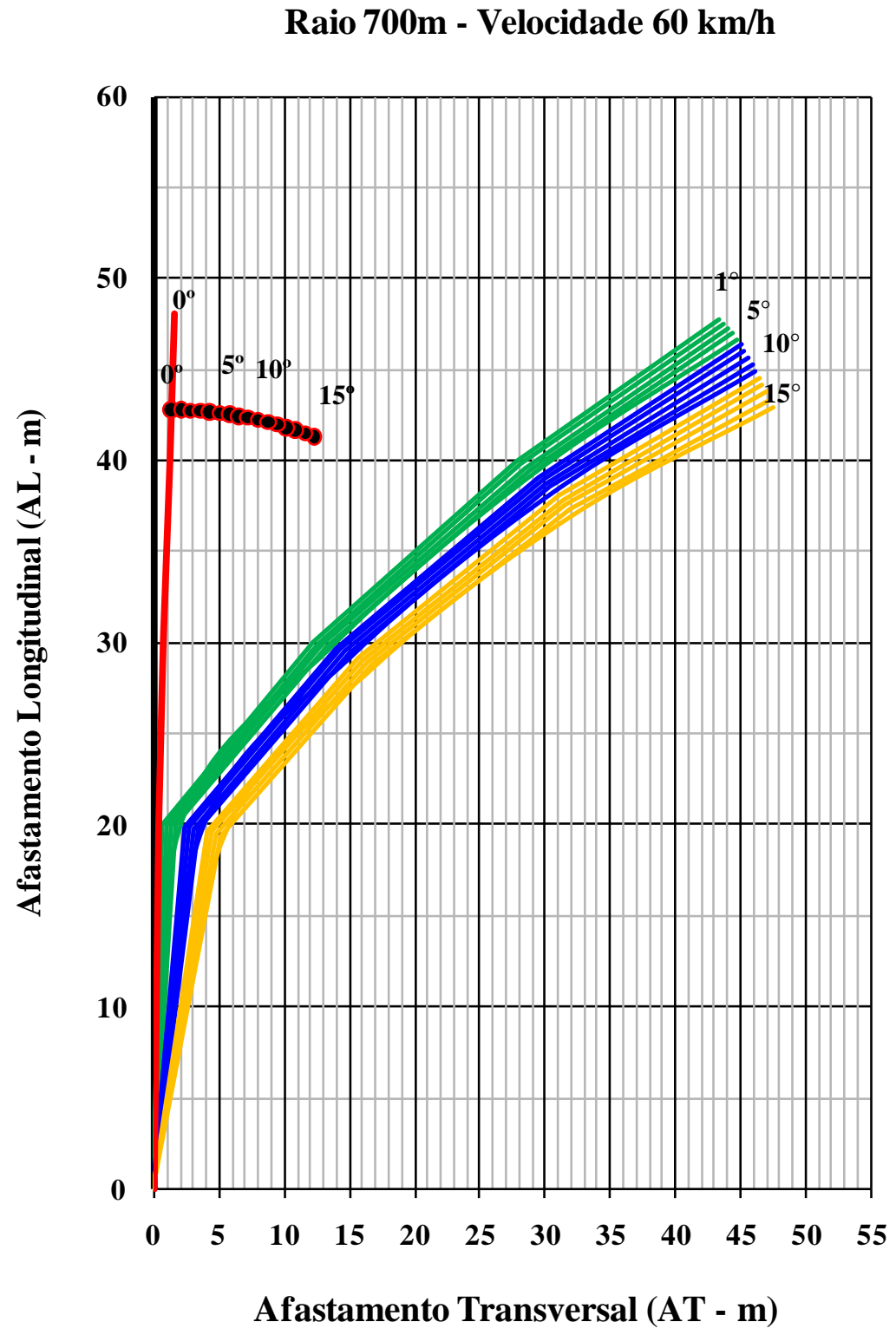


Raio 600m - Velocidade $120 \mathrm{~km} / \mathrm{h}$

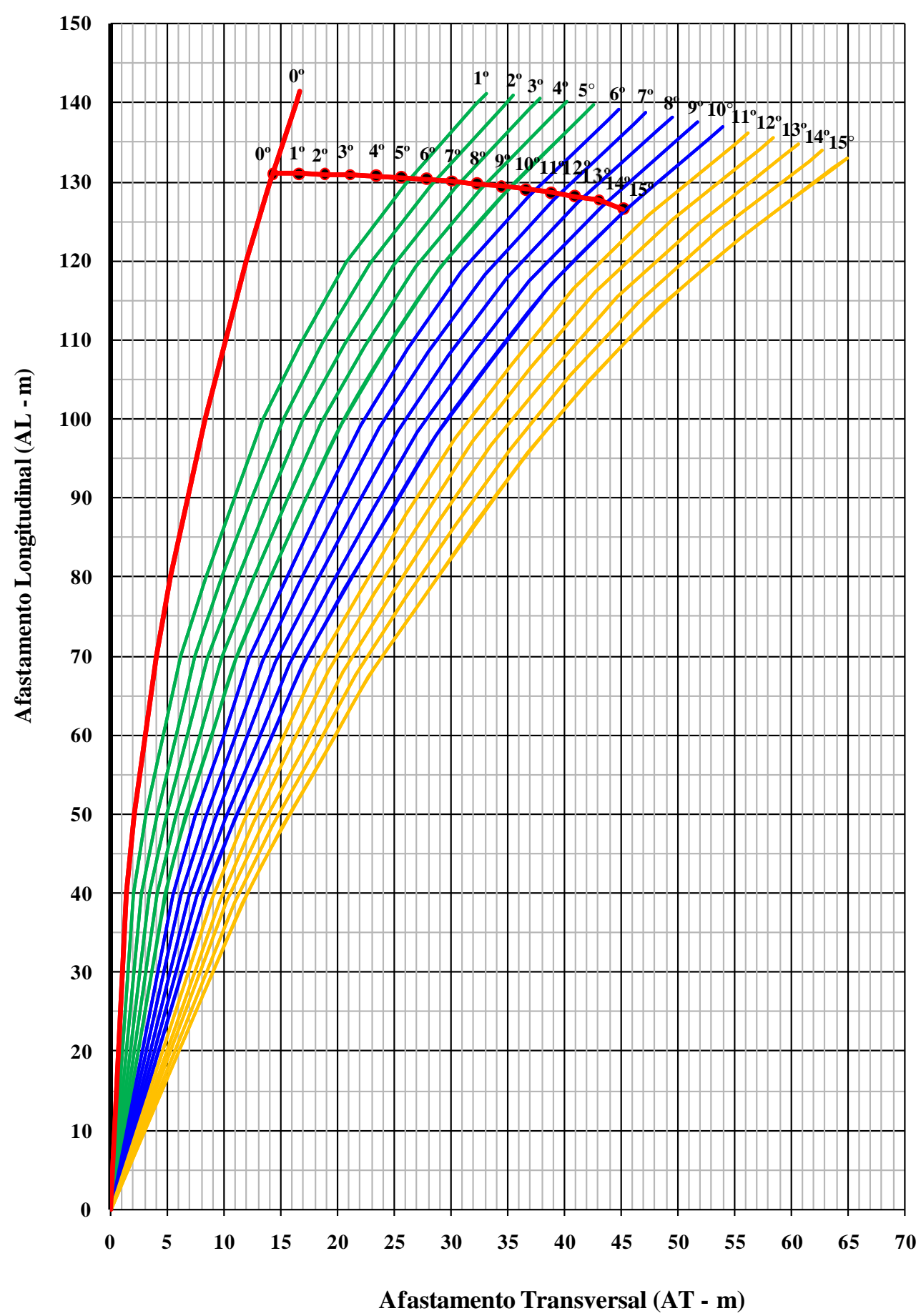


Raio 600m - Velocidade $110 \mathrm{~km} / \mathrm{h}$

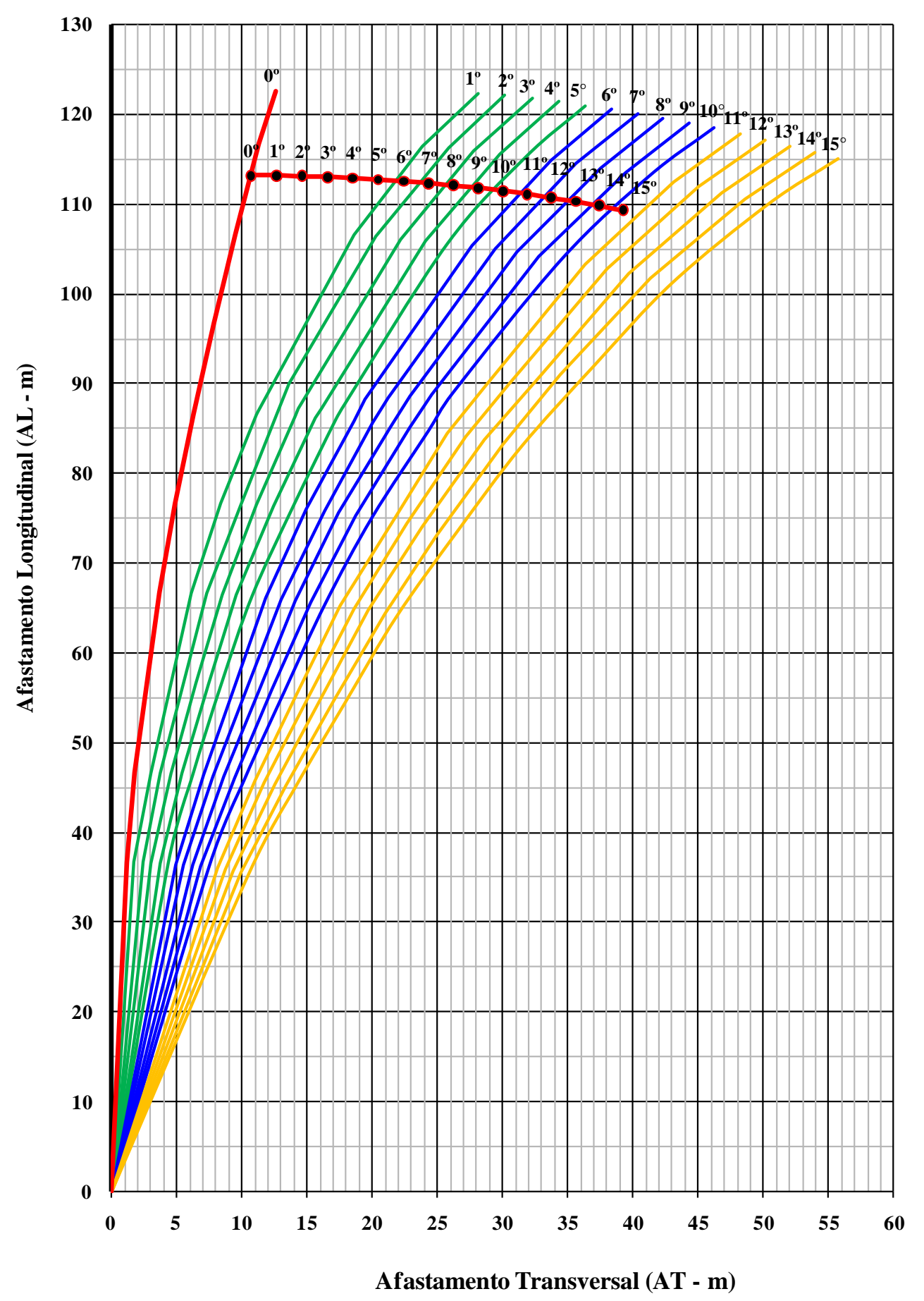


Raio 600m - Velocidade 100 km/h

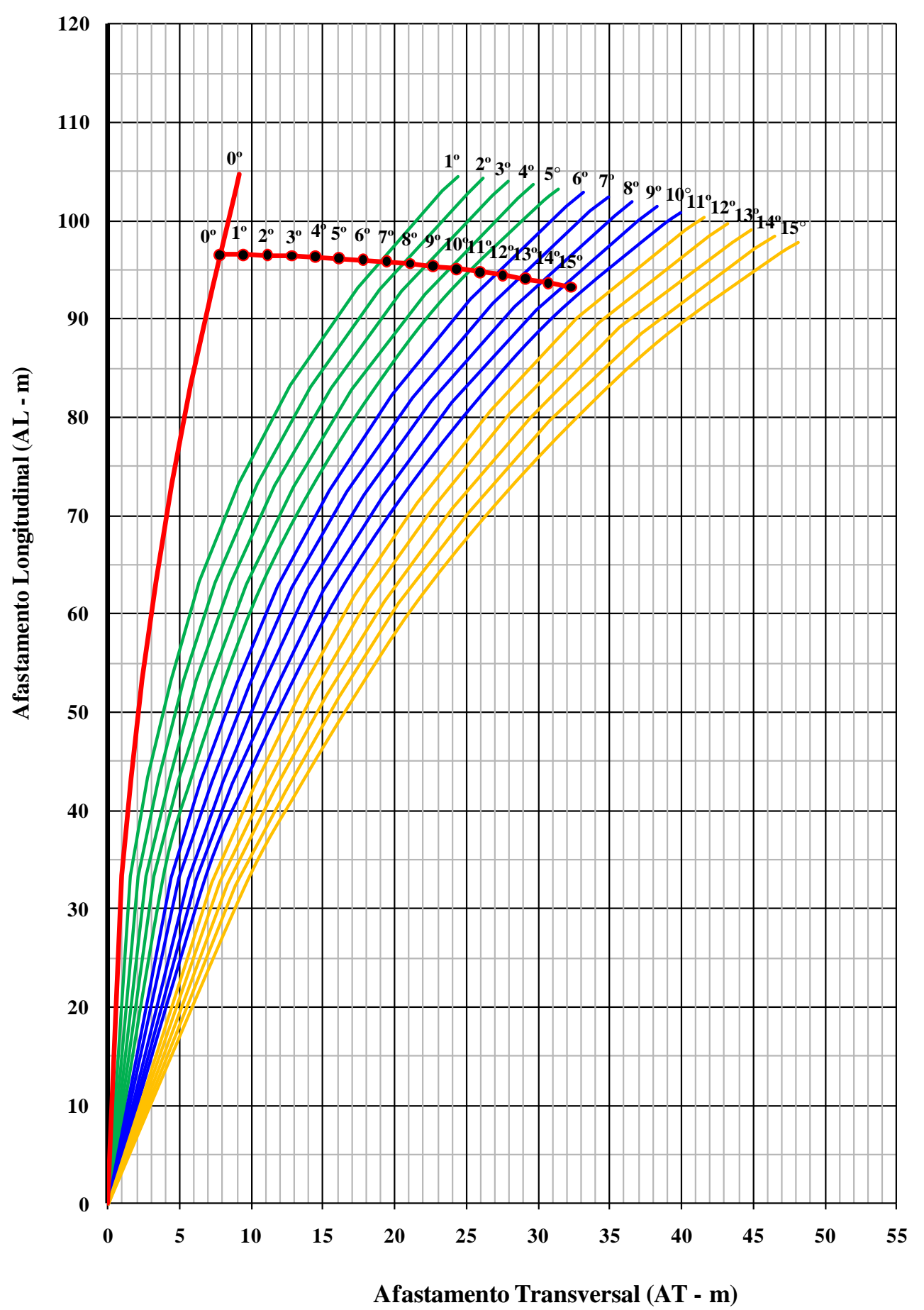




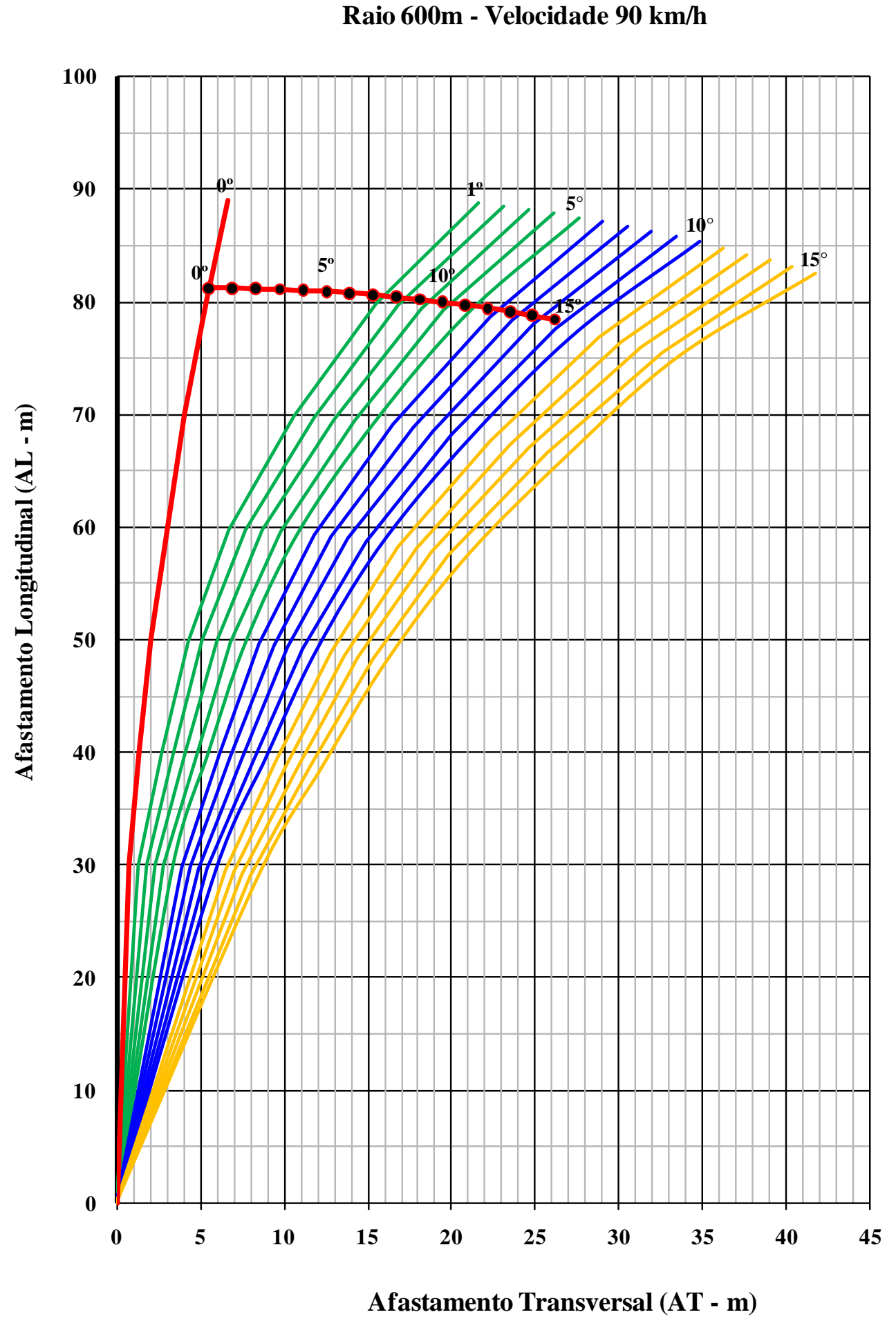


Raio 600m - Velocidade 80 km/h

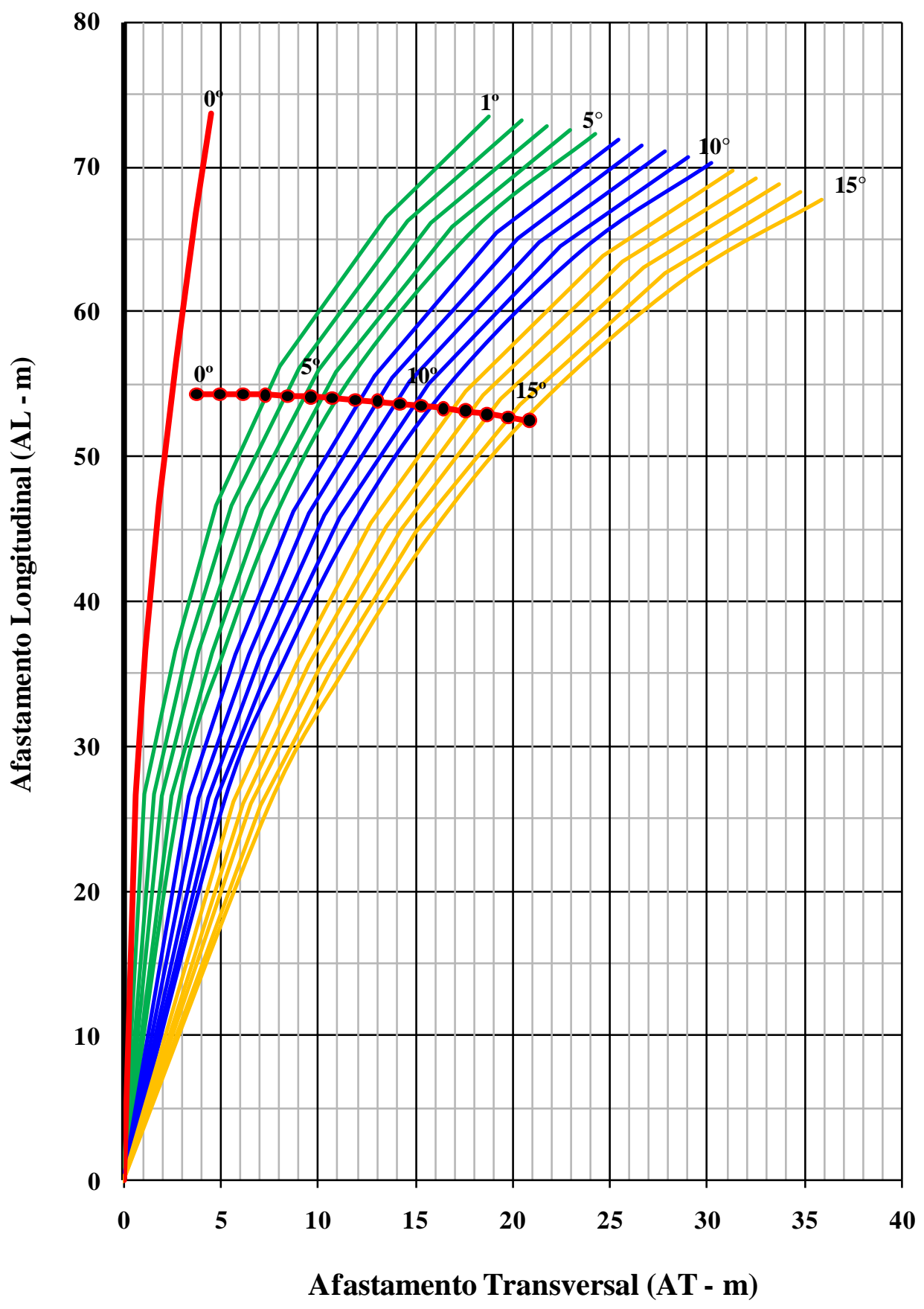




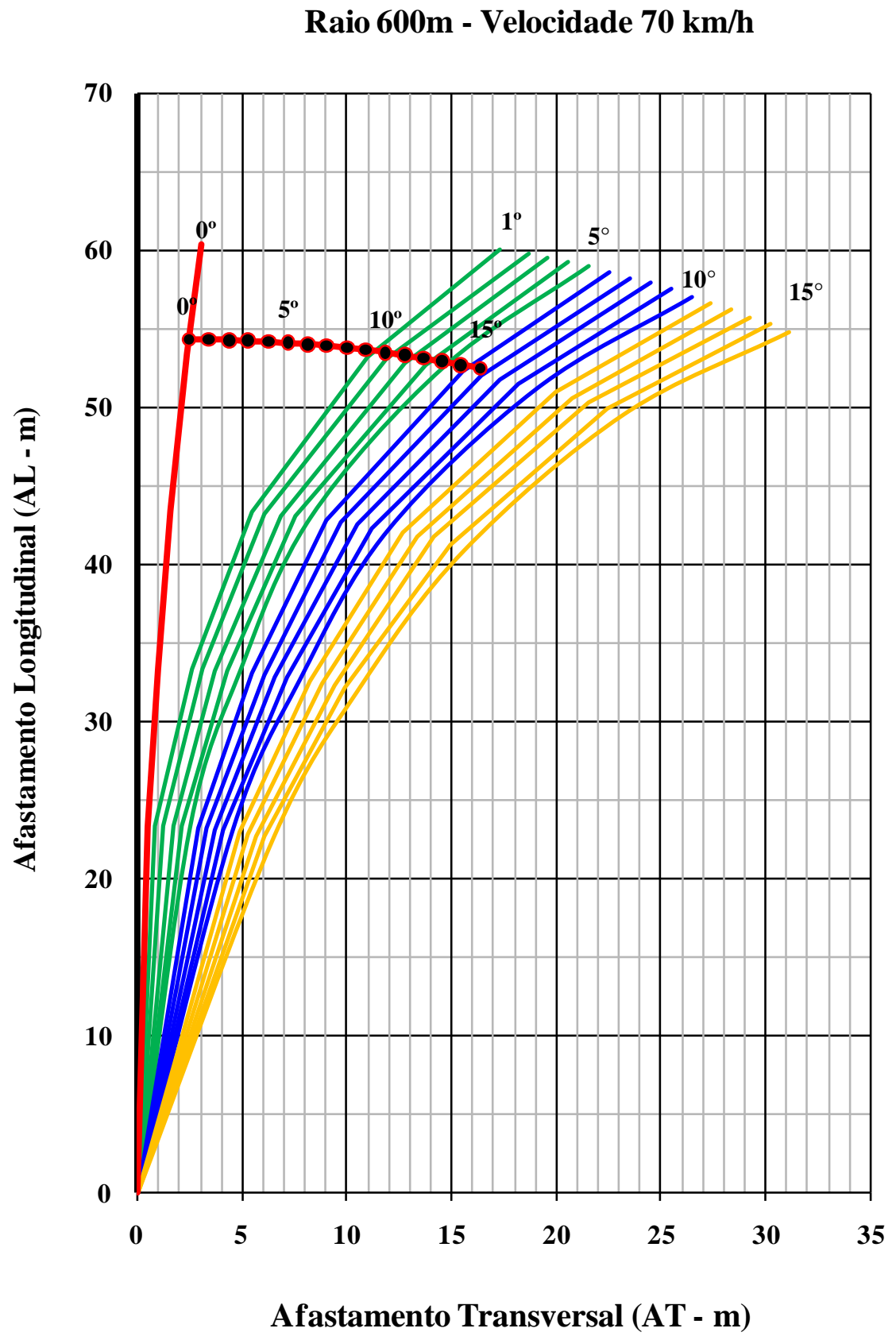




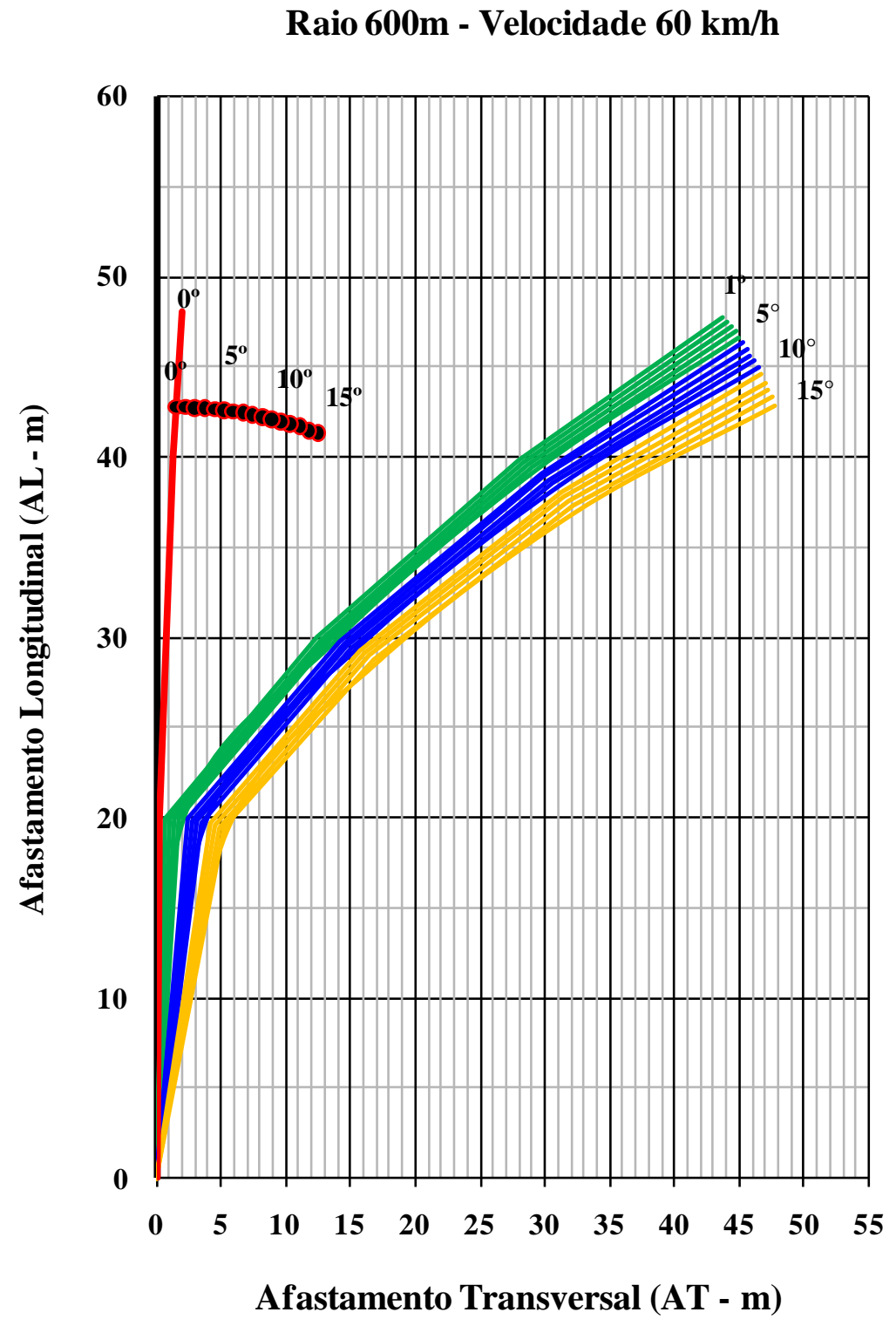


Raio 500m - Velocidade $120 \mathrm{~km} / \mathrm{h}$

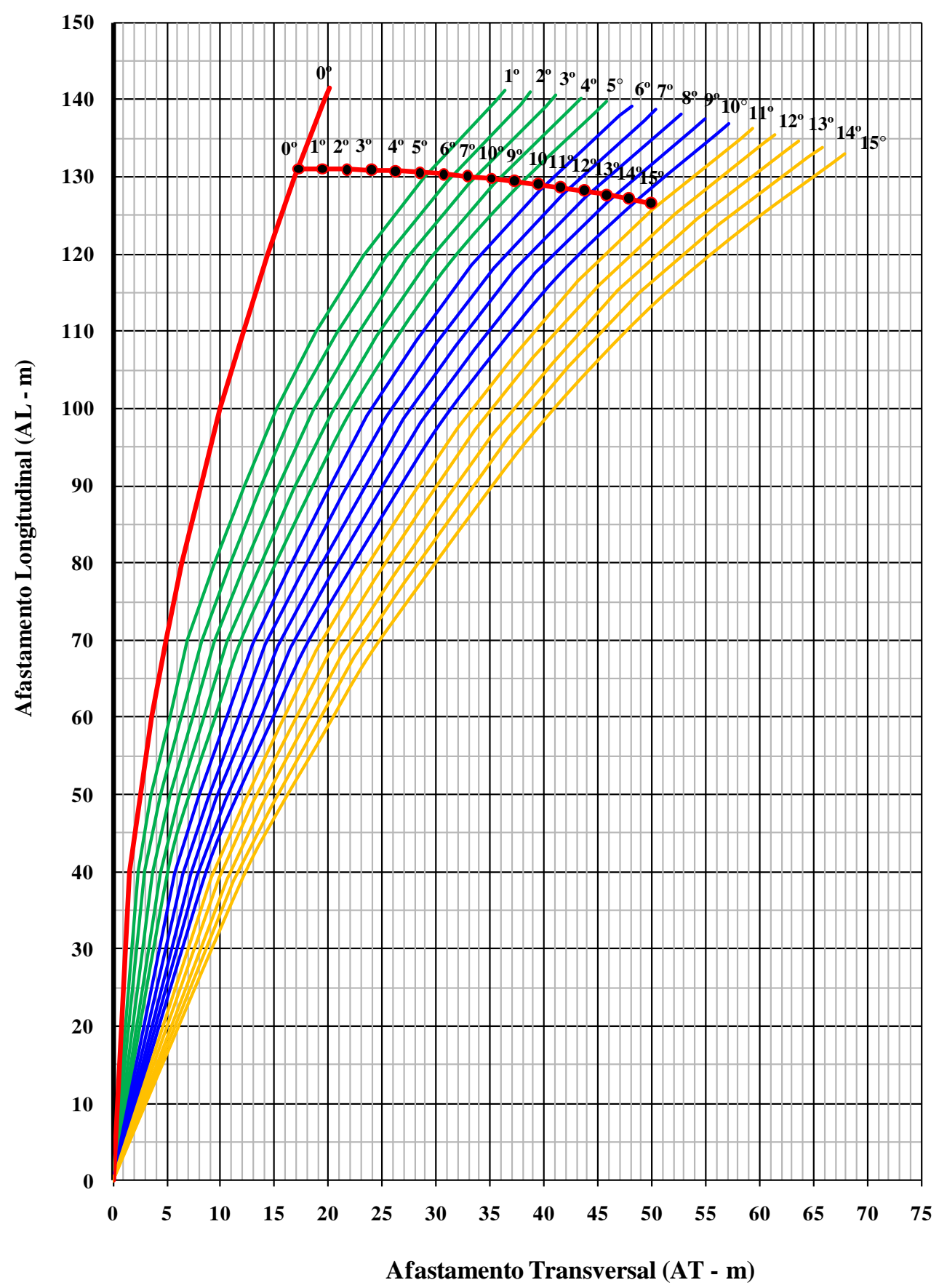


Raio 500m - Velocidade $110 \mathrm{~km} / \mathrm{h}$

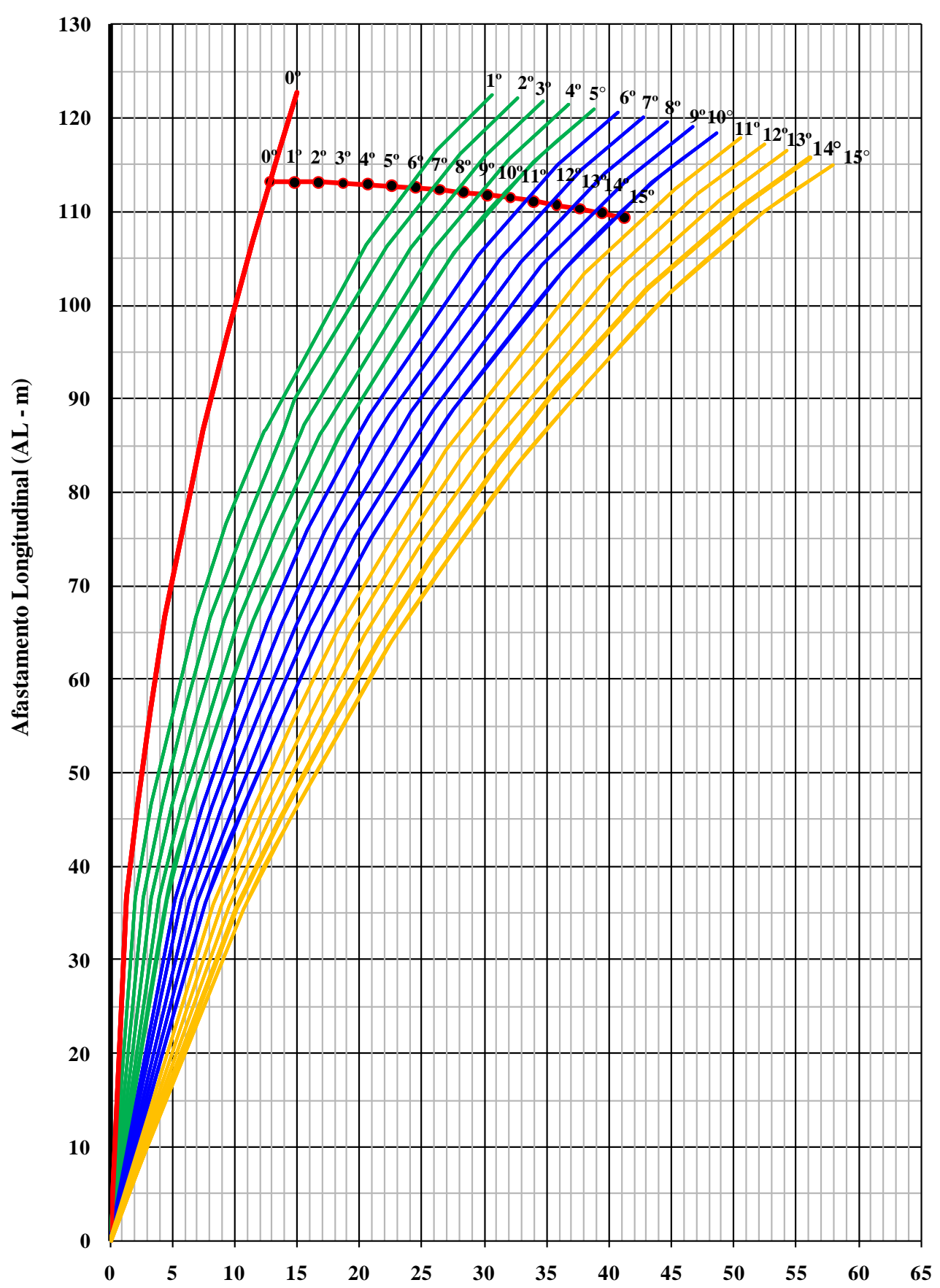

Afastamento Transversal (AT - m) 
Raio 500m - Velocidade $100 \mathrm{~km} / \mathrm{h}$

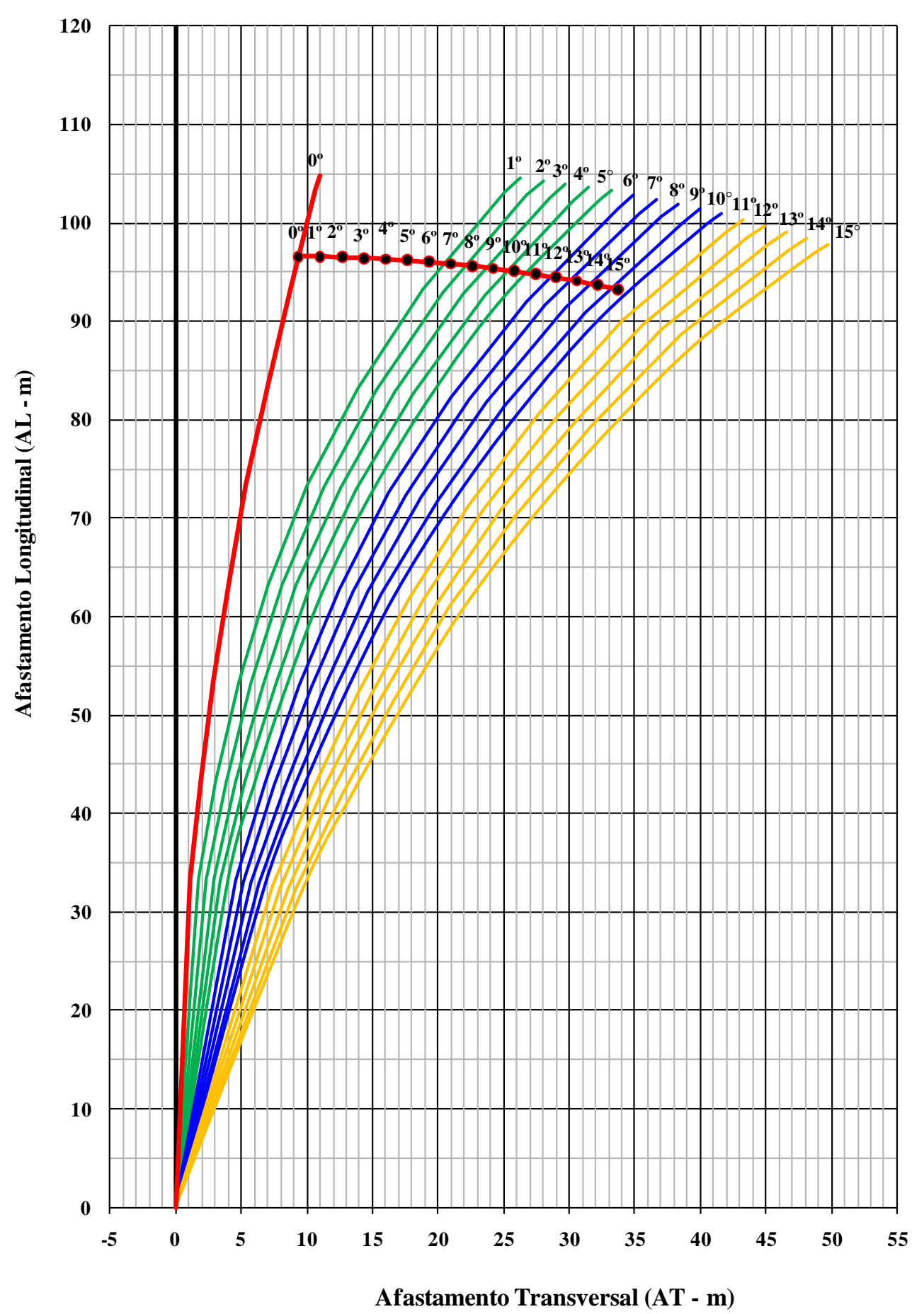


Raio 500m - Velocidade 90 km/h

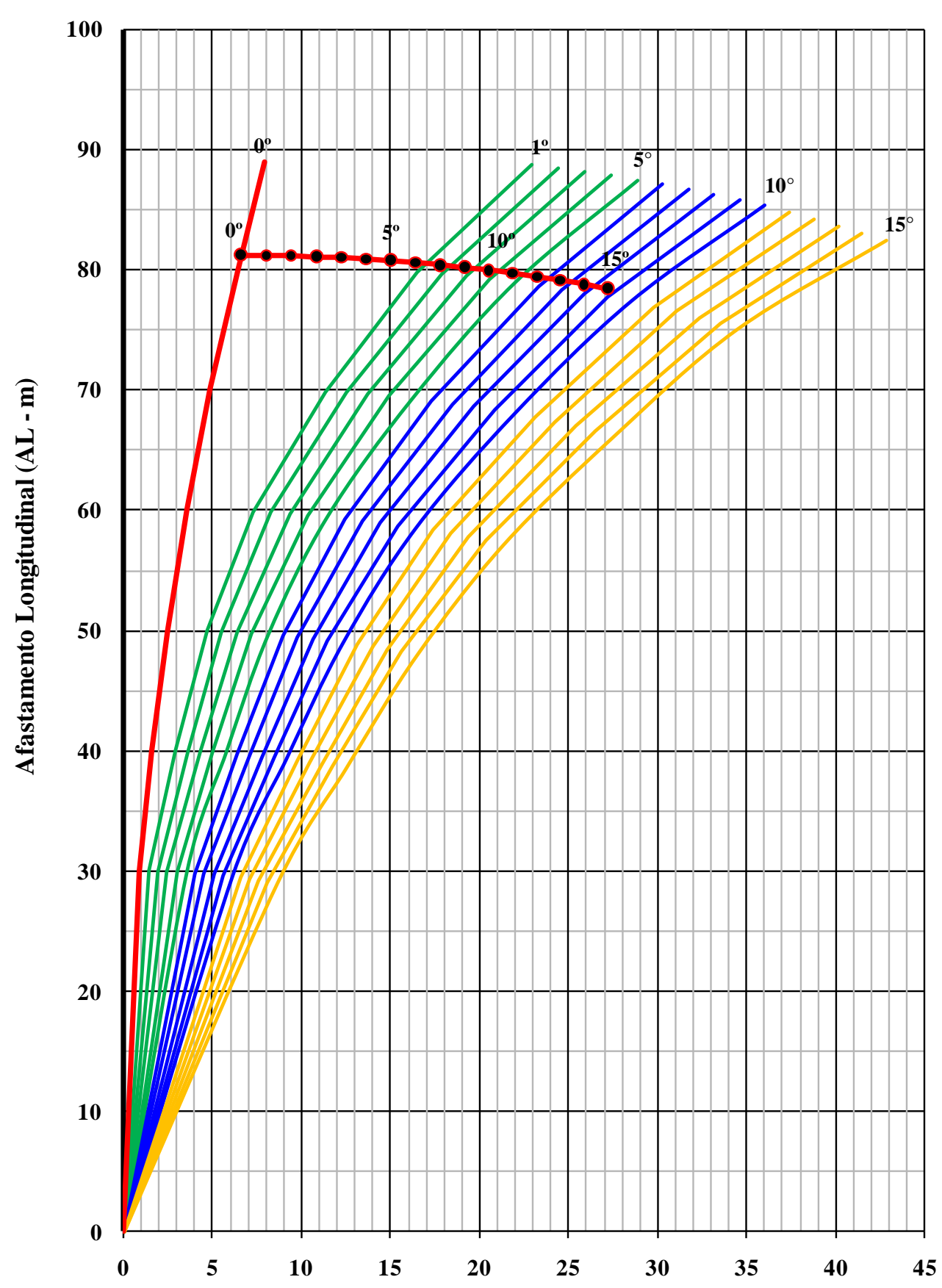

Afastamento Transversal (AT - m) 
Raio 500m - Velocidade 80 km/h

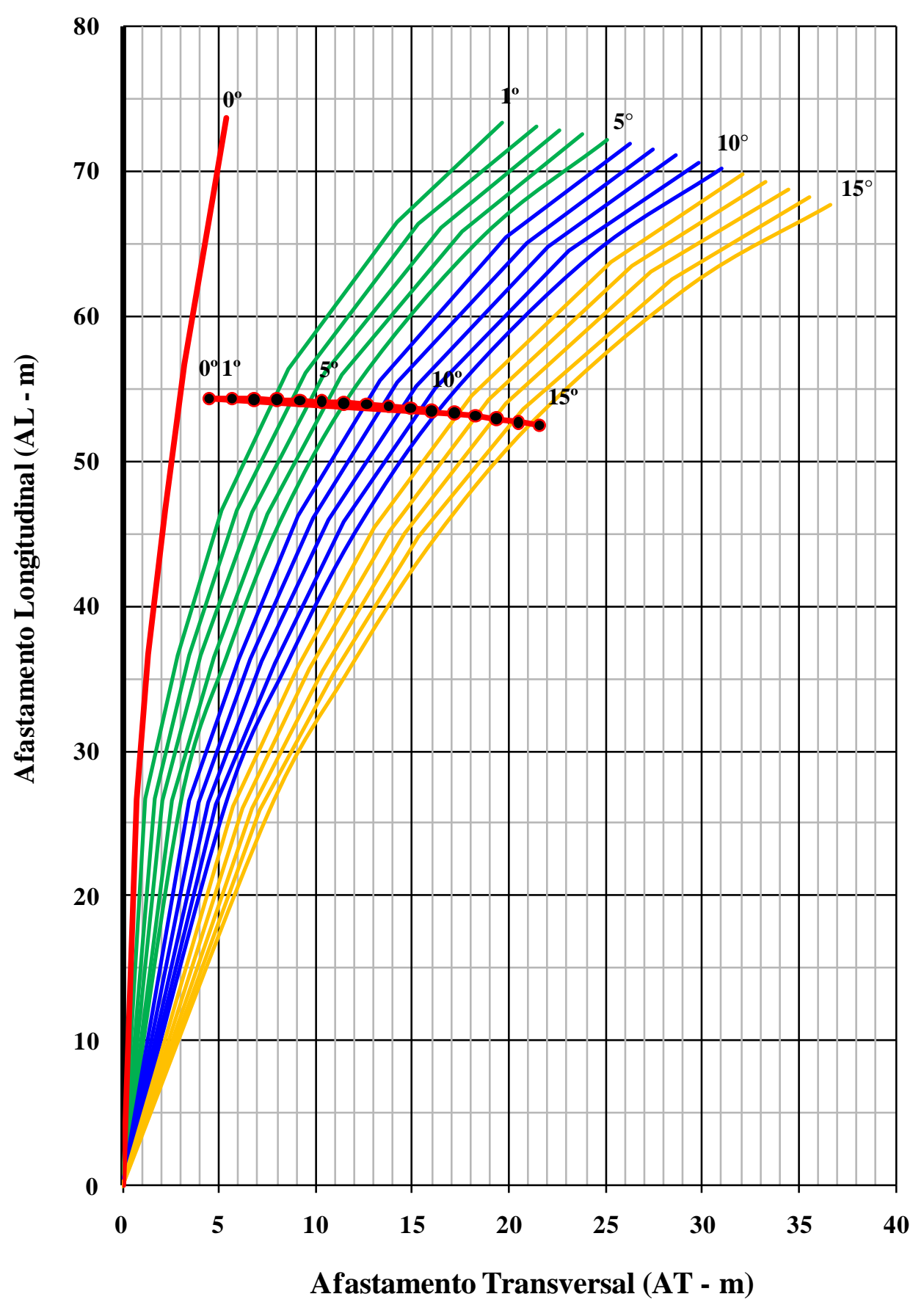


Raio 500m - Velocidade $70 \mathrm{~km} / \mathrm{h}$

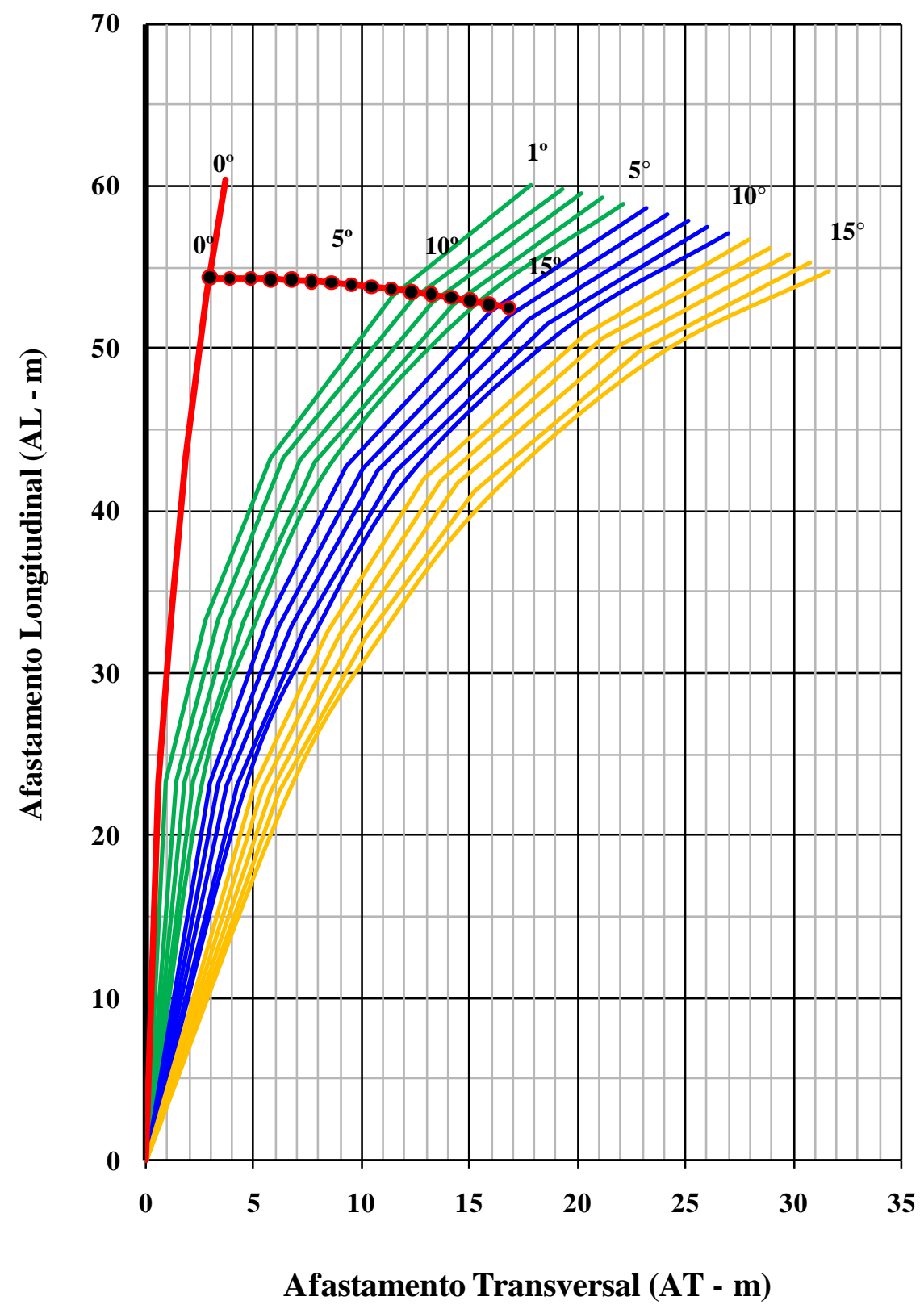




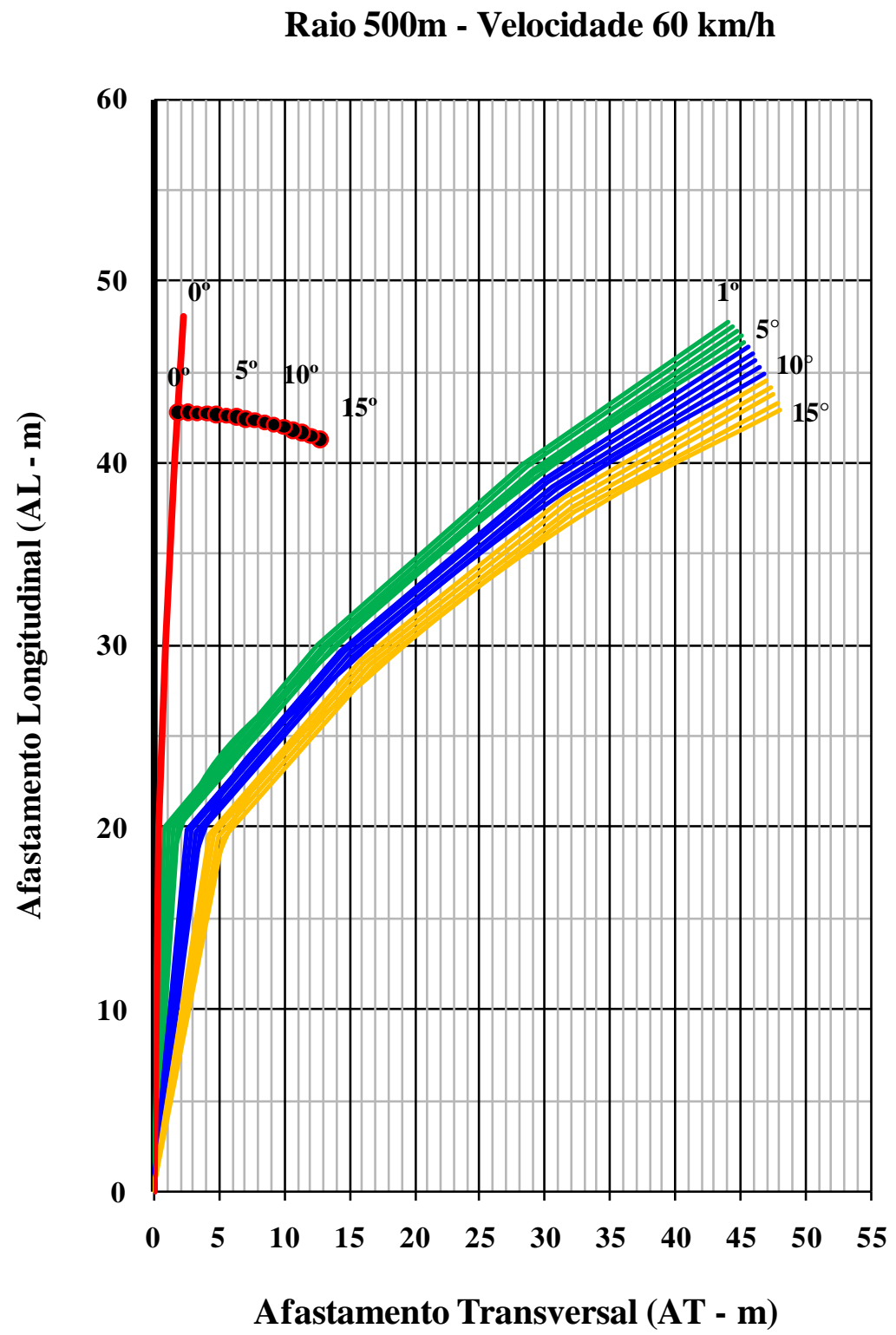


Raio 400m - Velocidade $110 \mathrm{~km} / \mathrm{h}$

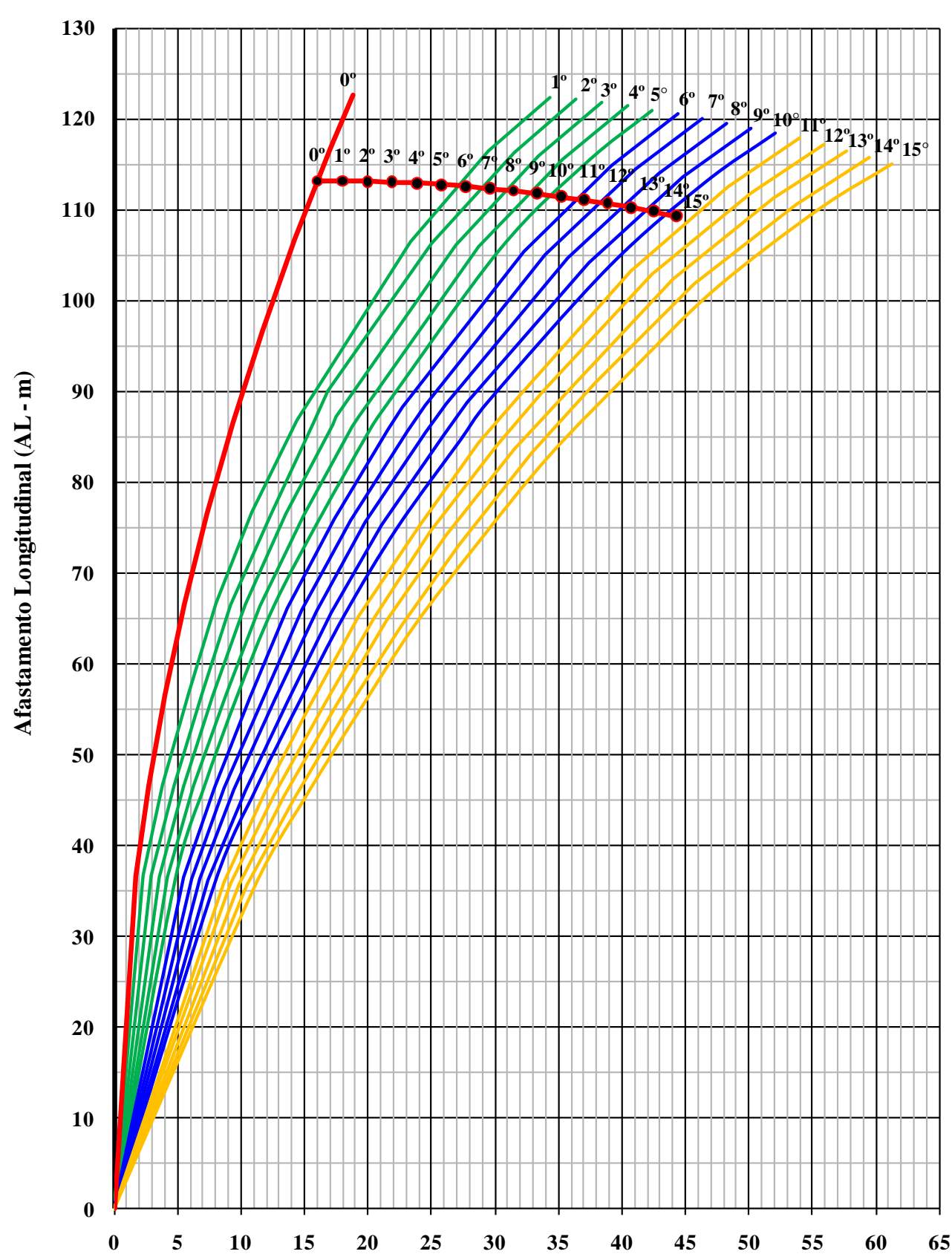

Afastamento Transversal (AT - m) 
Raio 400m - Velocidade 100 km/h

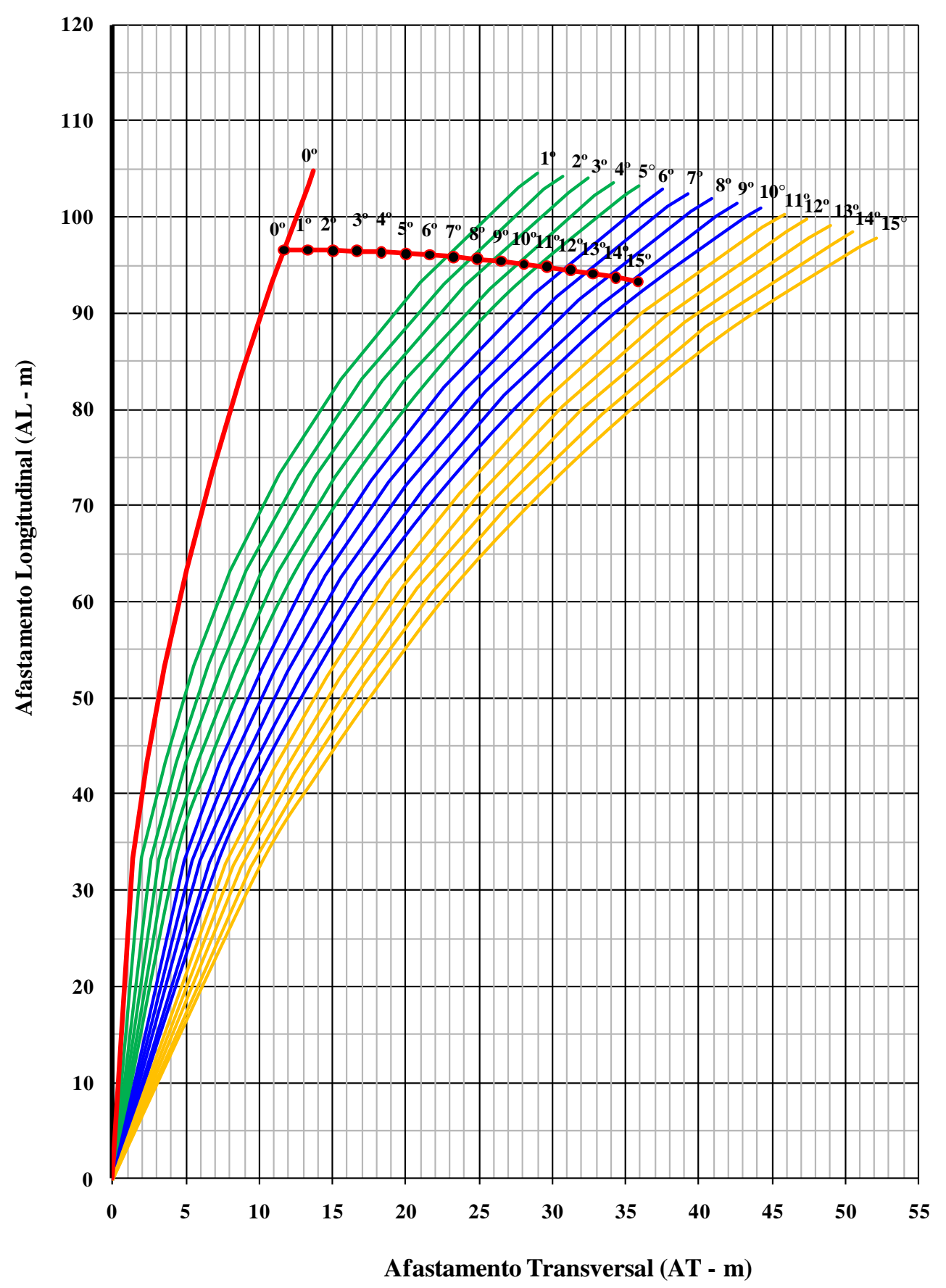


Raio 400m - Velocidade 90 km/h

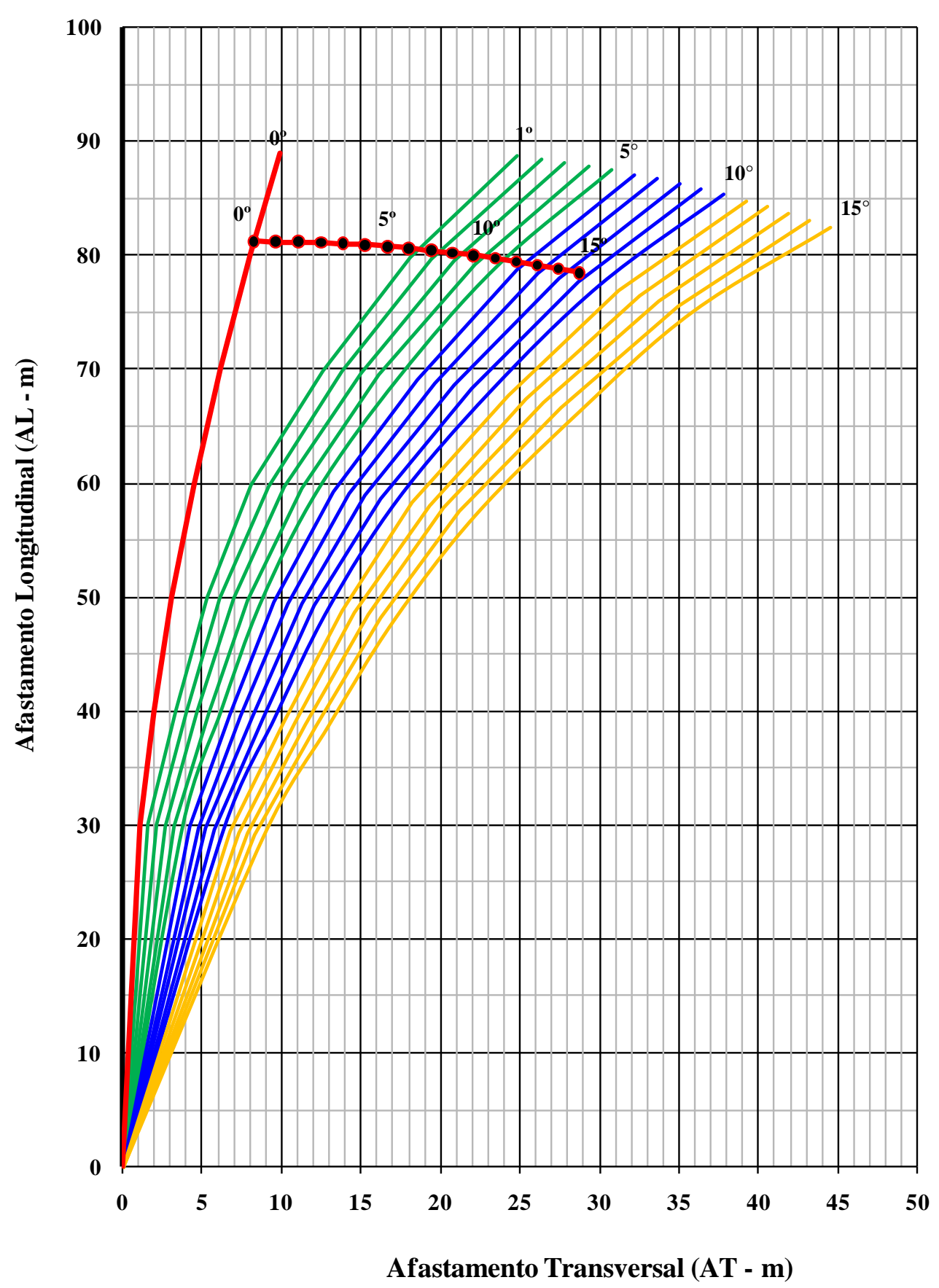


Raio 400m - Velocidade 80 km/h

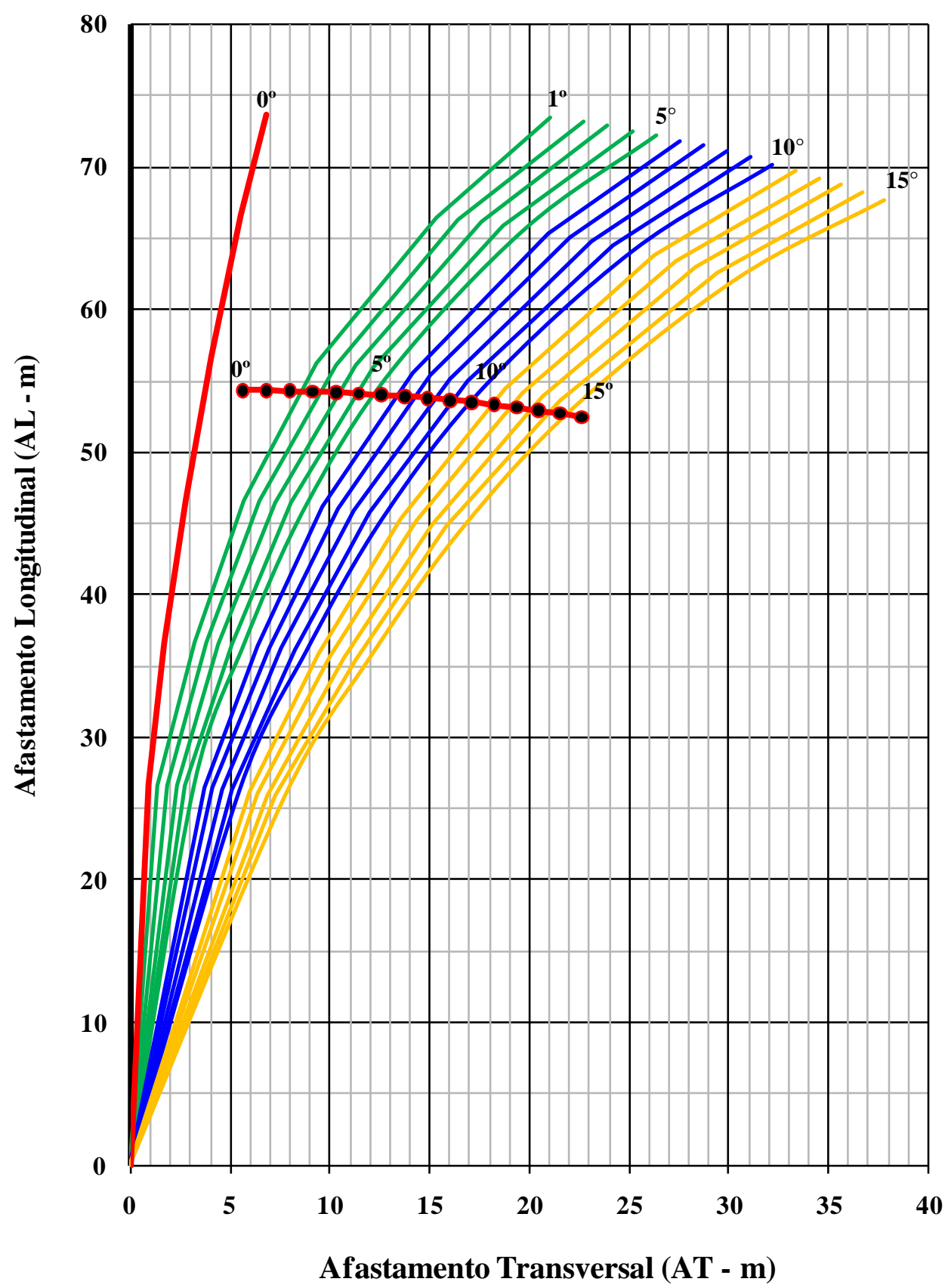




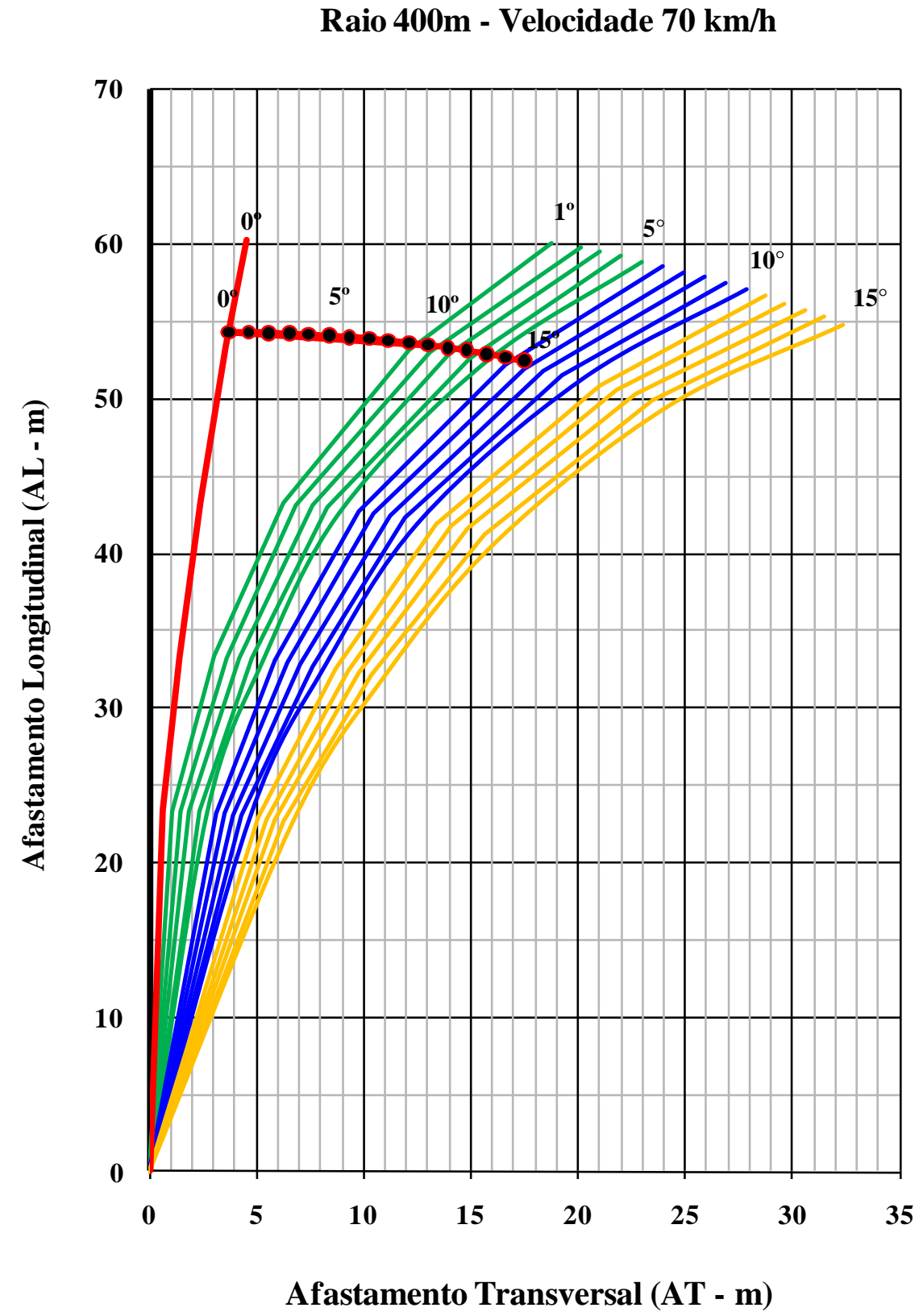




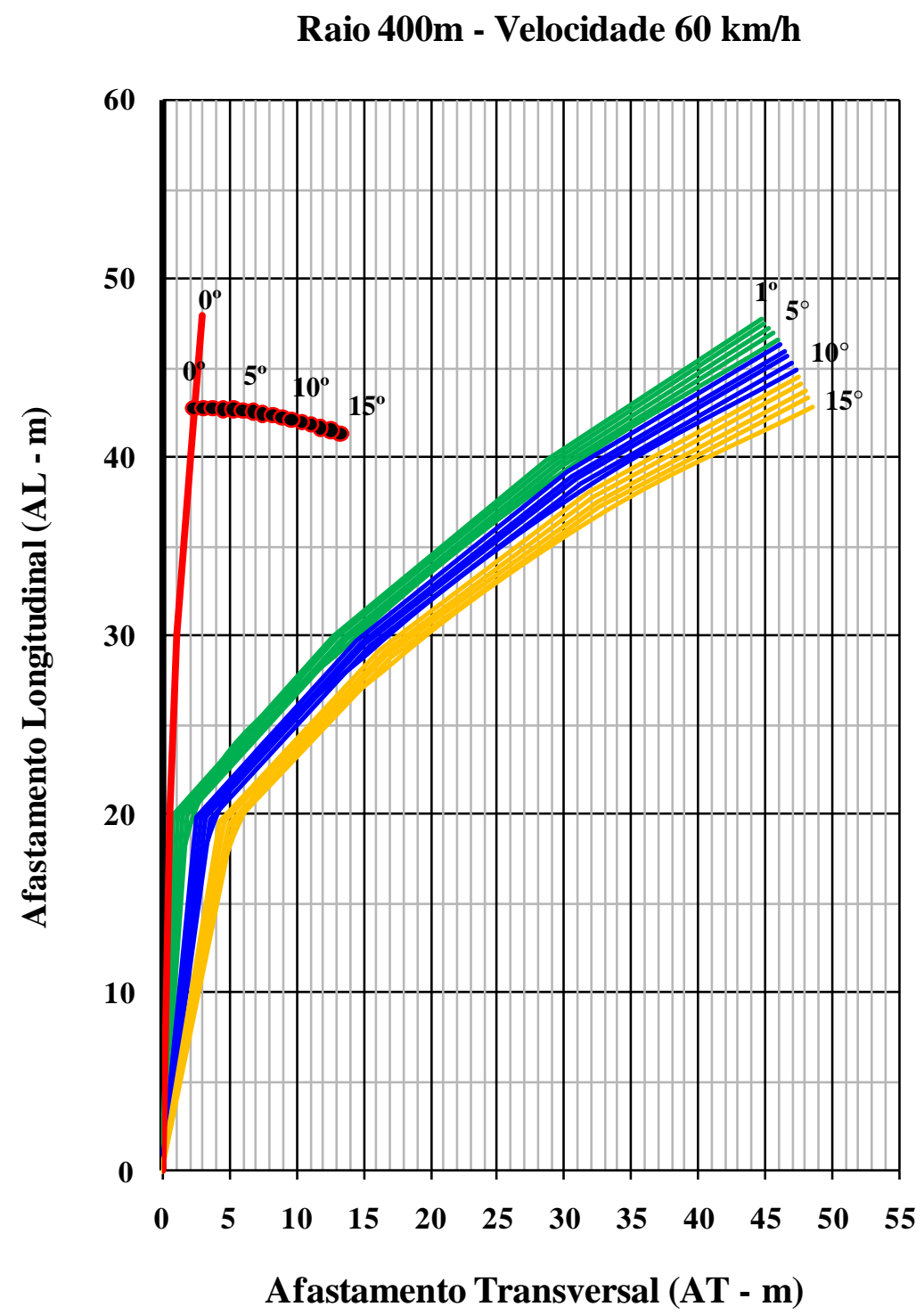


Raio 300m - Velocidade $100 \mathrm{~km} / \mathrm{h}$

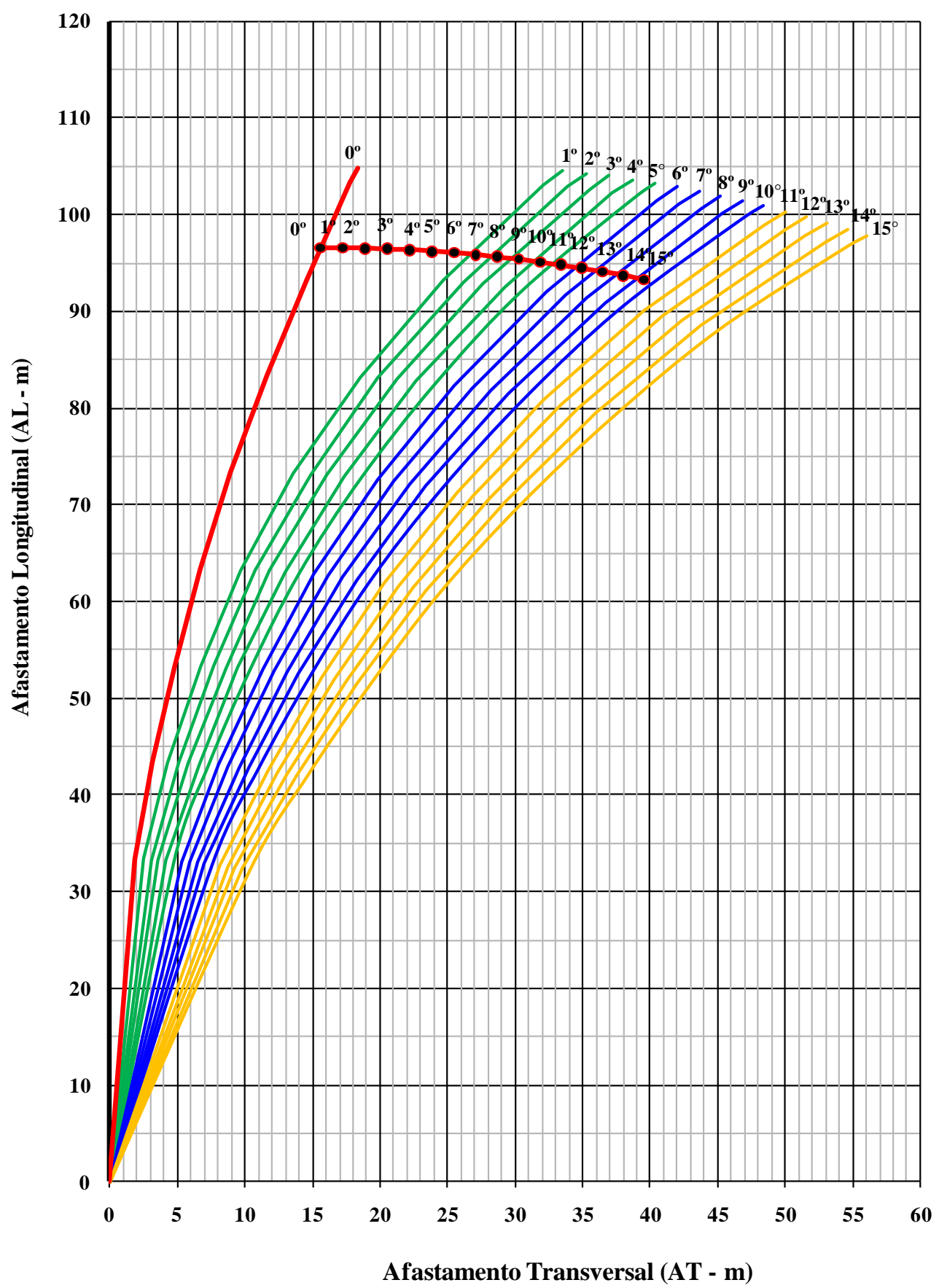


Raio 300m - Velocidade 90 km/h

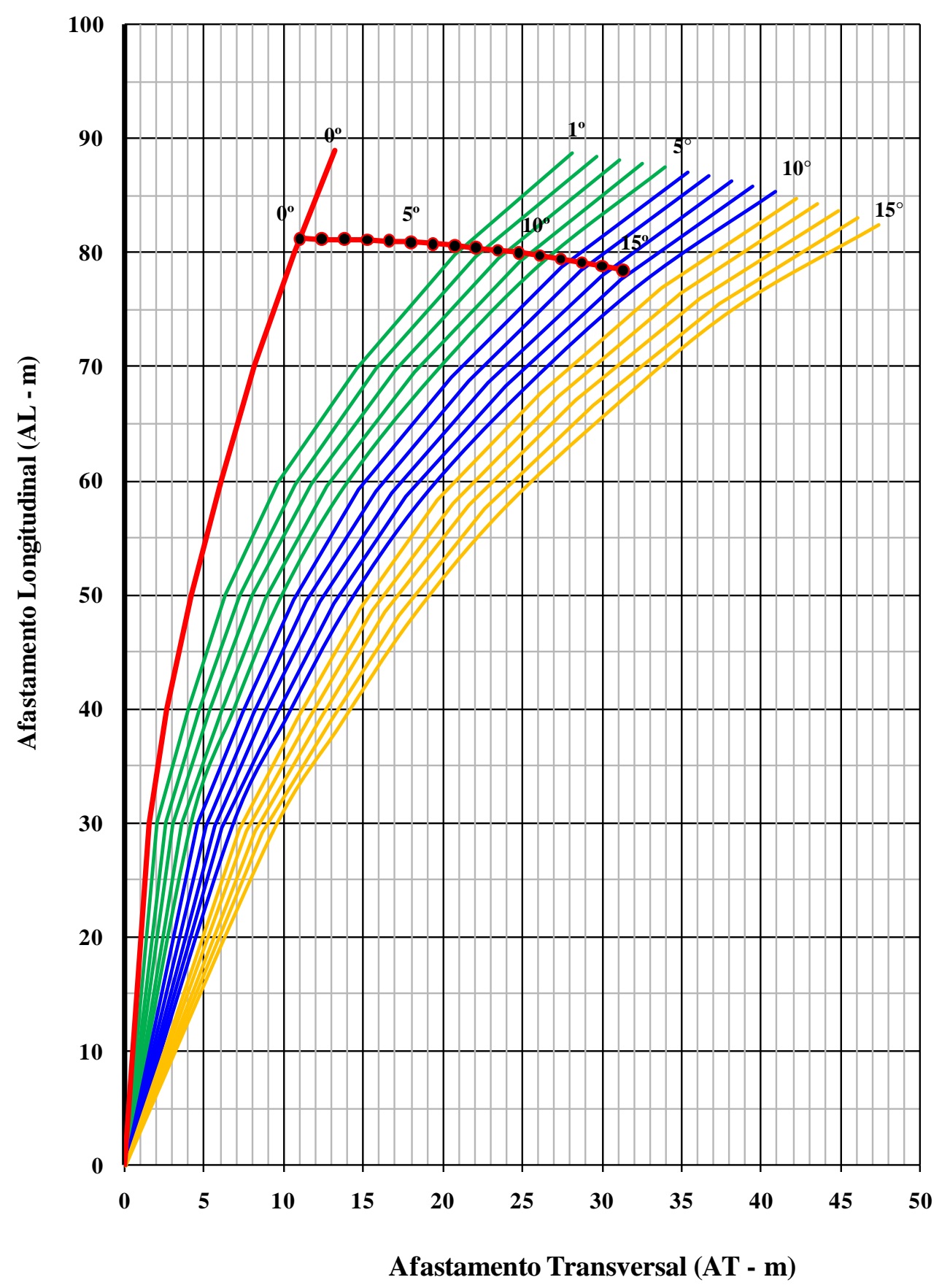


Raio 300m - Velocidade 80 km/h

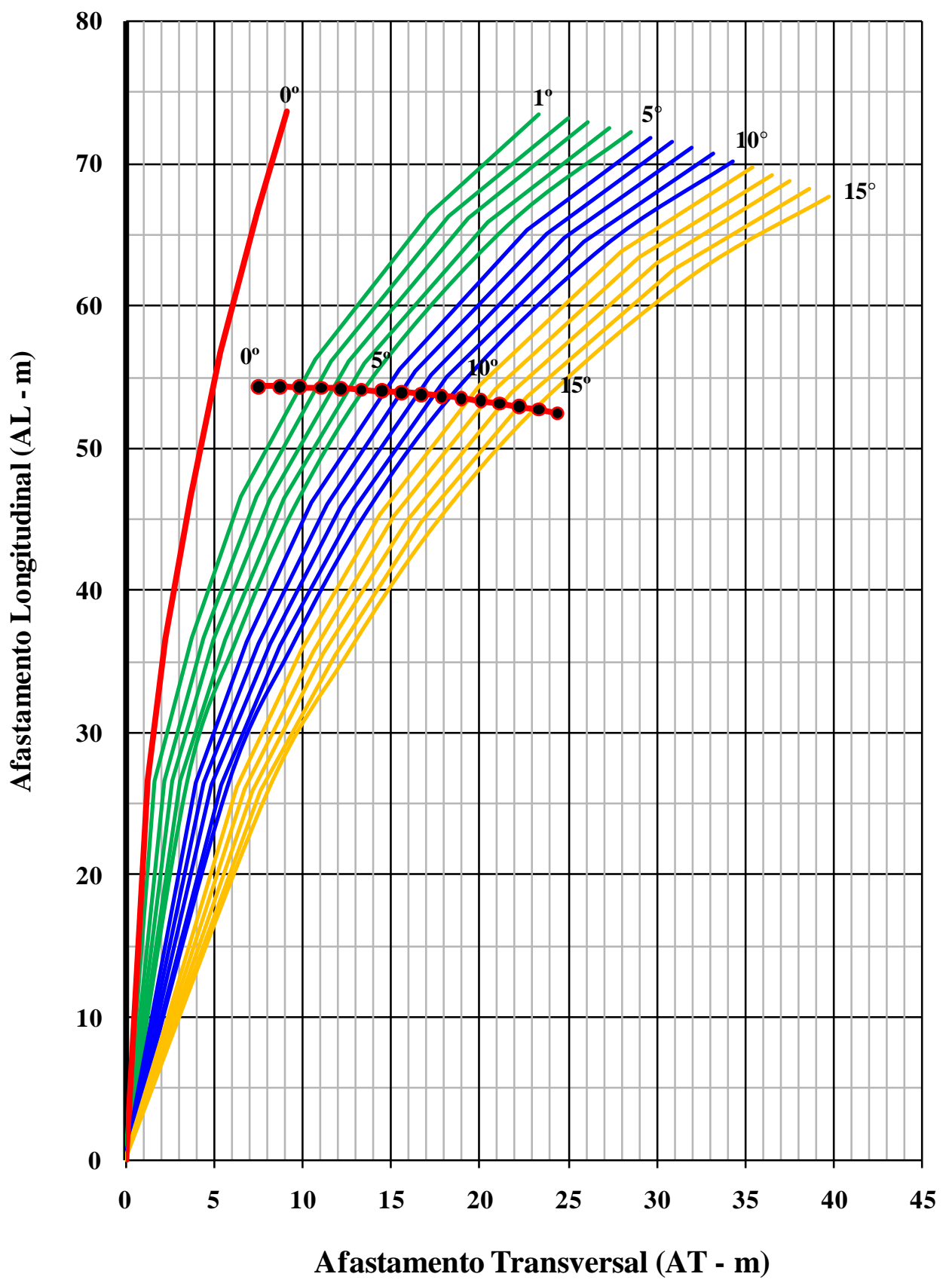


Raio 300m - Velocidade 70 km/h

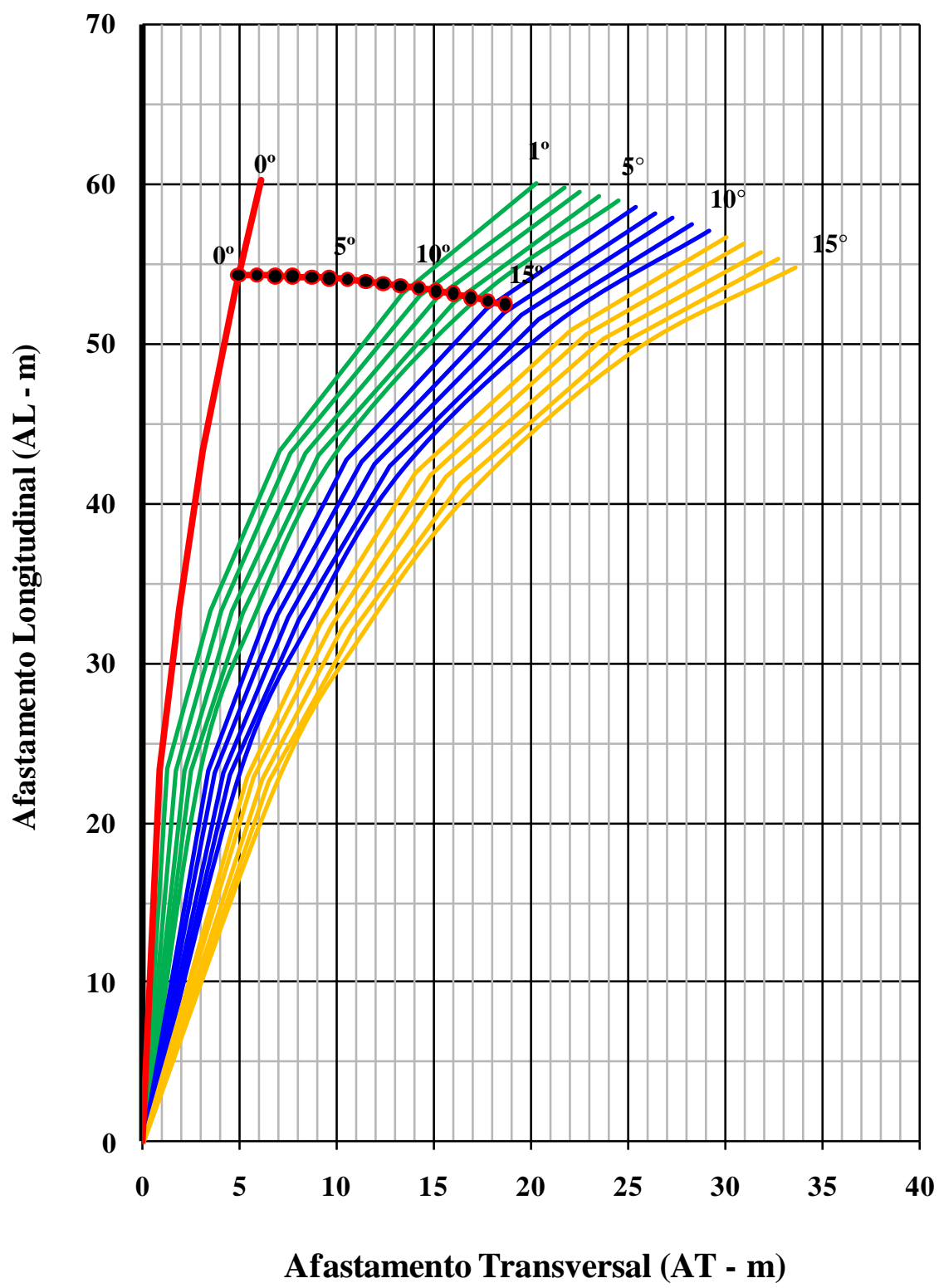




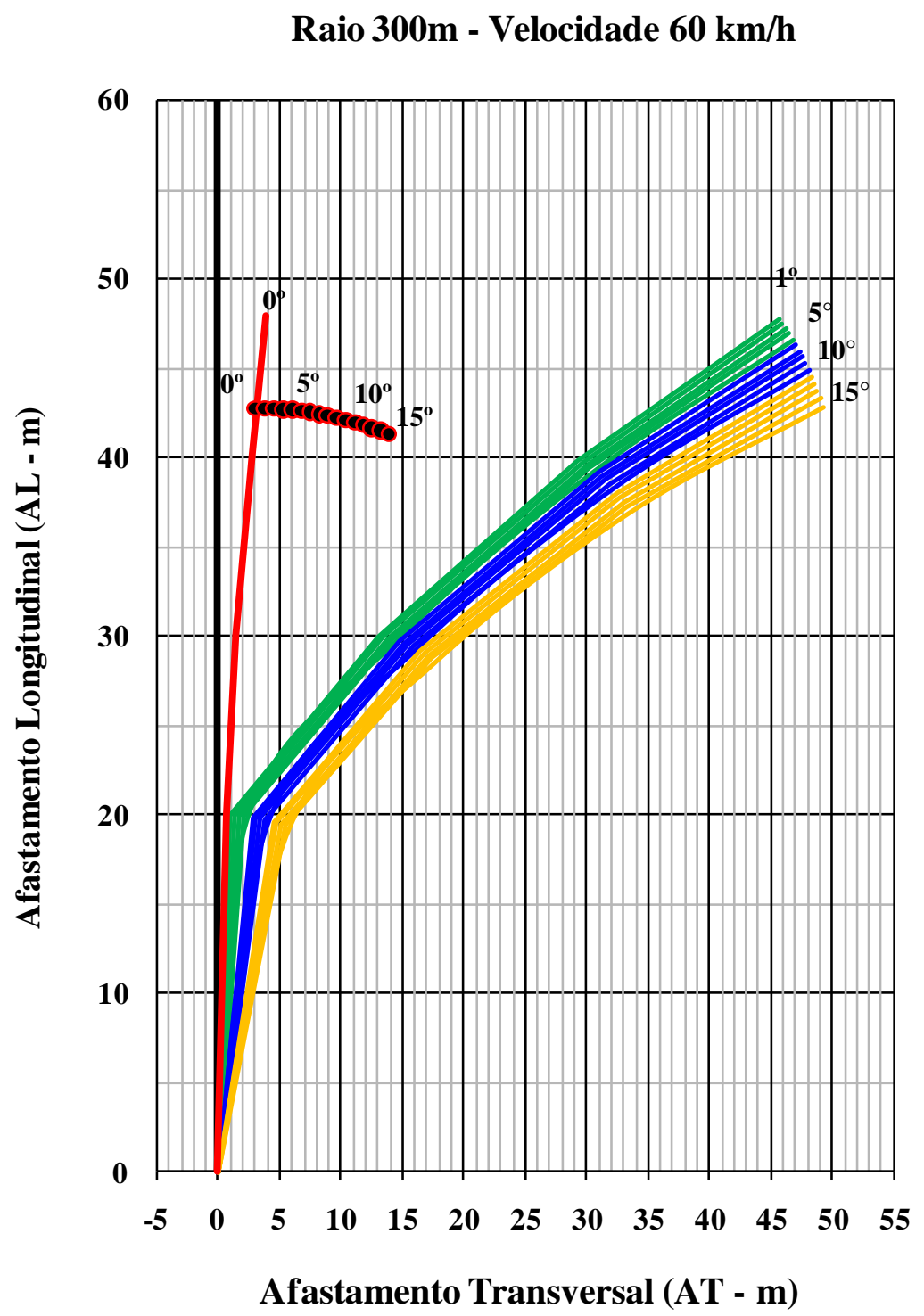


Raio 200m - Velocidade 90 km/h

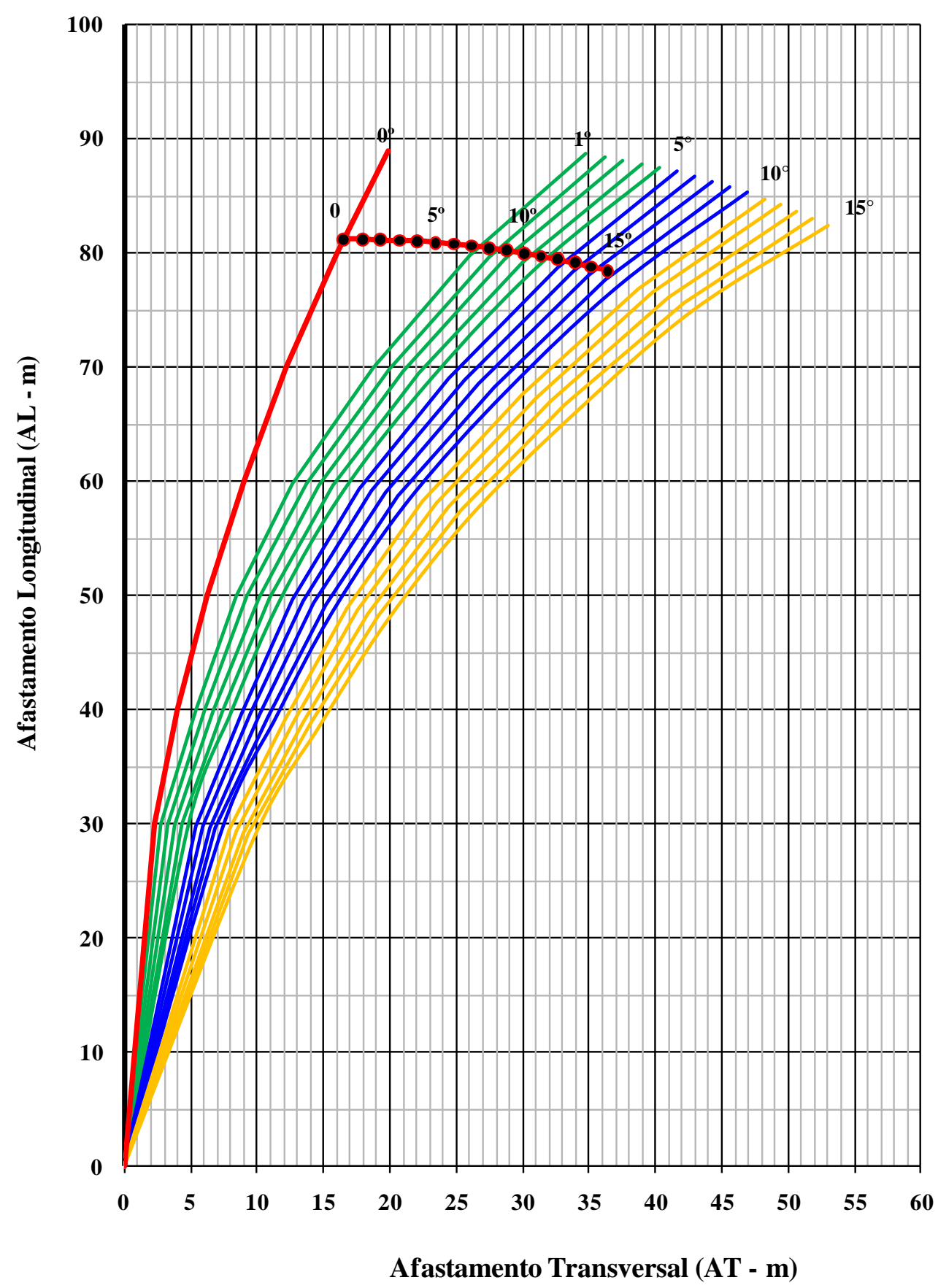


Raio 200m - Velocidade 80 km/h

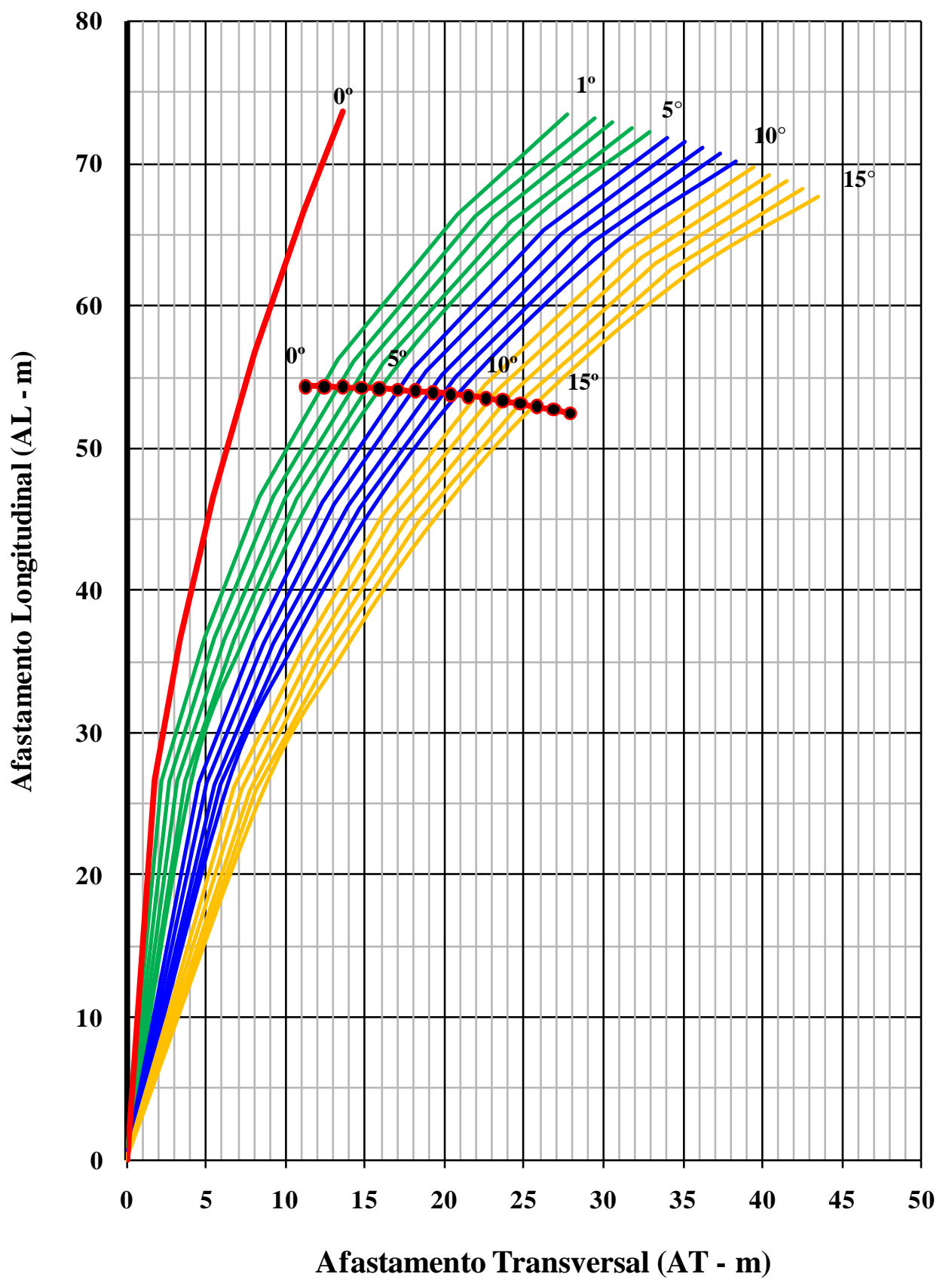


Raio 200m - Velocidade 70 km/h

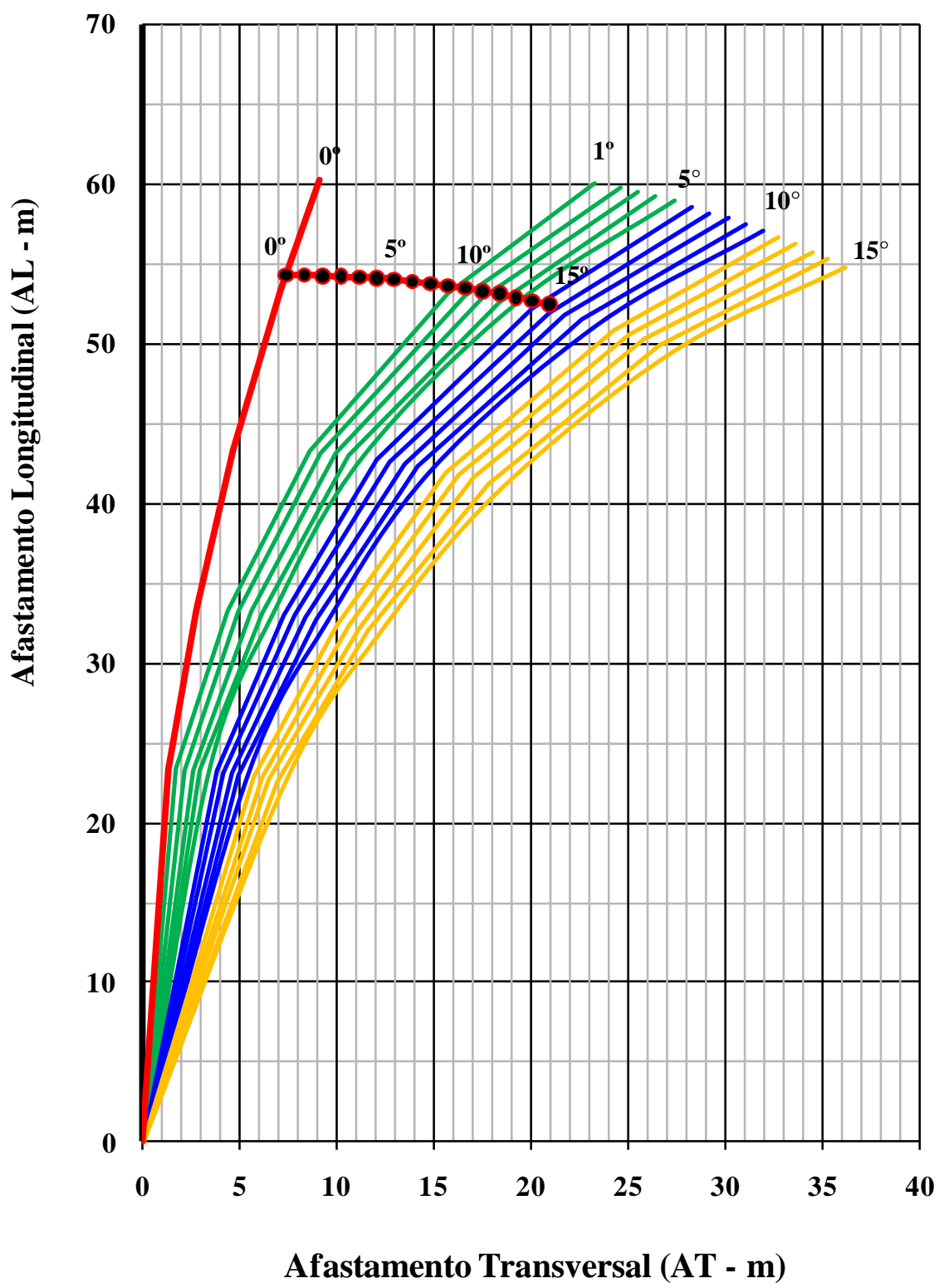




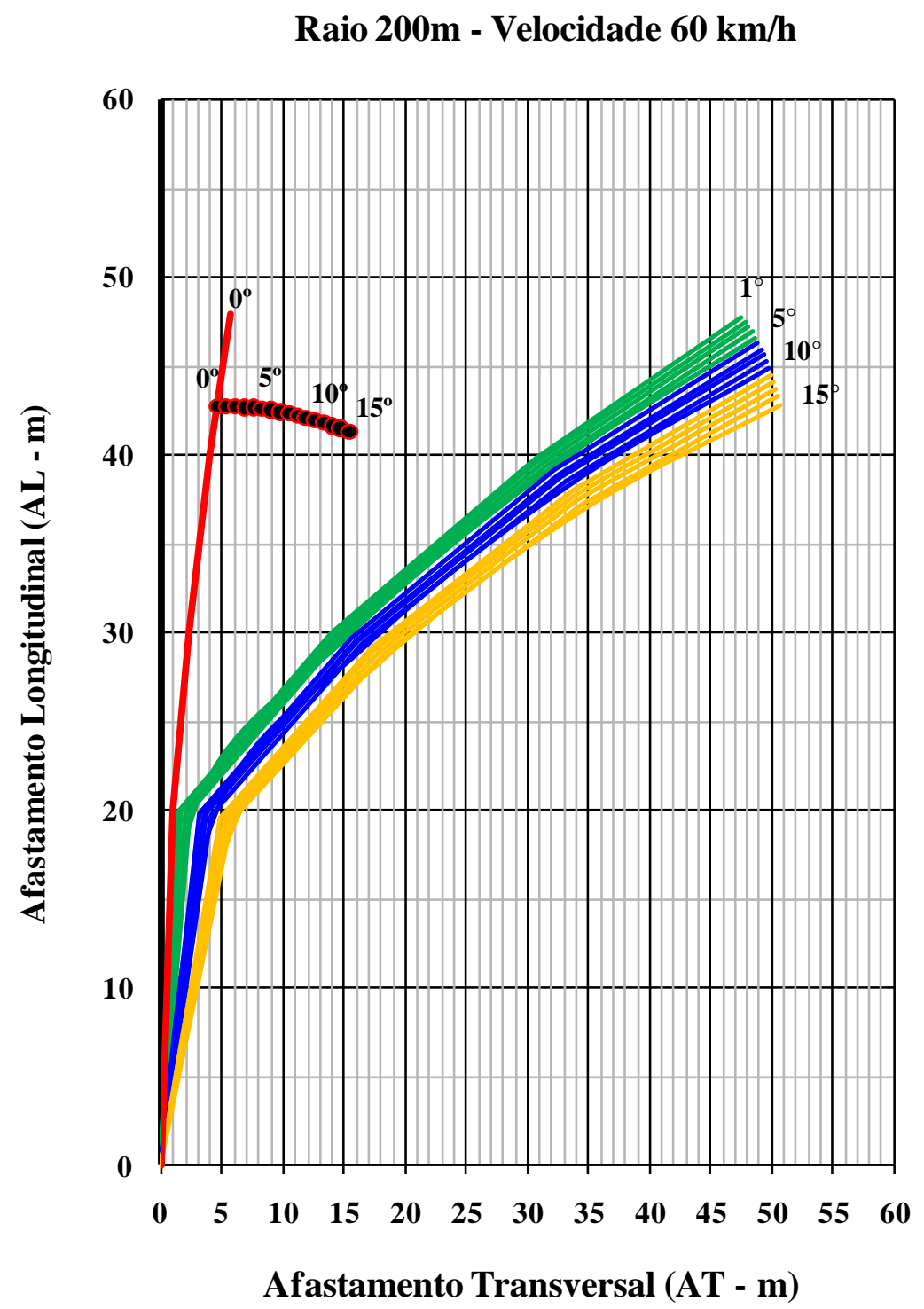


Raio 100m - Velocidade 70 km/h

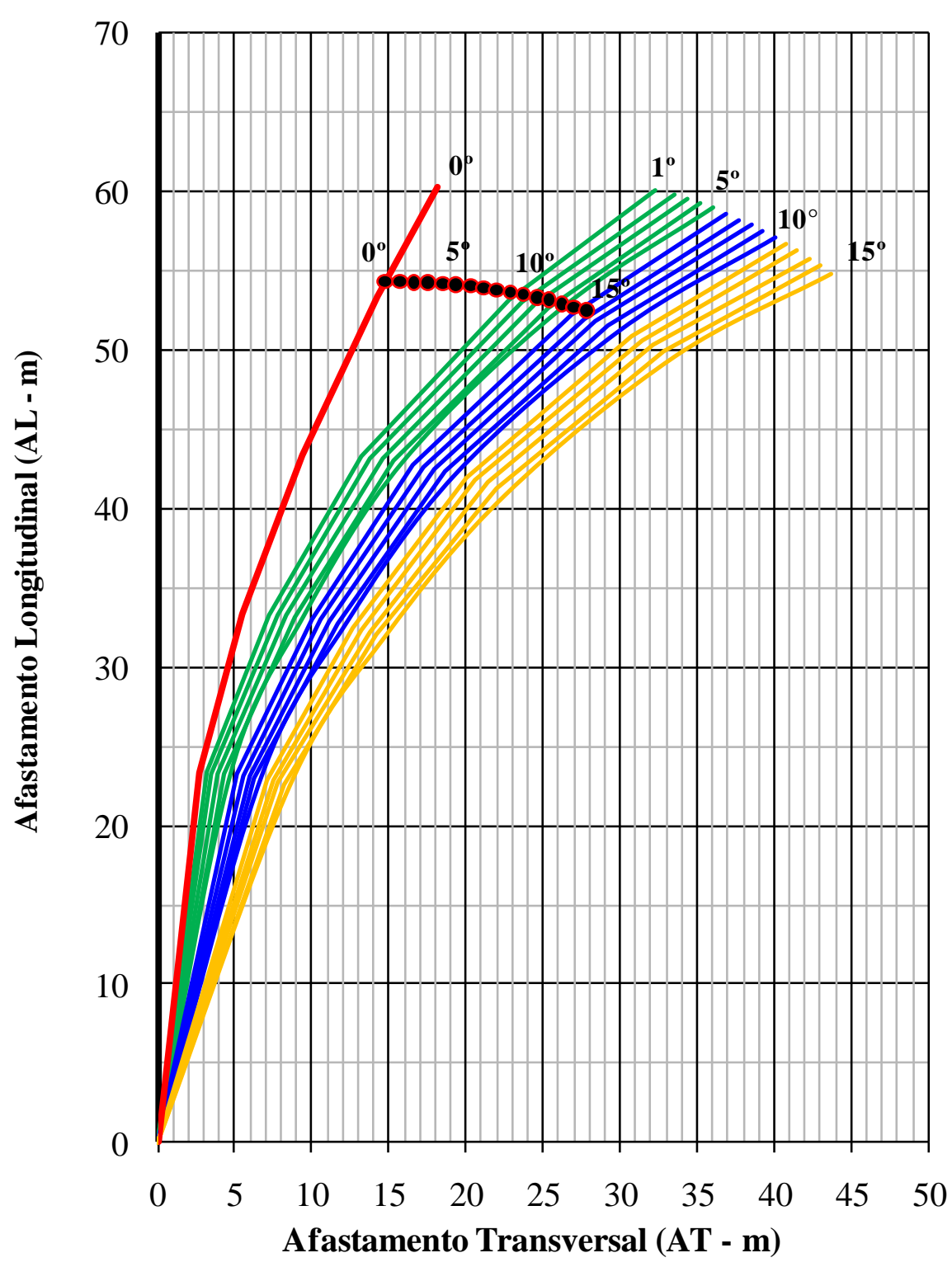




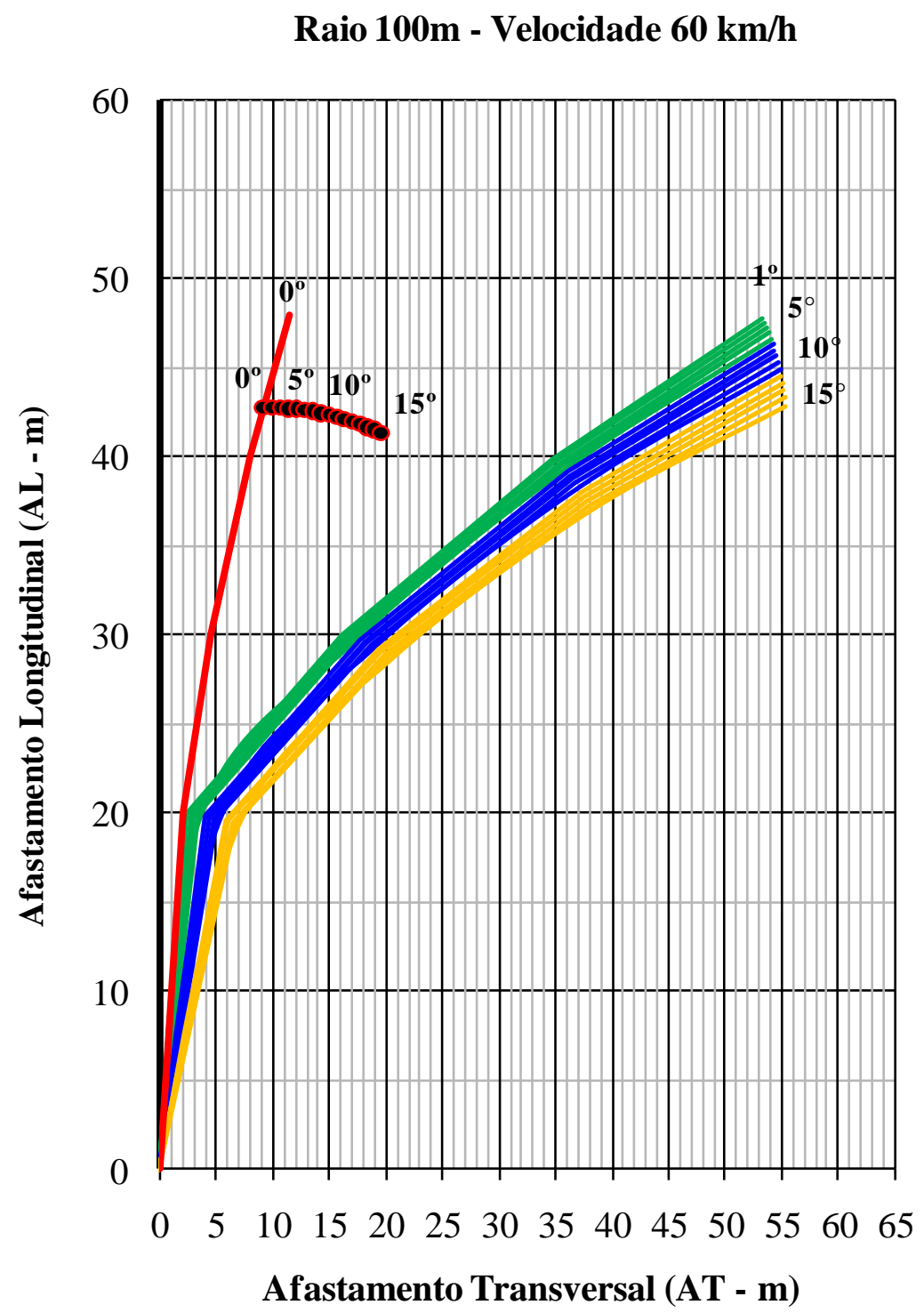

